\title{
Copyright
}

by

Sung Kuk Kim

2011 
The Dissertation Committee for Sung Kuk Kim Certifies that this is the approved version of the following dissertation:

\section{Calix[4]pyrrole-Based Ion Pair Receptors}

\section{Committee:}

\begin{tabular}{l}
\hline Jonathan L. Sessler, Supervisor \\
\hline Christopher W. Bielawski \\
\hline Dionicio R. Siegel \\
\hline Simon M. Humphrey \\
\hline Sean M. Kerwin \\
\hline Eric V. Anslyn
\end{tabular}




\title{
Calix[4]pyrrole-Based Ion Pair Receptors
}

$$
\text { by }
$$

\section{Sung Kuk Kim, B.S.; M.S.}

\author{
Dissertation \\ Presented to the Faculty of the Graduate School of \\ The University of Texas at Austin \\ in Partial Fulfillment \\ of the Requirements \\ for the Degree of \\ Doctor of Philosophy
}

The University of Texas at Austin

August 2011 


\section{Dedication}

In memory of my late mother

To my father 


\section{Acknowledgements}

I would first like to thank my advisor, Jonathan L. Sessler for giving me an opportunity to pursue the $\mathrm{Ph} . \mathrm{D}$ degree under his supervision. But for his constant support and encouragement, I could not have obtained the Ph.D degree.

Dr. Vicent M. Lynch has worked for me on the X-ray crystallography. I really appreciate his hard work and great helps.

I would also like to thank all members of the Sessler group members, past and present, for friendship. I also appreciate the collaborative efforts of Gabriela and Dr. Dustin E. Gross.

I would also like to give thanks to Profs. Jong Seung Kim of Korea University and Chang-Hee Lee of Kangwon National University for giving scientific suggestions and discussions.

Special thanks go to Yerim and Dong Sub for their true and deep friendship.

Finally but biggest, I would like to thank my father, my past mother, my brother and my sisters who always trust me. 


\title{
Calix[4]pyrrole-Based Ion Pair Receptors
}

\author{
Sung Kuk Kim, Ph. D. \\ The University of Texas at Austin, 2011
}

Supervisor: Jonathan L. Sessler

\begin{abstract}
Compared with simple ion receptors, ion pair receptors display significantly enhanced affinity to ions through allosteric effects and additional electrostatic interactions between the bound ions, as well as host-guest interactions. Taken in concert, these necessarily permit a higher level of control over ion recognition and transport than that obtainable from simple ion binding. However, in spite of their potential applications in various fields, such as salt solublization, extraction, and membrane transport, ion pair receptors, which are able to form simultaneous complexation with an anion and a cation, still remains in a relatively unexplored area in supramolecular chemistry. This dissertation describes efforts to develop such systems on the basis of calix[4]arenes and calix[4]pyrroles. Calix[4]pyrroles and calix[4]arene derivatives bearing crown ethers or ester groups are known to act as efficient receptors for anions and cations, respectively. Therefore, the synthetic combination or modification of these two macrocyclic subunits provides an entry into novel ion pair receptors. The focus of this dissertation is on matched systems that form strong and specific complexes with cesium or potassium salts, depending on the exact structure in question. The selectivity demonstrated by these receptors is ascribed to a tuning of the cation recognition sites and control of the calix[4]arene conformation. Solid state structural and ${ }^{1} \mathrm{H}$ NMR spectroscopic analyses reveal that potassium and cesium cations are bound to different sites within these ion pair
\end{abstract}


receptors. A strong dependence on the counter anion (e.g., fluoride, chloride and nitrate) is also seen. In some cases this dependence is near-absolute, thus mimicking $A N D$ logic gates. Noticeably, the ion pair receptor consisting of a 1,3-alterate calix[4]arene crown-5 and a calix[4]pyrrole is able to extract various cesium and potassium salts from a water phase into an organic phase in various binding modes, depending on the counter anions. Furthermore, the extraction behavior of this ion pair receptor towards such ion pairs can be controlled by cation switching and the use of different solvents. 


\section{Table of Contents}

List of Tables

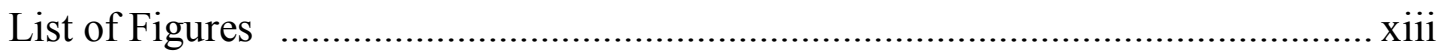

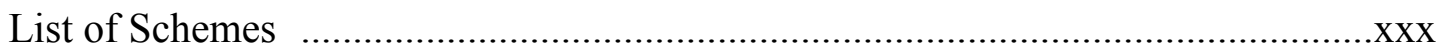

Chapter 1: General introduction to ion pair receptors ..............................................

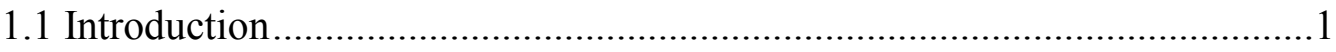

1.2 Ion pair receptors based on Lewis acidic groups for anion recognition .........4

1.3 Ion pair receptors based on urea groups for anion recognition......................15

1.4 Ion pair receptors that contain amide groups for anion recognition .............29

1.5. Ion pair receptors based on positively charged components for anion

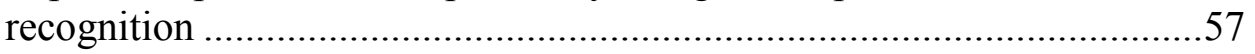

1.6 Phosphine oxide and sulfoxide-based ion pair receptors ..............................62

1.7 An ion pair receptor that is based on halogen bonding to achieve anion

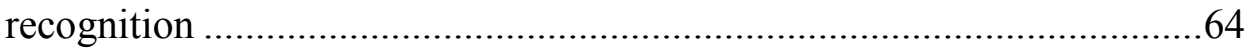

$1.8 \mathrm{An}$ ion pair receptor based on hydroxyl groups for anion recognition ........65

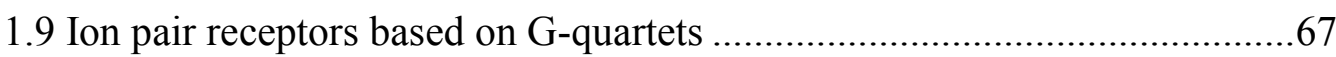

1.10 Ion pair receptors based on pyrroles and indoles for anion recognition ....70

1.11 Ion pair recognition achieved using dual host receptors..............................75

1.12 Ion pair recognition achieved using functionalized polymers .....................77

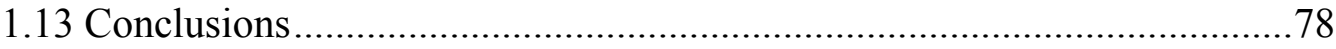

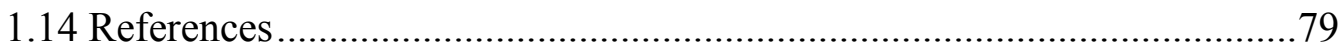

Chapter 2: N-Tosylpyrrolidine calix[4]pyrrole: synthesis and ion binding studies....86

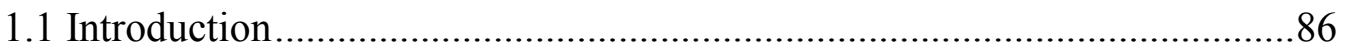

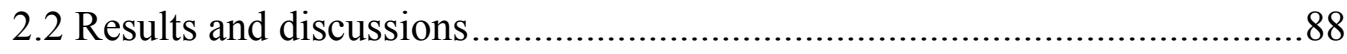

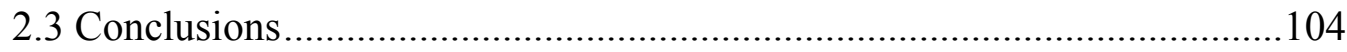

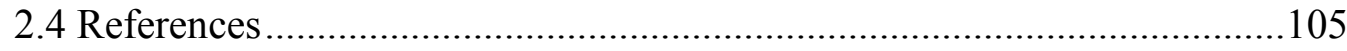

Chapter 3: Crown-6-calix[4]arene capped calix[4]pyrrole: An ion pair receptor for

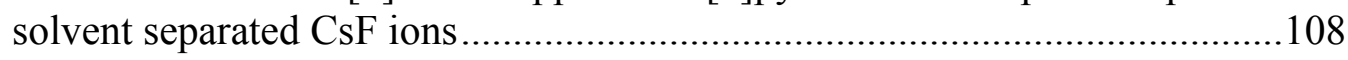

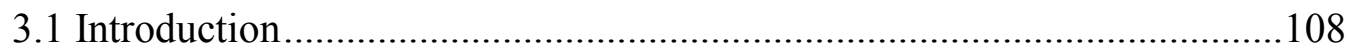




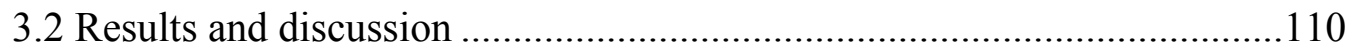

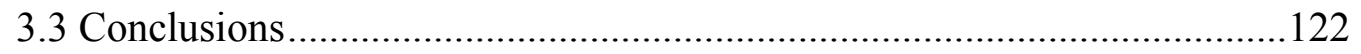

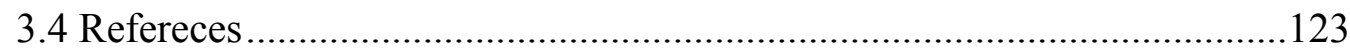

Chapter 4: A calix[4]arene strapped calix[4]pyrrole. An ion pair receptor displaying three different cesium cation recognition modes .............................................126

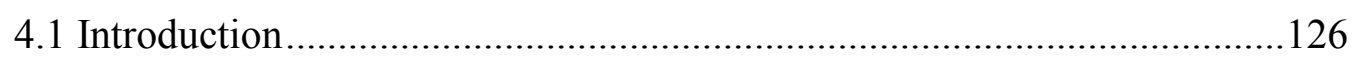

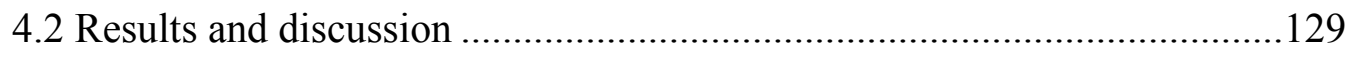

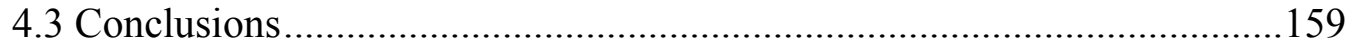

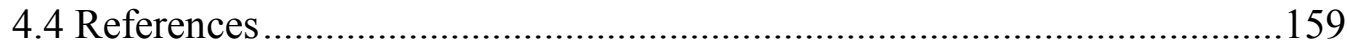

Chapter 5: Ion pair complexes of a calix[4]arene-crown-5 calix[4]pyrrole multitopic receptor. Evidence for cation metathesis ........................................................163

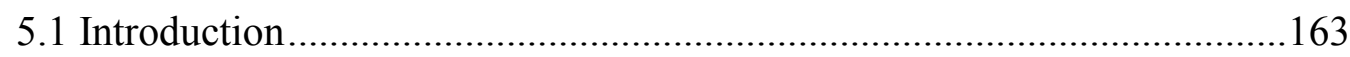

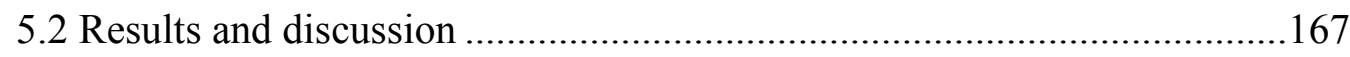

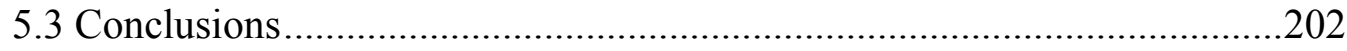

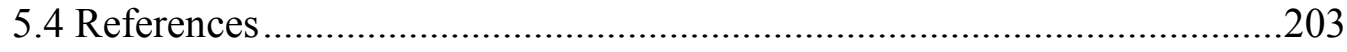

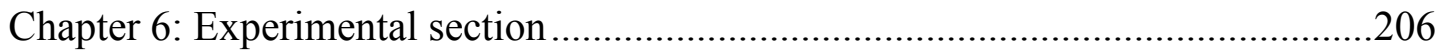

Appendix: X-ray experimental and crystallographic data ........................................219 


\section{List of Tables}

Table 1.1: Association constants corresponding to the interaction of receptor 1.16 and the control cyclen $\mathrm{Zn}\left(\mathrm{H}_{2} \mathrm{O}\right)$ system 1.17 with $\mathrm{NaH}_{2} \mathrm{PO}_{4}$ and $\mathrm{KH}_{2} \mathrm{PO}_{4}$ in HEPES buffer at pH 7.4 at RT..................................................12

Table 1.2: Percentage of MX complex formed with 1.21 and 1.22a,b after liquidsolid extraction using chloroform as the organic phase. 16

Table 1.3: Stability data for the anion complexes of $1.28,\left[1.28 \cdot \mathrm{Na}^{+}\right]$and $\left[1.28 \cdot \mathrm{K}^{+}\right]$ as determined in $\mathrm{CDCl}_{3} / \mathrm{CD}_{3} \mathrm{CN}(2 / 1, \mathrm{v} / \mathrm{v})$

Table 1.4: Solid-liquid extraction data for Group 1 halide and acetate salts recorded using 1.28 as the receptor and $\mathrm{CDCl}_{3}$ as the solvent. The results are given as the percentage of complex formation.

Table 1.5: Association constants, $\log K_{a}$, for the 1:1 host-guest complexes formed from the neutral and cation-bound forms of receptor $\mathbf{1 . 3 0}$ and selected anions. 22

Table 1.6: Association constants $\left(\mathrm{M}^{-1}\right)$ for the binding of halide anions to the ion pair receptor $\mathbf{1 . 4 2}$ for halides anion in the presence or absence of alkali metal ions. The values in parentheses are the change in the chemical shift of the NH protons $\left(\Delta \delta_{\max }\right.$ in $\left.\mathrm{ppm}\right)$.............................................31

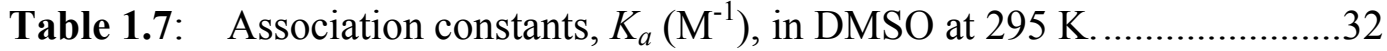

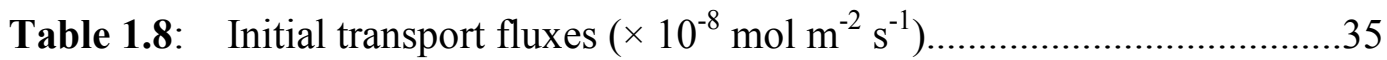

Table 1.9: Initial transport fluxes for SLMs containing different receptors......36

Table 1.10: Association constants $\left(K_{a}\right)$ corresponding to the binding of halide anions by receptor $\mathbf{1 . 4 8}$ and its metal complexes 38 
Table 1.11: Anion association constants $\left(K_{a}\right)$ for receptors 1.52 and $\mathbf{1 . 5 3}$ and that of their corresponding $\mathrm{Na}^{+}$and $\mathrm{K}^{+}$complexes (errors $<10 \%$ ).

Table 1.12: Binding constants recorded for 1.59 in the presence and absence of sodium picrate in $\mathrm{CDCl}_{3}$.

Table 1.13: Association constants between $\mathbf{1 . 6 9}$ and various ammonium salts...54

Table 1.14: Association constants $\left(K_{a}, \mathrm{M}^{-1}\right)$ between ion pair receptor 1.95 and halides recorded in the presence and absence of alkali metal salts (1.0 equiv) in $10 \%(\mathrm{v} / \mathrm{v}) \mathrm{DMSO}-d_{6} / \mathrm{CD}_{3} \mathrm{CN}$ at $297 \pm 1 \mathrm{~K} \ldots \ldots \ldots \ldots \ldots \ldots . . . . . . . . . . .72$

Table 2.1: $\quad$ Selected thermodynamic data derived from isothermal titration calorimetry (ITC) for the interactions of receptors 2.1 and 2.2 with tetraalkylammonium halides. Titrations were performed in $\mathrm{CHCl}_{3}$ at $25^{\circ} \mathrm{C}$.. .98

Table 3.1: $\quad$ ITC titration data of 3.1, 3.1 $\cdot \mathrm{F}^{-}$, and 3.1 $\cdot \mathrm{Cs}^{+}$measured at $298 \mathrm{~K} .121$

Table 5.1: ITC titration data for receptor 5.3 measured at 298 K...................176

Table A.1: Crystal data and structure refinement for $\mathbf{2 . 2} \cdot\left(\mathrm{CH}_{3} \mathrm{OH}\right)_{2} \ldots \ldots \ldots \ldots \ldots . .222$

Table A.2: Crystal data and structure refinement for $\mathbf{2 . 2} \cdot(\mathbf{D M F})_{\mathbf{4}} \cdot\left(\mathrm{CH}_{\mathbf{2}} \mathbf{C l}_{2}\right)_{1 / 2.2} .225$

Table A.3: Crystal data and structure refinement for 2.2 $\mathrm{TBACl}$..................228

Table A.4: Crystal data and structure refinement for $3.1 \cdot \mathrm{CsF} \cdot \mathrm{CH}_{3} \mathrm{OH} \cdot \mathrm{H}_{2} \mathrm{O} \cdot \mathrm{CHCl}_{3}$

Table A.5: Crystal data and structure refinement for $4.2 \cdot \mathrm{CH}_{3} \mathrm{OH} \ldots \ldots \ldots \ldots \ldots \ldots . . .235$

Table A.6: Crystal data and structure refinement for $4.2 \cdot \mathrm{CsF} \cdot \mathrm{H}_{2} \mathrm{O} \cdot \mathrm{CH}_{3} \mathrm{OH} \ldots . .238$

Table A.7: Crystal data and structure refinement for 5.3 $\mathrm{CH}_{3} \mathrm{CN}$..................241

Table A.8: Crystal data and structure refinement for 5.3• $\mathrm{KF} \bullet\left(\mathrm{CH}_{3} \mathrm{OH}\right)_{3} \ldots \ldots . .244$

Table A.9: Crystal data and structure refinement for $\mathbf{5 . 3} \cdot \mathrm{KNO}_{3} \bullet\left(\mathrm{C}_{5} \mathrm{H}_{12}\right)_{1 / 2} \bullet \mathrm{CH}_{3} \mathrm{Cl} \bullet$ $\mathrm{H}_{2} \mathrm{O}$. 247 
Table A.10: Crystal data and structure refinement for $\mathbf{5 . 3} \cdot \mathrm{CsF} \bullet\left(\mathrm{CH}_{3} \mathrm{OH}\right)_{2} \bullet\left(\mathrm{CHCl}_{3}\right)_{2}$

250

Table A.11: Crystal data and structure refinement for $5.3 \cdot \mathrm{CsCl} \cdot \mathrm{CHCl}_{3} \bullet\left(\mathrm{CH}_{3} \mathrm{CH}_{2} \mathrm{OH}\right)$

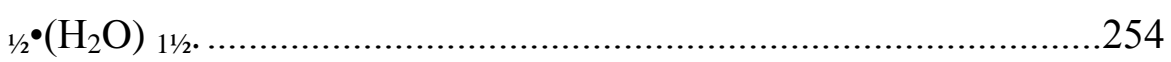

Table A.12: Crystal data and structure refinement for $\mathbf{5 . 3} \cdot \mathrm{CsNO}_{3} \cdot \mathrm{C}_{2} \mathrm{H}_{5} \mathrm{OH} \cdot \mathrm{C}_{6} \mathrm{H}_{14}$. 


\section{List of Figures}

Figure 1.1: Limiting ion-pair interactions relevant to receptor-mediated ion-pair recognition: (a) Contact, (b) solvent-bridged, and (c) host-separated. In this schematic, the anion is shown as "A-", the cation as " $\mathrm{C}+$ ", and the

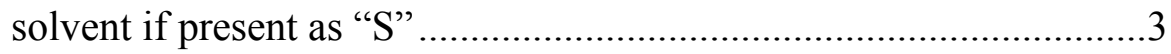

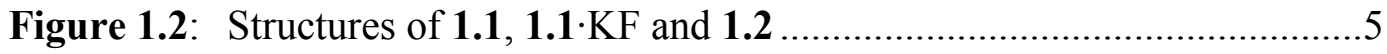

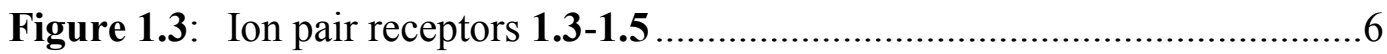

Figure 1.4: Uranyl-salophen based ion pair receptors...................................

Figure 1.5: Ion pair receptors based on calix[4]arenes and Zn-porphyrins and their proposed mode of interaction with ion pairs.................................. 9

Figure 1.6: Ditopic receptors used for the recognition of sodium or potassium cyanide ion pairs and schematic representations of their proposed

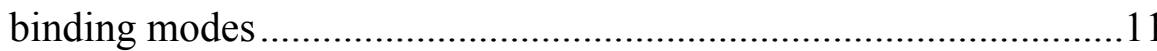

Figure 1.7: $\mathrm{Zn}\left(\mathrm{H}_{2} \mathrm{O}\right)$-complexed cyclen-based water soluble ion pair receptors used for the recognition of cyanide alkali metal salts 13

Figure 1.8: Ion pair receptors based on a combination of a Lewis acidic tin center and a benzocrown ether. Also shown are their binding modes.........14

Figure 1.9: Structure of the ion pair receptor 1.20. Also shown are the proposed ditopic binding modes that are thought to pertain in acetonitrile and methanol, respectively .......................................................... 15

Figure 1.10: Structures of ion pair receptors 1.21 and 1.22a,b ........................17

Figure 1.11: Proposed ion-induced molecular motions and associated binding modes for receptor 1.21 thought to pertain in the presence of $\mathrm{NaCl} \ldots \ldots \ldots . . .17$

Figure 1.12: Cation, anion and ditopic carriers for cation and anion transport.....18 
Figure 1.13: Calix[4]arene and urea based ion pair receptors 1.26-1.28 19

Figure 1.14: Structure of ditopic receptor 1.29

Figure 1.15: Tritopic receptor 1.30 and the binding modes that are thought to pertain in the presence of $\mathrm{Na}^{+}, \mathrm{Ag}^{+}$and various anions. 22

Figure 1.16: Proposed recognition of long-chain, ion-paired $\alpha, \omega$-alkanediyldiammonium salts by calix[5] arene-based heterotetratopic ion pair receptor $\mathbf{1 . 3 1}$ .24

Figure 1.17: Calix[4] arene-based monotopic and hetroditopic receptors 1.32-1.35 and depictions of the $N$-methylpyridinium and $N, N^{\prime}$-dimethylviologen salts used as guest molecules .25

Figure 1.18: Proposed recognition of an alkyl ammonium salt (2-phenylethylamine hydrochloride) by receptor $\mathbf{1 . 3 6}$ 26

Figure 1.19: Simple crown ether-urea and -thiourea based ion pair receptors 1.371.40 . .27

Figure 1.20: Crystal structures of (a) free receptor1.40, (b) its $\mathrm{NaCl}$ complex, and (c) the corresponding $\mathrm{NaNO}_{3}$ complex. This figure was redrawn using coordinates that were originally published in ref. 53

Figure 1.21: Chemical structure of the ion pair receptor 1.41 and its proposed binding mode with monopotassium salts of dicarboxylic acids (oxalic acid, malonic acid, methylmalonic acid, benzylmalonic acid, maleic acid, fumaric acid, succinic acid, Z-aminomalonic acid, Z-aspartic acid, and Zglutamic acid) and phenyl phosphonate 30

Figure 1.22: Amide-capped bicyclic ion pair receptors 1.42 and 1.43. 31 
Figure 1.23: Crystal structures of (a) $1.43 \cdot \mathrm{LiCl} \cdot \mathrm{H}_{2} \mathrm{O}$ and (b) $1.43 \cdot \mathrm{LiBr} \cdot \mathrm{H}_{2} \mathrm{O}$. The lithium cation is bound in the crown ether subunit in both cases. These structures were replotted using coordinates that were originally reported in ref. 57 34

Figure 1.24: Structures of control monotopic receptors 1.44 and 1.45 35

Figure 1.25: Crystal structures of (a) $1.43 \cdot \mathrm{KOAc}$, (b) $1.43 \cdot \mathrm{NaNO}_{3}$, (c) $1.43 \cdot \mathrm{KNO}_{3}$, (d) $1.43 \cdot \mathrm{LiNO}_{3} \cdot 2 \mathrm{H}_{2} \mathrm{O}$, and (e) $1.43 \cdot \mathrm{NaNO}_{2}$. The cation is bound in the crown subunit in all cases. This figure was produced using coordinates that originally appeared in ref. 59 .36

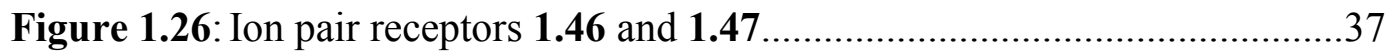

Figure 1.27: Structures of ion pair receptors 1.48 and 1.49a,b ..........................39

Figure 1.28: Receptors 1.50 and 1.51 and their proposed ion binding modes for anions or/and cations...............................................................40

Figure 1.29: Chemical structures of ion pair receptors 1.52-1.54 ...................42

Figure 1.30: Chemical structures of ion pair receptors 1.55-1.58 ....................43

Figure 1.31: Tripodal tris(amido benzo[15]crown-5) ion pair receptor 1.59 .......44

Figure 1.32: Calix[4]arene-based ion pair receptors 1.60a,b and 1.61a,b ..........46

Figure 1.33: Calix[6] arene-based ion pair receptor $\mathbf{1 . 6 2}$ and its proposed mode of binding for alkylammonium chloride contact ion pairs ..................47

Figure 1.34: Calix[6]arene-urea based ion pair receptors 1.63a-c and 1.64 „.......49

Figure 1.35: Chemical structures of molecular capsules 1.65a-e......................50

Figure 1.36: Two different views of the X-ray crystal structure of $1.65 a \cdot T M A C l$ $\left(\mathrm{TMA}^{+}=\right.$tetramethylammonium). This figure was produced using coordinates that originally appeared in ref. 77 . 
Figure 1.37: Chemical structure of the crowned squaramide ion pair receptor $\mathbf{1 . 6 6}$ and its predicted binding mode for $\mathrm{NaOAc}$ or KOAc contact ion pairs...51

Figure 1.38: Cyclopeptide-based ditopic receptors 1.67-1.69 ........................52

Figure 1.39: Formation of pseudorotaxane 1.72 via cooperative ion pair (1.71) recognition by $\mathbf{1 . 7 0}$ .55

Figure 1.40: Formation of [2]- and [3]-catenanes $\mathbf{1 . 7 4}$ and $\mathbf{1 . 7 5}$ by ring-closing metathesis using Grubbs' catalyst..............................................56

Figure 1.41: Pseudorotaxane 1.76 and catenane 1.77 formed using a calix[4]arenebased ion pair receptor and appropriately chosen pairs of anions and cations .57

Figure 1.42: An Ion pair receptor for $\mathrm{KCl}, \mathbf{1 . 7 8}$, that operates at low or neutral $\mathrm{pH}$. 58

Figure 1.43: Ion pair receptor 1.79 and its binding mode for $\mathrm{NiSO}_{4} \ldots \ldots \ldots \ldots \ldots . . . . .58$

Figure 1.44: Tripodal aza crown ether calix[4]arene 1.80 containing both cation and anion binding sites .59

Figure 1.45: Ditopic receptor 1.81 and its predicted binding mode for a zwitterionic $\omega$-amino carboxylate. Also shown is the control monotopic receptor $\mathbf{1 . 8 2}$

Figure 1.46: Ditopic receptor $(S, S)-\mathbf{1 . 8 3}$ and its proposed binding mode for $L$ tryptophan 61

Figure 1.47: Fluorescent ion pair sensor $\mathbf{1 . 8 4}$ that functions as an $A N D$ logic system 63

Figure 1.48: Macrocyclic phosphine oxide disulfoxide ion pair receptor $\mathbf{1 . 8 5}$ and its proposed interactions with monoalkylammonium cations, halide anions, and ion pairs containing these species 
Figure 1.49: Ion pair receptor $\mathbf{1 . 8 6}$ and its proposed NaI binding mode. Also shown is control compound $\mathbf{1 . 8 7}$ that lacks an XB donor 64

Figure 1.50: Crystal structure of 1.86 $\mathrm{NaI}$. This figure was produced using coordinates that originally appeared in ref. 95 . 65

Figure 1.51: Ion pair receptor 1.88 and control single ion receptors 1.84, 1.89 and 1.90 .66

Figure 1.52: Guanosine 1.91 (G 1) and the proposed binding modes displayed by the G-quartet built up from this monomer in the presence of $\mathrm{BaPic}_{2}$ and $\mathrm{SrPic}_{2}$ .68

Figure 1.53: Calix[4]arene-based guanosine $1.92($ G 2) and its water-mediated ion pair recognition. 69

Figure 1.54: G-quartet (G 3 $)_{4}$ and A-quartet (A 1 $)_{4}$ and their proposed cooperative recognition of $\mathrm{NaCl}$ 70

Figure 1.55: Biindole-diazacrown-based ion pair receptor 1.95 and diazacrowncapped sapphyrin 1.96 71

Figure 1.56: Calix[4]pyrrole 1.97, its binding mode for CsX and the crystal structure of 1.97·CsF. The X-ray structure shown was produced using coordinates that originally appeared in ref. 104 .74

Figure 1.57: Proposed thermodynamic steps used to model cesium salt extraction by calix[4]pyrrole 1.97. .74

Figure 1.58: Hosts and a guest used for binding studies involving so-called dual-host systems .76

Figure 1.59: Schematic representation of polymeric ion pair receptor 1.102 and various control systems. .77

Figure 2.1: Chemical structures of compouds 2.1 and 2.2 . 
Figure 2.2: Two different views of the single crystal structure of $\mathbf{2 . 2} \cdot(\mathrm{MeOH})_{2}$. Displacement ellipsoids are scaled to the $30 \%$ probability level. Hydrogen atoms have been removed for clarity. The macrocycle lies on a crystallographic inversion center at $1 / 2,1 / 2,1 / 2$

Figure 2.3: Two different views of the single crystal structure of 2.2.(DMF) $)_{2}$. Displacement ellipsoids are scaled to the $50 \%$ probability level. Hydrogen atoms have been removed for clarity. The macrocycle lies on a crystallographic inversion center at $1 / 2,1 / 2,1 / 2$ 90

Figure 2.4: Two different views of the single crystal structure of $\mathbf{2 . 2} \cdot \mathrm{Cl}^{-}$. Displacement ellipsoids are scaled to the $30 \%$ probability level. Compound 2.2 in this complex lies around a crystallographic 4-fold rotation axis at $1 / 2,1 / 2, z$. Most hydrogen atoms have been removed for clarity. Dashed lines are indicative of H-bonding interactions. The countercation, $\mathrm{TBA}^{+}$, sitting in the cavity formed by four sulfonyl groups, is disordered and is not shown 91

Figure 2.5: Partial ${ }^{1} \mathrm{H}$ NMR spectra recorded during the titration of receptor 2.2 with TBAF (tetrabutylammonium fluoride) in $\mathrm{CDCl}_{3} .{ }^{*}$ Denotes peaks due to the NMR solvent 92

Figure 2.6: Partial ${ }^{1} \mathrm{H}$ NMR spectra of (a) free $\mathbf{2 . 1}$ and (b) $2.1+2.82$ equiv of TBAF in $\mathrm{CD}_{3} \mathrm{Cl}$. 93

Figure 2.7: ${ }^{1} \mathrm{H}$ NMR titration curves of $\mathbf{2 . 2}$ with $\mathrm{TBAX}$ in $\mathrm{CDCl}_{3}$. Chemical shift on the $y$ axis is of the methyl groups on the tosyl moiety of 2.2. [2.2] = $0.003 \mathrm{M}$ .95 
Figure 2.8: Proton NMR spectra of $\mathbf{2 . 2}$ recorded in $\mathrm{CDCl}_{3}$ after adding quantities of TBAX (tetrabutylammonium halide) sufficient to induce no further observable spectral changes. Note the position of the NH signal. *Denotes peaks due to the NMR solvent and other residual impurities 96

Figure 2.9: ITC plots showing the titration of $\mathrm{TBACl}$ into chloroform solutions of calixpyrroles 2.1 (left, $10 \mathrm{mM}$ ) and $\mathbf{2 . 2}$ (right, $0.1 \mathrm{mM}$ ). A high concentration was used in the former case in an attempt to obtain a discernable binding isotherm .99

Figure 2.10: Partial ${ }^{1} \mathrm{H}$ NMR spectra corresponding to the titration of $\mathbf{2 . 2}$ with TEACl in $\mathrm{CDCl}_{3}$ 101

Figure 2.11: Proton NMR spectra of $\mathbf{2 . 2}$ recorded at room temperature in $\mathrm{CDCl}_{3}$ before and after the addition of $\mathrm{CsF}$ and $\mathrm{CsCl} .{ }^{*}$ and $\bullet$ denote the peaks of the NMR solvent and complexes $2.2 \cdot \mathrm{CsF}$ and $2.2 \cdot \mathrm{CsCl}$, respectively. Note the position of the $\mathrm{NH}$ signals 103

Figure 2.12: Chemical shift changes of 1 observed upon the addition of $\mathrm{CsF}$ and $\mathrm{CsCl}$ in $\mathrm{CDCl}_{3}$. $*$ and $\bullet$ denote peaks due to the NMR solvent and the complex 2.1. $\mathrm{CsF}$, respectively 104

Figure 3.1: Structures of receptors 3.1 and 3.2 109

Figure 3.2: View of the 3.1 $\cdot \mathrm{CsF}$ complex showing a partial atom labeling scheme. Displacement ellipsoids are scaled to the $30 \%$ probability level. Most hydrogen atoms have been removed for clarity. Atoms in the ether linkage are disordered, with the higher occupancy atoms being shown 
Figure 3.3: Partial ${ }^{1} \mathrm{H}$ NMR spectra for titration of receptor 3.1 with TBAF (tetrabutylammonium fluoride) in $\mathrm{CDCl}_{3}$

Figure 3.4: Partial ${ }^{1} \mathrm{H}$ NMR spectra of (a) free 3.1 and (b) $3.1+5$ equiv. of TBACl. (tetrabutylammonium chloride) in $\mathrm{CDCl}_{3}$ 114

Figure 3.5: Partial ${ }^{1} \mathrm{H}$ NMR spectra of (a) 3.1 + TBAF (1.2 equiv.) and (b) $\mathbf{3 . 1}+$ various anions ( 5 equiv) in $\mathrm{CDCl}_{3}$. $*$ denotes peaks ascribed to the NMR solvent. Both spectra (a) and (b) were referenced to TMS 114

Figure 3.6: Partial ${ }^{1} \mathrm{H}$ NMR spectra of (a) 3.1 only, (b) $3.1+5$ equiv. of TBAF, (c) 3.1 +5 equiv. of $\mathrm{CsClO}_{4}$, and (d) $3.1+5$ equiv. of $\mathrm{CsF}$ in $\mathrm{CD}_{3} \mathrm{OD} / \mathrm{CDCl}_{3}(1 / 9, \mathrm{v} / \mathrm{v})$ .116

Figure 3.7: Proposed binding interactions involving 3.1 and various $\mathrm{Cs}^{+}$and $\mathrm{F}^{-}$salts in $\mathrm{CD}_{3} \mathrm{OD} / \mathrm{CDCl}_{3}(1 / 9, \mathrm{v} / \mathrm{v})$ 117

Figure 3.8: Partial ${ }^{1} \mathrm{H} \mathrm{NMR}$ spectra for titration of 3.1. $\mathrm{CsClO}_{4}$ with $\mathrm{TBAF}$ in $\mathrm{CD}_{3} \mathrm{OD} / \mathrm{CDCl}_{3}(1 / 9, \mathrm{v} / \mathrm{v})$. Complex 3.1. $\mathrm{CsClO}_{4}$ was prepared in situ by mixing 2 equiv of $\mathrm{CsClO}_{4}$ in $\mathrm{CD}_{3} \mathrm{OD}$ with a solution of $\mathbf{3 . 1}$ in $\mathrm{CDCl}_{3}$

Figure 3.9: Partial ${ }^{1} \mathrm{H}$ NMR spectra of (a) 3.1 only, (b) 3.1 +5 equiv. of CsF, and (c) 3.1 + 5 equiv. of $\mathrm{CsF}, \mathrm{CsCl}, \mathrm{CsBr}$, and $\mathrm{CsI}$ in $\mathrm{CD}_{3} \mathrm{OD} / \mathrm{CDCl}_{3}(1 / 9, \mathrm{v} / \mathrm{v})$. * denotes peaks ascribed to the NMR solvents and to water. All spectra were referenced to TMS. 120

Figure 4.1: Chemical structures of compunds 4.1-4.3. 128

Figure 4.2: Two different views of the single crystal structure of $\mathbf{4 . 2} \cdot\left(\mathrm{CH}_{3} \mathrm{OH}\right)_{2}$. Displacement ellipsoids are scaled to the $30 \%$ probability level. Most hydrogen atoms have been removed for clarity. Dashed lines are indicative of H-bonding interactions 130 
Figure 4.3: Partial ${ }^{1} \mathrm{H}$ NMR spectra recorded during the titration of receptor 4.2 with TBAF (tetrabutylammonium fluoride) in $\mathrm{CDCl}$ 132

Figure 4.4: Partial ${ }^{1} \mathrm{H}$ NMR spectra of (a) 4.2 only, (b) $4.2+5$ equiv. of TBAF (tetrabutylammonium fluoride), (c) $4.2+5$ equiv. of $\mathrm{CsClO}_{4}$, and (d) 4.2 +5 equiv. of $\mathrm{CsF}$ in $\mathrm{CD}_{3} \mathrm{OD} / \mathrm{CDCl}_{3}(1: 9, \mathrm{v} / \mathrm{v})$

Figure 4.5: Proposed $A N D$ logic gate binding behavior of $\mathbf{4 . 2}$ towards a CsF ion pair in $\mathrm{CD}_{3} \mathrm{OD} / \mathrm{CDCl}_{3}(1: 9, \mathrm{v} / \mathrm{v})$ 135

Figure 4.6: Partial ${ }^{1} \mathrm{H}$ NMR spectra recorded during the titration of receptor 2 with $\mathrm{CsF}$ in $\mathrm{CD}_{3} \mathrm{OD} / \mathrm{CDCl}_{3}(1: 9, \mathrm{v} / \mathrm{v})$ 137

Figure 4.7: Partial ${ }^{1} \mathrm{H}$ NMR spectra recorded during the titration of receptor 4.1 with $\mathrm{CsF}$ in $\mathrm{CD}_{3} \mathrm{OD} / \mathrm{CDCl}_{3}(1: 9, \mathrm{v} / \mathrm{v})$ 138

Figure 4.8: Partial ${ }^{1} \mathrm{H}$ NMR spectra of (a) 4.2 only, (b) $4.2+5$ equiv. of TBAF (tetrabutylammonium fluoride), (c) $4.2+5$ equiv. of $\mathrm{CsClO}_{4}$, (d) $4.2+5$ equiv. of $\mathrm{CsF}$, and (e) $\mathbf{4 . 2}+5$ equiv. of $\mathrm{TBAF}+5$ equiv. of $\mathrm{CsClO}_{4}$ in $\mathrm{CD}_{3} \mathrm{OD} / \mathrm{CDCl}_{3}(1: 9, \mathrm{v} / \mathrm{v})$ 141

Figure 4.9: Partial ${ }^{1} \mathrm{H}$ NMR spectra of (a) 4.2 only, (b) $4.2+5$ equiv. of $\mathrm{CsCl}$, (c) 4.2 +5 equiv. of $\mathrm{CsBr}$, and (d) $4.2+5$ equiv. of $\mathrm{CsNO}_{3}$ in $\mathrm{CD}_{3} \mathrm{OD} / \mathrm{CDCl}_{3}(1: 9, \mathrm{v} / \mathrm{v})$. The spectra were recorded roughly 10 minutes after mixing. * and $\bullet$ denote peaks of the NMR solvent and the uncomplexed, respectively 142

Figure 4.10: Partial ${ }^{1} \mathrm{H}$ NMR spectra of 4.2 recorded in the presence of various cesium salts (5 equiv) in $\mathrm{CD}_{3} \mathrm{OD} / \mathrm{CDCl}_{3}(1: 9, \mathrm{v} / \mathrm{v})$ 143 
Figure 4.11: Partial ${ }^{1} \mathrm{H}$ NMR spectra of (a) 4.3 only, (b) $4.3+20$ equiv of $\mathrm{CsClO}_{4}$, (c) $4.3+20$ equiv of $\mathrm{CsCl}$, (d) $\mathbf{4 . 3}+20$ equiv of $\mathrm{CsF}$, (e) $\mathbf{4 . 3}+20$ equiv of $\mathrm{CsF}+20$ equiv of $\mathrm{CsCl}+20$ equiv of $\mathrm{CsBr}+20$ equiv. of $\mathrm{CsNO}_{3}$, and (f) $3+5$ equiv of $\mathrm{CsF}+5$ equiv of $\mathrm{CsCl}+5$ equiv of $\mathrm{CsBr}+5$ equiv of $\mathrm{CsNO}_{3}$ in $\mathrm{CD}_{3} \mathrm{OD} / \mathrm{CDCl}_{3}(1: 9, \mathrm{v} / \mathrm{v}) . *$ denotes peaks of the NMR solvent and impurity from the commercially purchased CsF salt 144

Figure 4.12: Two different views of the single crystal structure of 4.2. $\mathrm{CsF} \cdot \mathrm{CH}_{3} \mathrm{OH}$. $\mathrm{H}_{2} \mathrm{O}$. Displacement ellipsoids are scaled to the $50 \%$ probability level. Most hydrogen atoms have been removed for clarity..... 146

Figure 4.13: Binding modes of $\mathrm{CsF}$ ion pairs stabilized by receptors 4.1-4.3 and distances between the $\mathrm{Cs}^{+}$and $\mathrm{F}^{-}$ions seen in the complexes as determined by X-ray diffraction analysis. The structures of the CsF complexes of 4.1 and $\mathbf{4 . 3}$ were reported in references 12 and 10c, respectively

Figure 4.14: (a) Superposition of calculated versus observed (thin black tubes) geometries for the solvated form of $(\mathbf{4 . 2} \cdot \mathrm{CsF})$. (b) Calculated geometry for the encapsulated contact $\mathrm{CsF}$ ion pair obtained after solvent is removed. 148

Figure 4.15: Optimized geometries for $\left(4.2 \cdot \mathrm{Cs}^{+}\right)$with the $\mathrm{Cs}^{+}$cation located in the internal cavity (a) and external cavity (b) 149

Figure 4.16: (a) Calculated geometry for $(4.2 \cdot \mathrm{CsCl})$ with a water molecule coordinated to the ion pair. (b) Calculated geometry for $(\mathbf{4 . 2} \cdot \mathrm{CsCl}) \ldots . .151$

Figure 4.17: (a) Calculated geometry for $(4.2 \cdot \mathrm{CsBr})$ with a water molecule coordinated to the ion pair. (b) Calculated geometry for $(\mathbf{4 . 2} \cdot \mathrm{CsBr}) \ldots . .152$ 
Figure 4.18: (a) Calculated geometry for $\left(4.2 \cdot \mathrm{CsNO}_{3}\right)$ with a water molecule coordinated to the nitrate anion. (b) Calculated geometry for $\left(4.2 \cdot \mathrm{CsNO}_{3}\right)$ 153

Figure 4.19: Single crystal structure of $4.2_{2} \cdot(\mathrm{CsCl})_{2} \cdot \mathrm{CH}_{3} \mathrm{OH} \cdot \mathrm{H}_{2} \mathrm{O}$. Displacement ellipsoids are scaled to the $30 \%$ probability level. Most hydrogen atoms have been removed for clarity..... 156

Figure 4.20: Partial ${ }^{1} \mathrm{H}$ NMR spectra of (a) 4.2 only and (b) $4.2+5$ equiv of $\mathrm{CsCl}$ in $\mathrm{CD}_{3} \mathrm{OD} / \mathrm{CDCl}_{3}(1: 9, \mathrm{v} / \mathrm{v})$, and (c) $4.2+5$ equiv of $\mathrm{CsCl}$ in $\mathrm{CH}_{3} \mathrm{OH} / \mathrm{CDCl}_{3}(1: 9, \mathrm{v} / \mathrm{v})$. The spectra were recorded roughly 10 minutes after mixing 157

Figure 4.21: Two different views of the single crystal structure of $4.2 \cdot \mathrm{CsNO}_{3}$. Displacement ellipsoids are scaled to the $30 \%$ probability level. Most hydrogen atoms have been removed for clarity 158

Figure 5.1: Chemical structures of compound 5.1 and 5.2..............................165

Figure 5.2: Design concept underlying ion pair receptor 5.3 ……....................167

Figure 5.3: Two different views of the single crystal structure of $5.3 \cdot \mathrm{CH}_{3} \mathrm{CN} 169$

Figure 5.4: Partial ${ }^{1} \mathrm{H}$ NMR spectra recorded during the titration of receptor $\mathbf{5 . 3}$ with TBAF (tetrabutylammonium fluoride) in $\mathrm{CDCl}_{3}$

Figure 5.5: $\quad{ }^{1} \mathrm{H}$ NMR spectra of (a) $\mathbf{5 . 3}$ only, (b) $\mathbf{5 . 3}+5$ equiv. of TBACl (tetrabutylammonium chloride), and (c) $\mathbf{5 . 3}+5$ equiv. of $\mathrm{TBANO}_{3}$ (tetrabutylammonium nitrate) in $\mathrm{CDCl}_{3}$ 171

Figure 5.6: Partial ${ }^{1} \mathrm{H}$ NMR spectra of (a) $\mathbf{5 . 3}$ only, (b) $\mathbf{5 . 3}$ with 4.0 equiv of $\mathrm{KClO}_{4}$, (c) $\mathbf{5 . 3}$ with 4.0 equiv of $\mathrm{CsClO}_{4}$, (d) $\mathbf{5 . 3}$ with 4.0 equiv of $\mathrm{CsF}$, (e) $\mathbf{5 . 3}$ with 4.0 equiv of $\mathrm{KNO}_{3}$, and (f) $\mathbf{5 . 3}$ with 4.0 equiv of $\mathrm{CsNO}_{3}$ in $\mathrm{CD}_{3} \mathrm{OD} / \mathrm{CDCl}_{3}(1: 9, \mathrm{v} / \mathrm{v})$ 
Figure 5.7: Partial ${ }^{1} \mathrm{H}$ NMR spectra of (a) 5.3 only, (b) $\mathbf{5 . 3}$ with 4.0 equiv of $\mathrm{KClO}_{4}$, (c) 5.3 with 4.0 equiv of $\mathrm{CsClO}_{4}$, (d) $\mathbf{5 . 3}$ with 4.0 equiv of $\mathrm{CsF}$, (e) $\mathbf{5 . 3}$ with 4.0 equiv of $\mathrm{KNO}_{3}$, and (f) $\mathbf{5 . 3}$ with 4.0 equiv of $\mathrm{CsNO}_{3}$ in $\mathrm{CD}_{3} \mathrm{OD} / \mathrm{CDCl}_{3}(1: 9, \mathrm{v} / \mathrm{v})$ 174

Figure 5.8: Proposed binding interactions involving 5.3 and various $\mathrm{K}^{+}, \mathrm{Cs}^{+}$and $\mathrm{F}^{-}$ salts in $\mathrm{CD}_{3} \mathrm{OD} / \mathrm{CDCl}_{3}(1 / 9, \mathrm{v} / \mathrm{v})$ 175

Figure 5.9: Partial ${ }^{1} \mathrm{H}$ NMR spectra of (a) $\mathbf{5 . 3}$ only, (b) $\mathbf{5 . 3}+1.0$ equiv of $\mathrm{KClO}_{4}$, and (c) $\mathbf{5 . 3}+4.0$ equiv of $\mathrm{KClO}_{4}$ in $\mathrm{CD}_{3} \mathrm{OD} / \mathrm{CDCl}_{3}(1: 9, \mathrm{v} / \mathrm{v}) \ldots . .176$

Figure 5.10: Proposed binding interactions involving 5.3 and various $\mathrm{K}^{+}$and $\mathrm{Cs}^{+}$ion pairs in $\mathrm{CD}_{3} \mathrm{OD} / \mathrm{CDCl}_{3}(1 / 9, \mathrm{v} / \mathrm{v})$ 178

Figure 5.11: Partial ${ }^{1} \mathrm{H}$ NMR spectra recorded during the titration of receptor 5.3 with $\mathrm{CsF}$ in $\mathrm{CD}_{3} \mathrm{OD} / \mathrm{CDCl}_{3}(1: 9, \mathrm{v} / \mathrm{v})$.

Figure 5.12: Putative binding modes of 5.3 with various $\mathrm{K}^{+}$and $\mathrm{Cs}^{+}$salts in $\mathrm{CD}_{3} \mathrm{OD} / \mathrm{CDCl}_{3}(1 / 9, \mathrm{v} / \mathrm{v})$ 180

Figure 5.13: ITC plots showing the titrations of receptor $5.3(0.19 \mathrm{mM})$ with CsF $(2.95 \mathrm{mM})$ 181

Figure 5.14: Partial ${ }^{1} \mathrm{H}$ NMR spectra of (a) $\mathbf{5 . 3}$ only, (b) $\mathbf{5 . 3}+1.0$ equiv of KF, and (c) $\mathbf{5 . 3}+2.0$ equiv of $\mathrm{KF}$ in $\mathrm{CD}_{3} \mathrm{OD} / \mathrm{CDCl}_{3}(1: 9, \mathrm{v} / \mathrm{v})$ 182

Figure 5.15: Two different binding modes of $\mathbf{5 . 3}$ towards the $\mathrm{CsNO}_{3}$ ion pair and partial ${ }^{1} \mathrm{H}$ NMR spectra of (a) $\mathbf{5 . 3}$ only, (b) $\mathbf{5 . 3}+4.0$ equiv of $\mathrm{CsCl}$, and (c) $\mathbf{5 . 3}+4.0$ equiv of $\mathrm{CsNO}_{3}$ in $\mathrm{CD}_{3} \mathrm{OD} / \mathrm{CDCl}_{3}(1: 9, \mathrm{v} / \mathrm{v})$ 184

Figure 5.16: Phase change via cation switching between the $\mathrm{Cs}^{+}$and the $\mathrm{K}^{+}$cation in $\mathrm{CD}_{3} \mathrm{OD} / \mathrm{CDCl}_{3}(1 / 9, \mathrm{v} / \mathrm{v})$ 186 
Figure 5.17: Two different views of the single crystal structure of $5.3 \cdot \mathrm{KF} \cdot \mathrm{CH}_{3} \mathrm{OH}$. Solvent molecules not involved in the ion pair complex have been removed for clarity 187

Figure 5.18: Two different views of the single crystal structure of $\mathbf{5 . 3} \cdot \mathrm{KNO}_{3} \cdot \mathrm{H}_{2} \mathrm{O}$. Solvent molecules not involved in the ion pair complex have been removed for clarity

Figure 5.19: Schematic representation of extraction and recovery of $\mathrm{CsNO}_{3}$ using the ion pair receptor 5.3, including the proposed recycling process.....189

Figure 5.20: Partial ${ }^{1} \mathrm{H}$ NMR spectra of nitrobenzene solutions of $\mathbf{5 . 3}$ (a) after washed with water, (b) after extracted with aqueous $\mathrm{KNO}_{3}$ solution (5 equiv), (c) after extraction with aqueous $\mathrm{CsNO}_{3}$ solution (5 equiv), (d) after the nitrobenzene phase obtained from (c) was washed with water and then with aqueous $\mathrm{KClO}_{4}$ solution (5 equiv), and (e) after the organic phase obtained from (d) was washed with water and chloroform. 190

Figure 5.21: Partial ${ }^{1} \mathrm{H}$ NMR spectra of nitrobenzene solutions of 5.3 after extracted with (a) an ion-free aqueous solution, (b) an aqueous $\mathrm{NaNO}_{3}$ solution (5 equiv), (c) an aqueous $\mathrm{KNO}_{3}$ solution (5 equiv), and (d) an aqueous $\mathrm{KCl}$ solution (5 equiv)

Figure 5.22: Partial ${ }^{1} \mathrm{H}$ NMR spectra of nitrobenzene solutions of $\mathbf{5 . 2}$ after extracted with (a) an ion-free aqueous solution, (b) an aqueous $\mathrm{KNO}_{3}$ solution (5 equiv), and (c) an aqueous $\mathrm{CsNO}_{3}$ solution (5 equiv) 192

Figure 5.23: ${ }^{133} \mathrm{Cs}$ NMR of the water $\left(\mathrm{D}_{2} \mathrm{O}\right)$ phase after the $\mathbf{5 . 3} \cdot \mathrm{CsNO}_{3}$ in nitrobenzene was extracted with aqueous $\mathrm{KClO}_{4}$ solution. $1 \mathrm{M}$ solution of $\mathrm{CsNO}_{3}$ in $\mathrm{D}_{2} \mathrm{O}$ was used as a reference 193 
Figure 5.24: Partial ${ }^{1} \mathrm{H}$ NMR spectra of nitrobenzene solutions of $\mathbf{5 . 3}$ after extracted with (a) an ion-free aqueous solution, (b) an aqueous $\mathrm{CsF}$ solution (5 equiv), (c) an aqueous $\mathrm{CsCl}$ solution (5 equiv), (d) an aqueous $\mathrm{KF}$ solution (5 equiv) and (e) an aqueous $\mathrm{KCl}$ solution (5 equiv) ........195

Figure 5.25: Two different views of the single crystal structure of $5.3 \cdot \mathrm{CsF}^{\cdot} \mathrm{CH}_{3} \mathrm{OH}$. Solvent molecules not involved in the ion pair complex have been removed for clarity 197

Figure 5.26: Binding modes of CsF ion pairs by receptors 5.1 - 5.3 and distances between the $\mathrm{Cs}^{+}$and $\mathrm{F}^{-}$ions seen in the complexes as determined by $\mathrm{X}$ ray diffraction analysis. The structures of the CsF complexes of $\mathbf{5 . 1}$ and 5.2 were reported in references 11 and 13, respectively. 198

Figure 5.27: Two different views of the single crystal structure of $5.3 \cdot \mathrm{CsCl} \cdot \mathrm{H}_{2} \mathrm{O}$. Solvent molecules not involved in the ion pair complex have been removed for clarity. 199

Figure 5.28: Two different views of the single crystal structure of 5.3. $\mathrm{CsNO}_{3} \cdot \mathrm{CH}_{3} \mathrm{CH}_{2} \mathrm{OH}$. Solvent molecules not involved in the ion pair complex have been removed for clarity. 200

Figure A.1: View of the complex in $\mathbf{2 . 2}$ showing the atom labeling scheme. Displacement ellipsoids are scaled to the $30 \%$ probability level. Most hydrogen atoms have been removed for clarity. The macrocycle lies on a crystallographic inversion center at $1 / 2,1 / 2,1 / 2$. Atoms with labels appended by a' are related by 1-x, 1-y, 1-z. Dashed lines are indicative of H-bonding interactions. The geometry of these interactions is: N1a-

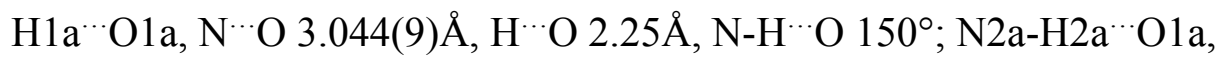
$\mathrm{N}^{\cdots} \mathrm{O}$ O 3.062(7) $\AA, \mathrm{H}^{\cdots \cdots} \mathrm{O} 2.27 \AA, \mathrm{N}-\mathrm{H}^{\cdots} \mathrm{O} 150^{\circ}$ .220 xxvi 
Figure A.2: Unit cell packing diagram for $\mathbf{2 . 2} \cdot\left(\mathrm{CH}_{3} \mathrm{OH}\right)_{2}$. The view is approximately down the a axis 221

Figure A.3: View of the macrocycle in $\mathbf{2 . 2}$ showing the atom labeling scheme. Displacement ellipsoids are scaled to the $50 \%$ probability level. The macrocycle lies on a crystallographic inversion center at $1 / 2,1 / 2,1 / 2$. Atoms with labels appended by a ' are related by 1-x, 1-y, 1-z. Two DMF molecules bound to the calix[4]pyrrole are omitted for clarity ......224

Figure A.4: View of the macrocycle chloride complex in $\mathbf{2 . 2} \cdot \mathrm{Cl}^{-}$showing the atom labeling scheme. Displacement ellipsoids are scaled to the $30 \%$ probability level. The methyl hydrogen atoms have been removed for clarity. The macrocycle lies around a crystallographic 4-fold rotation axis at $1 / 2,1 / 2, \mathrm{z}$. Dashed lines are indicative of $\mathrm{H}$-bonding interactions with geometry: N1-H1a ${ }^{\cdots} \mathrm{Cl} 11, \mathrm{~N}{ }^{\cdots} \mathrm{Cl}$ 3.372(5) $\AA, \mathrm{H}^{\cdots}{ }^{\cdots} \mathrm{Cl} 2.55 \AA, \mathrm{N}-\mathrm{H}{ }^{\cdots} \mathrm{Cl}$ $155^{\circ}$ .227

Figure A.5: View of the Cs complex in 3.1 showing a partial atom labeling scheme. Displacement ellipsoids are scaled to the $30 \%$ probability level. The hydrogen atoms have been removed for clarity. The higher occupancy atoms of the disordered ether link are shown .230 
Figure A.6: View of $\mathbf{4 . 2} \cdot\left(\mathrm{CH}_{3} \mathrm{OH}\right)_{2}$ showing the atom labeling scheme.

Displacement ellipsoids are scaled to the $30 \%$ probability level. Most hydrogen atoms have been removed for clarity.Dashed lines are indicative of $\mathrm{H}$-bonding interactions. The geometry of these interactions

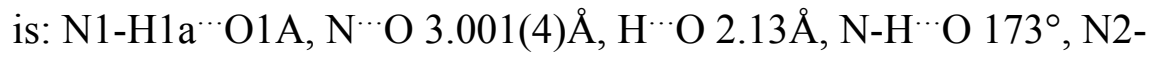

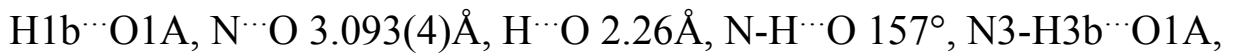

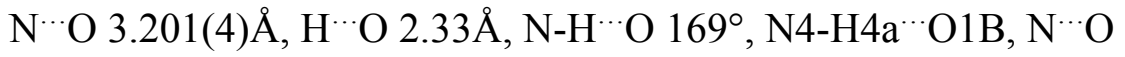

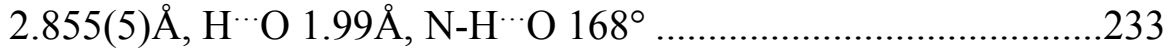

Figure A.7: Unit cell packing diagram for $\mathbf{4 . 2} \cdot\left(\mathrm{CH}_{3} \mathrm{OH}\right)_{2}$. The view is approximately down the a axis .234

Figure A.8: View illustrating the H-bonding interaction between the anions and the calixpyrrole $\mathrm{Cs}^{+}$complex in 4.2. Displacement ellipsoids are scaled to the $50 \%$ probability level. Most hydrogen atoms have been removed for clarity .237

Figure A.9: View of 5.3. $\mathrm{CH}_{3} \mathrm{CN}$ showing a partial atom labeling scheme. Displacement ellipsoids are scaled to the $50 \%$ probability level....240

Figure A.10: View of $\mathbf{5 . 3} \cdot \mathbf{K F} \bullet\left(\mathbf{C H}_{3} \mathbf{O H}\right)$ showing the atom labeling scheme. Displacement ellipsoids are scaled to the $30 \%$ probability level. The hydrogen atoms have been omitted for clarity) .243

Figure A.11: View of $\mathbf{5 . 3} \mathrm{K}^{+}$showing the atom labeling scheme. Displacement ellipsoids are scaled to the $50 \%$ probability level. 246

Figure A.12: View of 5.3. $\mathrm{CsF} \cdot\left(\mathrm{CH}_{3} \mathrm{OH}\right)_{2}$ showing the atom labeling scheme. Displacement ellipsoids are scaled to the $50 \%$ probability level. The hydrogen atoms have been removed for clarity..... .249 
Figure A.13: View of the $\mathrm{CsCl}$ complex in $\mathbf{5 . 3}$ showing a partial atom labeling scheme. Displacement ellipsoids are scaled to the $50 \%$ probability level. Most hydrogen atoms have been removed for clarity.....................253

Figure A14: View of the $\mathrm{CsNO}_{3}$ complex in $\mathbf{5 . 3}$ showing the atom labeling scheme. Displacement ellipsoids are scaled to the $30 \%$ probability level. The hydrogen atoms were removed for clarity. The disordered ethanol

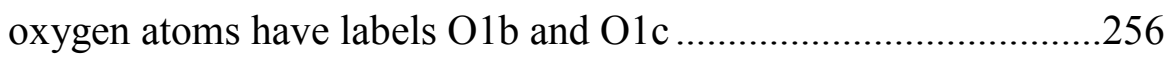




\section{List of Schemes}

Scheme 2.1: $\quad$ Synthesis of compound 2.2 …........................................... 88

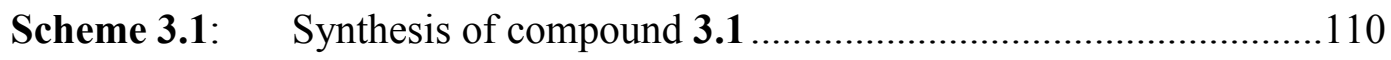

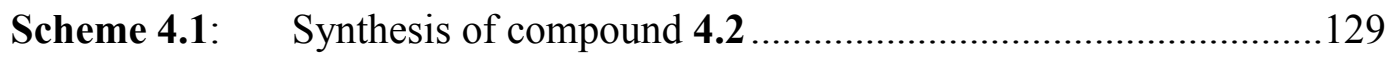

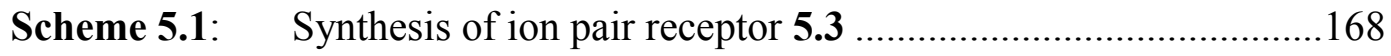




\section{Chapter 1: General introduction to ion pair receptors}

\subsection{INTRODUCTION}

Over the past several decades, a large number of acyclic and macrocyclic compounds have been synthesized as cation receptors and evaluated for their abilities to recognize cations. ${ }^{1-3}$ In recent years, as the importance of anions in biological and environmental systems has become increasingly recognized, attention has been directed towards the design and construction of anion receptors. As a consequence, both cation and anion recognition are now well-established branches of supramolecular chemistry. ${ }^{4-11}$ From this body of work it has become increasingly apparent that counterions can play a critical role in modulating the binding strength and selectivity of what appears to be the simplest of ion receptors. This appreciation has, in turn, led to the consideration that more elaborate systems, capable of forming simultaneously complexes with both a cation and an anion, might offer considerable advantages in terms of affinity or selectivity. ${ }^{12-14}$ These so-called pair receptors might also permit a greater level of control over ion recognition, extraction and through-membrane transport than simple ion receptors. In fact, in many cases, ion pair receptors containing binding sites for both cations and anions display affinities for ion pairs or their constituent pairs of ions that are enhanced relative to simple ion receptors. Often this is the result of allosteric effects, such as those derived from favorable electrostatic interactions between the co-bound ions. ${ }^{12-14}$ However, in spite of their potential applications in various fields, such as salt solubilization, extraction, and membrane transport, the number of well-characterized ion pair receptors remains limited. This could reflect a combination of synthetic challenges (the systems reported to date have not been easy to prepare) and experimental complexities associated with tracking multiple ionic species as well as the high inherent lability of many ion 
pairs. ${ }^{12-14}$ Nevertheless, the potential importance of the field leads us to propose that the area could benefit from additional contributions. Before turning to the candiate's work along these lines, it is appropriate to review the prior literature. This is done here with an emphasis on the underlying binding phenomena.

To effect anion recognition, most ion pair receptors take advantage of hydrogen bonding donors (urea, amide, imidazolium, pyrrole, and hydroxyl group), Lewis acidic sites (boron, aluminum and uranyl), and positively charged polyammonium groups. ${ }^{4-11}$ In contrast, the majority of ion pair receptors rely on lone pair electron donors including crown ethers ${ }^{15}$ and $\pi$-electron donors, such as functionalized calixarenes, for cation recognition. $^{16,17}$

For ion receptors for either cations or anions, their binding constants have been reported to vary significantly, especially in low dielectric constant media, depending on receptor concentration, ionic guest and its counterion concentrations, and nature of ions because interactions between receptors or/and between guests often make a remarkable influence on the formation of host/guest complexes. ${ }^{18-20}$ However, this disadvantage can be somewhat overcome by decreasing the concentration of free counter ions as a result of complexing both cations and anions simultaneously using ditopic receptors or molecularly separated binary host systems. This is attributable to the fact that the bound ion pairs are protected better from the forced interaction with other free ion pairs which have been known to make an adverse effect on complexation between receptors and ions.

In the limit, ion pair receptors can be classified as binding ion pairs in either a sequential or concurrent fashion. In the case of sequential binding, the receptor can bind one ion of the ion pair on its own. Once bound, this first ion enhances the affinity for the other ion of the ion pair through an allosteric effect or by providing an additional binding driving force, commonly a direct or solvent-mediated electrostatic interaction with its 
counter ion. ${ }^{12-14}$ By contrast, in the case of concurrent ion pair binding, the receptor literally forms a simultaneous complex with the anion and cation of the ion pair. Typically, this results in a complex where the two ions of the ion pair are in direct contact or spatially separated via one or more molecules of solvent or by the receptor skeleton. ${ }^{12-}$ 14

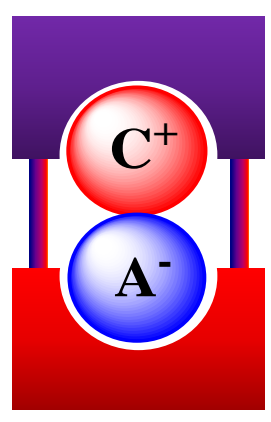

(a)

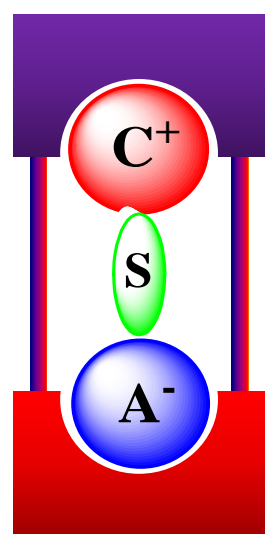

(b)

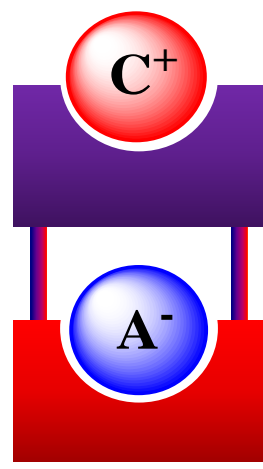

(c)

Figure 1.1 Limiting ion-pair interactions relevant to receptor-mediated ion-pair recognition: (a) Contact, (b) solvent-bridged, and (c) host-separated. In this schematic, the anion is shown as "A-", the cation as "C+", and the solvent if present as " $\mathrm{S}$ ".

Another way of classifying ion pair receptors is by how they bind the cations and the anions of targeted ion pairs. Here, three different binding modes can be defined. These limiting modes are depicted in Figure 1.1 and differ in how the ion pair is held within a host molecule. The first involves a contact ion pair, wherein the anion and the cation are in a direct contact (Figure 1.1a); the second, termed a solvent-bridged ion pair, is where one or more solvent molecules bridges the gap between the anion and the cobound cation (Figure 1.1b), while the third consists of a host-separated ion pair, wherein the anion and the cation are bound relatively far from one another, usually by the receptor framework (Figure 1.1c). ${ }^{12-14}$ Depending on the identities of co-bound ions, the separation distance between ion pairs, the nature of the constituent recognition sites, and 
the nature of the solvents, a given receptor can bind a given ion pair in one or more of these limiting modes.

\subsection{ION PAIR RECEPTORS BASED ON LEWIS ACIDIC GROUPS FOR ANION RECOGNITION}

One of the earliest examples of an ion pair receptor was reported by Reetz and coworkers in 1991. In this system, 1.1, a crown ether moiety introduced for cation recognition was coupled to a Lewis-acidic boron center for anion recognition to provide

compound 1.1 (Figure 1.2). ${ }^{21}$ It was demonstrated by ${ }^{11} \mathrm{~B}$ and ${ }^{13} \mathrm{C}$ NMR spectroscopy that, in contrast to simple ion receptors, such as a crown ether analogue without the boronic center and an arylboroic acid ester without the crown ether, receptor $\mathbf{1 . 1}$ forms a 1:1 complex with $\mathrm{KF}$ where the $\mathrm{K}^{+}$cation is bound within the crown ether and the $\mathrm{F}^{-}$ anion is covalently bound to the boronic center. One consequence is that this receptor allows the otherwise insoluble salt, KF, to dissolve in dichloromethane within $4 \mathrm{hrs}$. The crystal structure of the KF complex of receptor $\mathbf{1 . 1}$ was solved via standard X-ray diffraction means. It reveals that the $\mathrm{K}^{+}$ion is bound to the crown ether but interacts with an $\mathrm{F}^{-}$anion bound to a neighboring ion pair receptor. As the result of this close intermolecular ion pair contact, a supramolecular polymer is stabilized in the solid state. This same research group also reported in 1994 that ion pair receptor 1.2 (Figure 1.2), consisting of an aluminum phenolate moiety surrounded by a crown ether, is able to bind $\mathrm{LiCl}$ as an ion pair simultaneously via interactions with the Lewis acidic aluminum moiety and the crown ether ring. Ion pair binding was seen both in solution and in the solid state. $^{22}$ 


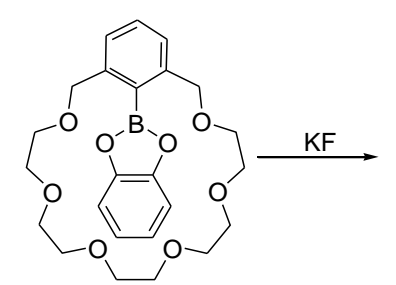

1.1

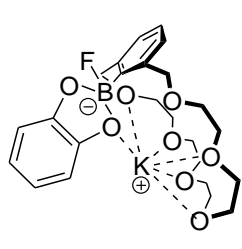

$1.1 \cdot \mathrm{KF}$

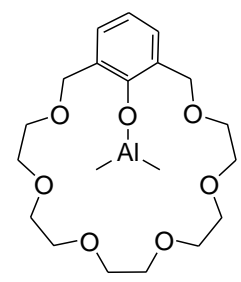

1.22

Figure 1.2 Structures of 1.1, 1.1 KF and 1.2.

Reinhoudt and co-workers reported the synthesis and the ion pair binding property of receptor $\mathbf{1 . 3}$ (Figure 1.3) in $1994 .^{23}$ This system contains a Lewis-acidic uranyl $\left(\mathrm{UO}_{2}{ }^{2+}\right)$ center covalently linked to two benzo[15]crown-5 units. Cyclic voltammetry and FAB-mass spectrometrometric analysis revealed that receptor $\mathbf{1 . 3}$ can complex $\mathrm{K}^{+}$and $\mathrm{H}_{2} \mathrm{PO}_{4}{ }^{-}$concurrently. ${ }^{23}$ In the resulting complex, the $\mathrm{K}^{+}$cation is sandwich-complexed by the two crown ether rings, while the phosphate anion interacts with the Lewis-acidic uranyl group. This team also reported ion pair receptor $\mathbf{1 . 4}$ in 1994. This latter system employs a calix[4]arene tetraethylester subunit as a cation recognition site, a subunit that is known to bind the $\mathrm{Na}^{+}$cation selectively and strongly. In accord with design expectations, this system was reported to capture $\mathrm{Na}^{+}$and $\mathrm{H}_{2} \mathrm{PO}_{4}{ }^{-}$ concurrently and to do so with a 1:1 (1.4: $\left.\mathrm{NaH}_{2} \mathrm{PO}_{4}\right)$ stoichiometry. ${ }^{24}$ Reinhoudt and coworkers also replaced the benzo[15]crown-5 of receptor 1.3 with a calix[4]crown-6, a moiety known to complex the $\mathrm{Cs}^{+}$cation well. This gave receptor $\mathbf{1 . 5} .^{25}$ Once in hand, the ability of $\mathbf{1 . 5}$ to transport $\mathrm{CsCl}$ and $\mathrm{CsNO}_{3}$ through a supported liquid membrane (SLM) was assessed. This SLM contained a porous polymeric support (Accurel) impregnated with $o$-nitrophenyl $n$-octyl ether (NPOE) as the hydrophobic barrier. Although the $\mathrm{Cl}^{-}$ 
anion is more hydrophilic than $\mathrm{NO}_{3}^{-}$, a higher rate of flux was observed through the hydrophobic membrane for $\mathrm{CsCl}\left(1.20 \times 10^{-7} \mathrm{~mol} \mathrm{~m}^{-2} \mathrm{~s}^{-1}\right)$ than for $\mathrm{CsNO}_{3}\left(0.89 \times 10^{-7}\right.$ mol m $\mathrm{m}^{-2} \mathrm{~s}^{-1}$ ) in the presence of $1.5 .{ }^{25}$ On the other hand, when monofunctional analogues of 1.5, control systems lacking the uranyl-salophen complex subunit, were used, selectivity for $\mathrm{CsNO}_{3}$ over $\mathrm{CsCl}$ was seen. This observation was considered consistent with the proposal that both binding sites are necessary to achieve efficient complexation and transport of $\mathrm{CsCl}^{25}$
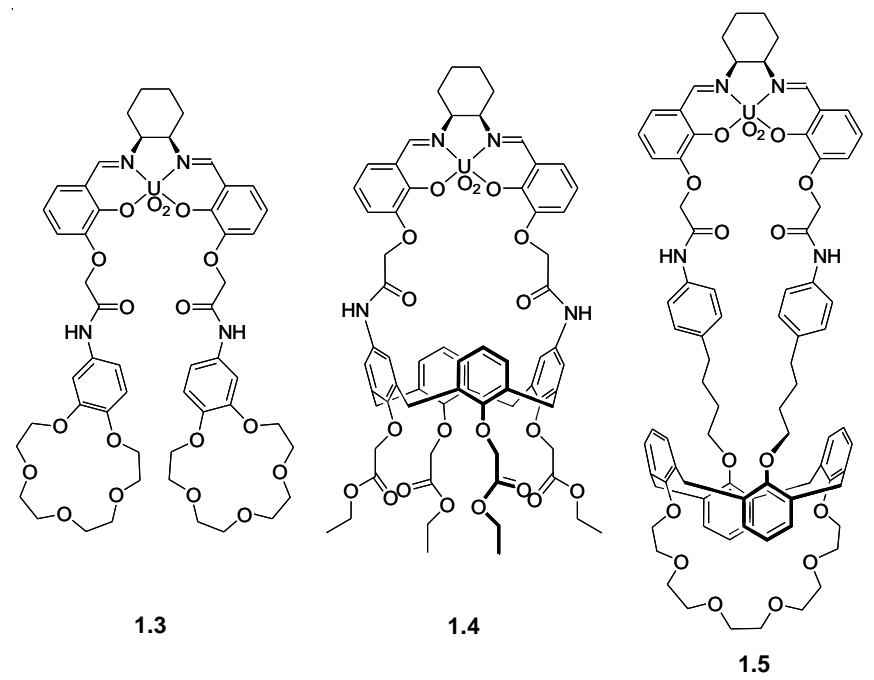

Figure 1.3 Ion pair receptors 1.3-1.5.

In 2003, Rissanen et al. described that uranyl-salophen complexes $\mathbf{1 . 7}$ and $\mathbf{1 . 8}$ (Figure 1.4), receptors bearing appended aromatic groups, behave as ion pair receptors for tetraalkylammonium halide salts. ${ }^{26}$ Compared with the control receptor 1.9 lacking aromatic side arms, receptors $\mathbf{1 . 7}$ and $\mathbf{1 . 8}$ were found to bind tetramethylammonium chloride and tetrabutylammonium chloride with improved efficiency. Evidence for 
binding came from ${ }^{1} \mathrm{H}$ NMR spectroscopic studies, as well as from an X-ray crystal structure. These analyses provided support for a stabilizing cation- $\pi$ interation between the tetramethylammonium cations and the appended aromatic rings. Evidence of Lewis acid-anion (chloride) interactions were also seen. ${ }^{26}$

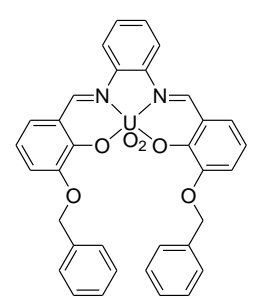

1.7

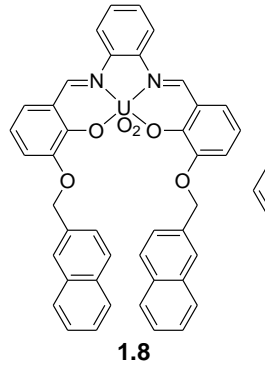

1.8

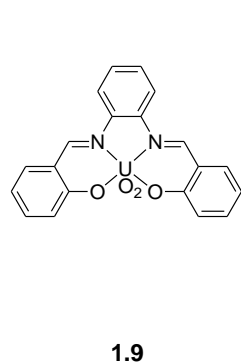

1.9

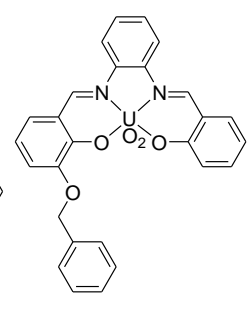

1.10

Figure 1.4 Uranyl-salophen based ion pair receptors.

Interestingly, unlike 1.9, ion pair receptor 1.7 was found to form complexes with alkaline halide salts. These complexes consist of contact ion pairs wherein the halide anions are bound to the uranyl center and directly interact with the alkaline cations that in turn are bound to the oxygen atoms and the $\pi$-electron surfaces of the benzylic groups. Solid state structural analyses revealed that $\mathrm{KCl}, \mathrm{RbCl}, \mathrm{CsF}$, and $\mathrm{CsCl}$ form capsule-like dimeric (2:2) complexes with $\mathbf{1 . 7}$, with the presence of a stabilizing $\pi$-metal interaction between the metal ions and the benzylic aromatic rings being specifically inferrred. ${ }^{27}$

Receptor 1.10, having one benzylic side arm, was also found to bind the $\mathrm{CsCl}$ ion pair but with a different binding stoichiometry. Specifically, X-ray diffraction analysis revealed that $\mathbf{1 . 1 0}$ forms a 4:2 (1.10: $\mathrm{CsCl})$ complex where four receptor molecules are assembled to provide a capsule-like arrangement. 
As a complement to the above studies, ${ }^{1} \mathrm{H}$ NMR spectroscopic titrations of 1.7-1.9 were carried out with various quaternary ammonium and iminium salts, such as acetylcholine chloride, $N$-methylpydinium iodide, and $N$-methylisoquinolinium iodide. On the basis of these studies, it was concluded that receptors $\mathbf{1 . 7}$ and $\mathbf{1 . 8}$, bearing pendant aromatic rings, bind quaternary salts much more effectively than does the control compound 1.9, which lacks a cation recognition site. Such findings provided additional support for the conclusion that the enhanced binding ability demonstrated by $\mathbf{1 . 7}$ and $\mathbf{1 . 8}$ reflects in part the stabilization provided by $\pi$-cation interactions. ${ }^{28}$

In 1995, Shinkai et al. synthesized the Lewis acidic Zn-porphyrin 1.11 strapped with calix[4] arene having a cation recognition site (Figure 1.5). ${ }^{29} \mathrm{The} \mathrm{Na}^{+}$and $\mathrm{K}^{+}$cations were found to bind to the upper amide groups thereby creating a cavity between these positively charged ions and $\mathrm{Zn}$ center of the porphyrin subunit. The $\mathrm{I}^{-}$anion was then taken up into this cavity, being bound there by a combination of hydrogen bonding interactions involving the lower amide groups and direct coordination to the Lewis acidic Zn-porphyrin center. Presumably, as the result of this latter binding interaction, a change in the color of the system is induced. Proton NMR spectroscopic analyses revealed that the $\mathrm{K}^{+}$complex of $\mathbf{1 . 1 1}$ binds the $\mathrm{I}^{-}$anion more efficiently than its $\mathrm{Na}^{+}$counterpart, a finding that is ascribable to the different electron accepting character of the $\mathrm{Na}^{+}$cation and the larger distance between the $\mathrm{Na}^{+}$cation and the $\mathrm{Zn}(\mathrm{II})$ center. ${ }^{29}$ 

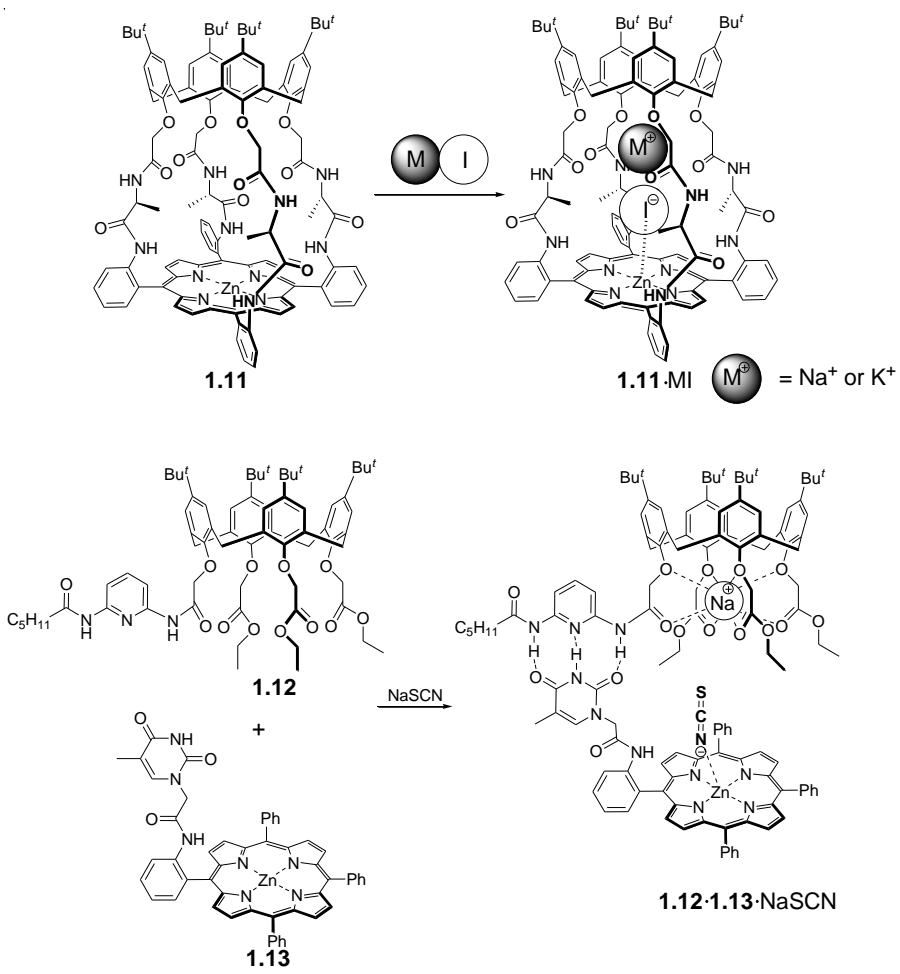

Figure 1.5 Ion pair receptors based on calix[4]arenes and Zn-porphyrins and their proposed mode of interaction with ion pairs.

In 1995 , the self-assembled ditopic receptor $\mathbf{1 . 1 2} \cdot \mathbf{1 . 1 3}$ (Figure 1.5) was synthesized by Reinhoudt and coworkers. ${ }^{30}$ This self-assembled system and its constituents were then evaluated for their ability to capture ion pairs. In the presence of the $\mathrm{Na}^{+}$cation, receptor $\mathbf{1 . 1 2}$ was found to interact with the anion receptor $\mathbf{1 . 1 3}$ to form the self-assembled system $\mathbf{1} \cdot 12 \cdot 1.13$. This complex is stabilized via hydrogen bonding interactions involving the diaminopyridine component and the thymine moiety. In the absence of an appropriate cation bound in the ethyl ester cavity, $\mathbf{1 . 1 2}$ does not interact with 1.13. Such a finding is ascribed to the fact that under these latter conditions, the diaminopyridine subunit is intramolecularly hydrogen bonded to the ester group and thus less prone to interact with the thymine group of $\mathbf{1 . 1 3}$. Complexation of the $\mathrm{Na}^{+}$cation by the ester groups of $\mathbf{1 . 1 2}$ serves to break the intramolecular hydrogen bonds and thus 
permits intermolecular self-assembly between receptors $\mathbf{1 . 1 2}$ and 1.13. The selfassembled bifunctional receptor $\mathbf{1 . 1 2} \cdot 1.13$ shows a higher affinity for the $\mathrm{SCN}^{-}$anion $\left(K_{a}\right.$ $\left.\approx 25,000 \mathrm{M}^{-1}\right)$ as compared to the isolated anion receptor $\mathbf{1 . 1 3}\left(K_{a} \approx 10 \mathrm{M}^{-1}\right) .{ }^{30}$

In 2002, Hong et al. synthesized the ditopic receptors 1.14a,b (Figure 1.6) and examined their interactions with various sodium salts. ${ }^{31}$ These systems consist of a Lewis acidic Zn-porphyrin covalently linked to a benzocrown-5 subunit. Changes in the UV/Vis spectra were used to monitor the resulting binding events. On this basis, it was concluded that both of these receptors bind $\mathrm{NaCN}$ in chloroform with high selectivity over other sodium salts. This binding of $\mathrm{NaCN}$ was accompanied by a color change from red to green as a result of the cyanide anion binding to the Lewis acidic $\mathrm{Zn}$ center. Upfield shifts were also observed for the proton signals corresponding to the crown ether moiety. These shifts were taken as evidence that the sodium cation is bound to the crown ether ring, implying that the $\mathrm{NaCN}$ is bound to receptors 1.14a,b in a ditopic fashion. More specific evidence for the strong nature of the complexation process came from two-phase extraction experiment. In notable contrast to what is seen for normal Zn-porphyrins without an appended crown ether moiety, receptors 1.14a,b were found capable of extracting $\mathrm{NaCN}$ from an aqueous phase into $\mathrm{CH}_{2} \mathrm{Cl}_{2}$, and forming kinetically stable complexes on the NMR time scale. 


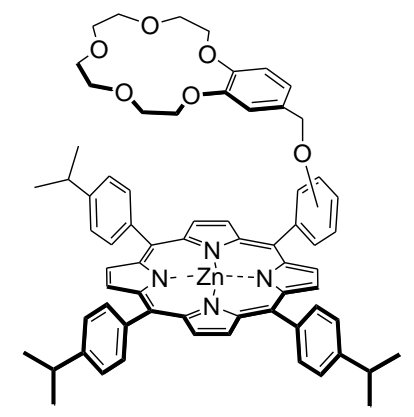

1.14a: para-derivative 1.14b: meta-derivative
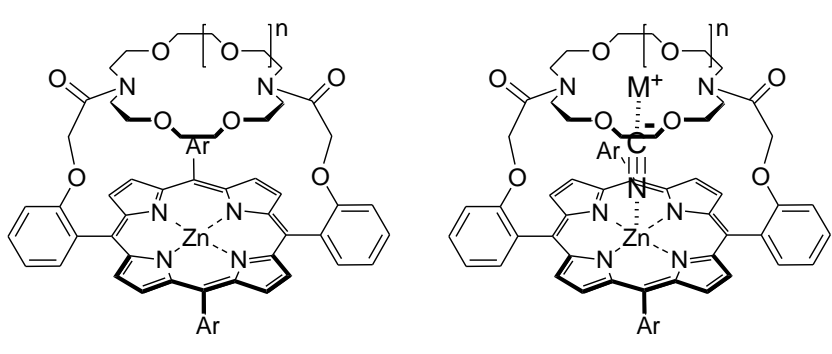

1.15a: $\mathrm{n}=0$ 1.15b: $\mathrm{n}=1$

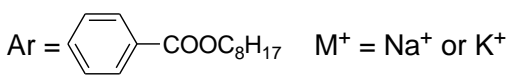

Figure 1.6 Ditopic receptors used for the recognition of sodium or potassium cyanide ion pairs and schematic representations of their proposed binding modes.

A similar approach to ditopic ion pair receptor construction was reported by Chen et al in $2005 .^{32}$ This research group prepared and then studied the diazacrown ethercapped Zn-porphyrins 1.15a,b (Figure 1.6), focusing on $\mathrm{KCN}$ and $\mathrm{NaCN}$ recognition and sensing. In this case, changes in UV/Vis and ${ }^{1} \mathrm{H}$ NMR spectrum led to the suggestion that, depending on the size of the crown ether ring, these receptors would selectively bind $\mathrm{NaCN}$ and $\mathrm{KCN}$ in a ditopic binding fashion in methanol. Specifically, it was found that receptor 1.15a binds $\mathrm{NaCN}$ about 56 times more strongly than $\mathrm{KCN}$, whereas receptor $\mathbf{1 . 1 5 b}$, a system having a bigger crown ether, is 13 times more selective for $\mathrm{KCN}$ than for $\mathrm{NaCN}$.

In 2003, Peacock and coworkers reported the water-soluble ion pair receptors 1.16 (Figure 1.7), which consists of a dibenzo-24-crown-8 subunit linked to a $\mathrm{Zn}\left(\mathrm{H}_{2} \mathrm{O}\right)$ complexed cyclen via a glycine bridge. ${ }^{33}$ Binding experiments, carried out using ${ }^{1} \mathrm{H}$ NMR spectroscopy, UV/Vis spectroscopy, and ITC (Isothermal Titration Calorimetry), revealed that receptor $\mathbf{1 . 1 6}$ binds $\mathrm{H}_{2} \mathrm{PO}_{4}{ }^{2-}$ 3-6 times more strongly than the cyclen $\mathrm{Zn}\left(\mathrm{H}_{2} \mathrm{O}\right)$ control compound 1.17. This finding provides support for the suggestion that an enhancement in the inherent affinity is obtained as the result of the ditopic binding 
mode permitted in the case of $\mathbf{1 . 1 6}$ as the result of the crown ether ring. While both sodium and potassium phosphates were bound by receptor 1.17 and with essentially identical affinities, potassium phosphate was bound by receptor $\mathbf{1 . 1 6}$ approximately twice as well as the corresponding sodium salt (cf. Table 1.1). This finding is rationalized in term of the size of the crown ether present in 1.16, which was expected to favor the $\mathrm{K}^{+}$ cation over the $\mathrm{Na}^{+}$cation. The difference in selectivity seen for $\mathbf{1 . 1 6}$ and $\mathbf{1 . 1 7}$ was taken as evidence that the crown ring and the $\mathrm{Zn}\left(\mathrm{H}_{2} \mathrm{O}\right)$-complexed cyclen moieties bind the potassium cation and the phosphate anion, respectively. It was thus concluded that compound 1.16 works as an ion pair receptor. Analogous cation-dependant results were observed for receptor 1.18 (Figure 1.7) having a smaller crown ether. ${ }^{34}$ In this case, it was found that the affinities for $\mathrm{LiH}_{2} \mathrm{PO}_{4}, \mathrm{NaH}_{2} \mathrm{PO}_{4}$, and $\mathrm{KH}_{2} \mathrm{PO}_{4}$ displayed by this twocomponent receptor were at least twice as high as those of the $\mathrm{Zn}\left(\mathrm{H}_{2} \mathrm{O}\right)$-complexed cyclen 1.17; again, this was interpreted in terms of the crown ether ring playing a critical role in recognizing these particular ion pairs. ${ }^{34}$

Table 1.1 Association constants corresponding to the interaction of receptor $\mathbf{1 . 1 6}$ and the control cyclen $\mathrm{Zn}\left(\mathrm{H}_{2} \mathrm{O}\right)$ system 1.17 with $\mathrm{NaH}_{2} \mathrm{PO}_{4}$ and $\mathrm{KH}_{2} \mathrm{PO}_{4}$ in HEPES buffer at $\mathrm{pH} 7.4$ at $\mathrm{RT}$.

\begin{tabular}{ccc}
\hline Ligand & Substrate & $\mathrm{K}\left(\mathrm{M}^{-1}\right)$ \\
\hline $\mathbf{1 . 1 6}$ & $\mathrm{NaH}_{2} \mathrm{PO}_{4}$ & $(4.93 \pm 0.72) \times 10^{4}$ \\
$\mathbf{1 . 1 7}$ & $\mathrm{KH}_{2} \mathrm{PO}_{4}$ & $(9.32 \pm 1.60) \times 10^{4}$ \\
$\mathbf{1 . 1 7}$ & $\mathrm{NaH}_{2} \mathrm{PO}_{4}$ & $(1.60 \pm 0.09) \times 10^{4}$ \\
$\mathbf{1 . 1 7}$ & $\mathrm{KH}_{2} \mathrm{PO}_{4}$ & $(1.52 \pm 0.19) \times 10^{4}$ \\
\hline
\end{tabular}




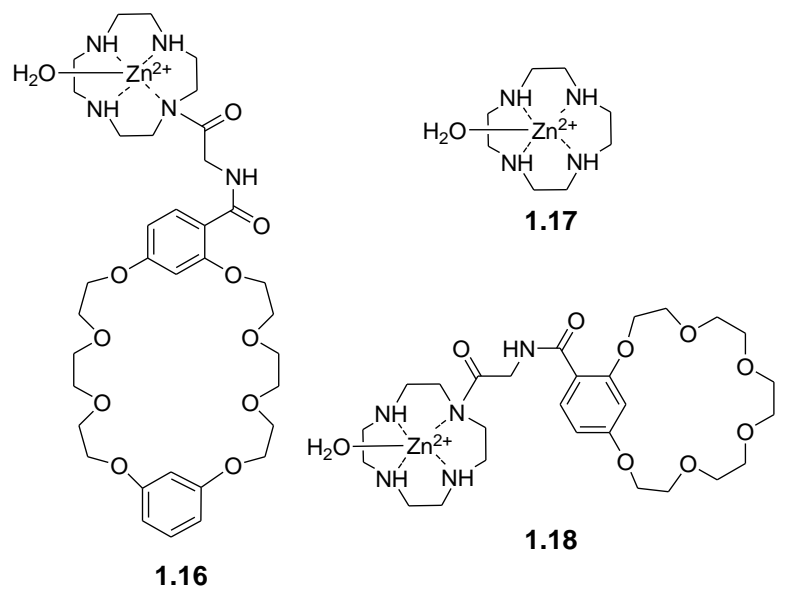

Figure 1.7 $\mathrm{Zn}\left(\mathrm{H}_{2} \mathrm{O}\right)$-complexed cyclen-based water soluble ion pair receptors used for the recognition of cyanide alkali metal salts.

In 2001, Willem and coworkers reported the synthesis of receptors 1.19a,b (Figure 1.8) comprised of a triphenyltin species linked to various sized benzocrown ethers via an ester bridge. These researchers demonstrated that these receptors were capable of complexing thiocyanate anion salts. The resulting complexes were characterized by their unusual zwitterionic nature (i.e., a degree of intramolecular charge separation), which is reflected in a relatively large distance between the $\mathrm{Na}^{+}$cation and the formally negatively charged tin center. ${ }^{35}$ A combination of ${ }^{1} \mathrm{H}$ NNR and ${ }^{117} \mathrm{Sn}$ NMR spectroscopy, as well as X-ray crystal structural analyses, established that for NaSCN and $\mathrm{KSCN}$, respectively, the $\mathrm{Na}^{+}$and $\mathrm{K}^{+}$cations are complexed by the crown ether component, whereas the $\mathrm{NCS}^{-}$anion interacts with the Sn atom (Figure 1.8). 


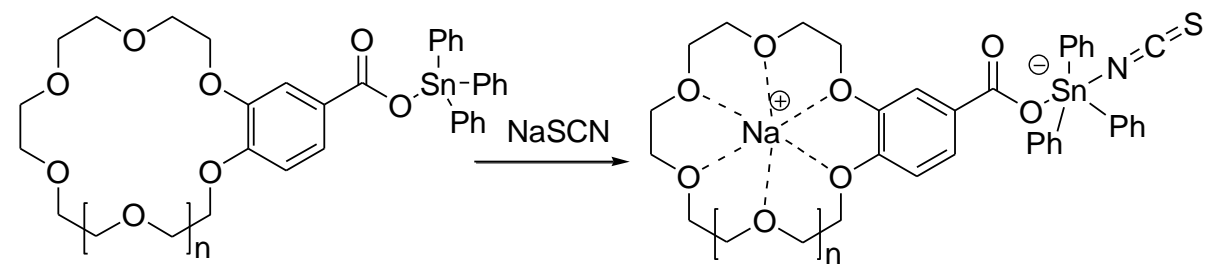

1.19a: $\mathrm{n}=0$

1.19b: $n=1$

Figure 1.8 Ion pair receptors based on a combination of a Lewis acidic tin center and a benzocrown ether. Also shown are their binding modes.

In 2007, Jurkschat et al. reported the bis(organostannyl)-methane derivative $\mathbf{1 . 2 0}$ bearing a crown ether. ${ }^{36,37}$ On the basis of ${ }^{1} \mathrm{H},{ }^{13} \mathrm{C},{ }^{19} \mathrm{~F}$, and ${ }^{119} \mathrm{Sn}$ NMR spectroscopy, as well as ESI mass spectrometry, it was proposed that receptor $\mathbf{1 . 2 0}$ binds $\mathrm{NaF}$ as an ion pair in acetonitrile, wherein the constituent ions are spatially separated by the host molecule. Presumably, as a consequence of being able to effect concurrent cation and anion binding, receptor $\mathbf{1 . 2 0}$ was found capable of dissolving solid $\mathrm{NaF}$ in acetonitrile, a solvent in which it is otherwise insoluble. On the other hand, an X-crystal structural analysis revealed that, in the presence of methanol, the $\mathrm{Na}^{+}$and $\mathrm{F}^{-}$ions bound to receptor $\mathbf{1 . 2 0}$ are bridged by a methanol molecule, thus forming a solvent-separated ion pair. ${ }^{38}$ 

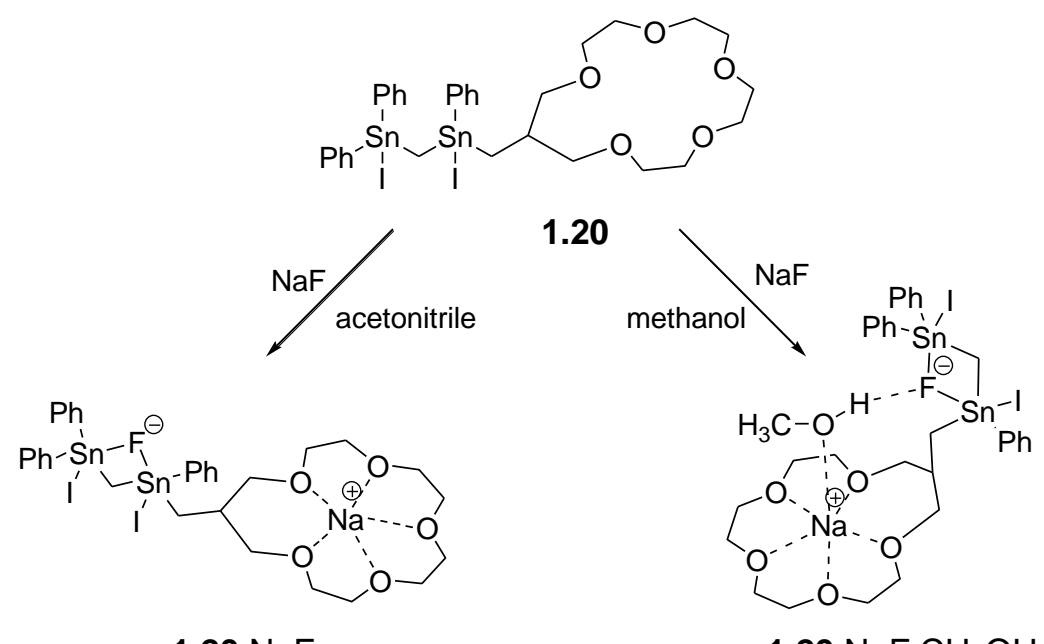

$1.20 \mathrm{NaF}$

$1.20 \mathrm{NaF} \cdot \mathrm{CH}_{3} \mathrm{OH}$

Figure 1.9 Structure of the ion pair receptor 1.20. Also shown are the proposed ditopic binding modes that are thought to pertain in acetonitrile and methanol, respectively.

\subsection{ION PAIR RECEPTORS BASED ON UREA GROUPS FOR ANION RECOGNITION}

The synthesis of the first urea-based ditopic ion pair receptors and their interactions with alkali halide salts were reported by Reinhoudt et al. in $1996 .{ }^{39}$ These researchers attached either two or four urea moieties to the upper rim of a calix[4]arene core that possessed the cation-recognizing tetra(ethyl ester) groups on the lower rim. This gave the ion pair receptors $\mathbf{1 . 2 1}$ and $\mathbf{1 . 2 2 a}, \mathbf{b}$ (Figure 1.10). In $\mathrm{CDCl}_{3}$, receptor $\mathbf{1 . 2 1}$ was found to adopt a pinched cone conformation, presumably as the result of intramolecular hydrogen bonding between the trans-like urea groups (Figure 1.11). These researchers proposed that these internal hydrogen bonds preclude anion binding to the urea moieties in the absence of $\mathrm{Na}^{+}$. However, in the presence of the $\mathrm{Na}^{+}$, cation-ester interactions at the lower rim of the calix[4]arene serve to alter the conformation of calix[4]arene, as shown in Figure 1.11. This proposed molecular motion serves to break the hydrogen bonds between the urea groups. As a result, halide ions, such as $\mathrm{Cl}^{-}$and $\mathrm{Br}^{-}$, 
are bound to the urea groups on the upper rim of the calixarene, as evidenced by downfield shift of the urea protons observed in the ${ }^{1} \mathrm{H}$ NMR spectra. Interestingly, no evidence of $\mathrm{Cs}^{+}$cation binding within the cavity was seen. Likely, this reflects the fact that the $\mathrm{Cs}^{+}$ion is too big to fit in the cavity. It was also shown via ${ }^{1} \mathrm{H}$ NMR spectroscopic analysis that receptors $\mathbf{1 . 2 2 a}, \mathbf{b}$, as well as $\mathbf{1 . 2 1}$, are able to extract certain solid sodium halide salts into chloroform solution with several potassium halide salts being partially solubilized (Table 1.2). Such findings are in agreement with the higher affinity displayed by the calix[4]arene tetra(ethyl ester) derivatives towards the $\mathrm{Na}^{+}$ cation than the $\mathrm{K}^{+}$cation. ${ }^{36}$ The binding mechanism proposed in the case of $\mathrm{NaCl}$ and $\mathrm{NaBr}$ is conceptually similar to the allosteric action of enzymes and biological receptors, wherein the binding of one ion induces a major conformational change in the receptor such that the affinity to the counter-ion is significantly improved.

Table 1.2 Percentage of MX complex formed with 1.21 and 1.22a,b after liquid-solid extraction using chloroform as the organic phase.

\begin{tabular}{cccccccccc}
\hline & & $\mathbf{1 . 2 1}$ & & \multicolumn{3}{c|}{$\mathbf{1 . 2 2 a}$} & \multicolumn{1}{c|}{$\mathbf{1 . 2 2 b}$} & \\
& $\mathrm{Na}^{+}$ & $\mathrm{K}^{+}$ & $\mathrm{Cs}^{+}$ & $\mathrm{Na}^{+}$ & $\mathrm{K}^{+}$ & $\mathrm{Cs}^{+}$ & $\mathrm{Na}^{+}$ & $\mathrm{K}^{+}$ & $\mathrm{Cs}^{+}$ \\
\hline $\mathrm{Cl}^{-}$ & 100 & - & - & 100 & 29 & - & 100 & 30 & - \\
$\mathrm{Br}^{-}$ & 100 & 16 & - & 100 & 62 & - & 100 & 75 & - \\
$\mathrm{I}^{-}$ & 100 & 100 & - & 100 & 100 & - & 100 & 100 & - \\
\hline
\end{tabular}




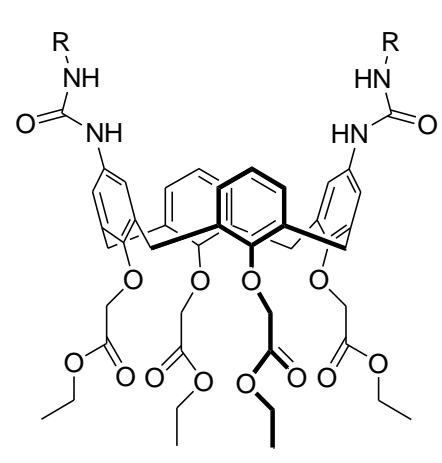

1.21: $\mathrm{R}=n$-octyl

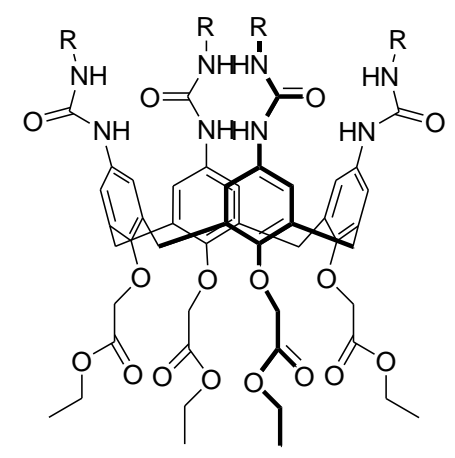

1.22a: $R=n$-octyl

1.22b: $R=$ tert-butyl

Figure 1.10 Structures of ion pair receptors 1.21 and $1.22 a, b$.

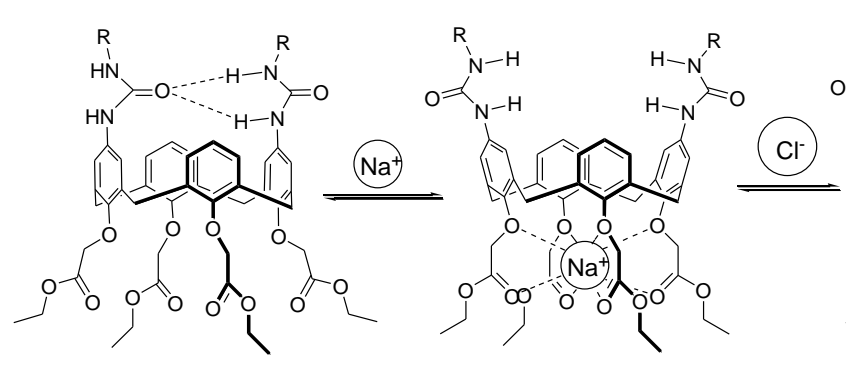

1.21

$1.21 \cdot \mathrm{Na}^{+}$

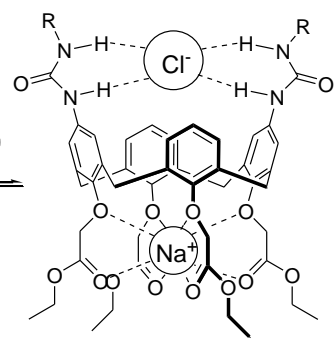

$1.21 \cdot \mathrm{NaCl}$

Figure 1.11 Proposed ion-induced molecular motions and associated binding modes for receptor 1.21 thought to pertain in the presence of $\mathrm{NaCl}$.

Reinhoudt and coworkers also investigated the ability of i) cation receptors $\mathbf{1 . 2 3 a}, \mathbf{b}$, ii) a mixture of $\mathbf{1 . 2 3}$ with $\mathbf{1 . 2 4}$, and iii) ditopic receptors $\mathbf{1 . 2 5 a}, \mathbf{b}$ to transport salts through SLMs (Figure 1.12). ${ }^{40}$ On this basis, they concluded that the mixture of 1.23a and 1.24 transports $\mathrm{CsCl}$ more efficiently than the corresponding mono-functional calix[4]crown-6 analogue 1.24 does on its alone. Moreover, ditopic receptors 1.25a and 1.25b proved capable of transporting $\mathrm{KCl}$ and $\mathrm{CsCl}$, respectively. Presumably, this reflects the fact that these receptors can form complexes with both the constituent cations 
and anions concurrently. It was also noted that receptor $1.25 \mathrm{~b}$ transports $\mathrm{CsCl}$ much more efficiently than the cation carrier 1.23b or the anion carrier 1.24. By contrast, at higher concentrations of $\mathrm{KCl}$, 1.25a is less effective for transporting $\mathrm{KCl}$ than is the monofunctional cation carrier 1.23a. This finding was attributed to the very low rate of diffusion of the bifunctional carrier complex. ${ }^{40}$

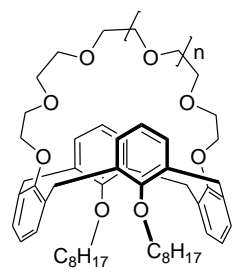

1.23a: $\mathrm{n}=0$ 1.23b: $n=1$

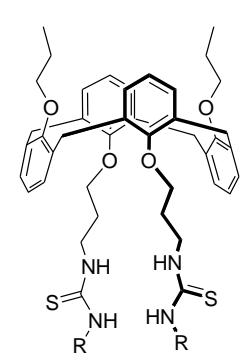

1.24

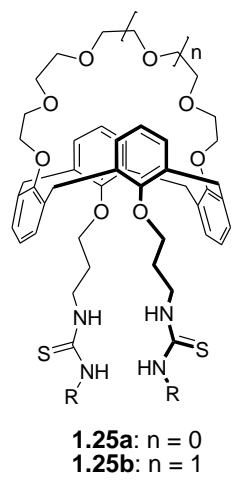

Figure 1.12 Cation, anion and ditopic carriers for cation and anion transport.

In 2002, a similar synthetic strategy was applied by Nam and coworkers and used to synthesize the ion pair receptor $\mathbf{1 . 2 6}$ (Figure 1.13). ${ }^{41}$ This system is based on a 1,3alternate calix[4]arene skeleton strapped by a crown-5 subunit, a moiety that is known to form very strong and very selective complexes with the $\mathrm{K}^{+}$cation. To permit anion recognition, two urea moieties were introduced onto the calix[4]arene framework. In the presence of 1.0 molar equiv. of $\mathrm{KClO}_{4}$, the association constants $\left(K_{a}\right)$ of $\mathbf{1 . 2 6}$ for $\mathrm{Cl}^{-}$ $\left(5,420 \mathrm{M}^{-1}\right), \mathrm{Br}^{-}\left(1,550 \mathrm{M}^{-1}\right)$, and $\mathrm{I}^{-}\left(808 \mathrm{M}^{-1}\right)$ were recorded to be 3.9-5.8 times larger than those measured in its absence. A year later, it was reported that receptor 1.27, which possesses a strong and selective binding site for the $\mathrm{Na}^{+}$cation, binds the $\mathrm{Cl}^{-}$and the $\mathrm{Br}^{-}$ anions 7.1 and 20 times more effectively, respectively, in the presence of the $\mathrm{Na}^{+}$cation than it does in the absence of a crown-bound cation. ${ }^{42}$ 


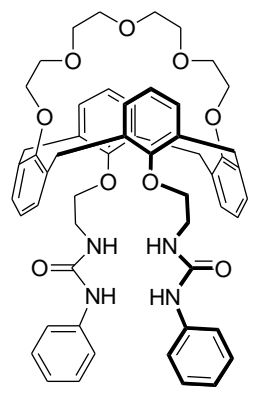

1.26

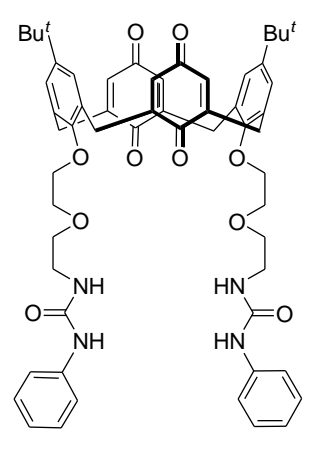

1.27

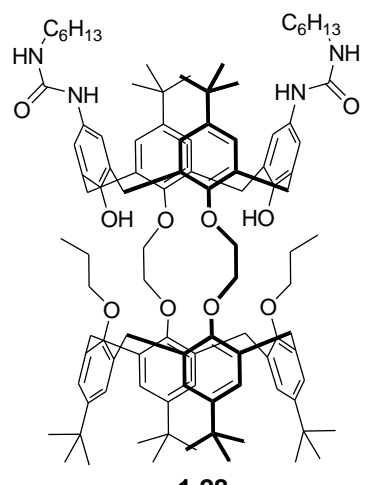

1.28

Figure 1.13 Calix[4] arene and urea based ion pair receptors 1.26-1.28.

In 2003, Webber and Beer reported the calix[4]arene-based ion pair receptor 1.28, a system that consists of a calix[4]semitube for cation binding and two urea groups for anion recognition. ${ }^{43}$ On the basis of ${ }^{1} \mathrm{H}$ NMR spectroscopic studies, receptor $\mathbf{1 . 2 8}$ was found to bind a range of sodium and potassium halide and acetate salts in a cooperative fashion in $\mathrm{CDCl}_{3} / \mathrm{CD}_{3} \mathrm{CN}(2 / 1, \mathrm{v} / \mathrm{v})$. Anion binding enhancements of over thirty-fold in the case of $\mathrm{Br}^{-}$were seen (Table 1.3). Extraction experiments carried out by these researchers also revealed that the ion pair receptor $\mathbf{1 . 2 8}$ can solubilize certain sodium and potassium salts in chloroform (cf. Table 1.4).

Table 1.3 Stability data for the anion complexes of $1.28,\left[1.28 \cdot \mathrm{Na}^{+}\right]$and $\left[1.28 \cdot \mathrm{K}^{+}\right]$as determined in $\mathrm{CDCl}_{3} / \mathrm{CD}_{3} \mathrm{CN}(2 / 1, \mathrm{v} / \mathrm{v})$.

\begin{tabular}{cccc}
\hline & \multicolumn{3}{c}{$K_{a}\left(\mathrm{M}^{-1}\right)$} \\
\cline { 2 - 4 } & Free 1.28 & {$\left[\mathbf{1 . 2 8} \cdot \mathrm{Na}^{+}\right]$} & {$\left[\mathbf{1 . 2 8} \cdot \mathrm{K}^{+}\right]$} \\
\hline $\mathrm{Cl}^{-}$ & 60 & N/A & $>730$ \\
$\mathrm{Br}^{-}$ & 20 & 620 & 550 \\
$\mathrm{I}^{-}$ & 15 & 280 & 310 \\
$\mathrm{OAc}^{-}$ & 110 & N/A & 710 \\
\hline
\end{tabular}


Table 1.4 Solid-liquid extraction data for Group 1 halide and acetate salts recorded using 1.28 as the receptor and $\mathrm{CDCl}_{3}$ as the solvent. The results are given as the percentage of complex formation.

\begin{tabular}{ccc}
\hline & \multicolumn{2}{c}{ Complex (\%) [lattice energy/kJ mol$\left.{ }^{-1}\right]$} \\
\cline { 2 - 3 } & $\mathrm{Na}^{+}$ & $\mathrm{K}^{+}$ \\
\hline $\mathrm{Cl}^{-}$ & $0[786]$ & $0[715]$ \\
$\mathrm{Br}^{-}$ & $3[747]$ & $13[682]$ \\
$\mathrm{I}^{-}$ & $27[704]$ & $95[649]$ \\
$\mathrm{OAc}^{-}$ & $0[763]$ & $13[682]$ \\
\hline
\end{tabular}

In 2003, Kilburn and coworkers reported ditopic receptor 1.29 (Figure 1.14), a system that coordinates alkali metal cations via the oxygen atoms, while binding the anion in a hydrogen bonding donor pocket formed by the two thiourea groups. ${ }^{44}$ In the absence of the $\mathrm{Na}^{+}$cation, receptor 1.29 binds the acetate anion selectively over the diphenyl phosphate anion. However, in the presence of the $\mathrm{Na}^{+}$cation, the selectivity is reversed. These observations are rationalized as follows: In the absence of the $\mathrm{Na}^{+}$cation, electrostatic repulsion between the phenoxy groups of the diphenyl phosphate anion and the ether oxygen atoms of the receptor prevents the receptor from binding the diphenyl phosphate anion. However, in the presence of the $\mathrm{Na}^{+}$cation, the phenoxy groups interact favorably with the bound $\mathrm{Na}^{+}$cation, leading to the observed strong binding of the ion pair. 


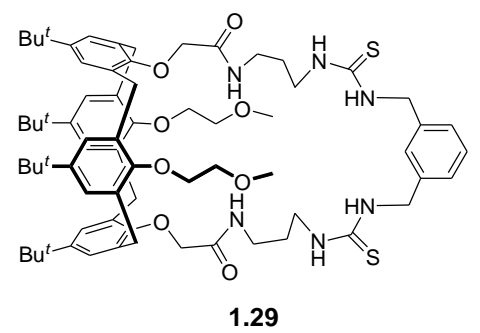

Figure 1.14 Structure of ditopic receptor 1.29.

Nabeshima et al. synthesized the more sophisticated tritopic ion receptor $\mathbf{1 . 3 0}$ (Figure 1.15) and examined the effects of cations on its anion binding efficiency. ${ }^{45}$ This receptor, reported in 2005, is composed of an oxygen-abundant cone calix[4]arene cavity and two bipyridine groups for hard and soft cation recognition, respectively; it also contains two appended urea moieties for anion recognition. It was demonstrated by ${ }^{1} \mathrm{H}$ NMR spectroscopy that either $\mathrm{Na}^{+}$cation binding to the calix[4]arene cavity or $\mathrm{Ag}^{+}$ cation binding to the bipyridine moietes enhances the affinity of $\mathbf{1 . 3 0}$ for the $\mathrm{NO}_{3}{ }^{-}$and $\mathrm{CF}_{3} \mathrm{SO}_{3}{ }^{-}$anions by a factor of 30-100. This result was rationalized in terms of preorganization of the urea groups into a face-to-face arrangement as the result of cation binding, as well as additional interactions between the bound cations and the incoming anions. In the presence of both $\mathrm{Na}^{+}$and $\mathrm{Ag}^{+}$, the cation-induced enhancement in the association constants $\left(K_{a}\right)$ of $\mathbf{1 . 3 0}$ reaches a factor of 1,500 and 2,000 for $\mathrm{NO}_{3}{ }^{-}$and $\mathrm{CF}_{3} \mathrm{SO}_{3}{ }^{-}$, respectively. ${ }^{45}$ 


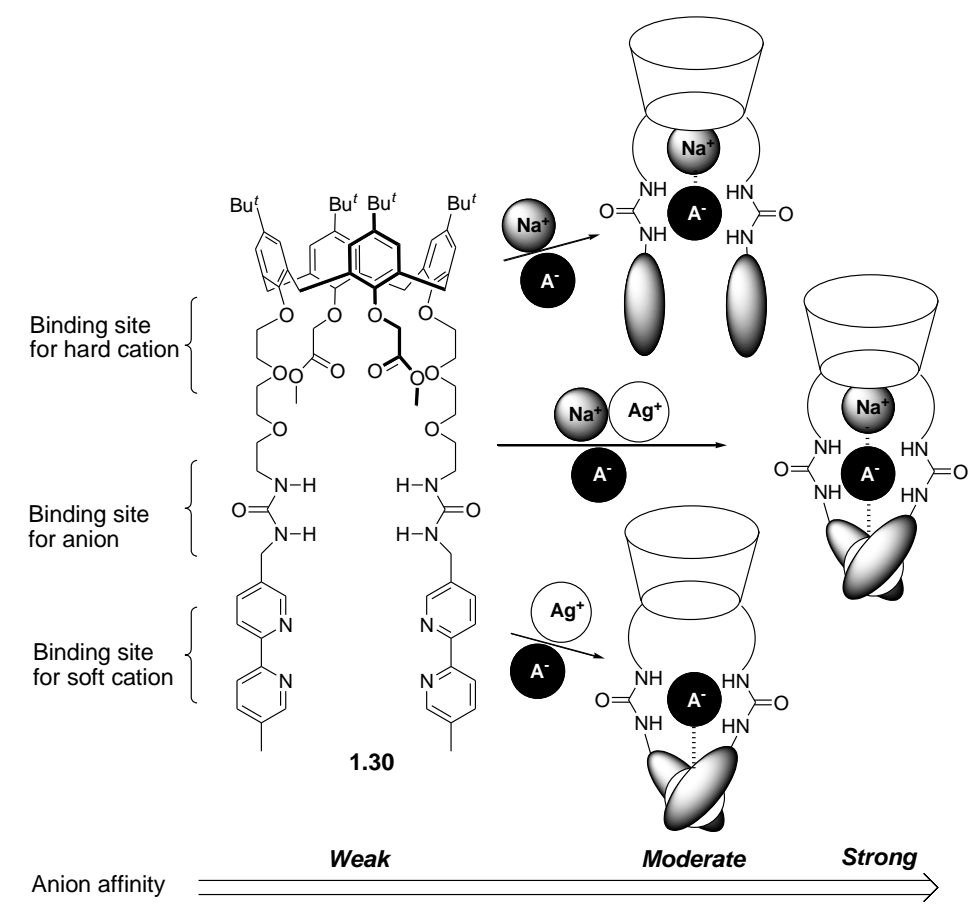

Figure 1.15 Tritopic receptor 1.30 and the binding modes that are thought to pertain in the presence of $\mathrm{Na}^{+}, \mathrm{Ag}^{+}$and various anions.

Table 1.5 Association constants, $\log K_{a}$, for the 1:1 host-guest complexes formed from the neutral and cation-bound forms of receptor $\mathbf{1 . 3 0}$ and selected anions. ${ }^{a}$

\begin{tabular}{cccc}
\hline host & $\mathrm{NO}_{3}^{-}$ & $\mathrm{CF}_{3} \mathrm{SO}_{3}^{-}$ & $\mathrm{BF}_{4}^{-}$ \\
\hline $\mathbf{1 . 3 0}$ & $1.88 \pm 0.03$ & $1.40 \pm 0.20$ & $b$ \\
$\mathbf{1 . 3 0} \cdot \mathrm{Ag}^{+}$ & $3.31 \pm 0.07$ & $3.40 \pm 0.07$ & $b$ \\
$\mathbf{1 . 3 0} \cdot \mathrm{Na}^{+}$ & $3.82 \pm 0.15$ & $3.32 \pm 0.11$ & $3.46 \pm 0.11$ \\
$\mathbf{1 . 3 0} \cdot \mathrm{Ag}^{+} \cdot \mathrm{Na}^{+}$ & $5.07 \pm 0.17$ & $4.70 \pm 0.20$ & $4.28 \pm 0.11$ \\
\hline
\end{tabular}

${ }^{a}$ Determined by ${ }^{1} \mathrm{H}$ NMR spectroscopy $\left(400 \mathrm{MHz}, \mathrm{CDCl}_{3} / \mathrm{CD}_{3} \mathrm{CN}\right.$ (9:1), [host] $=2.0 \times$ $\left.10^{-3} \mathrm{M}\right) .{ }^{b}$ Not determined due to the small chemical shift change.

In 2005, Pappalardo and coworkers reported the synthesis of receptor 1.31 (Figure 1.16). ${ }^{46}$ This system was designed for organic ion pair recognition. It contains two convergent and conformationally fixed calix[5]arene subunits for cation recognition and 
an 1,4-bis(ureido)phenylene moiety capable of binding two anions. ${ }^{46}$ Proton NMR and TROESY (transverse rotating-frame Overhauser effect) NMR spectroscopy, and electrospray mass spectrometry provided support for the conclusion that the heterotetratopic ion pair receptor $\mathbf{1 . 3 1}$ is able to bind long-chained and ion-paired $\alpha, \omega$ alkanediyldiammonium salts efficiently $\left(K_{a}>10^{6} \mathrm{M}^{-1}\right.$ for 1,12-dodeca- through 1,16hexadecanediammonium dichloride salts in $\left.\left(\mathrm{CDCl}_{2}\right)_{2} / \mathrm{CD}_{3} \mathrm{OD}(2: 1 \mathrm{v} / \mathrm{v})\right)$. Three different binding modes were suggested depending on the length of alkyl chains and the number of guest equivalents added. Large upfield shifts in the signals for the methylene protons of the guest molecule and significant downfield shifts of the $\mathrm{NH}$ resonances of the host molecule were seen in the ${ }^{1} \mathrm{H}$ NMR spectra. This was taken as evidence that receptor $\mathbf{1 . 3 1}$ recognizes the constituent ions of the ion pair concurrently and that the ammonium cations and chloride anions are bound to the host through $\pi$-cation and hydrogen bonding interactions, respectively. These spectroscopic analyses also revealed that long-chained $\alpha, \omega$-alkanediyldiammonium acetate and chloride salts induce remarkable downfield shifts in the NH resonance of the urea moiety. These shifts are more substantial than what is seen for $\mathrm{TBACl}$ (tetrabutylammonium chloride), whose cation is thought to be too big to be accommodated by the calix[5]arene unit (i.e., $\Delta \delta=0.75$ and $0.77 \mathrm{ppm}$ for TBACl and $\Delta \delta=2.37-2.72 \mathrm{ppm}$ for $\alpha, \omega$-alkanediyldiammonium salts). These findings were taken as evidence that receptor $\mathbf{1 . 3 1}$ forms stronger complexes with alkanediyldiammonium salts than with $\mathrm{TBA}^{+}$. Presumably, this reflects a cooperative interaction with the ion pairs, which are eventually separated by the host. ${ }^{46}$ This chemistry is summarized in Figure 1.16 . 


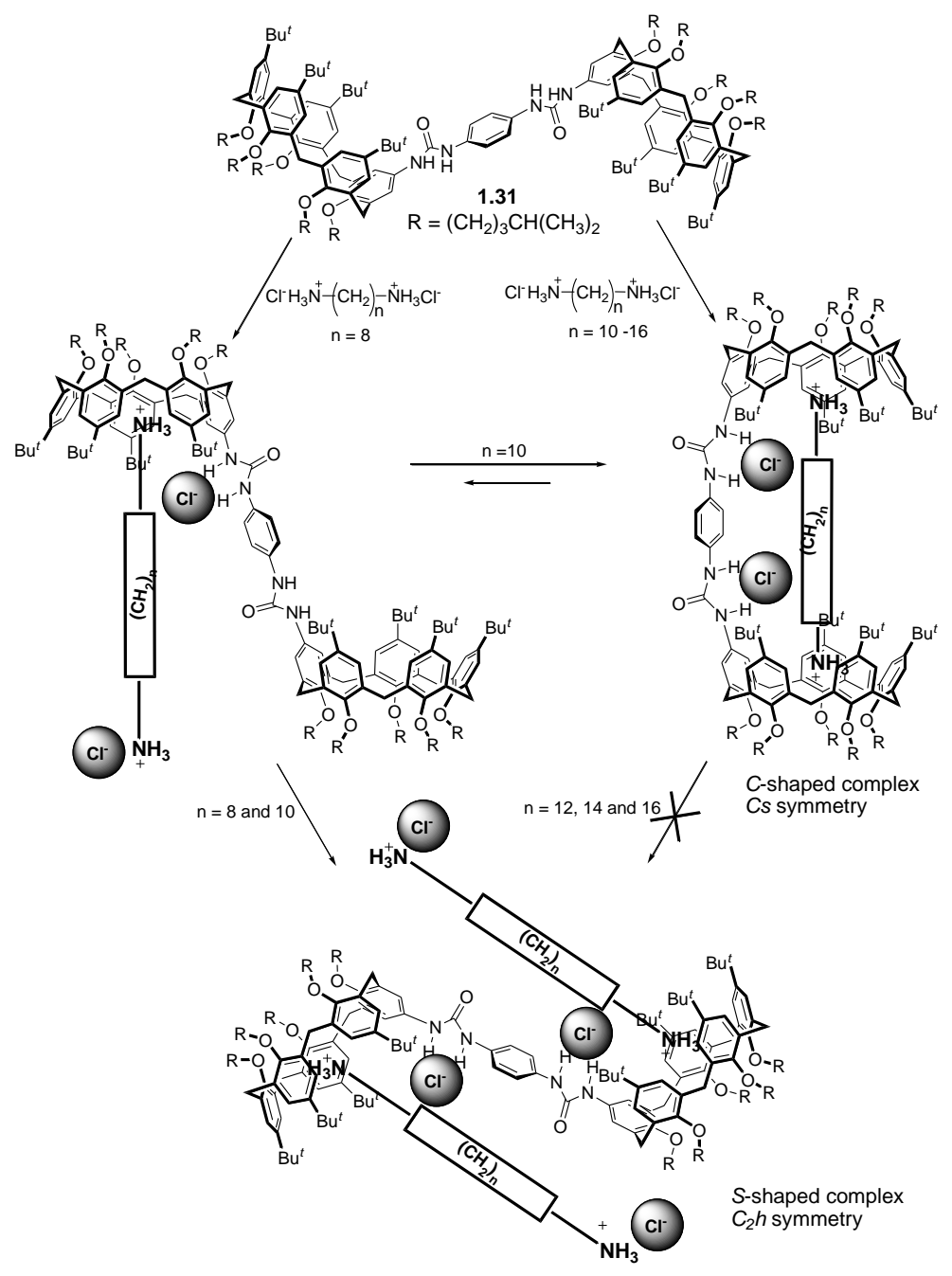

Figure 1.16 Proposed recognition of long-chain, ion-paired $\alpha, \omega$-alkanediyldiammonium salts by calix[5] arene-based heterotetratopic ion pair receptor $\mathbf{1 . 3 1}$.

In 2009, Secchi and coworkers described the ion pair receptors $\mathbf{1 . 3 2}$ and $\mathbf{1 . 3 3}$, where the upper rim of a cation recognizing cone-calix[4]arene moiety is covalently connected with an anion recognizing urea group through a methylene spacer ( $c f$. Figure 1.17). ${ }^{47}$ These workers demonstrated that these receptors display a binding ability that is enhanced by up to two orders of magnitude for organic salts, such as $N$-methylpyridinium 
and $N, N^{\prime}$-dimethylviologen, with respect to the simple cation receptors $\mathbf{1 . 3 4}$ and $\mathbf{1 . 3 5} .^{47}$ Proton NMR and UV/Vis spectroscopic and single crystal X-ray diffraction analyses provided support for the conclusion that ditopic receptors $\mathbf{1 . 3 2}$ and $\mathbf{1 . 3 3}$ form cooperative 2:1 (host:guest) complexes with such organic ion pairs. In the resulting complexes, the cations are bound to the electron-rich arene rings of the calix[4]arene moiety via cooperative $\mathrm{CH}-\pi$ and cation- $\pi$ interactions, while the anions interact with the urea moiety via hydrogen bonds. By contrast, the monotopic receptors (1.34 and 1.35) recognize these organic salts via only $\mathrm{CH}-\pi$ and cation- $\pi$ interactions (i.e., without the benefit of additional anion-host interactions) and form 1:1 (host:guest) complexes. ${ }^{47}$

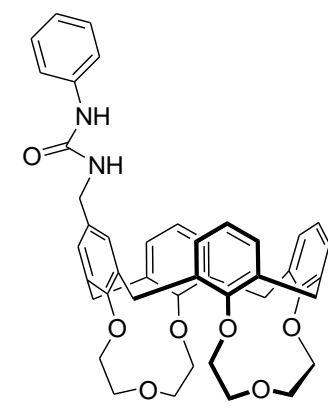

1.32

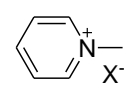

NMPX
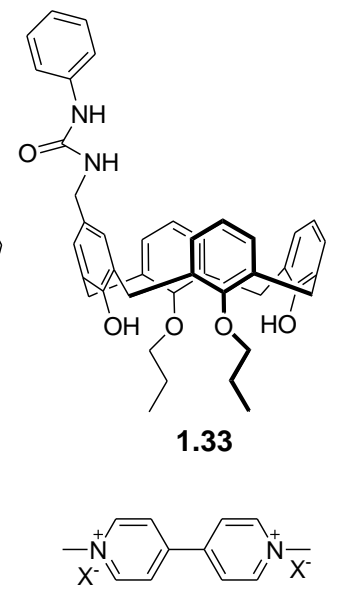

$\mathrm{PQX}{ }_{2}$
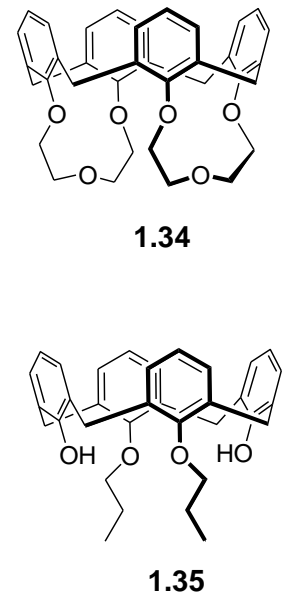

1.35

Figure 1.17 Calix[4]arene-based monotopic and hetroditopic receptors 1.32-1.35 and depictions of the $N$-methylpyridinium and $N, N^{\prime}$-dimethylviologen salts used as guest molecules.

Similarly, as reported by Ballistreri, a cone calix[5] arene derivative with a urea and four tert-butyl groups on the upper rim and five isohexyl groups on the lower rim binds zwitterionic $\gamma$ - and $\omega$-amino acids very efficiently as compared with its 
calix[5] arene derivative without a urea group. ${ }^{48}$ Proton NMR spectra measured in a solution of $\mathrm{C}_{2} \mathrm{D}_{2} \mathrm{Cl}_{2} / \mathrm{CD}_{3} \mathrm{OD}(2 / 1)$ or $\mathrm{C}_{2} \mathrm{D}_{2} \mathrm{Cl}_{2}$ only revealed that the strong interaction between the ureidocalix[5] arene with amino acids is achieved by the synergic action of the cation binding site and the anion binding site where the carboxylate moiety of amino acids is hydrogen-bonded to the NH protons of the urea group and its ammonium moiety is bound to the calix[5] arene cavity through the hydrogen bonding with phenolic oxygen atoms, as well as via $\pi$-cation interactions. ${ }^{48}$

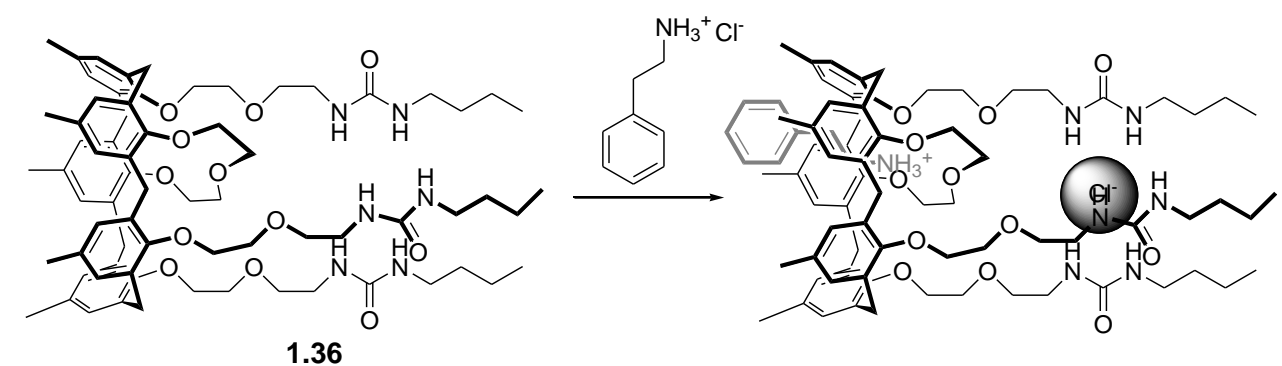

Figure 1.18 Proposed recognition of an alkyl ammonium salt (2-phenylethylamine hydrochloride) by receptor $\mathbf{1 . 3 6}$.

Also in 2009, Gargiulli et al. reported the synthesis of the ion pair receptor $\mathbf{1 . 3 6}$ (Figure 1.18) which consists of a cation recognizing calix[5] arene crown-3 in the cone conformation tethered to three anion recognizing urea units. ${ }^{49}$ It was shown that this system is capable of capturing $n$-butylammonium chloride and 2-phenylethylamine hydrochloride ion pairs. The binding mode was inferred from ${ }^{1} \mathrm{H}$ NMR spectroscopic analyses and semiempirical calculations carried out at the PM3 level. On this basis, it was proposed that the ammonium cation is bound to the calix[5]arene cavity, while the chloride anion is complexed by the three facing urea groups, as shown in Figure 1.18. The net result is a receptor-separated ion pair complex. 
Receptor 1.37 (Figure 1.19) reported by Kubo and coworkers in 2000 antedates the above systems. It also works as an ion pair receptor and is thought to operate on the basis of an allosteric effect. ${ }^{50}$ In the presence of the $\mathrm{K}^{+}$cation, the dibenzo-30-crown-10 portion of this receptor wraps around the $\mathrm{K}^{+}$ion. This brings the two thiourea moieties into close proximity and provides a preorganized binding cavity for the phosphate anion. Compared to the cation-free form of receptor $1.37\left(K_{a 1}=490 \mathrm{M}^{-1}\right)$, the association constants are significantly enhanced for the phosphate anion in the presence of both $\mathrm{K}^{+}$ $\left(K_{a l}=9,200 \mathrm{M}^{-1}\right)$ and $\mathrm{Cs}^{+}\left(K_{a l}=3,200 \mathrm{M}^{-1}\right)$. Prior to this work, it was demonstrated by Nishizawa and coworkers that the thiourea-functionalized benzo-15-crown-5 (1.38; Figure 1.19) binds a series of anions via presumed cooperative interactions with a prebound $\mathrm{Na}^{+}$cation. ${ }^{51}$ Specifically, in the presence of 2.0 molar equiv. of $\mathrm{Na}\left(\mathrm{BPh}_{4}\right)$ (conditions where the $\mathrm{Na}^{+}$complexation is $>95 \%$ ), receptor 1.38 in $\mathrm{CD}_{3} \mathrm{CN}$ exhibits an approximate ten-fold increase in its affinity for $\mathrm{NO}_{3}{ }^{-}\left(\mathrm{KNO}_{3}=6.0 \mathrm{M}^{-1}\right.$ vs. $\mathrm{KNO}_{3}\left(\mathrm{Na}^{+}\right)=$ $\left.66 \mathrm{M}^{-1}\right)$ and $\mathrm{Br}^{-}\left(\mathrm{KBr}=25 \mathrm{M}^{-1}\right.$ vs. $\left.\mathrm{KBr}\left(\mathrm{Na}^{+}\right)=260 \mathrm{M}^{-1}\right)$, and a five-fold increase for $\mathrm{I}^{-}$ $\left(\mathrm{KI}=4.3 \mathrm{M}^{-1}\right.$ vs. $\left.\mathrm{KI}\left(\mathrm{Na}^{+}\right)=20 \mathrm{M}^{-1}\right)$.

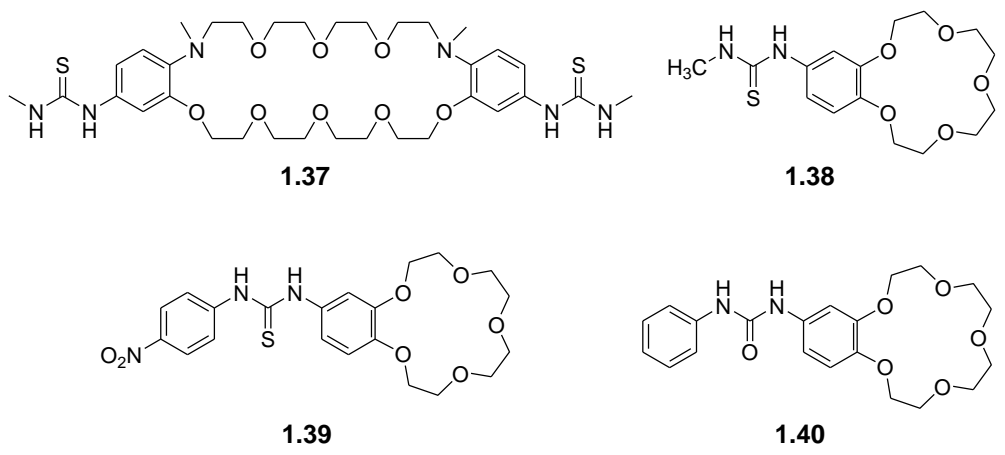

Figure 1.19 Simple crown ether-urea and -thiourea based ion pair receptors 1.37-1.40. 
Almost a decade after these early reports, Nam and coworkers synthesized the anion-dependant colorimetric ion pair receptor 1.39 (Figure 1.19) and evaluated its binding affinity for anions in the presence and absence of the $\mathrm{Na}^{+}$cation. ${ }^{52}$ This system contains a nitrophenyl group attached to the thiourea moiety. It displays a color change from colorless to yellow when treated with the fluoride, acetate, benzoate and dihydrogen phosphate anions in acetonitrile. However, the yellow color induced by fluoride anion disappears and returns to colorless upon the addition of the $\mathrm{Na}^{+}$cation. This was interpreted in terms of the fluoride anion leaving the thionurea moiety to form a contact ion pair with the sodium cation bound to the crown ether. To the extent such an interpretation is correct, receptor $\mathbf{1 . 3 9}$ exemplifies a negative cooperative effect on anion binding, which is induced by $\mathrm{Na}^{+}$. Interestingly, the affinities towards other anions are enhanced in the presence of the $\mathrm{Na}^{+}$cation (by 1.2 fold for the acetate anion, 1.1 fold for the chloride anion, 1.6 fold for the bromide anion, 2.0 fold for the iodide anion, and 2.3 fold for the hydrogen sulfate anion).

An ostensibly similar receptor, the crown-urea system 1.40 (Figure 1.19), was reported by Barboiu and coworkers in $2003 .{ }^{53}$ On the basis of X-ray crystallographic analyses and ${ }^{1} \mathrm{H}$ NMR spectra recorded at various concentrations, it was concluded that the free host $\mathbf{1 . 4 0}$ forms a tubular superstructure stabilized via head-to-tail urea hydrogen bonding, $\pi-\pi$, and $\mathrm{CH}-\pi$ interactions with an internal van der Waals diameter of $1.27 \AA$ and a spacing of $4.83 \AA$ between parallel off-centered macrocycles (Figure 1.20a). These researchers also demonstrated that receptor $\mathbf{1 . 4 0}$ is able to extract solid sodium salts, such as $\mathrm{NaF}, \mathrm{NaCl}, \mathrm{NaNO}_{3}$, and $\mathrm{NaCF}_{3} \mathrm{SO}_{3}$, into $\mathrm{CDCl}_{3}$ solution. Membrane transport experiments provided support for a direct relationship between the ability to effect synergetic ion pair recognition and mediate ion transport. Interestingly, receptor $\mathbf{1 . 4 0}$ was found to bind sodium salts in two different modes depending on the nature of the counter 
anions. For example, a 2:1 (host:guest) complex is formed with $\mathrm{NaCl}$ in which the constituent ions are separated by the receptor (Figure 1.20b). In contrast, a 2:2 contact ion pair complex is stabilized in the case of $\mathrm{NaNO}_{3}$, at least in the solid state (Figure 1.20c).

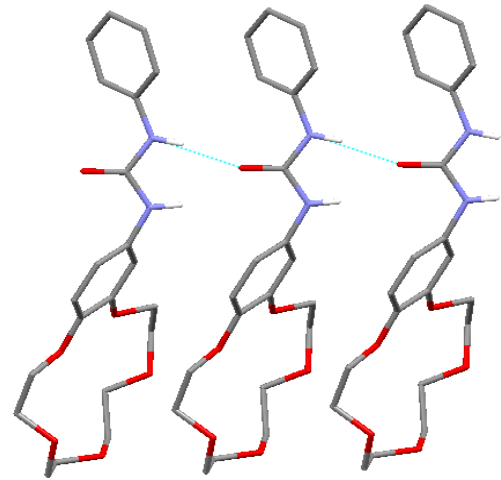

(a)

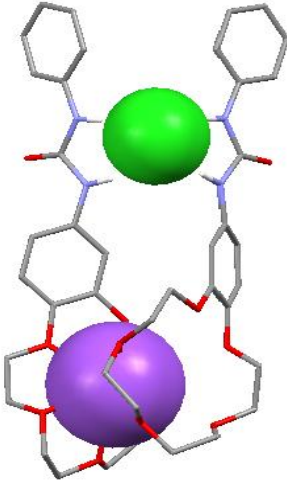

(b)

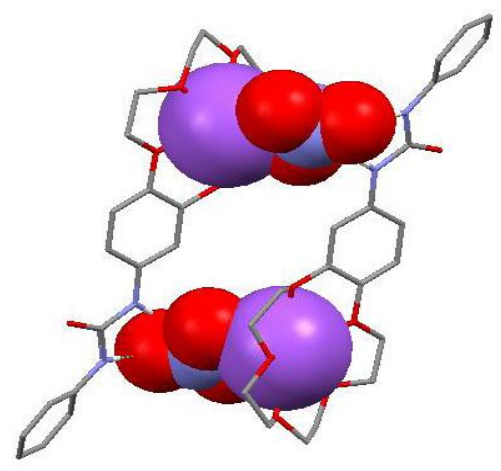

(c)

Figure 1.20 Crystal structures of (a) free receptor1.40, (b) its $\mathrm{NaCl}$ complex, and (c) the corresponding $\mathrm{NaNO}_{3}$ complex. This figure was redrawn using coordinates that were originally published in ref. 53.

\subsection{ION PAIR RECEPTORS THAT CONTAIN AMIDE GROUPS FOR ANION RECOGNITION}

Several groups have designed and synthesized crown ether derivatives that contain one or more amide groups strapped via a short linker and used the resulting system as receptors for the recognition of contact ion pairs. The attraction of this approach is that the partial destabilization resulting from charge separation of ion pairs, the so-called Columbic penalty, can be avoided. In an early example, Kilburn and coworkers showed that compound $\mathbf{1 . 4 1}$ forms strong complexes with the mono-potassium salts of dicarboxylic acids and phenyl phosphonate, binding these guests as contact ion pairs (Figure 1.21). ${ }^{54} \mathrm{~A}$ series of solid-liquid and liquid-liquid extraction experiments provided support for the suggestion that this ditopic receptor is able to effect the transfer 
of varying quantities of the mono-potassium salts of several dicarboxylic acids from water into $\mathrm{CDCl}_{3}$.

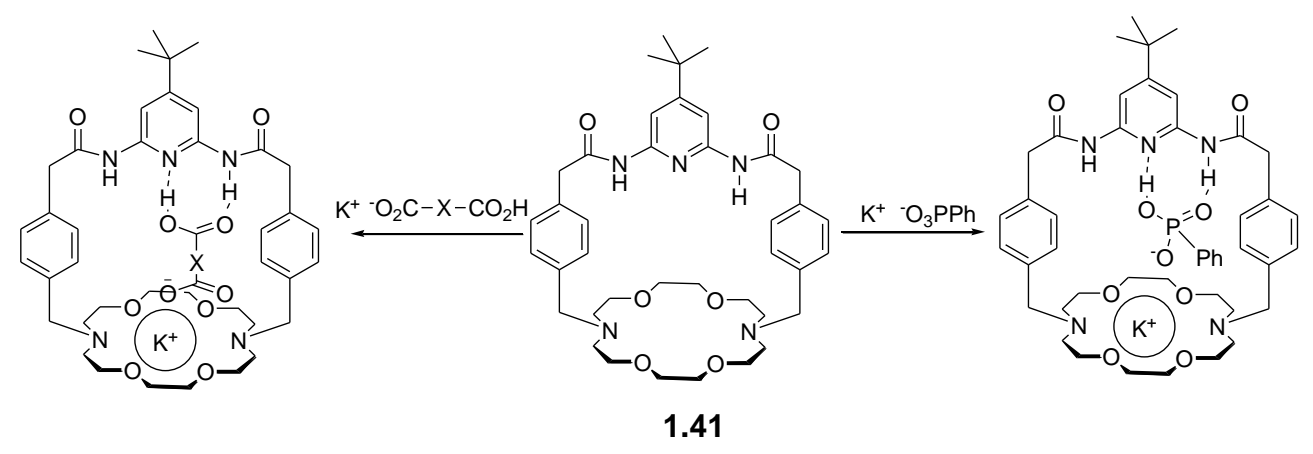

Figure 1.21 Chemical structure of the ion pair receptor 1.41 and its proposed binding mode with monopotassium salts of dicarboxylic acids (oxalic acid, malonic acid, methylmalonic acid, benzylmalonic acid, maleic acid, fumaric acid, succinic acid, $Z$-aminomalonic acid, $Z$-aspartic acid, and $Z$-glutamic acid) and phenyl phosphonate.

Seven years later, in 2000, Smith and co-workers prepared the preorganized bicyclic macromolecular ion pair receptor 1.42 by combining a dibenzo-18-crown- 6 with a 1,3-phenylenedicarboxamide subunit (Figure 1.22). ${ }^{55}$ Proton NMR spectroscopic studies carried out in pure DMSO- $d_{6}$ and in a $3: 1$ mixture of DMSO- $d_{6} / \mathrm{CD}_{3} \mathrm{CN}$, combined with single crystal X-ray structural analyses, served to show that receptor $\mathbf{1 . 4 2}$ is capable of forming a complex containing both alkali metal and chloride ions. A series of complexation experiments carried out in DMSO- $d_{6} / \mathrm{CD}_{3} \mathrm{CN}(3 / 1, \mathrm{v} / \mathrm{v})$ provided support for the suggestion that $\mathbf{1 . 4 2}$ binds sodium chloride and potassium chloride in the form of ion pairs and in a highly cooperative fashion. In the presence of 1.0 molar equiv. of $\mathrm{Na}^{+}$ or $\mathrm{K}^{+}$(added as their tetraphenylborate salts), the chloride anion affinity is enhanced relative to what is seen in the absence of a cation (Table 1.6). A single crystal X-ray structural analysis of the $\mathrm{NaCl}$ complex revealed that receptor $\mathbf{1 . 4 2}$ binds $\mathrm{NaCl}$ as a 
solvent-separated ion pair, at least in the solid-state. As expected, the $\mathrm{Na}^{+}$cation is bound within the dibenzocrown unit, with an axial water molecule completing the coordination sphere, whereas the $\mathrm{Cl}^{-}$anion is hydrogen-bonded to the two $\mathrm{NH}$ residues as well as to the $\mathrm{CH}$ of a chloroform molecule that serves to bridge the two ions of the ion pair. The central cavity is occupied by a $\mathrm{CHCl}_{3}$ molecule or two molecules of water, with the ionion separation being $7.31 \AA .^{55}$
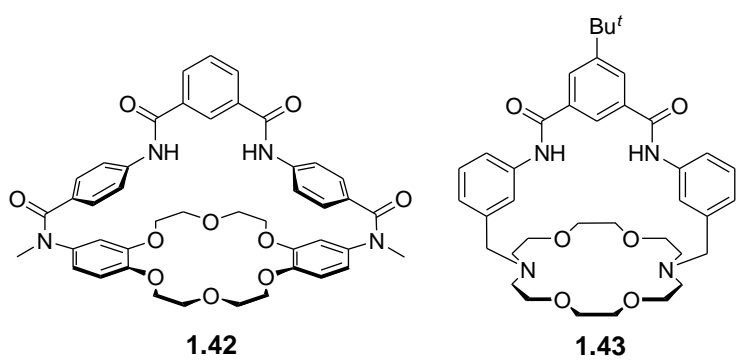

Figure 1.22 Amide-capped bicyclic ion pair receptors 1.42 and 1.43.

Table 1.6 Association constants $\left(\mathrm{M}^{-1}\right)$ for the binding of halide anions to the ion pair receptor $\mathbf{1 . 4 2}$ for halides anion in the presence or absence of alkali metal ions. The values in parentheses are the change in the chemical shift of the $\mathrm{NH}$ protons $\left(\Delta \delta_{\max }\right.$ in $\left.\mathrm{ppm}\right){ }^{a}$

\begin{tabular}{ccccc}
\hline anions $^{b}$ & $\mathbf{1 . 4 2}$ & $\mathbf{1 . 4 2}+\mathrm{Na}^{+c}$ & $\mathbf{1 . 4 2}+\mathrm{K}^{+c}$ & $\mathbf{1 . 4 2}+\mathrm{Cs}^{+c}$ \\
\hline $\mathrm{Cl}^{-}$ & $50(0.93)$ & $410(1.16)$ & $470(1.28)$ & $60(0.95)$ \\
$\mathrm{Br}^{-}$ & $9(0.18)$ & & $27(0.38)$ & \\
$\mathrm{I}^{-}$ & $<1(<0.01)$ & & $11(0.03)$ & \\
\hline
\end{tabular}

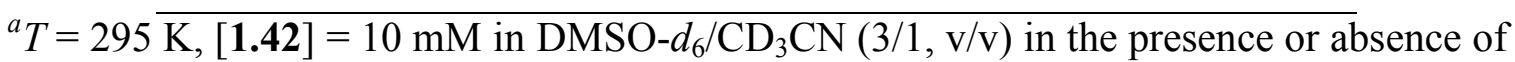
1.0 molar equiv. of the designated metal cations. Association constants are the average of all receptor protons that exhibit significant complexation-induced shifts; uncertainty $\pm 15 \%$. The $\Delta \delta_{\max }$ values represent the change in the $\mathrm{NH}$ chemical shift after adding 10 molar equiv. of the indicated anion. ${ }^{b}$ Anion added as the tetrabutylammonium salt. ${ }^{c}$ Cation added as the tetraphenlyborate salt. 
A year later, the ion pair receptor $\mathbf{1 . 4 3}$ (Figure 1.22), an analogue of 1.42, was reported by the same group. ${ }^{56}$ Receptor $\mathbf{1 . 4 3}$ was designed to have a smaller distance between the cation and anion binding sites and to recognize sodium and potassium halide salts as contact ion pairs. Single crystal X-ray diffraction structures of the $\mathrm{NaCl}$ and $\mathrm{KCl}$ complexes of $\mathbf{1 . 4 3}$ were solved, and revealed that this new receptor binds $\mathrm{NaCl}$ and $\mathrm{KCl}$ salts as contact ion pairs. This complexation mode stands in contrast to what is seen for 1.42, which binds $\mathrm{NaCl}$ as a solvent separated ion pair. The crystal structures of $1.43 \cdot \mathrm{NaCl}$ and $1.43 \cdot \mathrm{KCl}$ also show that, relative to the $\mathrm{KCl}$ complex, the effective cavity size of the diazacrown unit is reduced when the $\mathrm{Na}^{+}$cation is bound (average $\mathrm{K} \cdots \mathrm{O}$ distance is $2.77 \AA$ vs. $2.45 \AA$ for $\mathrm{Na} \cdots \mathrm{O}$ ). In addition, the average $\mathrm{Cl} \cdots \mathrm{O}$ distance in $43 \cdot \mathrm{NaCl}$ is much shorter $(4.20 \AA)$ than that observed in $1.43 \cdot \mathrm{KCl}(4.7 \AA)$. These differences provide support for the appealing suggestion that once a $\mathrm{K}^{+}$cation is bound, receptor $1.43 \cdot \mathrm{K}^{+}$is better able to bind the chloride counter anion to form a favorable contact ion-pair than in the case of $\mathbf{1 . 4 3} \cdot \mathrm{NaCl}$. Proton $\mathrm{NMR}$ spectroscopic titration experiments carried out in DMSO- $d_{6}$ revealed cooperative effects. Specifically, in the presence of either $\mathrm{Na}^{+}$and $\mathrm{K}^{+}$or $\mathrm{Cl}^{-}$, the association constants for complexation of the corresponding counter ion increased significantly (Table 1.7).

Table 1.7 Association constants, $K_{a}\left(\mathrm{M}^{-1}\right)$, in DMSO at $295 \mathrm{~K}^{a}$

\begin{tabular}{ccccccc}
\hline & $K_{a}$ for $\mathrm{Cl}^{-b}$ & & \multicolumn{2}{c}{$K_{a}$ for $\mathrm{Na}^{+c}$} & \multicolumn{2}{c}{$K_{a}$ for $\mathrm{K}^{+c}$} \\
\hline $\mathbf{1 . 4 3}$ & $\mathbf{1 . 4 3}+\mathrm{Na}^{+}$ & $\mathbf{1 . 4 3}+\mathrm{K}^{+}$ & $\mathbf{1 . 4 3}$ & $\mathbf{1 . 4 3}+\mathrm{Cl}^{-}$ & $\mathbf{1 . 4 3}$ & $\mathbf{1 . 4 3}+\mathrm{Cl}^{-}$ \\
\hline 35 & 50 & 460 & 5 & 25 & 8 & 340 \\
\hline
\end{tabular}

${ }^{a}$ Association constants are the average of all receptor protons which exhibit significant complexation-induced shifts; The initial $[\mathbf{1 . 4 3}]=10 \mathrm{mM}$; uncertainty $\pm 15 \%$. ${ }^{b} \mathbf{1 . 4 3} / \mathrm{Cl}^{-}$ association constant in the presence of 1 molar equiv. of metal tetraphenylborate. ${ }^{c} \mathbf{1 . 4 3} / \mathrm{M}^{+}$association constant in the presence of 1 molar equiv. of tetrabutylammonium chloride. 
It was also shown by single crystal X-ray diffraction analysis and ${ }^{1} \mathrm{H}$ NMR spectroscopy that receptor $\mathbf{1 . 4 3}$ can extract $\mathrm{LiCl}$ and $\mathrm{LiBr}$ from the solid state and bind these salts as water-separated ion pairs. On the other hand, it was found that $\mathrm{NaCl}, \mathrm{KCl}$, $\mathrm{NaBr}$ and $\mathrm{KBr}$ are bound as contact ion pairs. ${ }^{57}$ In the solid state, the complexes formed between 1.43 and $\mathrm{LiCl}$ and $\mathrm{LiCl}$ contain the $\mathrm{Li}^{+}$cation coordinated to three oxygen atoms and one nitrogen atom of the six heteroatoms in the diazacrown ether moiety, as well as to an additional oxygen atom provided by the water molecule (Figure 1.23). In contrast, the $\mathrm{Cl}^{-}$and $\mathrm{Br}^{-}$anions are hydrogen-bonded to the two amide $\mathrm{NH}$ protons and one $\mathrm{OH}$ proton from a water molecule. The average $\mathrm{Li} \cdots \mathrm{O}_{\text {crown }}$ distance in both cases is $2.21 \AA$ for the three coordinating oxygen atoms. The average $\mathrm{Li} \cdots \mathrm{O}_{\text {water }}$ distances are $1.90 \AA$ for the $\mathrm{LiCl}$ complex and $1.91 \AA$ for the $\mathrm{LiBr}$ complex. The $\mathrm{Li}-\mathrm{N}$ distances for the coordinating crown nitrogen are $2.37 \AA$ for the $\mathrm{LiCl}$ complex and $2.33 \AA$ for the $\mathrm{LiBr}$ complex. In the case of the chloride complexes, the average $\mathrm{N}_{\text {amide }}-\mathrm{Cl}$ distances are $3.30 \AA$ with the average $\mathrm{N}-\mathrm{H}-\mathrm{Cl}$ angle being $177.5^{\circ}$. The $\mathrm{Cl}-\mathrm{O}_{\text {water }}$ distance is $3.10 \AA$. In the case of the $\mathrm{LiBr}$ complex, the $\mathrm{Br}^{-}$anion is bound to the receptor with distances of $3.41 \AA$ and $3.29 \AA$ being observed for the $\mathrm{N}_{\text {amide }}-\mathrm{Cl}$ and $\mathrm{Br}-\mathrm{O}_{\text {water }}$ separations, respectively. The average $\mathrm{N}$ $\mathrm{H}-\mathrm{Br}$ angle is $176.9^{\circ}$ (Figure 1.23). 


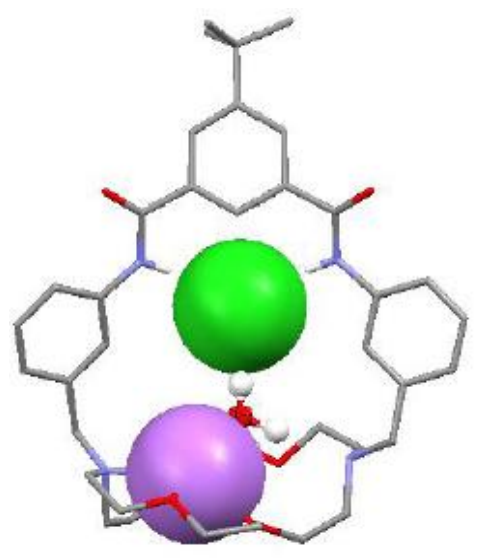

(a)

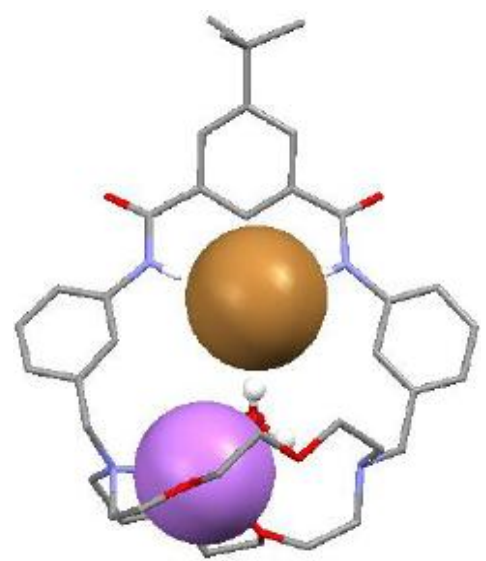

(b)

Figure 1.23 Crystal structures of (a) $1.43 \cdot \mathrm{LiCl} \cdot \mathrm{H}_{2} \mathrm{O}$ and (b) $1.43 \cdot \mathrm{LiBr} \cdot \mathrm{H}_{2} \mathrm{O}$. The lithium cation is bound in the crown ether subunit in both cases. These structures were replotted using coordinates that were originally reported in ref. 57.

Using a supported liquid membrane and a high salt concentration in the source phase, Smith and coworkers carried out transport experiments that involve the use of ion pair receptor $\mathbf{1 . 4 3}$ as a carrier for alkali halide salt. ${ }^{58}$ On the basis of these studies, it was concluded that the ditopic receptor $(\mathbf{1 . 4 3})$ can transport alkali halide salts up to 10 -fold more quickly than does the monotopic cation receptor $\mathbf{1 . 4 4}$ or the anion receptor $\mathbf{1 . 4 5}$ and twice as fast as does a 1:1 mixture of $\mathbf{1 . 4 4}$ and $\mathbf{1 . 4 5}$ (Table 1.8). The same qualitative order of ion selectivity is observed in all transport systems; that is, for a constant anion, the cation selectivity order is $\mathrm{K}^{+}>\mathrm{Na}^{+}>\mathrm{Li}^{+}$, and for a constant cation, the anion transport selectivity order is $\mathrm{I}^{-}>\mathrm{Br}^{-}>\mathrm{Cl}^{-}$. 

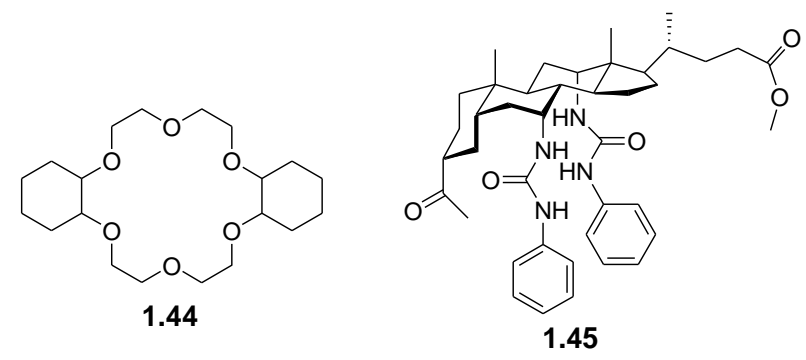

Figure 1.24 Structures of control monotopic receptors 1.44 and 1.45.

Table 1.8 Initial transport fluxes $\left(\times 10^{-8} \mathrm{~mol} \mathrm{~m}^{-2} \mathrm{~s}^{-1}\right){ }^{a}$

\begin{tabular}{ccc}
\hline Carrier & $\mathbf{1 . 4 3}$ & $\mathbf{1 . 4 4}$ \\
\hline $\mathrm{LiCl}$ & $6 \pm 1$ & $6 \pm 1$ \\
$\mathrm{NaCl}$ & $37 \pm 2$ & $5 \pm 1$ \\
$\mathrm{KCl}$ & $90 \pm 3$ & $12 \pm 1$ \\
$\mathrm{LiBr}$ & $10 \pm 1$ & $6 \pm 1$ \\
$\mathrm{NaBr}$ & $32 \pm 2$ & $3 \pm 1$ \\
$\mathrm{KBr}$ & $111 \pm 3$ & $20 \pm 1$ \\
$\mathrm{LiI}$ & $7 \pm 1$ & $7 \pm 1$ \\
$\mathrm{NaI}$ & $43 \pm 2$ & $27 \pm 2$ \\
$\mathrm{KI}$ & $160 \pm 5$ & $40 \pm 2$ \\
\hline
\end{tabular}

${ }^{a}$ Source phase, $1 \mathrm{M}$ salt; membrane, $50 \mathrm{mM}$ receptor in NOPE (o-nitrophenyl $n$-octyl ether); receiving phase, water. $T=25^{\circ} \mathrm{C}$.

Recent reports from the Smith group also show that the ditopic receptor $\mathbf{1 . 4 3}$ forms strong complexes with trigonal oxyanions, such as $\mathrm{NO}_{3}{ }^{-}$and $\mathrm{OAc}^{-}$, as well as with the halide anions. ${ }^{59}$ Proton NMR spectral studies provided confirmation that compound 1.43 is able to extract solid $\mathrm{NaNO}_{3}$ and $\mathrm{KCl}$ into chloroform. Single crystal X-ray diffraction analyses further revealed that receptor $\mathbf{4 3}$ binds $\mathrm{KOAc}, \mathrm{NaNO}_{3}, \mathrm{KNO}_{3}$, and $\mathrm{NaNO}_{2}$ as contact ion pairs and $\mathrm{LiNO}_{3}$ as a water-bridged ion pair (Figure 1.25). 
Table 1.9 Initial transport fluxes for SLMs containing different receptors. ${ }^{a}$

\begin{tabular}{ccccc}
\hline & $\mathbf{1 . 4 3}$ & $\mathbf{1 . 4 4}$ & $\mathbf{1 . 4 5}$ & $\mathbf{1 . 4 4}+\mathbf{1 . 4 5}$ \\
\hline Flux $\left(\times 10^{-8} \mathrm{~mol} \mathrm{~m}^{-2} \mathrm{~s}^{-1}\right)$ & $90 \pm 3$ & $12 \pm 1$ & $18 \pm 1$ & $50 \pm 2$
\end{tabular}

${ }^{a}$ Source phase, $1 \mathrm{M} \mathrm{KCl}$; membrane, $50 \mathrm{mM}$ receptor in NOPE; receiving phase, water. $T$ $=25{ }^{\circ} \mathrm{C}$.

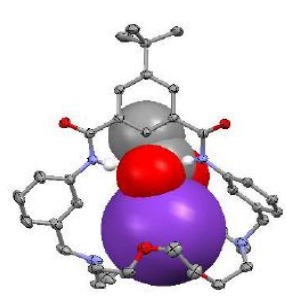

(a)

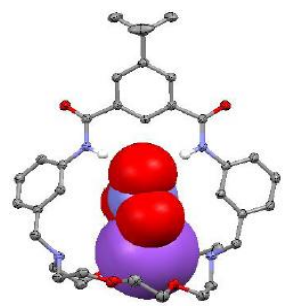

(b)

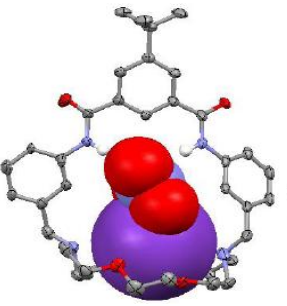

(c)

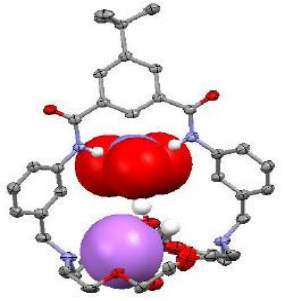

(d)

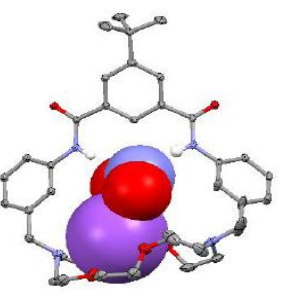

(e)

Figure 1.25 Crystal structures of (a) $1.43 \cdot \mathrm{KOAc}$, (b) $1.43 \cdot \mathrm{NaNO}_{3}$, (c) $1.43 \cdot \mathrm{KNO}_{3}$, (d) 1.43 $\cdot \mathrm{LiNO}_{3} \cdot 2 \mathrm{H}_{2} \mathrm{O}$, and (e) $1.43 \cdot \mathrm{NaNO}_{2}$. The cation is bound in the crown subunit in all cases. This figure was produced using coordinates that originally appeared in ref. 59.

A more elaborated analogue of compound $\mathbf{1 . 4 3}$ was introduced by Gale, Smith and coworkers in 2003. These researchers used a 2,5-diamidopyrrole strap but otherwise retained the same basic receptor design. This gave rise to the macrobicyclic receptor $\mathbf{1 . 4 6}$, which has an additional pyrrole-derived hydrogen bond donor site. Proton NMR spectroscopic titrations revealed that the affinity of ditopic receptor $\mathbf{1 . 4 6}$ for $\mathrm{Cl}^{-}$is three times higher than $\mathbf{1 . 4 3} .^{60}$ Moreover, it was found that the addition of one equivalent of the $\mathrm{Na}^{+}$cation fails to increase appreciably the affinity for $\mathrm{Cl}^{-}$. However, adding one equivalent of $\mathrm{K}^{+}$to $\mathbf{1 . 4 6}$ enhances the binding affinity for halide anions substantially. In the context of this work it was also confirmed via an X-ray crystallographic analysis of 
the $\mathrm{NaCl}$ complex $(\mathbf{1 . 4 6} \cdot \mathrm{NaCl})$ that the receptor coordinates $\mathrm{NaCl}$ as a contact ion pair. Such a coordination mode is consistent with the enhanced binding affinity for $\mathrm{Cl}^{-}$ observed for $\mathbf{1 . 4 6}$ as compared with 1.43. This same crystal structure also revealed that not only are the two amide NH's interacting with the anion but also that the pyrrolic NH proton participates in chloride recognition via hydrogen bonding interactions.

A somewhat analogous ion pair receptor, the ferrocene-strapped system $\mathbf{1 . 4 7}$ having an electrochemically-active sensing unit, was reported by Tuntulani et al. in 2005 (Figure 1.26). ${ }^{61}$ In this case, ${ }^{1} \mathrm{H}$ NMR spectroscopic titration of ions coupled with cyclic voltametric analyses confirmed that receptor $\mathbf{1 . 4 7}$ is unable to interact with the $\mathrm{Br}^{-}$anion. These same analyses also revealed that $\mathbf{1 . 4 7}$ binds the $\mathrm{Br}^{-}$anion $\left(K_{a}=16,096\right)$ selectively and efficiently in the presence of the $\mathrm{Na}^{+}$cation. Cyclic voltametric studies of $\mathbf{1 . 4 7}$ revealed reversible redox behavior and a value of $E_{1 / 2}=0.473 \mathrm{mV}$ for the ferrocene/ferrocinium couple. The addition of cations, such as $\mathrm{Na}^{+}$and $\mathrm{K}^{+}$, results in a slight anodic shift of the $\mathrm{CV}$ wave. Conversely, the addition of the $\mathrm{Cl}^{-}$induces a cathodic shift in the $\mathrm{Fc} / \mathrm{Fc}^{+}$redox couple with the wave disappearing as the $\mathrm{Cl}^{-}$concentration increases. It is thought that the reversibility of the $\mathrm{Fc} / \mathrm{Fc}^{+}$redox wave is lost as a consequence of ion pair association occurring within the receptor. ${ }^{61}$
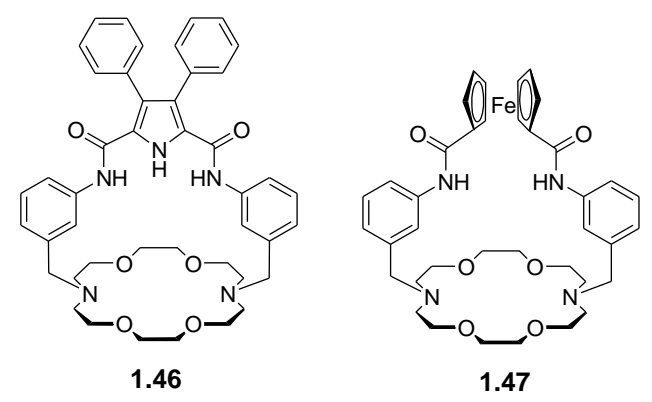

Figure 1.26 Ion pair receptors $\mathbf{1 . 4 6}$ and $\mathbf{1 . 4 7}$ 
For the recognition of more specific ion pairs, Beer and coworkers synthesized the ion pair receptor 1.48 (Figure 1.27). ${ }^{62}$ This system, reported in 2007, contains a cone calix[4] arene diester, a motif that is well known to bind the $\mathrm{Li}^{+}$and $\mathrm{Na}^{+}$cations strongly and selectively. ${ }^{62}$ It also has a strap with amide functionality for anion recognition. As expected, in the presence of the $\mathrm{Br}^{-}$anion, receptor 1.48 binds the $\mathrm{Li}^{+}$cation $\left(K_{a}>10,000\right.$ $\left.\mathrm{M}^{-1}\right)$ roughly five times effectively than its absence $\left(K_{a}=2,840 \mathrm{M}^{-1}\right)$, as determined by ${ }^{1} \mathrm{H}$ NMR spectroscopic titrations carried out in acetone- $d_{6}$. This finding was considered indicative of a positive cooperative interaction between the co-bound ions and the receptor. Interestingly, complexation of $\mathrm{Br}^{-}$anion reduces the propensity of receptor $\mathbf{1 . 4 8}$ to bind the $\mathrm{Na}^{+}$cation exhibiting $K_{a}$ value that is reduced by ca. a factor of 4.5 relative to what is seen for free 1.48. Conversely, pre-complexation of $\mathrm{Li}^{+}$and $\mathrm{Na}^{+}$cations (using salts of the non-coordinating anion, perchlorate) serves to boost by a factor of 6.4-9.3 the binding affinity of $\mathbf{1 . 4 8}$ for the $\mathrm{Br}^{-}$and $\mathrm{I}^{-}$anions (Table 1.10).

Table 1.10 Association constants $\left(K_{a}\right)$ corresponding to the binding of halide anions by receptor $\mathbf{1 . 4 8}$ and its metal complexes. ${ }^{a}$

\begin{tabular}{ccccc}
\hline & \multicolumn{4}{c}{$K_{a}\left(\mathrm{M}^{-1}\right)$} \\
\cline { 2 - 5 } & Free 1.48 & {$\left[\mathbf{1 . 4 8} \cdot \mathrm{LiClO}_{4}\right]$} & {$\left[\mathbf{1 . 4 8} \cdot \mathrm{NaClO}_{4}\right]$} & {$\left[\mathbf{1 . 4 8} \cdot \mathrm{KPF}_{6}\right]$} \\
\hline TBACl & 1,550 & $-^{b}$ & $-^{b}$ & $-^{b}$ \\
TBABr & 250 & 2,320 & 2,150 & $-^{b}$ \\
TBAI & 45 & 420 & 290 & $-^{b}$
\end{tabular}

${ }^{a}$ Solvent: Acetone- $d_{6}, 298 \mathrm{~K}$, association constant errors $<10 \% .{ }^{b}$ No association constant could be determined due to ion-pairing that takes place upon the addition of first equivalent of $\mathrm{TBA}^{+}$salt. 
Similar binding behavior was observed for the ion pair receptors 1.49a,b (Figure 1.27). ${ }^{63,64}$ In this case, binding studies carried out in acetonitrile using ${ }^{1} \mathrm{H}$ NMR and UV spectroscopy, as well as supporting calculations, revealed that receptors $1.49 \mathbf{a}, \mathbf{b}$ are able to bind an anion and cation simultaneously by stabilizing a contact ion pair within the receptors. Ditopic receptors 1.49 a,b do not bind small cations $\left(\mathrm{Na}^{+}, \mathrm{K}^{+}\right.$, and $\left.\mathrm{NH}_{4}^{+}\right)$ effectively in the absence of the $\mathrm{Cl}^{-}$anion. However, they form strong complexes with such cations in the presence of the $\mathrm{Cl}^{-}$anion and do so in a highly cooperative fashion. In the solid state, X-ray structural analyses confirmed that compound 1.49a binds $\mathrm{KCl}$ and $\mathrm{NH}_{4} \mathrm{Cl}$ as contact ion pairs. Interestingly, the resulting complexes display 1:1 and 2:2 stoichiometry, respectively. Also noteworthy is that receptor $1.49 \mathrm{a}$ binds $\mathrm{KCl}$ and $\mathrm{NH}_{4} \mathrm{Cl}$ in accord with $A N D$ logic. That is, compound 1.49a, unable to bind either the individual $\mathrm{K}^{+}$or $\mathrm{NH}_{4}^{+}$cations, nor the individual $\mathrm{Cl}^{-}$anion, is able to bind the ion pairs, $\mathrm{KCl}$ and $\mathrm{NH}_{4} \mathrm{Cl}$, very strongly in acetonitrile but only in the presence of both the constituent cations and anions. ${ }^{63,64}$
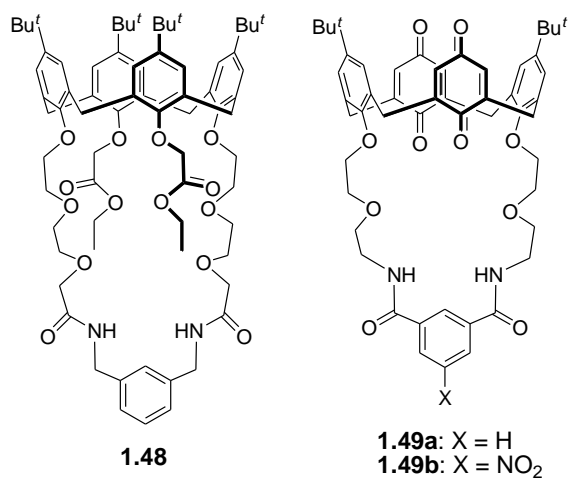

Figure 1.27 Structures of ion pair receptors 1.48 and $1.49 a, b$.

Quite early on (mid-1990's), the Beer group detailed the synthesis of the calix[4]arene derivatives containing benzo[15]crown-5 moieties via amide spacers (1.50 
and 1.51; Figure 1.28) ${ }^{65}$ These systems were expected to recognize ion pairs on the basis of a positive allosteric effect. ${ }^{65}$ Proton NMR spectroscopic binding studies carried out in acetonitrile- $d_{3}$ using various $\mathrm{Na}^{+}$and $\mathrm{K}^{+}$salts revealed that receptor $\mathbf{1 . 5 0}$ forms 1:5 (host:guest) complexes with these cations, wherein the tetraamide NH's do not cooperate to bind an anion. On the other hand, receptor $\mathbf{1 . 5 1}$ was found to form 1:1 complexes with the $\mathrm{K}^{+}, \mathrm{Ba}^{2+}$, and $\mathrm{NH}_{4}^{+}$cations in the same solvent. Here, it was proposed that the cations are sandwiched between the two benzo[15]crown-5 subunits, a recognition event that brings the amide NH's into the closer proximity. This, in turn, provides a preorganized cavity for anion recognition (Figure 1.28). Although receptor $\mathbf{1 . 5 1}$ in its free form was not found to bind anions, in the presence of potassium and ammonium cations cocomplexes with anions, such as $\mathrm{Cl}^{-}, \mathrm{NO}_{3}^{-}, \mathrm{HSO}_{4}^{-}$, and $\mathrm{H}_{2} \mathrm{PO}_{4}^{-}$, are stabilized. ${ }^{65}$
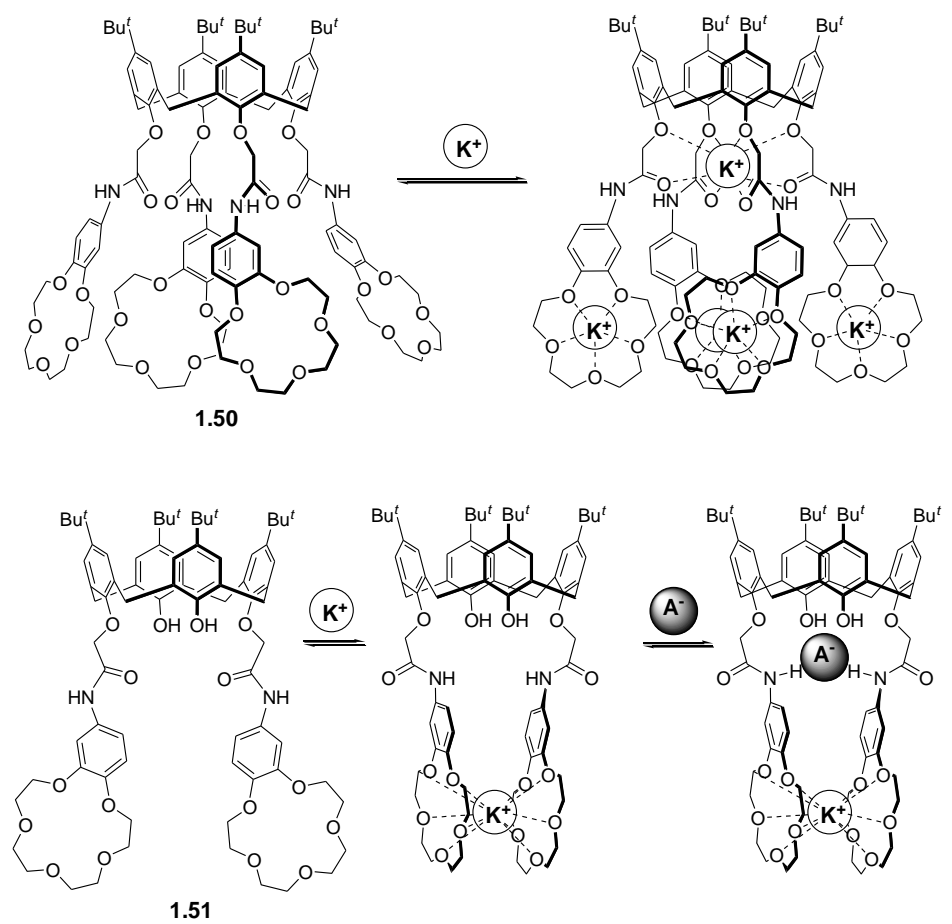

Figure 1.28 Receptors 1.50 and 1.51 and their proposed ion binding modes for anions or/and cations. 
In 2003, Evans and Beer described the ion pair receptors 1.52 and $\mathbf{1 . 5 3}$ that contain two benzo[15]crown-5 linked to the upper rim of a calix[4]arene via amide groups (Figure 1.29). ${ }^{66} \mathrm{~A}{ }^{1} \mathrm{H}$ NMR spectroscopic titration study carried out in DMSO$d_{6} / \mathrm{CD}_{3} \mathrm{CN}(1 / 1, \mathrm{v} / \mathrm{v})$ shows that the $\mathrm{K}^{+}$cation significantly enhances the binding ability of 1.52 and $\mathbf{1 . 5 3}$ for $\mathrm{Cl}^{-}, \mathrm{OBz}^{-}$, and $\mathrm{H}_{2} \mathrm{PO}_{4}{ }^{-}$. It is thought that this enhancement reflects the formation of a sandwich complex with the two benzo[15]crown-5 that, in turn, serves to provide a cavity appropriate for anion recognition. The result is ion pair binding that benefits from a positive allosteric effect. On the contrary, the $\mathrm{Na}^{+}$cation exerts a negative allosteric effect on anion binding, as can be seen from the affinity constants listed in Table 1.11. The effect of the $\mathrm{Na}^{+}$cation was rationalized in terms of these two receptors (1.52 and 1.53) forming 1:2 (host:guest) complexes wherein two $\mathrm{Na}^{+}$cations are bound to the receptor (i.e. one in each crown ether). Such a complexation mode, and the resulting electrostatic repulsion between the bound $\mathrm{Na}^{+}$cations, serves to separate the two amide $\mathrm{NH}$ protons that link each crown ring to the calix[4] arene core. As a result, these protons cannot bind the associated counter anions in a cooperative manner. ${ }^{66}$

Table 1.11 Anion association constants $\left(K_{a}\right)$ for receptors 1.52 and 1.53 and that of their corresponding $\mathrm{Na}^{+}$and $\mathrm{K}^{+}$complexes (errors $<10 \%$ ).

\begin{tabular}{cccccc}
\hline & \multicolumn{5}{c}{$K_{a}\left(\mathrm{M}^{-1}\right)$} \\
\cline { 2 - 6 } & $\mathbf{1 . 5 2}$ & {$\left[\mathbf{1 . 5 2} \cdot 2 \mathrm{Na}^{+}\right]$} & {$\left[\mathbf{1 . 5 2} \cdot \mathrm{K}^{+}\right]$} & {$\left[\mathbf{1 . 5 3} \cdot 2 \mathrm{Na}^{+}\right]$} & {$\left[\mathbf{1 . 5 3} \cdot \mathrm{K}^{+}\right]$} \\
\hline $\mathrm{Cl}^{-a}$ & 5 & $<5$ & 15 & $<5$ & 150 \\
$\mathrm{OBz}^{-a}$ & 25 & $<5$ & 270 & 20 & 205 \\
$\mathrm{H}_{2} \mathrm{PO}_{4}^{-b}$ & 10 & $<5$ & 60 & $<5$ & $c$ \\
\hline
\end{tabular}

${ }^{a}$ Solvent: DMSO- $d_{6} / \mathrm{CD}_{3} \mathrm{CN}(1 / 1, \mathrm{v} / \mathrm{v}) .{ }^{b}$ Solvent: $100 \%$ DMSO- $d_{6} \cdot{ }^{c}$ No satisfactory fit to the data could be obtained using EQNMR. 


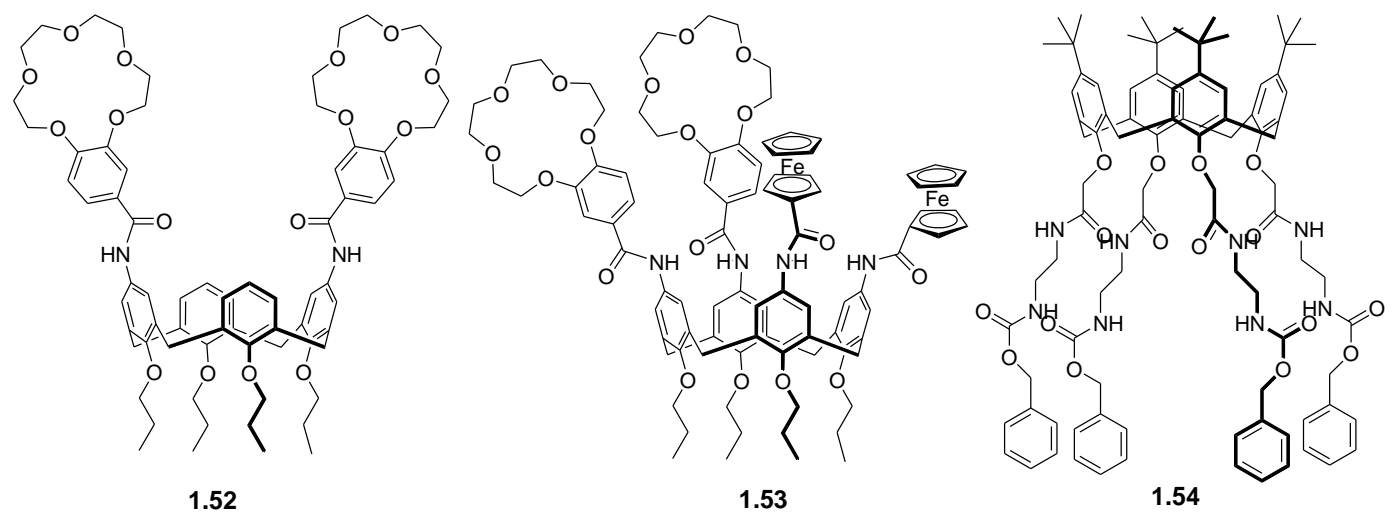

Figure 1.29 Chemical structures of ion pair receptors 1.52-1.54.

Receptor 1.54 (Figure 1.29), reported by Stibor et al. in 1997, was found to form a complex with the $\mathrm{Na}^{+}$cation and to bind various anions in a positive cooperative manner. ${ }^{67}$ Specifically, in the presence of the $\mathrm{Na}^{+}$cation, the affinities of receptor $\mathbf{1 . 5 4}$ towards $\mathrm{Br}^{-}, \mathrm{Cl}^{-}$, and $\mathrm{HSO}_{4}^{-}$were found to be increased by a factor of 5.5, 8 , and 14 , respectively.

In the late 1900's, the heteroditopic rhenium(I)-bipyridyl-bis(benzo[18]crown-6) receptor 1.55 (Figure 1.30) was synthesized by Beer and coworkers with the goal of exploiting positive binding cooperative effects to bind ion pairs. ${ }^{68,69}$ In the presence of 2.0 molar equiv. of the $\mathrm{K}^{+}$cation (added as the hexafluorophosphate salt), a cation that forms 1:1 complexes with the benzo[18]crown-6 moiety, the $\mathrm{Cl}^{-}$anion affinity was enhanced by 5-fold in DMSO. This enhancement was ascribed to favorable electrostatic and conformational effects. Analogous ion pair receptors, namely $\mathbf{1 . 5 6}$ and $\mathbf{1 . 5 7}$ (Figure 1.30), were prepared by linking two benzo[15]crown-5 subunits to ruthenium(II)- and rhenium(I)-bipyridyl groups via four amide groups. In this case, the crown ether moieties were expected to form 2:1 (crown: $\mathrm{K}^{+}$) sandwich complexes with the $\mathrm{K}^{+}$cation. Binding 
of $\mathrm{K}^{+}$serves not only to induce an allosteric effect via preorganization of the four amide groups into an orientation that favors anion binding, but also to cause a switch in the inherent anion selectivity.

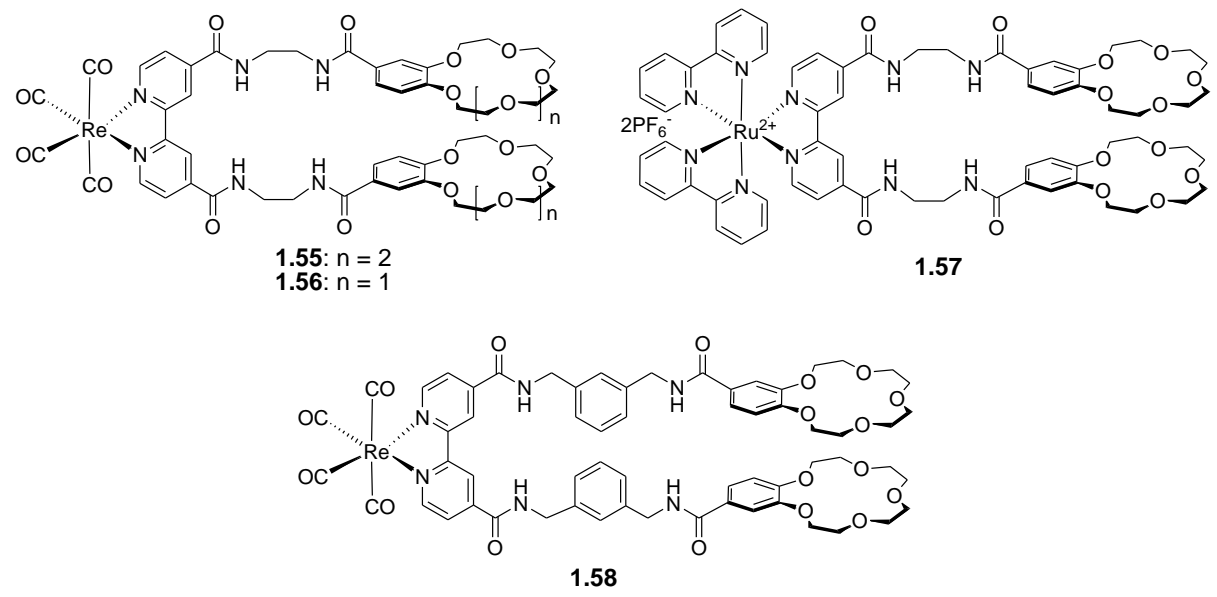

Figure 1.30 Chemical structures of ion pair receptors 1.55-1.58.

In the absence of the $\mathrm{K}^{+}$cation, both receptors bind the $\mathrm{H}_{2} \mathrm{PO}_{4}^{-}$anion more selectively than the $\mathrm{Cl}^{-}$anion in a 1:1 stoichiometry (for $1.56, K_{a}=205 \mathrm{M}^{-1}$ for $\mathrm{H}_{2} \mathrm{PO}_{4}^{-}$ vs. $K_{a}=55 \mathrm{M}^{-1}$ for $\mathrm{Cl}^{-}$in DMSO- $d_{6}$ ). However, the anion selectivity of both ion pair receptors is reversed after addition of $\mathrm{K}^{+}$, presumably because the two pendant benzo[15]crown-5 subunits form a sandwich complex with the $\mathrm{K}^{+}$cation. In this instance, the association constants of both receptors for $\mathrm{H}_{2} \mathrm{PO}_{4}^{-}$decrease while those for $\mathrm{Cl}^{-}$ increase (for 1.56, in the presence of $\mathrm{K}^{+}, K_{a}=35 \mathrm{M}^{-1}$ for $\mathrm{H}_{2} \mathrm{PO}_{4}{ }^{-} v s . K_{a}=300 \mathrm{M}^{-1}$ for $\mathrm{Cl}^{-}$ in DMSO- $d_{6}$ ). In a similar manner, adding $\mathrm{K}^{+}$to $\mathbf{1 . 5 8}$ serves to preorganize the four amide groups for anion recognition via formation of a crown-based sandwich complex. This gives rise to the result of enhancing the association constants for the acetate and chloride anions by a factor of 1.4 and 1.8 , respectively. ${ }^{70}$ 
Beer and co-workers also synthesized the ion pair receptor 1.59 (Figure 1.31), a tripodal tris(amido benzo[15]crown-5). ${ }^{71}$ This system, reported in 1999, was studied for its ability to extract and transport sodium halide salts and sodium perrhenate. In the presence of 1.0 equivalent of sodium picrate, compound 1.59 acts as a ditopic receptor, exhibiting enhanced affinities for $\mathrm{Cl}^{-}, \mathrm{I}^{-}$and $\mathrm{ReO}_{4}{ }^{-}$(Table 1.12). This result is ascribed to the cooperative binding of these anions via co-bound sodium cations complexed by the crown ether subunits. It was also found that receptor 1.59 can extract sodium pertechnetate $\left(\mathrm{NaTcO}_{4}\right)$ from water and transport it efficiently under mixed organic aqueous conditions designed to simulate conditions that might by applicable to treatment of aqueous waste streams containing this radioactive salt.

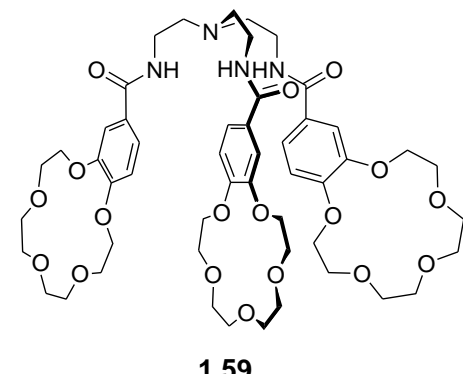

Figure 1.31 Tripodal tris(amido benzo[15]crown-5) ion pair receptor 1.59. 
Table 1.12 Binding constants recorded for $\mathbf{1 . 5 9}$ in the presence and absence of sodium picrate in $\mathrm{CDCl}_{3}$.

\begin{tabular}{cc}
\hline Anions & $K_{a}\left(\mathrm{M}^{-1}\right)$ \\
\hline $\mathrm{Cl}^{-}$ & $60^{a}$ \\
$\mathrm{Cl}^{-}\left(+\mathrm{Na}^{+}\right)^{b}$ & $520^{c}$ \\
$\mathrm{I}^{-}$ & $30^{a}$ \\
$\mathrm{I}^{-}\left(+\mathrm{Na}^{+}\right)^{b}$ & $390^{c}$ \\
$\mathrm{ReO}_{4}^{-}$ & $40^{a}$ \\
$\mathrm{ReO}_{4}^{-}\left(+\mathrm{Na}^{+}\right)^{b}$ & $840^{c}$ \\
\hline
\end{tabular}

${ }^{a}$ Determined at $298 \mathrm{~K}$, errors estimated to be $\leq 10 \% .{ }^{b}$ Titration carried out in the presence of 1.0 molar equiv. of sodium picrate. ${ }^{c}$ Determined at $298 \mathrm{~K}$, errors estimated to be $\leq 15 \%$.

In 2001, Beer and coworkers also demonstrated positive binding cooperativity in the case of the bis(calix[4]arene) rhenium(I)-bipyridyl receptors $\mathbf{1 . 6 0 a , b}$ (Figure 1.32). ${ }^{72}$ In the presence of 2.0 molar equiv. of alkali metal ions, such as $\mathrm{Li}^{+}, \mathrm{Na}^{+}$, and $\mathrm{K}^{+}$, the binding affinities for iodide were observed to increase by a factor of 4.5, 3.1, and 1.5, respectively. This finding was attributed to the complexation of the metal cations with the ester groups in the lower rim of the calix[4]arene. This complexation fixes the calixarene scaffold in a more rigid conformation, thereby preorganizing the central cavity for iodide recognition. It was found that calix[4]arene tetraester $\mathbf{1 . 6 0 b}$ shows the greatest enhancement in the $\mathrm{I}^{-}$binding affinity in the presence of $\mathrm{Na}^{+}$(in the presence of $\mathrm{NaClO}_{4}$, $K_{a}=320 \mathrm{M}^{-1}$ for TBAI vs. $K_{a}=40 \mathrm{M}^{-1}$ in its absence, for $\mathrm{I}^{-}$in $\left.\mathrm{CD}_{3} \mathrm{CN}\right)$. Ion pair receptors 1.61a,b, in which calix[4] arene esters are linked to a single ruthenium(II)- or rhenium(I)bipyridyl metal site, were also reported by Beer et al. in $2000 .^{73}$ It was found by separate ${ }^{1} \mathrm{H}$ NMR titration experiments, carried out in acetonitrile- $d_{3}$, that receptors $1.61 \mathbf{a , b}$ form 1:1 complexes with the $\mathrm{Br}^{-}$and $\mathrm{I}^{-}$anions (as the tetrabutylammonium salts), and the $\mathrm{Li}^{+}$ and $\mathrm{Na}^{+}$cations (as the perchlorate salts). The presence of 1.0 equiv. of the alkali metal 
cations significantly increases the $\mathrm{Br}^{-}$and $\mathrm{I}^{-}$affinities of receptors 1.61a,b. The enhancement in these anion affinities seen in the presence of the pre-bound cation is ascribed to i) the attraction between co-bound opposite charged-ions, ii) the preorganized cavity, and iii) the increased strength of the hydrogen bond interactions with the bound anion. This latter benefit is thought to result from cation complexation that serves to disrupt the intramolecular hydrogen bonds between the proximal amide NH proton and one or more of the calix[4]arene ester oxygen atoms.

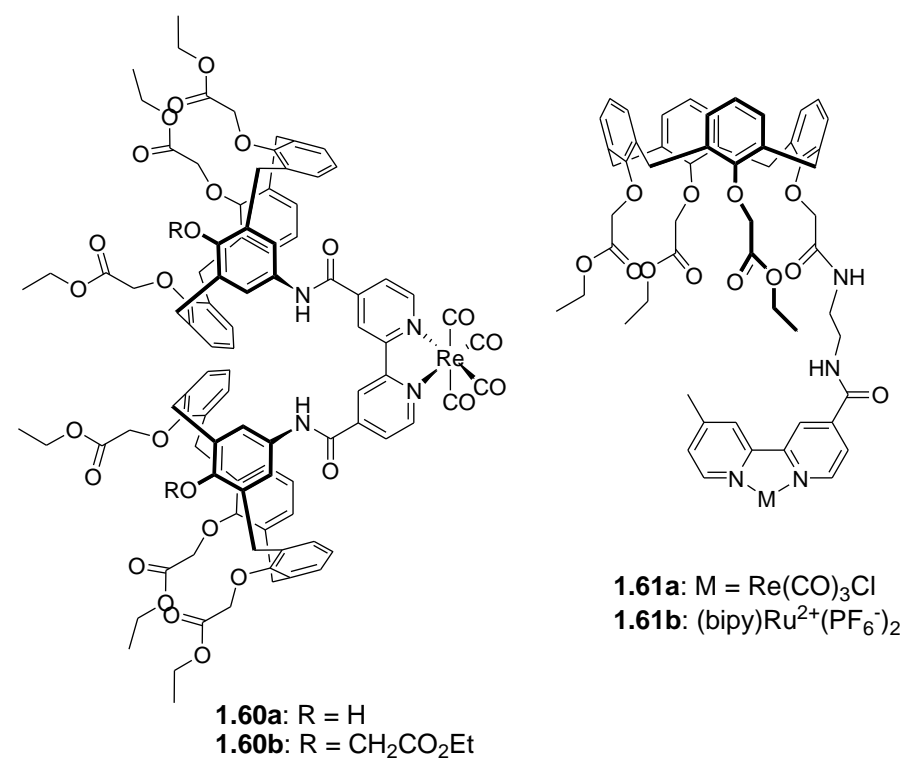

Figure 1.32 Calix[4] arene-based ion pair receptors $\mathbf{1 . 6 0 a , b}$ and $\mathbf{1 . 6 1 a , b .}$

In 2008, Le Gac and Jabin reported the synthesis of calix[6]cryptamide $\mathbf{1 . 6 2}$ (Figure 1.33), a receptor that was put forward as a host for neutral molecules and alkylammonium chloride ion pairs (alkyl = ethyl and propyl) ${ }^{74}$ Receptor $\mathbf{1 . 6 2}$ contains a calix[6]arene subunit that is designed to act as a cation recognition site. This core is linked to a cyclotriveratrylene skeleton via three diamide groups, thereby providing an 
anion recognition site. Upon addition of excess (up to 15 molar equiv) of ammonium salts $\mathrm{RNH}_{3}{ }^{+} \mathrm{Cl}^{-}(\mathrm{R}=$ ethyl or propyl) to a chloroform solution of $\mathbf{1 . 6 2}$, the resonance of the amide NH protons nearest to the calix[6]arene backbone undergoes a significant downfield shift ( $\Delta \delta>0.5 \mathrm{ppm}$ ), whereas the peaks of alkyl protons of the ammonium cations appear in abnormally low field ( $\delta \approx-1.0$ and -2.0 ppm for the methylene protons of propylammonium chloride). Such findings provide support for the notion that the alkylammonium chloride ion pairs are included in the receptor. That is, the chloride anion is hydrogen bonded to the amide groups and the alkylammonium cation is bound to the calix[6]arene cup via hydrogen bonds to the ethereal oxygen atoms, as well as $\mathrm{CH}-\pi$ interactions. Interestingly, neither the chloride anion nor the propylammonium cation with non-coordinating counterions, such as the tetrabutylammonium cation or the picrate anion, was bound to the receptor. This selectivity is consistent with the conclusion that this system is highly cooperative, and that interaction between the co-bound ions is essential for the formation of a stable host-guest ion pair complex. ${ }^{74}$

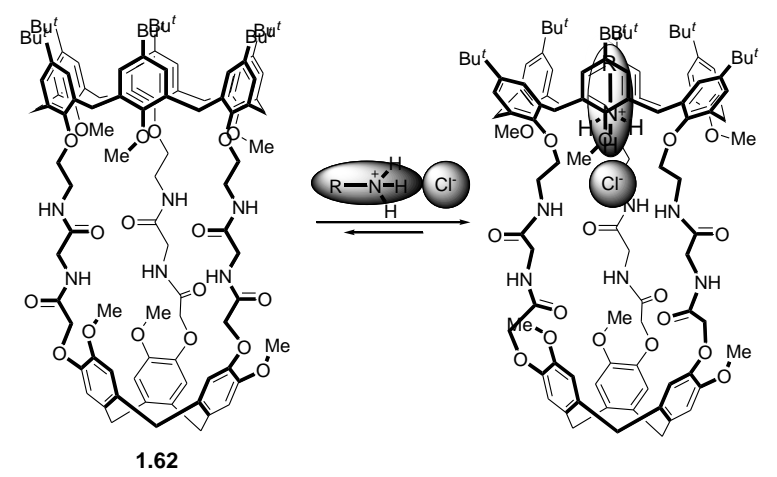

Figure 1.33 Calix[6]arene-based ion pair receptor $\mathbf{1 . 6 2}$ and its proposed mode of binding for alkylammonium chloride contact ion pairs. 
Ditopic receptors 1.63a-c (Figure 1.34) were also synthesized by the Jabin group in $2003{ }^{75}$ These systems contain three urea or thiourea groups attached to the calix[6]arene skeleton. In the presence of various anion salts containing the noncoordinating countercation, tetrabutylammonium $\left(\mathrm{TBA}^{+}\right)$, a significant downfield shift of the urea or thiourea NH resonances is seen in the ${ }^{1} \mathrm{H}$ NMR spectrum. This observation is consistent with the receptors being able to recognize directly the $\mathrm{Br}^{-}, \mathrm{I}^{-}, \mathrm{AcO}^{-}$, and $\mathrm{HSO}_{4}{ }^{-}$ anions. In contrast, no chemical shift change is observed in the presence of an excess of the propylammonium picrate, a finding interpreted in terms of these receptors being unable to bind alkyl ammonium cations as independent substrates. On the other hand, the addition of tetrabutylammonium chloride to a mixture of receptors 1.63a-c and propylammonium picrate produces a remarkable upfield shift in the propylammonium resonance (to $\delta \approx-1.0$ and $-2.0 \mathrm{ppm}$ for the propyl $\mathrm{CH}_{2} \mathrm{CH}_{2}$ signals) as well as large downfield shifts in the urea or thiourea NH signals. Such large, correlated changes in the ${ }^{1} \mathrm{H}$ NMR spectrum were taken as evidence that both the chloride anion and the propylammonium cation are bound concurrently to the receptors. To the extent this interpretation is correct, it implies that the chloride anion plays a crucial role in cation binding and that the system benefits from a positive cooperative interaction. Support for this appealing conclusion comes from studies of receptor $\mathbf{1 . 6 4}$ (Figure 1.34), a system that bears an independent recognition site for ammonium cations. As expected, this latter receptor was found to form a 1:1 complex with propylammonium chloride and to do so with a positive cooperativity. ${ }^{76}$ 


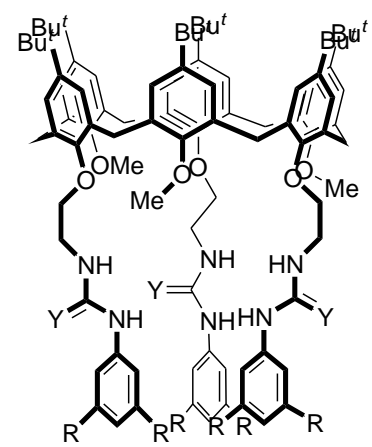

1.63a: $Y=O, R=H$ 1.63b: $Y=O, R=\mathrm{CF}_{3}$ 1.63c: $Y=S, R=H$

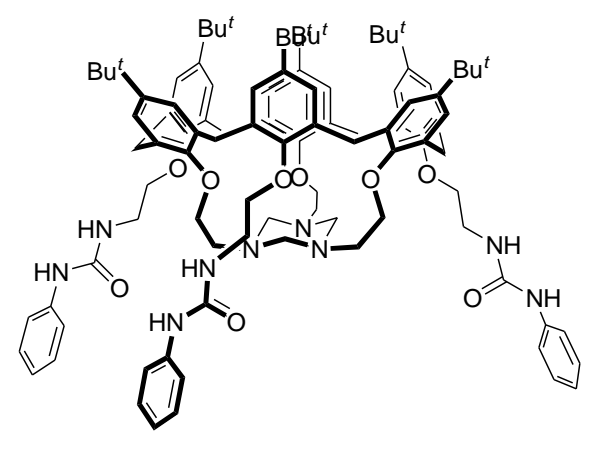

1.64

Figure 1.34 Calix[6]arene-urea based ion pair receptors 1.63a-c and 1.64.

A different type of receptor, namely 1.65a-e (Figure 1.35), containing amides and designed for organic ion pair recognition, was reported by Atwood et al. First reported in 2002, these systems are based on resorcin[4]arene frameworks that are linked to additional aromatic rings via a Mannich reaction to provide a hydrophobic cavity. ${ }^{77,78}$ Four amide groups on the upper rim of the capsule-like molecule then complete the structure. In a mixture of $\mathbf{1 . 6 5 a - c}$ in chloroform containing an excess of TMACl (tetramethylammonium chloride), the proton peak of the $\mathrm{TMA}^{+}$cation appears at $\delta=-$ 0.57 in the ${ }^{1} \mathrm{H}$ NMR spectrum, while the NH signals appear at $9.6 \mathrm{ppm}$. These correspond to upfield and downfield shifts of +1.6 and $-1.6 \mathrm{ppm}$, respectively. These findings provide support for the conclusion that the $\mathrm{TMA}^{+}$cation is encapsulated in the cavity while the chloride anion is hydrogen bonded to the amide NH protons. The X-ray crystal structure of 1.65a $\cdot \mathrm{TMACl}$ was solved (Figure 1.36). It revealed that the receptor forms a simultaneous complex with both the cation and the anion as a contact ion pair. In the presence of excess TMACl, the existence of two sets of distinguishable proton peaks for the TMA cation (one for the complex, the other for the free) is seen in the ${ }^{1} \mathrm{H}$ NMR spectrum. This is consistent with the equilibrium between the complexed and the 
uncomplexed $\mathrm{TMA}^{+}$cation being slow on the NMR time scale and that the complex is kinetically and thermodynamically stable. Compounds $\mathbf{1 . 6 5 d}, \mathbf{e}$, having more acidic NH's, were thought on the basis of ${ }^{1} \mathrm{H}$ NMR spectroscopic studies to form an ion pair complex with other tetramethylammonium halides, such as TMABr and TMAI, as well as TMACl. ${ }^{77,78}$

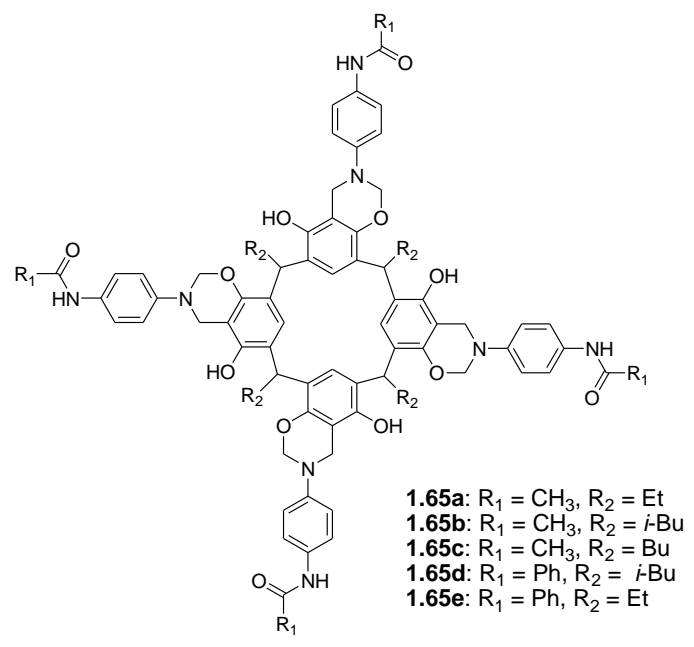

Figure 1.35 Chemical structures of molecular capsules 1.65a-e.
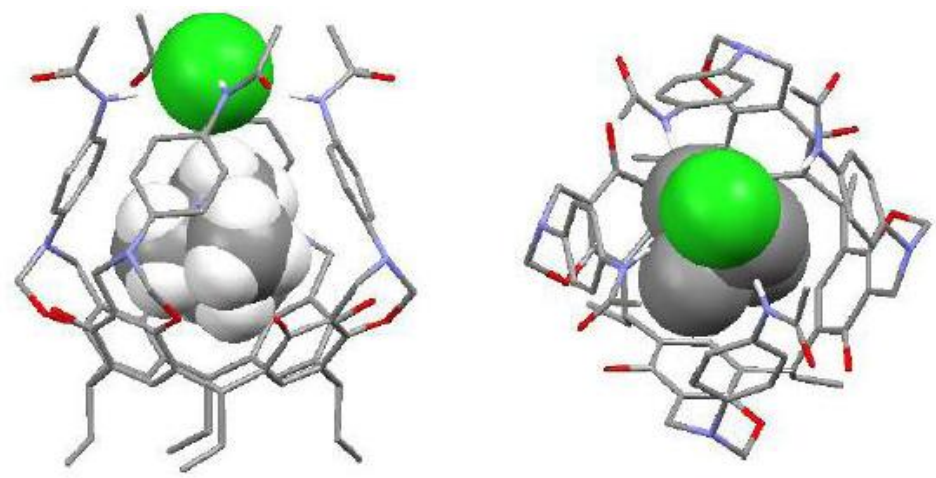

Figure 1.36 Two different views of the X-ray crystal structure of 1.65a $\cdot \mathrm{TMACl}\left(\mathrm{TMA}^{+}=\right.$ tetramethylammonium). This figure was produced using coordinates that originally appeared in ref. 77. 
In 2005, Frontera et al. reported that a squaramide moiety connected to a [18]crown-6 subunit (receptor 1.66; Figure 1.37) is able to bind both the $\mathrm{K}^{+}$or $\mathrm{Na}^{+}$cation and the acetate $\left(\mathrm{OAc}^{-}\right)$anion concurrently, as evidenced by ${ }^{1} \mathrm{H}$ NMR spectroscopy and supporting PB86/optimized structures. ${ }^{79}$ Receptor $\mathbf{1 . 6 6}$ was also found to dissolve otherwise insoluble carboxylate salts, such as sodium benzoate and sodium acetate in chloroform.

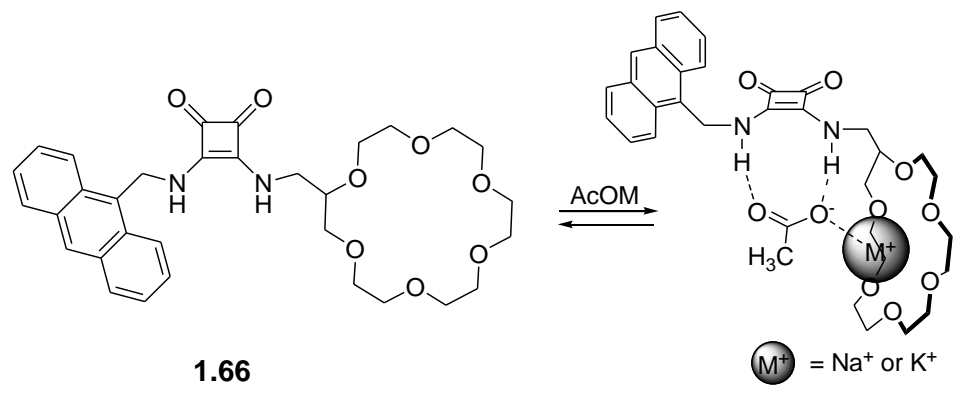

Figure 1.37 Chemical structure of the crowned squaramide ion pair receptor $\mathbf{1 . 6 6}$ and its predicted binding mode for $\mathrm{NaOAc}$ or KOAc contact ion pairs.

Another approach to binding ion pairs involves the use of cyclopeptides. These systems are multi-amides and can thus interact with anions via hydrogen bond donating NH residues and cations via carbonyl lone pair electrons. A pioneer in this area is Kubik, who synthesized the cyclopeptide $\mathbf{1 . 6 7}$ (Figure 1.38). ${ }^{80}$ This receptor contains $L$-glutamic acid and 3-aminobenzoic acid subunits linked in an alternating sequence. It was examined for its ability to bind both anions and cations. For instance, ${ }^{1} \mathrm{H}$ NMR spectroscopic analyses revealed that receptor $\mathbf{1 . 6 7}$ forms a 1:1 complex with $n$ butyltrimethylammonium iodide (BTMAI). An upfield shift in the proton resonance of the $\mathrm{BTMA}^{+}$cation in conjunction with an unchanged $\mathrm{NH}$ peak in the ${ }^{1} \mathrm{H}$ NMR spectrum 
was taken as evidence that macrocycle $\mathbf{1 . 6 7}$ is able to recognize the ammonium cation via a $\pi$-cation interaction $\left(K_{a}=300 \mathrm{M}^{-1}\right)$, but not the $\mathrm{I}^{-}$anion.

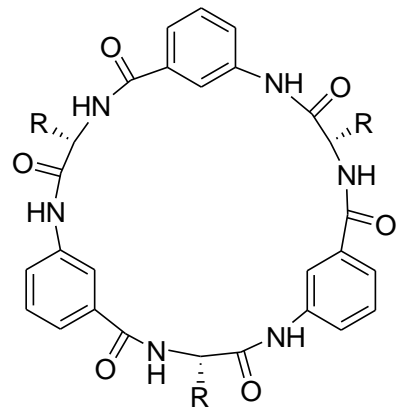

1.67: $\mathrm{R}=\mathrm{CH}_{2} \mathrm{CH}_{2} \mathrm{COOCH}\left(\mathrm{CH}_{3}\right)_{2}$

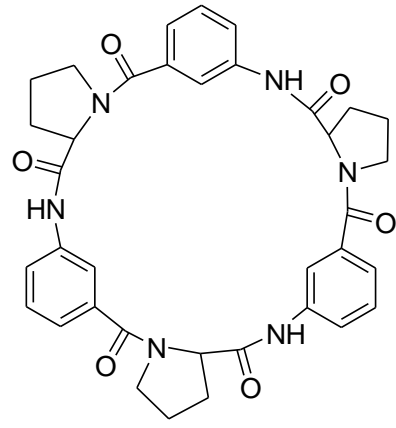

1.68

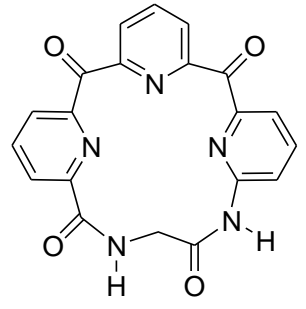

1.69

Figure 1.38 Cyclopeptide-based ditopic receptors 1.67-1.69.

In addition to the $\mathrm{BTMA}^{+}$cation, receptor 1.67 was found to bind certain anions, including tosylates and phosphates via hydrogen bonding interactions involving the amide NH protons and the bound anions. It was also noted that in the presence of the tosylate anion, the affinity of cyclopeptide $\mathbf{1 . 6 7}$ for the $\mathrm{BTMA}^{+}, \mathrm{Na}^{+}$, and $\mathrm{K}^{+}$cations was significantly enhanced. This increase (up to a factor of $10^{3}-10^{4}$ ) was ascribed to an increase in the preorganization of the cyclopeptide by the bound anion, as well as to an enhanced electrostatic interaction between the anions and cationic substrates in the final complex. That is, the binding of the tosylate anion via interaction with the six amide $\mathrm{NH}$ protons serves to enforce a calix[4]arene-like cone conformation, i.e., one, in which all the carbonyl oxygen atoms, as well as aromatic groups, point in the same direction. The net result is the stabilization of a bowl-shaped cavity suitable for cation binding. Accordingly, substrate binding is highly cooperative.

Kubik, together with Goddard, also synthesized cyclopeptide 1.68 (Figure 1.38), which contains $L$-proline and 3-aminobenzoic acid subunits linked in an alternating 
sequence. ${ }^{81}$ With most ion pairs tested, compound $\mathbf{1 . 6 8}$ was found to display binding behavior similar to that of compound 1.67. An exception to this generalization is BTMAI. Receptor $\mathbf{1 . 6 8}$ was found to recognize BTMAI in a highly cooperative fashion, as evidenced by the observation of a significant upfield shift in the proton resonance $(\Delta \delta=-$ $1.1 \mathrm{ppm}$ for $\mathbf{1 . 6 8}$ and $\Delta \delta=-0.02$ for $\mathbf{1 . 6 7}$ ) of the ammonium cation (in both cases the chemical shifts of the $N$-methyl protons were monitored). The stability constant of cyclopeptide $\mathbf{1 . 6 8}\left(K_{a}=21,100 \mathrm{M}^{-1}\right)$ for BTMAI is almost two orders of magnitude higher than that of $\mathbf{1 . 6 7}\left(K_{a}=300 \mathrm{M}^{-1}\right)$.

In 2005, Gibb and Gong reported that the macrocyclic compound 1.69 (Figure 1.38), composed of a tripyridyl unit cyclized with a diamide linker, acts as an ion pair receptor for monoalkylammonium salts, being especially effective for salts of $L$ phenylalanine methyl ester. ${ }^{82}$ Little or no change in the ${ }^{1} \mathrm{H}$ NMR spectrum was seen in the presence of anions paired with the non-coordinating counter cation, tetrabutylammonium. This observation led these authors to suggest that the anions were not bound strongly to the receptor. In contrast, when salts of smaller mono-alkyl ammonium cations were used, relatively large downfield shifts was seen for both the amide $(\Delta \delta>0.5 \mathrm{ppm})$ and pyridyl $(\Delta \delta=0.1-0.2 \mathrm{ppm})$ signals. These spectroscopic changes were interpreted in terms of both the anion and the cation being bound to the receptor. Compared to what was seen for anions studied using non-coordinating counter cations, the enhancement in the association constants seen when these ion pairs were used with 1.69 is remarkable. Not surprisingly, this increase was ascribed to cooperative interactions between the co-bound ions (see Table 1.13). To the extent this interpretation is true, it shows that when both components of ion pairs are bound concurrently, much stronger complexes can be attained. 
Table 1.13 Association constants between $\mathbf{1 . 6 9}$ and various ammonium salts. ${ }^{a}$

\begin{tabular}{|c|c|c|c|c|}
\hline${ }^{+} \mathrm{NBu}_{4}$ salt & $K_{a}\left(\mathrm{M}^{-1}\right)$ & $\begin{array}{c}{ }^{+} \mathrm{NH}_{3} \mathrm{CH}(\mathrm{Bn})-\mathrm{CO}_{2} \mathrm{Me} \\
\text { salt }\end{array}$ & $K_{a}\left(\mathrm{M}^{-1}\right)$ & $\begin{array}{c}\text { Coopera- } \\
\text { tivity factor }\end{array}$ \\
\hline $\mathrm{F}^{-}$ & 110 & $\mathrm{~F}^{-}$ & $-^{c}$ & $-^{c}$ \\
\hline $\mathrm{Cl}^{-}$ & 63 & $\mathrm{Cl}^{-}$ & 12,100 & 190 \\
\hline $\mathrm{Br}^{-}$ & 40 & $\mathrm{Br}^{-}$ & 1,900 & 48 \\
\hline $\mathrm{I}^{-}$ & 32 & $\mathrm{I}^{-}$ & 400 & 13 \\
\hline $\mathrm{PF}_{6}^{-}$ & $-{ }^{d}$ & $\mathrm{PF}_{6}^{-}$ & $-^{c}$ & $-^{c}$ \\
\hline $\mathrm{NO}_{3}^{-}$ & 70 & $\mathrm{NO}_{3}^{-}$ & 18,400 & 257 \\
\hline $\mathrm{CF}_{3} \mathrm{CO}_{2}^{-}$ & 52 & $\mathrm{CF}_{3} \mathrm{CO}_{2}^{-}$ & 6,300 & 121 \\
\hline $\mathrm{TsO}^{-}$ & 42 & $\mathrm{TsO}^{-}$ & 1,500 & 36 \\
\hline
\end{tabular}

Efforts to apply ion pair recognition principles to the synthesis of more elaborate systems, such as rotaxanes and catenanes, were made by Beer and coworkers. ${ }^{83,84}$ In what is arguably the first example of work along these lines, the pseudorotaxane $\mathbf{1 . 7 2}$ (Figure 1.39) was made by mixing macrocyclic compound 1.70, acting as an ion pair receptor, with the organic ion pair 1.71. In acetone solution, this organic ion pair (1.71) threads through the ion pair receptor (1.70). Presumably, this threading is driven by complementary chloride binding by the NH protons of $\mathbf{1 . 7 0}$ and $\mathbf{1 . 7 1}$, as well as by additional hydrogen bonding interactions involving the positively charged $N$-methyl protons and the crown ether ring (Figure 1.39). In addition, a charge transfer complex, stabilized by $\pi$ donor-acceptor interactions between the pyridinium cation and the two hydroquinone moieties of $\mathbf{1 . 7 0}$, provides another driving force for the formation of psedorotaxane 1.72. The formation of this latter product is evidenced by the appearance 
of a broad band at approximately $370 \mathrm{~nm}$ in the UV/Vis spectrum, features that correspond to color change from colorless to pale yellow. Consistent with this proposed mechanism, it was found that pseudorotaxane $\mathbf{1 . 7 2}$ is not formed in protic solvents because of competition from the solvents. ${ }^{83,84}$

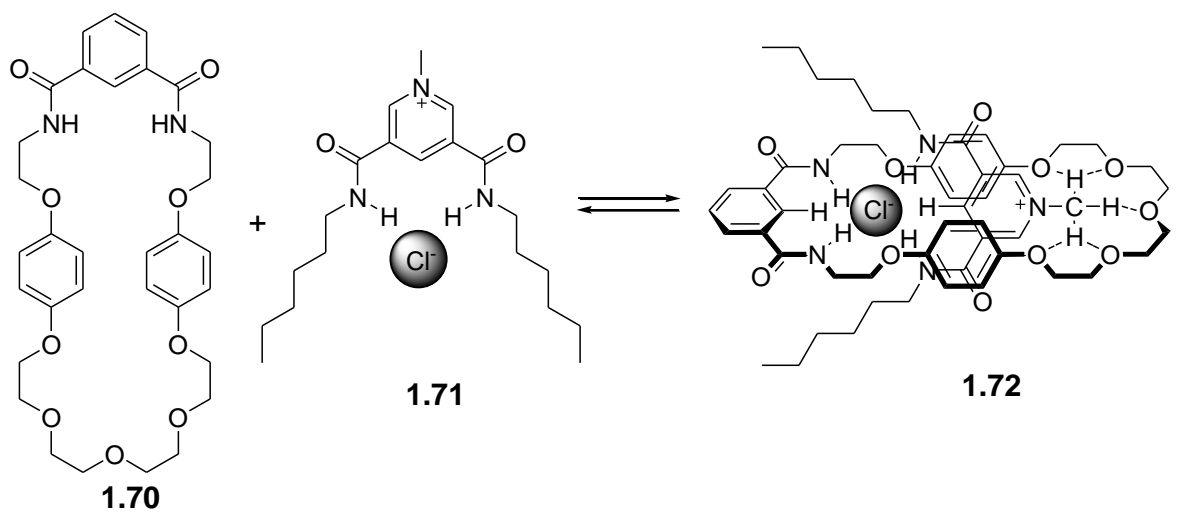

Figure 1.39 Formation of pseudorotaxane 1.72 via cooperative ion pair (1.71) recognition by $\mathbf{1 . 7 0}$.

In contrast, the permanently interlocked [2]- and [3]-catenanes $\mathbf{1 . 7 4}$ and $\mathbf{1 . 7 5}$ can be formed from the ion pair receptor 1.70 and the organic ion pair 1.73 by ring-closing metathesis (Figure 1.39). ${ }^{85}$ In dichloromethane, the addition of $10 \mathrm{wt} \%$ Grubbs' catalyst to the pre-formed pseudorotaxane between $\mathbf{1 . 7 0}$ and $\mathbf{1 . 7 3}$ gives [2]- and [3]-catenanes $\mathbf{1 . 7 4}$ and $\mathbf{1 . 7 5}$ in $45 \%$ and $<5 \%$ yield, respectively (Figure 1.40). Furthermore, removal of the $\mathrm{Cl}^{-}$template from catenane $\mathbf{1 . 7 4}$ by $\mathrm{AgPF}_{6}$ provides the anion-free catenane, which is able to act as anion receptor for $\mathrm{Cl}^{-}, \mathrm{H}_{2} \mathrm{PO}_{4}{ }^{-}$, and ${ }^{-} \mathrm{OAc}$ anions. ${ }^{85}$ 


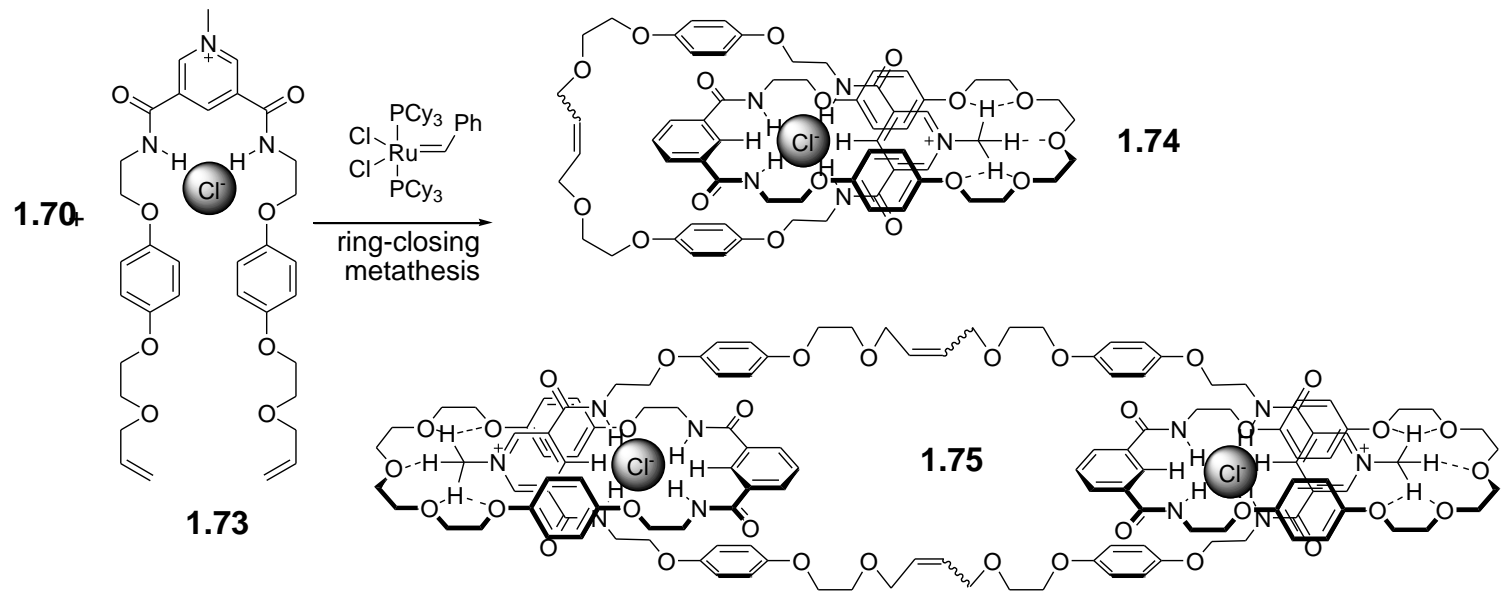

Figure 1.40 Formation of [2]- and [3]-catenanes 1.74 and $\mathbf{1 . 7 5}$ by ring-closing metathesis using Grubbs' catalyst.

In 2007, the Beer group further reported the use of a calix[4]arenes strapped with a diamide ring (e.g., 1.74) for ion paired thread recognition instead of compound $\mathbf{1 . 7 0}{ }^{86}$ The oxygen atoms of this calix[4]arene in the cone conformation bind the positively charged $N$-methyl group of appropriately chosen substrates via hydrogen bonds, whereas the amides recognize the chloride anion to form pseudorotaxanes, such as $\mathbf{1 . 7 6}$ (Figure 1.41). Finally, catenane $\mathbf{1 . 7 7}$ could be formed from the starting diamide calixarene receptor via the combined use of a functionalized substrate and Grubbs' catalyst (Figure $1.41)$. 

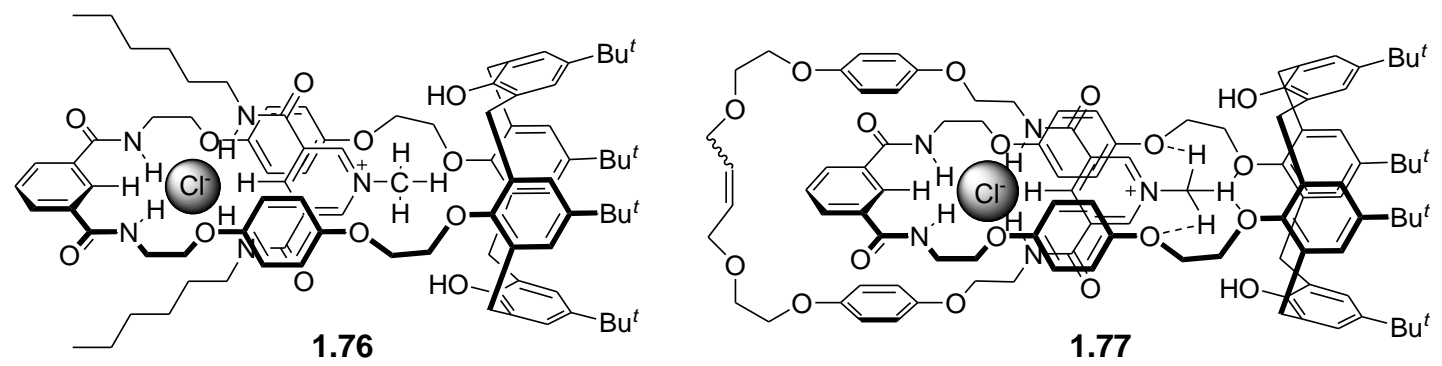

Figure 1.41 Pseudorotaxane 1.76 and catenane 1.77 formed using a calix[4]arene-based ion pair receptor and appropriately chosen pairs of anions and cations.

\subsection{ION PAIR RECEPTORS BASED ON POSITIVELY CHARGED COMPONENTS FOR ANION RECOGNITION}

Subunits that provide positively charged centers have proved effective for the construction of ion pair receptors. Several that rely on protonated ammoniums have proved useful at low $\mathrm{pH}$. An early example, dating from 1992, was reported by Lockhart et al. These researchers synthesized compound $\mathbf{1 . 7 8}$ (Figure 1.42), consisting of two benzo[5]crown-15 moieties linked via a tetraammonium spacer, and examined its ability to bind $\mathrm{KCl}$ (Figure 1.42). ${ }^{87}$ Detailed ${ }^{35} \mathrm{Cl} \mathrm{NMR}$ and ${ }^{39} \mathrm{~K}$ NMR spectroscopic analyses provided support for the notion that receptor $\mathbf{1 . 7 8}$ forms a complex with the $\mathrm{KCl}$, wherein the central tetraammonium linker wraps around the $\mathrm{Cl}^{-}$anion so as to bring the two benzo[5]crown-15 ether ring into closer proximity. This wrapping allows the $\mathrm{K}^{+}$cation to be bound in a "sandwich-like" fashion. In this case, ion pair binding to receptor $\mathbf{1 . 7 8}$ takes place on the basis of a positive allosteric effect. 


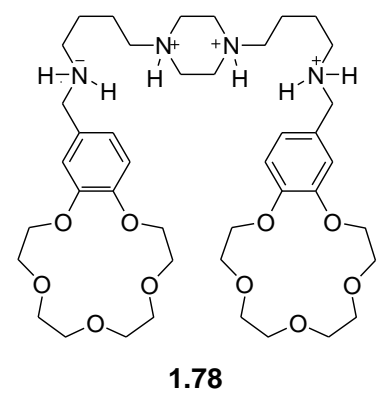

Figure 1.42 An Ion pair receptor for $\mathrm{KCl}, \mathbf{1 . 7 8}$, that operates at low or neutral $\mathrm{pH}$.

In 1999, White and coworkers reported an ion pair receptor that can be used for the separation of transition metal salts $\left[\mathrm{M}^{2+} \mathrm{X}^{2-}\right]$ through solvent extraction. This system, receptor 1.79 (Figure 1.43), incorporates into a lipophilic framework a dianionic binding site for transition metal cations and a dicationic binding site for anions. ${ }^{88}$ Transition metal cations, such as $\mathrm{Cu}^{2+}$ and $\mathrm{Ni}^{2+}$, are bound to the salen-based cation-recognition site, inducing proton transfer from the phenolic ring to the nitrogen atoms of the morpholine moieties. This provides positively charged ammonium species and also serves to bring the two ammonium units into proximity for cooperative anion recognition (Figure 1.43).

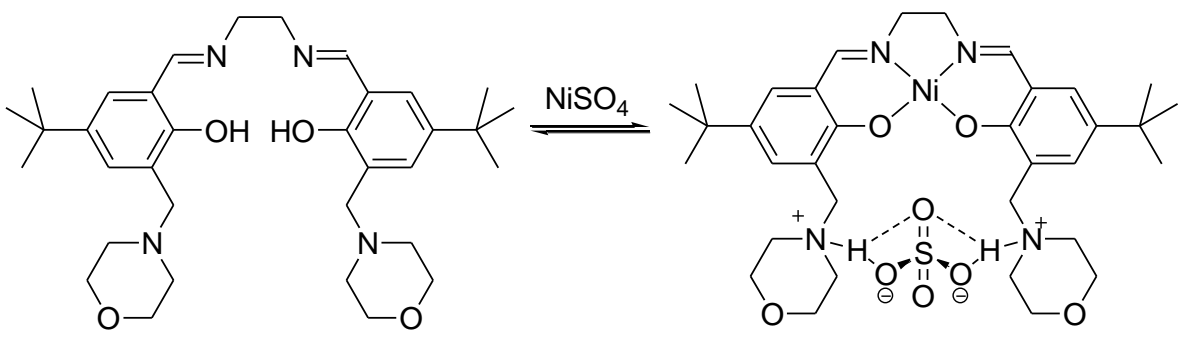

1.79

Figure 1.43 Ion pair receptor 1.79 and its binding mode for $\mathrm{NiSO}_{4}$.

As evidenced by the X-ray crystal structure of $1.79 \cdot \mathrm{NiSO}_{4}$, in the solid state the sulfate dianion and $\mathrm{Ni}^{2+}$ cation are spatially separated, being bound to the protonated 
central amines via two hydrogen bonds and the deprotonated phenol units of the salen subunit, respectively. Sulfate anion binding is presumably reinforced by electrostatic interactions involving the salen-bound $\mathrm{Ni}^{2+}$ cation. Liquid-liquid extraction experiments were also carried out and served to demonstrate that ion pair receptor $\mathbf{1 . 7 9}$ is able to extract $\mathrm{CuSO}_{4}$ into chloroform from an aqueous solution of $\mathrm{CuSO}_{4}$ at $\mathrm{pH} 3.8$.

In 2001, Tuntulani et al. reported the synthesis of the ion pair receptor $\mathbf{1 . 8 0}$ (Figure 1.44), a tripodal aza crown ether calix[4]arene, and its interaction with halide anions and alkali metal cations. ${ }^{89}$ In this case, ${ }^{1} \mathrm{H}$ NMR spectroscopic analyses revealed that compound $\mathbf{1 . 8 0}$ can form complexes with anions such as $\mathrm{Br}^{-}$and $\mathrm{I}^{-}$but not $\mathrm{F}^{-}$, as well as with cations, such as $\mathrm{Na}^{+}$and $\mathrm{K}^{+}$cations in $100 \%$ DMSO- $d_{6}$ and in a mixture of $\mathrm{CDCl}_{3}$ and $\mathrm{CD}_{3} \mathrm{OD}$. In the presence of the $\mathrm{K}^{+}$cation, the association constant of compound $\mathbf{1 . 8 0}$ for the $\mathrm{Br}^{-}$anion was found to be enhanced by nearly 1.5 fold.

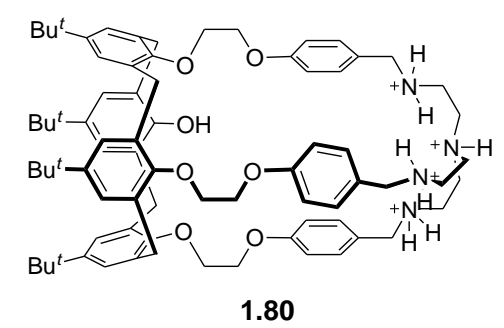

Figure 1.44 Tripodal aza crown ether calix[4]arene 1.80 containing both cation and anion binding sites.

For recognition of zwitterionic amino acids, Schmidtchen synthesized the ditopic receptor 1.81 (Figure 1.45).$^{90}$ This system, reported in 1986, contains a triaza[18]crown-6 subunit covalently linked to a tetraammonium macrocylic anion recognition motif via a para-xylene tether. In this case, a ${ }^{1} \mathrm{H}$ NMR spectroscopic binding study revealed that receptor $\mathbf{1 . 8 1}$ is able to bind certain zwitterionic amino acids, such as $\gamma$-aminobutyric acid 
and 6-aminohexanoic acid in $90 \%$ aqueous methanol. The association constants $\left(K_{a}\right)$ of compound $\mathbf{1 . 8 1}$ for some primary ammonium guests as determined from competition experiments were found to be reduced as compared to those obtained with the monotopic control compound 1.82. The selectivity of ditopic receptor $\mathbf{1 . 8 1}$ for zwitterionic amino acids is, however, increased by a factor of 2.5 as compared to the monotopic receptor 1.82 .

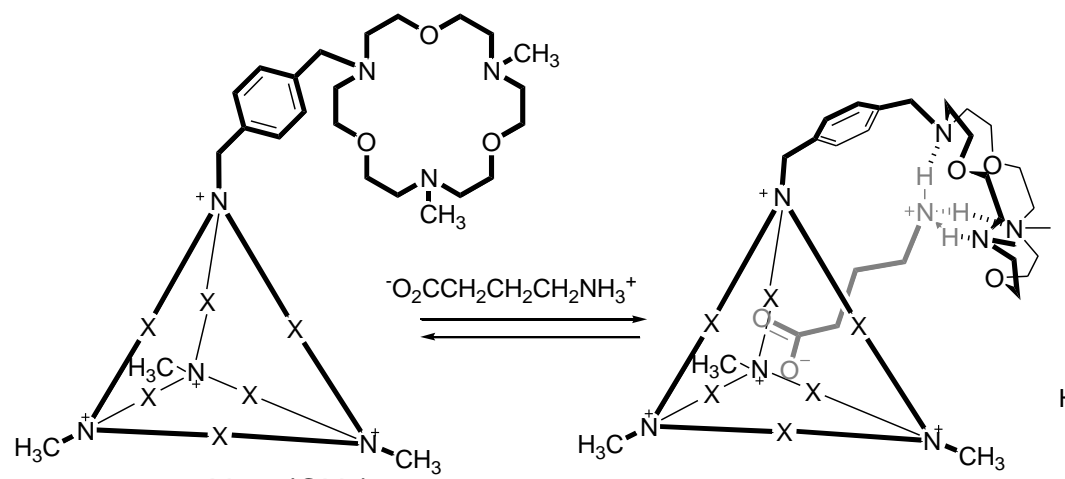

1.81: $\mathrm{X}=-\left(\mathrm{CH}_{2}\right)_{6}^{-}$

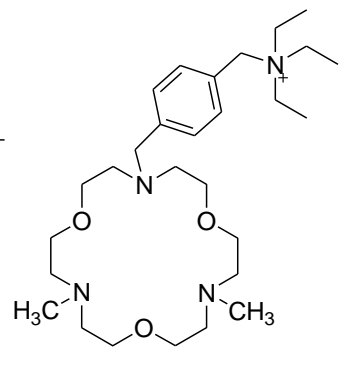

1.82

Figure 1.45 Ditopic receptor 1.81 and its predicted binding mode for a zwitterionic $\omega$ amino carboxylate. Also shown is the control monotopic receptor $\mathbf{1 . 8 2}$.

In an effort to produce a more sophisticated receptor for amino acids, Mendoza and coworkers prepared the chiral receptor 1.83 (Figure 1.46). ${ }^{91}$ This system, reported in 1992, contains a guanidinium group for carboxylate anion recognition and a monoaza[18]crown-6 for ammonium cation recognition. ${ }^{91}$ The appended aromatic naphthalene ring was designed to provide an additional interaction with the side chain of aromatic amino acids via $\pi-\pi$ interactions. The chiral nature of receptor $\mathbf{1 . 8 3}$ was expected to provide for the enantioselective recognition of phenylalanine and tryptophan. The affinity of compound $\mathbf{1 . 8 3}$ towards amino acids was determined by liquid-liquid 
single extraction experiments using water and $\mathrm{CH}_{2} \mathrm{Cl}_{2}$. The extraction efficiencies (i.e., fraction of receptor molecules occupied by substrate) in the organic phase, determined by integration of the NMR spectra, were $c a .40 \%$ for both $L$-Trp and $L$-Phe. On the other hand, $L$-Val without an aromatic side chain was not extracted to an appreciable extent. This led to the conclusion that the aromatic naphthalene pendant plays a critical role in recognizing aromatic amino acids. Enantioselective recognition of $L$-Trp and $L$-Phe by $(S, S)-\mathbf{1 . 8 3}$ was confirmed by ${ }^{1} \mathrm{H}$ NMR spectroscopic analysis. Conversely, the other antipode, receptor $(R, R) \mathbf{- 1 . 8 3}$, was found to extract selectively $D$-Trp and $D$-Phe, but not their corresponding $L$-enantiomers.

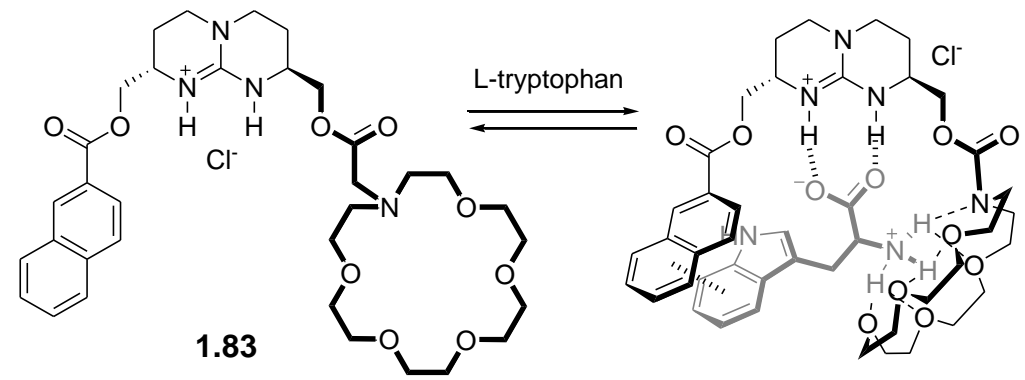

Figure 1.46 Ditopic receptor $(S, S)$-1.83 and its proposed binding mode for $L$-tryptophan.

Ion pair receptors, suitably functionalized with a fluorophore or chromophore, can act as optical sensors for ion pairs, exhibiting an easily detectable signal change in color or fluorescence intensity. An example of such a system comes from de Silva and coworkers who synthesized the fluorogenic compound 1.84 (Figure 1.47). ${ }^{92}$ This system, reported in 2003, contains both anion and cation binding sites, namely a $\mathrm{Na}^{+}$-selective benzo[15]crown-5 moiety and $\mathrm{a}_{2} \mathrm{PO}_{4}{ }^{-}$-selective polyammonium group linked via an anthracene fluorophore. In the absence of substrates (ions), the fluorescence intensity of 
receptor $\mathbf{1 . 8 4}$ is inherently low because of PET (photo-induced electron transfer) from both the benzo[15]crown-5 and the benzylic amine lone pair to the anthracene. The PET processes can be inhibited by complexation of the $\mathrm{Na}^{+}$cation by the benzo[15]crown- 5 and $\mathrm{H}_{2} \mathrm{PO}_{4}{ }^{-}$binding to the polyammonium moiety, respectively. Thus, in the presence of both ions the fluorescence is enhanced. However, in the presence of a single ion (either $\mathrm{Na}^{+}$or $\mathrm{H}_{2} \mathrm{PO}_{4}{ }^{-}$studied using a non-coordinating counter ion), the fluorescence is still weak. Presumably, this is because PET from either the benzylic amine lone pair or the benzene ring of the crown ether suffices to quench the intensity of the anthracene fluorescence. Only the simultaneous complexation of both a $\mathrm{Na}^{+}$cation and an $\mathrm{H}_{2} \mathrm{PO}_{4}{ }^{-}$ anion gives rise to fluorescence enhancement. Therefore, receptor $\mathbf{1 . 8 4}$ acts as a rudimentary photoionic $A N D$ logic gate.

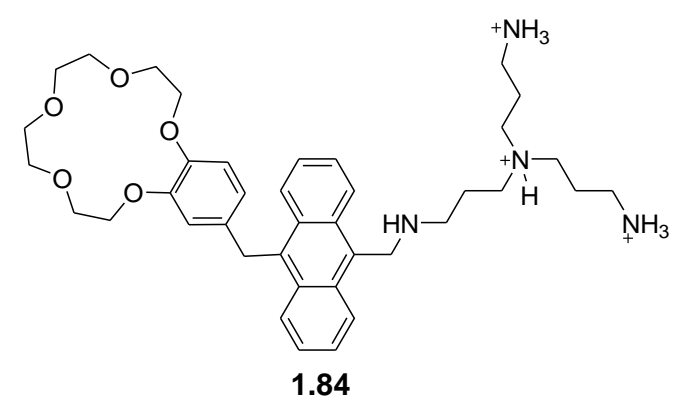

Figure 1.47 Fluorescent ion pair sensor 1.84 that functions as an $A N D$ logic system.

\subsection{PHOSPHINE OXIDE AND SULFOXIDE-BASED ION PAIR RECEPTORS}

An alternative approach to the design of ion pair receptors involves the use of phosphine oxide and sulfoxide groups as cation recognition sites. These are moieties that are known to be strong hydrogen bond acceptors, but weak Brønsted bases. ${ }^{93,94}$ Recognizing the utility of these motifs, Gellman et al. synthesized the macrocyclic 
phosphine oxide disulfoxide $\mathbf{1 . 8 5}$ (Figure 1.48). This system, first reported in 1993, was found to bind monoalkylammonium cations and certain halide anions with noncoordinating counter ions via hydrogen bondings and through interactions with the positive ends of the $\mathrm{S}=\mathrm{O}$ and $\mathrm{P}=\mathrm{O}$ dipoles, respectively. In the case of monoalkylammonium halide ion pairs, ${ }^{1} \mathrm{H}$ NMR spectroscopic studies revealed that receptor $\mathbf{1 . 8 5}$ is able to bind the monoalkylammonium cation via hydrogen bonding interactions with the three oxygen atoms present on the sulfur and phosphorus atoms. These interactions serve to induce polarization and to preorganize the receptor. The result is a cavity better suited to bind the $\mathrm{Cl}^{-}, \mathrm{Br}^{-}$or $\mathrm{I}^{-}$counter ion on the opposite face as shown in Figure 1.48. ${ }^{93,94}$

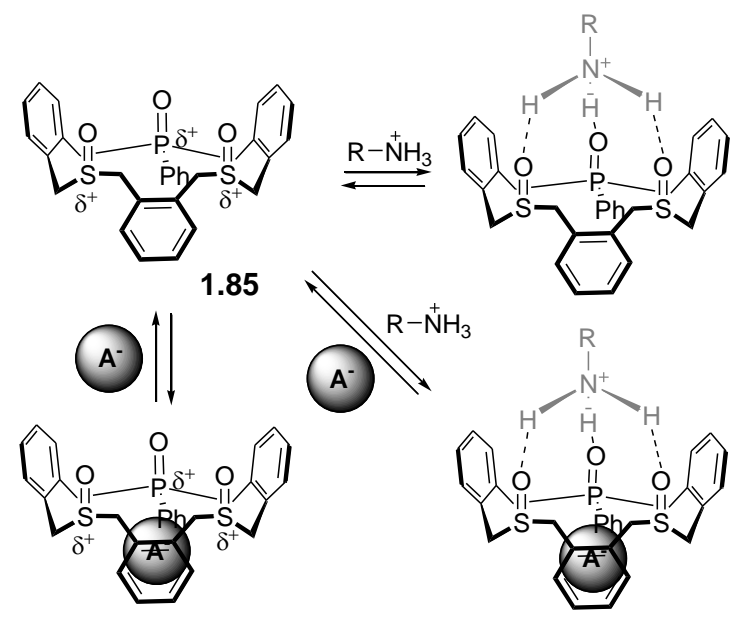

Figure 1.48 Macrocyclic phosphine oxide disulfoxide ion pair receptor $\mathbf{1 . 8 5}$ and its proposed interactions with monoalkylammonium cations, halide anions, and ion pairs containing these species. 


\subsection{AN ION PAIR RECEPTOR THAT IS BASED ON HALOGEN BONDING TO ACHIEVE ANION RECOGNITION}

In 2005, Resnati and coworkers reported the tripodal ion pair receptor $\mathbf{1 . 8 6}$ that relies on halogen bonding $(\mathrm{XB})$ for the recognition of anions, such as halides (Figure 1.49). ${ }^{95}$ The four strong electron-withdrawing fluorine atoms on the aromatic ring of receptor $\mathbf{8 6}$ make the iodine atom an effective XB donor. An X-ray crystal structure of the $\mathrm{NaI}$ complex revealed that in the solid state, receptor $\mathbf{1 . 8 6}$ binds both the $\mathrm{Na}^{+}$cation and the $\mathrm{I}^{-}$anion concurrently. However, as can be inferred from an inspection of Figure 1.50 , these latter species are spatially separated by the receptor at a distance of ca. 5.59 $\AA$. This structure also revealed that the $\mathrm{Na}^{+}$cation is completely encompassed by the arms of the receptor and that the $\mathrm{I}^{-}$anion is bound to the iodine atom of the tetrafluoroaromatic ring via an $\mathrm{XB}$ interaction. Compared to that of compound $\mathbf{1 . 8 7}$, which lacks an XB donor $\left(K_{a}=1.3 \times 10^{4} \mathrm{M}^{-1}\right)$, the binding constant of receptor $\mathbf{1 . 8 6}$ was found to be 20 times larger $\left(K_{a}=2.6 \times 10^{5} \mathrm{M}^{-1}\right)$. On this basis, it was concluded that the $\mathrm{I}^{\cdots} \mathrm{I}^{-} \mathrm{XB}$ interaction has a positive effect on the $\mathrm{Na}^{+}$binding in the case of receptor $\mathbf{1 . 8 6}$.
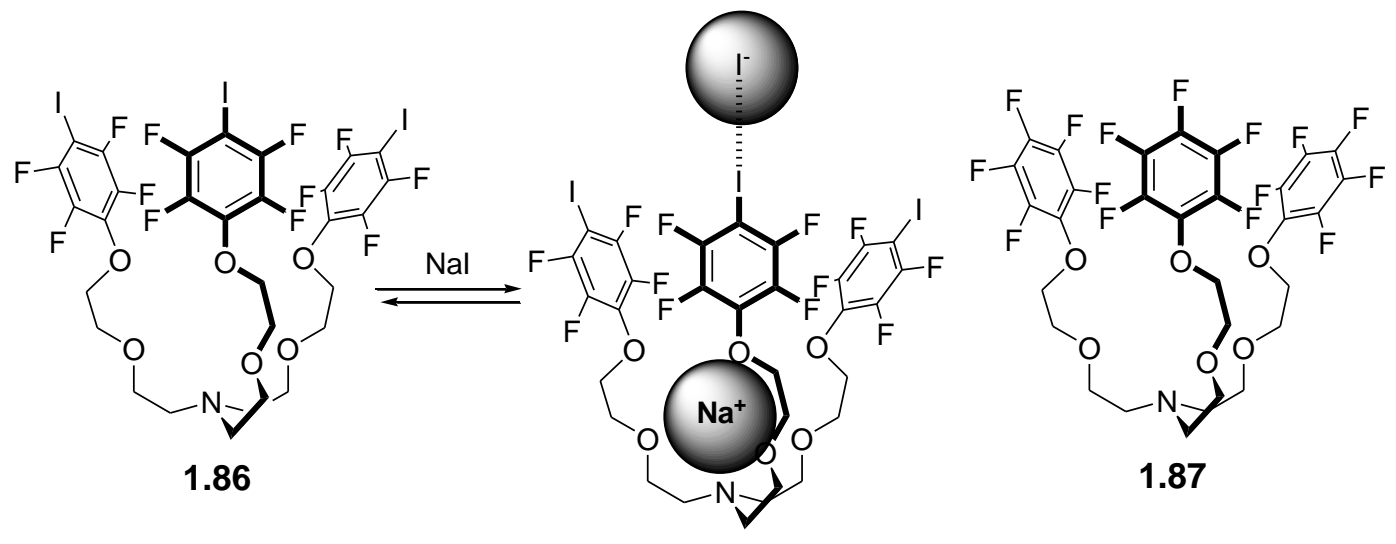

1.87

Figure 1.49 Ion pair receptor $\mathbf{1 . 8 6}$ and its proposed NaI binding mode. Also shown is control compound $\mathbf{1 . 8 7}$ that lacks an XB donor. 


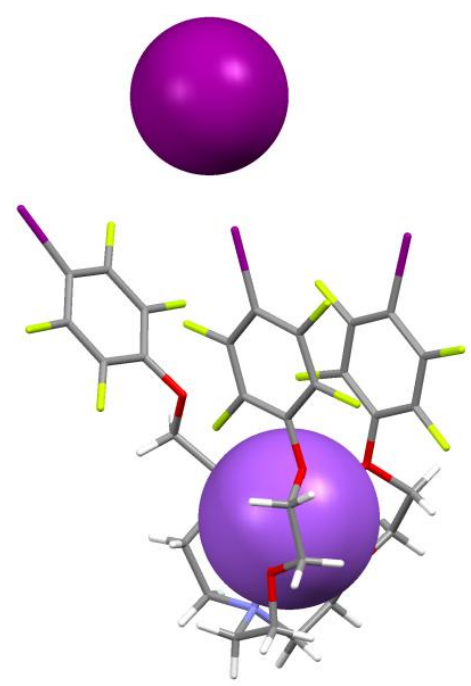

Figure 1.50 Crystal structure of $\mathbf{1 . 8 6} \cdot \mathrm{NaI}$. This figure was produced using coordinates that originally appeared in ref. 95.

\subsection{AN ION PAIR RECEPTOR BASED ON HYDROXYL GROUPS FOR ANION RECOGNITION}

The hydroxyl group is also able to form hydrogen bonds with anions. This motif was exploited by Pochini and coworkers, who in 2001 reported that the flexible conecalix[4]arene (1.88), bearing four 4-hydroxybenzyl groups on the upper rim, can act as an ion pair receptor for tetramethylammonium salts (Figure 1.51). ${ }^{96}$ In this case, ${ }^{1} \mathrm{H}$ NMR spectroscopic studies carried out in $\mathrm{CDCl}_{3}$ provided support for the notion that receptor 1.88 binds the tetramethylammonium cation via $\mathrm{CH}-\pi$ interactions, while anions such as $\mathrm{OTs}^{-}, \mathrm{Cl}^{-}, \mathrm{OAc}^{-}, \mathrm{CF}_{3} \mathrm{COO}^{-}$, and picrate are bound via hydrogen bonds involving the four hydroxy groups. In contrast to receptor $\mathbf{1 . 8 8}$, the corresponding analogue $\mathbf{1 . 8 9}$ showed no tendency to bind such ion pairs. These results are thus consistent with the suggestion that anion binding by the hydroxy groups present in $\mathbf{1 . 8 8}$ plays a crucial role in stabilizing the receptor-bound ion pair. While the simple ion receptor $\mathbf{1 . 3 4}$ was found to form strong complexes with loose ion paired tetramethylammonium salts, such as TMATFA or 
TMAPic, receptor $\mathbf{1 . 8 8}$ was found to form strong complexes with tightly bound ion pairs such as TMACl and TMAOTs. This observation led to the conclusion that receptor $\mathbf{1 . 8 8}$ binds such ion pairs via a cooperative interaction that involves the two binding sites and the co-bound ions. To obtain further support for this suggestion, a dual host system, consisting of a mixture of hosts $\mathbf{1 . 8 8}$ and $\mathbf{1 . 3 4}$, as well as the specific anion receptor (1.90) for the $\mathrm{Cl}^{-}$anion was analyzed (Figure 1.51). In the presence of the chloride receptor (1.90), the binding constant $\left(K_{a}\right)$ of single ion receptor 1.34 for TMACl in chloroform is enhanced from $80 \mathrm{M}^{-1}$ to $428 \mathrm{M}^{-1}$. This increase is attributed to a breaking up of the ion pairing TMACl ion pair caused by complexation of the chloride anion by receptor 1.90. In contrast, compound $\mathbf{1 . 3 4}$ serves to decrease the binding constant of receptor 1.88 from $3,526 \mathrm{M}^{-1}$ to $440 \mathrm{M}^{-1}$. Presumably, this latter finding reflects the fact that the $\mathrm{Cl}^{-}$anion is bound to the hydroxy groups of $\mathbf{1 . 8 8}$ less strongly as the result of competition.
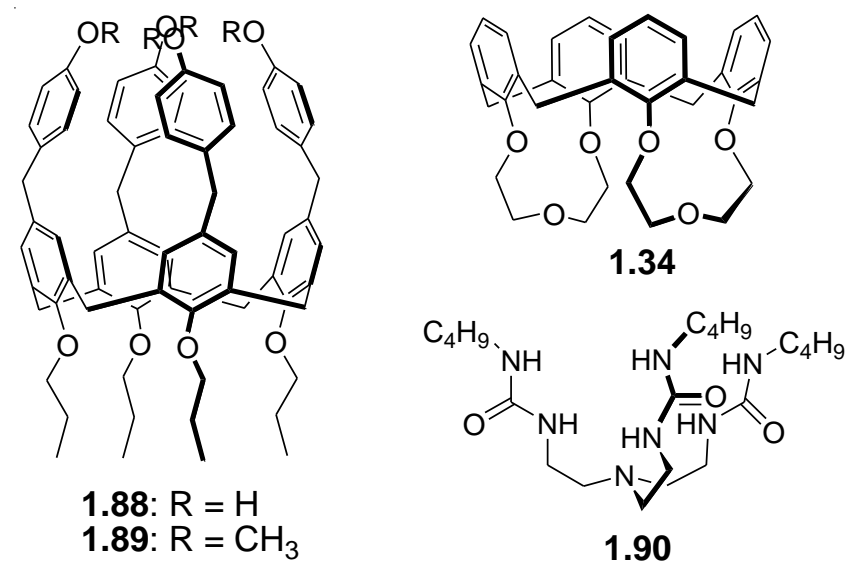

Figure 1.51 Ion pair receptor 1.88 and control single ion receptors 1.84, 1.89 and 1.90. 


\subsection{ION PAIR RECEPTORS BASED ON G-QUARTETS}

Guanine nucleotides are known to bind alkali metal cations in water via formation of inter alia G-quartets, wherein the cations are bound to four nucleotide-derived carbonyl oxygen atoms oriented towards the center of what is a self-assembled core. These cation-containing G-quartets stack to form octamers, dodecamers, hexadecamers, and higher aggregates. In 2001, Davis and coworkers reported that the guanosine nucleotide 1.91 forms G-quadruplex-based hexadecamers in the presence of $\mathrm{BaPic}_{2}$ and $\mathrm{SrPic}_{2}$. The resulting systems were proposed to consist of two $C_{4}$-symmetric $1.91_{8} \cdot \mathrm{M}^{2+}$ octamers as shown in Figure 1.52. ${ }^{97}$ An X-ray crystal structure provided support for this conclusion and revealed that the G-quartets within each octamer are stacked head-to-tail with a $30^{\circ}$ rotation between the layers. As a result, the divalent $\mathrm{Ba}^{2+}$ and $\mathrm{Sr}^{2+}$ cations are sandwiched between the G-quartets and separated from their picrate counterion at a distance of $>8.5 \AA$. In contrast, the four picrate counter anions are involved in hydrogen bonding interactions involving the outer $\mathrm{NH}_{\mathrm{b}}$ of the amino group. The net result is two metal-filled octamers of formal stoichiometry $\mathbf{1 . 9 1}_{16} \cdot 2 \mathrm{M}^{2+} \cdot 4 \mathrm{Pic}^{-}$. Proton NMR spectroscopic analyses provided support for the conclusion that the picrate anions play a critical role in maintaining the G-quadruplex in solution. The kinetic stability of the hexadecamer was confirmed by a cross-over experiment. In this experiment, crystalline $\mathbf{1 . 9 1}_{16} \cdot 2 \mathrm{Sr}^{2+} \cdot 4 \mathrm{Pic}^{-}$and $\mathbf{1 . 9 1}_{16} \cdot 2 \mathrm{Ba}^{2+} \cdot 4 \mathrm{Pic}^{-}$were mixed in a $1: 1$ ratio in $\mathrm{CD}_{2} \mathrm{Cl}_{2}$ to give a new G-quadruplex, namely the mixed hexadecamer $1.91_{8} \cdot 2 \mathrm{Sr}^{2+} \cdot \mathbf{1 . 9 1}_{8} \cdot 2 \mathrm{Ba}^{2+} \cdot 4 \mathrm{Pic}^{-} \cdot{ }^{1} \mathrm{H}$ NMR spectroscopy revealed the slow formation of the mixed hexadecamer $\left(t_{1 / 2}=42 \mathrm{~h}\right)$, as would be expected for a structure wherein the four picrate anions serves to hold the Gquardruplex together tightly in solution. By contrast, when the thiocyanate anion, a species incapable of bridging the $1.91_{8} \cdot 2 \mathrm{M}^{2+}$ octamers as effectively as the picrate, was

used, the mixed hexadecamer, $1.911_{8} \cdot 2 \mathrm{Sr}^{2+} \cdot \mathbf{1 . 9 1}_{8} \cdot 2 \mathrm{Ba}^{2+} \cdot 4 \mathrm{SCN}^{-}$, is formed significantly 
faster $\left(t_{1 / 2}=0.5 \mathrm{~h}\right)$. These findings lend credence to the proposal that the strength of the anion binding interaction, as well as the nature of the cation, have a remarkable effect on the kinetic stability of the hexadecamers. ${ }^{97}$

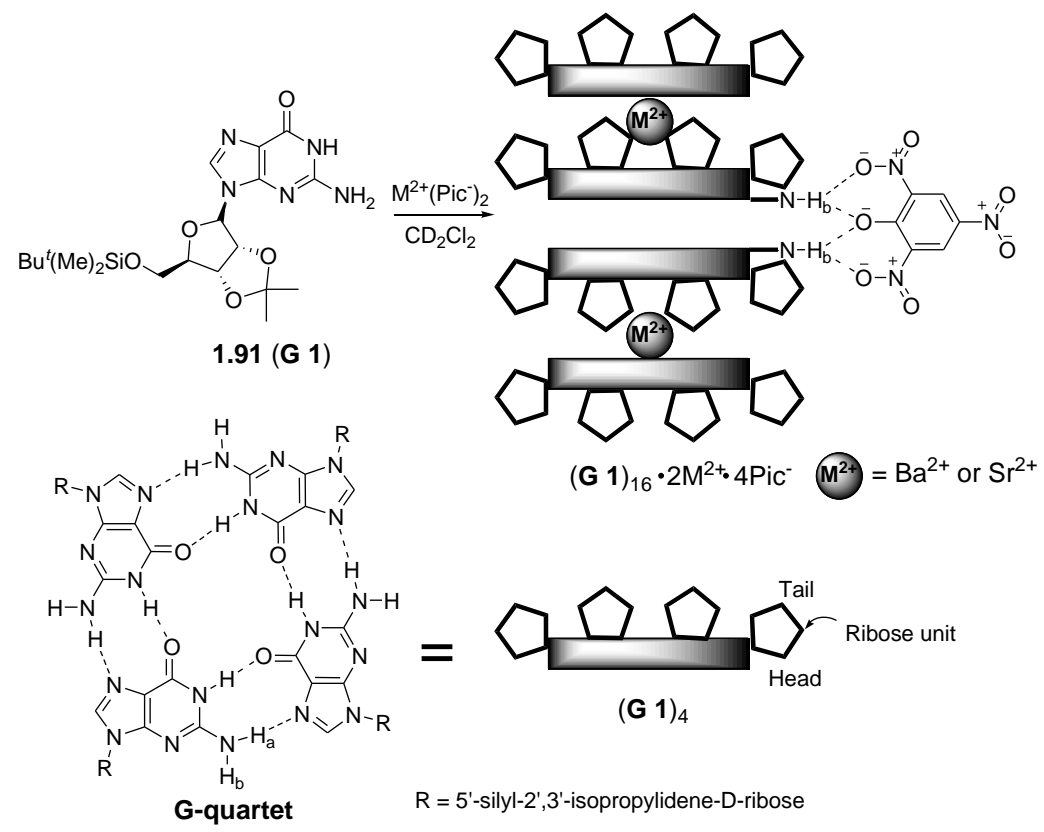

Figure 1.52 Guanosine 1.91 (G 1) and the proposed binding modes displayed by the Gquartet built up from this monomer in the presence of $\mathrm{BaPic}_{2}$ and $\mathrm{SrPic}_{2}$.

In 2003, this same group also synthesized the calix[4]arene-guanosine conjugate 1.92 ( G 2) and investigated its properties of the formation of a G-quartet and its ability to effect ion pair recognition (Figure 1.53). ${ }^{98}$ This calix[4]arene nucleotide (1.92 (G 2)) is poorly soluble in dry $\mathrm{CDCl}_{3}$ and gave an ill-resolved ${ }^{1} \mathrm{H}$ NMR spectrum in this solvent. Such a finding is consistent with this nucleotide 1.92 (G 2) forming one or more nonspecific aggregates in the absence of water. Nucleotide 1.92 (G 2) is much more soluble in $\mathrm{D}_{2} \mathrm{O}$-saturated $\mathrm{CDCl}_{3}$, and under these more polar solvent conditions gives two sets of well-resolved ${ }^{1} \mathrm{H}$ NMR signals for the guanosine moieties. This latter observation 
let to the suggestion that the inherent D2 symmetry is destroyed and that $1.92(\mathbf{G ~ 2})$ is dimerized via the formation of a G-quartet (Figure 1.53). On the basis of ${ }^{1} \mathrm{H}$ NMR and 2D NMR spectroscopic analyses, the resulting dimer, $\mathbf{1 . 9 2}_{2} \cdot\left(\mathrm{H}_{2} \mathrm{O}\right)_{\mathrm{n}}$ was found to bind certain ion pairs and to extract them from an aqueous environment into a chloroform phase. The dimer is thought to recognize cations, such as $\mathrm{K}^{+}$and $\mathrm{Na}^{+}$, via the carbonyl oxygen atoms of the G-quartet formed under these conditions, as well as anions, such as $\mathrm{Br}^{-}$and $\mathrm{Cl}^{-}$, via hydrogen bonds involving the amide $\mathrm{NH}$ protons and the anions. Selectivity for $\mathrm{K}^{+}$over $\mathrm{Na}^{+}$and $\mathrm{Br}^{-}$over $\mathrm{Cl}^{-}$was seen in these extractions.

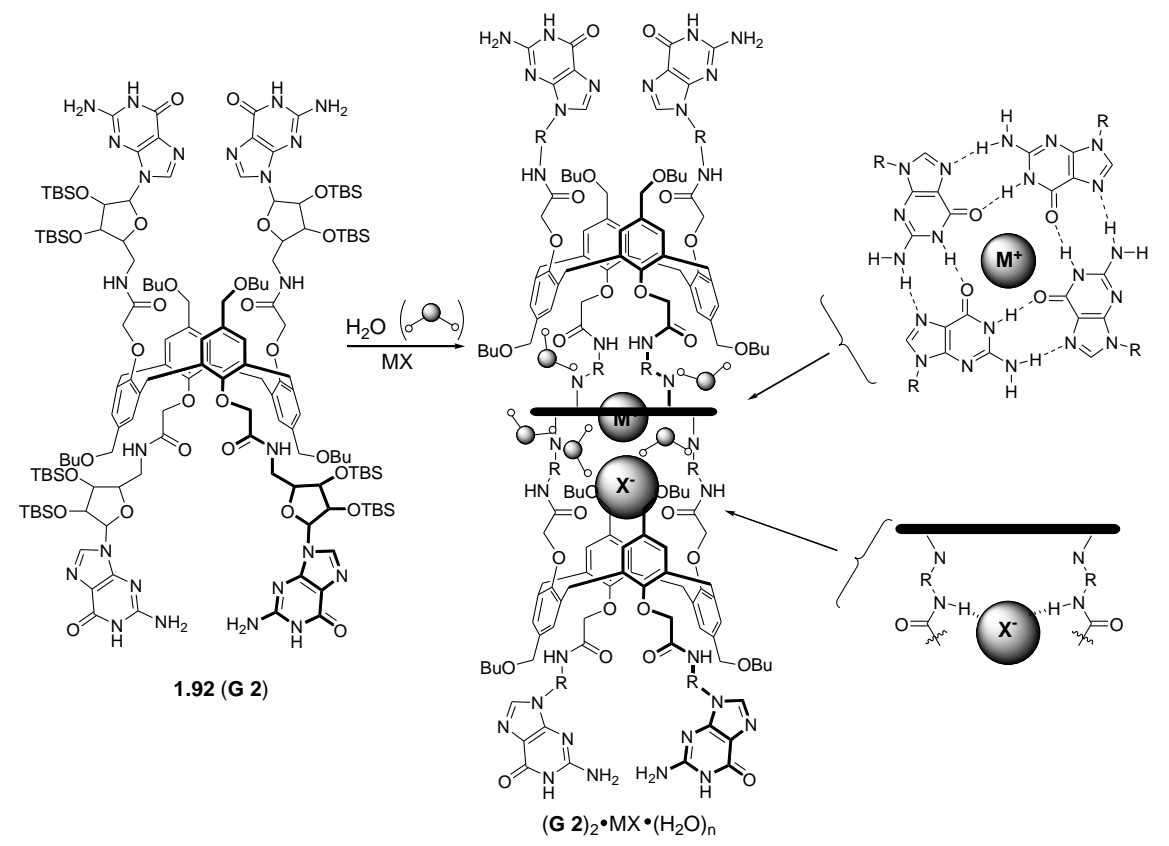

Figure 1.53 Calix[4]arene-based guanosine 1.92 (G 2) and its water-mediated ion pair recognition.

More recently, the Lippert group presented computational evidence that two stacked DNA-base quartets, namely a G-quartet (G 3) ${ }_{4}$ and an A-quartet (A 1) $)_{4}$, are able to bind the $\mathrm{NaCl}$ ion pair in a cooperative fashion (Figure 1.54). ${ }^{99}$ Nucleobases $\mathbf{1 . 9 3}$ and 
1.94 which combine to form a G-quartet (G 3) $)_{4}$ and an A-quartet (A 1) $)_{4}$, respectively, recognize the $\mathrm{Na}^{+}$cation and the $\mathrm{Cl}^{-}$anion. The ion-filled DNA-base quartets are thought to stack so as to allow a direct interaction between the bound $\mathrm{Na}^{+}$cation and $\mathrm{Cl}^{-}$anion (Figure 1.54).
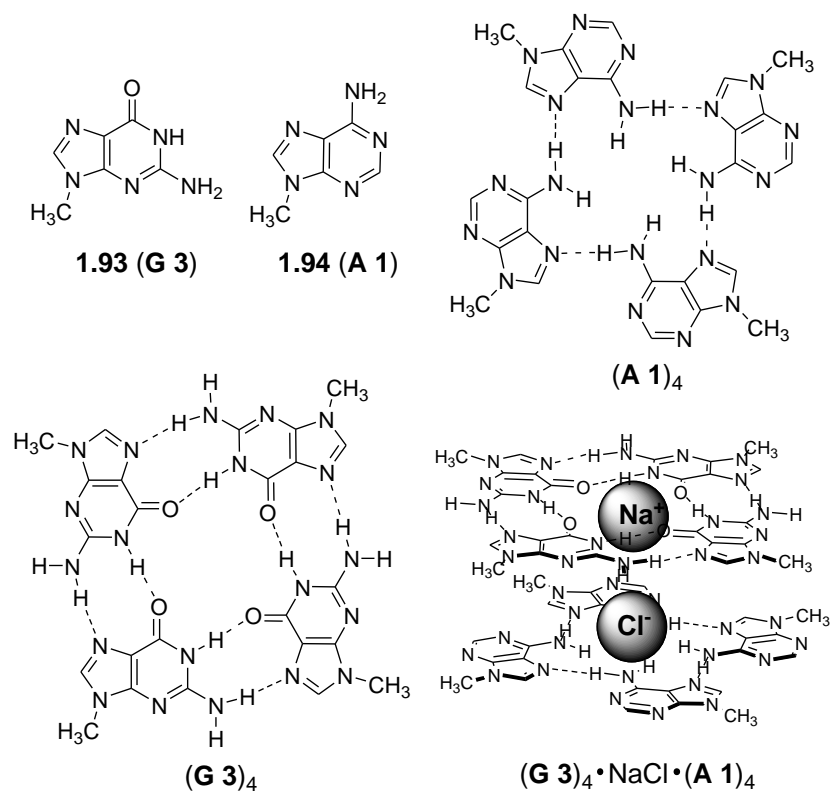

Figure 1.54 G-quartet (G 3) ${ }_{4}$ and A-quartet (A 1 $)_{4}$ and their proposed cooperative recognition of $\mathrm{NaCl}$.

\subsection{ION PAIR RECEPTORS BASED ON PYRROLES AND INDOLES FOR ANION RECOGNITION}

Pyrroles and indoles can also act as hydrogen bond donors for anion recognition. Not surprisingly, therefore, such motifs have been used to create ion pair receptors. One recent example comes from Jeong and coworkers. Specifically, in 2007 this group reported the preparation of receptor 1.95 (Figure 1.55) that contains both a diazacrown ether for cation binding and an adjacent rigid biindole scaffold for anion recognition. ${ }^{100}$ Detailed ${ }^{1} \mathrm{H}$ NMR titration experiments, carried out in DMSO- $d_{6} / \mathrm{CD}_{3} \mathrm{CN}$, provided 
evidence that the presence of alkali metal ions bound within the azacrown ether ring enhances the affinity of receptor $\mathbf{1 . 9 5}$ for anions. For example, the association constant of the complex of $1.95 \cdot \mathrm{Na}^{+}$for $\mathrm{Cl}^{-}$is $c a \cdot 2,000$ times higher than that of the metal-free form of 1.95 (Table 1.14). This increase in anion affinity was ascribed to the additional electrostatic interaction between the co-bound ions. An energy-minimized structure of 1.95 $\mathrm{NaCl}$ generated with a MacroModel 9.1, MMFFs force field, provided support for the proposal that $\mathrm{NaCl}$ is bound to the receptor as a contact ion pair.

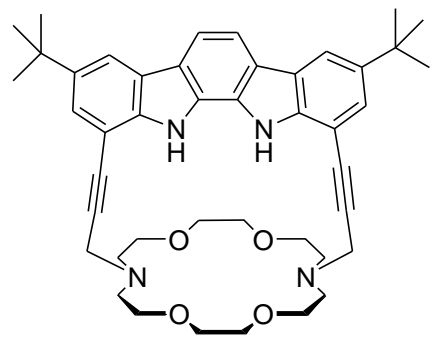

1.95

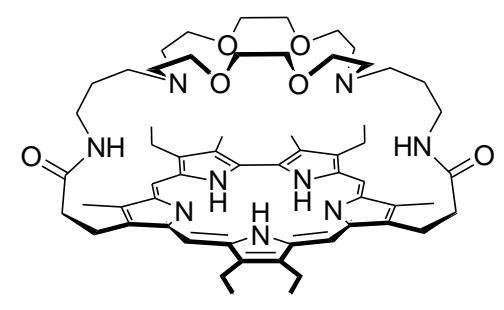

1.96

Figure 1.55 Biindole-diazacrown-based ion pair receptor 1.95 and diazacrown-capped sapphyrin 1.96. 
Table 1.14 Association constants $\left(K_{a}, \mathrm{M}^{-1}\right)$ between ion pair receptor 1.95 and halides recorded in the presence and absence of alkali metal salts (1.0 equiv) in $10 \%$ $(\mathrm{v} / \mathrm{v}) \mathrm{DMSO}-d_{6} / \mathrm{CD}_{3} \mathrm{CN}$ at $297 \pm 1 \mathrm{~K}$.

\begin{tabular}{ccc}
\hline Halide $^{a}$ & Cation additive & Association constant $\left(\mathrm{M}^{-1}\right)$ \\
\hline $\mathrm{Cl}^{-}$ & None & 7 \\
& $\mathrm{LiClO}_{4}$ & 120 \\
& $\mathrm{NaClO}_{4}$ & 14,000 \\
& $\mathrm{KPF}_{6}$ & 6,200 \\
\hline $\mathrm{Br}^{-}$ & $\mathrm{None}$ & $-{ }^{b}$ \\
& $\mathrm{LiClO}_{4}$ & 24 \\
& $\mathrm{NaClO}_{4}$ & 600 \\
$\mathrm{KPF}_{6}$ & 200 \\
\hline $\mathrm{I}^{-}$ & $\mathrm{None}$ & $-{ }^{b}$ \\
& $\mathrm{LiClO}_{4}$ & 9 \\
& $\mathrm{NaClO}_{4}$ & 61 \\
& $\mathrm{KPF}_{6}$ & 45 \\
\hline
\end{tabular}

${ }^{a}$ Halide anions were studied as the corresponding tetrabutylammonium salts. ${ }^{b}$ The chemical shift changes during the titration were too small to determine accurately an association constant.

Very early on (1995), Sessler and Brucker synthesized the diazacrown-capped sapphyrin 1.96 (Figure 1.55) as a possible ion pair receptor. ${ }^{101}$ In this case, ${ }^{1} \mathrm{H}$ NMR and $\mathrm{UV} / \mathrm{Vis}$ spectroscopic analyses carried out in $10 \% \mathrm{CD}_{3} \mathrm{OD}$ in $\mathrm{CDCl}_{3}$ revealed that the diprotonated form of compound $\mathbf{1 . 9 6}$ (bis- $\mathrm{HCl}$ salt) is able to bind an ammonium cation and a fluoride anion simultaneously.

First reported in 1886 by Bayer, ${ }^{102}$ the tetrapyrrolic macrocycle 1.97 (Figure 1.56), calix[4]pyrrole, was found in 1996 by Sessler et al. to be able to bind certain anions in organic solvents. ${ }^{103}$ In 2005, Moyer, Sessler, Gale and coworkers reported that calix[4]pyrrole 1.97 can act as an ion pair receptor for various cesium salts and certain organic halide salts in the solid state (Figure 1.56). ${ }^{104}$ X-ray crystal structures of several 
cesium and organic cation-containing anion complexes of calix[4]pyrrole $\mathbf{1 . 9 7}$ were solved, Taken in concert, they revealed that the anions are bound to the pyrrolic NH protons via hydrogen bonds. These interactions, which were expected on the basis of prior studies, serve to fix the calix[4]pyrrole in the cone conformation. This conformational locking, in turn, provides an electron-rich bowl-shaped cavity into which, e.g., cesium cation is bound via a combination of $\pi$-metal and dipole interactions.

Further evidence that calix[4]pyrrole $\mathbf{1 . 9 7}$ is effective for ion pair recognition came from liquid-liquid extraction studies carried out by Wintergerst et al. ${ }^{105}$ This study demonstrated that compound 1.97 can extract $\mathrm{CsCl}$ and $\mathrm{CsBr}$, but not $\mathrm{CsNO}_{3}$, from an aqueous phase into nitrobenzene, a relatively polar organic phase. The solvent extraction process was modeled in terms of three thermochemical steps (Figure 1.57). The first of these steps involves a partitioning of the cesium cations and the halide anions into the nitrobenzene phase from the water phase. The second step involves a conformational change of the calix[4]pyrrole such that it adopts the cone conformation, a geometry it maintains as the result of halide anion binding. The third step involves the cesium cation binding within the bowl-shaped calix cavity created as the result of the conformational change taking place in step 2 . While thermodynamically equivalent in terms of the final state, it was appreciated that these steps could be taking place concurrently. The key point is that under conditions of this extraction, calix[4]pyrrole $\mathbf{1 . 9 7}$ binds both the cesium cation and a halide anion $\left(\mathrm{Cl}^{-}\right.$or $\left.\mathrm{Br}^{-}\right)$. 


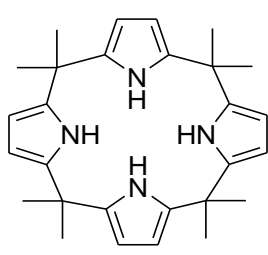

1.97
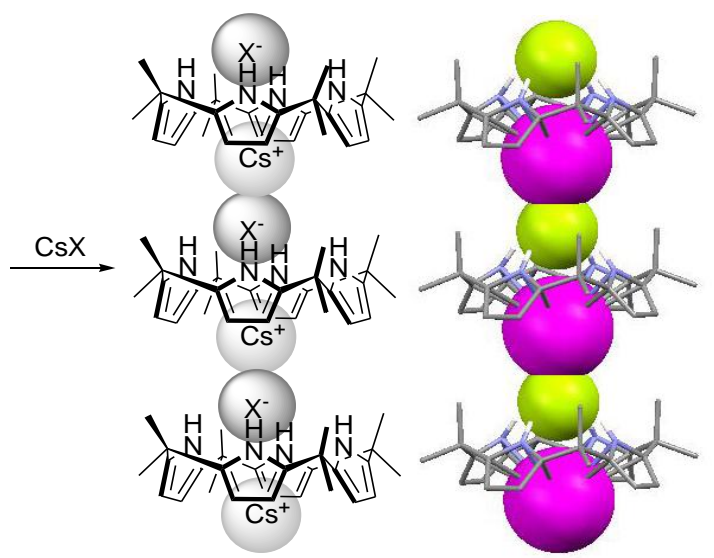

Figure 1.56 Calix[4]pyrrole 1.97, its binding mode for CsX and the crystal structure of 1.97. CsF. The X-ray structure shown was produced using coordinates that originally appeared in ref. 104.

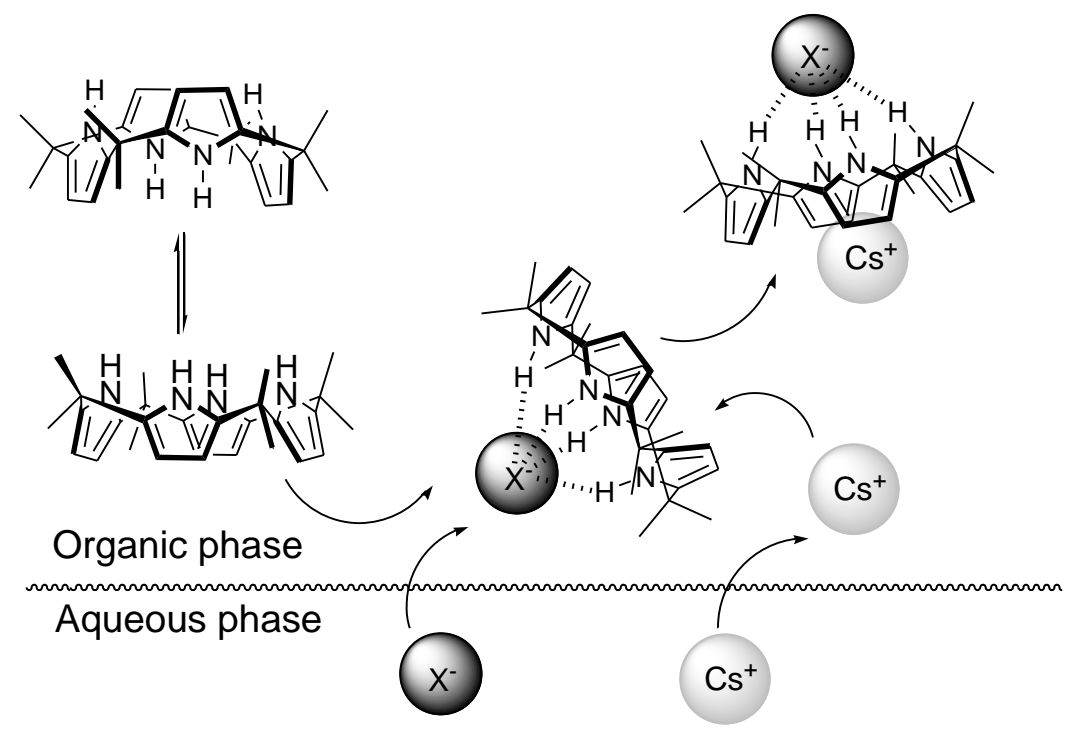

Figure 1.57 Proposed thermodynamic steps used to model cesium salt extraction by calix[4]pyrrole 1.97.

Very recently, transmembrane transport experiments were carried out with calix[4]pyrrole 1.97. ${ }^{107}$ It was found that this simple-to-obtain receptor transports $\mathrm{CsCl}$ across phospholipid bilayers with significant selectivity and with an efficiency that is 
enhanced relative to other alkaline chloride salts. Such findings provide further support for the conclusion that calix[4]pyrrole 1.97 can act as an ion pair receptor under appropriate conditions.

\subsection{ION PAIR RECOGNITION ACHIEVED USING DUAL HOST RECEPTORS}

A different approach to ion pair recognition, and one that is potentially simpler, than the creation of a ditopic receptor system, involves the use of an anion receptor in conjunction with a cation binding motif. This so-called dual-host approach was used by Cafeo et al. to bind organic ion pairs (Figure 1.58). ${ }^{107}$ Here, it was found that upon addition of $n \mathrm{BuNH}_{3}{ }^{+} \mathrm{Cl}^{-}$to a solution of anion receptor 1.98 in $\mathrm{CD}_{2} \mathrm{Cl}_{2}$, little in the way of discernible chemical shifts were seen in the ${ }^{1} \mathrm{H}$ NMR spectrum. This led to the suggestion that the host-guest interaction between calix[6]pyrrole $\mathbf{1 . 9 8}$ and the $\mathrm{Cl}^{-}$anion is weak. On the other hand, it was found that when solutions of the three dimensional p-tertbutylcalix[5]arenes 1.99a-c, receptors that are known to form selective 1:1 complexes with linear alkylammonium cations, ${ }^{107}$ were treated with $n \mathrm{BuNH}_{3}{ }^{+} \mathrm{Cl}^{-}$, two sets of

distinguishable proton signals in the corresponding ${ }^{1} \mathrm{H}$ NMR spectra were seen. These signals correspond to the uncomplexed and the $n \mathrm{BuNH}_{3}{ }^{+}$complexed forms of these receptors, respectively.

On the basis of these findings, the authors suggested that the binding of $n \mathrm{BuNH}_{3}{ }^{+}$ by 1.99a-c is slow on the NMR timescale. In the case of $1.99 \mathrm{a}$, the cation-bound form makes up less than $2 \%$ of the equilibrium mixture. On the other hand, the addition of 1.0 molar equiv. of the putative anion receptor 1.98 to a $1: 1$ mixture of 1.99a and $n \mathrm{BuNH}_{3}{ }^{+} \mathrm{Cl}^{-}$causes the proton signal of the free guest $\left(n \mathrm{BuNH}_{3}{ }^{+}\right)$to disappear. Such a dramatic change is attributed to the complete complexation of the ions making up $n \mathrm{BuNH}_{3}{ }^{+} \mathrm{Cl}^{-}$by this particular combination of anion and cation receptors. Evidence that 
the $n \mathrm{BuNH}_{3}{ }^{+}$cation and the $\mathrm{Cl}^{-}$anion are bound to the calix[5]arene (1.99a) and calix[6]pyrrole (1.98) subunits, respectively, came from ${ }^{1} \mathrm{H}$ NMR spectral analyses. Specifically, after formation of the proposed complexes, the proton signals of the $n \mathrm{BuNH}_{3}{ }^{+}$cation appear in the high field region (i.e., from $\delta=-0.4 \mathrm{ppm}$ to $\delta=-2.0 \mathrm{ppm}$ ), characteristic of a cation inclusion complex. The NH proton signal of the calix[6]pyrrole moiety 1.98 was found to be shifted to lower field (i.e., from $\delta=7.74 \mathrm{ppm}$ to $\delta=10.91$ ppm), as would be expected upon anion binding. These findings show that a weak anion or cation receptor can be transformed into a powerful one via the synergic action of a complementary receptor.
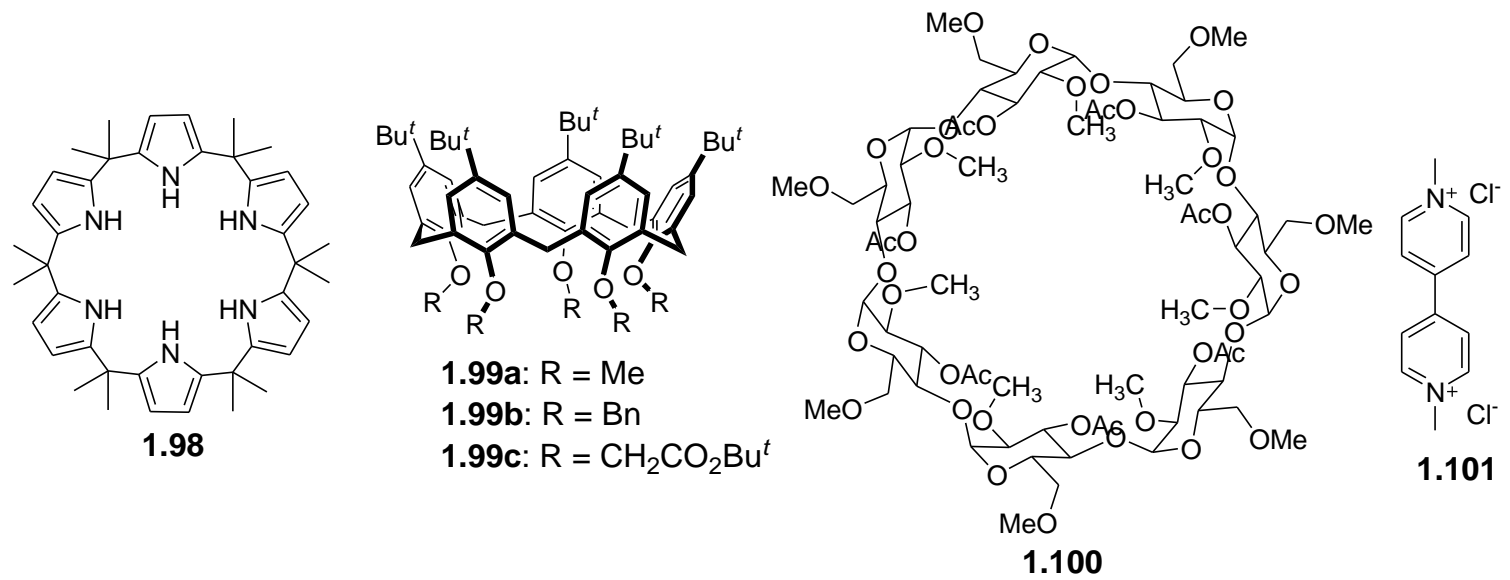

Figure 1.58 Hosts and a guest used for binding studies involving so-called dual-host systems.

This same group also demonstrated that the combined action of the anion receptor 98 and the $\beta$-cyclodextrin-based cation receptor $\mathbf{1 . 1 0 0}$ (Figure 1.58) is able to solubilize the otherwise sparingly soluble organic ion pair 1.101, paraquat chloride, in $\mathrm{CD}_{3} \mathrm{CN}$ and $\mathrm{CD}_{2} \mathrm{Cl}_{2}{ }^{108}$ Furthermore, this dual-host system was found to extract paraquat chloride 1.101 from an aqueous phase into dichloromethane. Such a finding was also rationalized 
in terms of a synergic effect involving this particular set of paired anion and cation receptors.

\subsection{ION PAIR RECOGNITION ACHIEVED USING FUNCTIONALIZED POLYMERS}

In 2008, a new approach to the recognition of ion pairs was introduced by Sessler, Bielawski, and coworkers. This approach relies on the use of polymer containing both anion and cation recognition groups. In their report, the synthesis, characterization, and extraction properties of the mixed MMA (methyl methacrylate) copolymer 1.102 (Figure 1.59) were detailed. This system (i.e., copolymer 1.102) bears both pendant calix[4]pyrrole and benzo-[15]crown-5 subunits, recognition motifs known to be capable of binding halide anions in organic media and forming a 2:1 sandwich complex with the $\mathrm{K}^{+}$cation, respectively (Figure 1.59). ${ }^{109}$ The control MMA copolymers $\mathbf{1 . 1 0 3}$ and $\mathbf{1 . 1 0 4}$ containing either the calix[4]pyrrole subunits or the benzo-[15]crown-5 were also synthesized. The monomeric simple ion receptors $\mathbf{1 . 1 0 5}$ and $\mathbf{1 . 1 0 6}$ were included in this study (Figure 1.59).

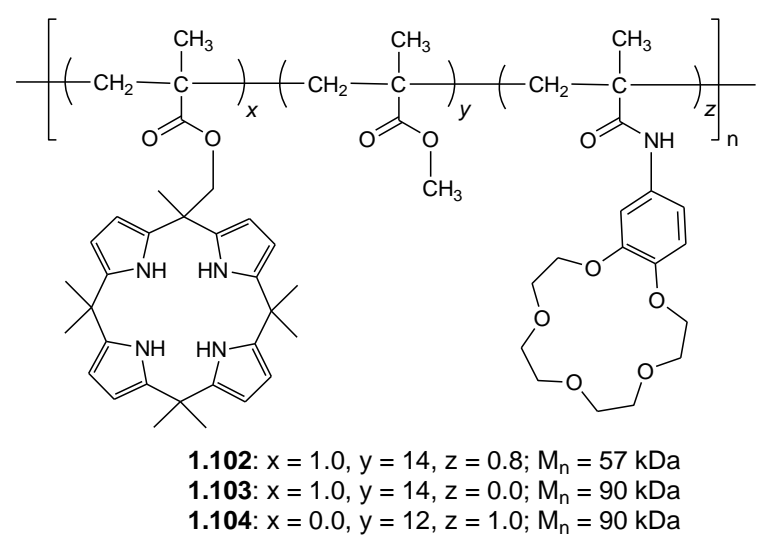

Figure 1.59 Schematic representation of polymeric ion pair receptor 1.102 and various control systems.
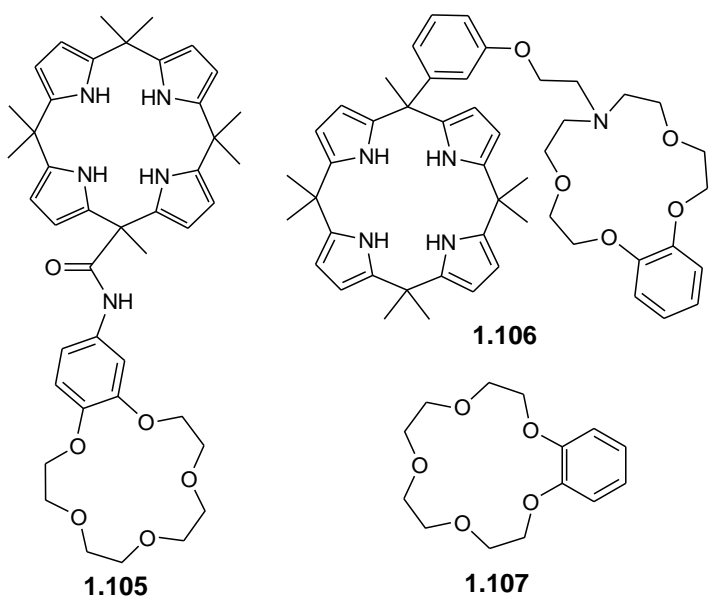
On the basis of ${ }^{1} \mathrm{H}$ NMR spectroscopic analyses, it was concluded that compounds $\mathbf{1 . 1 0 5}$ and $\mathbf{1 . 1 0 6}$ or a 1:1 mixture of $\mathbf{1 . 9 7}$ and $\mathbf{1 . 1 0 7}$ are unable to extract hard alkaline halide salts, such as $\mathrm{KF}$ and $\mathrm{KCl}$, from $\mathrm{D}_{2} \mathrm{O}$ into a dichloromethane- $d_{2}$. In marked contrast, polymer $\mathbf{1 . 1 0 2}$ containing both cation and anion receptors was found to extract $\mathrm{KF}$ and $\mathrm{KCl}$ under these same conditions. Further support for this conclusion came from ${ }^{1} \mathrm{H},{ }^{19} \mathrm{~F} \mathrm{NMR}$, and flame emission spectroscopic analyses. It was thus proposed that the polymer backbone can play an important role in enhancing the ability of ion receptors to bind ion pairs, or at least pairs of ions. In addition, it was found that polymer $\mathbf{1 . 1 0 2}$ is capable of extracting both $\mathrm{KF}$ and $\mathrm{KCl}$ much more effectively than either polymers $\mathbf{1 . 1 0 3}$ and $\mathbf{1 . 1 0 4}$. This provides support for the notion that the presence of both cation and anion recognition sites is essential if efficient binding and extraction of ion pairs is to be achieved. ${ }^{109}$

\subsection{CONCLUSIONS}

In chapter 1 , I have attempted to classify the various ion pair receptors reported so far on the basis of the anion recognition motif used to effect their creation. While a summary introduction of this nature cannot be fully comprehensive, a strong effort has been made to describe the binding ability and properties of representative examples of ion pair receptors. Compared with simple ion receptors capable of binding either cations or anions, ion pair receptors, possessing both cation and anion recognition sites, have attracted relatively little attention. Presumably, this reflects their synthetic difficulties, as well as experimental complexities resulting from the more elaborate nature of the binding phenomena involved. Nevertheless, we believe that the design and study of ion pair receptors is worthwhile. As detailed herein, such systems often display an enhanced ability to solubilize otherwise insoluble ions, a sometimes remarkable capacity to extract 
certain ion pairs from water, and selectivities for targeted ions that are superior to that of simple ion receptors. On this basis, the candidate set to prepare new ion pair receptors. The results of these efforts are described in subsequent chapters.

\subsection{REFERENCES}

(1) Lehn, J.-M. Supramolecular Chemistry: Concepts and Perspectives; VCH, Weinheim, 1995.

(2) Steed, J. W.; Atwood, J. L. Supramolecular Chemistry: An Introduction, Wiley, Chichester, 2000.

(3) Gokel, G. W. Molecular Recognition, Receptors for Cationic Guests, in Comprehensive Supramolecular Chemistry, eds. Lehn, J.-M.; Atwood, J. L.; Davies, J. E. D.; MacNicol, D. D.; Vogtle, F. Vol. 1, Pergamon, Oxford, 1996.

(4) Sessler,J. L.; Gale, P. A.; Cho, W.-S. Anion Receptor Chemistry, Royal Society of Chemistry, Cambridge, 2006.

(5) Gale, P. A.; García-Garrido, S. E.; Garric, J. Chem. Soc. Rev. 2008, 37, 151-190.

(6) Gale, P. A.; Quesada, R. Coord. Chem. Rev. 2006, 250, 3219-3244.

(7) Supramolecular Chemistry of Anions, eds. Bianchi, A.; Bowman-James, K.; García-España, E. Wiley-VCH, New York, 1997.

(8) Gale, P. A. in The Encyclopedia of Supramolecular Chemistry, eds. Atwood, J. L.; Steed, J. W. Dekker, New York, 2004, pp. 31-41.

(9) Beer, P. D.; Gale, P. A. Angew. Chem., Int. Ed. 2001, 40, 486-516.

(10) Caltagirone, C.; Gale, P. A. Chem. Soc. Rev. 2009, 38, 520-563.

(11) Martínez-Máñez, R.; Sancenán, F. Chem. Rev. 2003, 103, 4419-4476.

(12) Smith, B. D. In Ion Pair Recognition by Ditopic Receptors, Macrocyclic Chemistry: Current Trends and Future Perspectives, eds. Gloe, K.; Antonioli, B. Kluwer, London, 2005, pp. 137-151.

(13) Kirkovits, G. J.; Shriver, J. A.; Gale, P. A.; Sessler, J. L. J. Incl. Phenom. Macrocycl. Chem. 2001, 41, 69-75. 
(14) Antonisse, M. M. G.; Reinhoudt, D. N. Chem. Commun. 1998, 443-448.

(15) Gokel, G. W.; Leevy, W. M.; Weber, M. E. Chem. Rev. 2004, 104, 2723-2750.

(16) Ikeda, A.; Shinkai, S. Chem. Rev. 1997, 97, 1713-1734.

(17) Kim, J. S.; Quang, D. T. Chem. Rev. 2007, 107, 3780-3799.

(18) Jones, J. W.; Gibson, H. W. J. Am. Chem. Soc. 2003, 125, 7001-7004.

(19) Huang, F.; Jones,;J. W.; Slebodnick, C.; Gibson, H. W. J. Am. Chem. Soc. 2003, $125,14458-14464$.

(20) Huang, F.; Jones, J. W.; Gibson, H. W. J. Org. Chem. 2007, 72, 6573-6576.

(21) Reetz, M. T.; Niemeyer, C. M.; Harms, K. Angew. Chem., Int. Ed. 1991, 30, $1472-$ 1474.

(22) Reetz, M. T.; Johnson, B. M.; Harms, K. Tetrahedron Lett. 1994, 35, 2525-2528.

(23) Rudkevich, D. M.; Brzozka, Z.; Palys, M.; Visser, H. C.; Verboom, W.; Reinhoudt, D. N. Angew. Chem., Int. Ed. 1994, 33, 467-468.

(24) Rudkevich, D. M.; Verboom, W.; Reinhoudt, D. N. J. Org. Chem. 1994, 59, 36833686 .

(25) Rudkevich, D. M.; Mercer-Chalmers, J. D.; Verboom, W.; Ungaro, R.; de Jong, F.; Reinhoudt, D. N. J. Am. Chem. Soc. 1995, 117, 6124-6125.

(26) Cametti, M.; Nissinen, M.; Cort, A. D.; Mandolini, L.; Rissanen, K. Chem. Commun. 2003, 2420-2421.

(27) Cametti, M.; Nissinen, M.; Cort, A. D.; Mandolini, L.; Rissanen, K. J. Am. Chem. Soc. 2005, 127, 3831-3837.

(28) Cametti, M.; Nissinen, M.; Cort, A. D.; Mandolini, L.; Rissanen, K. J. Am. Chem. Soc. 2007, 129, 3641-3648.

(29) Nagasaki, T.; Fujishima, H.; Takeuchi, M.; Shinkai, S. J. Chem. Soc. Perkin Trans. $1, \mathbf{1 9 9 5}, 1883-1888$.

(30) Rudkevich, D. M.; Shivanyuk, A. N.; Brzozka, Z.; Verboom, W.; Reinhoudt, D. N. Angew. Chem., Int. Ed. 1995, 34, 2124-2126. 
(31) Kim, Y.-H.; Hong, J.-I. Chem. Commun. 2002, 512-513.

(32) Liu, H.; Shao, X.-B.; Jia, M.-X.; Jiang, X.-K.; Li, Z.-T.; Chen,;G.-J. Tetrahedron, 2005, 61, 8095-8100.

(33) Gunning, P.; Benniston, A. C.; Peacock, R. D. Chem. Commun. 2004, 2226-2227.

(34) Gunning, P. T. Org. Biomol. Chem. 2005, 3, 3877-3879.

(35) Kemmer, M.; Biesemans, M; Gielen, M.; Martins, J. C.; Gramlich, V.; Willem, R. Chem. Eur. J. 2001, 7, 4686-4695.

(36) Reeke, G.; Bradtmöller, G.; Schürmann, M.; Jurkschat, K. Chem. Eur. J. 2007, 13, 10239-10245.

(37) Reeke, G.; Schürmann, M.; Costisella, B.; Jurkschat, K. Organometallics, 2007, 26, 4170-4179.

(38) Reeke, G.; Schürmann, M.; Jurkschat, K. Dalton Trans. 2008, 3398-3400.

(39) Scheerder, J.; van Duynhoven, J. P. M.; Engbersen, J. F. J.; Reinhoudt, D. N. Angew. Chem., Int. Ed. 1996, 35, 1090-1093.

(40) Chrisstoffels,;L. A. J.; de Jong, F.; Reinhoudt, D. N.; Sovelli, S.; Gazzola, L.; Casnati, A.; Ungaro, R. J. Am. Chem. Soc. 1999, 121, 10142-10151.

(41) Kang, S. O.; Nam, K. C. Bull. Korean Chem. Soc. 2002, 23, 640-642.

(42) Oh, J. M.; Cho, E. J.; Ryu, B. J.; Lee, Y. J.; Nam, K. C. Bull. Korean Chem. Soc. 2003, 24, 1538-1540.

(43) Webber, P. R. A.; Beer, P. D. Dalton Trans. 2003, 2249-2252.

(44) Tumcharern, G.; Tuntulani, T.; Coles, S. J.; Hursthouse, M. B.; Kilburn, J. D. Org. Lett. 2003, 5, 4971-4974.

(45) Nabeshima, T.; Saiki, T.; Iwabuchi, J.; Akine, S. J. Am. Chem. Soc. 2005, 127, 5507-5511.

(46) Garozzo, D.; Gattuso, G.; Notti, A.; Pappalardo, A.; Pappalardo, S.; Parisi, M. F.; Perez, M.; Pisagatti, I. Angew. Chem., Int. Ed. 2005, 44, 4892-3896. 
(47) Pescatori, L.; Arduini, A.; Pochini, A.; Secchi, A.; Massera, C.; Ugozzoli, F. Org. Biomol. Chem. 2009, 7, 3698-3708.

(48) Ballistreri, F. P.; Notti, A.; Pappalardo, S.; Parisi, M. F.; Pisagatti, I. Org. Lett. 2003, 5, 1071-1074.

(49) Gargiulli, C.; Gattuso, G.; Liotta, C.; Notti, A.; Parisi, M. F.; Pisagatti, I.; Pappalardo, S. J. Org. Chem. 2009, 74, 4350-4353.

(50) Tozawa, T.; Misawa, Y.; Tokita, S.; Kubo, Y. Tetrahedron Lett. 2000, 41, 52195223.

(51) Nishizawa, S.; Shigemori, K.; Teramae, N. Chemistry Lett. 1999, 1185-1186.

(52) Jeon, N. J.; Yeo, H. M.; Nam, K. C. Bull. Korean Chem. Soc. 2008, 29, 663-665.

(53) Barboiu, M.; Vaughan, G.; van der Lee, A. Org. Lett. 2003, 5, 3073-3076.

(54) Flack, S. S.; Chaumette, J.-L.; Kilburn, J. D.; Langley, G. J.; Webster, M. J. Chem. Soc., Chem. Commun. 1993, 399-401.

(55) Deetz, M. J.; Shang, M.; Smith, B. D. J. Am. Chem. Soc. 2000, 122, 6201-6207.

(56) Mahoney, J. M.; Beatty, A. M.; Smith, B. D. J. Am. Chem. Soc. 2001, 123, 58475858.

(57) Mahoney, J. M.; Beatty, A. M.; Smith, B. D. Inorg. Chem. 2004, 43, 7617-7621.

(58) Mahoney,;J. M.; Nawaratna, G. U.; Beatty, A. M.; Duggan, P. J.; Smith, B. D. Inorg. Chem. 2004, 43, 5902-5907.

(59) Mahoney, J. M.; Stucker, K. A.; Jiang, H.; Carmichael, I.; Brinkmann, N. R.; Beatty, A. M.; Noll, B. C.; Smith, B. D. J. Am. Chem. Soc. 2005, 127, 2922-2928.

(60) Mahoney, J. M.; Marshall, R. A.; Beatty, A. M.; Smith, B. D.; Camiolo, S.; Gale, P. A. J. Supramol. Chem. 2003, 1, 289-292.

(61) Suksai, C.; Leeladee, P.; Jainuknan, D.; Tuntulani, T.; Muangsin, N.; Chailapakul, O.; Kongsaeree, P.; Pakavatchai, C. Tetrahedron Lett. 2005, 46, 2765-2769.

(62) Lankshear, M. D.; Dudley, I. M; Chan, K.-M.; Beer, P. D. New J. Chem. 2007, 31, 684-690. 
(63) Lankshear, M. D.; Cowley, A. R.; Beer, P. D. Chem. Commun. 2006, 612-614.

(64) Lankshear, M. D.; Dudley, I. M.; Chan, K.-M.; Cowley, A. R.; Santos, S. M.; Felix, V.; Beer, P. D. Chem. Eur. J. 2008, 14, 2248-2263.

(65) Beer,;P. D.; Drew, M. G. B.; Knubley, R. J.; Ogden, M. I. J. Chem. Soc., Dalton Trans. 1995, 3117-3123.

(66) Evans, J.; Beer, P. D. Dalton Trans. 2003, 4451-4456.

(67) Stibor, I.; Hafeed, D. S. M.; Lhoták, P.; Hodačová, J.; Koča, J.; Cajan, M. Gazz. Chim. Ital. 1997, 127, 673.

(68) Redman, E.; Beer, P. D.; Dent, S. W.; Drew, M. G. B. Chem. Commun. 1998, 231232.

(69) Beer, P. D.; Dent, S. W. Chem. Commun. 1998, 825-826.

(70) Uppadine,H.; Redman, J. E.; Dent, S. W.; Drew, M. G. B.; Beer, P. D. Inorg. Chem. 2001, 40, 2860-2869.

(71) Beer, P. D.; Hopkins, P. K.; Mckinney, J. D. Chem. Commun. 1999, 1253-1254.

(72) Cooper, J. B.; Drew, M. G. B.; Beer, P. D. J. Chem. Soc., Dalton Trans. 2001, 392401.

(73) Cooper, J. B.; Drew, M. G. B.; Beer, P. D. J. Chem. Soc., Dalton Trans. 2000, 2721-2728.

(74) Le Gac, S.; Jabin, I. Chem. Eur. J. 2008, 14, 548-557.

(75) Hamon, M.; Ménand, M; Le Gac, S.; Luhmer, M.; Dalla, V.; Jabin, I. J. Org. Chem. 2008, 73, 7067-7071.

(76) Le Gac, S.; Ménand, M.; Jabin, I. Org. Lett. 2008, 10, 5195-5198.

(77) Atwood, J. L.; Szumna, A. J. Am. Chem. Soc. 2002, 124, 10646-10647.

(78) Atwood, J. L.; Szumna, A. Chem. Commun. 2003, 940-941.

(79) Frontera, A.; Orell, M.; Garau, C.; Quiñonero, D.; Molins, E.; Mata, I.; Morey, J. Org. Lett. 2005, 7, 1437-1440. 
(80) Kubik, S. J. Am. Chem. Soc. 1999, 121, 5846-5855.

(81) Kubik, S.; Goddard, R. J. Org. Chem. 1999, 64, 9475-9486.

(82) Gong, J.; Gibb, B. C. Chem. Commun. 2005, 1393-1395.

(83) Wisner, J. A.; Beer, P. D.; Berry, N. G.; Tomapatanaget, B. Proc. Natl. Acad. Sci. USA, 2002, 99, 4983-4986.

(84) Wisner, J. A.; Beer, P. D.; Drew, M. G. B. Angew. Chem., Int. Ed. 2001, 40, 36063609.

(85) Sambrook, R.; Beer, P. D.; Wisner, J. A.; Paul, R. L.; Cowley, A. R. J. Am. Chem. Soc. 2004, 126, 15364-15365.

(86) Lankshear, D.; Evans, N. H.; Bayly, S. R.; Beer, P. D. Chem. Eur. J. 2007, 13, 3861-3870.

(87) Arafa, E. A.; Kinnear, K. I.; Lackhart, J. C. J. Chem. Soc.,Chem. Commun. 1992, 61-64.

(88) White, D. J.; Laing, N.; Miller, H.; Parsons, S.; Coles, S.; Tasker, P. A. Chem. Commun. 1999, 2077-2078.

(89) Tuntulani, T.; Poompradub, S.; Thavornyutikarn, P.; Jaiboon, N.; Ruangpornvisuti, V.; Chaichit, N.; Asfari, Z.; Vicens, J. Tetrahedron Lett. 2001, 42, 5541-5544.

(90) Schmidtchen, F. P. J. Org. Chem. 1986, 51, 5161-5168.

(91) Galán, A.; Andreu, D.; Echavarren, A. M.; Prados, P.; de Mendoza, J. J. Am. Chem. Soc. 1992, 114, 1511-1512.

(92) de Silva, P.; McClean, G. D.; Pagliari, S. Chem. Commun. 2003, 2010-2011.

(93) Savage, P. B.; Holmgren, S. K.; Gellman, S. H. J. Am. Chem. Soc. 1993, 115, 79007901.

(94) Savage, P. B.; Holmgren, S. K.; Gellman, S. H. J. Am. Chem. Soc. 1994, 116, 40694070 .

(95) Mele, A.; Metrangolo, P.; Neukirch, H.; Pilati, T.; Resnati, G. J. Am. Chem. Soc. 2005, 127, 14972-14973. 
(96) Arduini, A.; Giorgi, G.; Pochini, A.; Secchi, A.; Ugozzoli, F. J. Org. Chem. 2001, 66, 8302-8308.

(97) Shi, X.; Fettinger, J. C.; Davis, J. T. Angew. Chem. 2001, 40, 2827-2831.

(98) Kotch, F. W.; Sidorov, V.; Lam, Y.-F.; Kayser, K. J.; Li, H.; Kaucher, M. S.; Davis, J. T. J. Am. Chem. Soc. 2003, 125, 15140-15150.

(99) van der Wijst, T.; Guerra, C. F.; Swart, M.; Bickelhaupt, F. M.; Lippert, B. Angew. Chem., Int. Ed. 2009, 48, 3285-3287.

(100) Chae, M. K.; Lee, J.-I.; Kim, N.-K.; Jeong, K.-S. Tetrahedron Lett. 2007, 48, 66246627.

(101) Sessler, J. L.; Brucker, E. A. Tetrahedron Lett. 1995, 36, 1175-1176.

(102) Baeyer, A. Ber. Dtsch. Chem. Ges. 1886, 19, 2184-2185.

(103) Gale, P. A.; Sessler, J. L.; Král, V.; Lynch, V. J. Am. Chem. Soc. 1996, 118, 51405141.

(104) Custelcean, R.; Delmau, L. H.; Moyer, B. A.; Sessler, J. L.; Cho, W.-S.; Gross, D.; Bates, G. W.; Brooks, S. J.; Light, M. E.; Gale, P. A. Angew. Chem., Int. Ed. 2005, 44, 2537-2542.

(105) Wintergerst, M. P.; Levitskaia, T. G.; Moyer, B. A.; Sessler, J. L.; Delmau, L. H. J. Am. Chem. Soc. 2008, 130, 4129-4139.

(106) Tong, C.; Quesada, R.; Sessler, J. L.; Gale, P. A. Chem. Commun. 2008, 63216323.

(107) Cafeo, G.; Gattuso, G.; Kohnke, F. H.; Notti, A.; Occhipinti, S.; Pappalardo, S.; Parisi, M. F. Angew. Chem., Int. Ed. 2002, 41, 2122-2126.

(108) Cafeo, G.; Gargiulli, C.; Gattuso, G.; Kohnke, F. H.; Notti, A.; Occhipinti, S.; Pappalardo, S.; Parisi, M. F. Tetrahedron Lett. 2002, 43, 8103-8106.

(109) Aydogan, A.; Coady, D. J.; Kim, S. K.; Akar, A.; Bielawski, C. W.; Marquez, M.; Sessler, J. L. Angew. Chem., Int. Ed. 2008, 47, 9648-9652. 


\section{Chapter 2: N-Tosylpyrrolidine Calix[4]pyrrole: Synthesis and Ion Binding Studies}

\subsection{INTRODUCTION}

A century after it was first synthesized in 1886 by Baeyer, ${ }^{1}$ mesooctamethylcalix[4]pyrrole 2.1, a tetrapyrrolic macrocycle, was found in 1996 by Sessler and coworkers to act as an efficient receptor for specific anions, such as halides, carboxylates, and phosphates. ${ }^{2,3}$ Since that time, increasing attention has been paid to calix[4]pyrrole 2.1 as an anion receptor, ${ }^{4}$ with considerable effort having been devoted to enhancing the binding affinity and selectivity for specific anionic guests. These efforts have led, inter alia, to the development of calix[4]pyrrole-based anion receptors, such as strapped calix[4]pyrroles ${ }^{5}$ and $\beta$-substituted calixpyrroles. ${ }^{6}$ In addition, calix[4]pyrrole derivatives equipped with various chromogenic, fluorogenic, or redox-active units have been synthesized for anion sensing. ${ }^{6,7}$ As a general rule, calix[4]pyrrole derivatives with improved anion recognition features have been obtained by modifying either the mesopositions or the $\beta$-pyrrolic positions with various functional groups. ${ }^{5-8}$ However, in both cases the underlying syntheses are subject to limitations. For instance, the use of asymmetric ketones leads to a mixture of configurational isomers, which complicates purification efforts. ${ }^{8}$ In contrast, functionalization of the pyrrolic $\beta$-positions leads to unfavorable steric interactions with the methyl groups on the meso carbon atoms. ${ }^{9}$ Therefore, only relatively small groups such as halogen, oxygen, and sulfur atoms, but not methylene $\left(-\mathrm{CH}_{2}-\right)$, can be introduced directly into the $\beta$-pyrrolic positions via the standard acid-catalyzed pyrrole + ketone condensation strategy typically used to prepare calix[4]pyrroles. ${ }^{6,9}$ In some cases, the introduction of $\beta$-pyrrolic substituents decreases the anion affinity, presumably as the result of destabilizing the cone conformation that favors calix[4]pyrrole-anion interactions. ${ }^{9,10}$ Nevertheless, we consider $\beta$-carbon functionalized 
calix[4]pyrroles bearing methylene substitutents to be worthy synthetic targets. In particular, we suggest that, if appropriately elaborated, such species could prove useful as ion pair receptors. Ion pair receptors, species capable of forming simultaneously a complex with both a cation and an anion, are interesting in that they generally display higher selectivities and affinities than do simple ion receptors. ${ }^{4 b, 11}$ The Sessler group recently reported that calix[4]pyrrole $\mathbf{2 . 1}$ can form a complex with cesium halide ion pairs in the solid state where anions are bound to the pyrrolic NH protonss through hydrogen bonds and the $\mathrm{Cs}^{+}$cation is held within the cone-like cavity of the calix[4]pyrrole via apparent $\pi$-cation interactions. ${ }^{12}$ In this chapter, the candidate would like to report that the introduction of $N$-tosylpyrrolidine units, specifically when fused onto the $\beta$-pyrrolic positions, gives rise to a system, 2.2, that displays anion affinities that are enhanced relative to calix[4]pyrrole 2.1. This new $\beta$-octaalkyl substituted calix[4]pyrrole acts as an effective receptor for cesium halide ion pairs in chloroform solution.

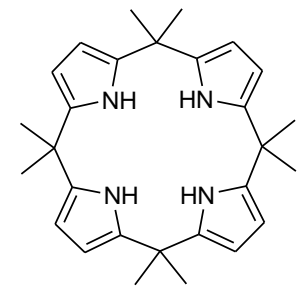

2.1

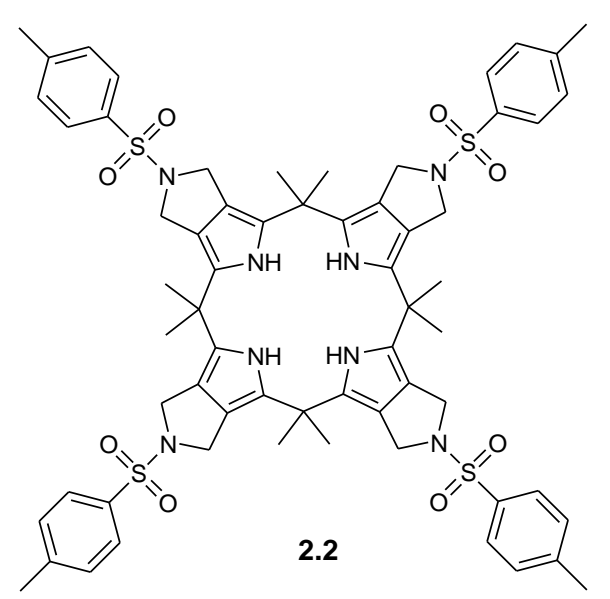

Figure 2.1 Chemical structures of compouds 2.1 and 2.2. 


\subsection{RESUlTS AND DiSCUSSIONS}

The synthesis of $\mathbf{2 . 2}$ is outlined in Scheme 2.1. It starts with diethyl pyrrole-3,4dicarboxylate $\mathbf{2 . 3},{ }^{13}$ which was subjected to N-protection by treating with tosyl chloride. The diester groups of $\mathbf{2 . 4}$ were then reduced with LAH to the afford $N-p$ toluenesulfonlylpyrrole-3,4-dimethanol (2.5). Bromination of this latter diol using $\mathrm{PBr}_{3}$, followed by cyclization with TsNHNa, gave the bicyclic pyrrole (2.7) in moderate yield. Treatment of this ditosyl pyrrole (2.7) with excess sodium methoxide (30 equiv) in a mixture of THF/methanol (3/1) served to remove only the tosyl group on the pyrrole moiety leaving that on the pyrrolidine moiety untouched; this gave $N-p$ toluenesulfonylpyrrolidinylpyrrole $\mathbf{2 . 8}$ in $91 \%$ yield. Condensation of this latter pyrrole with acetone in the presence of 1 equiv of trifluoroacetic acid (TFA) then gave the desired $\beta$-octaalkyl substituted calix[4]pyrrole derivative 2.2 in $20 \%$ yield.

Scheme 2.1 Synthesis of compound 2.2

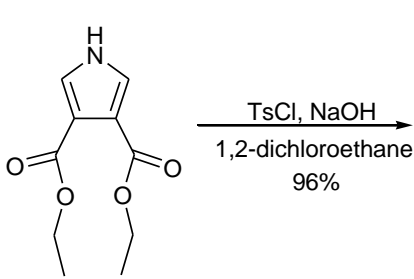

2.3

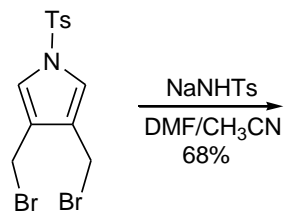

2.6
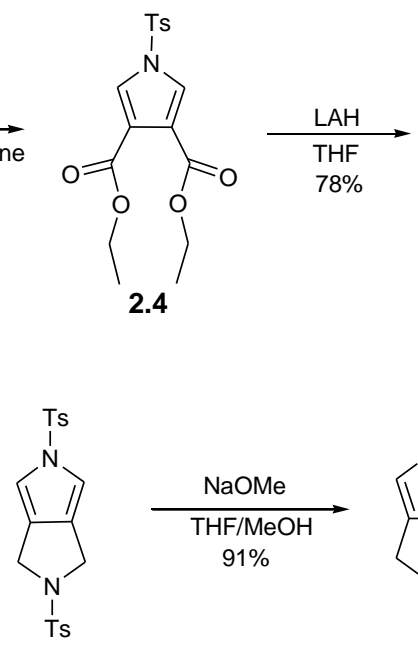

2.7

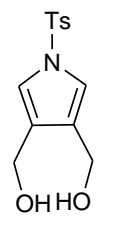

$\underset{\text { Dichloromethane }}{\mathrm{PB \%}}$
PBr

2.5

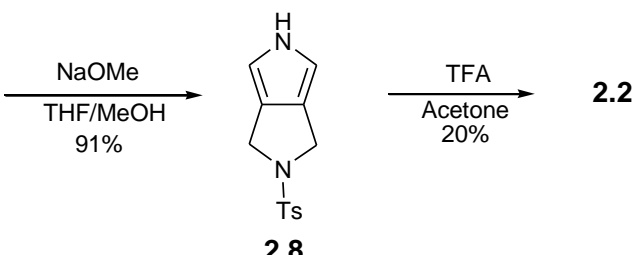


Calix[4]pyrrole 2.2 was characterized by standard spectroscopic techniques as well as by single crystal X-ray diffraction analysis. Two crystals of the anion-free form of 2.2 suitable for such analyses were obtained. They were grown by slow evaporation of solutions of 2.2 made up in chloroform/methanol (1/1) and dichloromethane/DMF (10/1). In both cases, the resulting structures revealed that calix[4]pyrrole $\mathbf{2 . 2}$ adopts the socalled 1,2-alternate conformation in the solid state with two solvent molecules bound to the pyrrolic $\mathrm{NH}$ protons (Figures 2.2 and 2.3). In the single crystal structure of 2.2 $(\mathrm{MeOH})_{2}$, two tosyl groups are directed in towards the inside of the calix[4]pyrrole cavity, while the other two point towards the outside of the macrocycle. In contrast, in the case 2.2 $(\mathrm{DMF})_{2}$ all of four tosyl groups point towards the outside of the cavity; such a finding is consistent with the expected steric repulsion between the tosyl groups and the two bound DMF molecules.
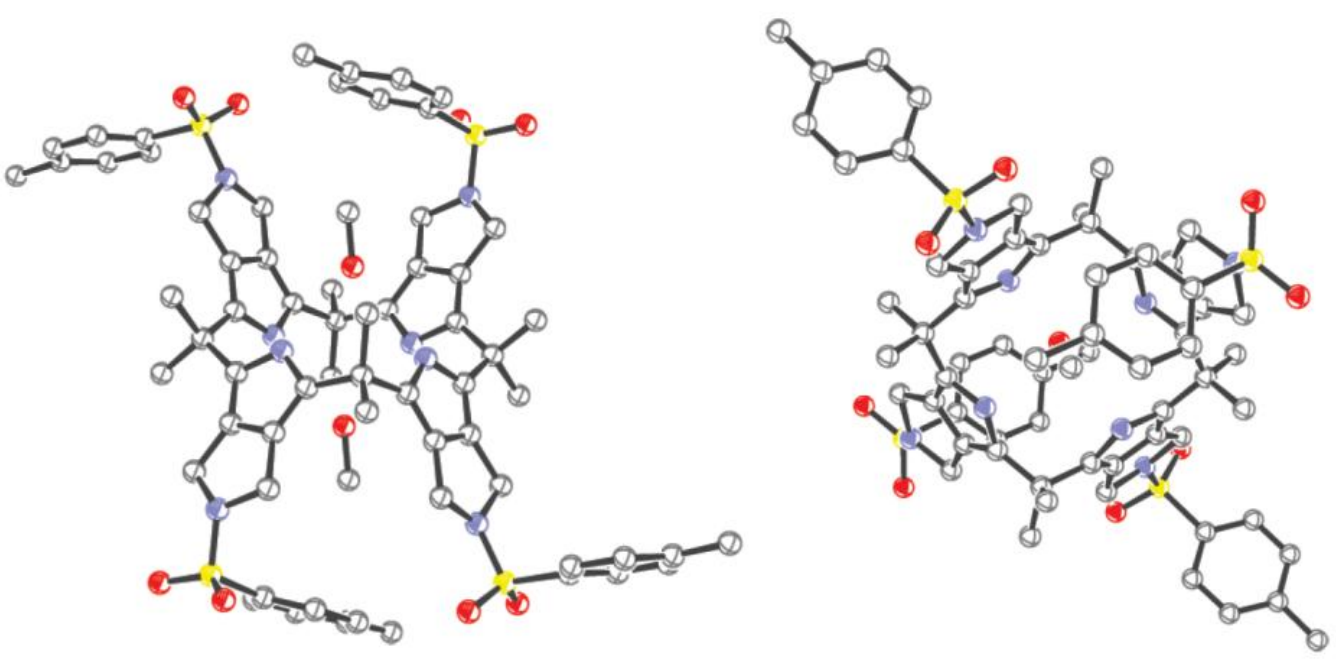

Figure 2.2 Two different views of the single crystal structure of $\mathbf{2 . 2} \cdot(\mathrm{MeOH})_{2}$. Displacement ellipsoids are scaled to the $30 \%$ probability level. Hydrogen atoms have been removed for clarity. The macrocycle lies on a crystallographic inversion center at $1 / 2,1 / 2,1 / 2$. 

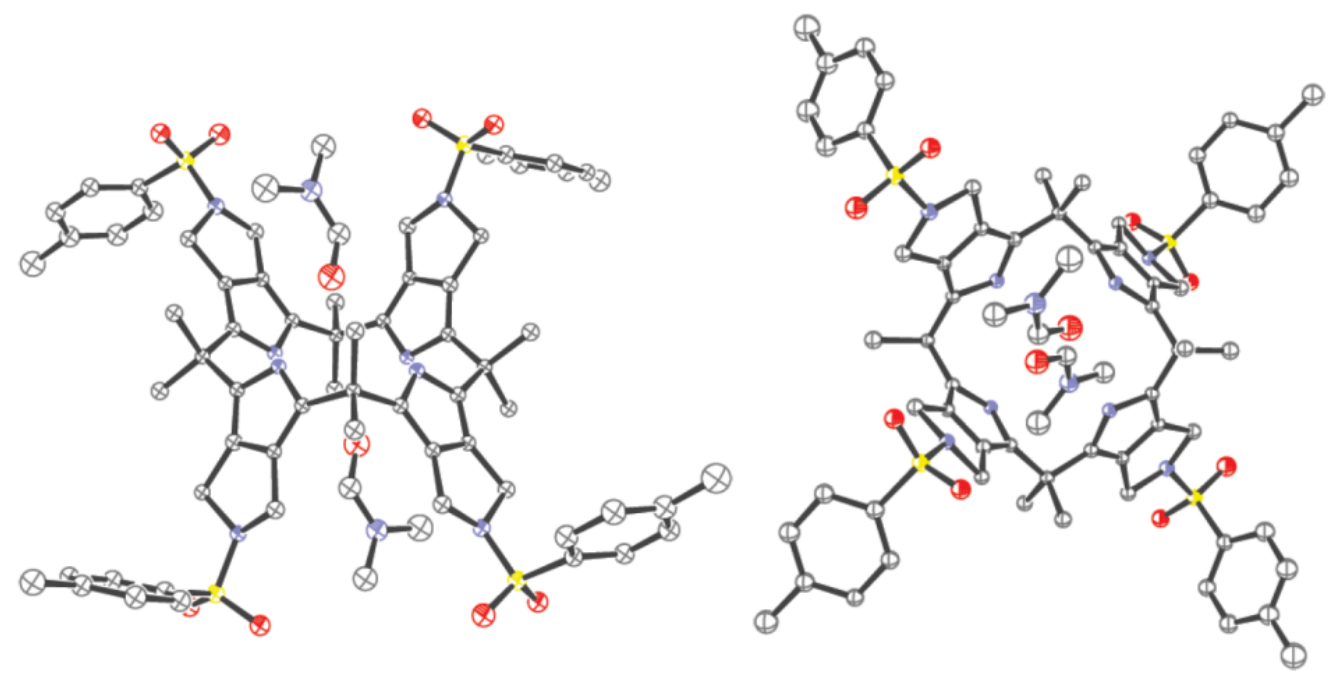

Figure 2.3 Two different views of the single crystal structure of $\mathbf{2 . 2}(\mathrm{DMF})_{2}$. Displacement ellipsoids are scaled to the $50 \%$ probability level. Hydrogen atoms have been removed for clarity. The macrocycle lies on a crystallographic inversion center at $1 / 2,1 / 2,1 / 2$.

The first evidence that compound 2.2 is capable of forming a complex with an anion came from a single crystal X-ray diffraction analysis of the presumed chloride anion complex, $2.2 \cdot \mathrm{Cl}^{-}$(Figure 2.4). The resulting structure confirmed that in this complex calix[4]pyrrole adopts the cone conformation and that the four pyrrolic $\mathrm{NH}$ protons participate in hydrogen bonding interactions with the chloride anion (Figure 2.4). The distance between the chloride anion and nitrogen atoms is $3.372 \AA$ and the $\mathrm{N}-\mathrm{H}^{\cdots} \mathrm{Cl}^{-}$ angle is ca. $155^{\circ}$. 


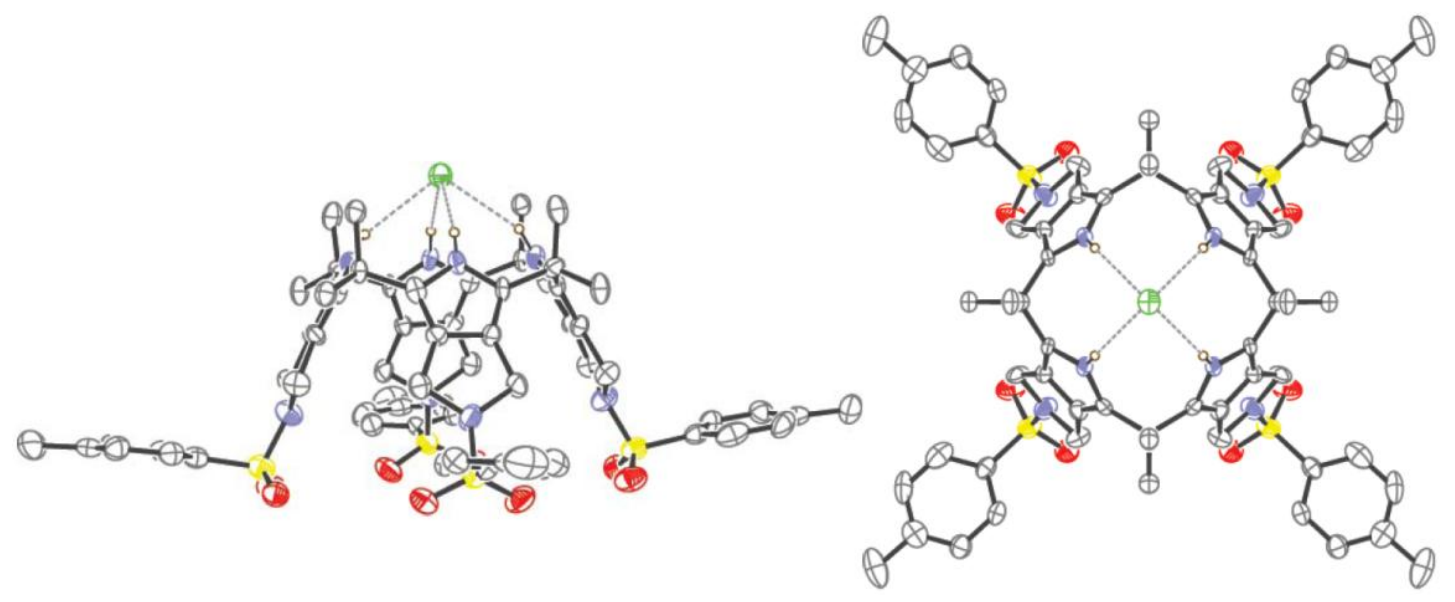

Figure 2.4 Two different views of the single crystal structure of $\mathbf{2 . 2} \cdot \mathrm{Cl}^{-}$. Displacement ellipsoids are scaled to the $30 \%$ probability level. Compound $\mathbf{2 . 2}$ in this complex lies around a crystallographic 4 -fold rotation axis at 1/2, 1/2, z. Most hydrogen atoms have been removed for clarity. Dashed lines are indicative of H-bonding interactions. The countercation, $\mathrm{TBA}^{+}$, sitting in the cavity formed by four sulfonyl groups, is disordered and is not shown.

Initial evidence that calix[4]pyrrole 2.2 could bind halide anions in solution came from ${ }^{1} \mathrm{H}$ NMR spectroscopic analyses carried out in $\mathrm{CDCl}_{3}$. As shown in Figure 2.5, the anion-free form of 2.2 displays a singlet peak for the $H_{a}$ and $H_{b}$ protons at 4.27 ppm. Such a finding is consistent with the rate of conformation change being fast on the NMR time scale, as is true for most other anion-free calix[4]pyrrole derivatives. However, upon the addition of increasing quantities of tetrabutylammonium fluoride (TBAF), the singlet peak of $\mathrm{H}_{\mathrm{a}}$ and $\mathrm{H}_{\mathrm{b}}$ first becomes broadened, something that is apparent after the addition of fewer than 0.38 equiv, and then becomes split. This splitting gives rise to two doublets $(J=10.8 \mathrm{~Hz})$ in an AB pattern, and is consistent with the conformation of $\mathbf{2 . 2}$ becoming fixed in the cone conformation as the result of fluoride anion binding (Figures 2.5). 

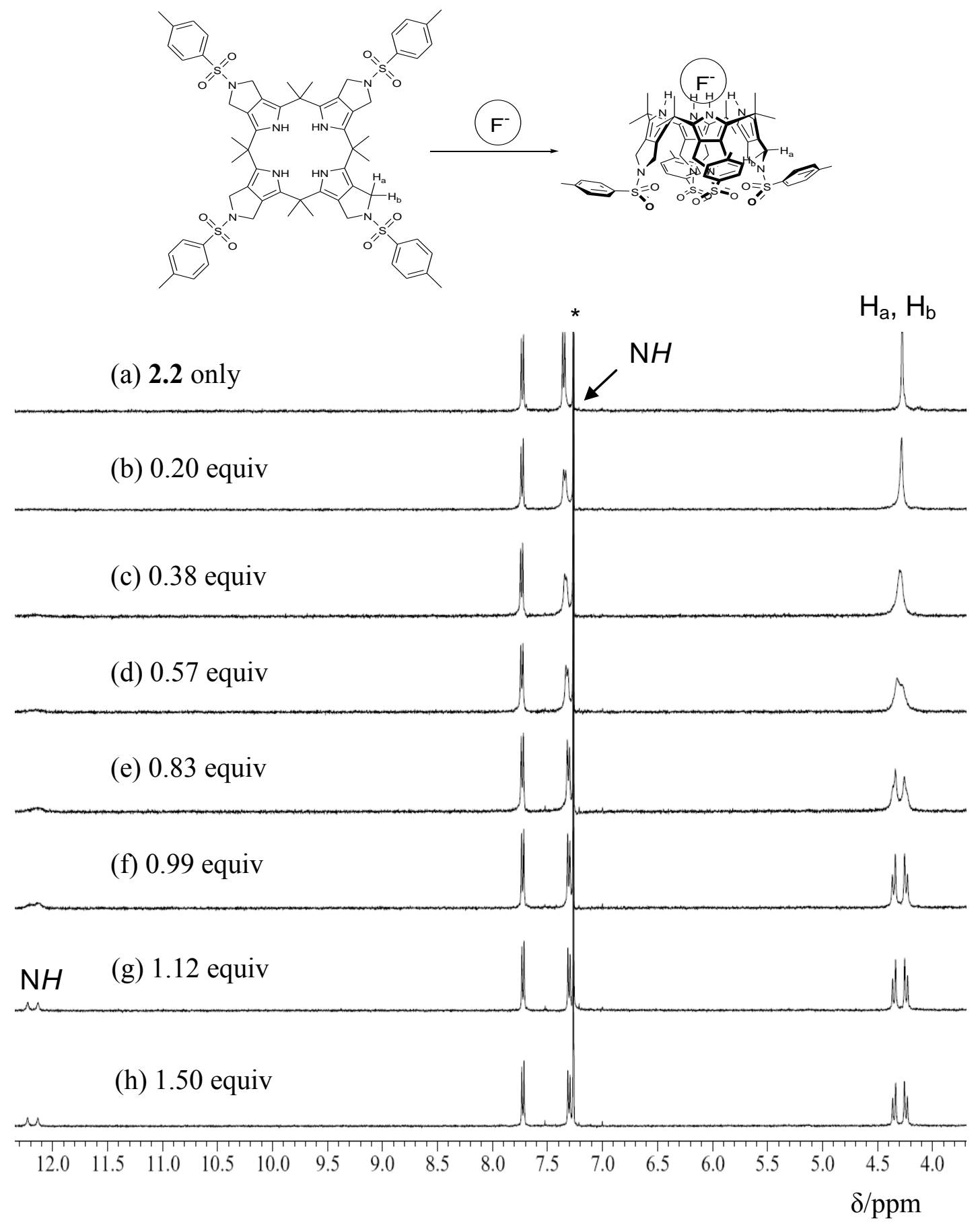

Figure 2.5 Partial ${ }^{1} \mathrm{H}$ NMR spectra recorded during the titration of receptor 2.2 with TBAF (tetrabutylammonium fluoride) in $\mathrm{CDCl}_{3}$. $*$ Denotes peaks due to the NMR solvent. 
This anion-induced conformational locking stands in contrast to what is seen in the case of calix[4]pyrrole 2.1; at room temperature in $\mathrm{CDCl}_{3}$, the conformation of this latter system is not fixed via fluoride anion binding, as evidenced by the fact that the meso carbons of 2.1 still appear as a singlet in the ${ }^{1} \mathrm{H}$ NMR spectrum after the addition of excess TBAF (Figure 2.6). This difference led us to postulate that the new calix[4]pyrrole derivative, 2, binds fluoride anion more strongly than does the parent system $\mathbf{1 . 1}$.
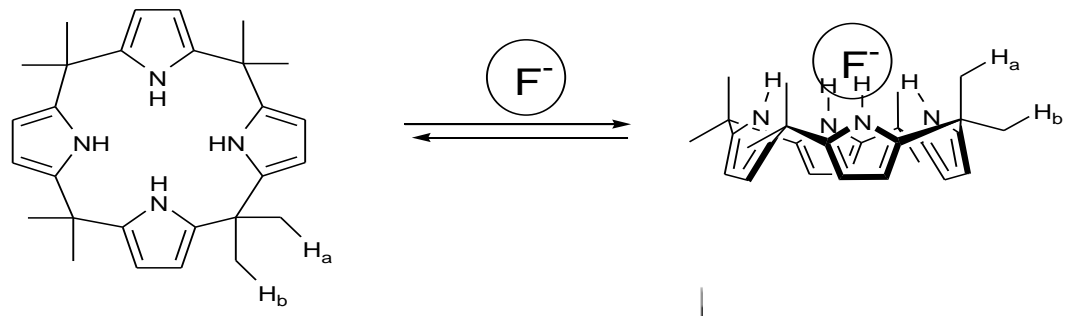

(a) 2.1 only

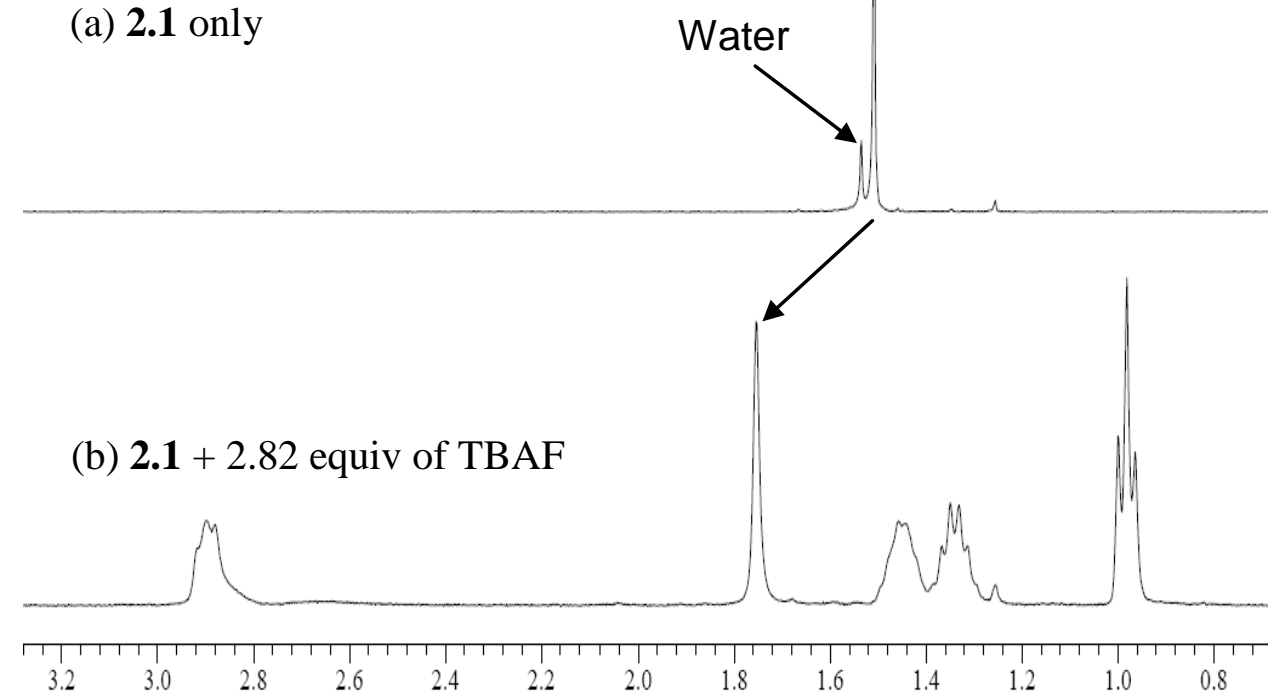

Figure 2.6 Partial ${ }^{1} \mathrm{H}$ NMR spectra of (a) free $\mathbf{2 . 1}$ and (b) $\mathbf{2 . 1}+2.82$ equiv of TBAF in $\mathrm{CD}_{3} \mathrm{Cl}$. 
In an effort to test the above assumption, more detailed titrations were carried out. As shown in Figures 2.5 and 2.7, these titrations revealed that the changes in the spectrum are essentially complete after receptor $\mathbf{2 . 2}$ is treated with ca. 1.0 equiv of TBAF, whereas ca. 2.8 equiv are required to achieve saturation in the case of calix[4]pyrrole 2.1. Further support for the conclusion that $\mathbf{2 . 2}$ is a better fluoride anion receptor under these solution phase conditions came from the observation that the $\mathrm{NH}$ proton resonance of $\mathbf{2}$ is split into a doublet $\left(J_{H F}=29.6 \mathrm{~Hz}\right)$ at room temperature in the presence of the fluoride anion, presumably as the result of coupling between the bound fluoride anion the $\mathrm{NH}$ protons. ${ }^{14}$ A significant downfield shift in the NH proton peak (by roughly $5 \mathrm{ppm}$; final $\delta$ $\approx 12.7 \mathrm{ppm}$ ) was also seen in the presence of TBAF (Figure 2.5).

In analogy to what is seen in the case of fluoride, the singlet corresponding to the meso $\mathrm{H}_{\mathrm{a}}$ and $\mathrm{H}_{\mathrm{b}}$ resonances of $\mathbf{2}$ was found to split into two doublets upon the addition of $\mathrm{TBACl}\left(\mathrm{CDCl}_{3}\right.$ solution; room temperature). As above, this was taken as evidence that the chloride anion binds strongly to $\mathbf{2}$ and also serves to fix the conformation on the NMR time scale. This serves to lock the calix[4]pyrrole framework into the cone conformation, which places protons $\mathrm{H}_{\mathrm{a}}$ and $\mathrm{H}_{\mathrm{b}}$ in a diastereotopic environment (Figure 2.8). Such an interpretation is fully consistent with the crystal structure of the chloride anion complex of 2.2 discussed above (cf. Figure 2.4). The further observation that the changes in the $\mathrm{NH}$ proton chemical shift of $\mathbf{2}$ become saturated upon the addition of ca. 1.0 equiv of TBACl provides, as above, further support for the notion that the chloride anion is strongly bound by 2.2. In contrast to what was seen with TBAF and TBACl, when 2 was subject to the titration with the TBA salts of bromide and iodide, the $\mathrm{H}_{\mathrm{a}}$ and $\mathrm{H}_{\mathrm{b}}$ signals 
did not split, but rather remained in the form of a singlet at room temperature. This lack of change is ascribed to the fact that the bromide and the iodide anions are bound only weakly and that calix[4]pyrrole undergoes fast conformational "flipping" in the presence of these two anions. Support for this conclusion comes from the fact that only relatively small downfield shifts in the $\mathrm{NH}$ proton resonance are seen upon the addition of $\mathrm{TBABr}$ or TBAI (Figure 2.8).

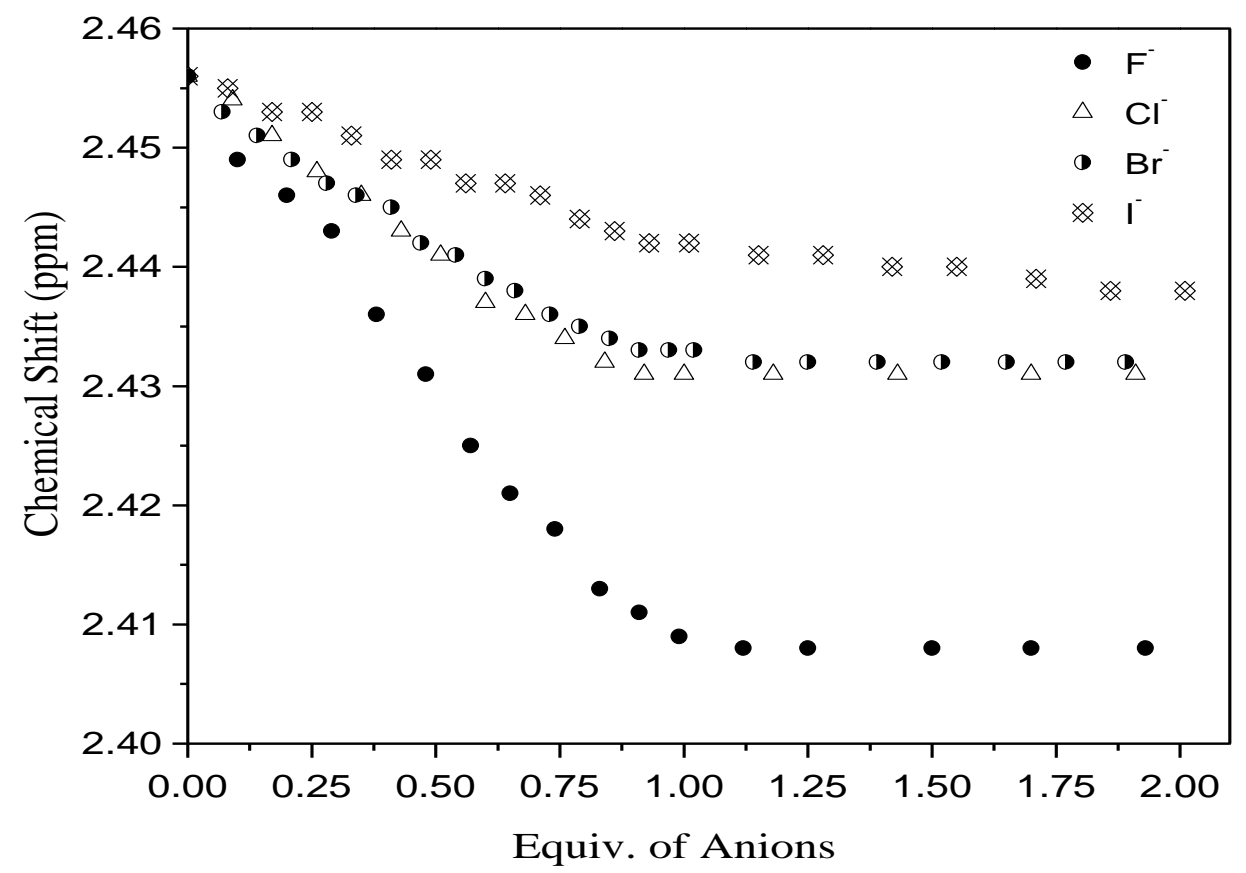

Figure 2.7 ${ }^{1} \mathrm{H}$ NMR titration curves of 2.2 with $\mathrm{TBAX}$ in $\mathrm{CDCl}_{3}$. Chemical shift on the $\mathrm{y}$ axis is of the methyl groups on the tosyl moiety of 2.2. [2.2] $=0.003 \mathrm{M}$. 


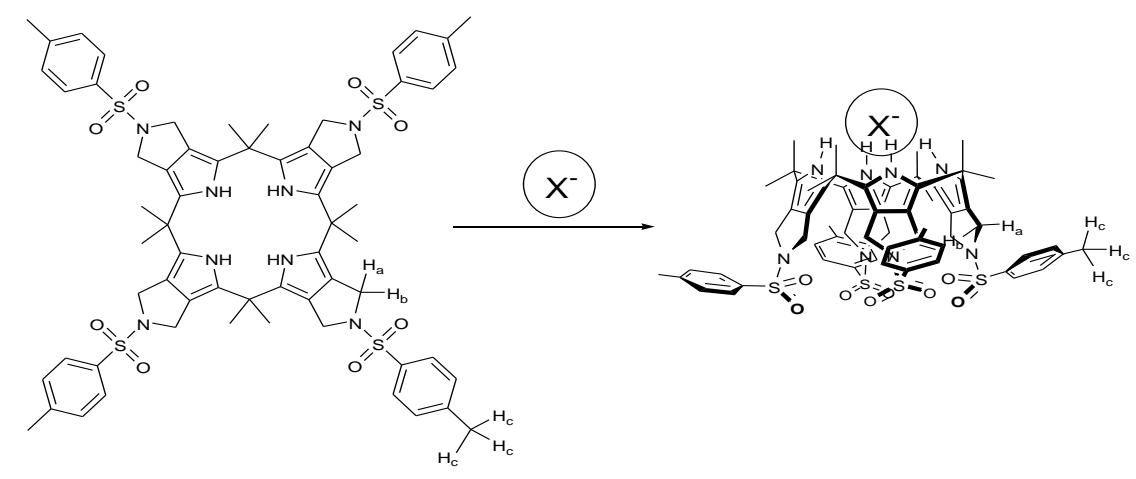

(a) 2.2 only

(b) 1.12 equiv of TBAF $\mathrm{NH}$

(c) 1.50 equiv of $\underset{\mathrm{NH}}{\mathrm{HBACl}}$

(d) 1.51 equiv of $\mathrm{TBABr}$

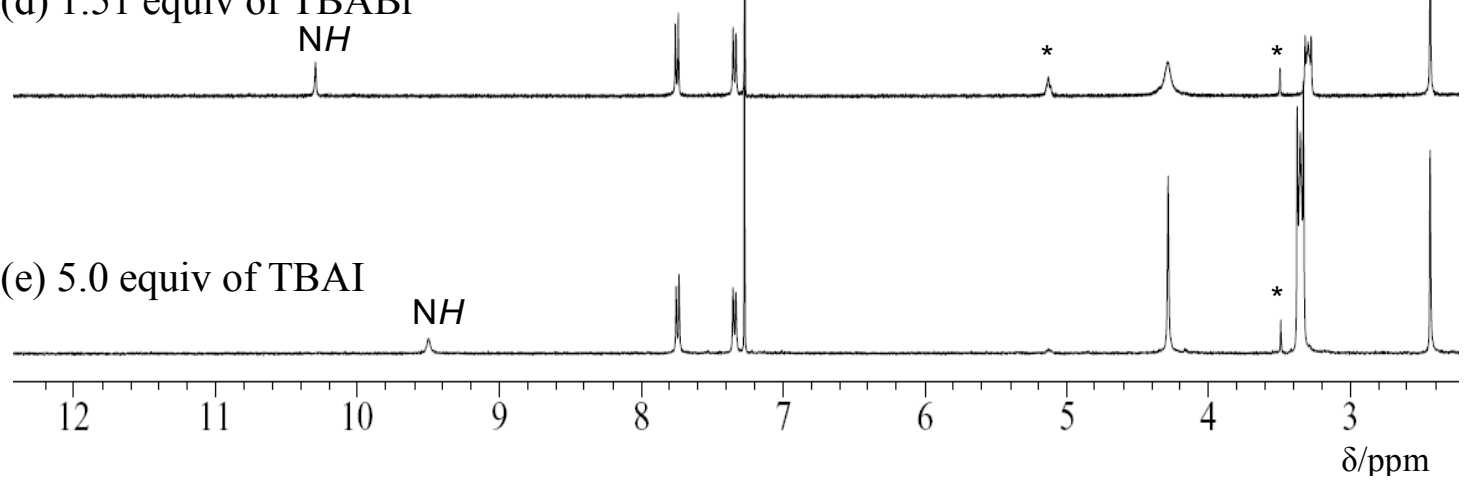

Figure 2.8 Proton NMR spectra of 2.2 recorded in $\mathrm{CDCl}_{3}$ after adding quantities of TBAX (tetrabutylammonium halide) sufficient to induce no further observable spectral changes. Note the position of the NH signal. *Denotes peaks due to the NMR solvent and other residual impurities. 
Unfortunately, in the case of the fluoride and chloride anions, kinetics and difficulties associated with integrating the signals for the separate species precluded the use of ${ }^{1} \mathrm{H}$ NMR spectroscopic methods to obtain quantitative measures of the anion affinities in the case of 2.2. Therefore, isothermal titration calorimetry (ITC) analyses were carried out. In contrast to NMR spectroscopic methods, ITC analyses provide direct access to the energetics of the binding event without the necessity of a structural probe (e.g., an NMR spectroscopic signal). While these two techniques necessarily probe different aspects of the presumed binding event, the Sessle group has recently demonstrated, in collaboration with Gale and Schmidtchen, that NMR spectroscopic titrations and ITC analyses give rise to concordant results when the conditions for the measurements are comparable. ${ }^{15}$ Accordingly, ITC methods were explored in an effort to quantify the anion affinities of calixpyrrole $\mathbf{2 . 2}$. 
Table 2.1 Selected thermodynamic data derived from isothermal titration calorimetry (ITC) for the interactions of receptors $\mathbf{2 . 1}$ and $\mathbf{2 . 2}$ with tetraalkylammonium halides. Titrations were performed in $\mathrm{CHCl}_{3}$ at $25^{\circ} \mathrm{C}$.

\begin{tabular}{|c|c|c|c|c|c|c|c|c|}
\hline & \multirow[b]{2}{*}{$\begin{array}{l}\text { Salt } \\
\mathrm{mM}\end{array}$} & \multirow[b]{2}{*}{$\begin{array}{l}\text { Host } \\
\mathrm{mM}\end{array}$} & \multirow[b]{2}{*}{$\begin{array}{l}\text { Original } \\
\mathrm{N}\end{array}$} & \multirow[b]{2}{*}{$\begin{array}{l}\text { Original } \\
K_{a}\left(\mathrm{M}^{-1}\right)\end{array}$} & \multicolumn{4}{|c|}{$\begin{array}{l}\text { Data obtained after adjusting Host concentration } \\
\text { to obtain a value of } 1 \text { for N (stoichiometry) }{ }^{a}\end{array}$} \\
\hline & & & & & $\begin{array}{c}\Delta G \\
\mathrm{kcal} \cdot \mathrm{mol}^{-1}\end{array}$ & $\begin{array}{c}\Delta H \\
\mathrm{kcal} \cdot \mathrm{mol}^{-1}\end{array}$ & $\begin{array}{c}T \Delta S \\
\mathrm{kcal} \cdot \mathrm{mol}^{-1}\end{array}$ & $\begin{array}{c}K_{\mathrm{a}} \\
\left(\mathrm{M}^{-1}\right)\end{array}$ \\
\hline \multicolumn{9}{|c|}{ TBA-Cl } \\
\hline 2.1 & 23.1 & 1.1 & $-{ }^{b}$ & $<10^{2}$ & $-b$ & $-b$ & $-b$ & $<10^{2}$ \\
\hline 2.2 & 2.71 & 0.21 & 0.83 & $2.5 \times 10^{6}$ & -8.70 & -8.27 & 0.43 & $2.4 \times 10^{6}$ \\
\hline 2.2 & 0.09 & 1.57 & 1.19 & $1.6 \times 10^{6}$ & -8.65 & -8.96 & -0.30 & $2.2 \times 10^{6}$ \\
\hline \multicolumn{9}{|c|}{ TEA-Cl } \\
\hline 2.1 & 21.0 & 1.64 & 0.99 & $7.0 \times 10^{3}$ & -5.26 & -8.60 & -3.34 & $7.0 \times 10^{3}$ \\
\hline 2.2 & 4.74 & 0.21 & 0.83 & $1.8 \times 10^{7}$ & -9.89 & -8.97 & 0.92 & $1.8 \times 10^{7}$ \\
\hline \multicolumn{9}{|c|}{ TBA-Br } \\
\hline 2.2 & 10.3 & 1.0 & 0.85 & $2.2 \times 10^{5}$ & -7.29 & -6.38 & 0.91 & $2.2 \times 10^{5}$ \\
\hline \multicolumn{9}{|c|}{ TEA-Br } \\
\hline 2.2 & 16.4 & 1.0 & 0.75 & $8.9 \times 10^{5}$ & -8.11 & -5.01 & 3.10 & $8.9 \times 10^{5}$ \\
\hline \multicolumn{9}{|c|}{ TBA-I } \\
\hline 2.2 & 11.9 & 1.0 & 0.77 & $4.4 \times 10^{2}$ & -3.60 & -5.21 & -1.61 & $4.4 \times 10^{2}$ \\
\hline \multicolumn{9}{|c|}{ TEA-I } \\
\hline 2.2 & 12.2 & 1.0 & 0.85 & $1.5 \times 10^{4}$ & -5.70 & -1.86 & 3.84 & $1.5 \times 10^{4}$ \\
\hline
\end{tabular}

ITC experiments were carried out under conditions chosen to given an $\mathrm{N}$ value (calculated stoichiometry) close to 1 . Under varying host-guest ratios, different $\mathrm{N}$ values between 0.5 and 2.0 could be obtained depending on the exact salt and concentration. This variation, which in all cases remained within a factor of less than two, is thought to 
reflect ion-pairing effects. Such effects are significant in this system as noted below. Nevertheless, the possibility of forming complexes of non-1:1 stoichiometry, especially under conditions where either the host or guest is present in great excess, cannot be eliminated. Therefore, in order to allow inter-comparisons between different anion binding processes the host concentration (i.e., concentration of 2.2) was adjusted to obtain an $\mathrm{N}$ value of 1 . The uncorrected $K_{a}$ values are, however, also shown in Table 2.1 for purpose of reference.

Interestingly, the interactions of $\mathbf{2 . 2}$ with halide anions are driven almost entirely by enthalpy. For example, the chloride complex is formed with $\Delta H$ contributing $>95 \%$ to the interaction energy. In conjunction with a modest entropic term, this gives rise to a favorable (negative) $\Delta G$ and a $K_{a}$ of $2.4 \times 10^{6} \mathrm{M}^{-1}$ in $\mathrm{CHCl}_{3}$ (Table 2.1). This represents a considerable increase in affinity relative to the parent, unsubstituted calix[4]pyrrole $\mathbf{2 . 1}$ $\left(K_{a}<10^{2} \mathrm{M}^{-1}\right.$ in $\left.\mathrm{CHCl}_{3}\right)$. This ca. four order of magnitude difference can be noted qualitatively from an inspection of the associated titration plots (Figure 2.9).
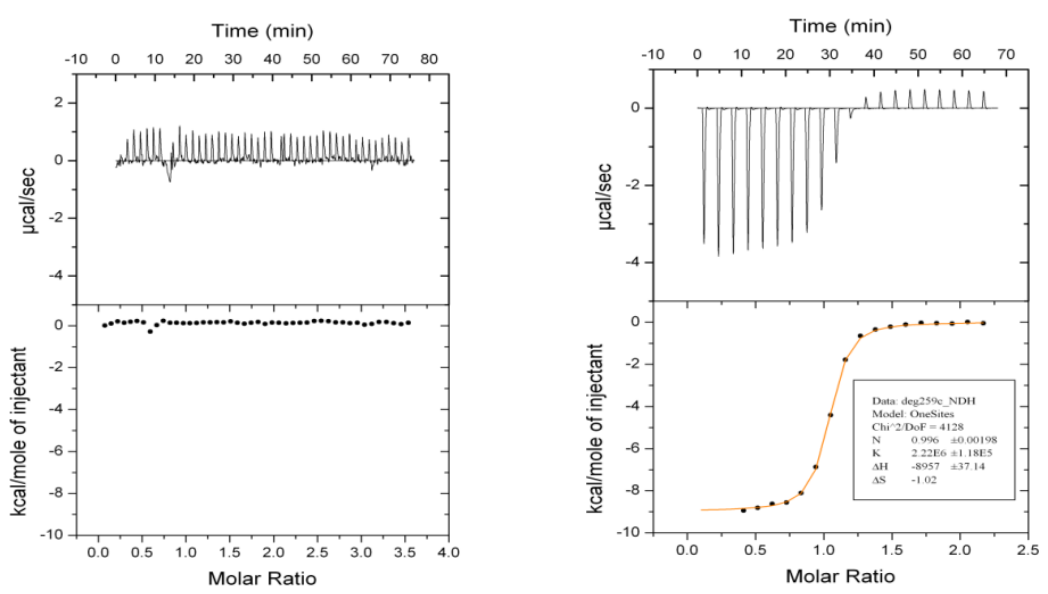

Figure 2.9 ITC plots showing the titration of $\mathrm{TBACl}$ into chloroform solutions of calixpyrroles 2.1 (left, $10 \mathrm{mM}$ ) and 2.2 (right, $0.1 \mathrm{mM}$ ). A high concentration was used in the former case in an attempt to obtain a discernable binding isotherm. 
The affinities of receptor $\mathbf{2 . 2}$ for other halide anions, such as bromide and iodide, are also substantially enhanced as compared with calix[4]pyrrole 2.1. Whereas no appreciable interaction with these latter anions could be discerned under the conditions of ITC analysis, binding constants $\left(K_{a}\right)$ of $8.9 \times 10^{5}$ for TEABr and $1.5 \times 10^{4}$ for TEAI, respectively, could be derived in the case 2.2. As detailed further below, the relatively high affinities seen in the case of $\mathbf{2 . 2}$ are ascribed in part to additional interactions between the counter-cations and the four tosyl groups. Such interactions are not possible in the case of the unsubstituted system 2.1. Another evidence for the interactions between the counter cation and the tosyl groups came from the ${ }^{1} \mathrm{H}$ NMR titration of receptor $\mathbf{2 . 1}$ with TEACl (tetraethylammonium chloride) (Figure 2.10). In the presence of less than 1.00 equiv. of TEACl $([2.2]>[\mathrm{TEACl}])$, the ethyl peak of the tetramethylammonium cation appears to be significantly upfield sifted, which is attributable to the encapsulation of the cation by the tosyl group forming an ion pair complex. Furthermore, the addition of 0.59 equiv. of TEACl gives rise to two sets of distinguishable resonances for $\mathrm{H}_{\mathrm{a}}$ and $\mathrm{H}_{\mathrm{b}}$ proton signals. These peaks are ascribed to the ion pair-free and TEACl bound forms of 2.2 and are consistent the ion pair binding/decomplexation equilibrium being slow on the ${ }^{1} \mathrm{H}$ NMR time scale resulting from stronger binding of TEACl to receptor 2.2 . 


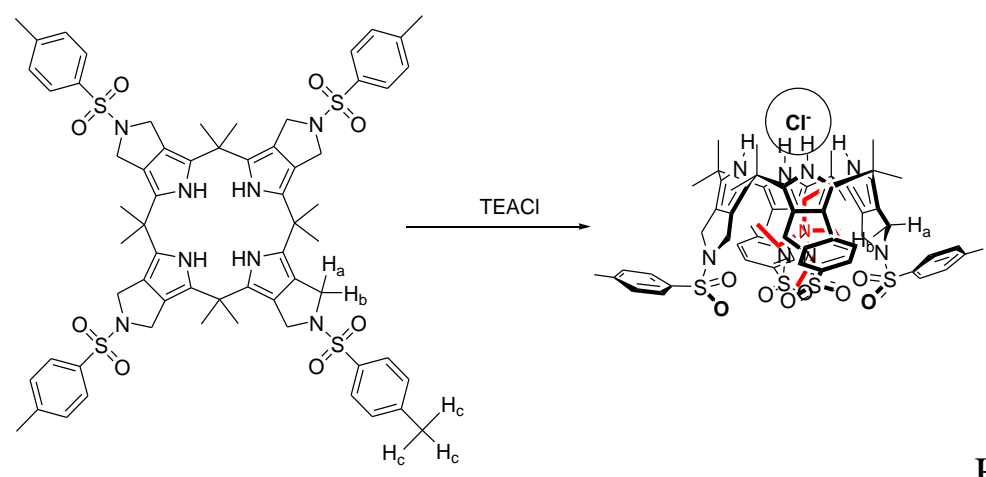

(a) 2.2 only

$\mathrm{H}_{\mathrm{a}}, \mathrm{H}_{\mathrm{b}}$

(b) 0.59 equiv

TEA $^{+}$

(c) 1.00 equiv

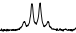

(d) 1.13 equiv

M

(e) 1.49 equiv
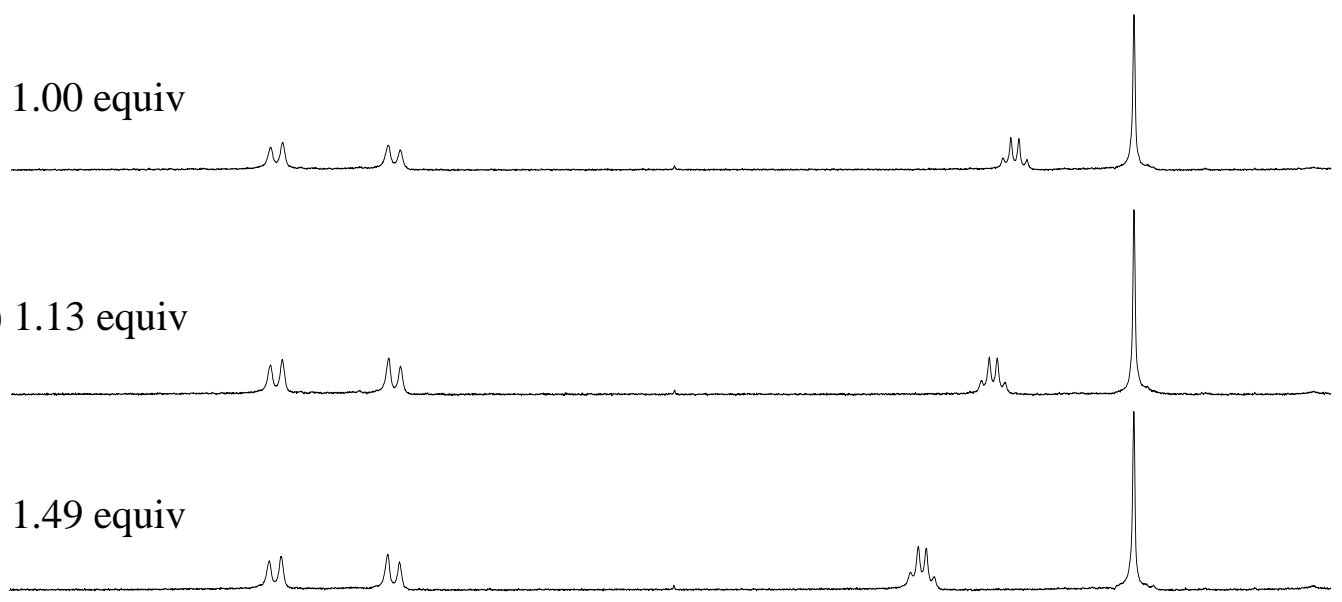

(f) 2.35 equiv

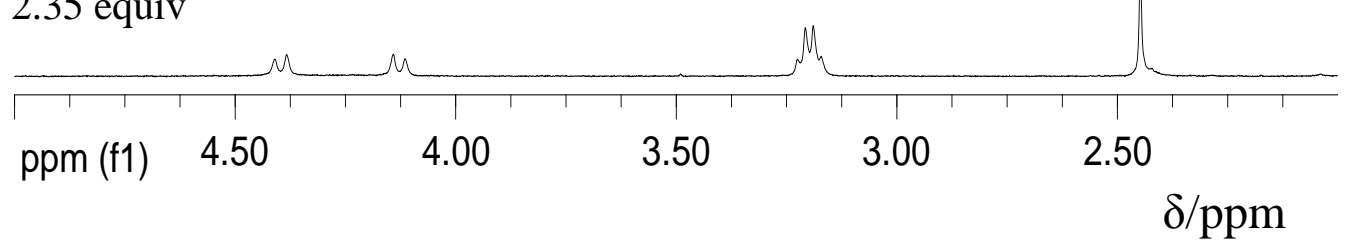

Figure 2.10 Partial ${ }^{1} \mathrm{H}$ NMR spectra corresponding to the titration of 2.2 with TEACl in $\mathrm{CDCl}_{3}$. 
The ability of calix[4]pyrrole $\mathbf{2 . 2}$ to act as an ion pair receptor was tested and compared with that of normal calix[4]pyrrole 2.1. This was done via solid-liquid extraction experiments using the chloroform-insoluble salts, $\mathrm{CsF}$ and $\mathrm{CsCl}$, as test ion pairs. After of subjecting $\mathrm{CDCl}_{3}$ solutions of 2.1 and 2.2 to sonication for $1 \mathrm{~h}$ in the presence of 5.0 equiv of $\mathrm{CsF}$ and $\mathrm{CsCl}$, the soluble portion of the samples were monitored by ${ }^{1} \mathrm{H}$ NMR spectroscopy. Under these experimental conditions, two sets of distinguishable peaks, corresponding to the free calix[4]pyrroles and their ion pair complexes, were seen in the ${ }^{1} \mathrm{H}$ NMR spectra of $2.1 \cdot \mathrm{CsF}, 2.2 \cdot \mathrm{CsF}$, and $2.2 \cdot \mathrm{CsCl}$ (Figures 2.11 and 2.12). Such findings are consistent with the formation of ion pair complexes, albeit under conditions of slow equilibrium. Comparison of the peak integral ratios for the free form of calix[4]pyrrole 2.1 and its corresponding ion pair complexes (cf. Figure 2.12 ) revealed that $<10 \%$ of the receptor was involved in ion pair recognition in the case of $\mathrm{CsF}$ and essentially none in the case of $\mathrm{CsCl}$. In contrast, under these solid-to-solution extraction conditions ca. $95 \%$ and ca. $15 \%$ of the available calix[4]pyrrole 2.2 in solution was tied up in the form of $\mathrm{CsF}$ and $\mathrm{CsCl}$ ion pairs, respectively, (Figure 2.11). These results lead us to suggest that receptor 2.2 acts as an ion pair receptor and is even more effective for this purpose than calix[4]pyrrole 2.1. This, it is proposed, reflects participation of the tosyl groups of $\mathbf{2 . 2}$ in the cesium cation binding process. Support for this supposition comes from the observation that relatively larger downfield shifts are seen for the signals of the aromatic protons of the tosyl groups upon complexation of $\mathrm{CsF}$ and $\mathrm{CsCl}$ than are observed upon treatment with $\mathrm{TBAF}$ and TBACl. Relatively larger splittings in the $\mathrm{H}_{\mathrm{a}}$ and $\mathrm{H}_{\mathrm{b}}$ proton peaks are also seen. 

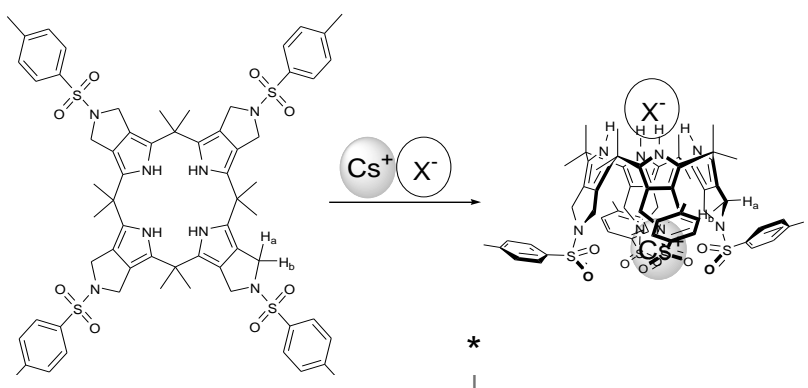

(a) 2.2 only

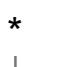

$\mathrm{H}_{\mathrm{a}}, \mathrm{H}_{\mathrm{b}}$

(b) 5 equiv. of $\mathrm{CsF}$

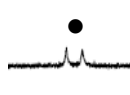

(c) 5 equiv. of $\mathrm{CsCl}$

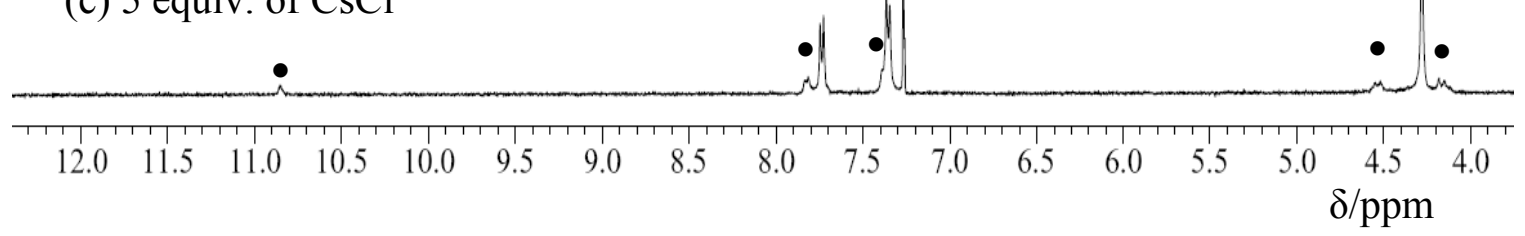

Figure 2.11 Proton NMR spectra of 2.2 recorded at room temperature in $\mathrm{CDCl}_{3}$ before and after the addition of $\mathrm{CsF}$ and $\mathrm{CsCl} .{ }^{*}$ and $\cdot$ denote the peaks of the NMR solvent and complexes $2.2 \cdot \mathrm{CsF}$ and $2.2 \cdot \mathrm{CsCl}$, respectively. Note the position of the NH signals. 


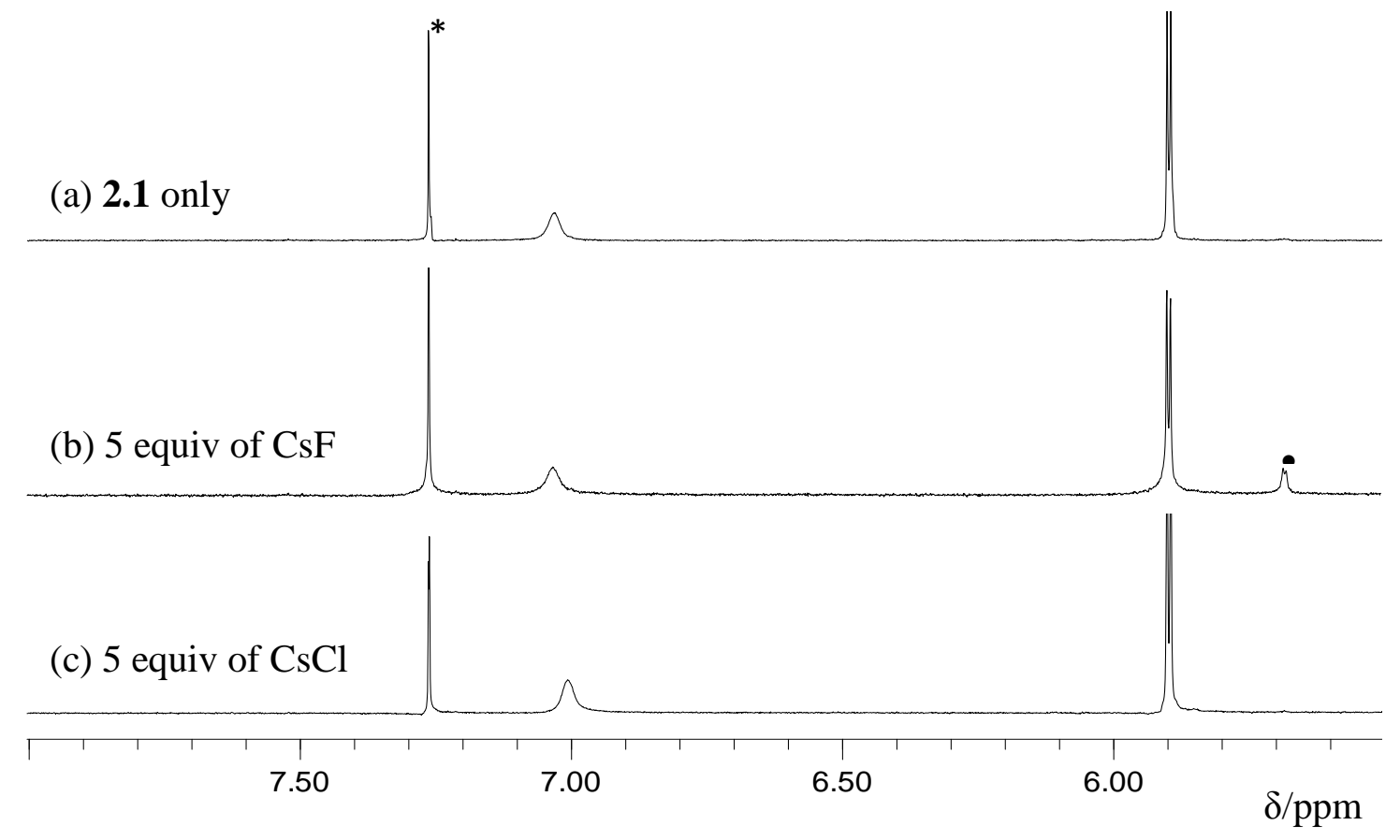

Figure 2.12 Chemical shift changes of 1 observed upon the addition of $\mathrm{CsF}$ and $\mathrm{CsCl}$ in $\mathrm{CDCl}_{3}$. $*$ and $\cdot$ denote peaks due to the NMR solvent and the complex 2.1. CsF, respectively.

\subsection{ConClusions}

It has been shown here that it is possible to obtain a $\beta$-substituted calix[4]pyrrole, in this case one bearing fused $N$-tosyl pyrrolidine subunits (i.e. 2.2), via a direct condensation of an appropriately chosen pyrrolic precursor and acetone under conditions of acid catalysis (TFA in the present instances). Taken in concert, ${ }^{1} \mathrm{H}$ NMR spectroscopic titration experiments and isothermal titration calorimetry (ITC) analyses provide support for the conclusion that calix[4]pyrrole $\mathbf{2 . 2}$ recognizes halide anions much more effectively than normal calix[4]pyrrole 2.1. Especially, receptor 2.2 is a good receptor for 
certain chloride salts depending on the counter cation. Likewise, compound 2.2 appears to be a considerably better ion pair receptor for cesium salts than 2.1. For instance, the $N$ tosyl pyrrolidine functionalized calix[4]pyrrole $\mathbf{2 . 2}$ is able to extract solid cesium fluoride and cesium chloride into chloroform solution well under conditions where calix[4]pyrrole 2.1 is not particularly effective. This latter increase in efficacy, as well as the enhancement in anion affinities, is ascribed at least in part to ancillary interactions between the tosyl groups present in receptor $\mathbf{2 . 2}$ and the counter-cations in question. These interactions appear particularly favorable in the case of cesium cations.

\subsection{REFERENCES}

(1) Baeyer, A. Ber. Dtsch. Chem. Ges. 1886, 19, 2184-2185.

(2) (a) Gale, P. A.; Sessler, J. L.; Král, V.; Lynch, V. J. Am. Chem. Soc. 1996, 118, 5140-5141. (b) Allen, W. E.; Gale, P. A.; Brown, C. T.; Lynch, V. M.; Sessler, J. L. J. Am. Chem. Soc. 1996, 118, 12471-12472.

(3) Gale, P. A.; Sessler, J. L.; Král, V. Chem. Commun. 1998, 1-8.

(4) (a) Sessler, J. L.; Gale, P. A.; Cho, W.-S. Anion Receptor Chemistry; Monographs in Supramolecular Chemistry, Stoddart, J. F., Ed.; RSC Publishing: Cambridge, U.K., 2006. (b) Beer, P. D.; Gale, P. A. Angew. Chem. Int. Ed. 2001, 40, 486-516. (c) Gale, P. A. Coord. Chem. Rev. 2003, 240, 191-221. (d) Gale, P. A.; Quesada, R. Coord. Chem. Rev. 2006, 250, 3219-3244. (e) Gale, P. A.; García-Garrido, S. E.; Garric, J. Chem. Soc. Rev. 2008, 37, 151-190.

(5) (a) Lee, C.-H.; Miyaji, H.; Yoon, D.-W.; Sessler, J. L. Chem. Commun. 2008, 24-34 and references therein. (b) Yoon, D.-W.; Gross, D. E.; Lynch, V. M.; Sessler, J. L.; Hay, B. P.; Lee, C.-H. Angew. Chem., Int. Ed. 2008, 47, 50385042.

(6) (a) Sessler, J. L.; Anzenbacher, P., Jr.; Shriver, J. A.; Jursíková, K.; Lynch, V. M.; Marquez. M. J. Am. Chem. Soc. 2000, 122, 12061-12062. (b) Sessler, J. L.; Cho, W.-S; Gross, D. E.; Shriver, J. A.; Lynch, V. M.; Marquez, M. J. Org. Chem. 2005, 70, 5982-5986. (c) Nielsen, K. A.; Jeppesen, J. O.; Levillain, E.; Becher, J. Angew. Chem., Int. Ed. 2003, 42, 187-191. (d) Nielsen, K. A.; Cho, 
W.-S; Lyskawa, J.; Levillain, E.; Lynch, V. M.; Sessler, J. L.; Jeppesen, J. O. J. Am. Chem. Soc. 2006, 128, 2444-2451.

(7) (a) Miyaji, H.; Anzenbacher, P., Jr.; Sessler, J. L.; Bleasdale, E. R.; Gale, P. A. Chem. Commun. 1999, 1723-1724. (b) Anzenbacher, P., Jr.; Jursíková, K.; Sessler, J. L. J. Am. Chem. Soc. 2000, 122, 9350-9351. (c) Miyaji, H.; Sato, W.; Sessler, J. L. Angew. Chem., Int. Ed. 2000, 39, 1777- 1780. (d) Miyaji, H.; Sato, W.; Sessler, J. L.; Lynch, V. M. Tetrahedron Lett. 2000, 41, 1369-1373. (e) Miyaji, H.; Sato, W.; An, D.; Sessler, J. L. Collect. Czech. Chem. Commun. 2004, 69, 1027-1049. (f) Nishiyabu, R.; Anzenbacher, P., Jr. J. Am. Chem. Soc. 2005, 127, 8270-8271. (g) Nishiyabu, R.; Palacios, M. A.; Dehaen, W.; Anzenbacher, P., Jr. J. Am. Chem. Soc. 2006, 128, 11496-11504. (h) Palacios, M. A.; Nishiyabu, R.; Marquez, M.; Anzenbacher, P., Jr. J. Am. Chem. Soc. 2007, 129, 7538-7544.

(8) (a) Anzenbacher, P., Jr.; Jursíková, K.; Lynch, V. M.; Sessler, J. L. J. Am. Chem. Soc. 1999, 121, 11020-11021. (b) Bonomo, L.; Solari, E.; Toraman, G.; Scopelliti, R.; Floriani, C.; Latronico, M. Chem. Commum. 1999, 2413-2414. (c) Gil-Ramírez, G.; Benet-Buchholz, J.; Escudero-Adán, E. C.; Ballester, P. J. Am. Chem. Soc. 2007, 129, 3820-3821. (d) Gil-Ramírez, G.; Escudero-Adán, E. C.; Benet-Buchholz, J.; Ballester, P. Angew. Chem., Int. Ed. 2008, 47, 4114- 4118. (e) Verdejo, B.; Gil-Ramírez, G.; Ballester, P. J. Am. Chem. Soc. 2009, 131, 3178-3179. (f) Ballester, P.; Gil-Ramírez, G. Proc. Natl. Acad. Sci. 2009, 106, 10455-10459. (g) Chas, M.; Gil-Ramírez, G.; Escudero-Adán, E. C.; Ballester, P. Org. Lett. 2010, 12, 1740-1743. (h) Gil-Ramírez, G.; Chas, M.; Ballester, P. J. Am. Chem. Soc. 2010, 132, 2520-2521.

(9) Gale, P. A.; Sessler, J. L.; Allen, W. E.; Tvermoes, N. A.; Lynch, V. Chem. Commun. 1997, 665-666.

(10) Sessler, J. L.; Roznyatovskiy, V. V.; Lynch, V. M. J. Porph. Phthalocy. 2009, $13,322-355$.

(11) (a) Smith, B. D. In Ion-pair Recognition by Ditopic Receptors, Macrocyclic Chemistry: Current Trends and Future Perspectives; Gloe, K.; Antonioli, B.,Eds.; Kluwer, London, U.K., 2005; pp 137-152. (b) Kirkovits, G. J.; Shriver, J. A.; Gale, P. A.; Sessler, J. L. J. Incl. Phenom. Macrocycl. Chem. 2001, 41, 6975. (c) Kim, S. K.; Sessler, J. L. Chem. Soc. Rev. 2010, 39, 3784-3809 and references therein.

(12) Custelcean, R.; Delmau, L. H.; Moyer, B. A.; Sessler, J. L.; Cho, W.-S.; Gross, D.; Bates, G. W.; Brooks, S. J.; Light, M. E.; Gale, P. A. Angew. Chem. Int. Ed. 2005, 44, 2537-2542. 
(13) Bush, L. C.; Heath, R. B.; Feng, X. U.; Wang, P. A.; Maksimovic, L.; Song, A. I.; Chung, W.-S.; Berinstain, A. B.; Scaiano, J. C.; Berson, J. A. J. Am. Chem. Soc. 1997, 119, 1406-1415.

(14) Sato, W.; Miyaji, H.; Sessler, J. L. Tetrahedron Lett. 2000, 41, 6731-6736.

(15) Sessler, J. L.; Gross, D. E.; Cho, W.-S.; Lynch, V. M.; Schmidtchen, F. P.; Bates, G. W.; Light, M. E.; Gale, P. A. J. Am. Chem. Soc. 2006, 128, 1228112288. 


\section{Chapter 3: Crown-6-Calix[4]arene Capped Calix[4]pyrrole: An Ion Pair Receptor for Solvent Separated CsF Ions}

\subsection{INTRODUCTION}

Over the past several decades, a large number of macrocyclic compounds have been synthesized and studied as potential cation receptors. ${ }^{1}$ Moreover, as the importance of anions in biology, the environment, and medicine has become increasingly well recognized, attention has focused on the design and construction of anion receptors. ${ }^{2}$ However, in spite of their potential utility in such areas as salt solublization, ion extraction, and through-membrane transport, relatively little effort has been devoted to the synthesis and study of so-called ion pair receptors, species that are able to complex concurrently and with specificity both an anion and a cation. ${ }^{3-6}$ While a number of host systems are known that contain both an anion and cation binding site, enhanced binding of an ion pair, where binding of the cation enhances binding of the anion or vice versa, is generally seen only in systems wherein the two ion binding sites are held in close

proximity. $^{7}$ This has the consequence that in most cases it is so-called contact ion pairs, rather than solvent or spatially separated ion pairs, that are bound thereby avoiding the presumably unfavorable separation of two oppositely charged ions. ${ }^{5,6,8}$ In fact, we are aware of only two closely related examples of structurally characterized spatially separated ion pair complexes. ${ }^{\text {a-c }}$ However, in neither case was strong ion pair binding observed in solution. ${ }^{9}$ Therefore, it was deemed worthwhile to explore whether it would be possible to produce a receptor that could bind a specific cation-anion pair with high affinity and in the form of a solvent separated ion pair. Here, a prime goal was to find a system that could be used to stabilize ion pairs involving the cesium cation, because of its

importance in solvent separations targeted for use in radioactive waste purification. ${ }^{10}$ With such considerations in mind, the candidate set out to prepare the calix[4]arene 
crown-6 "capped" calix[4]pyrrole 3.1. In this chapter, it is shown that this psudodimer 1) forms a solvent separated ion pair complex with $\mathrm{CsF}$ in the solid state and 2) binds its constituent ions $\left(\mathrm{Cs}^{+}\right.$and $\left.\mathrm{F}^{-}\right)$in a highly cooperative fashion in organic solvents (e.g., 9:1 $\left.\mathrm{CDCl}_{3} / \mathrm{CD}_{3} \mathrm{OD}\right)$.

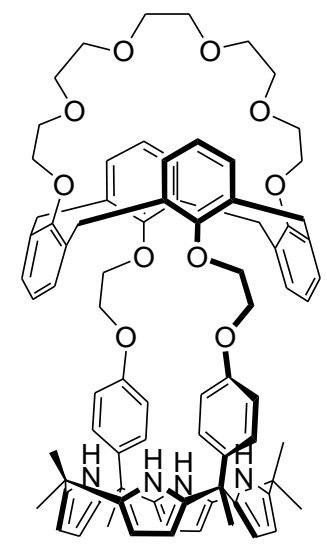

3.1

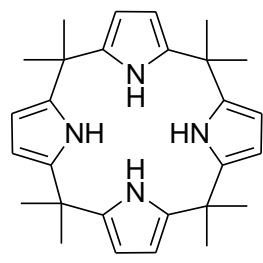

3.2

Figure 3.1 Structures of receptors 3.1 and 3.2.

The ion pair receptor $\mathbf{3 . 1}$ was designed to bring together both an anion binding core and a cation-recognizing subunit in such a way that a large separation between the constituent ions of a bound ion pair would be enforced. Calix[4]pyrrole (3.2) ${ }^{11}$ and calix[4]arene crown- $6^{12}$ were chosen as the anion and cation binding species, respectively. Previous work had served to establish that these receptor systems, when studied individually, could be used to effect the binding of fluoride anion and cesium cation, at least in organic media. Accordingly, CsF was selected as the target salt for possible ion pair complexation. 


\subsection{RESULTS AND DiSCUSSION}

The synthesis of receptor $\mathbf{3 . 1}$ is shown in Scheme 3.1. First, the calix[4]arene crown-6 ditosylate $3^{13}$ was reacted with 4 '-hydroxyacetophenone in acetonitrile in the presence of excess $\mathrm{K}_{2} \mathrm{CO}_{3}$ at reflux; this afforded diketone 3.4 in quantitative yield. Subsequent condensation of the latter species with pyrrole in the presence of excess trifluoroacetic acid at $65{ }^{\circ} \mathrm{C}$ then gave the dipyrromethane 3.5 in $46 \%$ yield. This key precursor was then condensed with acetone in the presence of a catalytic amount of $\mathrm{BF}_{3} \cdot \mathrm{OEt}_{2}$ to give $\mathbf{3 . 1}$ in $18 \%$ yield. ${ }^{14}$

Scheme 3.1 Synthesis of compound 3.1
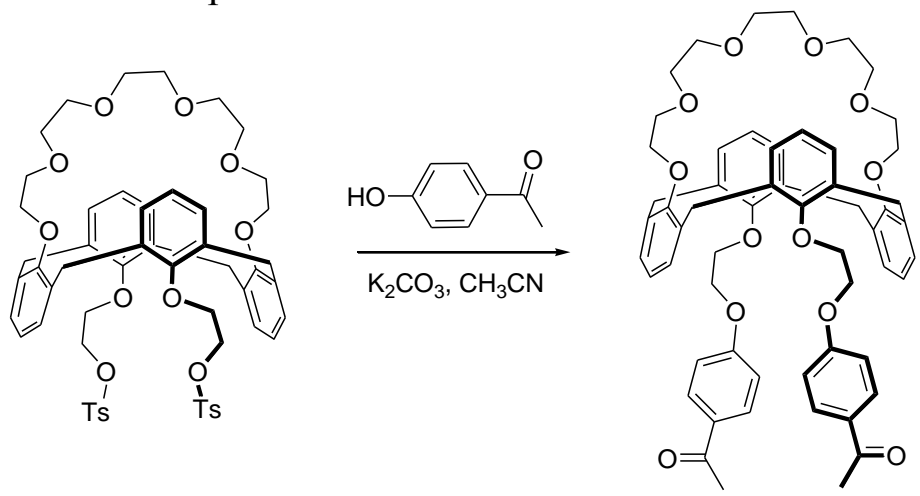

3.3
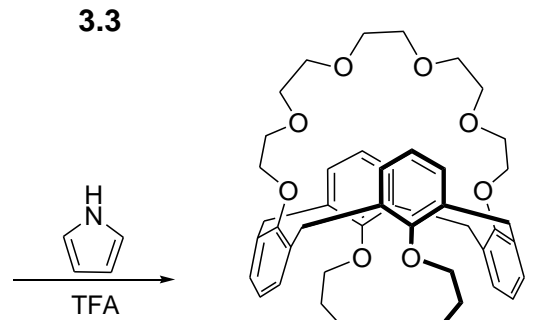

3.4

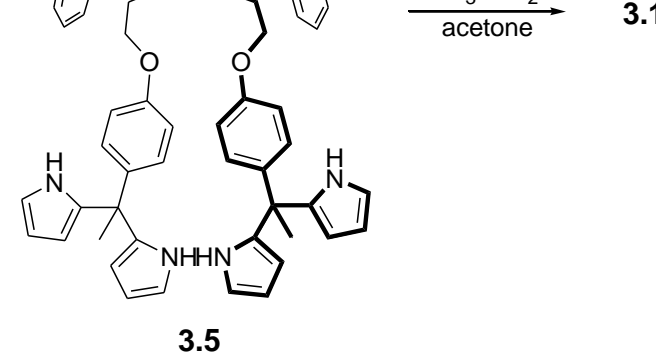


Initial evidence that $\mathbf{3 . 1}$ can act as a receptor for $\mathrm{CsF}$ in the form of a solvent separated ion pair came from single crystal X-ray diffraction analysis. Suitable crystals were obtained by allowing a chloroform/methanol solution of receptor 3.1 to undergo slow evaporation in the presence of excess cesium fluoride. The resulting structure revealed that $\mathbf{3 . 1}$ forms a 1:1 complex with cesium fluoride, 3.1 $\mathrm{CsF}$ (cf. Figure 3.2). The $\mathrm{Cs}^{+}$ion in 3.1. $\mathrm{CsF}$ is included in the calix[4] arene crown ether ring with the $\mathrm{Cs}^{+} \cdots \mathrm{O}$ distances of $3.08-3.36 \AA$, while a distance of $3.43-3.63 \AA$ characterizes the presumed $\pi$ - cation interactions involving the $\mathrm{Cs}^{+}$ion and the aromatic carbon atoms at the metaand para-position to the phenoxy groups. On the other hand, the bound $\mathrm{F}^{-}$anion is hydrogen-bound to the NH's of the calix[4]pyrrole subunit (the $\mathrm{N}^{\cdots} \mathrm{F}^{-}$distances are in the range of $2.74-2.78 \AA$ ) and is also hydrogen-bound to a molecule of methanol. The presence of this bound methanol molecule serves to ensure that there is no direct interaction between the co-bound, spatially-separated $\mathrm{Cs}^{+}$and $\mathrm{F}^{-}$ions in the solid state complex 3.1. CsF. This absence of interaction is likely reinforced by the large gap between the calix[4]pyrrole anion binding subunit and the crown-strapped calix[4]arene cation recognition site. In fact, the separation between the $\mathrm{Cs}^{+}$and the $\mathrm{F}^{-}$ions seen in the solid state structure of 3.1. $\mathrm{CsF}, 10.92 \AA$, is much longer than the $\mathrm{Cs}^{+} \cdots \mathrm{F}^{-}$distances seen in the solid state structure of the CsF complex of meso-octamethylcalix[4]pyrrole 3.2. ${ }^{15,16}$ This latter species, although capable of functioning as an ion pair receptor under certain biphasic extraction conditions, ${ }^{10 a}$ contains no independent cation recognition site. On the basis of these findings, we suggest that, at least in the solid state, the formation of a strong complex, 3.1. CsF, with individual, solvent-separated ions, is energetically favorable relative to other possible scenarios such as complexation of a contact ion pair. 


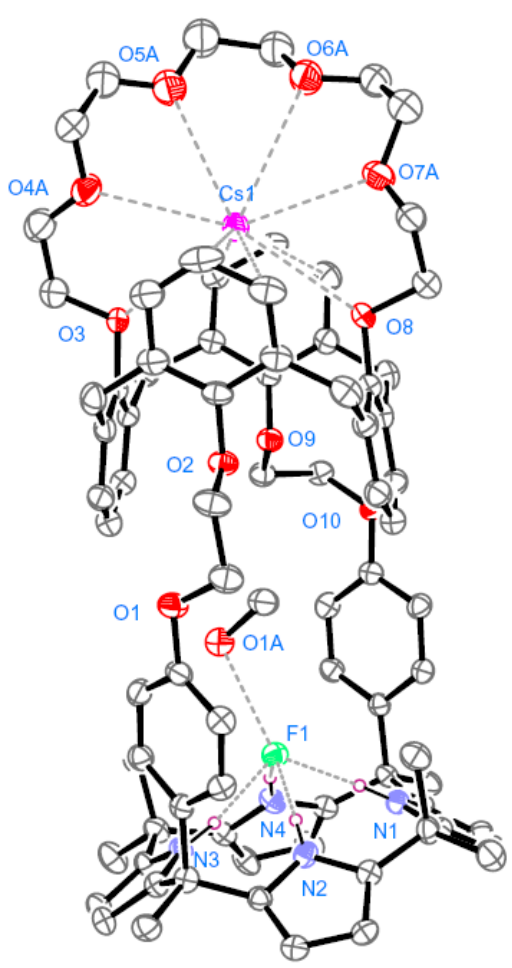

Figure 3.2 View of the 3.1. $\mathrm{CsF}$ complex showing a partial atom labeling scheme. Displacement ellipsoids are scaled to the $30 \%$ probability level. Most hydrogen atoms have been removed for clarity. Atoms in the ether linkage are disordered, with the higher occupancy atoms being shown.

The ability of $\mathbf{3 . 1}$ to bind halide anion salts in solution was probed via ${ }^{1} \mathrm{H}$ NMR spectroscopy using initially $\mathrm{CDCl}_{3}$ as the solvent. In contrast to what was seen in the case of other calix[4]pyrrole derivatives, including the various other strapped calix[4]pyrroles prepared to date, in this solvent system only the addition of soluble fluoride anion salts (e.g., tetrabutylammonium fluoride, TBAF) served to engender spectroscopic changes consistent with anion binding (i.e., no other TBA halide anion salts had an effect on the ${ }^{1} \mathrm{H}$ NMR spectrum). This apparent selectivity is thought to reflect a combination of a less 
accessible anion binding site and a more rigid calix[4]pyrrole core enforced by the rather inflexible phenoxy spacers (Figures 3.3-3.5).
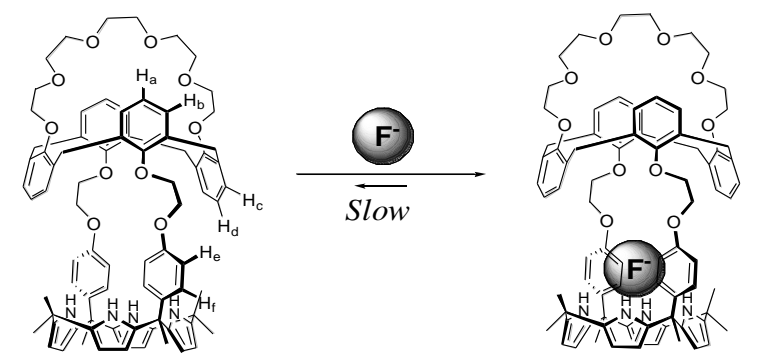

(a) 3.1 only

(b) 0.4 equiv

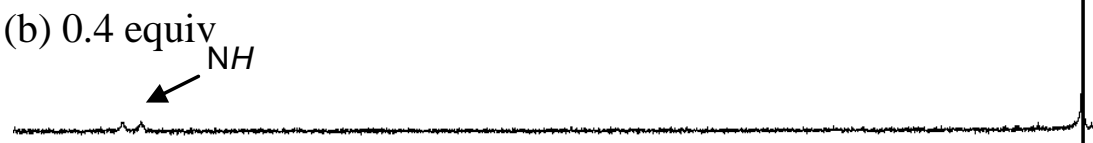

(c) 0.8 equiv

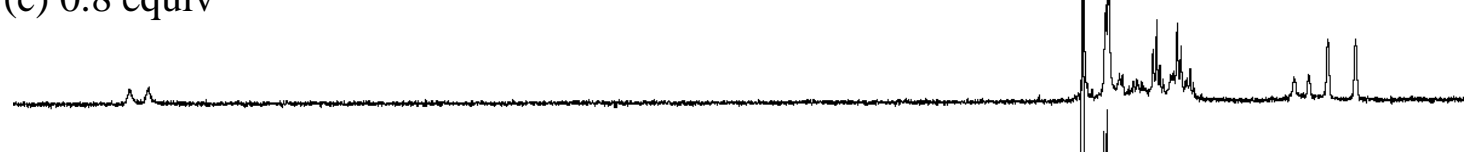

(d) 1.2 equiv

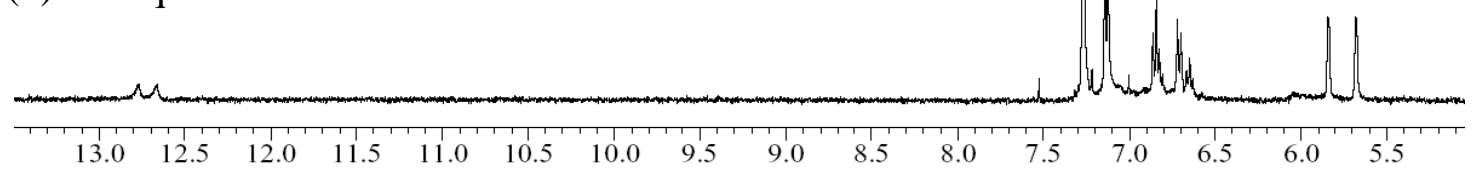

Figure 3.3 Partial ${ }^{1} \mathrm{H}$ NMR spectra for titration of receptor 3.1 with TBAF (tetrabutylammonium fluoride) in $\mathrm{CDCl}_{3}$. 


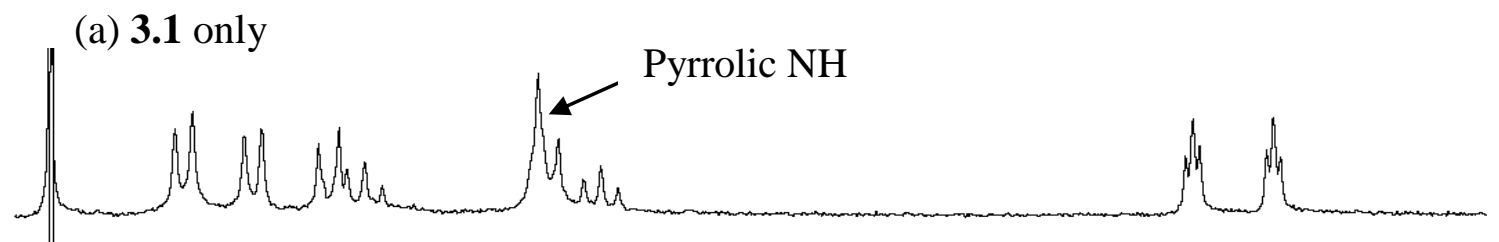

(b) 5.0 equiv. of $\mathrm{TBACl}$

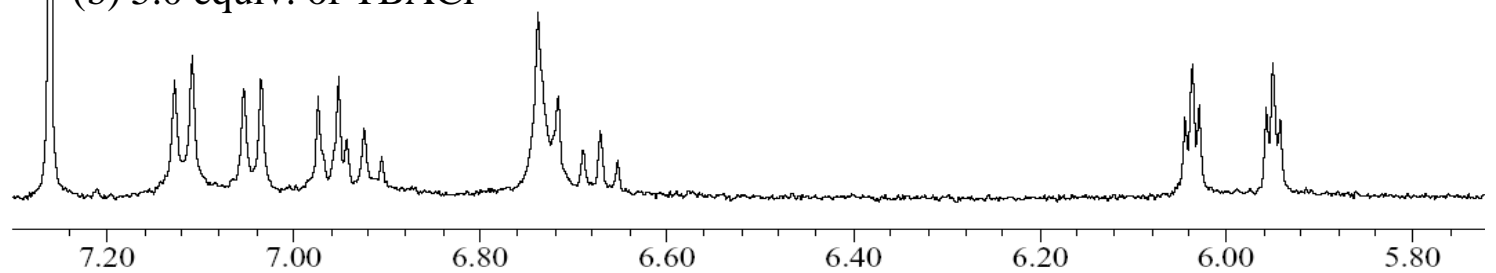

Figure 3.4 Partial ${ }^{1} \mathrm{H}$ NMR spectra of (a) free 3.1 and (b) $3.1+5$ equiv. of TBACl. (tetrabutylammonium chloride) in $\mathrm{CDCl}_{3}$.

(a) $3.1+$ TBAF

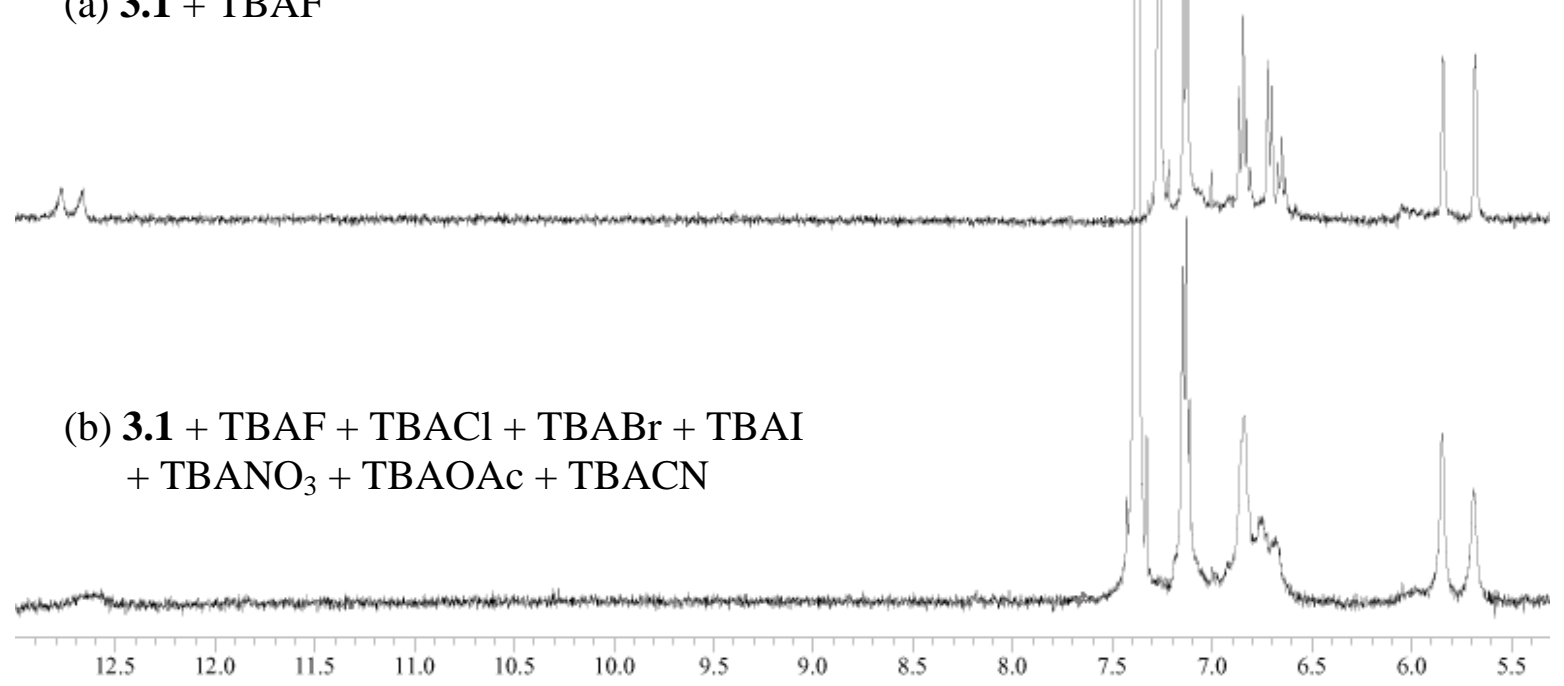

Figure 3.5 Partial ${ }^{1} \mathrm{H}$ NMR spectra of (a) 3.1 + TBAF (1.2 equiv.) and (b) $\mathbf{3 . 1}+$ various anions (5 equiv) in $\mathrm{CDCl}_{3}$. $*$ denotes peaks ascribed to the NMR solvent. Both spectra (a) and (b) were referenced to TMS.

The changes observed in the ${ }^{1} \mathrm{H}$ NMR spectrum when 3.1 is subject to titration with $\mathrm{TBAF}$ in $\mathrm{CDCl}_{3}$ are shown in Figure 3.3. The anion-free form of $\mathbf{3 . 1}$ displays a 
broad singlet at $\delta=6.74 \mathrm{ppm}$ for the NH's and two triplets at $\delta=6.04 \mathrm{ppm}$ and $\delta=5.95$ ppm, respectively, for the $\beta$-pyrrolic protons. Addition of 0.4 and 0.8 equivalents of TBAF gives rise to two sets of distinguishable resonances for all proton signals. These peaks are ascribed to the anion-free and fluoride bound forms of $\mathbf{3 . 1}$ and are consistent with the anion binding/decomplexation equilibrium being slow on the ${ }^{1} \mathrm{H}$ NMR time scale. Such slow exchange kinetics are consistent with strong anion binding, a conclusion further supported by the observation of significant changes in the $\beta$-pyrrolic and, especially, the pyrrolic $\mathrm{NH}$ proton signals. The singlet associated with the $\mathrm{NH}$ proton resonance seen in free 3.1 is shifted to lower field by roughly $6 \mathrm{ppm}$ (final $\delta \approx 12.7 \mathrm{ppm}$ ) upon the addition of fluoride anion. The signal also becomes split into a doublet $(J=44.0$ $\mathrm{Hz}$ ), a finding that is ascribable to coupling between the bound fluoride anion and the $\mathrm{NH}$ protons. $^{17}$

Very different behavior is seen when analogous ${ }^{1} \mathrm{H}$ NMR spectroscopic analyses are carried out in $10 \%(\mathrm{v} / \mathrm{v}) \mathrm{CD}_{3} \mathrm{OD}$ in $\mathrm{CDCl}_{3}$. Under these conditions, no evidence of fluoride anion binding is seen when $\mathbf{3 . 1}$ is treated with 5 equiv. of TBAF (cf. Figure 2). ${ }^{18}$ This lack of appreciable interaction is attributed to the stronger solvation of the fluoride ions by this more polar medium (Figure 3.6b). 


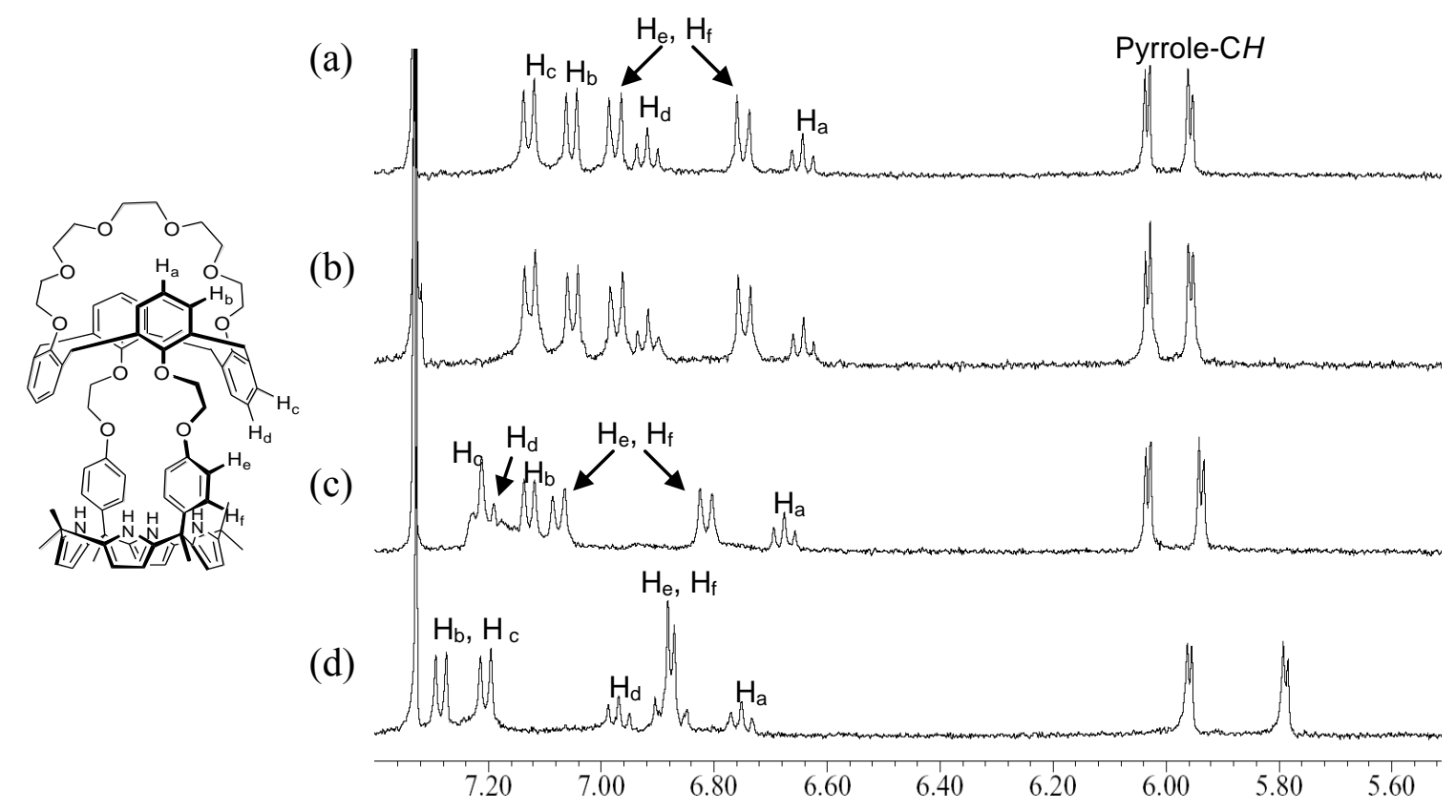

Figure 3.6 Partial ${ }^{1} \mathrm{H}$ NMR spectra of (a) 3.1 only, (b) $3.1+5$ equiv. of TBAF, (c) $3.1+$ 5 equiv. of $\mathrm{CsClO}_{4}$, and (d) $3.1+5$ equiv. of $\mathrm{CsF}$ in $\mathrm{CD}_{3} \mathrm{OD} / \mathrm{CDCl}_{3}(1 / 9$, $\mathrm{v} / \mathrm{v})$.

In contrast to what is seen with TBAF, the addition of 5 equiv. of cesium perchlorate induces remarkable changes in the signals for both the aromatic protons of the calix[4]arene core and in the aliphatic protons of the crown-6 ring. Particularly noteworthy is the considerable downfield shift of the $H_{d}$ proton on the inverted phenoxy group, as would be expected if the oxygen atom of this moiety were involved in cesium cation complexation (Figure 3.6c). This stands in contrast to the $\beta$-pyrrolic and the mesoaromatic proton signals associated with the calix[4]pyrrole subunit; here, little appreciable change is seen. Taken together, these findings are consistent with the expectation that the addition of $\mathrm{CsClO}_{4}$ leads to the formation of a cation-bound complex, 
wherein the cesium cation is encapsulated in the calix[4]arene crown- 6 ring and the perchlorate anion is either not bound strongly or bound at all by the calix[4]pyrrole core (cf. Figures 3.6c and 3.7).

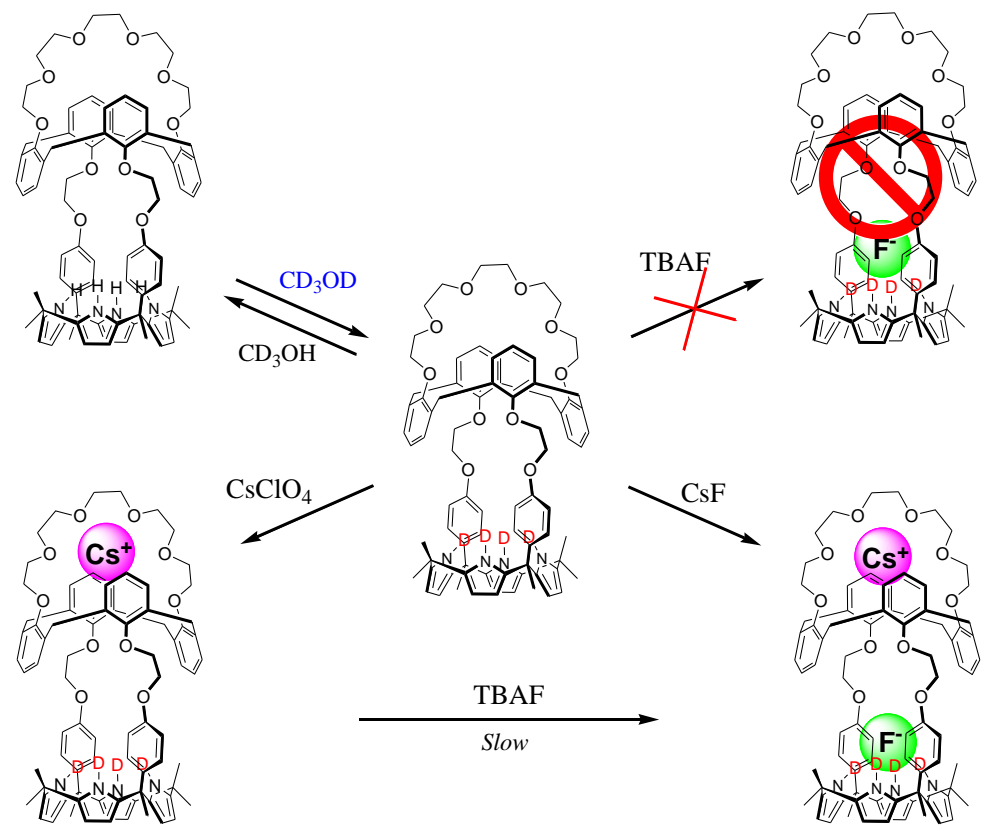

Figure 3.7 Proposed binding interactions involving 3.1 and various $\mathrm{Cs}^{+}$and $\mathrm{F}^{-}$salts in $\mathrm{CD}_{3} \mathrm{OD} / \mathrm{CDCl}_{3}(1 / 9, \mathrm{v} / \mathrm{v})$.

In analogy to what is seen with $\mathrm{CsClO}_{4}$, the addition of 5 equiv. of $\mathrm{CsF}$ to receptor 3.1 in $10 \% \mathrm{CD}_{3} \mathrm{OD}$ in $\mathrm{CDCl}_{3}$ leads to downfield shifts in the proton signals of both the calix[4]arene and the crown-6 ring (see Figure 3.6d); this is as would be expected if the $\mathrm{Cs}^{+}$cation were also being bound well in this case. ${ }^{12}$ However, in contrast to what was seen with TBAF, the use of CsF leads to significant upfield changes in the signals of both the $\beta$-pyrrolic protons and the meso-aromatic protons of the calix[4]pyrrole moiety (cf. Figures 3.6d and 3.7). Such observations are fully consistent 
with the fluoride anion being bound to the calix[4]pyrrole cavity of receptor 3.1 thus binding both $\mathrm{Cs}^{+}$and $\mathrm{F}^{-}$ions as an ion pair complex, 3.1 $\mathrm{CsF}$ analogous to what is seen in the solid sate. It is thus concluded that the binding of the cesium cation to the crown ether ring plays a very critical role in inducing fluoride anion binding to the calix[4]pyrrole portion of receptor 3.1, anion binding that is otherwise not observed in the absence of $\mathrm{Cs}^{+}$in this solvent system. No other cations tested, specifically $\mathrm{Li}^{+}, \mathrm{Na}^{+}$and $\mathrm{K}^{+}$, were found to give rise to such an effect.

Further support for the above conclusion came from the finding that addition of TBAF to a preformed cesium complex (i.e., 3.1 $\cdot \mathrm{Cs}^{+}$, formed by Eq. 3.1) gives rise to the formation of a co-bound $\mathrm{CsF}$ complex analogous to that produced from $\mathrm{CsF}$ alone, albeit at a rate that is slow on the NMR time scale (cf. Figure 3.8); presumably, this reflects the slow kinetics associated with counter anion exchange (cf. Eq 3.2). In the event, it is noteworthy that a diffraction grade single crystal grown in the presence of both cesium perchlorate $\left(\mathrm{CsClO}_{4}\right)$ and tetrabutylammonium fluoride (TBAF) gave rise to the exactly same structure as a datum crystal grown in the presence of CsF only (structure shown in Figure 3.2).

$$
\begin{aligned}
\mathrm{CsClO}_{4}+3.1 & \rightarrow[3.1 \cdot \mathrm{Cs}] \mathrm{ClO}_{4} \\
{[3.1 \cdot \mathrm{Cs}] \mathrm{ClO}_{4}+\mathrm{TBAF} } & \rightarrow[3.1) \mathrm{CsF}]+\mathrm{TBAClO}_{4}
\end{aligned}
$$



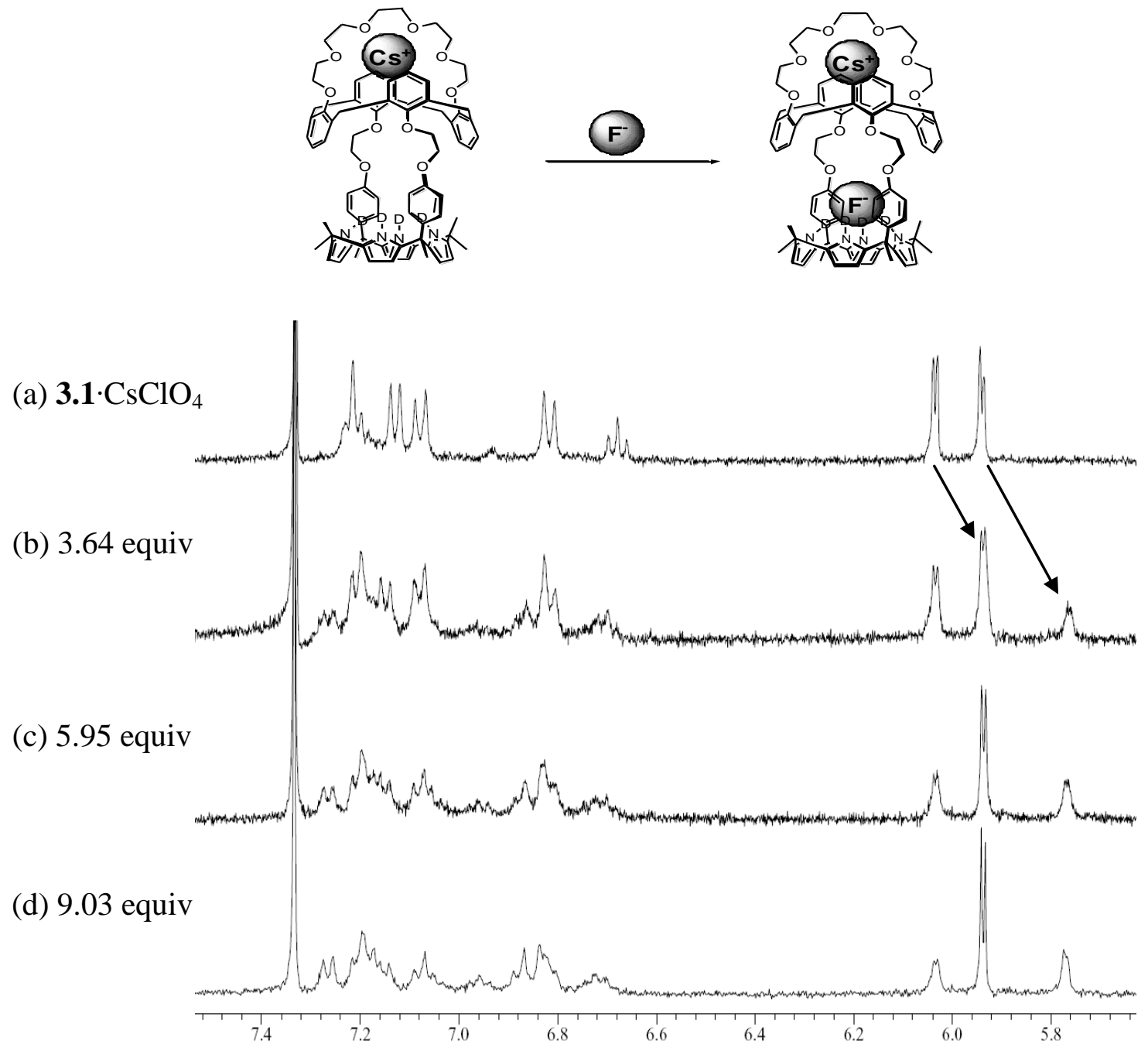

Figure 3.8 Partial ${ }^{1} \mathrm{H}$ NMR spectra for titration of $3.1 \cdot \mathrm{CsClO}_{4}$ with $\mathrm{TBAF}$ in $\mathrm{CD}_{3} \mathrm{OD} / \mathrm{CDCl}_{3}(1 / 9, \mathrm{v} / \mathrm{v})$. Complex $3.1 \cdot \mathrm{CsClO}_{4}$ was prepared in situ by mixing 2 equiv of $\mathrm{CsClO}_{4}$ in $\mathrm{CD}_{3} \mathrm{OD}$ with a solution of $\mathbf{3 . 1}$ in $\mathrm{CDCl}_{3}$.

On the other hand, we also measured the ${ }^{1} \mathrm{H}$ NMR spectrum with receptor 3.1 in the presence of other cesium salts such as $\mathrm{CsCl}, \mathrm{CsBr}$, and $\mathrm{CsI}$, as well as $\mathrm{CsF}$ to see its selectivity for cesium salts. The resulting ${ }^{1} \mathrm{H}$ NMR spectrum is found to be exactly identical to that measured with $\mathrm{CsF}$ only, indicating that receptor 3.1 is highly selective for CsF over others (Figure 3.9). 


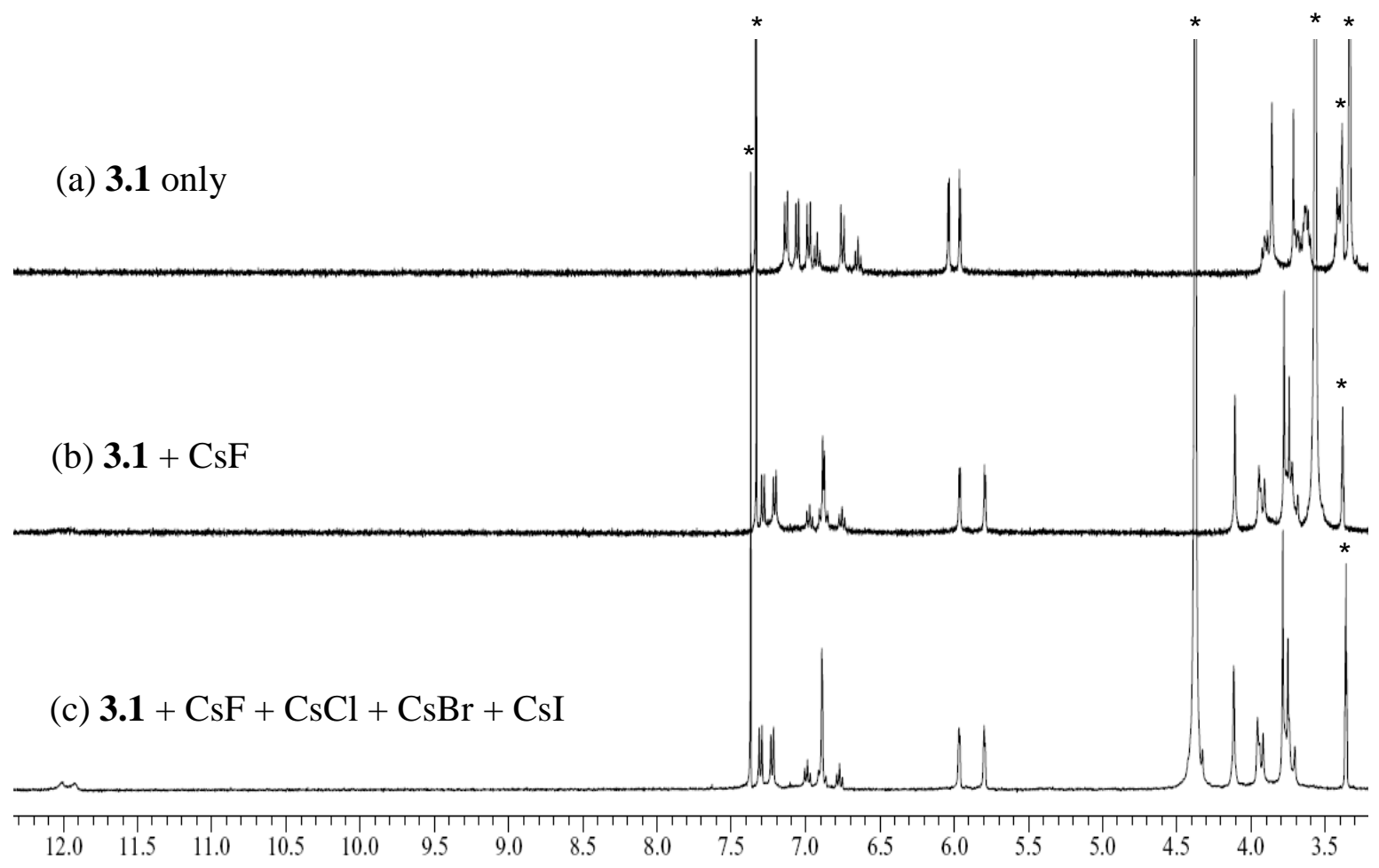

Figure 3.9 Partial ${ }^{1} \mathrm{H}$ NMR spectra of (a) 3.1 only, (b) $3.1+5$ equiv. of $\mathrm{CsF}$, and (c) 3.1 +5 equiv. of $\mathrm{CsF}, \mathrm{CsCl}, \mathrm{CsBr}$, and $\mathrm{CsI}$ in $\mathrm{CD}_{3} \mathrm{OD} / \mathrm{CDCl}_{3}(1 / 9, \mathrm{v} / \mathrm{v})$. * denotes peaks ascribed to the NMR solvents and to water. All spectra were referenced to TMS.

Isothermal titration calorimetry (ITC) was utilized to quantify the affinity of compound 3.1 for $\mathrm{Cs}^{+}$and $\mathrm{F}^{-}$in a solvent mixture analogous to that used for the latter ${ }^{1} \mathrm{H}$ NMR spectroscopic studies (i.e. $10 \% \mathrm{MeOH}$ in $\mathrm{CHCl}_{3}$ ). The resulting titration of $\mathrm{CsF}$ [0.08 mM] with $3.1[1.1 \mathrm{mM}]$ was highly enthalpic $\Delta H=-16.2 \mathrm{kcal} / \mathrm{mol}$. The data could be fit well to a 1:1 binding profile, yielding a binding energy of $\Delta G=-7.6 \mathrm{kcal} / \mathrm{mol}$ and a $K_{a}=3.8 \times 10^{5} \mathrm{M}^{-1}$, while revealing a strong opposing entropy $(T \Delta S=-8.6 \mathrm{kcal} / \mathrm{mol})$ (Table 3.1). However, upon increasing the concentration of both 3.1 and CsF, a second event in the early stages of the titration becomes prevalent. While further study is in 
order, it is possible that this latter finding reflects changes in overall solvation that are not accounted for in simple receptor-free control experiments.

Table 3.1 ITC titration data of 3.1, 3.1 $\cdot \mathrm{F}^{-}$, and $\mathbf{3 . 1} \cdot \mathrm{Cs}^{+}$measured at $298 \mathrm{~K}{ }^{a}$

\begin{tabular}{ccccccc}
\hline Host & Solvent & Guest & $\begin{array}{c}\Delta H \\
(\mathrm{kcal} / \mathrm{mol})\end{array}$ & $\begin{array}{c}T \Delta S \\
(\mathrm{kcal} / \mathrm{mol})\end{array}$ & $\begin{array}{c}\Delta G \\
(\mathrm{kcal} / \mathrm{mol})\end{array}$ & $\begin{array}{c}K_{a} \\
\left(\mathrm{M}^{-1}\right)\end{array}$ \\
\hline $\mathbf{3 . 1}$ & $\mathrm{CH}_{3} \mathrm{CN}$ & $\mathrm{CsTPB}^{b}$ & -6.7 & 1.3 & -8.1 & $8.0 \times 10^{5}$ \\
$\mathbf{3 . 1} \cdot \mathrm{F}^{-}$ & $\mathrm{CH}_{3} \mathrm{CN}$ & $\mathrm{CsTPB}^{b}$ & -6.0 & 2.3 & -8.3 & $1.2 \times 10^{6}$ \\
$\mathbf{3 . 1}$ & $\mathrm{CH}_{3} \mathrm{CN}$ & $\mathrm{TBAF}^{c}$ & -6.2 & 0.8 & -7.0 & $1.3 \times 10^{5}$ \\
$\mathbf{3 . 1} \cdot \mathrm{Cs}^{+}$ & $\mathrm{CH}_{3} \mathrm{CN}$ & $\mathrm{TBAF}^{c}$ & -7.2 & -0.4 & -6.8 & $1.1 \times 10^{5}$ \\
& $\mathrm{CH}_{3} \mathrm{OH} / \mathrm{CHCl}$ & & & & & \\
$\mathbf{3 . 1}$ & $(1 / 9, \mathrm{VsF} / \mathrm{v})$ & & -16.2 & -8.6 & -7.6 & $3.4 \times 10^{5}$ \\
\hline
\end{tabular}

${ }^{a}$ Errors estimated to be less than $15 \% .{ }^{b} \mathrm{CsTPB}=$ cesium tetraphenylborate. ${ }^{c}$ TBAF $=$ tetrabutylammonium fluoride.

Efforts to analyze the individual ion binding events were also made using ITC. In this case, titrations using TBAF and cesium tetraphenylborate (CsTPB) were carried out, albeit in acetonitrile due to solubility considerations. ${ }^{19}$ First CsTPB was titrated into 3.1; this resulted in a $K_{\mathrm{a}}$ value of $8.0 \times 10^{5} \mathrm{M}^{-1}$. Next, CsTPB was titrated into a 3:1 mixture of TBAF:3.1; this gave rise to first a set of exothermic signals, followed by a series of endothermic traces towards the end of the titration. Fitting to a 1:1 profile proved clean and gave rise to a $K_{\mathrm{a}}$ value of $1.2 \times 10^{6} \mathrm{M}^{-1}$, a small increase in the affinity as compared to what was observed in the absence of fluoride. 
In a separate experiment, the interaction of TBAF with 3.1 was studied; this yielded a $K_{\mathrm{a}}$ of $1.3 \times 10^{5} \mathrm{M}^{-1}$. TBAF was then titrated into a 2:1 mixture of CsTPB:3.1, and the resulting isotherm again showed an initial exothermic interaction, followed by endothermic signals towards the end of the titration. However, as above, this data could be fit well to a 1:1 binding isotherm, yielding a $K_{\mathrm{a}}$ value of $1.1 \times 10^{6} \mathrm{M}^{-1}$. Thus, in acetonitrile it appears that the binding of the individual ions is virtually independent of one another and that the affinity of $\mathbf{3 . 1}$ for cesium is about an order of magnitude greater than for fluoride. Such behavior stands in marked contrast to what is seen in 9:1 $\mathrm{CDCl}_{3} / \mathrm{CD}_{3} \mathrm{OD}$ (vide supra) and leads to the conclusion that the binding behavior of $\mathbf{3 . 1}$,

like that of simple calix[4]pyrrole $\mathbf{3 . 1},{ }^{11 \mathrm{a}, 11 \mathrm{e}}$ is subject to a strong solvent dependence. This is perhaps not surprising given the interplay of the relatively complicated and contradictory effects involved (e.g., receptor, salt, and individual ion solvation, ionpairing, receptor-cation, receptor-anion, and receptor-ion pair interactions). However, the key point is that in all solvents tested to date, including acetonitrile, concurrent binding of both an anion $\left(\mathrm{F}^{-}\right)$and a cation $\left(\mathrm{Cs}^{+}\right)$can be effected using receptor 3.1.

\subsection{CONCLUSIONS}

An ion pair receptor 3.1 containing both cation- and anion-recognition sites has been synthesized. The X-ray crystal structure and the ${ }^{1} \mathrm{H}$ NMR spectroscopic analysis provide support for the conclusion that $\mathbf{3 . 1}$ forms a stable 1:1 complex with CsF in spite of the large separation enforced between the anion and the cation. In more competitive media, such as $10 \%$ methanol in chloroform, little evidence of fluoride anion binding is observed in the absence of a co-bound cesium cation, on the basis of which it is suggested that binding of this cation to the crown ether strapped calix[4]arene makes possible complexation of a fluoride anion within the calix[4]pyrrole core of $\mathbf{3 . 1}$. 


\subsection{REFERECES}

(1) Comprehensive Supramolecular Chemistry, Lehn, J. -M., Chair Ed.; Atwood, J. L., Davies, J. E. D., MacNicol, D. D., Vögtle, F., Eds.; Pergamon: Oxford, 1996; Vol. 1. (b) Lehn, J.-M. Supramolecular Chemistry: Concepts and Perspectives; VCH: Weinheim, 1995.

(2) (a) Beer, P. D.; Gale, P. A. Angew. Chem., Int. Ed. 2001, 40, 486-516. (b) Sessler, J. L.; Gale, P. A.; Cho, W.-S. Anion Receptor Chemistry (Monographs in Supramolecular Chemistry; Stoddart, J. F., Ed.); The Royal Society of Chemistry: Cambridge, 2006.

(3) Smith, B. D. In Ion Pair Recognition by Ditopic Receptors, Macrocyclic Chemistry: Current Trends and Future Perspectives; Gloe, K., Antonioli, B., Eds.; Kluwer: London, 2005; pp 137-152.

(4) (a) Pfeifer, J. R.; Rei $\beta$, P.; Koert, U. Angew. Chem., Int. Ed. 2006, 45, 501-504. (b) Sisson, A. L.; Shah, M. R.; Bhosale, S.; Matile, S. Chem. Soc. Rev. 2006, 35, 1269-1286. (c) Nakamura, T.; Akutagawa, T.; Honda, K.; Underhill, A. E.; Coomber, A. T.; Friend, R. H. Nature 1998, 394, 159-162. (d) Gokel, G. W.; Leevy, W. M.; Weber, M. E. Chem. Rev. 2004, 104, 2723-2750. (e) Davis, A. P.; Sheppard, D. N.; Smith, B. D. Chem. Soc. Rev. 2007, 36, 348-357.

(5) (a) Chrisstoffels, L. A. J.; De Jong, F.; Reinhoudt, D. N.; Sivelli, S.; Gazzola, L.; Casnati, A.; Ungaro, R. J. Am. Chem. Soc. 1999, 121, 10142-10151. (b) Rudkevich, D. M.; Mercer-Chalmers, J. D.; Verboom, W.; Ungaro, R.; Reinhoudt, D. N. J. Am. Chem. Soc. 1999, 117, 6124-6125. (c) Schreeder, J.; van Duynhoven, J. P. M.; Engbersen, J. F. J.; Reinhoudt, D. N. Angew. Chem. Int. Ed. Engl. 1996, $35,1090-1093$.

(6) (a) Mahoney, J. M.; Stucker, K. A.; Jiang, H.; Carmichael, I.; Brinkmann, N. R.; Beatty, A. M.; Noll, B. C.; Smith, B. D. J. Am. Chem. Soc. 2005, 127, 2922-2928.

(b) Deetz, M. J.; Shang, M.; Smith, B. D. J. Am. Chem. Soc. 2000, 122, 62016207. (c) Mahoney, J. M.; Beatty, A. M.; Smith, B. D. Inorg. Chem. 2004, 43, 7617-7621. (d) Mahoney, J. M.; Davis, J. P.; Smith, B. D. J. Org. Chem. 2003, 68, 9819-6820. (e) Mahoney, J. M.; Beatty, A. M.; Smith, B. D. J. Am. Chem. Soc. 2001, 123, 5847-5858. (f) Mahoney, J. M.; Nawaratna, G. U.; Beatty, A. M.; Duggan, P. J.; Smith, B. D. Inorg. Chem. 2004, 43, 5902-5907.

(7) While a number of systems were prepared early on that contained both anion and cation binding subunits constrained at remote sites within the same molecular framework, few of these displayed cooperative anion plus cation binding in solution or coupled anion and cation complexation in the solid state. They are thus not considered as bona fide ion pair receptors. For reviews of these systems, see: (a) Kirkovits, G. J.; Shriver, J. A.; Gale, P. A.; Sessler, J. L. J. Incl. Phenom. 
Macrocycl. Chem. 2001, 41, 69-75. (b) Gale, P. A. Coord. Chem. Rev. 2003, 240, 191-221.

(8) Marcus, Y.; Hefter, G. Chem. Rev. 2006, 106, 4585-4621.

(9) Binding constants for the complexation of ion pairs were not actually recorded, perhaps due to a combination of poor solubility and slow binding kinetics. However, modest increases in the anion binding affinities were observed in the presence of cations. ${ }^{6 \mathrm{a}-\mathrm{c}}$

(10) (a) Wintergerst, M. P.; Levitskaia, T. G.; Moyer, B. A.; Sessler, J. L.; Delmau, L. H. J. Am. Chem. Soc. 2008, 130, 4129-4139. (b) Levitskaia, T. G.; Bryan, J. C.; Sachleben, R. A.; Lamb, J. D.; Moyer, B. A. J. Am. Chem. Soc. 2000, 122, 554562. (c) Sachleben, R. A.; Bryan, J. C.; Engle, N. L.; Haverlock, T. J.; Hay, B. P.; Urvoas, A.; Moyer, B. A. Eur. J. Org. Chem. 2003, 4862-4869.

(11) (a) Sessler, J. L.; Gross, D. E.; Cho, W.-S.; Lynch, V. M.; Schmidtchen, F. P.; Bates, G. W.; Light, M. E.; Gale, P. A. J. Am. Chem. Soc. 2006, 128, 1228112288. (b) Gale, P. A.; Sessler, J. L.; Král, V.; Lynch, V. M. J. Am. Chem. Soc. 1996, 118, 5140-5141. (c) Gale, P. A.; Sessler, J. L.; Král, V. Chem. Commun. 1998, 1-8. (d) Lee, C.-H.; Miyaji, H.; Yoon, D.-W.; Sessler, J. L. Chem. Commun. 2008, 24-34. (e) Gross, D. E.; Schmidtchen, F. P.; Antonius, W.; Gale, P. A.; Lynch, V. M.; Sessler, J. L. Chem.-Eur. J., 2008, 14, 7822-7827.

(12) (a) Kim, S. K.; Lee, J. K.; Lee, S. H.; Lim, M. S.; Lee, S. W.; Sim, W.; Kim, J. S. J. Org. Chem. 2004, 69, 2877-2880. (b) Lee, J. K.; Kim, S. K.; Bartsch, R. A.; Vicens, J.; Miyano, S.; Kim, J. S. J. Org. Chem. 2003, 68, 6720-6725. (c) Kim, S. K.; Sim, W.; Vicens, J.; Kim, J. S. Tetrahedron Lett. 2003, 44, 805-809. (d) Kim, S. K.; Vicens, J.: Park, K. M.; Lee, S. S.; Kim, J. S. Tetrahedron Lett. 2003, 44, 993-997.

(13) (a) No, K.; Lee, H. J.; Park, K. M.; Lee, S. S.; Noh, K. H.; Kim, S. K.; Lee, J. Y.; Kim, J. S. Journal of Heterocyclic Chemistry 2004, 41, 211-219. (b) Kim, J. S.; Shon, O. J.; Ko, J. W.; Cho, M. H.; Yu, I. Y.; Vicens, J. J. Org. Chem. 2000, 65, 2386-2392.

(14) Yoon, D.-W.; Hwang, H.; Lee, C.-H. Angew. Chem., Int. Ed. 2002, 41, 1757-1759.

(15) In the CsF complex of 3.2, the $\mathrm{F}^{-}$ion is symmetrically bound to the four NH's of the calix[4]pyrrole via four hydrogen bonds at a $\mathrm{N}^{\cdots} \mathrm{F}^{-}$distance of $2.79 \AA$, whereas the $\mathrm{Cs}^{+}$is symmetrically encapsulated within the cone-like cavity of the calix[4]pyrrole via $\pi$ - cation interactions with a distance of $3.39 \AA$ between the $\mathrm{Cs}^{+}$ion and the centroids of the pyrrole rings. The $\mathrm{F}^{-}$ion interacts both with the $\mathrm{Cs}^{+}$ion within the same complex and with the one in an adjacent complex, and does so with separation distances of $3.69 \AA$ and $2.77 \AA$, respectively. 
(16) Custelcean, R.; Delmau, L. H.; Moyer, B. A.; Sessler, J. L.; Cho, W. -S.; Gross, D.; Bates, G. W.; Brooks, S. J.; Light, M. E.; Gale, P. A. Angew. Chem. Int. Ed. 2005, 44, 2537-2542.

(17) Sato, W.; Miyaji, H.; Sessler, J. L. Tetrahedron Lett. 2000, 41, 6731-6736.

(18) In this solvent system, the pyrrolic $\mathrm{NH}$ proton signal, originally seen at $\delta=6.74$ in $\mathrm{CDCl}_{3}$, either shifts to lower field as the result of interaction with the $\mathrm{CD}_{3} \mathrm{OD}$ solvent or disappears as a consequence of $\mathrm{D} / \mathrm{H}$ exchange.

(19) CsTPB is not appreciably soluble in either chloroform or $10 \%$ methanol in chloroform. 


\section{Chapter 4: A Calix[4]arene Strapped Calix[4]pyrrole. An Ion Pair Receptor Displaying Three Different Cesium Cation Recognition Modes}

\subsection{INTRODUCTION}

The importance of supramolecular interactions in nature has been increasingly recognized in recent years, as has the utility of artificial receptors capable of recognizing selectively ions or neutral substrates. ${ }^{1-3}$ Most ion pair receptors studied thus far have been designed to recognize selectively either cations or anions, but not both. ${ }^{2-4}$ However, as the importance of counter ion effects have come to be increasingly appreciated, attention has turned to the synthesis of so-called ion pair receptors that permit the concurrent complexation of both cations and anions. ${ }^{5}$ Compared to simple ion receptors, ion pair receptors generally display significantly enhanced affinities for ions as the result of, e.g., allosteric effects and enhanced electrostatic interactions between the co-bound ions. As such, they are potentially attractive for use in such areas as salt solublization, ion extraction, and through-membrane transport. ${ }^{6-9}$

Ion pair receptors generally bind cations and anions in three limiting modes depending on the size of ions, distance between the anion and co-bound cation, the nature of the constituent recognition sites, and solvent, among other effects. These different ionpair binding arrangements are shown schematically in Figure 1.1 in Chapter 1. They are conveniently defined as $i$ ) contact ion pairs, where the anion and cation are held in close proximity (Figure 1.1a); ${ }^{8}$ ii) solvent-bridged ion pairs, in which solvent molecules help link the anion to the co-bound cation (Figure 1.1b), ${ }^{8 \mathrm{a}-\mathrm{c}, 11}$ and iii) host-separated ion pairs, an arrangement characterized by ostensibly independent anion and cation recognition sites (Figure 1.1c). ${ }^{10}$ Examples of all three host-guest arrangements are now known. However, as a general rule, these arrangements have been defined in the context of different receptor systems. Indeed, most ion pair receptors reported to date operate on the 
basis of only one or, in very rare cases, two of the binding modes shown in Figure 1.1. ${ }^{8 \mathrm{a}-}$ c,10c To the best of the candidate's knowledge, there are no synthetic receptor capable of stabilizing all three limiting interactions using a single molecular framework. In this chapter, the first receptor that binds ion pairs in accord with all three limiting modes shown in Figure 1.1 is presented. This flexibility in binding, which has been fully documented via single crystal X-ray diffraction analyses, is of particular interest because the underlying ion pair recognition behavior can be modified by simply changing the counter anion.

As detailed in chapter $\mathbf{3}$, the ion pair receptor 4.1 was recently prepared. This system is characterized by the presence of two strong ion-binding sites (a calix[4]pyrrole and calix[4]arene crown- 6 subunits for anion and cation recognition, respectively). ${ }^{12}$ In the solid state, X-ray diffraction analysis revealed the presence of a 1:1 CsF complex that was characterized by a large $(>10 \AA) \mathrm{Cs}^{+}$and $\mathrm{F}^{-}$separation. In spite of this large separation, in 10\% methanol-chloroform (v/v), compound 4.1 was found to bind both the $\mathrm{F}^{-}$anion and $\mathrm{Cs}^{+}$cation strongly, and to do so in a sequential manner. ${ }^{12}$ In order to gain greater insights into the nature of the binding interactions in 4.1, we have now prepared, and wish to report here, the crown-free ion pair receptor (4.2). This new system, which lacks the calix[4]-crown-6 cation recognition site, ${ }^{13}$ displays anion-dependant ion pair binding that differs dramatically from that observed in the case of $\mathbf{4 . 1}$ or, indeed, any other synthetic receptor system of which we are aware. As will be discussed further below, it has been found that in 10\% methanol-chloroform, receptor $\mathbf{4 . 2}$ fails to bind either $\mathrm{Cs}^{+}$or $\mathrm{F}^{-}$when exposed to these ions in the form of salts containing other counter ions (i.e., $\mathrm{ClO}_{4}{ }^{-}$and tetrabutylammonium $\left(\mathrm{TBA}^{+}\right.$), for $\mathrm{Cs}^{+}$and $\mathrm{F}^{-}$, respectively). However, it forms a very strong and selective complex with $\mathrm{CsF}$, when mixed with $\mathrm{CsF}$ or with various combinations of salts that provide a source of $\mathrm{CsF}$ in situ. Further, in contrast to 127 
what is true for 4.1, the binding of the $\mathrm{Cs}^{+}$and $\mathrm{F}^{-}$ions takes place concurrently, rather than sequentially, on the NMR time scale in $10 \% \mathrm{CD}_{3} \mathrm{OD}: \mathrm{CDCl}_{3}$. Also noteworthy is that in 4.1 the $\mathrm{Cs}^{+}$cation is bound in the crown ether strap, whereas in 4.2 it is bound closer to the $\mathrm{F}^{-}$anion and within the receptor pocket. The result is a solvent-bridged ion pair structure in the case of $\mathbf{4 . 2}$ wherein the cation and anion are separated by roughly $5.6 \AA$ in the solid state. This binding mode is protean and can be modified by the choice of counter anion. For instance, no solvent bridging is seen in the case of the $\mathrm{CsNO}_{3}$ complex; here, solid-state structural analysis confirms the existence of a contact ion pair within the receptor cavity. Finally, in the case of $\mathrm{CsCl}$, single crystal X-ray structural analysis reveals the existence of an unprecedented 2:2 complex characterized by two different ion pair binding modes, including one that is best described as host-separated. Such host-separated ion pairing has been observed recently in the case of $\mathrm{Cs}^{+}$salts of simple calix[4]pyrrole, 4.3. ${ }^{10 \mathrm{c}}$ However, the ability to "adjust" the ion pair recognition as a function of specific conditions is to the best of the candidate's knowledge a unique feature of receptor 4.2 and could make this new system of interest as a selective ion recognition agent, in accord with very recent literature suggestions. ${ }^{14}$
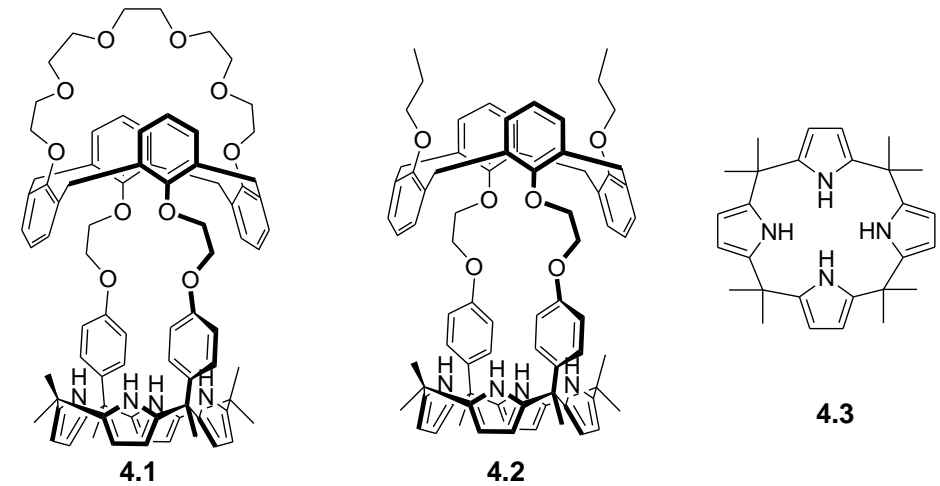

Figure 4.1 Chemical structures of compunds 4.1-4.3. 


\subsection{RESUlTS AND DisCUSSION}

Receptor 4.2 was synthesized using a synthetic procedure similar to that used to prepare compound 4.1. ${ }^{12}$ As shown in Scheme 1, the reaction of calix[4]arene ditosylate 4.1 ${ }^{15}$ with 4'-hydroxyacetophenone in the presence of excess $\mathrm{K}_{2} \mathrm{CO}_{3}$ in acetonitrile under reflux gave the calix[4]arene diketone $\mathbf{4 . 5}$ in its 1,3-alternate conformation in $80 \%$ yield; subsequent condensation with pyrrole in the presence of excess trifluoroacetic acid (ca. 23 equiv.) at $65{ }^{\circ} \mathrm{C}$ then gave the dipyrromethane $\mathbf{4 . 6}$ in $48 \%$ yield. Compound $\mathbf{4 . 6}$ was further condensed with acetone in the presence of a catalytic amount of $\mathrm{BF}_{3} \cdot \mathrm{OEt}_{2}$ to give the target compound (4.2) in $12 \%$ yield. ${ }^{12,16}$

Scheme 4.1 Synthesis of compound 4.2

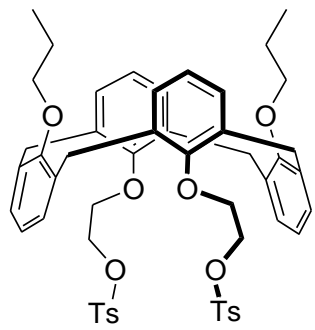

4.4

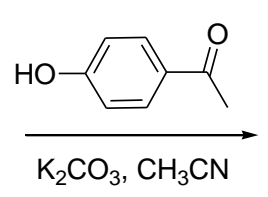

$\mathrm{K}_{2} \mathrm{CO}_{3}, \mathrm{CH}_{3} \mathrm{CN}$

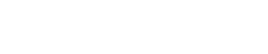

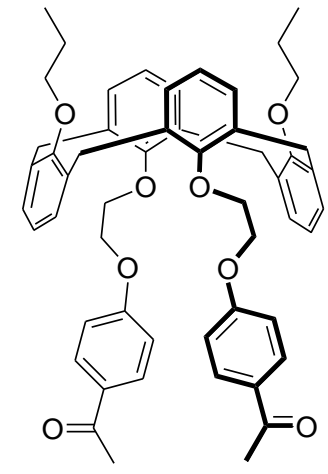

4.5
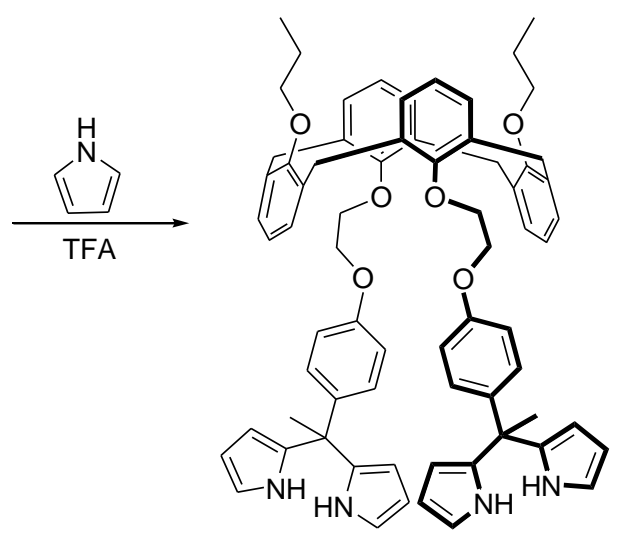

4.6 
Compound 4.2 was fully characterized by standard spectroscopic means, as well as by single crystal X-ray diffraction analysis (Figure 4.2). The datum crystal used for this latter analysis was obtained by subjecting $\mathbf{4 . 2}$ in its ion-free form to slow evaporation from a chloroform-methanol $(1: 1, \mathrm{v} / \mathrm{v})$ solvent mixture. The resulting structure revealed that, in the solid state, the calix[4]arene moiety adopts the expected 1,3-alternate conformation, while the calix[4]pyrrole moiety is in a partial cone conformation with two methanol molecules bound to the four pyrrolic NH protons.
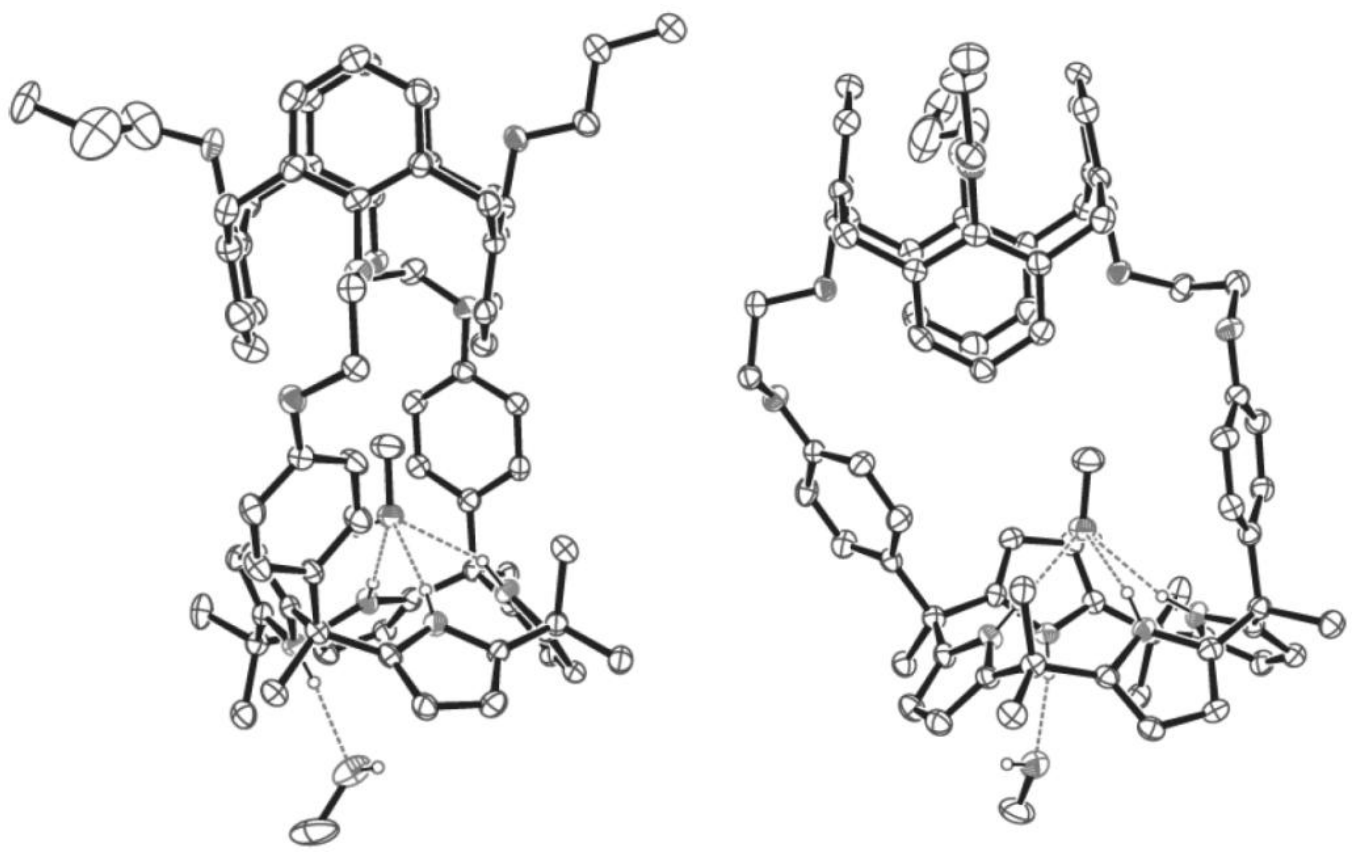

Figure 4.2 Two different views of the single crystal structure of $\mathbf{4 . 2} \cdot\left(\mathrm{CH}_{3} \mathrm{OH}\right)_{2}$. Displacement ellipsoids are scaled to the $30 \%$ probability level. Most hydrogen atoms have been removed for clarity. Dashed lines are indicative of H-bonding interactions. 
As a first step towards analyzing the ion recognition properties of $\mathbf{4 . 2}$, its ability to bind halide anion salts in $\mathrm{CDCl}_{3}$ solution was investigated via ${ }^{1} \mathrm{H}$ NMR spectroscopy. In analogy to what was found to be true in the case of the ion pair receptor $4.1,{ }^{12}$ significant chemical shift changes in the NMR spectrum of 4.2 were observed when the receptor was treated with fluoride anion salts (e.g., tetrabutylammonium fluoride, TBAF), but not other analogous halide anion salts (Figure 4.3). Such findings lead us to suggest that, like the earlier system 4.1, receptor 4.2 is selective for the fluoride anion. This stands in contrast to what is true for normal calix[4]pyrrole $\mathbf{4 . 3}$, which is able to bind other halide anions in $\mathrm{CDCl}_{3}$ and other solvent systems. ${ }^{17}$ As shown in Figure 4.3, the ${ }^{1} \mathrm{H}$ NMR spectrum of free 4.2 is characterized by a broad singlet at $\delta=6.75 \mathrm{ppm}$ for the NH protons, as well as two triplets, resonating at about $\delta=6.03 \mathrm{ppm}$ and $\delta=5.95 \mathrm{ppm}$, for the $\beta$-pyrrolic protons, respectively. 


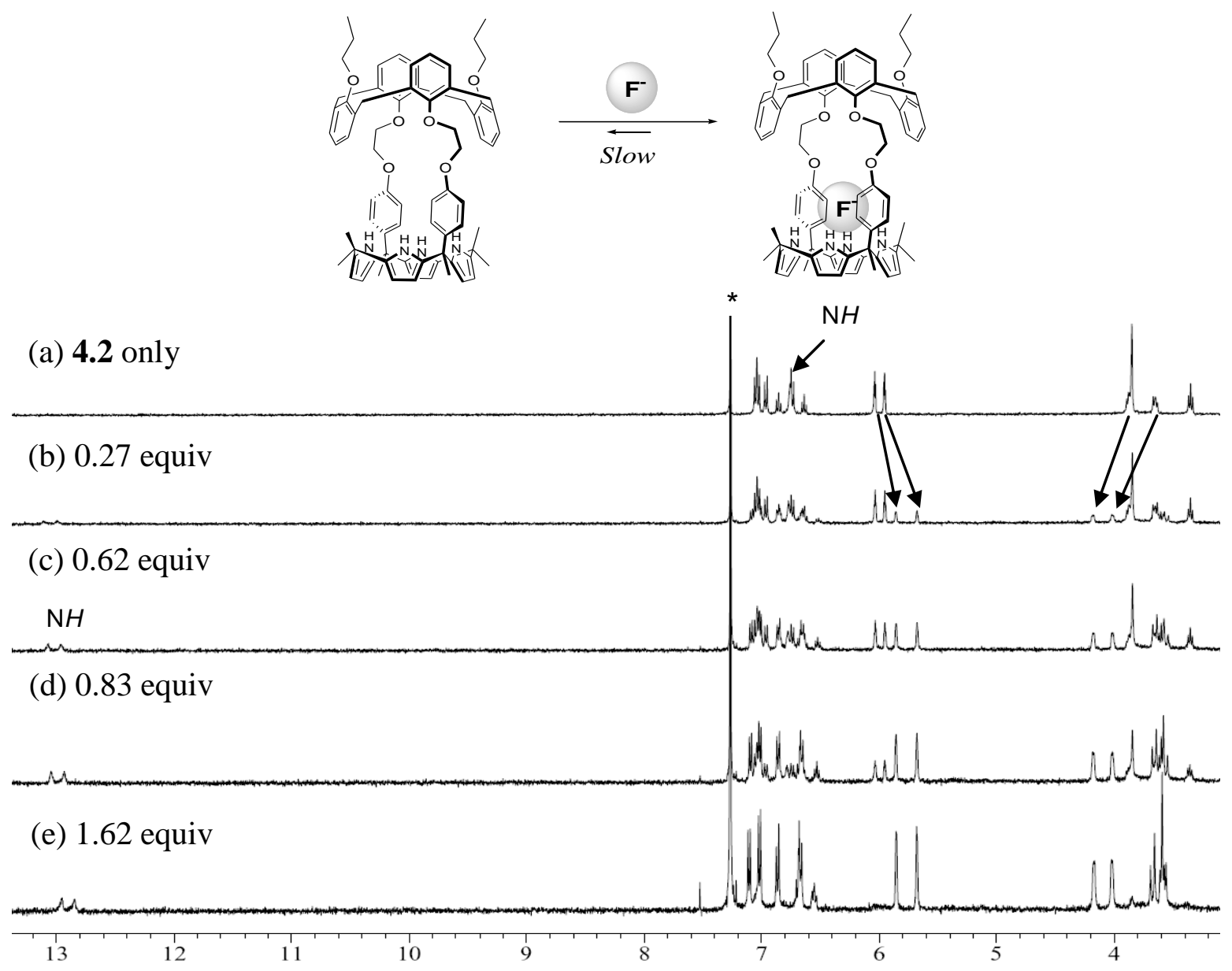

Figure 4.3 Partial ${ }^{1} \mathrm{H}$ NMR spectra recorded during the titration of receptor 4.2 with TBAF (tetrabutylammonium fluoride) in $\mathrm{CDCl}_{3}$.

Upon subjecting compound 4.2 to titration with TBAF in $\mathrm{CDCl}_{3}$, two sets of resonances were seen for all observable proton signals in the various ${ }^{1} \mathrm{H}$ NMR spectra recorded before saturation was achieved. The deconvoluted spectra were found to reflect, as expected, the presence of both the ion-free and fluoride-bound forms of 4.2. As such, these studies serve to indicate that the kinetics of fluoride anion binding/release is slow on the NMR time scale (Figure 4.3). They also provide support for the notion that fluoride anion is strongly bound by receptor $\mathbf{4 . 2}$ in this solvent medium. 
The presumed strong complexation between receptor 4.2 and fluoride anion in $\mathrm{CDCl}_{3}$ was further supported by the observation of significant chemical shift changes in the $\beta$-pyrrolic proton signals and, especially, the pyrrolic NH protons (Figure 4.3). Upon reaching saturation, the NH proton signal in the ${ }^{1} \mathrm{H}$ NMR spectrum was shifted downfield to $\delta \approx 13.0 \mathrm{ppm}(\Delta \delta \approx 6.3 \mathrm{ppm})$. This resonance, initially a singlet, was also split into a doublet $(J=45.6 \mathrm{~Hz})$, a finding ascribed to coupling between the NH protons and the bound fluoride anion (Figure 4.3). ${ }^{18}$ In contrast, the triplet peaks corresponding to the $\beta$ pyrrolic protons were shifted up-field and to appear as two singlets (at $5.85 \mathrm{ppm}$ and 5.67 ppm, respectively; cf. Figure 4.3) at the end of the titration; this is as would be expected given the anion-induced changes in the electronic features of the calix[4]pyrrole portion of receptor 4.2.

Very different binding behavior was observed when experiments analogous to those described above were carried out in $10 \% \mathrm{CD}_{3} \mathrm{OD}$ in $\mathrm{CDCl}_{3}(\mathrm{v} / \mathrm{v})$. In this more polar medium, no appreciable change in any of the chemical shifts was seen in the ${ }^{1} \mathrm{H}$ NMR spectrum of receptor 4.2, even upon treatment with 5.0 equiv. of TBAF. This result, interpreted in terms of receptor 4.2 not binding the fluoride anion under these particular experimental conditions, is ascribed to the strong solvation of fluoride anions by the $\mathrm{CD}_{3} \mathrm{OD}$ present in this solvent mixture (Figures 4.4 and 4.5). 
(a)
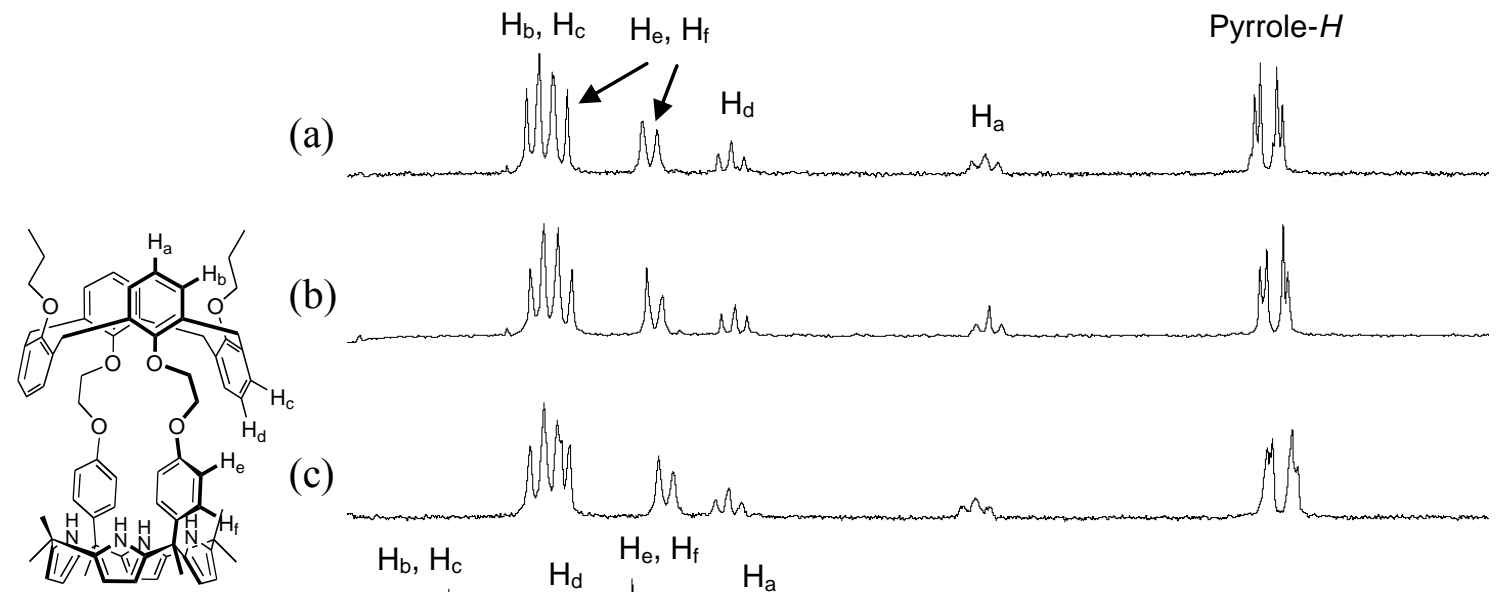

(b)

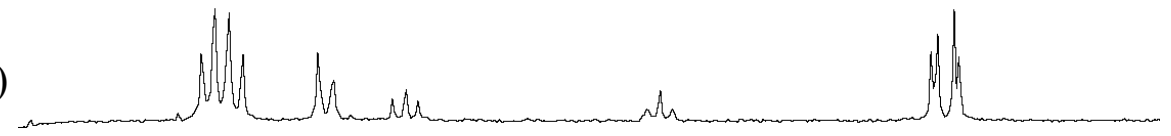

(c)

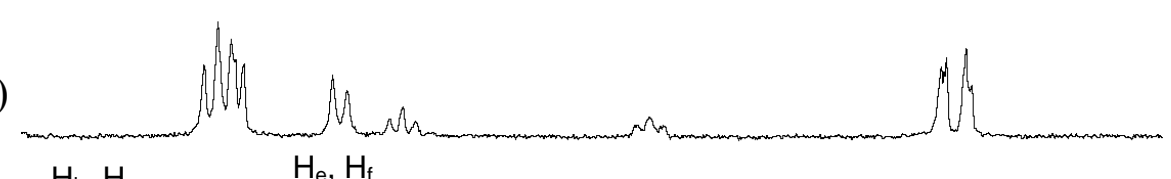

(d)

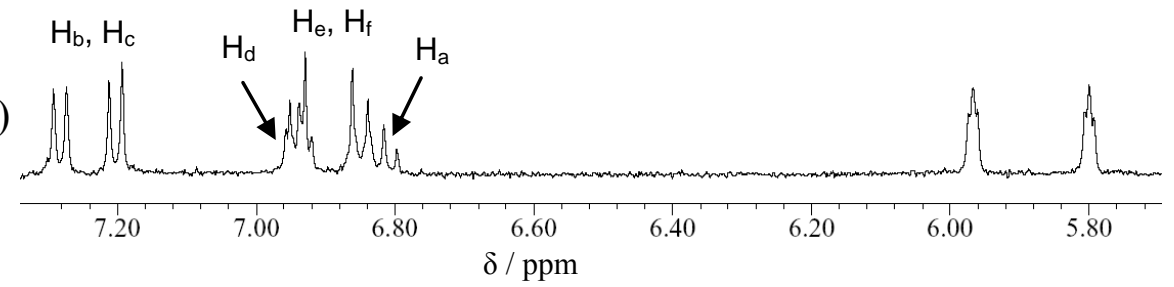

Figure 4.4 Partial ${ }^{1} \mathrm{H}$ NMR spectra of (a) 4.2 only, (b) $4.2+5$ equiv. of TBAF (tetrabutylammonium fluoride), (c) $4.2+5$ equiv. of $\mathrm{CsClO}_{4}$, and (d) $4.2+5$ equiv. of $\mathrm{CsF}$ in $\mathrm{CD}_{3} \mathrm{OD} / \mathrm{CDCl}_{3}(1: 9, \mathrm{v} / \mathrm{v})$.

Simple calix[4]pyrrole $\mathbf{4 . 3}$ is known to complex the cesium cation weakly, if at all, in organic media. ${ }^{10 \mathrm{c}}$ Therefore, as expected, little evidence of an interaction between compound 4.2 and the $\mathrm{Cs}^{+}$cation was seen when this receptor was treated with 5.0 equiv. of $\mathrm{CsClO}_{4}$ in $10 \% \mathrm{CD}_{3} \mathrm{OD}$ in $\mathrm{CDCl}_{3}(\mathrm{v} / \mathrm{v})$, as evidenced by the absence of chemical shift changes in the ${ }^{1} \mathrm{H}$ NMR spectrum (Figure 4.4c).

In contrast to what is seen with $\mathrm{TBAF}$ or $\mathrm{CsClO}_{4}$, the addition of $\mathrm{CsF}$ (5.0 equiv.) to a solution of 4.2 in $10 \% \mathrm{CD}_{3} \mathrm{OD}$ in $\mathrm{CDCl}_{3}$ causes significant changes in the proton signals of both the calix[4] arene and the calix[4]pyrrole moiety in the ${ }^{1} \mathrm{H}$ NMR spectrum (Figure 4.4d). Such findings are consistent with the CsF being bound to receptor $\mathbf{4 . 2}$ as an ion pair. Further, since the combination of both ionic species is required to trigger both $\mathrm{Cs}^{+}$and $\mathrm{F}^{-}$complexation, the binding process mimics a cooperative $A N D$ logic gate. ${ }^{19}$ 
Specifically, in accord with the logic rules governing such devices, only the combined presence of two inputs induces $\mathrm{CsF}$ binding by 4.2 (i.e., both the $\mathrm{Cs}^{+}$cation and the $\mathrm{F}^{-}$ anion, but neither the $\mathrm{Cs}^{+}$cation nor the $\mathrm{F}^{-}$anion alone, triggers the change); presumably, this complexation leads to formation of a solvent separated-ion pair, just as it does in the solid state (cf. discussion below).

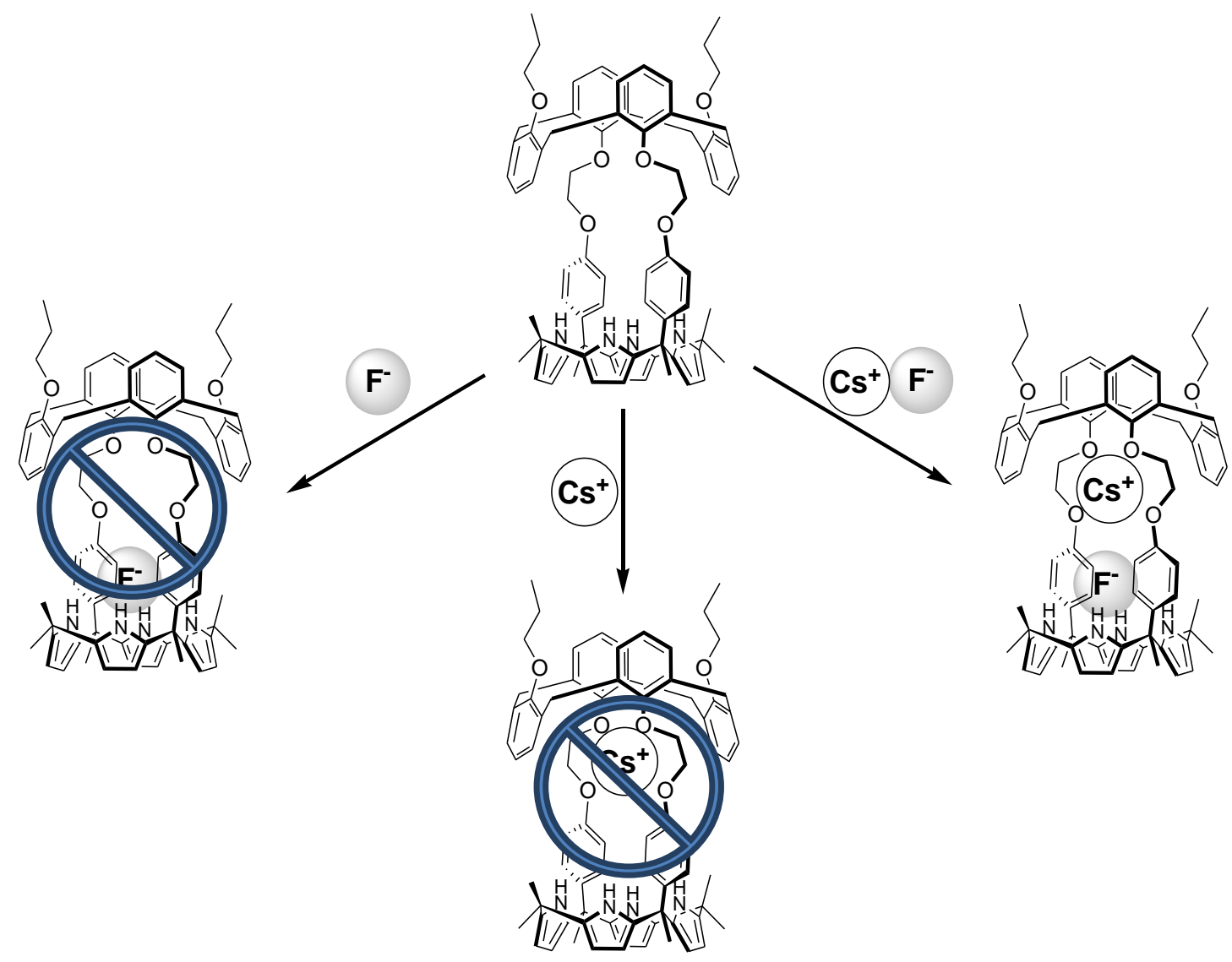

Figure 4.5 Proposed $A N D$ logic gate binding behavior of $\mathbf{4 . 2}$ towards a $\mathrm{CsF}$ ion pair in $\mathrm{CD}_{3} \mathrm{OD} / \mathrm{CDCl}_{3}(1: 9, \mathrm{v} / \mathrm{v})$.

A noteworthy feature of the spectra shown in Figure 4.4d, is the CsF-induced downfield shift in all the proton signals associated with the calix[4]arene subunit. Such a 
finding is fully consistent with the 1,3-alternate calix[4]arene moiety, which is known to be a weak $\mathrm{Cs}^{+}$receptor, ${ }^{13}$ being involved in $\mathrm{Cs}^{+}$cation complexation. The fact that changes are seen in the signals ascribed to protons $H_{a}$ and $H_{b}$ confirms that the oxygen atoms of the calix[4]arene phenoxy groups participate in $\mathrm{Cs}^{+}$cation recognition. In contrast, the upfield shift seen for both the $\beta$-pyrrolic and meso-aromatic proton signals of the calix[4]pyrrole moiety, as well as the significant downfield shift and splitting (into a doublet) observed for the pyrrolic $\mathrm{N} H$ resonance, are taken as strong evidence that $\mathrm{F}^{-}$ anion binding takes place within the calix[4]pyrrole moiety (Figure 4.4d). These findings are consistent with the structure of $\mathbf{4 . 2} \cdot \mathrm{CsF}$ determined in the solid state via X-ray diffraction analysis (vide infra).

Further evidence that receptor 4.2 forms a strong complex with $\mathrm{CsF}$ came from ${ }^{1} \mathrm{H}$ NMR spectroscopic titrations carried out with CsF. Specifically, addition of $0.57-1.79$ equivalents of $\mathrm{CsF}$ to a solution of 4.2 in $\mathrm{CD}_{3} \mathrm{OD} / \mathrm{CDCl}_{3}(1: 9, \mathrm{v} / \mathrm{v})$ was found to give rise to two sets of distinguishable resonances for all proton signals. These sets of peaks are attributed to the ion-free and $\mathrm{CsF}$ bound forms of 4.2, respectively. The presence of two separate signals is consistent with the ion pair binding/decomplexation equilibrium being slow on the ${ }^{1} \mathrm{H}$ NMR time scale, as noted above. As proved true after the titration was complete (cf. discussion of Fig. 3d above), a detailed analysis of the signals associated with the CsF complex (Figure 4.6) revealed that shifts are seen for both the pyrrolic $\mathrm{NH}$ and protons $H_{a}$ and $H_{b}$ of the calix[4]arene. This is consistent with the $\mathrm{Cs}^{+}$cation and $\mathrm{F}^{-}$ anion being bound concurrently, at least on the ${ }^{1} \mathrm{H}$ NMR time scale (Eq. 4.1). 


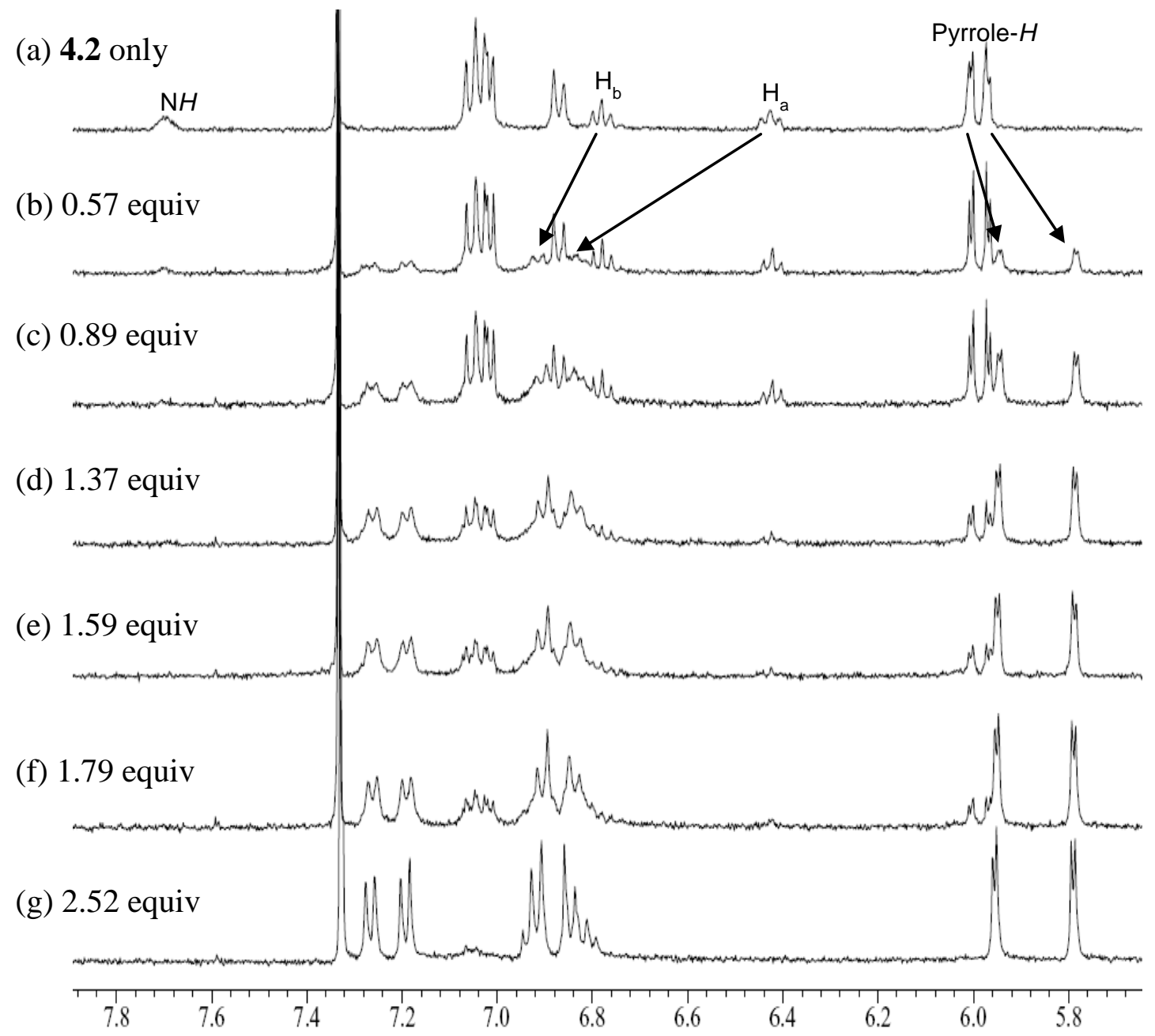

Figure 4.6 Partial ${ }^{1} \mathrm{H}$ NMR spectra recorded during the titration of receptor 2 with $\mathrm{CsF}$ in $\mathrm{CD}_{3} \mathrm{OD} / \mathrm{CDCl}_{3}(1: 9, \mathrm{v} / \mathrm{v})$.

The binding behavior for the new receptor 4.2 is very different for what is seen for compound 4.1. In the case of the latter species, addition of $0.57-1.79$ equivalents of $\mathrm{CsF}$ gives rise at first to changes in the proton signals of the calix[4]arene moiety and the crown-6 ring, but not those of the calix[4]pyrrole moiety (Figure 4.7). Such a finding is consistent with the $\mathrm{Cs}^{+}$cation being bound to the calix[4]crown- 6 ring before the $\mathrm{F}^{-}$anion 
is bound to the calix[4]pyrrole (Eq. 4.2). Only after the $\mathrm{Cs}^{+}$cation is bound to the calix[4]arene crown-6 ring of 4.1 does complexation of the $\mathrm{F}^{-}$counter anion occur, ${ }^{12}$ as expected, this gives rise to two distinct (and distinguishable) sets of pyrrolic $\beta$-proton signals during the course of the titration (Figure 4.7).
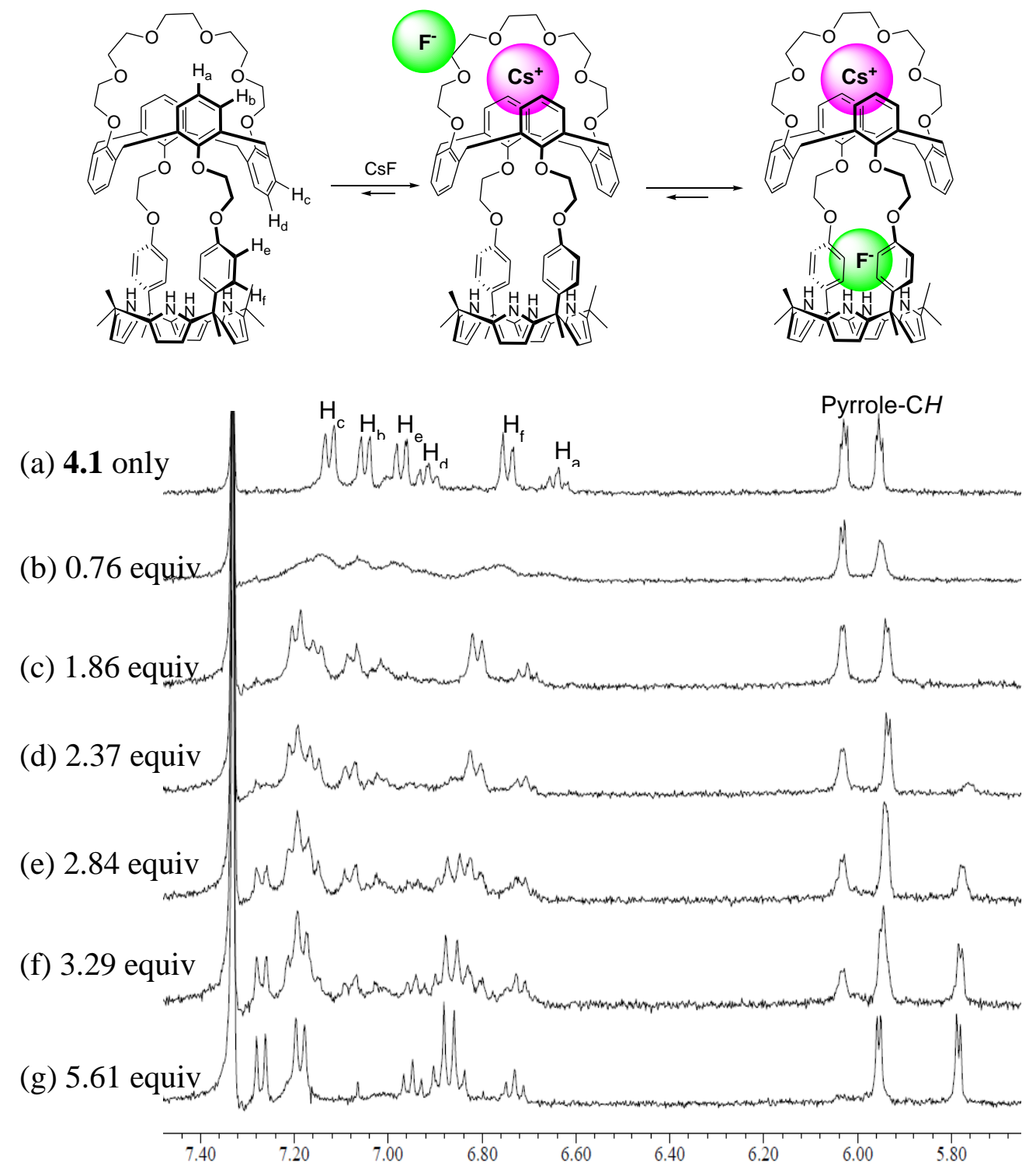

Figure 4.7 Partial ${ }^{1} \mathrm{H}$ NMR spectra recorded during the titration of receptor 4.1 with $\mathrm{CsF}$ in $\mathrm{CD}_{3} \mathrm{OD} / \mathrm{CDCl}_{3}(1: 9, \mathrm{v} / \mathrm{v})$. 


$$
\begin{gathered}
{[4.2]+C s F \rightarrow[4.2 \cdot C s F]} \\
{[4.1]+C s F \rightarrow[4.1 \cdot C s] F} \\
{[4.1 \cdot C s] F+C s F \rightarrow[4.1 \cdot C s F]+C s F}
\end{gathered}
$$

ITC was utilized to quantify the $\mathrm{CsF}$ affinity of receptor 4.2. To maintain consistency with the prior ${ }^{1} \mathrm{H}$ NMR spectroscopic analyses, a solvent mixture consisting of $10 \% \mathrm{MeOH}$ in $\mathrm{CHCl}_{3}(\mathrm{v} / \mathrm{v})$ was employed. This choice reflects the fact that no other solvent systems allowed for interpretable data to be obtained for either this salt or other combinations of $\mathrm{F}^{-}$and $\mathrm{Cs}^{+}$and various counter ions. In $10 \% \mathrm{CH}_{3} \mathrm{OH}$ in $\mathrm{CHCl}_{3}(\mathrm{v} / \mathrm{v})$, the titration of $\mathrm{CsF}[1.0 \mathrm{mM}]$ with $4.2[11.2 \mathrm{mM}]$ is characterized by a highly favorable enthalpic term $(\Delta H=-14.4 \mathrm{kcal} / \mathrm{mol})$, with a strong opposing entropy term $(T \Delta S=-8.7$ $\mathrm{kcal} / \mathrm{mol}$ ). The overall binding energy, $\Delta G=-5.7 \mathrm{kcal} / \mathrm{mol}$, corresponds to a $K_{a}=1.3 \times$ $10^{4} \mathrm{M}^{-1}$, when fit to a 1:1 binding equation. This affinity is an order of magnitude lower than what was observed for compound 4.1, which contains a calix[4]arene crown-6 ring $\left(\Delta H=-16.2 \mathrm{kcal} / \mathrm{mol}, T \Delta S=-8.6 \mathrm{kcal} / \mathrm{mol}, \Delta G=-7.6 \mathrm{kcal} / \mathrm{mol}\right.$, and $K_{a}=3.77 \times 10^{5}$ $\left.\mathrm{M}^{-1}\right) .{ }^{12}$ The lower CsF affinity of $\mathbf{4 . 2}$ presumably reflects the absence of the strong calix[4]crown-6 cesium binding site, but may also be the result of reduced flexibility and associated steric limitations to either anion or cation binding. Nevertheless, even if the binding is reduced compared to $\mathbf{4 . 1}$, it is to be appreciated that in absolute terms, compound 4.2 is a highly effective receptor for $\mathrm{CsF}$, at least in this moderately polar solvent mixture. 
The binding behavior of $\mathbf{4 . 2}$ towards the $\mathrm{Cs}^{+}$cation and the $\mathrm{F}^{-}$anion was further studied in the presence of various cations and anions. The concurrent addition of both TBAF and $\mathrm{CsClO}_{4}$, neither of which is individually bound to compound $\mathbf{4 . 2}$, gives rise to ${ }^{1} \mathrm{H}$ NMR spectral changes in $10 \% \mathrm{CD}_{3} \mathrm{OD}$ in $\mathrm{CDCl}_{3}(\mathrm{v} / \mathrm{v})$ that are very similar to those seen upon the addition CsF (Figure 4.8e). Such observations provide support for the conclusion that compound $\mathbf{4 . 2}$ is able to capture selectively the $\mathrm{Cs}^{+}$cation and the $\mathrm{F}^{-}$ anion (as an ion pair) through a process involving counter ion exchange (Eq. 4.4). By contrast, in the presence of perchlorate salts of other metal ions (i.e., $\mathrm{Li}^{+}, \mathrm{Na}^{+}, \mathrm{K}^{+}, \mathrm{Rb}^{+}$ and $\mathrm{NH}_{4}{ }^{+}$, as opposed to $\mathrm{Cs}^{+}$), no spectral changes are observed; this lends credence to the notion that the $\mathrm{F}^{-}$anion is bound by compound $\mathbf{4 . 2}$, but only in the presence of $\mathrm{Cs}^{+}$.

$$
[4.2]+\mathrm{CsClO}_{4}+\mathrm{TBAF} \rightarrow[4.2 \cdot \mathrm{CsF}]+\mathrm{TBAClO}_{4}
$$

In the presence of TBA salts of other anions $\left(\mathrm{Cl}^{-}, \mathrm{Br}^{-}\right.$and $\left.\mathrm{NO}_{3}^{-}\right)$, the $\mathrm{Cs}^{+}$cation is strongly complexed by receptor 4.2, as inferred from ${ }^{1} \mathrm{H}$ NMR spectral measurements (cf. Figures 4.8 and 4.9). However, even though such complexes are formed when $\mathrm{CsCl}$, $\mathrm{CsBr}$, and $\mathrm{CsNO}_{3}$ are added independently (Figure 4.9), receptor 4.2 binds only $\mathrm{CsF}$ when a mixture of cesium salts $\left(\mathrm{CsF}, \mathrm{CsCl}, \mathrm{CsBr}\right.$, and $\left.\mathrm{CsNO}_{3}\right)$ is used. Thus, selectivity for $\mathrm{CsF}$ is seen (Figure 4.10). As such, This work serves to extend the findings of Beer and coworkers who noted that appropriately designed heteroditopic calix[4]diquinone receptors will form complexes with several ions and/or contact ion pairs, albeit not with the selectivity demonstrated by $\mathbf{4 . 2}{ }^{20}$ 


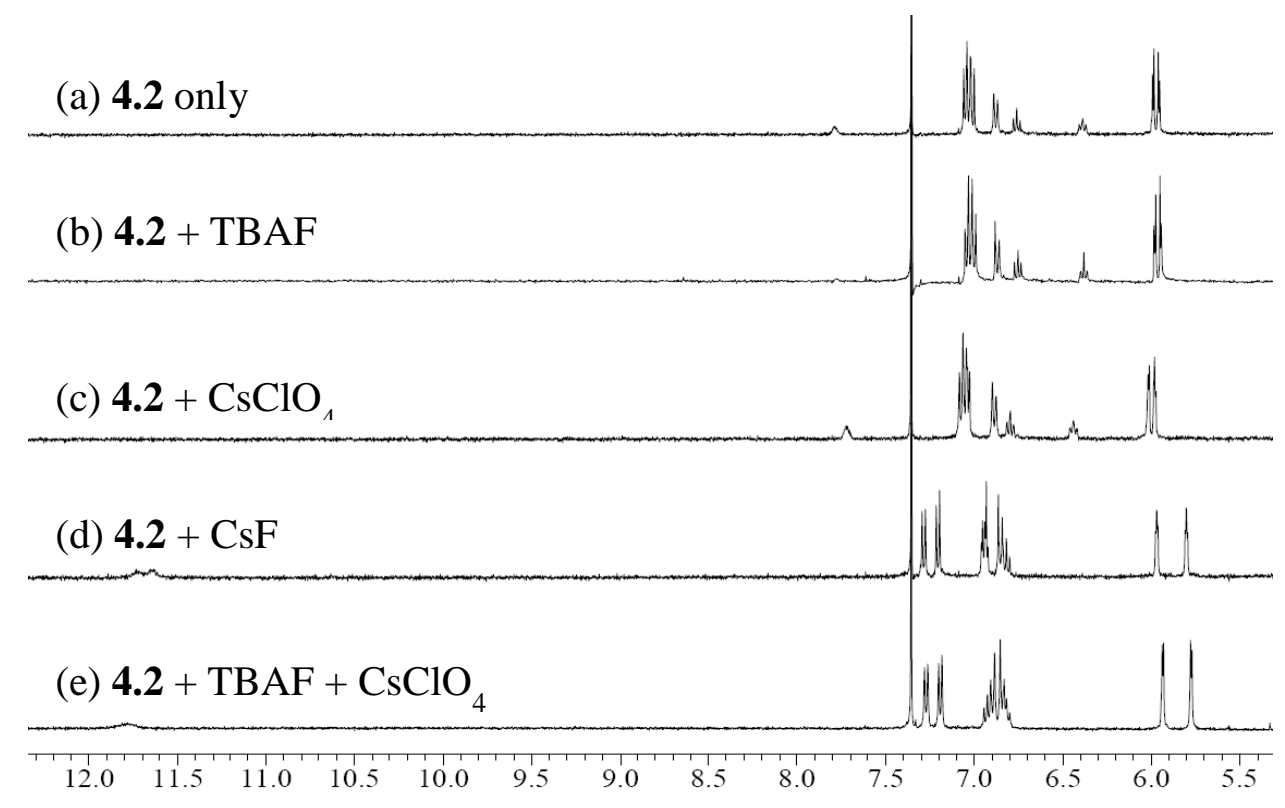

Figure 4.8 Partial ${ }^{1} \mathrm{H}$ NMR spectra of (a) 4.2 only, (b) $4.2+5$ equiv. of TBAF (tetrabutylammonium fluoride), (c) $4.2+5$ equiv. of $\mathrm{CsClO}_{4}$, (d) $\mathbf{4 . 2}+5$ equiv. of $\mathrm{CsF}$, and (e) $\mathbf{4 . 2}+5$ equiv. of $\mathrm{TBAF}+5$ equiv. of $\mathrm{CsClO}_{4}$ in $\mathrm{CD}_{3} \mathrm{OD} / \mathrm{CDCl}_{3}(1: 9, \mathrm{v} / \mathrm{v})$. 


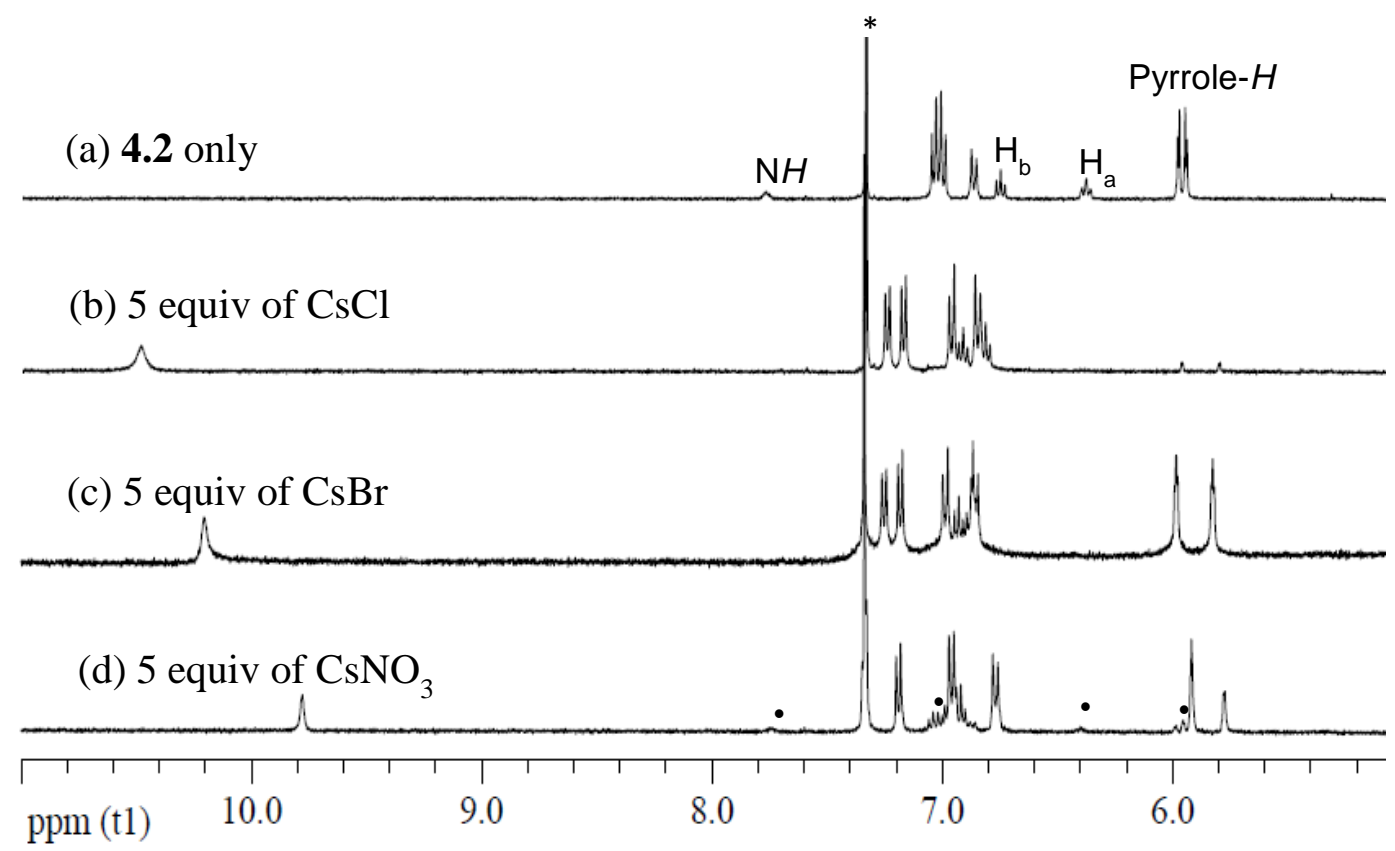

Figure 4.9 Partial ${ }^{1} \mathrm{H}$ NMR spectra of (a) 4.2 only, (b) $4.2+5$ equiv. of $\mathrm{CsCl}$, (c) $4.2+5$ equiv. of $\mathrm{CsBr}$, and (d) $\mathbf{4 . 2}+5$ equiv. of $\mathrm{CsNO}_{3}$ in $\mathrm{CD}_{3} \mathrm{OD} / \mathrm{CDCl}_{3}(1: 9, \mathrm{v} / \mathrm{v})$. The spectra were recorded roughly 10 minutes after mixing. $*$ and $\bullet$ denote peaks of the NMR solvent and the uncomplexed, respectively. 


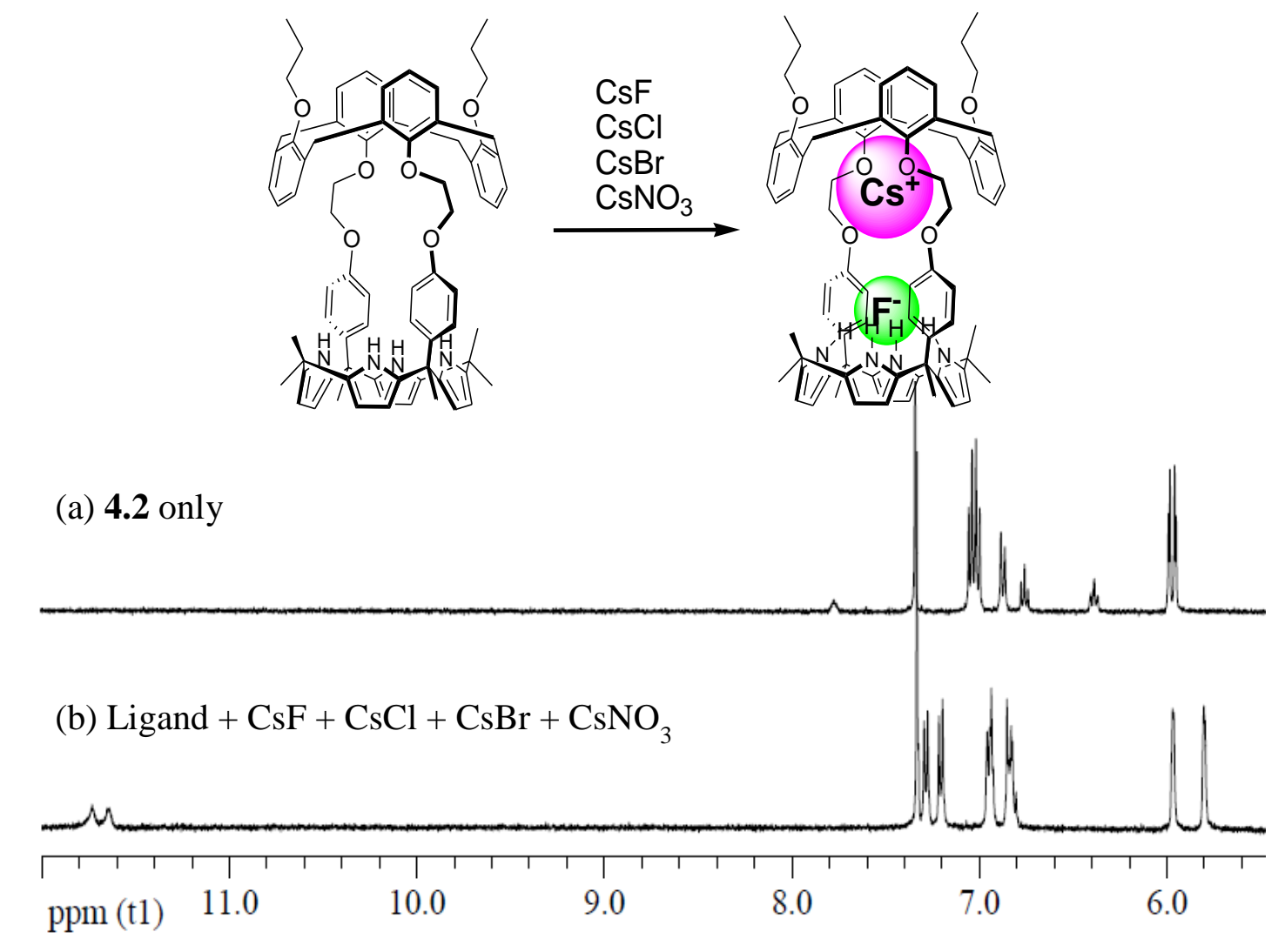

(a) 4.2 only

Figure 4.10 Partial ${ }^{1} \mathrm{H}$ NMR spectra of 4.2 recorded in the presence of various cesium salts (5 equiv) in $\mathrm{CD}_{3} \mathrm{OD} / \mathrm{CDCl}_{3}(1: 9, \mathrm{v} / \mathrm{v})$.

The strong preference for $\mathrm{CsF}$ displayed by 4.2 in $10 \% \mathrm{CD}_{3} \mathrm{OD}$ in $\mathrm{CDCl}_{3}(\mathrm{v} / \mathrm{v})$ stands in marked contrast to what is true for simple calix[4]pyrrole 4.3. This latter system has been observed to bind a number of different anions under a wide variety of conditions and thus high selectivity for CsF was not expected. ${ }^{17}$ Indeed, when tested under conditions identical to those used above (i.e., exposure to a mixture of cesium salts), this unfunctionalized "parent" system was found to interact with a variety of anions in $10 \%$ $\mathrm{CD}_{3} \mathrm{OD}$ in $\mathrm{CDCl}_{3}(\mathrm{v} / \mathrm{v})$, rather than just fluoride, as seen for 4.2 (cf. Figure 4.11). 


$\underbrace{*}_{\mathrm{NH}}$ (a) 4.3 only

(b) $4.3+\mathrm{CsClO}_{4}$ (20 equiv)

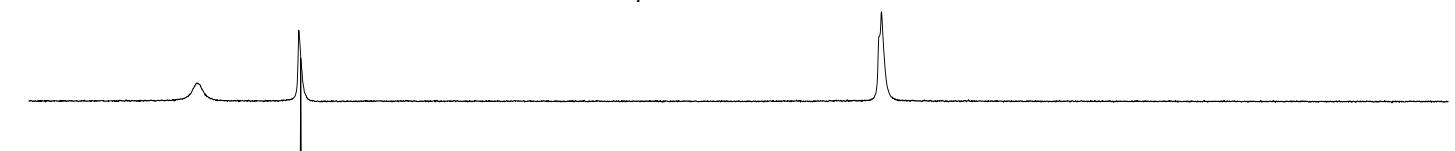

(c) $4.3+\mathrm{CsCl}$ (20 equiv)

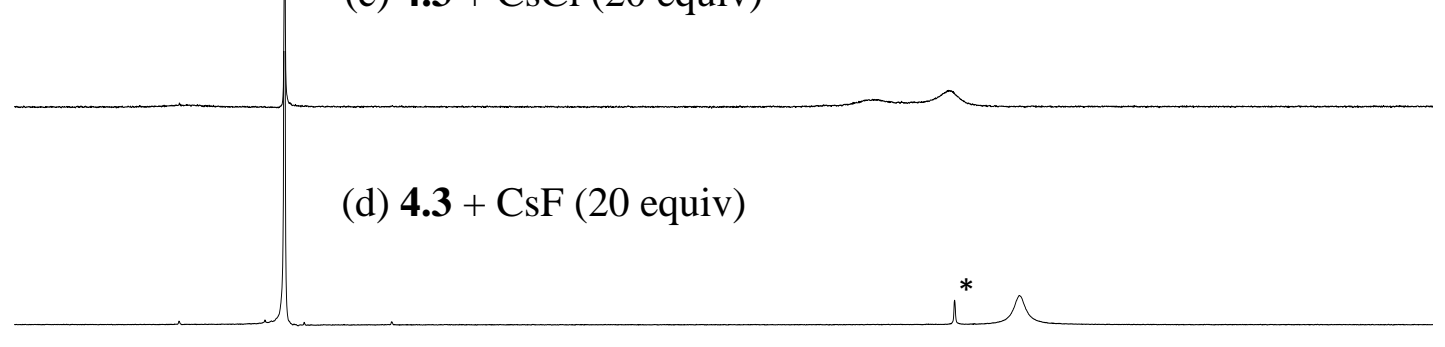

(e) $4.3+\mathrm{CsF}+\mathrm{CsCl}+\mathrm{CsBr}+\mathrm{CsNO}_{3}(20$ equiv)

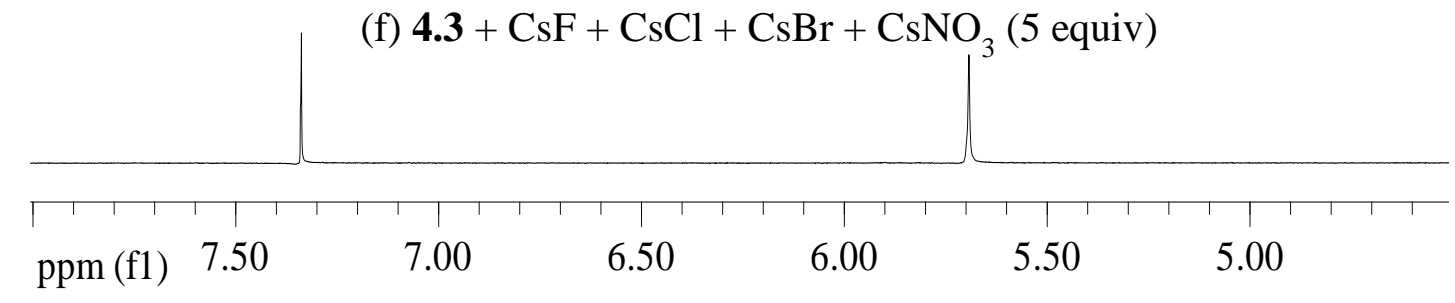

Figure 4.11 Partial ${ }^{1} \mathrm{H}$ NMR spectra of (a) 4.3 only, (b) $4.3+20$ equiv of $\mathrm{CsClO}_{4}$, (c) 4.3 +20 equiv of $\mathrm{CsCl}$, (d) $\mathbf{4 . 3}+20$ equiv of $\mathrm{CsF}$, (e) $\mathbf{4 . 3}+20$ equiv of $\mathrm{CsF}+$ 20 equiv of $\mathrm{CsCl}+20$ equiv of $\mathrm{CsBr}+20$ equiv. of $\mathrm{CsNO}_{3}$, and (f) $\mathbf{3}+5$ equiv of $\mathrm{CsF}+5$ equiv of $\mathrm{CsCl}+5$ equiv of $\mathrm{CsBr}+5$ equiv of $\mathrm{CsNO}_{3}$ in $\mathrm{CD}_{3} \mathrm{OD} / \mathrm{CDCl}_{3}(1: 9, \mathrm{v} / \mathrm{v})$. * denotes peaks of the NMR solvent and impurity from the commercially purchased $\mathrm{CsF}$ salt.

The high selectivity for $\mathrm{CsF}$ seen in the case of $\mathbf{4 . 2}$ relative to $\mathbf{4 . 3}$ is thought to reflect favorable ion pairing interactions. However, it may also reflect a reduced 
accessibility to the anion binding site compared to simple calix[4]pyrrole $4.3 .{ }^{10 \mathrm{c}}$ Presumably, this reduced accessibility is a consequence of the greater rigidity of the calix[4]pyrrole core that results from the use of relatively inflexible ethylene glycol spacers between the calix[4]pyrrole and calix[4]arene subunits. The phenoxy groups flanking the calix[4]pyrrole binding site may also serve to limit accessibility to the cavity.

Single crystals of the CsF complex of $4.2(4.2 \cdot \mathrm{CsF})$ were obtained by subjecting a chloroform/methanol solution of receptor 4.2 to slow evaporation in the presence of excess cesium fluoride. The resulting structure revealed that $\mathbf{4 . 2}$ forms a 1:1 complex with cesium fluoride, and that the latter is bound in the form of an ion pair wherein the constituent ions are separated by a water molecule. As expected, the $\mathrm{Cs}^{+}$cation is bound strongly to the 1,3-alternate conformation of the calix[4]arene through ion-dipole interactions with two phenoxy oxygen atoms and $\pi$-cation interactions involving the two arene rings: ${ }^{21} \mathrm{Cs}^{+} \cdots \mathrm{O}$ distances of 2.98 and $3.09 \AA$; $\mathrm{Cs}^{+} \cdots$ arene centroid distances of 3.28 and $3.40 \AA$ (Figure 4.12). The $\mathrm{Cs}^{+}$cation is also coordinated by a molecule of methanol $\left(\mathrm{Cs}^{+} \cdots \mathrm{O}\right.$ distance $\left.=3.04 \AA\right)$ and a water molecule $\left(\mathrm{Cs}^{+} \cdots \mathrm{O}\right.$ distance $\left.=3.22 \AA\right)$. The distal oxygen atoms of the ethylene glycol spacers exhibit long $\mathrm{Cs}^{+} \cdots \mathrm{O}$ distances, 3.66 and $4.25 \AA$, leading us to suggest that they do not play a significant role in cation binding (vide infra). The $\mathrm{F}^{-}$anion is bound to the $\mathrm{NH}$ protons of the calix[4]pyrrole with distances of $2.79-2.81 \AA\left(\mathrm{N} \cdots \mathrm{F}^{-}\right.$interaction), and is also bound to the water molecule with a distance of $2.52 \AA\left(\mathrm{O} \cdots \mathrm{F}^{-}\right.$interaction). The distance between the $\mathrm{Cs}^{+}$cation and the $\mathrm{F}^{-}$anion in $4.2 \cdot \mathrm{CsF}$ is found to be $5.62 \AA$, which is much shorter than the distance (10.92 $\AA$ ) seen in the CsF complex of 4.1. It is also much longer than the intra- $(3.69 \AA)$ 
and intercomplex $(2.77 \AA)$ distances seen in the solid state structure of the CsF complex of simple meso-octamethylcalix[4]pyrrole 4.3 (Figure 4.13 ). ${ }^{10 \mathrm{c}}$ In the previously reported $\mathrm{CsF}$ complex of 4.3, the $\mathrm{Cs}^{+}$cation is symmetrically encapsulated with the cone-like cavity of the calix[4]pyrrole via apparent $\pi$ - cation interactions with a distance of $3.39 \AA$ between the $\mathrm{Cs}^{+}$ion and the centroids of the pyrrole rings. ${ }^{10 \mathrm{c}}$
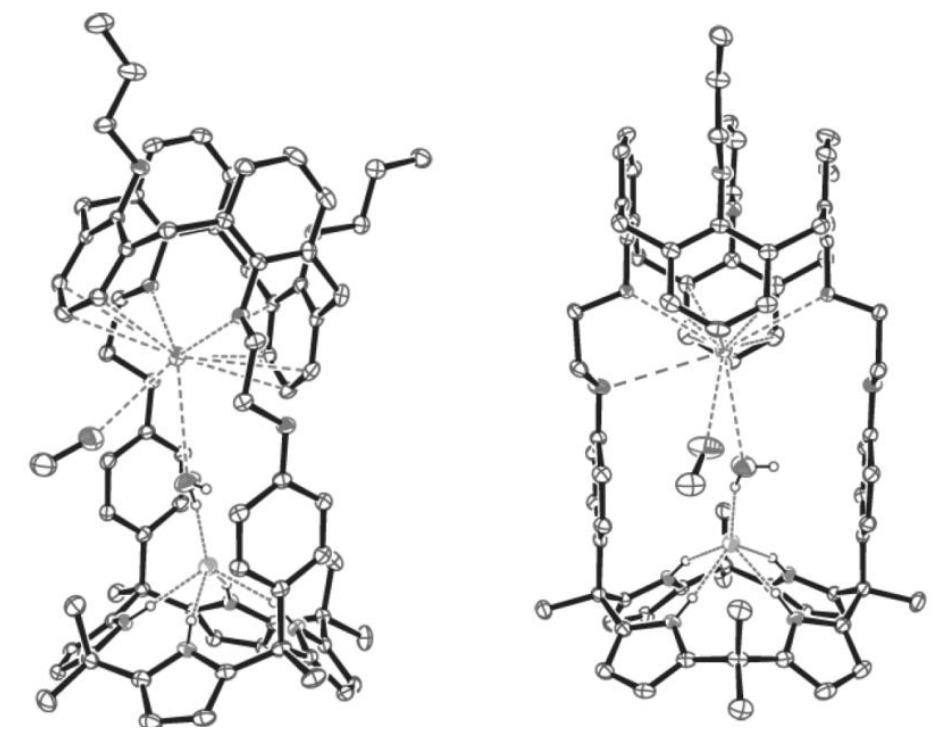

Figure 4.12 Two different views of the single crystal structure of $4.2 \cdot \mathrm{CsF} \cdot \mathrm{CH}_{3} \mathrm{OH} \cdot \mathrm{H}_{2} \mathrm{O}$. Displacement ellipsoids are scaled to the $50 \%$ probability level. Most hydrogen atoms have been removed for clarity. 


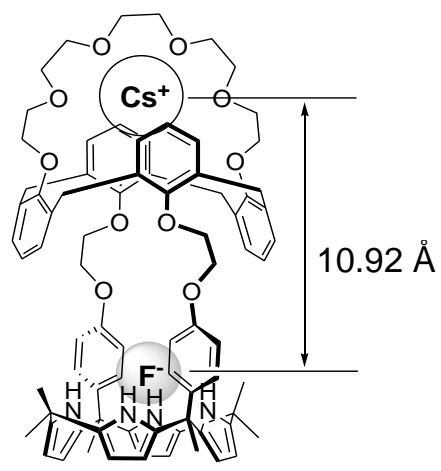

4.1. CsF

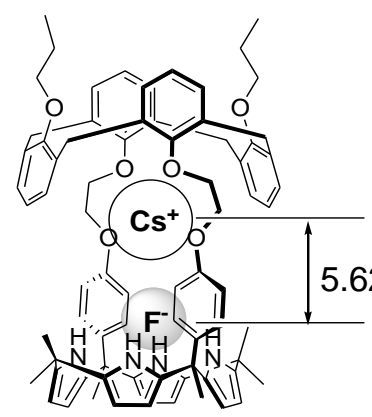

4.2. $\mathrm{CsF}$

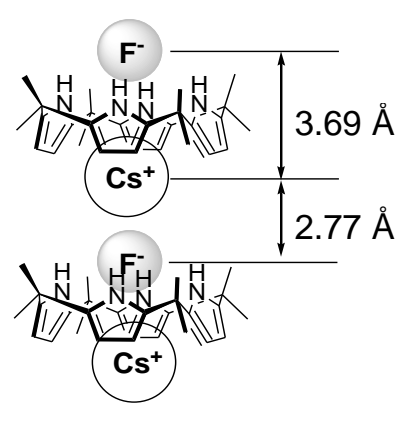

4.3 $\mathrm{CsF}$

Figure 4.13 Binding modes of $\mathrm{CsF}$ ion pairs stabilized by receptors 4.1-4.3 and distances between the $\mathrm{Cs}^{+}$and $\mathrm{F}^{-}$ions seen in the complexes as determined by X-ray diffraction analysis. The structures of the CsF complexes of $\mathbf{4 . 1}$ and $\mathbf{4 . 3}$ were reported in references 12 and $10 \mathrm{c}$, respectively.

Molecular mechanics calculations were performed to gain further insight into the ion pair binding interactions. Definition of van der Waals parameters for the $\mathrm{Cs}^{+}$cation, ${ }^{22}$ allowed calculations to be performed with the MMFF94 force field model. ${ }^{23}$ Starting from the X-ray coordinates, geometry optimization of the solvated $(4.2 \cdot \mathrm{CsF})$ complex resulted in only minor changes to the structure. Figure 4.14a shows the superposition of the optimized geometry on the X-ray geometry, yielding a root mean squared displacement for heavy atom positions of $0.24 \AA$. After removal of the two solvent molecules, further optimization results in a displacement of the $\mathrm{Cs}^{+}$cation from the calix[4]arene pocket toward the $\mathrm{F}^{-}$anion, going from a water-separated ion pair $\mathrm{Cs}^{\cdots} \mathrm{F}$ distance of $5.33 \AA$ to a contact ion pair distance of $2.79 \AA$ (see Figure 4.14b). Thus, the addition of a water spacer is required in order for both the cation and anion of this ion pair to contact their corresponding binding sites within $\mathbf{4 . 2}$. 


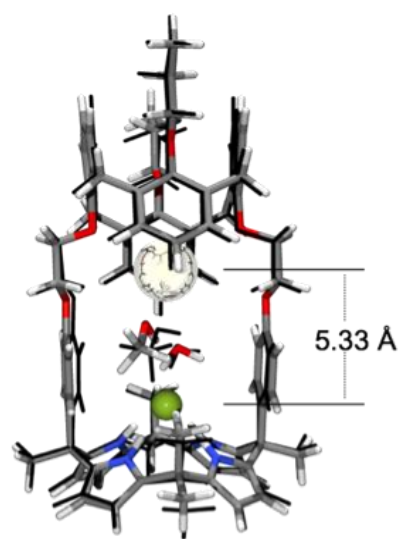

(a)

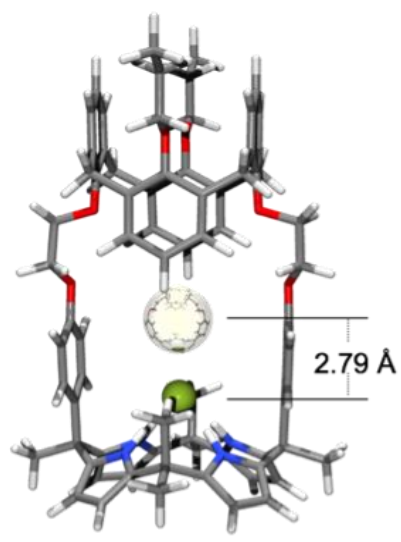

(b)

Figure 4.14 (a) Superposition of calculated versus observed (thin black tubes) geometries for the solvated form of $(4.2 \cdot \mathrm{CsF})$. (b) Calculated geometry for the encapsulated contact $\mathrm{CsF}$ ion pair obtained after solvent is removed.

Further calculations were performed to evaluate the participation of the distal ethylene glycol oxygen atoms in $\mathrm{Cs}^{+}$binding. Conformational analysis of the methoxysubstituted analog of $(4.2 \cdot \mathrm{CsF})$ yielded a $C_{2}$ symmetric conformer as the global minimum, $1.9 \mathrm{kcal} / \mathrm{mol}$ lower in energy than the $\mathrm{X}$-ray conformation. On removal of $\mathrm{F}^{-}$ followed by optimization, the $\mathrm{Cs}^{+}$cation moves into the internal calix[4]arene cavity (Figure $4.15 \mathrm{a}$ ) with a binding energy of $-39.8 \mathrm{kcal} / \mathrm{mol}$. As with the X-ray structure, the $\mathrm{Cs}^{+} \cdots \mathrm{O}$ distances to the calix[4]arene oxygen atoms $(2.91 \AA)$ are significantly shorter than the distances to the distal oxygen atoms (3.31 $\AA$ ). Figure $4.15 \mathrm{~b}$ shows the optimized structure obtained after moving the $\mathrm{Cs}^{+}$to the external calix[4]arene cavity. This position, which lacks the extra two oxygen atoms, yields a $\mathrm{Cs}^{+}$binding energy of $-38.4 \mathrm{kcal} / \mathrm{mol}$. These values can be compared with the value of $-38.6 \mathrm{kcal} / \mathrm{mol}$, which is obtained when 
this model is used to compute the $\mathrm{Cs}^{+}$binding energy to the 1,3-alternate conformation of tetramethoxycalix[4]arene. The results confirm that the elongated $\mathrm{Cs}^{+} \cdots \mathrm{O}$ distances observed in the X-ray structure represent weak contacts that are worth less than 1 $\mathrm{kcal} / \mathrm{mol}$ apiece; in other words, the four calix[4]arene donor sites account for the majority of $\mathrm{Cs}^{+}$binding in the case of $\mathbf{4 . 2}$.

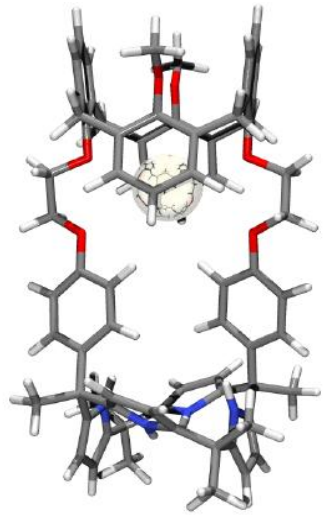

(a)

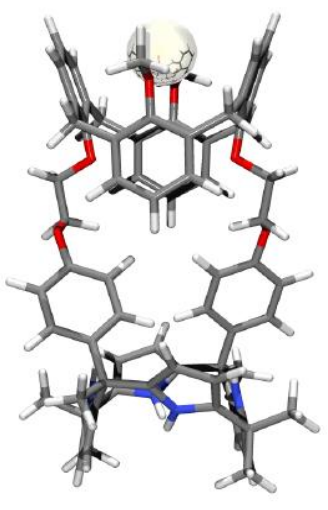

(b)

Figure 4.15 Optimized geometries for $\left(4.2 \cdot \mathrm{Cs}^{+}\right)$with the $\mathrm{Cs}^{+}$cation located in the internal cavity (a) and external cavity (b).

Taken together, the solid state results obtained for the CsF complexes of compounds 4.1-4.3, leads to the conclusion that the $\mathrm{Cs}^{+}$cation complexation is "opportunistic", with the binding taking place in a way that leads, as expected, to a minimization of the overall energetics. Considered in a different light, the differences seen within this series serve to underscore the fact that the formation of complexes, 4.1 $\cdot \mathrm{CsF}$, which represents a host-separated ion pair, and $4.2 \cdot \mathrm{CsF}$, which represents a solvent-bridged ion pair, allows the unfavorable energetics associated with $\mathrm{Cs}^{+}$and $\mathrm{F}^{-}$ 
charge separation to be overcome. The fact that a solvent-bridged ion pair was observed in the case of $(4.2 \cdot \mathrm{CsF})$ led us to consider that the cavity in this receptor might accommodate Cs salts of larger anions, and thus be useful as a cesium cation extractant.

To test whether receptor $\mathbf{4 . 2}$ could be used to effect cesium cation extraction, preliminary extraction studies were carried out using the set up described previously. ${ }^{24}$ Specifically, cesium salts were subject to extraction from an aqueous phase into a nitrobenzene layer containing 4.2 at $10 \mathrm{mM}$. Measuring the cesium distribution ratios as a function of the cesium salt concentration revealed that $\mathrm{CsCl}, \mathrm{CsBr}$, and $\mathrm{CsNO}_{3}$ were extracted as ion pairs in accord with the following thermodynamic equation

$$
\mathrm{Cs}^{+}+\mathrm{X}^{-}+\overline{4.2} \stackrel{\mathrm{K}}{\longleftrightarrow} \overline{\mathrm{CsX} 4.2}
$$

where $\mathrm{X}^{-}$represents nitrate, chloride, or bromide, and a superscripted line denotes species present in the organic phase. Preliminary thermodynamic modeling of the results is consistent with the presence of dissociated ion pairs at low salt concentration and ion pairing at higher salt concentration, a finding that leads credence to the suggestion that conditions appropriate for crystal growth could stabilize the formation of ion-paired complexes.

The nature of the extracted ion-paired complexes was evaluated with further modeling studies. ${ }^{22,23}$ Calculations on $\mathrm{CsCl}$ (Figure 4.16) indicate that the cavity of $\mathbf{4 . 2}$ is too small to contain a water-separated ion pair, but too large for the contact ion pair. When a water molecule is present it binds to the side of the $\mathrm{CsCl}$ ion pair with a $\mathrm{Cs} \cdots \mathrm{O}$ distance of $3.09 \AA$ and a $\mathrm{Cl} \cdots \mathrm{H}$ distance of $2.14 \AA$. This microsolvation results in an ion separation of $3.54 \AA$ (Figure 4.16a). When the water is removed, the separation distance 
decreases to $3.30 \AA$ as the $\mathrm{Cs}^{+}$cation is dragged toward the anion (Figure 4.16b). Although the effect is not as dramatic as with CsF, where the addition of solvent separates the two ions by $2.54 \AA$ (see Figure 4.14), the coordination of water to the side of the $\mathrm{CsCl}$ contact ion pair increases the ion separation by $0.24 \AA$; this allows a more favorable interaction between the calix[4]arene binding site and the $\mathrm{Cs}^{+}$cation. Similar behavior is observed with $\mathrm{CsBr}$, but given the larger size of this anion, the increase in ion separation on water coordination is smaller, $0.17 \AA$ (Figure 4.17).

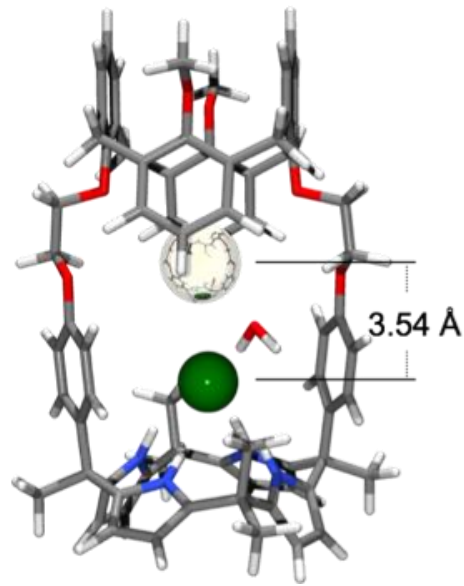

(a)

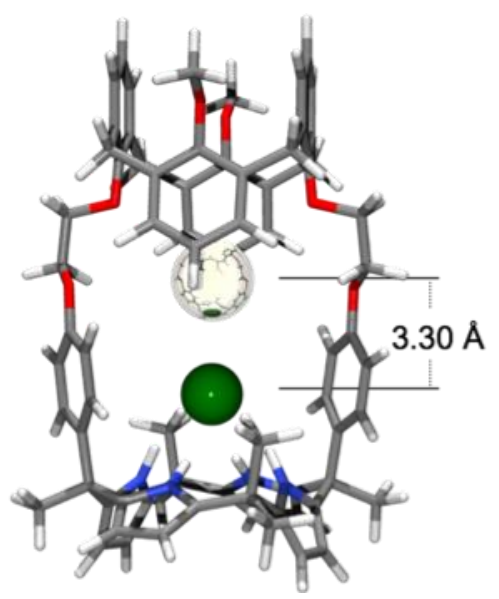

(b)

Figure 4.16 (a) Calculated geometry for $(4.2 \cdot \mathrm{CsCl})$ with a water molecule coordinated to the ion pair. (b) Calculated geometry for $(\mathbf{4 . 2} \cdot \mathrm{CsCl})$. 


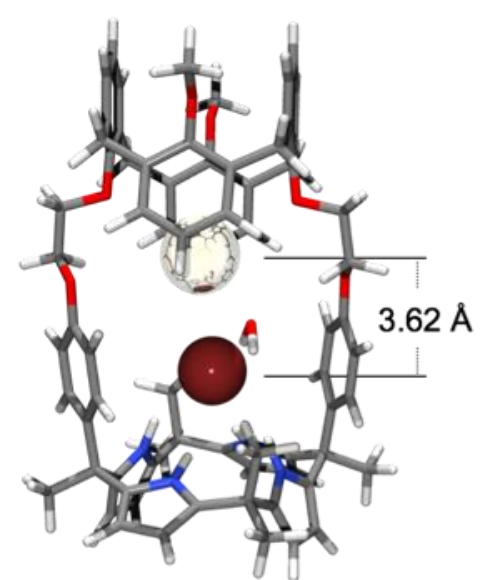

(a)

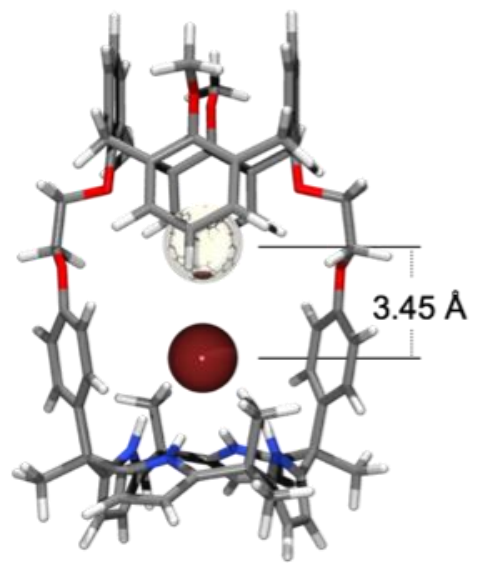

(b)

Figure 4.17 (a) Calculated geometry for $(4.2 \cdot \mathrm{CsBr})$ with a water molecule coordinated to the ion pair. (b) Calculated geometry for $(4.2 \cdot \mathrm{CsBr})$.

The largest ion pair, $\mathrm{CsNO}_{3}$, exhibits the best match to the cavity of $\mathbf{4 . 2}$ (Figure 4.18). Unlike the cesium halide salts where the water interacts with both members of the ion pair, in this case the added water interacts only through hydrogen bonding with the $\mathrm{NO}_{3}{ }^{-}$anion (Figure 4.18a). When the water is removed, the ion separation decreases by only $0.06 \AA$ (Figure $4.18 \mathrm{~b}$ ), with a drop in Cs $\cdots \mathrm{O}$ distance of 3.17 to $3.11 \AA$. These calculated values are consistent with $\mathrm{Cs} \cdots \mathrm{O}$ (nitrate) distances observed in the Cambridge Structural Database (CSD), ${ }^{25} 3.20 \pm 0.09 \AA$, leading to the prediction that $\mathbf{4 . 2}$ should host $\mathrm{CsNO}_{3}$ as a true contact ion pair. 


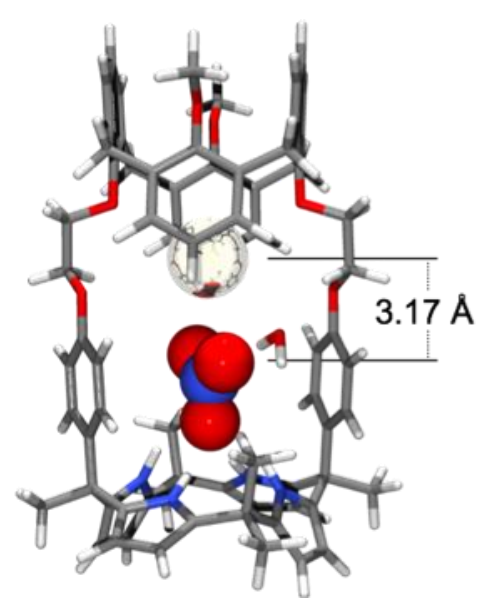

(a)

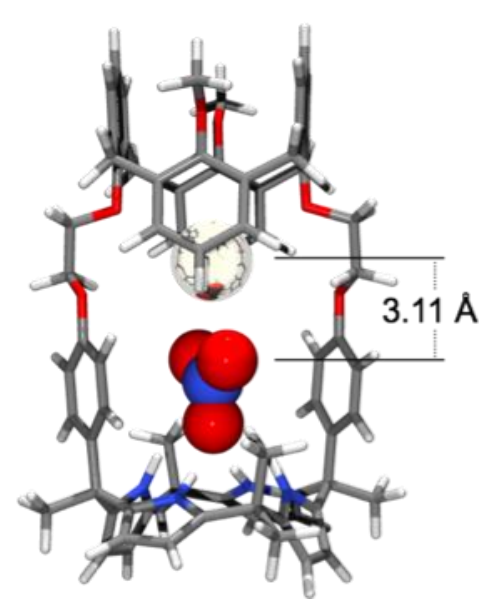

(b)

Figure 4.18 (a) Calculated geometry for $\left(4.2 \cdot \mathrm{CsNO}_{3}\right)$ with a water molecule coordinated to the nitrate anion. (b) Calculated geometry for $\left(4.2 \cdot \mathrm{CsNO}_{3}\right)$.

The solvent extraction and modeling studies provide support for the conclusion that receptor 4.2 should be able to include cesium salts other than CsF, either as "solventloosened" contact ion pairs in the case of $\mathrm{CsCl}$ and $\mathrm{CsBr}$ or as a true contact ion pair in the case of $\mathrm{CsNO}_{3} .{ }^{1} \mathrm{H}$ NMR spectral analyses were carried out in $10 \% \mathrm{CD}_{3} \mathrm{OD}$ in $\mathrm{CDCl}_{3}$ to test whether 4.2 would function in this manner. This solvent mixture, dictated by solubility considerations, permitted qualitative studies but, unfortunately, precluded quantitative measurements.

As in the case of CsF, salt-induced spectral shifts were seen in the presence of $\mathrm{CsCl}, \mathrm{CsBr}$, and $\mathrm{CsNO}_{3}$, consistent with the formation of ion pair inclusion complexes with 4.2 (Figure 4.9). It is of particular interest that $\mathbf{4 . 2}$, unable to complex Lewis basic anions, such as fluoride, in a relatively nonpolar organic solvent system (chloroform), was found to bind a variety of anions (specifically $\mathrm{F}^{-}, \mathrm{Cl}^{-}, \mathrm{Br}^{-}$, and $\mathrm{NO}_{3}^{-}$) in a more polar 
environment $\left(10 \% \mathrm{CD}_{3} \mathrm{OD}\right.$ in $\left.\mathrm{CDCl}_{3}\right)$ provided a presumably co-bound cesium cation is present; this underscores the fact that under these experimental conditions compound $\mathbf{4 . 2}$ is acting as a bona fide ion pair receptor.

Even though quantitative studies of affinities could not be carried out, it is important to appreciate that small differences in the spectra corresponding to the ion pair complexes were observed in the case of the various test cesium salts. For instance, treatment with $\mathrm{CsCl}$ and $\mathrm{CsBr}$ complexes give rise to similar chemical shifts, a reduction of the intensity for the $\beta$-pyrrolic protons was seen in the case of $\mathrm{CsCl}$, but not $\mathrm{CsBr}$, as discussed further below. Moreover, in the case of the $\mathrm{CsNO}_{3}$ complex, the various peaks are split further than in the case of the $\mathrm{CsCl}$ and $\mathrm{CsBr}$ complexes (cf. Figure 4.9).

Explanations for these small differences came from solid-state structural analyses. For instance, unlike the 1:1 solvent-bridged CsF complex obtained when receptor $\mathbf{4 . 2}$ is exposed to $\mathrm{Cs}^{+}$and $\mathrm{F}^{-}$, a 2:2 complex is obtained with $\mathrm{CsCl}\left(\mathbf{4 . 2}_{2} \bullet(\mathrm{CsCl})_{2}\right)$, at least in the solid state. Here, a single crystal X-ray diffraction analysis revealed two different binding modes (Figure 4.19). One cesium ion is bound within the receptor pocket in analogy to what is seen in the CsF complex. In contrast, the other cesium ion forms a sandwich complex with two cone-shaped calix[4]pyrroles (from different receptors). That is, one $\mathrm{CsCl}$ in 4.2 exists as a "solvent-loosened" contact ion pair within the receptor cavity as predicted by modeling (Figure 4.16) and the other is spatially separated by the receptor (i.e., host-separated as per Figure 1.1 in Chapter 1). The crystal structure of the $\mathrm{CsCl}$ complex also shows that the $\mathrm{Cs}^{+}$cation within the pocket, labeled as $\mathrm{Cs} 2$, is further coordinated by a water molecule with $\mathrm{Cs}^{+} \cdots \mathrm{O}$ distance of $3.17 \AA$ (Figure 4.19). This 
cesium cation interacts with the chloride anion labeled as Cl1a, forming the "solventloosened" contact ion pair that, in turn, is bound to $\mathrm{NH}$ protons of the calix[4]pyrrole via hydrogen bonds with distances of $3.32-3.39 \AA\left(\mathrm{N}^{\cdots} \mathrm{Cl}^{-}\right.$interaction). In contrast, the other cesium cation, labeled as Cs1, is sandwiched between two cone-shaped calix[4]pyrrole via a $\pi$-cation interactions characterized by $\mathrm{Cs}^{+} \cdots \mathrm{C}($ pyrrole) distances of $3.28-3.66 \AA$. The chloride anion (C11), spatially separated from Cs1 by the calix[4]pyrrole skeleton, is also bound to the NH's of the calix[4]pyrrole and an $\mathrm{OH}$ of a molecule of methanol via hydrogen bonds with distances of $3.24-3.27 \AA$ for the $\mathrm{N}^{\cdots} \mathrm{Cl}^{-}$ interaction. Such distances are shorter than those for the interaction between Cl1a and the nitrogen atoms of the calix[4]pyrrole subunit, a finding that is attributable to a stronger interaction of the chloride anion with Cs2. The distances between the $\mathrm{Cs}^{+}$cation and the $\mathrm{Cl}^{-}$anion in $4.2_{2} \cdot(\mathrm{CsCl})_{2}$ are found to be $3.60 \AA$ for the contact ion pair $(\mathrm{Cs} 2 \cdots \mathrm{Cl} 1 \mathrm{a}$ interaction) and to be $4.93 \AA$ for the host-separated ion pair (Cs1 $\cdots \mathrm{Cl}$ interaction), respectively. By contrast, the distance between $\mathrm{Cs} 1$ and $\mathrm{Cl1}$ a is found to be $6.25 \AA$, which is interpreted in terms of Cs1 interacting with Cl1 more strongly than with Cl1a. 


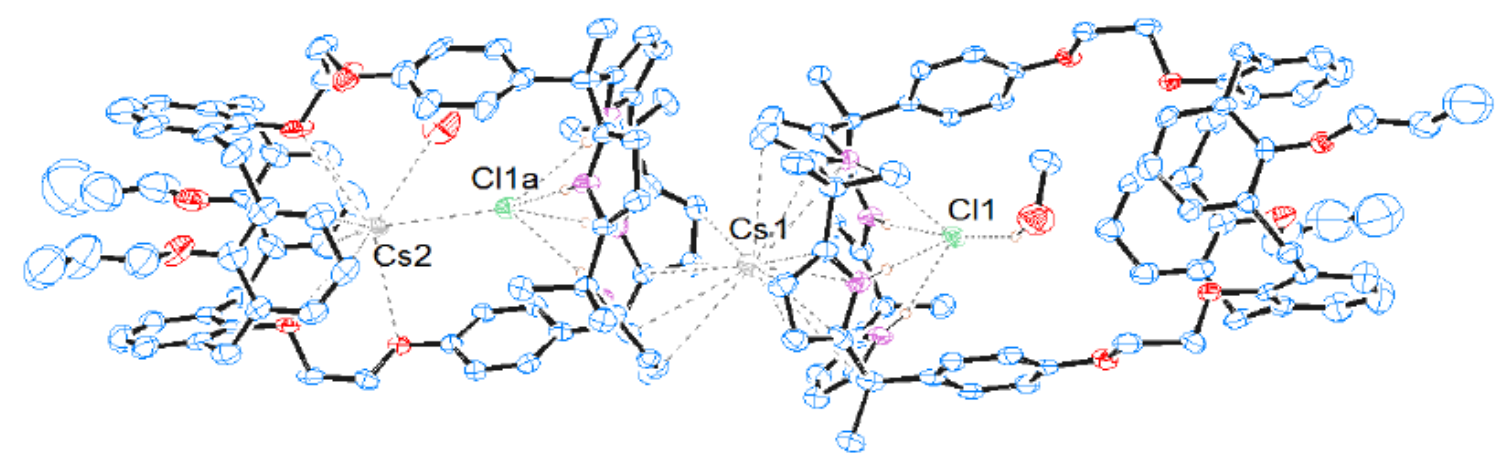

Figure 4.19 Single crystal structure of $4.2_{2} \bullet(\mathrm{CsCl})_{2} \bullet \mathrm{CH}_{3} \mathrm{OH} \cdot \mathrm{H}_{2} \mathrm{O}$. Displacement ellipsoids are scaled to the $30 \%$ probability level. Most hydrogen atoms have been removed for clarity.

Further evidence for the proposed interaction between the cesium cation and the calix[4]pyrrole moiety came from the finding that the $\beta$-protons of the pyrrole subunits undergo D-for-H exchange in $\mathrm{CD}_{3} \mathrm{OD}$ in the presence of $\mathrm{CsCl}$. This is a reaction that has not hitherto been observed in the context of calix[4]pyrrole chemistry. As shown in Figures 4.9 and 4.20 , the peaks of the $\beta$-pyrrolic protons of calix[4]pyrrole subunits are almost absent from the ${ }^{1} \mathrm{H}$ NMR spectra of 4.2 recorded roughly 10 minutes after the addition of 5.0 equiv of $\mathrm{CsCl}$ in $10 \% \mathrm{CD}_{3} \mathrm{OD}$ in $\mathrm{CDCl}_{3}(\mathrm{v} / \mathrm{v})$. In contrast, when the corresponding experiment is run using $10 \% \mathrm{CH}_{3} \mathrm{OH}$ (a proton-containing solvent) in $\mathrm{CDCl}_{3}(\mathrm{v} / \mathrm{v})$, the peaks for the $\beta$-pyrrolic protons are still observed in the presence $\mathrm{CsCl}$ (Figure 4.20c). Such observations are completely consistent with the suggestion that the disappearance of the $\beta$-pyrrolic proton peak in the presence of $\mathrm{CD}_{3} \mathrm{OD}$ is due to deuterium exchange and that this exchange is abetted by $\pi$-metal complexation involving the cesium cation and the four pyrrolic subunits that make up the calix[4]pyrrole core. It is important to note that facile $\mathrm{D}$-for-H exchange is not seen in the case of the $\mathrm{CsBr}$ or 156 
$\mathrm{CsNO}_{3}$ complexes of $\mathbf{4 . 2}$ (Figure 4.9), lending credence to the suggestion that the ion pair binding mode differs for these two salts. ${ }^{26}$
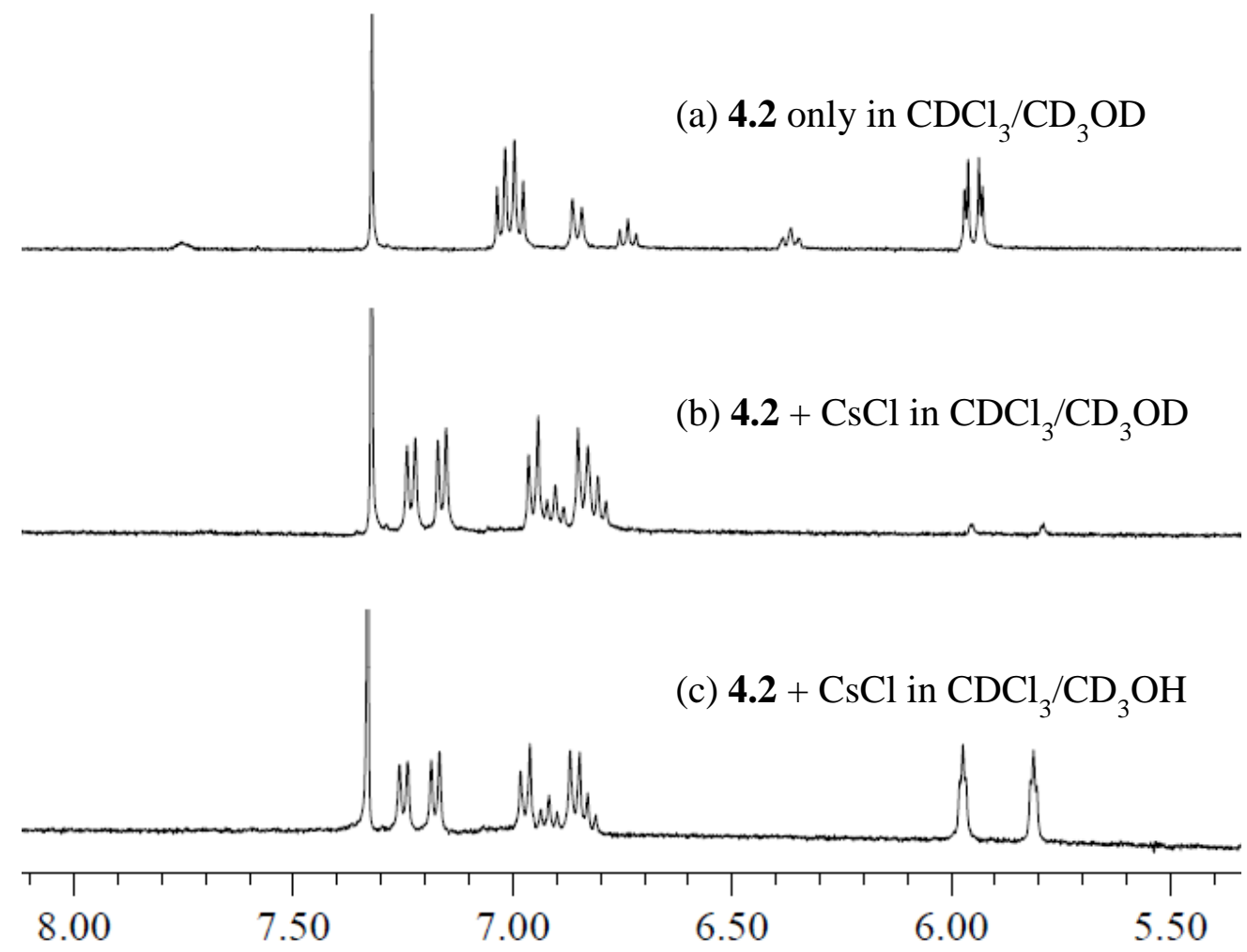

Figure 4.20 Partial ${ }^{1} \mathrm{H}$ NMR spectra of (a) 4.2 only and (b) $4.2+5$ equiv of $\mathrm{CsCl}$ in $\mathrm{CD}_{3} \mathrm{OD} / \mathrm{CDCl}_{3}(1: 9, \mathrm{v} / \mathrm{v})$, and (c) $4.2+5$ equiv of $\mathrm{CsCl}$ in $\mathrm{CH}_{3} \mathrm{OH} / \mathrm{CDCl}_{3}$ $(1: 9, \mathrm{v} / \mathrm{v})$. The spectra were recorded roughly 10 minutes after mixing.

Considering the extraction studies, modeling results, and the absence of D-for- $\mathrm{H}$ exchange seen in $10 \% \mathrm{CD}_{3} \mathrm{OD}-\mathrm{CDCl}_{3}(\mathrm{v} / \mathrm{v})$ (vide supra), it was considered likely that 4.2 would bind $\mathrm{CsBr}$ and $\mathrm{CsNO}_{3}$ as contact pairs. Concrete support for this conclusion, at least in the solid state, came from single crystal diffraction analyses of the latter salt. The structure of the $\mathrm{CsNO}_{3}$ complex, obtained from crystals grown by slow evaporation of a 
chloroform/methanol solution of receptor $\mathbf{4 . 2}$ in the presence of $\mathrm{CsClO}_{4}$ and $\mathrm{TBANO}_{3}$, is shown in Figure 4.21. It reveals that the nitrate anion is coordinated to the $\mathrm{Cs}^{+}$cation with two oxygen atoms and the third oxygen atom is bound to the calix[4]pyrrole moiety via hydrogen bonding contacts characterized by $\mathrm{N}^{\cdots} \mathrm{O}^{-}$distances of $2.95-3.04 \AA$. The distance between the cesium cation and the two oxygen atoms of the nitrate anion (3.12 and $3.17 \AA$ ) are in excellent agreement with those predicted by modeling (3.11 $\AA$, Figure 4.18) and observed in other crystal structures bearing contact $\mathrm{CsNO}_{3}$ ion pairs $(3.20 \pm$ $0.09 \AA$ ); confirming that the cesium cation and the nitrate anion exist as a true contact ion pair in this complex.
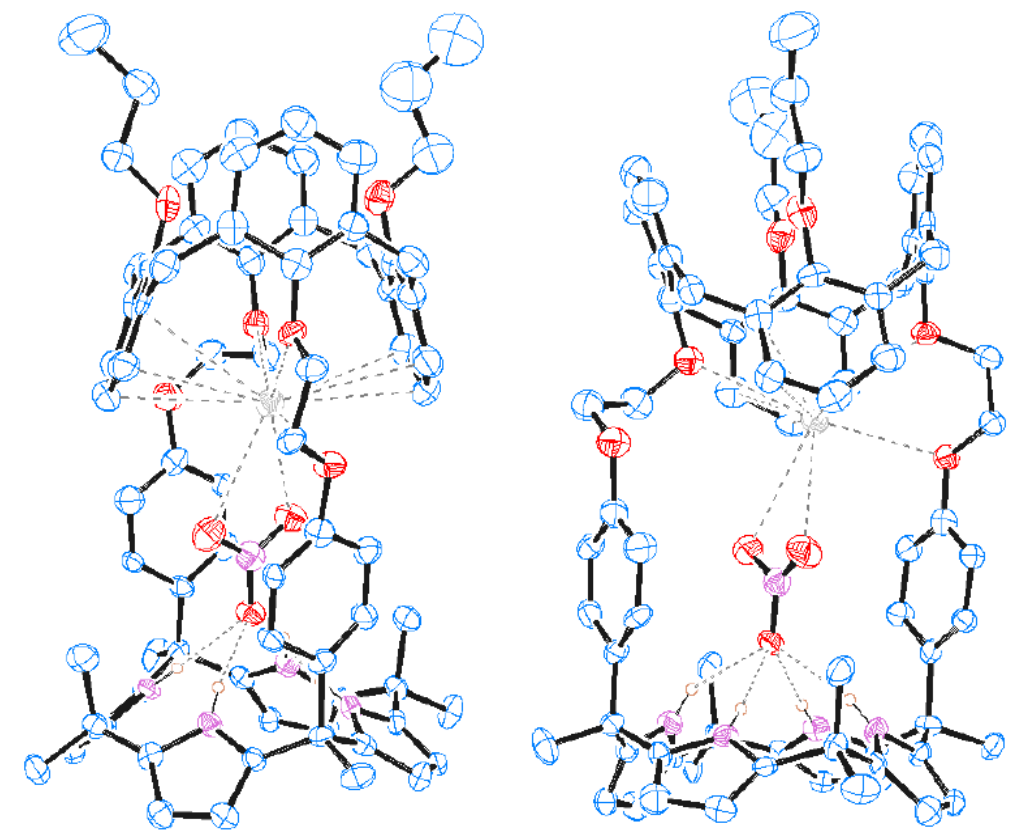

Figure 4.21 Two different views of the single crystal structure of $4.2 \cdot \mathrm{CsNO}_{3}$. Displacement ellipsoids are scaled to the $30 \%$ probability level. Most hydrogen atoms have been removed for clarity. 


\subsection{ConClusions}

In conclusion, an ion pair receptor, 4.2, derived by coupling a strong anionbinding site with a weak cation recognition site, has been synthesized and characterized by standard spectroscopic means, as well as through the use of single crystal X-ray diffraction analysis. Taken in concert, the X-ray crystal structural data and the ${ }^{1} \mathrm{H}$ NMR spectroscopic analyses reveal that in both the solid state and in mixed methanolchloroform solution, receptor $\mathbf{4 . 2}$ forms a stable 1:1 complex with a solvent-bridged CsF species, but only if both the anion and cation are both present. Such behavior, which follows the terms associated with an $A N D$ logic gate, stands in marked contrast to what was seen for the earlier system, 4.1. This previously reported receptor binds the two constituent ions sequentially, with the $\mathrm{Cs}^{+}$cation being bound before the $\mathrm{F}^{-}$anion. Receptor 4.2 was also found to bind other cesium salts in mixed methanol-chloroform solution on the basis of an $A N D$ logic gate even though it fails to bind the constituent counter anions (as the tetrabutylammonium salts) in pure chloroform. Receptor $\mathbf{4 . 2}$ forms an unprecedented 2:2 complex with $\mathrm{CsCl}$ characterized by two different ion pair binding modes, including one where the anion and cation are separated by the host framework. In contrast, single crystal X-ray diffraction analyses and ${ }^{1} \mathrm{H}$ NMR spectroscopic studies reveal that 4.2 forms only a 1:1 complex with $\mathrm{CsNO}_{3}$, wherein the anion and cation are held together in close proximity as contact ion pairs. These findings reveal receptor $\mathbf{4 . 2}$ to be a versatile ion pair receptor whose binding behavior can be modulated via an appropriate choice of the counter anion.

\subsection{REFERENCES}

(1) (a) Lehn, J.-M. Supramolecular Chemistry: Concepts and Perspectives; VCH: Weinheim, Germany, 1995. (b) Steed, J. W.; Atwood, J. L. Supramolecular Chemistry: An Introduction, Wiley, Chichester, U.K., 2000. (c) Beer, P. D.; Gale, P. A.; Smith, D. K. Supramolecular Chemistry, OUP, Oxford, U.K.,1999. 
(2) Sessler, J. L.; Gale, P. A.; Cho, W.-S. Anion Receptor Chemistry; Monographs in Supramolecular Chemistry, Stoddart, J. F., Ed.; RSC Publishing: Cambridge, U.K., 2006.

(3) Gokel, G. W. In Comprehensive Supramolecular Chemistry: Molecular Recognition, Receptors for Cationic Guests; Lehn, J.-M.; Atwood, J. L.; Davies, J. E. D.; MacNicol, D. D.; Vögtle, F., Eds.; Pergamon: Oxford, U.K., 1996; Vol. 1.

(4) (a) Beer, P. D.; Gale, P. A. Angew. Chem. Int. Ed. 2001, 40, 486-516. (b) Gale, P. A. Coord. Chem. Rev. 2003, 240, 191-221. (c) Gale, P. A.; Quesada, R. Coord. Chem. Rev. 2006, 250, 3219-3244. (d) Gale, P. A.; García-Garrido, S. E.; Garric, J. Chem. Soc. Rev. 2008, 37, 151-190.

(5) (a) Smith, B. D. In Ion-pair Recognition by Ditopic Receptors, Macrocyclic Chemistry: Current Trends and Future Perspectives; Gloe, K.; Antonioli, B.,Eds.; Kluwer, London, U.K., 2005; pp 137-152. (b) Kirkovits, G. J.; Shriver, J. A.; Gale, P. A.; Sessler, J. L. J. Incl. Phenom. Macrocycl. Chem. 2001, 41, 69-75.

(6) (a) Pfeifer, J. R.; Reiss, P.; Koert, U. Angew. Chem. Int. Ed. 2006, 45, 501-504. (b) Sisson, A. L.; Shah, M. R.; Bhosale, S.; Matile, S. Chem. Soc. Rev. 2006, 35, 12691286. (c) Nakamura, T.; Akutagawa, T.; Honda, K.; Underhill, A. E.; Coomber, A. T.; Friend, R. H. Nature 1998, 394, 159-162. (d) Gokel, G. W.; Leevy, W. M.; Weber, M. E. Chem. Rev. 2004, 104, 2723-2750. (e) Davis, A. P.; Sheppard, D. N.; Smith, B. D. Chem. Soc. Rev. 2007, 36, 348-357.

(7) (a) Chrisstoffels, L. A. J.; De Jong, F.; Reinhoudt, D. N.; Sivelli, S.; Gazzola, L.; Casnati, A.; Ungaro, R. J. Am. Chem. Soc. 1999, 121, 10142-10151. (b) Rudkevich, D. M.; Mercer-Chalmers, J. D.; Verboom, W.; Ungaro, R.; Reinhoudt, D. N. J. Am. Chem. Soc. 1999, 117, 6124-6125. (c) Tong, C. C.; Quesada, R.; Sessler, J. L.; Gale, P. A. Chem. Commun. 2008, 6321-6323.

(8) (a) Mahoney, J. M.; Stucker, K. A.; Jiang, H.; Carmichael, I.; Brinkmann, N. R.; Beatty, A. M.; Noll, B. C.; Smith, B. D. J. Am. Chem. Soc. 2005, 127, 2922-2928. (b) Deetz, M. J.; Shang, M.; Smith, B. D. J. Am. Chem. Soc. 2000, 122, 6201-6207. (c) Mahoney, J. M.; Beatty, A. M.; Smith, B. D. Inorg. Chem. 2004, 43, 7617-7621. (d) Mahoney, J. M.; Davis, J. P.; Smith, B. D. J. Org. Chem. 2003, 68, 9819-6820. (e) Mahoney, J. M.; Beatty, A. M.; Smith, B. D. J. Am. Chem. Soc. 2001, 123, 5847-5858. (f) Mahoney, J. M.; Nawaratna, G. U.; Beatty, A. M.; Duggan, P. J.; Smith, B. D. Inorg. Chem. 2004, 43, 5902-5907. (g) Mahoney, J. M.; Marshall, R. A.; Beatty, A. M.; Smith, B. D.; Camiolo, S.; Gale, P. A. J. Supramol. Chem. 2003, 1, 289-292. 
(9) Reeske, G.; Bradtmöller, G.; Schürmann, M.; Jurkschat, K. Chem. Eur. J. 2007, 13, 10239-10245.

(10) (a) Scheerder, J.; van Duynhoven, J. P. M.; Engbersen, J. F. J.; Reinhoudt, D. N. Angew. Chem. Int. Ed. 1996, 35, 1090-1093. (b) Mele, A.; Metrangolo, P.; Neukirch, H.; Pilati, T.; Resnati, G. J. Am. Chem. Soc. 2005, 127, 14972-14973. (c) Custelcean, R.; Delmau, L. H.; Moyer, B. A.; Sessler, J. L.; Cho, W. -S.; Gross, D.; Bates, G. W.; Brooks, S. J.; Light, M. E.; Gale, P. A. Angew. Chem. Int. Ed. 2005, 44, 2537-2542.

(11) Reeske, G.; Schürmann, M.; Jurkschat, K. Dalton Trans. 2008, 3398-3400.

(12) Sessler, J. L.; Kim, S. K.; Gross, D. E.; Lee, C. -H.; Kim, J. S.; Lynch, V. M. J. Am. Chem. Soc. 2008, 130, 13162-13166.

(13) Note: calix[4]arenes in their 1,3-alternate are known to bind $\mathrm{Cs}^{+}$weakly, whereas calix[4]crown-6 is known to complex $\mathrm{Cs}^{+}$strongly. See: (a) Iwamoto, K.; Araki, K.; Shinkai, S. Tetrahedron 1991, 47, 4325-4342. (b) Verboom, W.; Datta, S.; Asfari, Z.; Harkema, S.; Reinhoudt, D. N. J. Org. Chem. 1992, 57, 5394-5398. (c) Meier, U. C.; Detellier, C. J. Phys. Chem. A 1998, 102, 1888-1893.

(14) Roelens, S.; Vacca, A.; Francesconi, O.; Venturi, C. Chem. Eur. J. 2009, 15, 82968302.

(15) (a) No, K.; Lee, H. J.; Park, K. M.; Lee, S. S.; Noh, K. H.; Kim, S. K.; Lee, J. Y.; Kim, J. S. J. Heterocycl. Chem. 2004, 41(2), 211-219. (b) Kim, J. S.; Shon, O. J.; Ko, J. W.; Cho, M. H.; Yu, I. Y.; Vicens, J. J. Org. Chem. 2000, 65, 2386-2392.

(16) Yoon, D.-W.; Hwang, H.; Lee, C.-H. Angew. Chem. Int. Ed. 2002, 41, 1757-1759.

(17) (a) Gale, P. A.; Sessler, J. L.; Král, V.; Lynch, V. J. Am. Chem. Soc. 1996, 118, 5140-5141. (b) Sessler, J. L.; Gross, D. E.; Cho, W. -S.; Lynch, V. M.; Schmidtchen, F. P.; Bates, G. W.; Light, M. E.; Gale, P. A. J. Am. Chem. Soc. 2006, $128,12281-12288$.

(18) Sato, W.; Miyaji, H.; Sessler, J. L. Tetrahedron Lett. 2000, 41, 6731-6736.

(19) (a) de Silva, A. P.; Uchiyama, S. Nature Nanotech. 2007, 2, 399-410. (b) de Silva, A. P.; McClenaghan, N. D. Chem. Eur. J. 2004, 10, 574-586. (c) Magri, D. C.; Brown, G. J.; McClean, G. D.; de Silva, A. P. J. Am. Chem. Soc. 2006, 128, 49504951. (d) de Silva, A. P.; Gunaratne, H. Q. N.; McCoy, C. P. J. Am. Chem. Soc. 1997, 119, 7891-7892. (e) de Silva, R. A.; Gunaratne, H. Q. N.; McCoy, C. P. Nature 1993, 364, 42-44. 
(20) Lankshear, M. D.; Dudley, I. M.; Chan, K.-M.; Cowley, A. R.; Santos, S. M.; Felix, V.; Beer, P. D. Chem. Eur. J. 2008, 14, 2248-2263.

(21) (a) Hay, B. P.; Nicholas, J. B.; Feller, D. J. Am. Chem. Soc. 2000, 122, 1008310089. (b) Nicholas, J. B.; Hay, B. P. J. Phys. Chem. A 1999, 103, 9815-9820.

(22) MMFF94 van der Waals parameters for the $\mathrm{Cs}^{+}$cation were adapted from the default values used for the $\mathrm{K}^{+}$cation by altering the atomic polarizability from 1.0 to $2.0 \AA^{3}$.

(23) Halgren, T. A. J. Comp. Chem. 1996, 17, 490-519.

(24) Wintergerst, M. P.; Levitskaia, T. G.; Moyer, B. A.; Sessler, J. L.; Delmau, L. H. J. Am. Chem. Soc. 2008, 130, 4129-4139.

(25) Allen, F. H.; Kennard, O.; Taylor, R. Acc. Chem. Res. 1983, 16, 146-153.

(26) The basis for the $\mathrm{CsCl}$-selective deuterium exchange may reflect the favorable cone angle established in this particular anion complex. The cone angle is expected to be larger in the case of the corresponding fluoride complex. This and the existence of more favorable ion pair binding modes would preclude the presence of substantial quantities of $\mathrm{Cs}^{+}$in the calix[4]pyrrole "cup". Conversely, in the case of the other cesium salts examined, $\mathrm{CsBr}$ and $\mathrm{CsNO}_{3}$, anion complexation will produce structures with smaller cone angles. Thus, even though binding within the cup of calix [4]pyrrole might occur to a certain extent (it is not the dominant mode as noted in the text proper), the resulting complexes would lack an optimal geometry for Dfor-H exchange. 


\section{Chapter 5: Ion Pair Complexes of a Calix[4]arene-Crown-5 Calix[4]pyrrole Multitopic Receptor. Evidence for Cation Metathesis}

\subsection{INTRODUCTION}

It is widely appreciated that ions, both cations and anions, play critical roles in various fields of biological and environmental science. Not surprisingly, therefore, over the past several decades, considerable effort has been devoted to the design and synthesis

of ion receptors. ${ }^{1-3}$ Most artificial ion receptors reported thus far have been designed and developed to recognize or bind either cations or anions, but not both. ${ }^{2-4}$ However, recently, as the important role played by counterions in modulating the binding strength and selectivity of ion receptors has come to be better appreciated, increasing attention has been devoted to the synthesis of so-called ion pair receptors. ${ }^{5}$ Broadly speaking, ion pair receptors are species which have two or more different ion recognition sites and are able to bind both cations and anions. Included among the systems reported so far are Smith's and Beer's pioneering ditopic systems that in the early days served to establish that, compared to single ion receptors, ion pair receptors can display a significantly enhanced affinity and selectivity for ions. While not get established unequivocally, these enhanced features probably result from allosteric effects and enhanced electrostatic interactions between the co-bound ions present in the ion pair complexes. In purely operational terms, the putative improvements seen relative to monotopic or single site receptors has made ion pair receptors alternative for use in salt solublization, ion extraction, trans-membrane ion transport, ion sensing applications and as logic gates. ${ }^{6-11}$ However, in spite of their significant advantages, only a limited number of well characterized ion pair receptors are currently known. We attribute this to the synthetic difficulties associated with incorporating two disparate binding motifs into a single framework as well as to experimental complexities associated with tracking multiple 
ionic species, a problem compound by the poor solubility of many of the ion pairs (salts) that are commonly tested. ${ }^{5-11}$

As detailed in chapters 1 and 4, ion pair receptors can be classified according to whether they bind ion pairs in a sequential or concurrent fashion under the conditions of analysis. ${ }^{12}$ In the case of sequential binding, the receptor binds one ion of the ion pair on its own. Once bound, the first ion increases the affinity for the other ion of the ion pair. ${ }^{12}$ For example, in the presence of $\mathrm{CsF}$ in a $10 \%$ solution of methanol in chloroform, the ion pair receptor 5.1 was found to bind the $\mathrm{Cs}^{+}$cation first via complexation to the calix[4]arene crown-6. This binding results in an affinity for the $\mathrm{F}^{-}$anion that is enhanced. This anion then bind to the calix[4]pyrrole moiety to complete the formation of the CsF complex. ${ }^{13}$ In the case of concurrent binding, the receptor literally forms a complex simultaneously with both the anion and cation of the ion pair. ${ }^{11}$ For instance, receptor 5.2 binds both the $\mathrm{Cs}^{+}$cation and the $\mathrm{F}^{-}$anion concurrently on the NMR time scale in $10 \%$ methanol/chloroform. ${ }^{11}$ This kinetic definition is useful and can provide insights beyond those obtained from strict thermodynamic analyses of the ion pair binding modes.

The author has recently defined three limiting binding modes, namely, contact ion pair (direct interaction between anion and cation), solvent separated ion pair (where one or more solvent molecules serve to bridge the anion and cation), and receptor-separated ion pair (where the bound anion and cation are physically separated by the receptor framework). ${ }^{11,12}$ The determinants that lead one mode to be favored over another are still far from being fully understood.

Although a number of ion pair receptors have been synthesized and studied, ${ }^{5,12}$ few have been studied with a view to proving such fundamental questions. ${ }^{11}$ Such an understanding is deemed essential if ion pair receptors are to be designed that are 164 
maximally effective as carriers, extractants, or chemical sensor elements. In order to obtain greater insight into ion pair receptors, we recently synthesized ion pair receptor $\mathbf{5 . 1}$ bearing two strong ion binding sites (a calix[4]arene-crown- 6 for the $\mathrm{Cs}^{+}$cation and a calix[4]pyrrole for anions) and demonstrated its ability to act as an ion pair receptor for the CsF ion pair. ${ }^{13}$ Proton NMR spectra and X-ray diffraction analyses revealed that, in spite of a large $\mathrm{Cs}^{+}-\mathrm{F}^{-}$separation $(>10 \AA)$, receptor $\mathbf{5 . 1}$ forms a stable 1:1 ion pair complex with CsF both in the solution and the solid state. ${ }^{13}$ In contrast, the crown-free ion pair receptor $\mathbf{5 . 2}$ was found to form complexes with various cesium salts, including $\mathrm{CsF}, \mathrm{CsCl}, \mathrm{CsBr}$, and $\mathrm{CsNO}_{3}$, in various ion pair recognition modes. ${ }^{11}$ In these latter complexes, the $\mathrm{Cs}^{+}$cations were found to bind to the ethylene glycol moieties between the calix[4]pyrrole subunit and the calix[4]arene "cap". Interestingly, this latter binding motif did not act as an independent binding site for the $\mathrm{Cs}^{+}$cation in the absence of a cobound anion complexed within the calix[4]pyrrole subunit. As a result, ion pair recognition by receptor $\mathbf{5 . 2}$ was found to be governed by the rules of an $A N D$ logic, in that both species had to be present to see effective binding. ${ }^{11}$

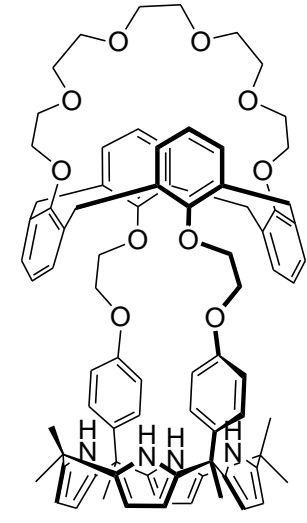

5.1

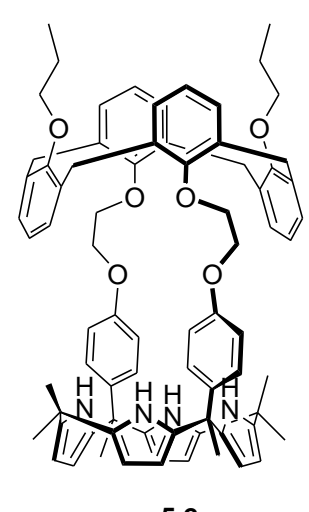

5.2

Figure 5.1 Chemical structures of compound 5.1 and 5.2. 
In an effort to understand in greater detail the correlation between receptor structure and ion pair binding function, The author have now prepared and herein report the first ion pair receptor $\mathbf{5 . 3}$ having multiple cation recognition sites for two different cations as well as a strong anion binding site. This receptor has one fewer oxygen atom in the calix[4]arene crown ring than does receptor 5.1. Specifically, it incorporates a calix[4]arene crown-5 strapping moiety. This change was expected to provide a system with a dedicated $\mathrm{K}^{+}$binding site with a relative affinity for $\mathrm{K}^{+}$that was much larger than that of the calix[4]arene crown-5 subunit, the ethylene glycol spacers, or the calix[4]pyrrole bowl (a site known to favor $\mathrm{Cs}^{+}$cation complexation) for the $\mathrm{Cs}^{+}$ cation. $^{11,14-16}$

As detailed below, ${ }^{1} \mathrm{H}$ NMR spectroscopic studies and X-ray crystal diffraction analysis reveal that receptor $\mathbf{5 . 3}$ binds both $\mathrm{K}^{+}$and $\mathrm{Cs}^{+}$salts, but via different binding modes and with different binding kinetics on the NMR time scale. In particular, receptor 5.3 recognizes the $\mathrm{Cs}^{+}$cation via two different binding sites depending on the counteranions bound to the calix[4]pyrrole. We also demonstrate that, in $\mathbf{5 . 3}$, the calix[4]crown-5 moiety, which is known to act as a weak binding site for the $\mathrm{Cs}^{+}$ cation, ${ }^{16}$ is capable of forming very strong complexes with the $\mathrm{Cs}^{+}$cations in the presence of a co-bound counteranion. We also show that upon the addition of the $\mathrm{K}^{+}$cation as its perchlorate salt to pre-formed $\mathrm{CsX}\left(\mathrm{X}=\mathrm{F}, \mathrm{Cl}\right.$, and $\left.\mathrm{NO}_{3}\right)$ complexes, cation metathesis occurs. Specifically, the $\mathrm{K}^{+}$cation displaces the $\mathrm{Cs}^{+}$cation bound to the calix[4]arene crown-5 cavity. This results in the formation of the corresponding $\mathrm{KX}(\mathrm{X}=\mathrm{F}, \mathrm{Cl}$, and $\mathrm{NO}_{3}$ ) complexes. These generally precipitate, leaving the $\mathrm{Cs}^{+}$cation free in solution. As illustrated in Figure 5.2, the differing cation affinity may be exploited for purification. For instance, the $\mathrm{Cs}^{+}$cation can be extracted from an aqueous phase into a nitrobenzene phase by receptor 5.3. It may then be recovered via cation metathesis by washing with 
aqueous solutions containing the $\mathrm{K}^{+}$cation. In addition, the receptor can then be recovered by washing with water and chloroform. Separate from this, ion pair receptor 5.3 proved capable of extracting various potassium salts from an aqueous phase into a nitrobenzene layer, a finding ascribed to the formation of two different ion pair complexes depending on the specific counteranion involved.

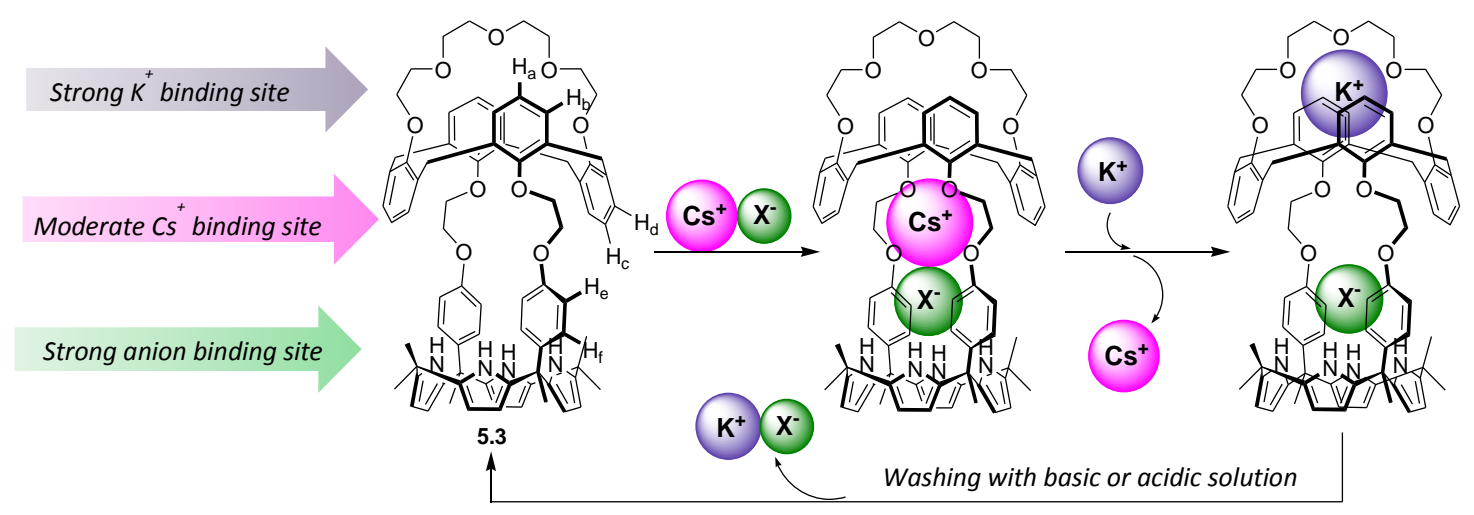

Figure 5.2 Design concept underlying ion pair receptor 5.3.

\subsection{RESULTS AND DISCUSSION}

The synthesis of ion pair receptor $\mathbf{5 . 3}$ is summarized in Scheme 5.1. The hydroxyl group of 1-[4-(2-hydroxyethoxy)phenyl]ethanone $\mathbf{5 . 4}$ is tosylated using $\mathrm{NaOH}$ and $\mathrm{TsCl}$ in THF to give tolsylate $\mathbf{5 . 5}$ in high yield. This intermediate was subsequently condensed with pyrrole in the presence of 20 equivalents of trifluoroacetic acid at $65{ }^{\circ} \mathrm{C}$ to produce dipyromethane 5.6 in $62 \%$ yield. The dipyromethane tosylate (5.6) was reacted with the calix[4]arene monocrown-5 (5.7) ${ }^{17}$ in the presence of 3.0 equivalents of $\mathrm{Cs}_{2} \mathrm{CO}_{3}$ in acetonitrile under reflux to afford the calix[4]arene crown-5 dipyromethane $\mathbf{5 . 8}$ in the 1,3-alternate conformation in $61 \%$ yield. Further condensation of compound 5.8 with 
acetone in the presence of a catalytic amount of $\mathrm{BF}_{3} \cdot \mathrm{OEt}_{2}$ gave ion pair receptor $\mathbf{5 . 3}$ in $18 \%$ yield. $^{11,13}$

Scheme 5.1 Synthesis of ion pair receptor $\mathbf{5 . 3}$
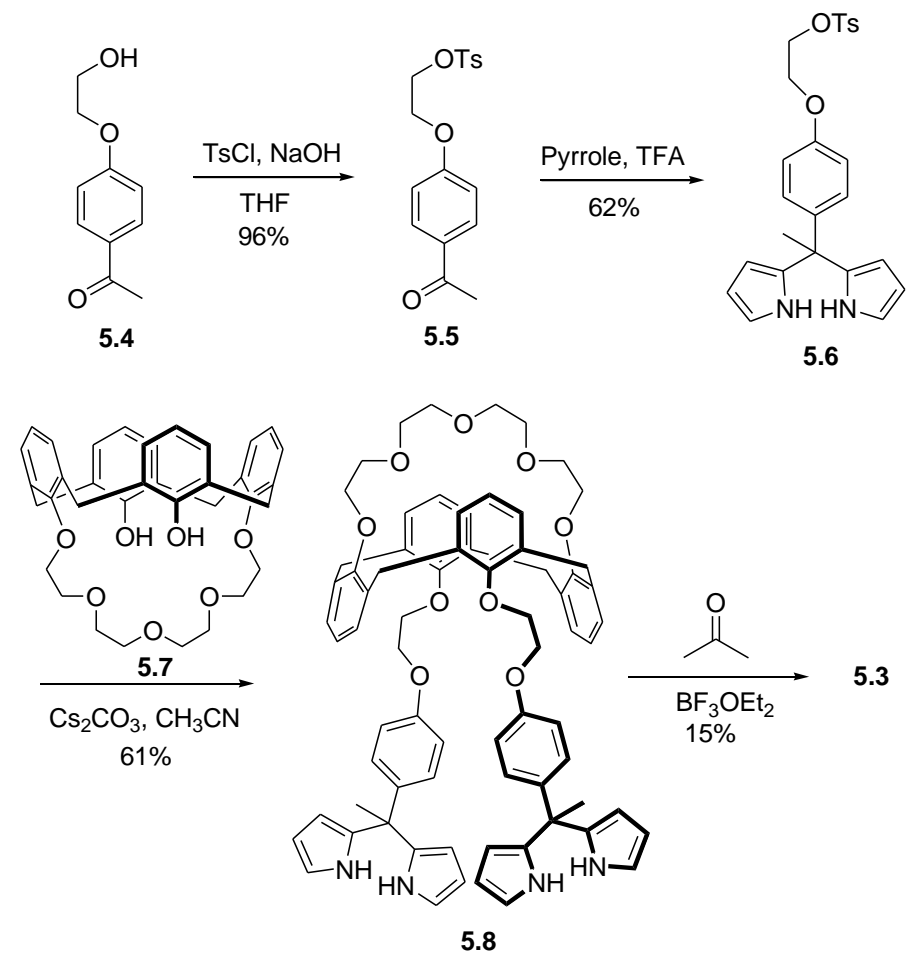

Compound 5.3 was fully characterized by standard spectroscopic means, as well as by single crystal X-ray diffraction analysis (Figure 5.3). Suitable crystals were obtained by allowing methanol vapor to diffuse into an acetonitrile solution containing receptor 5.3 in its ion-free form. The resulting crystal structure revealed that the calix[4]arene subunit adopts the expected 1,3-alternate conformation, whereas the calix[4]pyrrole subunit is in the cone conformation with one acetonitrile molecule hydrogen-bonded to the pyrrolic NH protons. 

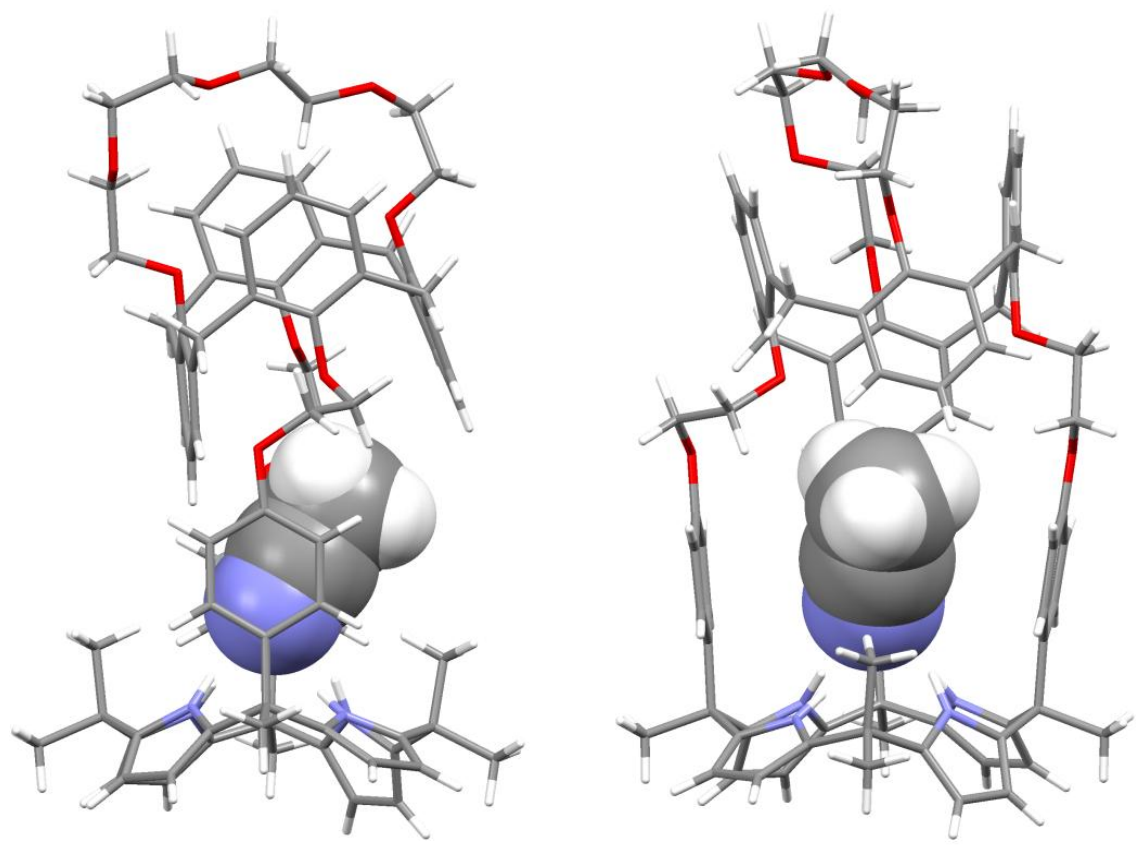

Figure 5.3 Two different views of the single crystal structure of $5.3 \cdot \mathrm{CH}_{3} \mathrm{CN}$.

In a first set of analyses, the ability of ion pair receptor $\mathbf{5 . 3}$ to bind halide anions and the nitrate anion in $\mathrm{CDCl}_{3}$ solution was investigated via ${ }^{1} \mathrm{H}$ NMR spectroscopy. In analogy to what was found to be true in the cases of receptors $\mathbf{5 . 1}$ and 5.2, significant chemical shift changes in the NMR spectrum of $\mathbf{5 . 3}$ were observed when the receptor was subjected to titration with fluoride anion salts (e.g., tetrabutylammonium fluoride, TBAF) (Figure 5.4). ${ }^{11,13}$ However, other anions tested (TBACl, TBABr, TBAI, and $\mathrm{TBANO}_{3}$ ) induced no appreciable chemical shift changes in the NMR spectra of receptor $\mathbf{5 . 3}$ in $\mathrm{CDCl}_{3}$. This finding provides support for the conclusion that, like the earlier systems $\mathbf{5 . 1}$ and 5.2, receptor $\mathbf{5 . 3}$ is highly selective for the fluoride anion under these solvent conditions (Figures 5.4 and 5.5). ${ }^{11,13}$ 
(a) $\mathbf{5 . 3}$ only
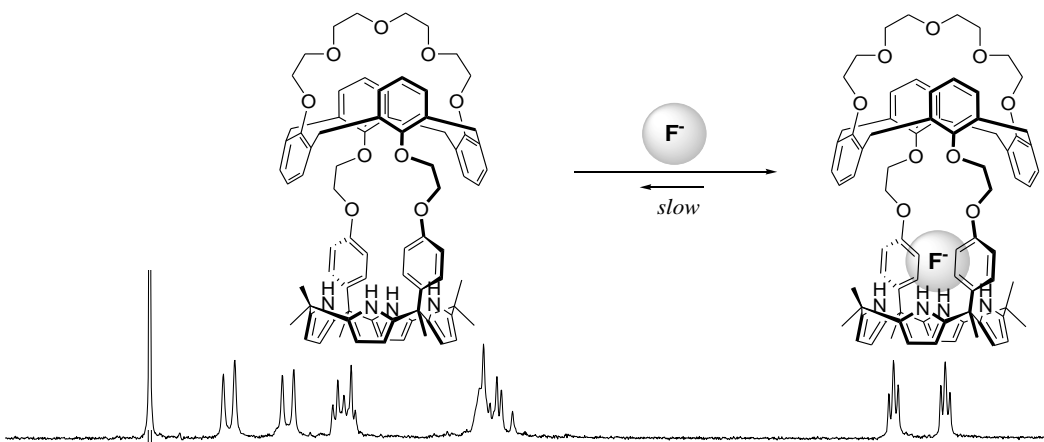

(b) 0.28 equiv

(c) 0.79 equiv
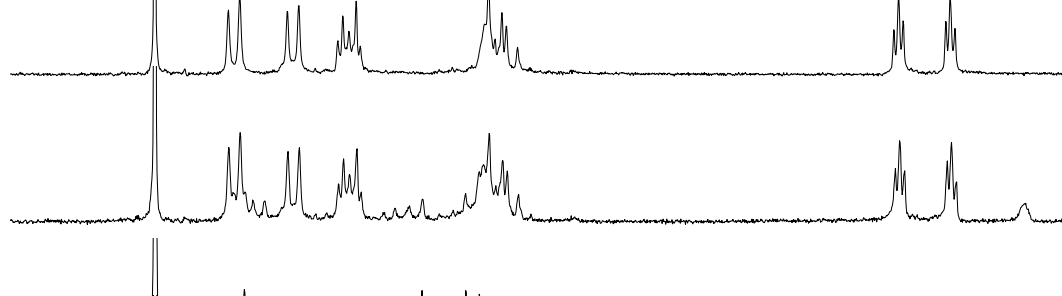

(d) 1.25 equiv

(e) 3.00 equiv

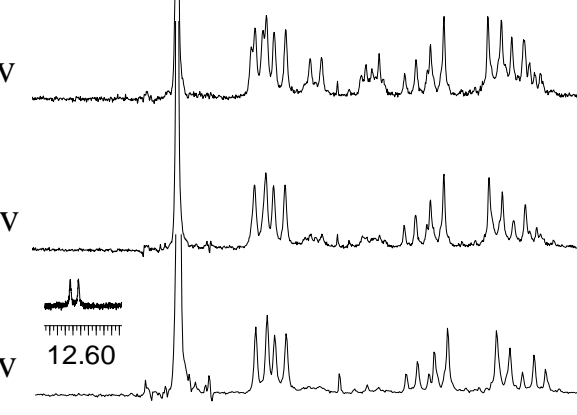

7.00

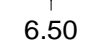

6.00

Figure 5.4 Partial ${ }^{1} \mathrm{H}$ NMR spectra recorded during the titration of receptor $\mathbf{5 . 3}$ with TBAF (tetrabutylammonium fluoride) in $\mathrm{CDCl}_{3}$.

As shown in Figure 5.4, receptor $\mathbf{5 . 3}$ in its ion free form displays a broad singlet at $\delta=6.71 \mathrm{ppm}$ for the NH protons and two triplets about $\delta=6.04 \mathrm{ppm}$ and $\delta=5.95 \mathrm{ppm}$ for the $\beta$-pyrrolic protons in ${ }^{1} \mathrm{H}$ NMR spectra, respectively. When receptor $\mathbf{5 . 3}$ was titrated with $\mathrm{TBAF}$ in $\mathrm{CDCl}_{3}$, two sets of distinguishable resonances for all proton signals were seen in the ${ }^{1} \mathrm{H}$ NMR spectra before saturation was achieved. This was ascribed to the free form of $\mathbf{5 . 3}$ and its fluoride anion complex, respectively, This observation of two sets of peaks is consistent with the binding/release equilibrium between compound $\mathbf{5 . 3}$ and the fluoride anion being slow on the NMR time scale (Figure 5.4). This slow 
exchange kinetics presumably reflects strong complexation between the fluoride anion and receptor $\mathbf{5 . 3}$ as the result of direct anion-receptor interaction involving the calix[4]pyrrole moiety. This conclusion was further supported by the observation of significant chemical shift changes in the signal for the $\beta$-pyrrolic protons and, especially, the pyrrolic NH protons as the titration progressed (Figure 5.4). Over the course of the addition, the singlet ascribed to the pyrrolic NH protons is downfield-shifted to $\delta \approx 12.7$ $\operatorname{ppm}(\Delta \delta \approx 6.0 \mathrm{ppm})$ and becomes split into a doublet $(J=40.0 \mathrm{~Hz})$. This latter splitting is a typical feature of calix[4]pyrrole- $\mathrm{F}^{-}$complexes and is ascribed to a coupling of the bound fluoride anion with the $\mathrm{NH}$ protons (Figure 5.4). ${ }^{18}$ The triplet peaks corresponding to the $\beta$-pyrrolic protons were likewise shifted upfield during the titration and ultimately appeared as two singlet peaks at $5.83 \mathrm{ppm}$ and $5.68 \mathrm{ppm}$, respectively (Figure 5.4). Thses latter chemical shift changes are attributable to the enhanced anionic character of the pyrroles resulting from hydrogen bonding interaction between the anion and the pyrrolic NH protons.

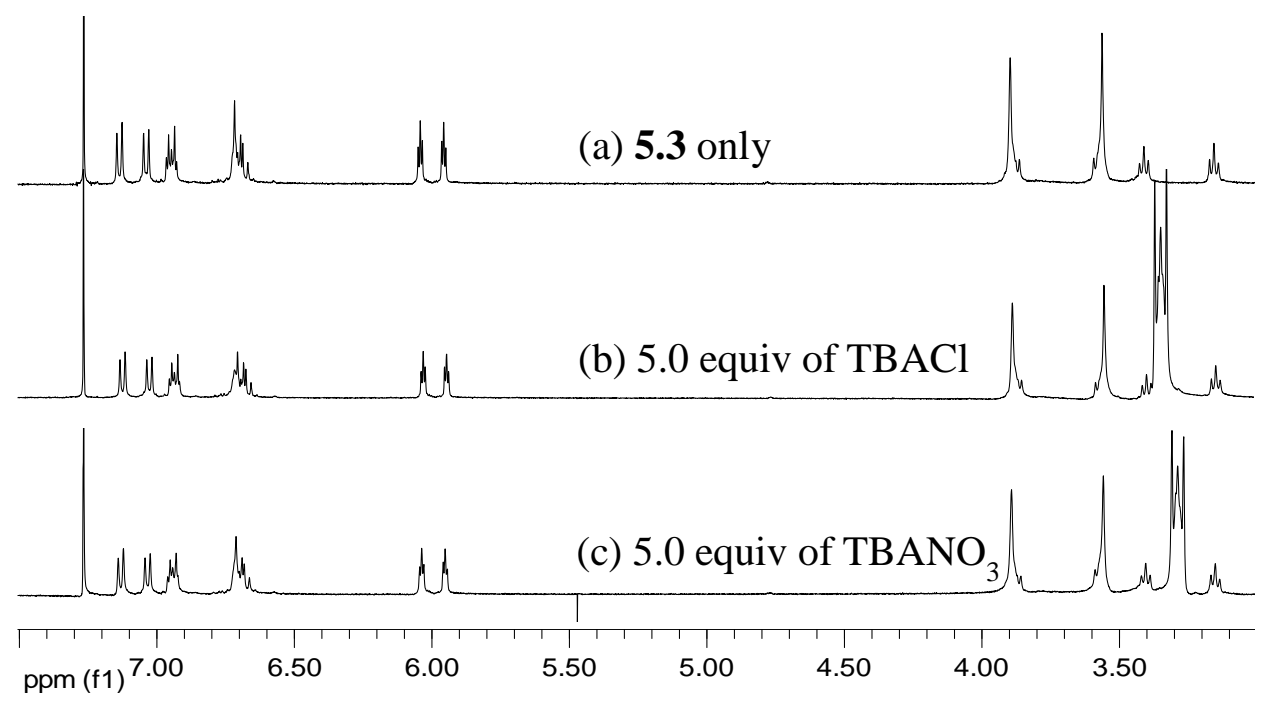

Figure $5.5{ }^{1} \mathrm{H}$ NMR spectra of (a) 5.3 only, (b) $5.3+5$ equiv. of $\mathrm{TBACl}$ (tetrabutylammonium chloride), and (c) $\mathbf{5 . 3}+5$ equiv. of $\mathrm{TBANO}_{3}$ (tetrabutylammonium nitrate) in $\mathrm{CDCl}_{3}$. 
Since receptor $\mathbf{5 . 3}$ possesses two kinds of cation binding sites for $\mathrm{K}^{+}$and $\mathrm{Cs}^{+}$as well as an anion binding site, its binding properties towards various potassium and cesium salts were expected to be complexed. They are investigated initially via ${ }^{1} \mathrm{H}$ NMR spectroscopy in a mixed solvent system consisting of $\mathrm{CDCl}_{3}$ and $\mathrm{CD}_{3} \mathrm{OD}(9 / 1, \mathrm{v} / \mathrm{v})$. This particular choice of solvents was dictated by solubility of the salts under study. A further consideration is that this solvent system had been used in the cases of $\mathbf{5 . 1}$ and $\mathbf{5 . 2}$, thus permitting comparisons. In analogy to what was seen with receptors $\mathbf{5 . 1}$ and 5.2, no appreciable change in ${ }^{1} \mathrm{H}$ NMR spectrum of $\mathbf{5 . 3}$ was observed even upon treatment with 5 equiv of TBAF, a finding that lead us to suggest that receptor $\mathbf{5 . 3}$ is unable to bind the $\mathrm{F}^{-}$ anion in this more polar solvent system. Presumably the $\mathrm{F}^{-}$anion is strongly solvated by the methanol molecules present in this mixed solvent system. Remarkably different spectral behavior was observed when receptor $\mathbf{5 . 3}$ was treated with various ion pairs containing the $\mathrm{K}^{+}$or $\mathrm{Cs}^{+}$cation. As shown in Figure 5.6, the addition of $\mathrm{KClO}_{4}$ and $\mathrm{CsClO}_{4}$ led to significant chemical shift change in the signals for both the aromatic protons of the calix[4]arene core and the alipathic protons of the crown ether ring (Figures 5.6, 5.7 and 5.8). These changes are consistent with the cations being encapsulated by the crown ether ring with the aid of the aromatic rings of the calix[4]arene perhaps via a $\pi$-metal interaction. Notably, the addition of these salts did not induce a substantial change in the proton signals of the calix[4]pyrrole moiety. This lack of change means that the perchlorate anion is bound either very weakly or not at all by the calix[4]pyrrole moiety. Taken in concert, these findings are thus consistent with the expectation that the addition of $\mathrm{KClO}_{4}$ and $\mathrm{CsClO}_{4}$ leads to the formation of the cation-bound complexes $\left(\left[\mathbf{5 . 3} \cdot \mathrm{K}^{+}\right] \mathrm{ClO}_{4}^{-}\right.$and $\left.\left[\mathbf{5 . 3} \cdot \mathrm{Cs}^{+}\right] \mathrm{ClO}_{4}^{-}\right)$, where the $\mathrm{ClO}_{4}^{-}$ counteranion is not co-bound. 


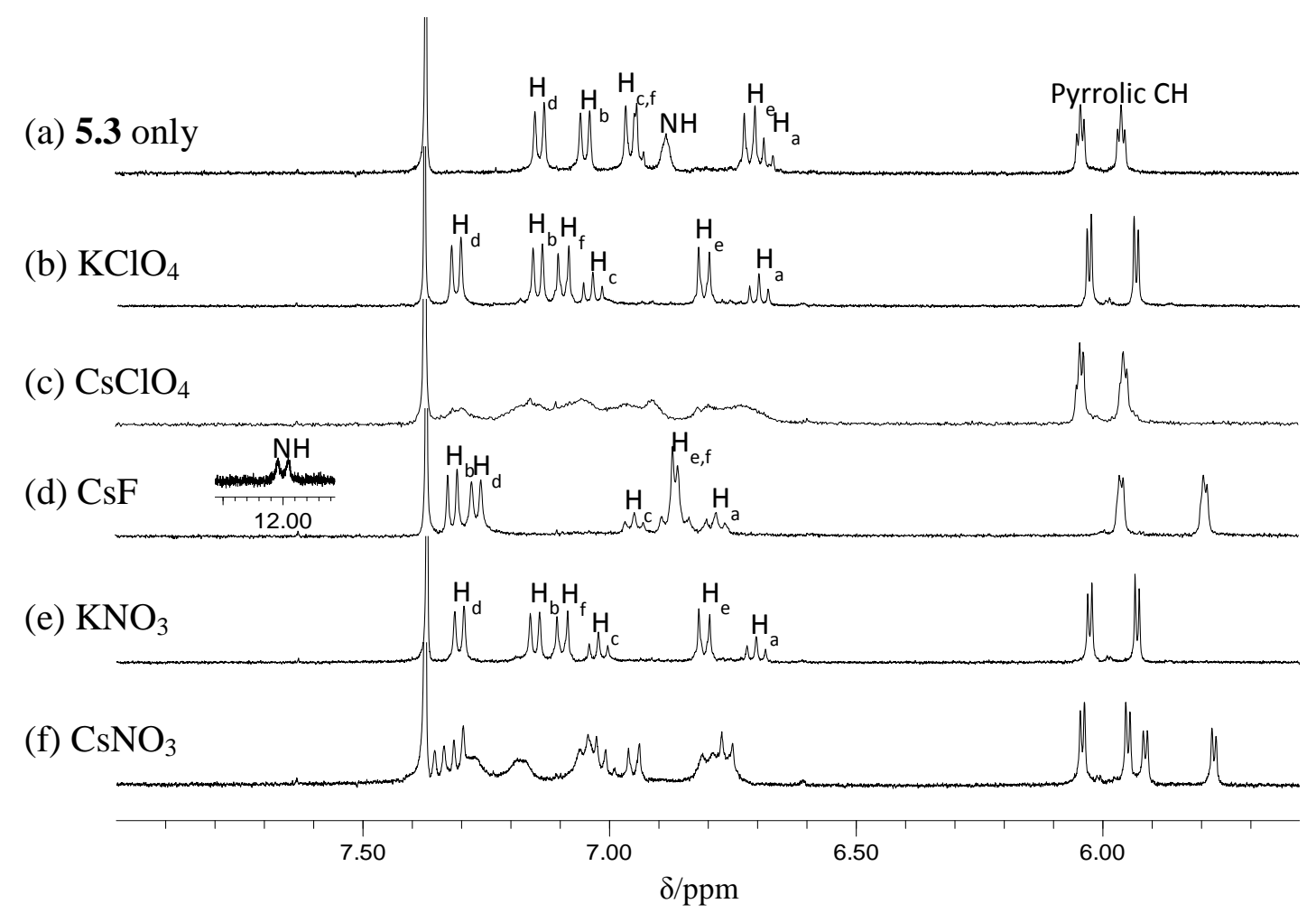

Figure 5.6 Partial ${ }^{1} \mathrm{H}$ NMR spectra of (a) 5.3 only, (b) 5.3 with 4.0 equiv of $\mathrm{KClO}_{4}$, (c) $\mathbf{5 . 3}$ with 4.0 equiv of $\mathrm{CsClO}_{4}$, (d) $\mathbf{5 . 3}$ with 4.0 equiv of $\mathrm{CsF}$, (e) $\mathbf{5 . 3}$ with 4.0 equiv of $\mathrm{KNO}_{3}$, and (f) $\mathbf{5 . 3}$ with 4.0 equiv of $\mathrm{CsNO}_{3}$ in $\mathrm{CD}_{3} \mathrm{OD} / \mathrm{CDCl}_{3}$ (1:9, $\mathrm{v} / \mathrm{v}$ ).

Analyzing the spectra in greater detail reveals that the peaks of both the aromatic protons of the calix[4]arene moiety and the crown ring appear are broadened in the presence of $\mathrm{CsClO}_{4}$ while they still remain sharp in the presence of $\mathrm{KClO}_{4}$ (Figures 5.6 and 5.7). Such findings are consistent with the expectation that receptor $\mathbf{5 . 3}$ binds the $\mathrm{K}^{+}$ cation more strongly than the $\mathrm{Cs}^{+}$cation. This stronger binding interaction between receptor $\mathbf{5 . 3}$ and the $\mathrm{K}^{+}$cation was further evidenced by a ${ }^{1} \mathrm{H}$ NMR spectrum measured in the presence of 1 equiv of $\mathrm{KClO}_{4}$, where two sets of distinguishable proton signals were seen corresponding to the free receptor and its $\mathrm{K}^{+}$complex, respectively (Figure 5.9). 
This observation is consistent with slow exchange and strong $\mathrm{K}^{+}$complexation. Indeed, binding constant of receptor $\mathbf{5 . 3}$ for the $\mathrm{K}^{+}$cation measured by isothermal titration calorimetry (ITC) in acetonitrile using KTPB (potassium tetraphenylborate) was found to be much higher than that for the $\mathrm{Cs}^{+}$cation $\left(K_{a}=6.5 \times 10^{6} \mathrm{M}^{-1}\right.$ for $\mathrm{K}^{+} v s . K_{a}=3.3 \times 10^{4}$ $\mathrm{M}^{-1}$ for $\mathrm{Cs}^{+}$) (Table 5.1).

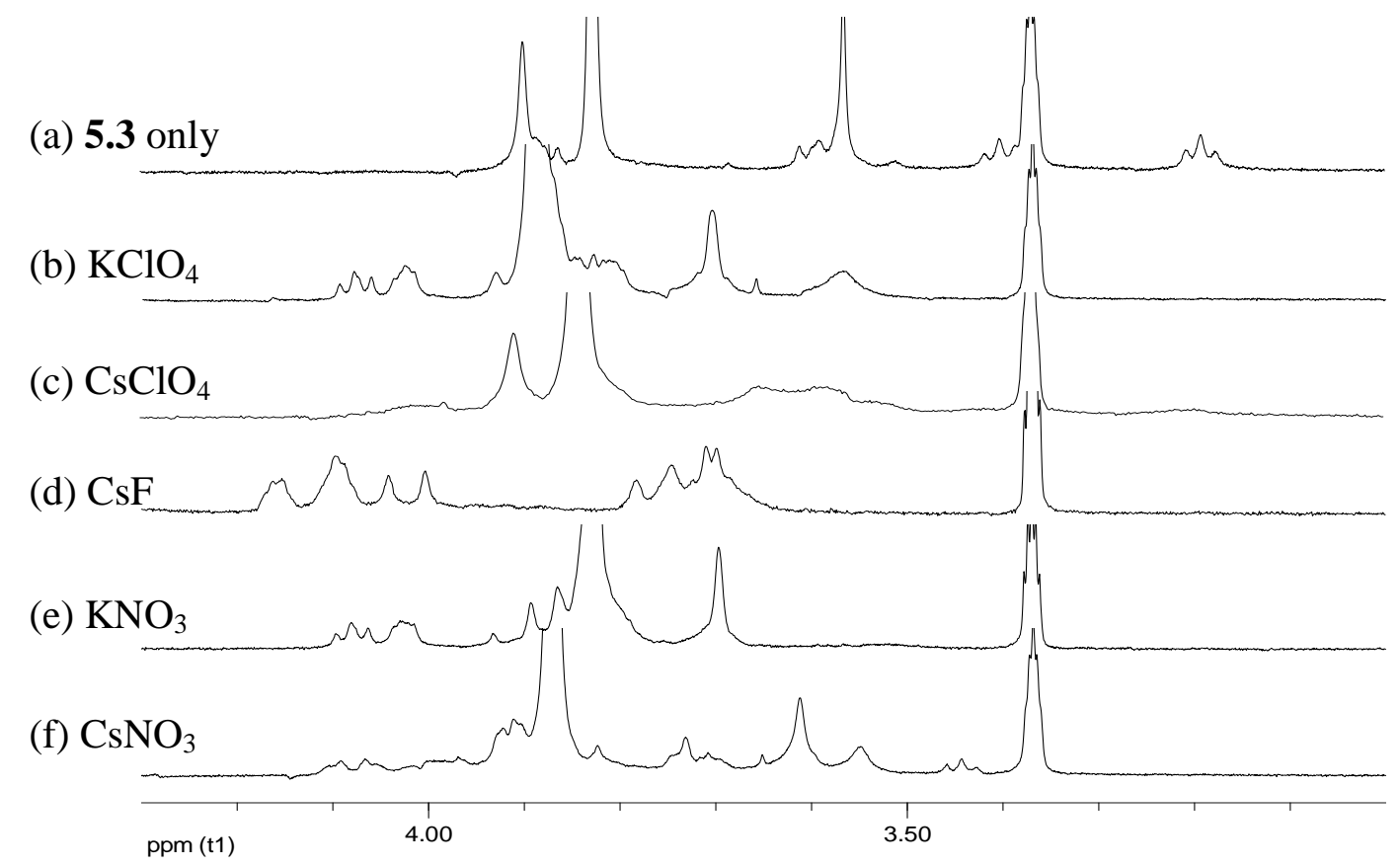

Figure 5.7 Partial ${ }^{1} \mathrm{H}$ NMR spectra of (a) 5.3 only, (b) 5.3 with 4.0 equiv of $\mathrm{KClO}_{4}$, (c) $\mathbf{5 . 3}$ with 4.0 equiv of $\mathrm{CsClO}_{4}$, (d) $\mathbf{5 . 3}$ with 4.0 equiv of $\mathrm{CsF}$, (e) $\mathbf{5 . 3}$ with 4.0 equiv of $\mathrm{KNO}_{3}$, and (f) $\mathbf{5 . 3}$ with 4.0 equiv of $\mathrm{CsNO}_{3}$ in $\mathrm{CD}_{3} \mathrm{OD} / \mathrm{CDCl}_{3}$ (1:9, $\mathrm{v} / \mathrm{v}$ ). 


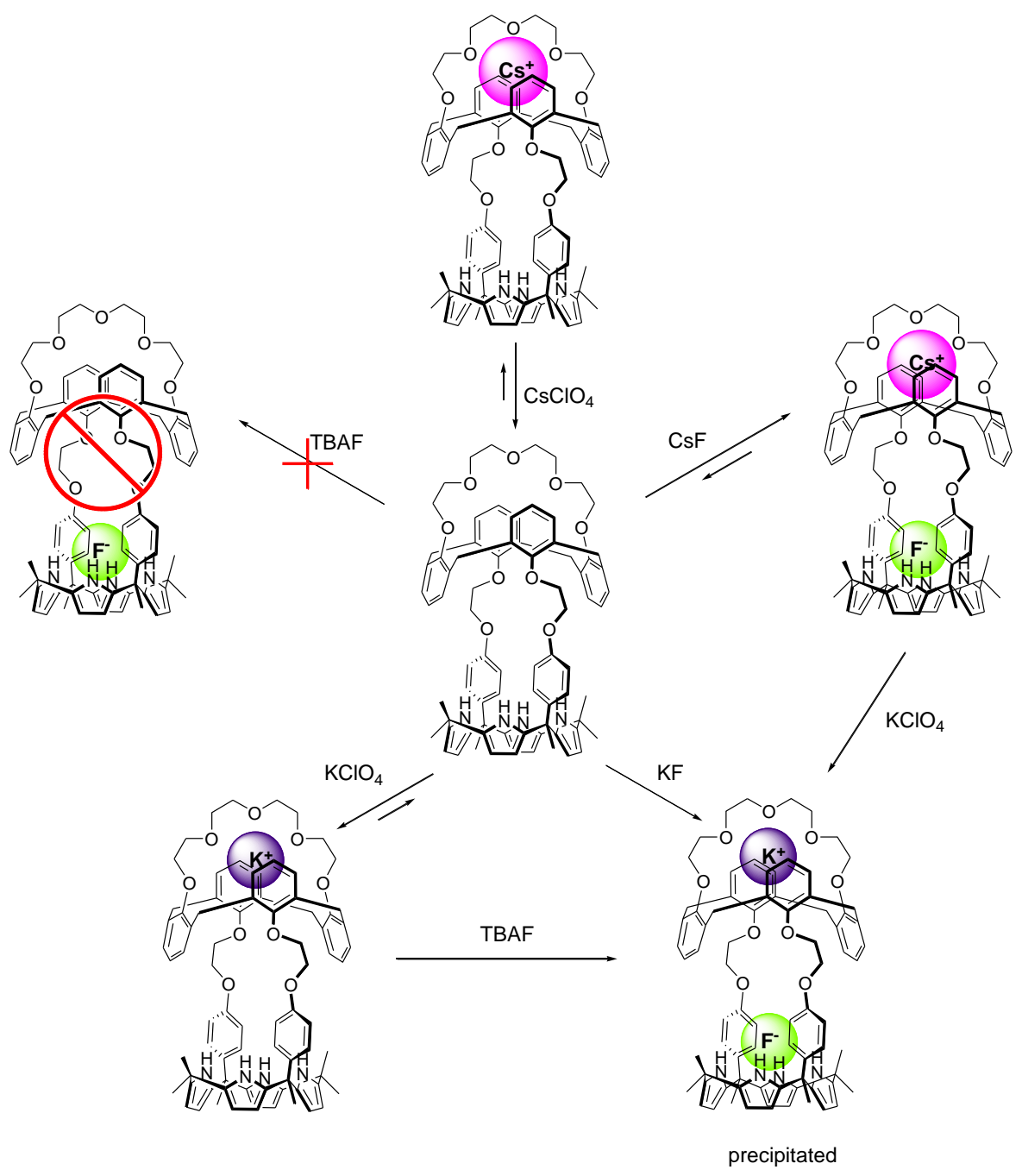

Figure 5.8 Proposed binding interactions involving 5.3 and various $\mathrm{K}^{+}, \mathrm{Cs}^{+}$and $\mathrm{F}^{-}$salts in $\mathrm{CD}_{3} \mathrm{OD} / \mathrm{CDCl}_{3}(1 / 9, \mathrm{v} / \mathrm{v})$. 


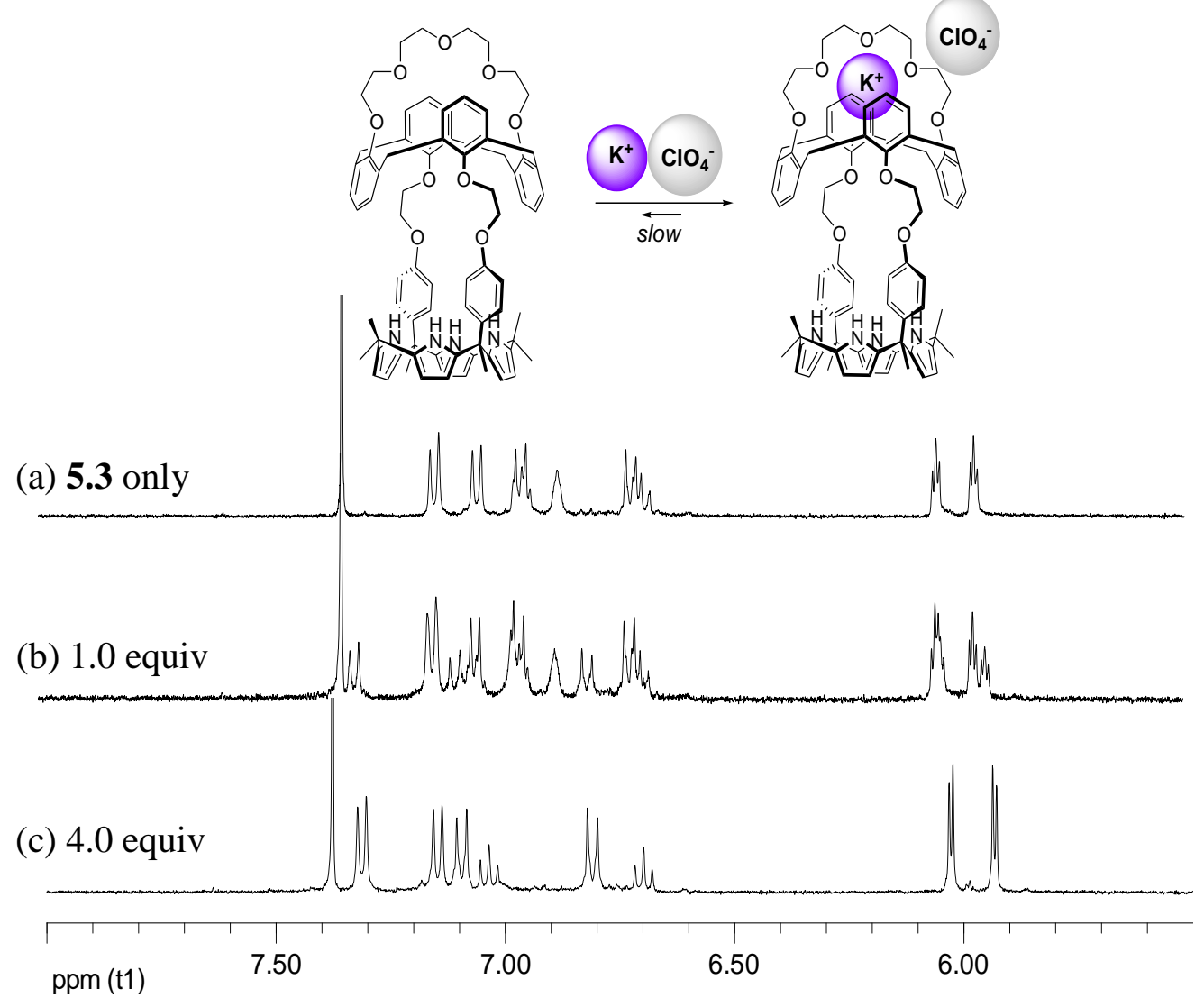

Figure 5.9 Partial ${ }^{1} \mathrm{H}$ NMR spectra of (a) 5.3 only, (b) $\mathbf{5 . 3}+1.0$ equiv of $\mathrm{KClO}_{4}$, and (c) $\mathbf{5 . 3}+4.0$ equiv of $\mathrm{KClO}_{4}$ in $\mathrm{CD}_{3} \mathrm{OD} / \mathrm{CDCl}_{3}(1: 9, \mathrm{v} / \mathrm{v})$.

Table 5.1 ITC titration data for receptor $\mathbf{5 . 3}$ measured at $298 \mathrm{~K}$.

\begin{tabular}{ccccccc}
\hline host & solvent & guest $^{a}$ & $\begin{array}{c}\Delta H \\
(\mathrm{kcal} / \mathrm{mol} \\
)\end{array}$ & $\begin{array}{c}T \Delta S \\
(\mathrm{kcal} / \mathrm{mol} \\
)\end{array}$ & $\begin{array}{c}\Delta G \\
(\mathrm{kcal} / \mathrm{mol}\end{array}$ & $K_{a}$ \\
\hline $\mathbf{5 . 3}$ & $\mathrm{CH}_{3} \mathrm{CN}$ & TEAF & -3.9 & 3.6 & -7.5 & $6.0 \times 10^{5}$ \\
$\mathbf{5 . 3}$ & $\mathrm{CH}_{3} \mathrm{CN}$ & $\mathrm{KTPB}$ & -13.2 & -4.0 & -9.2 & $6.5 \times 10^{6}$ \\
$\mathbf{5 . 3}$ & $\mathrm{CH}_{3} \mathrm{CN}$ & $\mathrm{CsTPB}$ & -4.7 & 1.4 & -6.1 & $3.3 \times 10^{4}$ \\
$\mathbf{5 . 3}$ & $\mathrm{CH}_{3} \mathrm{OH} / \mathrm{CHCl}_{3}{ }^{b}$ & $\mathrm{CsF}$ & -15.3 & -9.0 & -6.3 & $4.1 \times 10^{4}$ \\
\hline${ }^{2}$ TEAF is tetraethylammonium fluoride; KTPB is potassium tetraphenylborate; CsTPB is
\end{tabular}
cesium tetraphenylborate. ${ }^{b} 10 \%(\mathrm{v} / \mathrm{v})$. 
In contrast to what is seen with $\mathrm{ClO}_{4}^{-}$, in the presence of cesium and potassium salts of coordinating anions, such as $\mathrm{F}^{-}$and $\mathrm{Cl}^{-}$, receptor $\mathbf{5 . 3}$ forms strong ion pair complexes wherein the cation is bound to the calix[4]arene crown-5 moiety and the anion to the calix[4]pyrroles cavity (Figures 5.8 and 5.10). As shown in Figure 5.6d, the addition of $\mathrm{CsF}$ caused all proton signals of receptor $\mathbf{5 . 3}$ including the $\beta$-pyrrolic resonances of the calix[4]pyrrole moiety to be significantly shifted. This is taken as evidence that both the calix[4]arene crown-5 and the calix[4]pyrrole moiety take part in ion pair complexation. The presumed strong interaction between the $\mathrm{F}^{-}$anion and receptor 5.3 was further evidenced by the observation that the singlet pyrrolic NH signal is split into a doublet. This splitting, which occurs upon exposure to CsF or KF, is accompanied by a remarkable down field shift in the NH proton signals. Changes in other spectral regions are also seen. For instance, when $\mathbf{5 . 3}$ was titrated with $\mathrm{CsF}$, a new set of sharp peaks corresponding the $\beta$-pyrrolic protons gradually appeared upon addition of $0.72-1.38$ equiv while other peaks corresponding to the aromatic protons of the calix[4]arene moiety were broadened (Figure 5.11). Such findings provide support for the notion that there are two different kinds of binding interactions involving receptor $\mathbf{5 . 3}$ and the $\mathrm{CsF}$ ion pair. In one set, only the $\mathrm{Cs}^{+}$cation but not the $\mathrm{F}^{-}$anion is weakly bound to the crown-5 ring to form a cesium complex $\left(\left[\mathbf{5 . 3} \cdot \mathrm{Cs}^{+}\right] \mathrm{F}^{-}\right)$where the $\mathrm{F}^{-}$counteranion is not co-bound. This complex exists in the fast equilibrium with the free receptor, as evidenced by peak broadening seen for the aromatic protons of the calix[4]arene moiety. By contrast, in the other binding mode, the $\mathrm{Cs}^{+}$cation and the $\mathrm{F}^{-}$anion are concurrently and strongly bound to the receptor $\mathbf{5 . 3}$ being stabilized by the ethylene glycol spacers and the calix[4]pyrrole moiety, respectively (Figure 5.11). This complexation process is in the slow equilibrium and favored. This mode is similar to what was seen in the case of the CsF complex of compound $\mathbf{5 . 2}$ which gives rise to the new distinguishable peaks seen in 
the ${ }^{1} \mathrm{H}$ NMR spectrum. ${ }^{11}$ After the $\mathrm{Cs}^{+}$cation is bound to the ethylene glycol spacer, it moves to the crown-5 ring to form a thermodynamically more stable ion pair complex ([5.3•CsF]) (Figures 5.10, and 5.12).

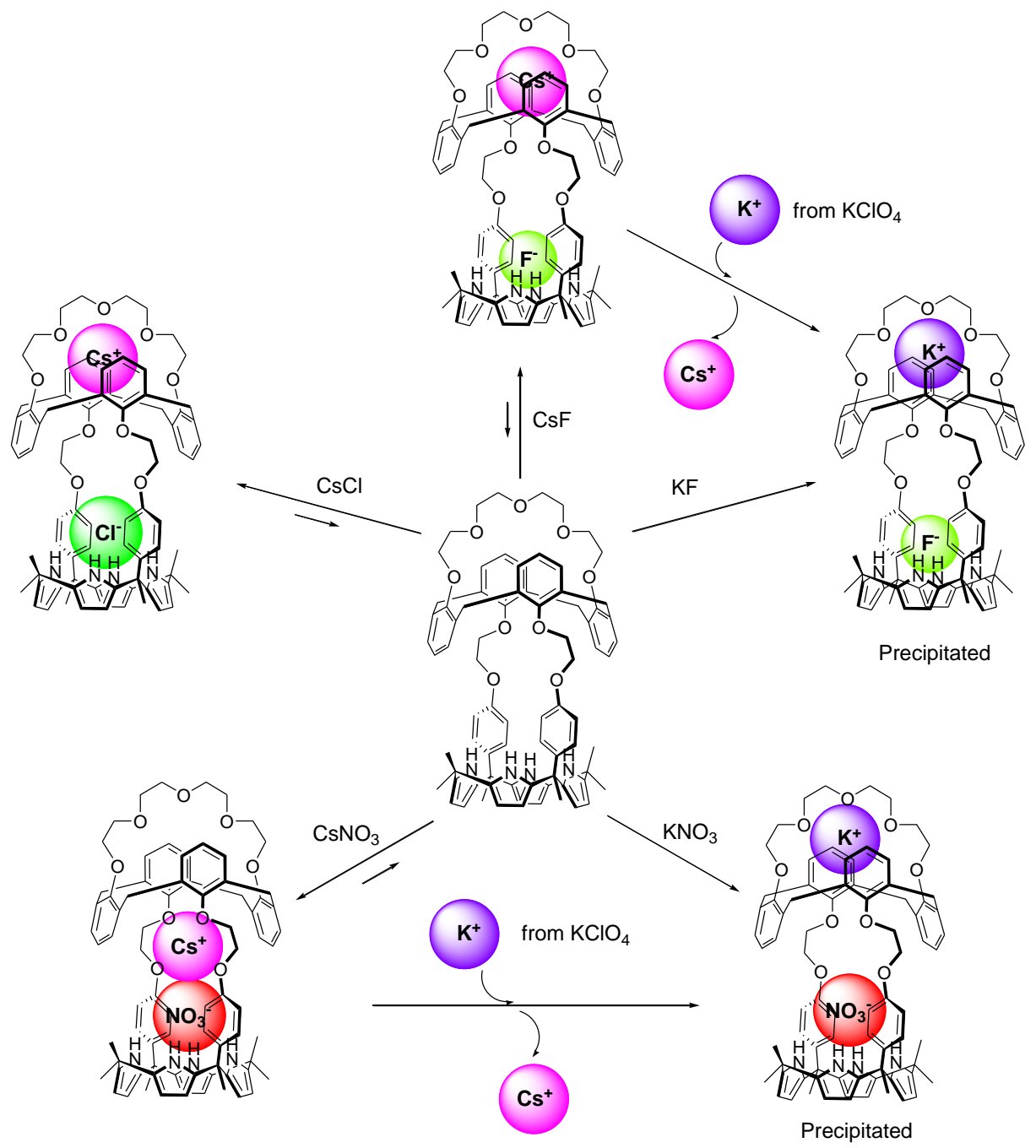

Figure 5.10 Proposed binding interactions involving 5.3 and various $\mathrm{K}^{+}$and $\mathrm{Cs}^{+}$ion pairs in $\mathrm{CD}_{3} \mathrm{OD} / \mathrm{CDCl}_{3}(1 / 9, \mathrm{v} / \mathrm{v})$. 


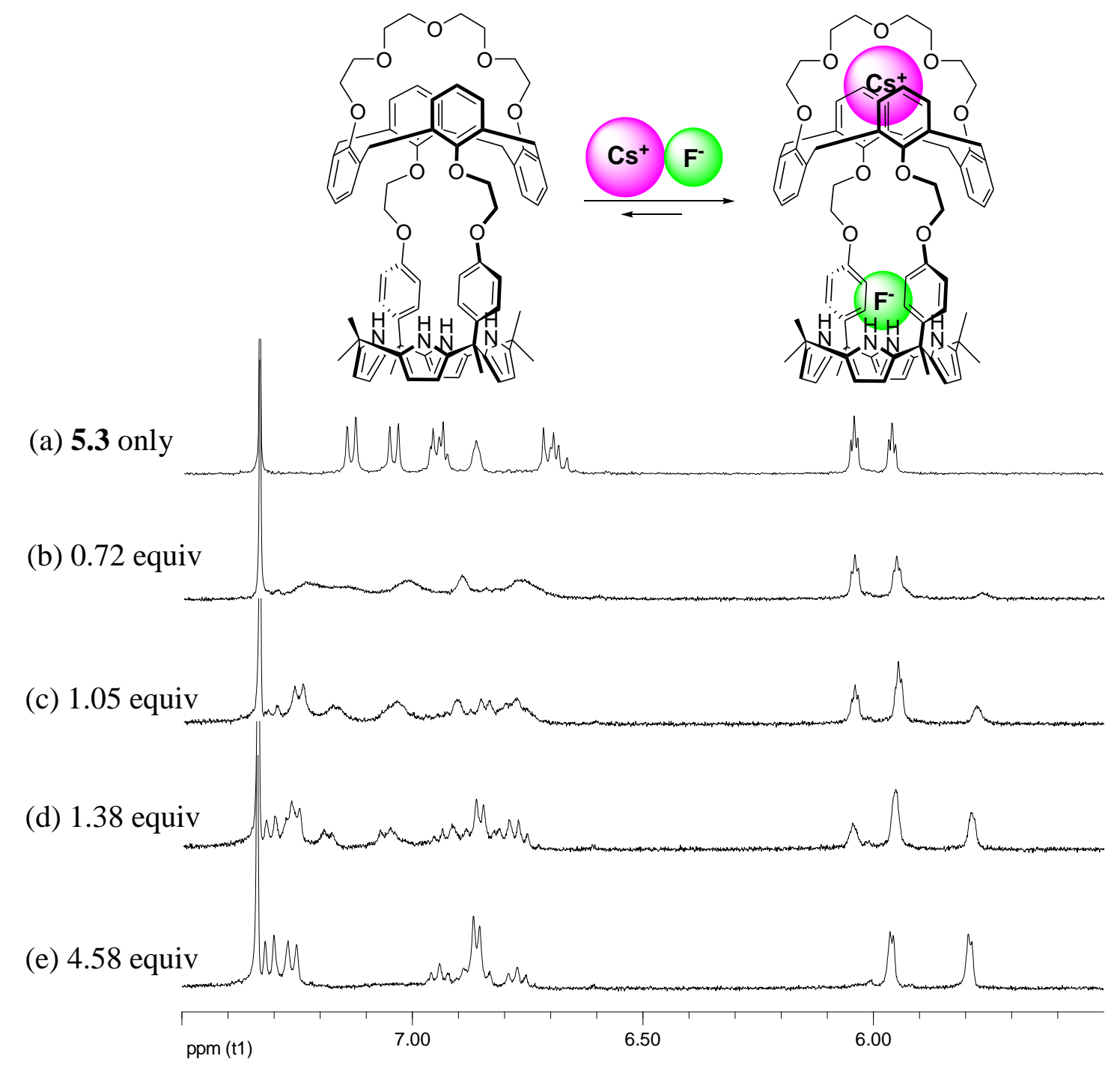

Figure 5.11 Partial ${ }^{1} \mathrm{H}$ NMR spectra recorded during the titration of receptor $\mathbf{5 . 3}$ with $\mathrm{CsF}$ in $\mathrm{CD}_{3} \mathrm{OD} / \mathrm{CDCl}_{3}(1: 9, \mathrm{v} / \mathrm{v})$. 

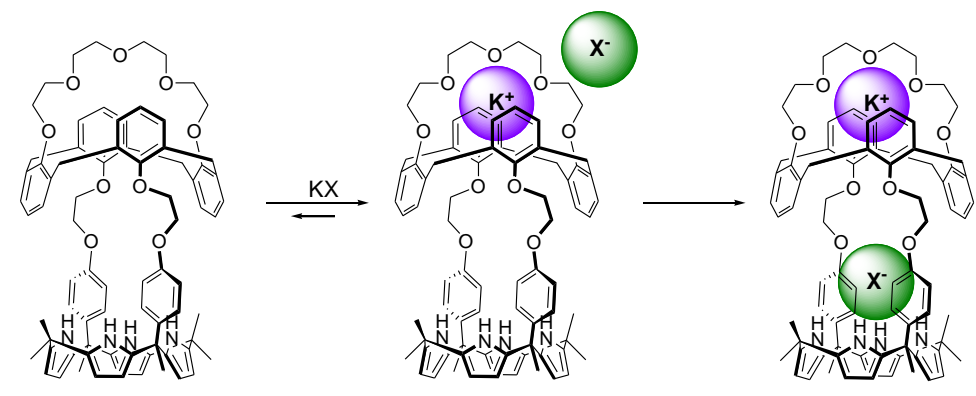

$\mathrm{X}^{-}=\mathrm{F}^{-}, \mathrm{Cl}^{-}, \mathrm{NO}_{3}{ }^{-}$

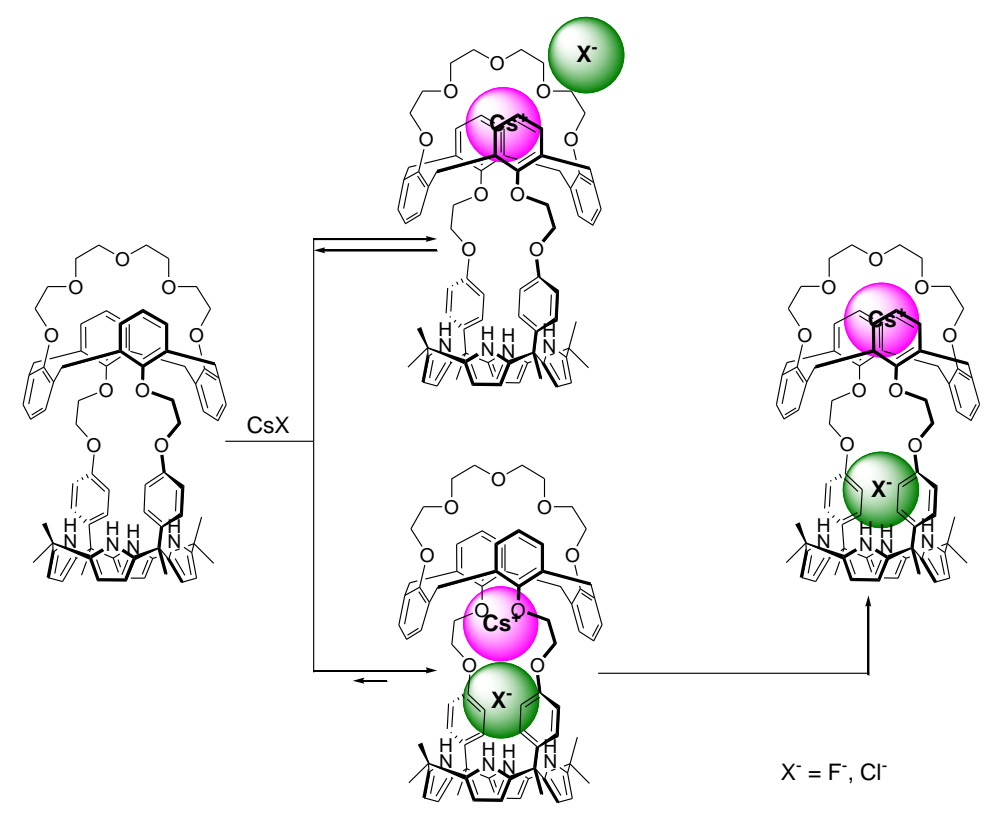

Figure 5.12 Binding modes of $\mathbf{5 . 3}$ proposed to exist in the absence and presence of various $\mathrm{K}^{+}$and $\mathrm{Cs}^{+}$salts in $\mathrm{CD}_{3} \mathrm{OD} / \mathrm{CDCl}_{3}(1 / 9, \mathrm{v} / \mathrm{v})$.

The affinity of receptor $\mathbf{5 . 3}$ for $\mathrm{CsF}$ in $10 \% \mathrm{MeOH}$ in $\mathrm{CHCl}_{3}$ was quantified by isothermal titration calorimetry (ITC). The resulting data reveal that the titration of CsF [2.95 mM] with $5.3[0.19 \mathrm{mM}]$ is highly exothermic $(\Delta H=-15.3 \mathrm{kcal} / \mathrm{mol})$ and that the binding between $\mathbf{5 . 3}$ and $\mathrm{CsF}$ is enthalpy-driven with $\Delta G=-6.3 \mathrm{kcal} / \mathrm{mol}$ and $K_{a}=4.1 \times$ $10^{4}$ (Table 5.1 and Figure 5.13). 


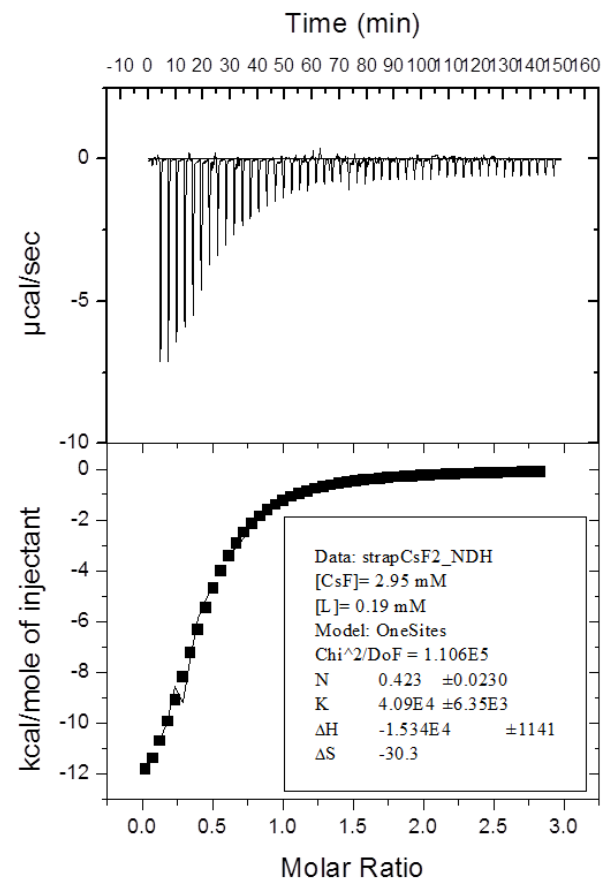

Figure 5.13 ITC plots showing the results of titrating receptor $5.3(0.19 \mathrm{mM})$ with CsF (2.95 mM).

Receptor $\mathbf{5 . 3}$ also forms a thermodynamically stable 1:1 ion pair complex with KF wherein the $\mathrm{K}^{+}$cation is bound to the calix[4]arene crown-5 ring and the $\mathrm{F}^{-}$anion to the calix[4]pyrrole moiety. However, in terms of kinetics on the NMR time scale, the binding of $\mathrm{KF}$ is quite different from that of $\mathrm{CsF}$. Upon addition of $\mathrm{KF}$ to a solution of receptor 5.3 in $10 \% \mathrm{CD}_{3} \mathrm{OD}$ in $\mathrm{CDCl}_{3}$, the proton signals of the calix[4] arene crown-5 were seen to undergo a significant shift while those of the calix[4]pyrrole moiety were largely unchanged (Figure 5.14). Such observations are consistent with receptor $\mathbf{5 . 3}$ coordinating the $\mathrm{K}^{+}$cation first through the calix[4]arene crown-5 ring without the $\mathrm{F}^{-}$anion being bound to the calix[4]pyrrole moiety. Once the $\mathrm{K}^{+}$is bound to receptor 5.3, the resulting potassium complex $\left(\left[\mathbf{5 . 3} \cdot \mathrm{K}^{+}\right]\right)$facilitates the binding of the $\mathrm{F}^{-}$counteranion. The anion is 
bound to the calix[4]pyrrole moiety to give the KF ion pair complex $([5.3 \cdot \mathrm{KF}])$, which then precipitates (Figures 5.10, 5.12 and 5.14). The stepwise binding seen for receptor $\mathbf{5 . 3}$ and $\mathrm{KF}$ is very similar to what was seen in the case of compound $\mathbf{5 . 1}$ and $\mathrm{CsF}^{13}$ Therefore, it is concluded that receptors $\mathbf{5 . 1}$ and 5.3, although they contain two different binding sites whose binding strength is different, display similar complexation dynamics. Specifically, a strongly bound cation $\left(\mathrm{Cs}^{+}\right.$or $\mathrm{K}^{+}$in the case of $\mathbf{5 . 1}$ and 5.3) is bound first. Only then does complexation of the counteranion by the anion binding site take place (Figure 5.12). Meanwhile, an ion pair receptor, such as receptor 5.3, bearing two moderate or weak binding sites for a specific cation (for instance, receptor $\mathbf{5 . 3}$ with $\mathrm{Cs}^{+}$) interacts with the cations via both binding sites (Figure 5.12).

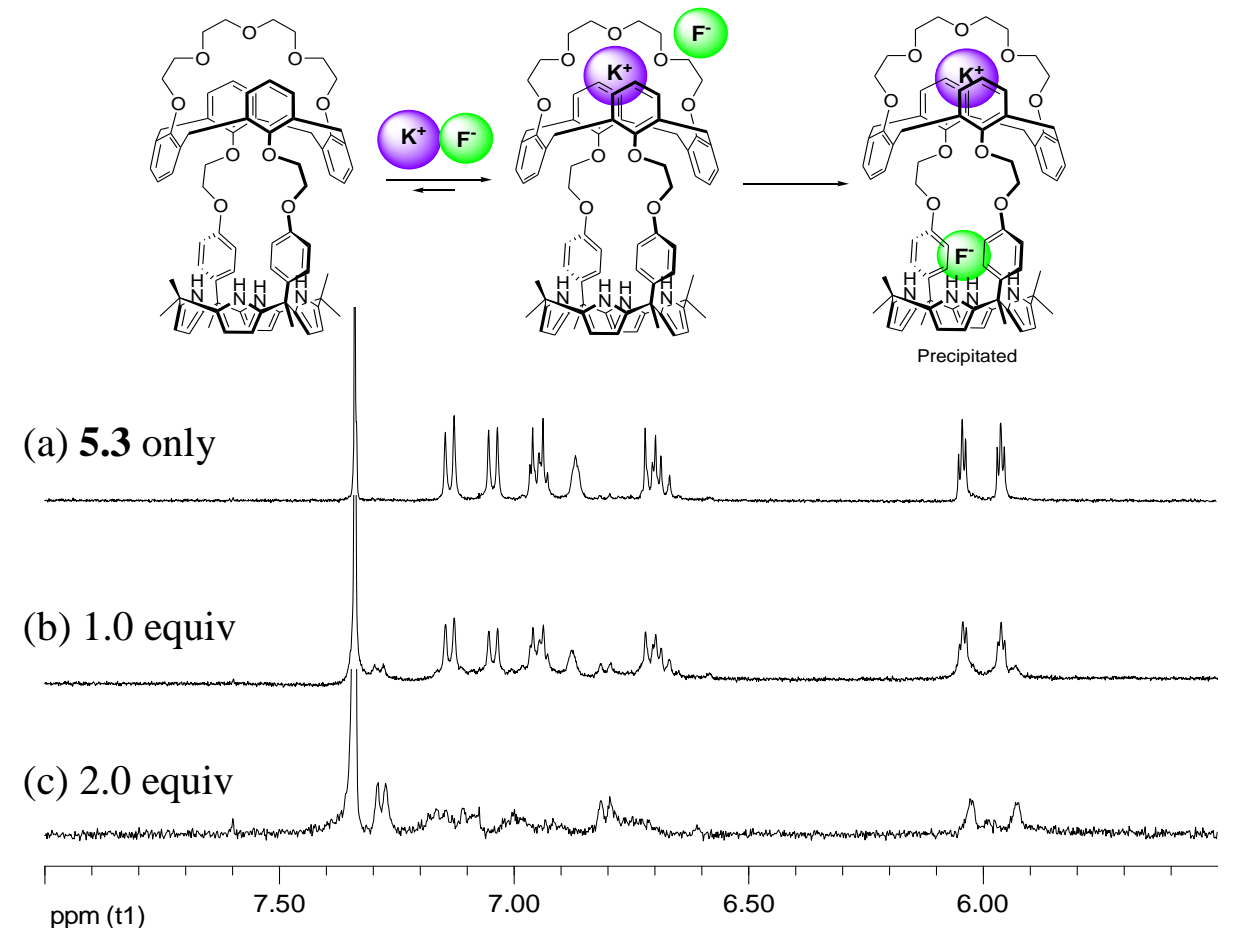

Figure 5.14 Partial ${ }^{1} \mathrm{H}$ NMR spectra of (a) $\mathbf{5 . 3}$ only, (b) $\mathbf{5 . 3}+1.0$ equiv of KF, and (c) $\mathbf{5 . 3}$ +2.0 equiv of $\mathrm{KF}$ recorded in $\mathrm{CD}_{3} \mathrm{OD} / \mathrm{CDCl}_{3}(1: 9, \mathrm{v} / \mathrm{v})$. 
Similarly to what was seen in the case of KF, receptor $\mathbf{5 . 3}$ forms a 1:1 ion pair complex with $\mathrm{KNO}_{3}$. It does so in a sequential manner as inferred from the ${ }^{1} \mathrm{H}$ NMR spectroscopic analyses. Specifically, the $\mathrm{NO}_{3}{ }^{-}$anion is bound to the calix[4]pyrrole moiety only after the complexation of the $\mathrm{K}^{+}$cation with the calix[4]arene crown-5 moiety (Figures 5.6 and 5.12). However, as inferred from the ${ }^{1} \mathrm{H}$ NMR spectra of relevance, the rate of $\mathrm{NO}_{3}^{-}$anion binding to the pre-formed $\left[5.3 \cdot \mathrm{K}^{+}\right]$is significantly slower than that of $\mathrm{F}^{-}$anion binding to preformed $\left[\mathbf{5 . 3} \cdot \mathrm{K}^{+}\right]$. This leads us to suggest that the formation of $\left[5.3 \cdot \mathrm{K}^{+}\right] \mathrm{NO}_{3}{ }^{-}$is kinetically more favorable than that of $\left[5.3 \cdot \mathrm{KNO}_{3}\right]$. Once the ion pair complex of receptor $\mathbf{5 . 3}$ with $\mathrm{KNO}_{3}\left(\left[\mathbf{5 . 3} \cdot \mathrm{KNO}_{3}\right]\right)$ is formed, it starts to precipitate from solution (Figures 5.5, 5.10 and 5.12). As a consequence, complexation of these potassium salts by $\mathbf{5 . 3}$ becomes irreversible.

In contrast to the binding behavior observed between $\mathbf{5 . 3}$ and $\mathrm{KNO}_{3}, \mathrm{CsNO}_{3}$ interacts with receptor $\mathbf{5 . 3}$ in two different modes that are similar to what was seen for $\mathrm{CsF}$; that is, $\left[\mathbf{5 . 3} \cdot \mathrm{CsNO}_{3}\right]$ can be formed directly by a simultaneous binding of $\mathrm{Cs}^{+}$and $\mathrm{NO}_{3}^{-}$to form an ion pair complex or via complexation of the $\mathrm{Cs}^{+}$cation by the calix[4]arene crown-5 moiety with the $\mathrm{NO}_{3}^{-}$anion remaining unbound by the calix[4]pyrrole moiety (Figures 5.12 and 5.15). This gives $\left[\mathbf{5 . 3} \cdot \mathrm{Cs}^{+}\right] \mathrm{NO}_{3}{ }^{-}$. 


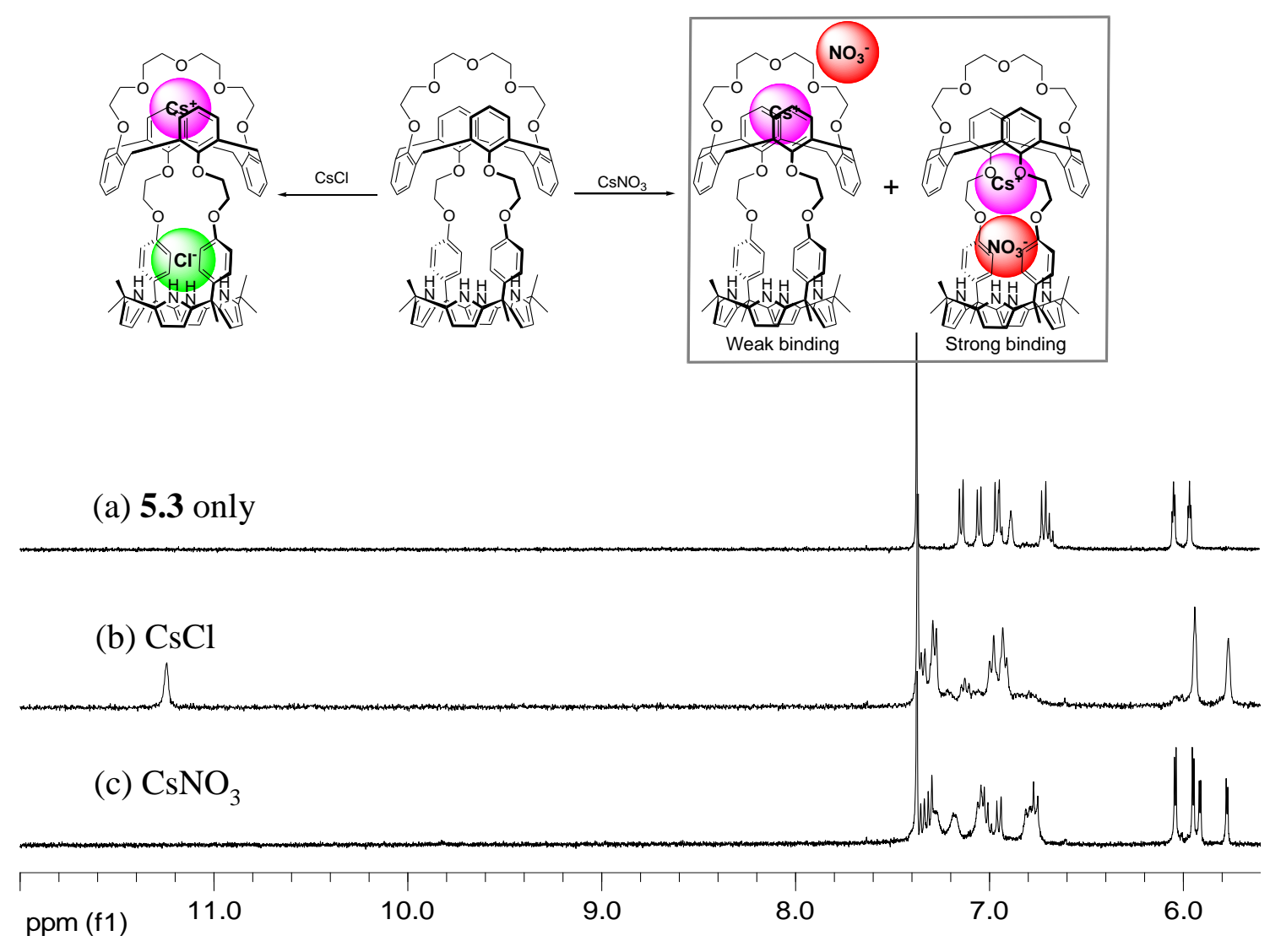

Figure 5.15 Two different limiting binding modes of $\mathbf{5 . 3}$ observed upon exposure to the $\mathrm{CsNO}_{3}$ in $\mathrm{CD}_{3} \mathrm{OD} / \mathrm{CDCl}_{3}(1: 9$, v/v) as inferred from an analysis of the partial ${ }^{1} \mathrm{H}$ NMR spectra recorded for (a) $\mathbf{5 . 3}$ only, (b) $\mathbf{5 . 3}+4.0$ equiv of $\mathrm{CsCl}$, and (c) $\mathbf{5 . 3}+4.0$ equiv of $\mathrm{CsNO}_{3}$.

To provide support for the inferences drawn from the ${ }^{1} \mathrm{H}$ NMR spectral measurements, namely that receptor $\mathbf{5 . 3}$ binds both cesium salts and potassium salts but displays high selectivity for potassium salts over the cesium salts, we investigated whether cation metathesis would occur when a pre-complexed $\mathrm{Cs}^{+}$cation ion pair complex was exposed to $\mathrm{K}^{+}$. These studies were carried out by adding $\mathrm{KClO}_{4}$ to $10 \%$ $\mathrm{CD}_{3} \mathrm{OD} / \mathrm{CDCl}_{3}$ solutions of $[\mathbf{5 . 3} \cdot \mathrm{CsF}]$ and $\left[\mathbf{5 . 3} \cdot \mathrm{CsNO}_{3}\right]$ complex, respectively (Figure 5.10). When a solution of $\mathrm{KClO}_{4}$ in a mixture of methanol- $\mathrm{d}_{4} /$ chloroform-d $(1 / 9, \mathrm{v} / \mathrm{v})$ was 
added to a solution of complex $[5.3 \cdot \mathrm{CsF}]$ in the same solvent, formation of a precipitate occurred. This phase change is ascribed to the formation of the insoluble $[\mathbf{5 . 3} \cdot \mathrm{KF}]$ ion pair complex as a result of cation exchange, namely replacement of $\mathrm{Cs}^{+}$by $\mathrm{K}^{+}$(Figures 5.10 and eq 5.1). In contrast, the addition of analogous $\mathrm{KClO}_{4}$ solutions to solutions of free receptor $\mathbf{5 . 3}$ or simply solutions of $\mathrm{CsF}$ in the absence of receptor $\mathbf{5 . 3}$ did not lead to precipitation. We thus conclude that adding $\mathrm{KClO}_{4}$ to a solution of complex $[\mathbf{5 . 3} \cdot \mathrm{CsF}]$ gives rise to the corresponding $\mathrm{KF}$ complex, [5.3.KF] (Figure 5.16). A similar precipitation process was observed upon the addition of a solution of $\mathrm{KClO}_{4}$ to the $\mathrm{CsNO}_{3}$ complex of 5.3. Again, this is interpreted in terms of the $\mathrm{CsNO}_{3}$ complex being converted into the $\mathrm{KNO}_{3}$ complex via cation exchange. The fact that cation metathesis occurs in several cesium cation complexes of receptor 5.3 with more than one potassium salt provides further support for this conclusion. Additional evidence came from single crystal X-ray diffraction analyses of the $\mathrm{KF}$ and $\mathrm{KNO}_{3}$ complexes, both of which were obtained from the crystals grown by adding $\mathrm{KClO}_{4}$ to corresponding the $\mathrm{CsF}$ and $\mathrm{CsNO}_{3}$ complexes. (cf. Figures 5.10, 5.17 and 5.18 and discussion below).

$$
\begin{gathered}
{[5.3]+\mathrm{Cs} X \rightarrow[5.3 \cdot \mathrm{Cs} X]} \\
{[5.1)} \\
{[\mathbf{5 . 3} \cdot \mathrm{CsX}]+\mathrm{KClO}_{4} \rightarrow[\mathbf{5 . 3} \cdot \mathrm{KX}]+\mathrm{CsClO}_{4}(5.2), \text { where } \mathrm{X}=\mathrm{F}_{\text {or } \mathrm{NO}_{3}}}
\end{gathered}
$$




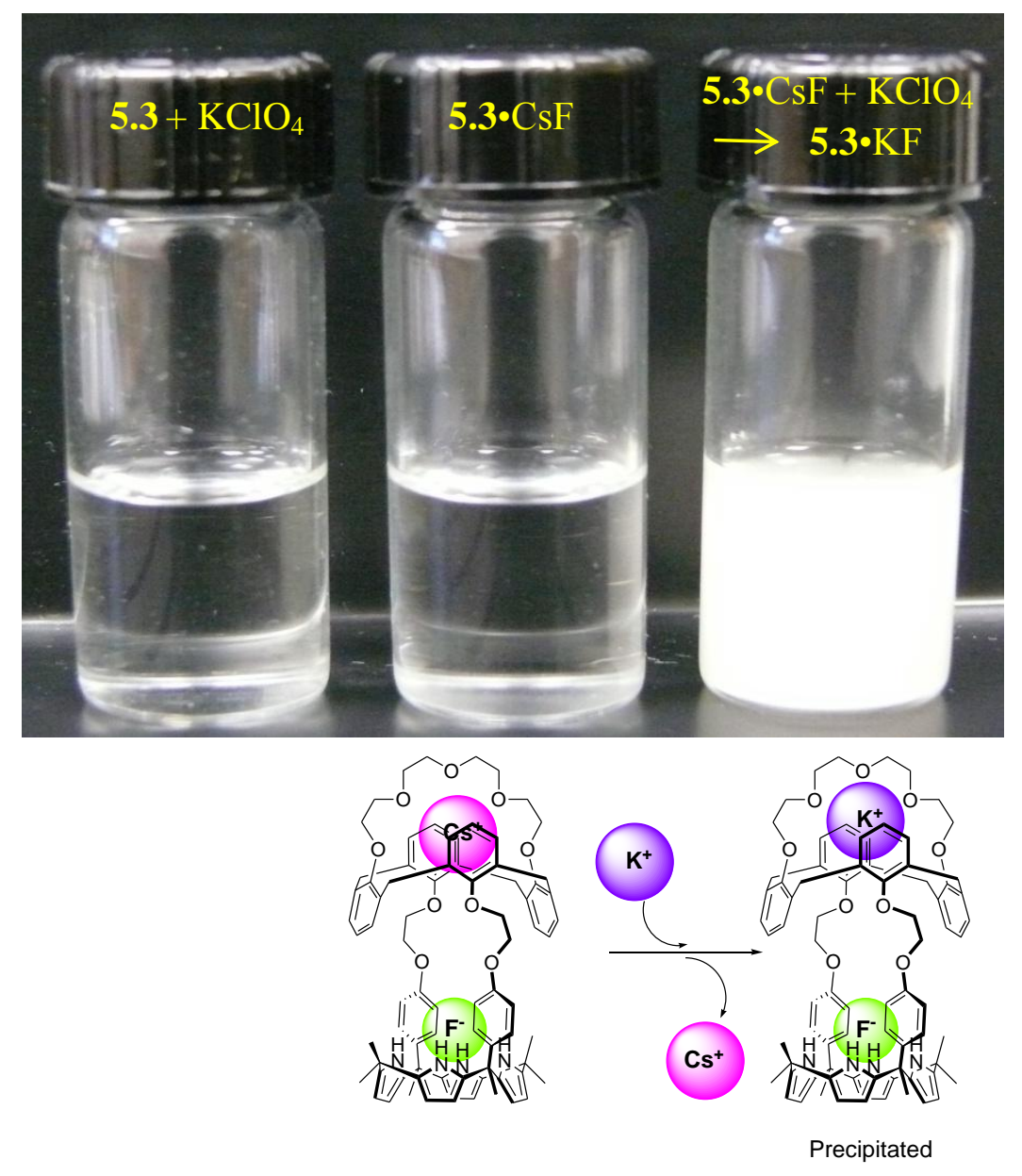

Figure 5.16 Precipitation induced via cation metathesis is observed upon adding the $\mathrm{K}^{+}$ cation to the preformed $\mathrm{CsF}$ complex of $\mathbf{5 . 3}$ in $\mathrm{CD}_{3} \mathrm{OD} / \mathrm{CDCl}_{3}(1 / 9, \mathrm{v} / \mathrm{v})$. 

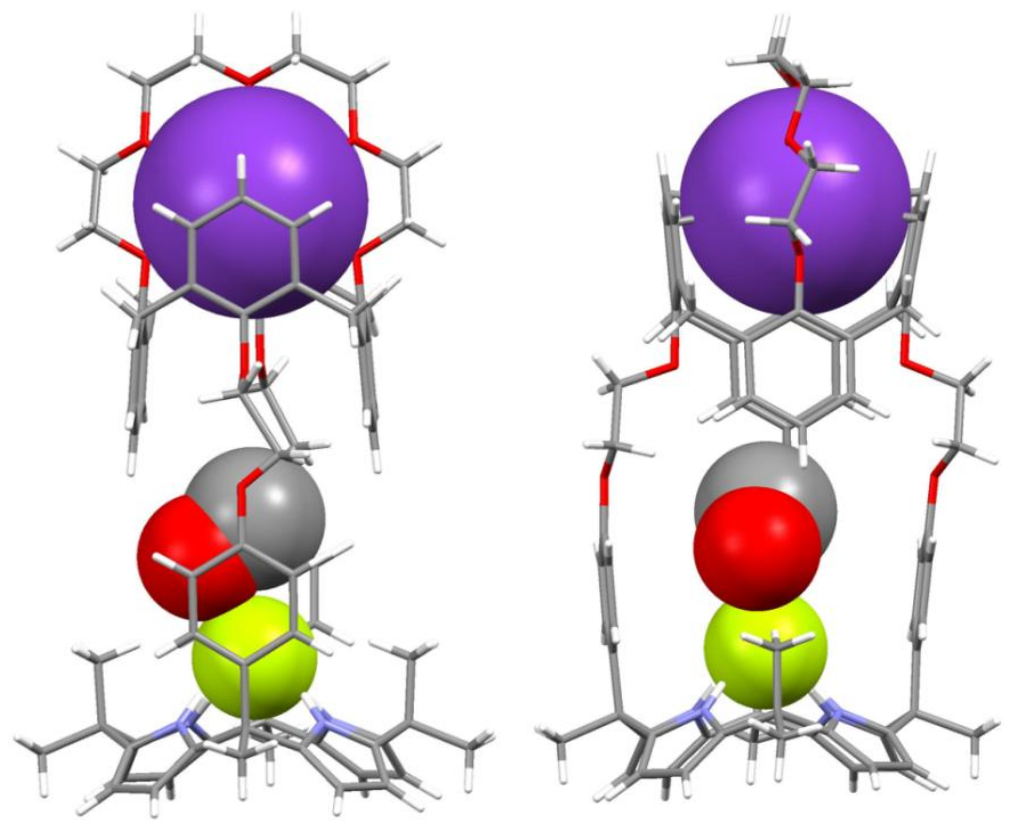

Figure 5.17 Two different views of the single crystal X-ray diffraction structure of 5.3 $\cdot \mathrm{KF} \cdot \mathrm{CH}_{3} \mathrm{OH}$. Solvent molecules not involved in the ion pair complex have been removed for clarity.
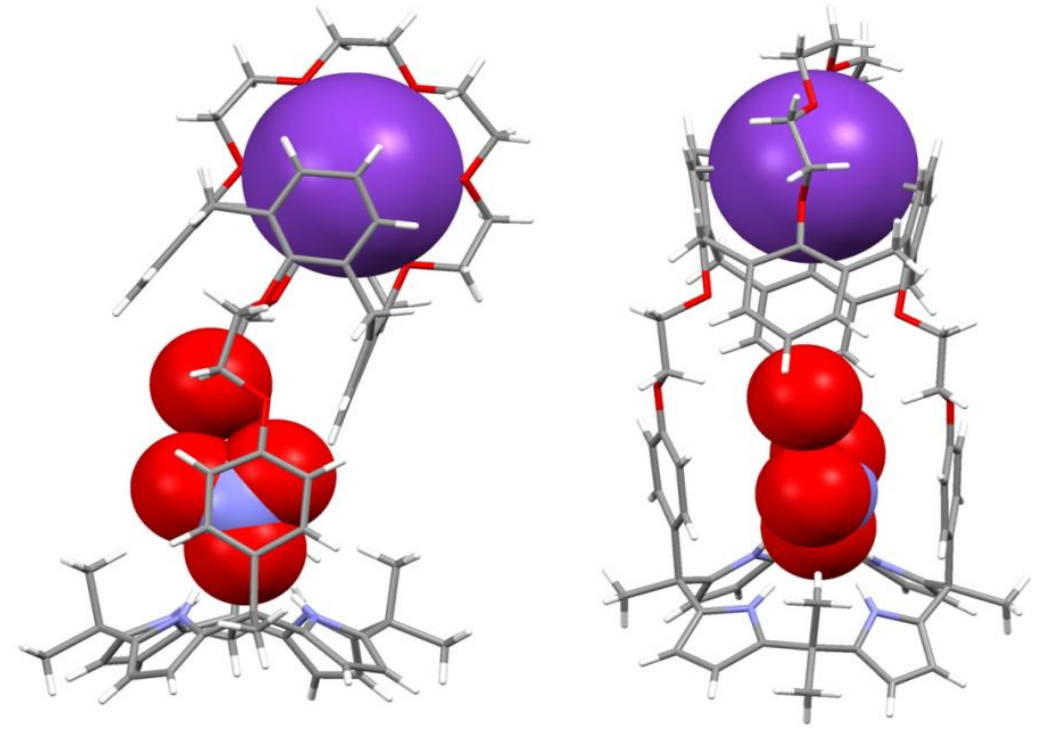

Figure 5.18 Two different views of the single crystal X-ray diffraction structure of 5.3• $\mathrm{KNO}_{3} \cdot \mathrm{H}_{2} \mathrm{O}$. Solvent molecules not involved in the ion pair complex have been removed for clarity. 
The fact that receptor $\mathbf{5 . 3}$ binds the potassium salts selectively over the cesium salts but complexes the $\mathrm{Cs}^{+}$cation in the absence of the potassium salts led us to consider that it could have use as an extractant. In particular, it was thought that it could be used to extract the $\mathrm{Cs}^{+}$cation from aqueous media and then to recover the cation by the cation release upon exposure to the $\mathrm{K}^{+}$. This concept is shown schematically in Figure 5.19. In terms of experiment, ${ }^{1} \mathrm{H}$ NMR spectroscopy was used in conjunction with a two phase system consisting of $\mathrm{D}_{2} \mathrm{O}$ and nitrobenzene- $\mathrm{d}_{5}$. Upon exposure of receptor $\mathbf{5 . 3}$ in $\mathrm{C}_{6} \mathrm{D}_{5} \mathrm{NO}_{2}$ to aqueous $\left(\mathrm{D}_{2} \mathrm{O}\right)$ solutions of $\mathrm{NaNO}_{3}, \mathrm{KNO}_{3}$, and $\mathrm{CsNO}_{3}$, respectively, significant changes in the ${ }^{1} \mathrm{H}$ NMR spectra were observed in the case of $\mathrm{KNO}_{3}$ and $\mathrm{CsNO}_{3}$ but not $\mathrm{NaNO}_{3}$ (Figures 5.20 and 5.21). This is taken as evidence that receptor 5.3 is capable of extracting both $\mathrm{KNO}_{3}$ and $\mathrm{CsNO}_{3}$ from an aqueous environment into a nitrobenzene organic phase. Differences between these two salts were observed. In the case of $\mathrm{KNO}_{3}$ extraction, the proton signals of both the aromatic ring of the calix[4]arene moiety and the crown-5 ring were seen to shift towards lower field whereas the peaks of the $\beta$-pyrrolic protons underwent little shifting (Figure 5.20b). On the basis of the studies described above, we propose that only the $\mathrm{K}^{+}$cation of the $\mathrm{KNO}_{3}$ ion pair is bound appreciably by receptor $\mathbf{5 . 3}$ to generate $\left[\mathbf{5 . 3} \cdot \mathrm{K}^{+}\right] \mathrm{NO}_{3}{ }^{-}$in the organic phase (Figure 5.21). This binding mode is in marked contrast with what is seen in the case of that of receptor 5.2, a system that lacks an independent $\mathrm{K}^{+}$recognition site. While not tested previously, significant chemical shift changes in both the calix[4]arene and the calix[4]pyrrole moiety are seen when receptor 5.2 in $\mathrm{C}_{6} \mathrm{D}_{5} \mathrm{NO}_{2}$ is exposed to aqueous $\left(\mathrm{D}_{2} \mathrm{O}\right)$ solutions of $\mathrm{KNO}_{3}$ (Figure 5.22). We thus propose that receptor 5.2 also extracts $\mathrm{KNO}_{3}$ from this aqueous environment into a nitrobenzene phase. However, it does so by forming an ion pair complex, $\left[\mathbf{5 . 2} \cdot \mathrm{KNO}_{3}\right.$ ], wherein the $\mathrm{K}^{+}$cation and the $\mathrm{NO}_{3}{ }^{-}$anion are co-bound to the calix[4]arene moiety and the calix[4]pyrrole subunit, respectively. Similarly, upon the 
extraction of $\mathrm{CsNO}_{3}$ by receptor 5.3, a significant downfield shift in the proton signals of the calix[4]arene crown-5 protons and upfield shifts in the signal of the $\beta$-pyrrolic protons of the calix[4]pyrrole moiety were also observed (Figure 5.20c). Such changes are attributable to the formation of an ion pair complex between $\mathrm{CsNO}_{3}$ and receptor $\mathbf{5 . 3}$ to give $\left[5.3 \cdot \mathrm{CsNO}_{3}\right]$ (Figure 5.19). The conclusion that the $\mathrm{NO}_{3}{ }^{-}$anion is bound to the calix[4]pyrrole cavity with the $\mathrm{Cs}^{+}$cation bound to the calix[4]arene crown-5 ring was further supported by the finding that the $\mathrm{NH}$ signal of the calix[4]pyrrole moiety undergoes a downfield shift $(\Delta \delta \approx 2.5 \mathrm{ppm})$ upon exposure to $\mathrm{CsNO}_{3}$ under these two phase conditions (Figure 5.20c).

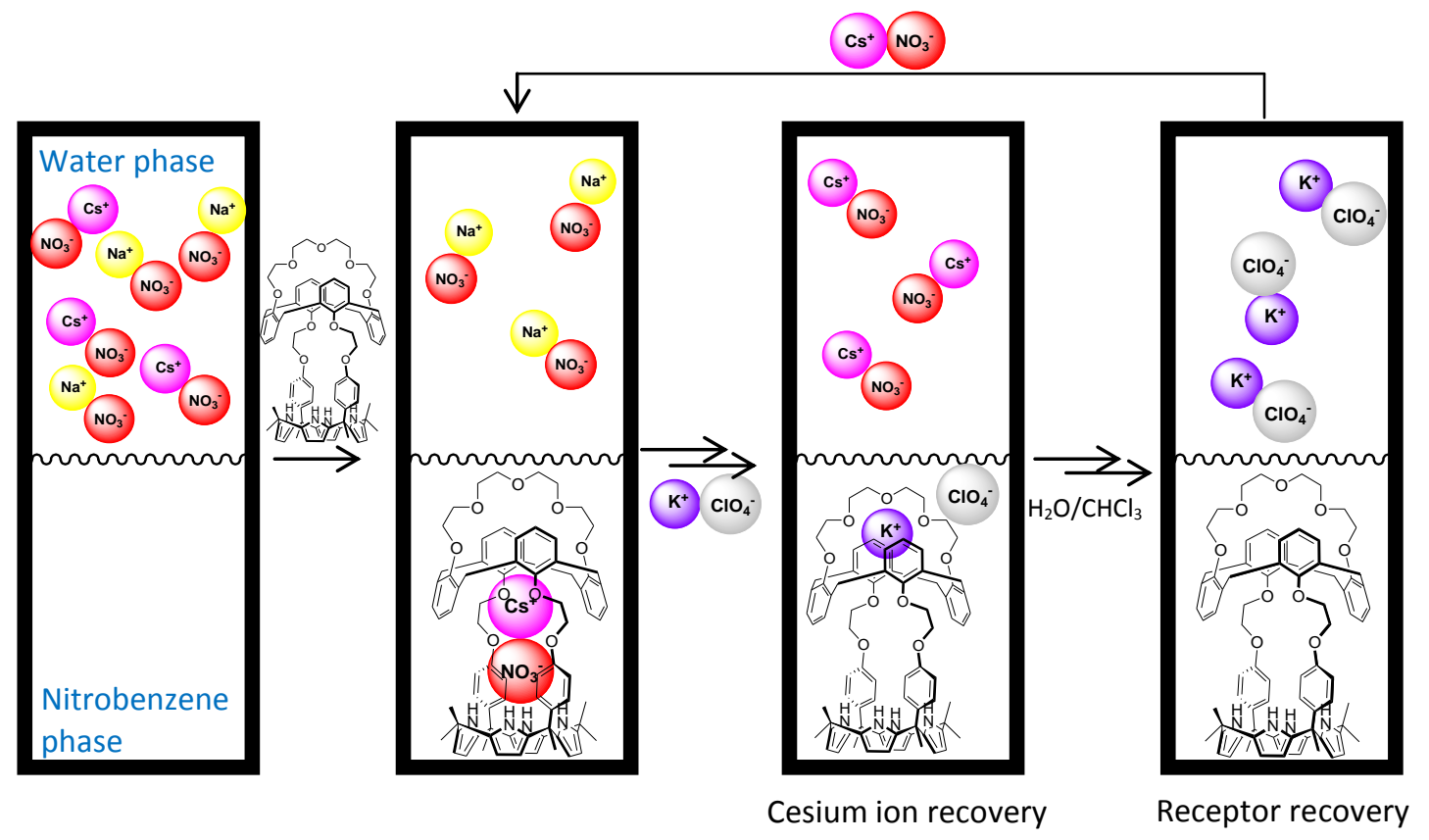

Figure 5.19 Schematic representation of extraction and recovery of $\mathrm{CsNO}_{3}$ using the ion pair receptor $\mathbf{5 . 3}$, including the proposed recycling process. 
(a) 5.3 only

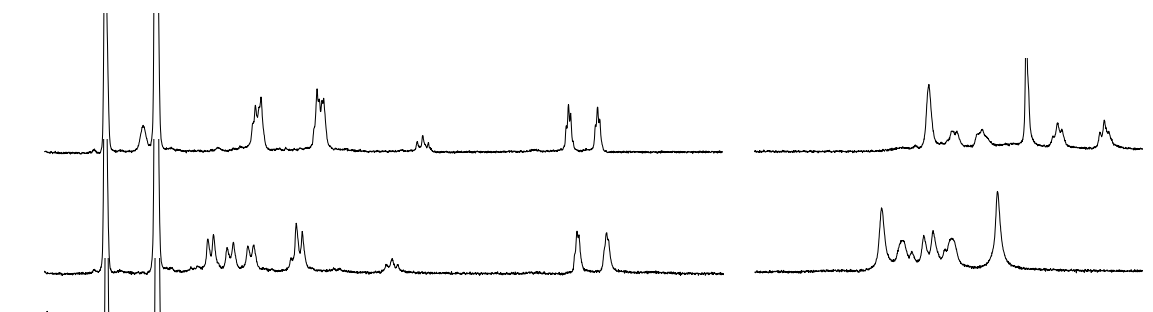

(c) $\mathrm{CsNO}_{3}$

(d) $\mathbf{5 . 3} \cdot \mathrm{CsNO}_{3}+\mathrm{KClO}_{4}$

$\longrightarrow 5.3 \cdot \mathrm{KClO}_{4}$

(e) $5.3 \cdot \mathrm{KClO}_{4}+\mathrm{H}_{2} \mathrm{O}+\mathrm{CHCl}_{3}$

$\longrightarrow$ Free 5.3
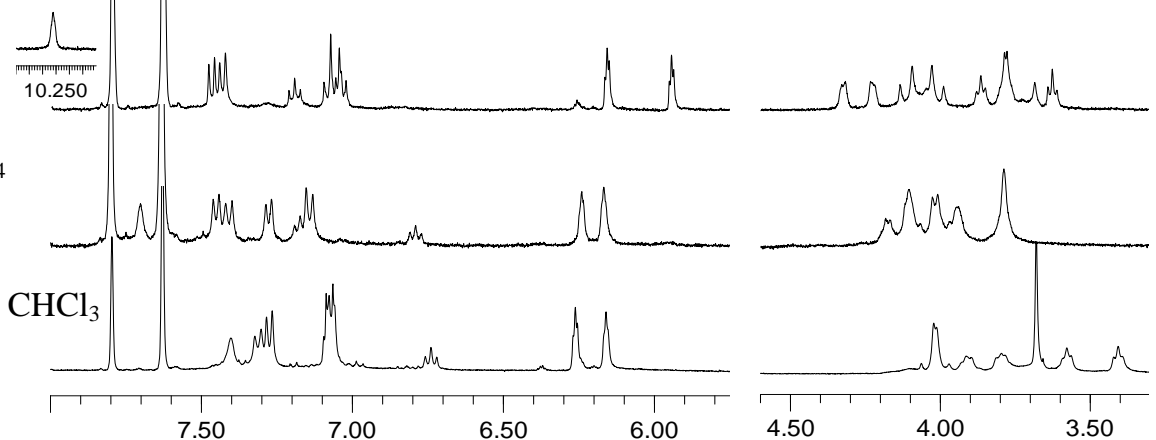

$\delta / \mathrm{ppm}$

Figure 5.20 Partial ${ }^{1} \mathrm{H}$ NMR spectra of nitrobenzene solutions of 5.3 (a) after washed with water, (b) after extracted with aqueous $\mathrm{KNO}_{3}$ solution (5 equiv), (c) after extraction with aqueous $\mathrm{CsNO}_{3}$ solution (5 equiv), (d) after the nitrobenzene phase obtained from (c) was washed with water and then with aqueous $\mathrm{KClO}_{4}$ solution (5 equiv), and (e) after the organic phase obtained from (d) was washed with water and chloroform. 

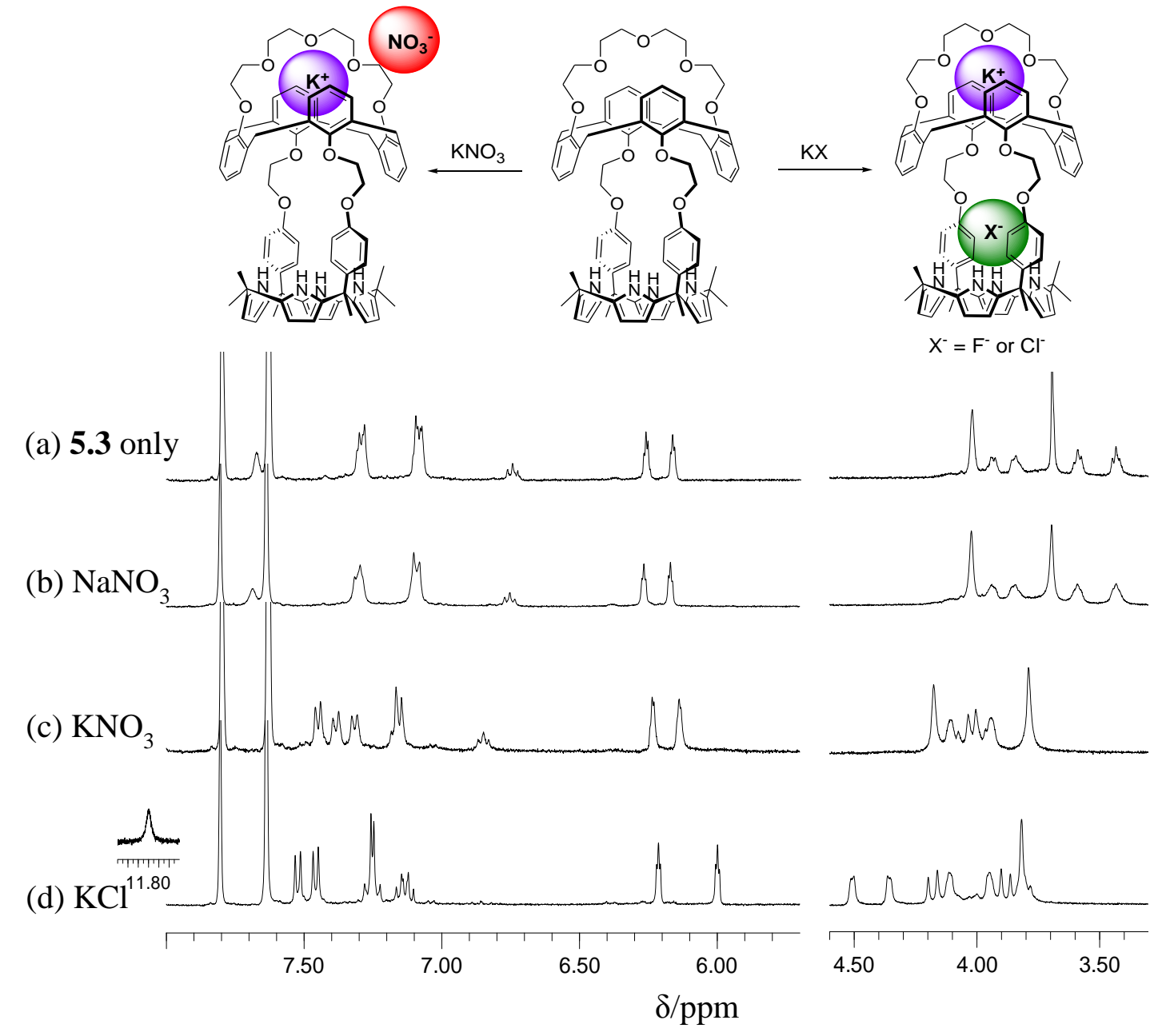

Figure 5.21 Partial ${ }^{1} \mathrm{H}$ NMR spectra of nitrobenzene solutions of $\mathbf{5 . 3}$ after exposure to (a) an ion-free aqueous $\mathrm{D}_{2} \mathrm{O}$ solution, (b) an aqueous $\mathrm{D}_{2} \mathrm{O}$ solution of $\mathrm{NaNO}_{3}(5$ equiv), (c) an aqueous $\mathrm{D}_{2} \mathrm{O}$ solution of $\mathrm{KNO}_{3}$ (equiv), and (d) an aqueous $\mathrm{D}_{2} \mathrm{O}$ solution of $\mathrm{KCl}$ (5 equiv). 

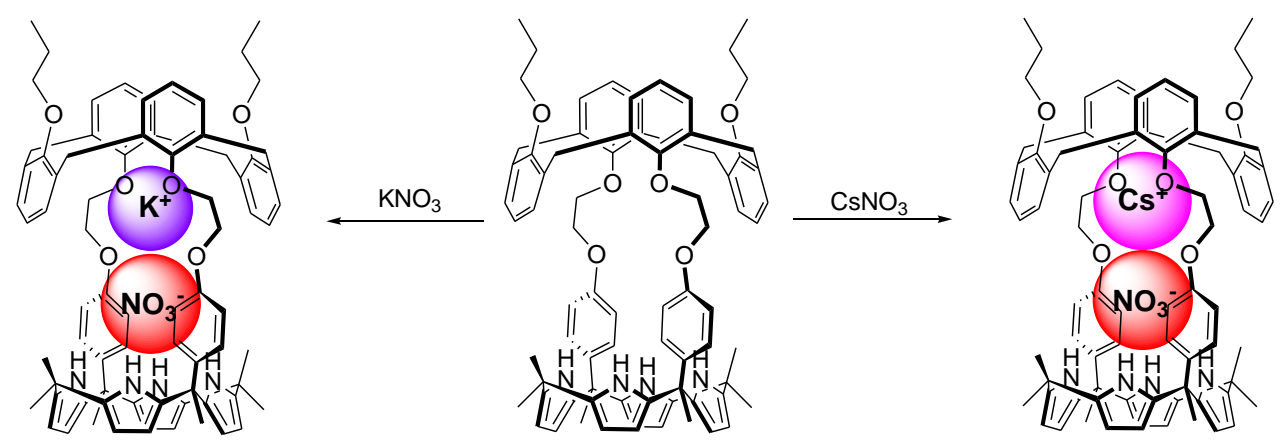

(a) 5.2 only

(b) $\mathrm{KNO}_{3}$

(c) $\mathrm{CsNO}_{3}$
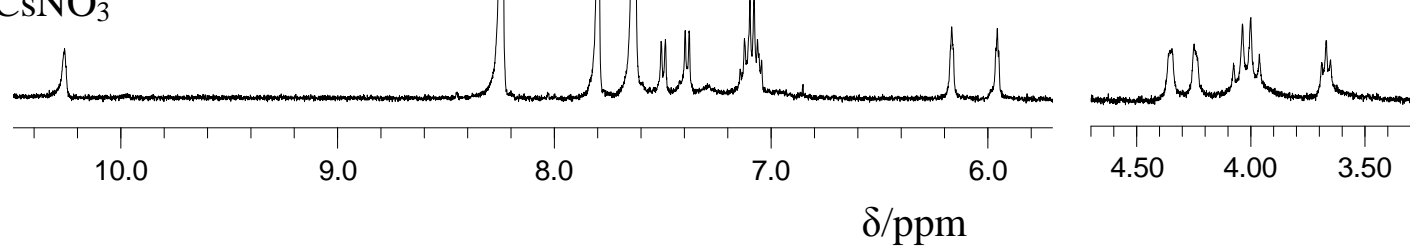

Figure 5.22 Partial ${ }^{1} \mathrm{H}$ NMR spectra of nitrobenzene- $\mathrm{d}_{5}$ solutions of $\mathbf{5 . 2}$ after exposure to (a) an ion-free aqueous $\mathrm{D}_{2} \mathrm{O}$ solution, (b) an aqueous $\mathrm{D}_{2} \mathrm{O}$ solution of $\mathrm{KNO}_{3}$ (5 equiv), and (c) an aqueous $\mathrm{D}_{2} \mathrm{O}$ solution of $\mathrm{CsNO}_{3}(5$ equiv).

Once $\left[5.3 \cdot \mathrm{CsNO}_{3}\right]$ is formed via extraction, the organic phase containing [5.3. $\left.\mathrm{CsNO}_{3}\right]$ may be washed with an aqueous solution of $\mathrm{KClO}_{4}$. Such a wash causes the $\mathrm{K}^{+}$cation to replace the $\mathrm{Cs}^{+}$cation that originally occupied the calix[4]arene crown-5 ring. This releases the $\mathrm{CsNO}_{3}$ ion pair from receptor 5.3, upon which it probably moves into the water phase (Figures 5.19 and 5.20). This metathesis is ascribed in part to the incipient electrostatic repulsion between the two cations in question, namely the pre- 
bound $\mathrm{Cs}^{+}$cation and the entering $\mathrm{K}^{+}$cation. ${ }^{15}$ As a result of this metathesis, a new complex, $\left[\mathbf{5 . 3} \cdot \mathrm{K}^{+}\right] \mathrm{ClO}_{4}{ }^{-}$, is produced in the organic phase. This is evidenced by the emergence of ${ }^{1} \mathrm{H}$ NMR spectrum similar to that of the $\mathrm{KNO}_{3}$ complex where only the proton signals of the calix[4]arene crown-5 moiety but not those of the calix[4]pyrrole moiety including the NH protons appeared to be shifted (Figure 5.20d). In accord with expectations, the ${ }^{133} \mathrm{Cs}$ NMR spectrum of the water phase measured after extraction of [5.3. $\mathrm{CsNO}_{3}$ ] with the aqueous $\mathrm{KClO}_{4}$ solution revealed the presence of the $\mathrm{Cs}^{+}$cation, presumably reflecting the existence of a solubilized $\mathrm{CsNO}_{3}$ ion pair in the water phase (Figure 5.23).

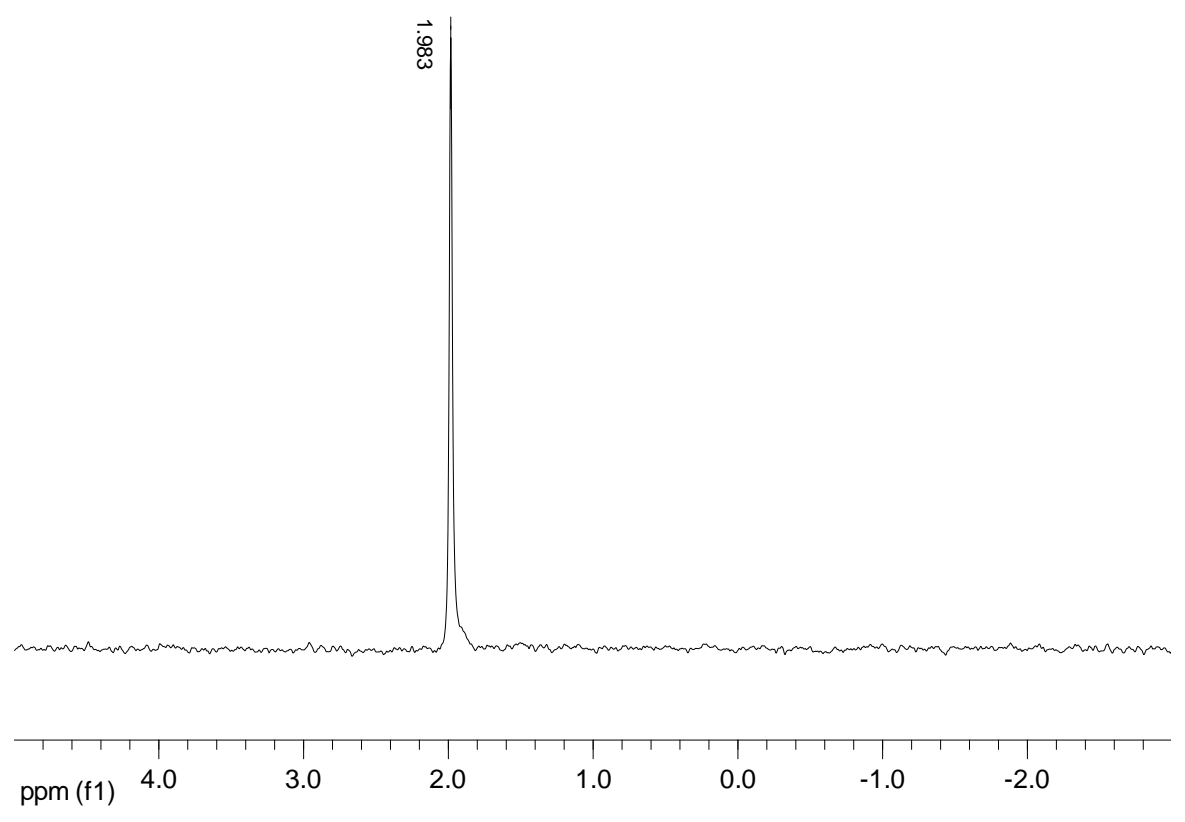

Figure 5.23 ${ }^{133} \mathrm{Cs} \mathrm{NMR}$ of the aqeous $\left(\mathrm{D}_{2} \mathrm{O}\right)$ phase after the preformed $\mathbf{5 . 3} \cdot \mathrm{CsNO}_{3}$ complex in nitrobenzene was washed with an aqueous $\mathrm{D}_{2} \mathrm{O}$ solution of $\mathrm{KClO}_{4}$. A $1 \mathrm{M}$ solution of $\mathrm{CsNO}_{3}$ in $\mathrm{D}_{2} \mathrm{O}$ (not shown) was used as a reference. 
These finding are noteworthy given that the standard molar Gibbs free energies for hydration of the $\mathrm{K}^{+}$cation $\left(\Delta_{\mathrm{hyd}} G=-295 \mathrm{~kJ} / \mathrm{mol}\right)$ and the $\mathrm{ClO}_{4}{ }^{-}\left(\Delta_{\mathrm{hyd}} G=-430 \mathrm{~kJ} / \mathrm{mol}\right)$ are much lower than those of the $\mathrm{Cs}^{+}$cation $\left(\Delta_{\text {hyd }} G=-250 \mathrm{~kJ} / \mathrm{mol}\right)$ and the $\mathrm{NO}_{3}{ }^{-}\left(\Delta_{\text {hyd }} G=\right.$ $-300 \mathrm{~kJ} / \mathrm{mol}$ ), respectively. ${ }^{19}$ In accord with its design features, receptor $\mathbf{5 . 3}$ extracts the $\mathrm{KClO}_{4}$ better than it does $\mathrm{CsNO}_{3}$. It thus serves to overcome the hydration energy bias that would favor extraction of the latter ion salt. ${ }^{19}$

In a further step of note, it was found that washing the organic phase containing [5.3. $\left.\mathrm{K}^{+}\right] \mathrm{ClO}_{4}{ }^{-}$with chloroform and water (twice) leaves receptor $\mathbf{5 . 3}$ in the free form in the organic phase (Figure 5.19 and 5.20e). After separation of the organic phase followed by removal of chloroform in vacuo, receptor $\mathbf{5 . 3}$ can be recycled for further extraction and recovery of the $\mathrm{Cs}^{+}$cation. The series of processes in question is depicted in Figure 5.19. Here, it is suggested that not only may the $\mathrm{Cs}^{+}$cation be extracted and recovered for reuse but receptor $\mathbf{5 . 3}$ can be also recovered for recycling.

The simple salts, $\mathrm{KCl}$ and $\mathrm{KF}$, are even more strongly hydrated than $\mathrm{CsNO}_{3}$ and $\mathrm{KNO}_{3}\left(\Delta_{\text {hyd }} G=-340 \mathrm{~kJ} / \mathrm{mol}\right.$ for $\mathrm{Cl}^{-} ; \Delta_{\text {hyd }} G=-465 \mathrm{~kJ} / \mathrm{mol}$ for $\left.\mathrm{F}^{-}\right)$. This makes them particularly challenging to extract from water. ${ }^{19,20}$ In contrast to what was seen for $\mathrm{KNO}_{3}$, upon subjecting aqueous solutions of $\mathrm{KCl}$ and $\mathrm{KF}$ to the extraction conditions noted above, the proton signals of the calix[4]pyrrole moiety, as well as those of the calix[4]arene crown-5 ring, were seen to undergo significant shifts in the ${ }^{1} \mathrm{H}$ NMR spectra. This leads us to suggest that both the $\mathrm{K}^{+}$cation and the anions are bound to the receptor as ion pairs (Figures 5.20, 5.21 and 5.24). Particularly, large chemical shift changes in the $\mathrm{NH}$ signals are seen $(\Delta \delta \approx 4.1$ and $5.1 \mathrm{ppm}$ for $\mathrm{KCl}$ and $\mathrm{KF}$, respectively). This is consistent with the interactions between the anions and the receptor being very strong. 
(a) 5.3 only

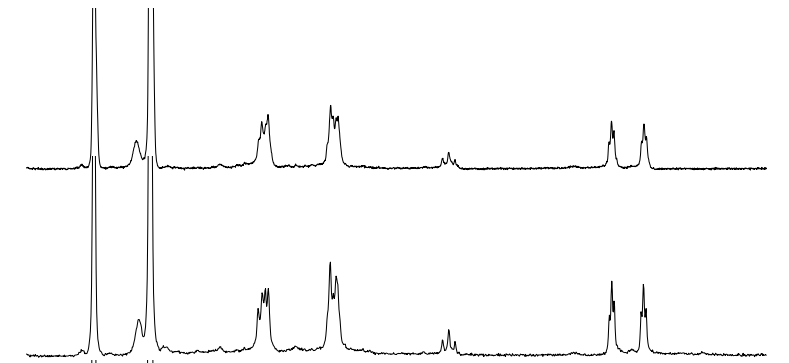

(b) $\mathrm{CsF}$

5.3 only

(c)

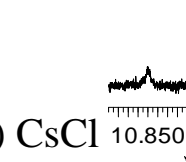

(d) $\mathrm{KF}$

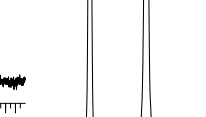

(1)
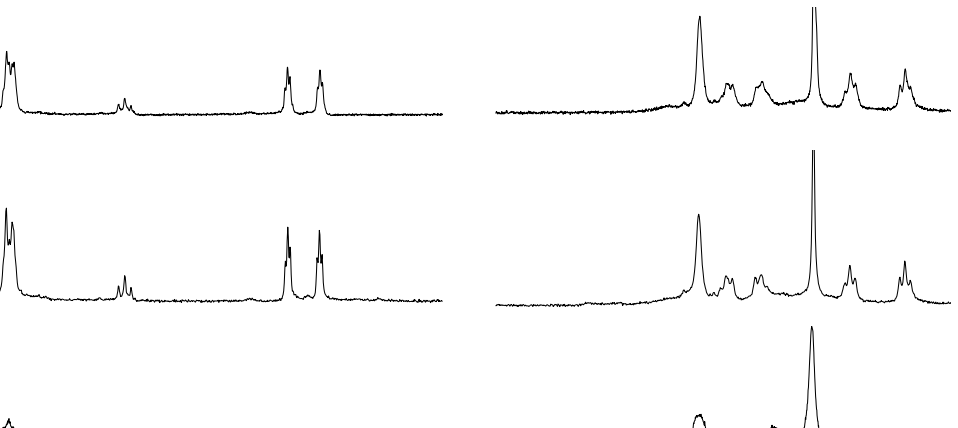

(e) $\mathrm{KCl}$

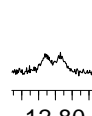

-
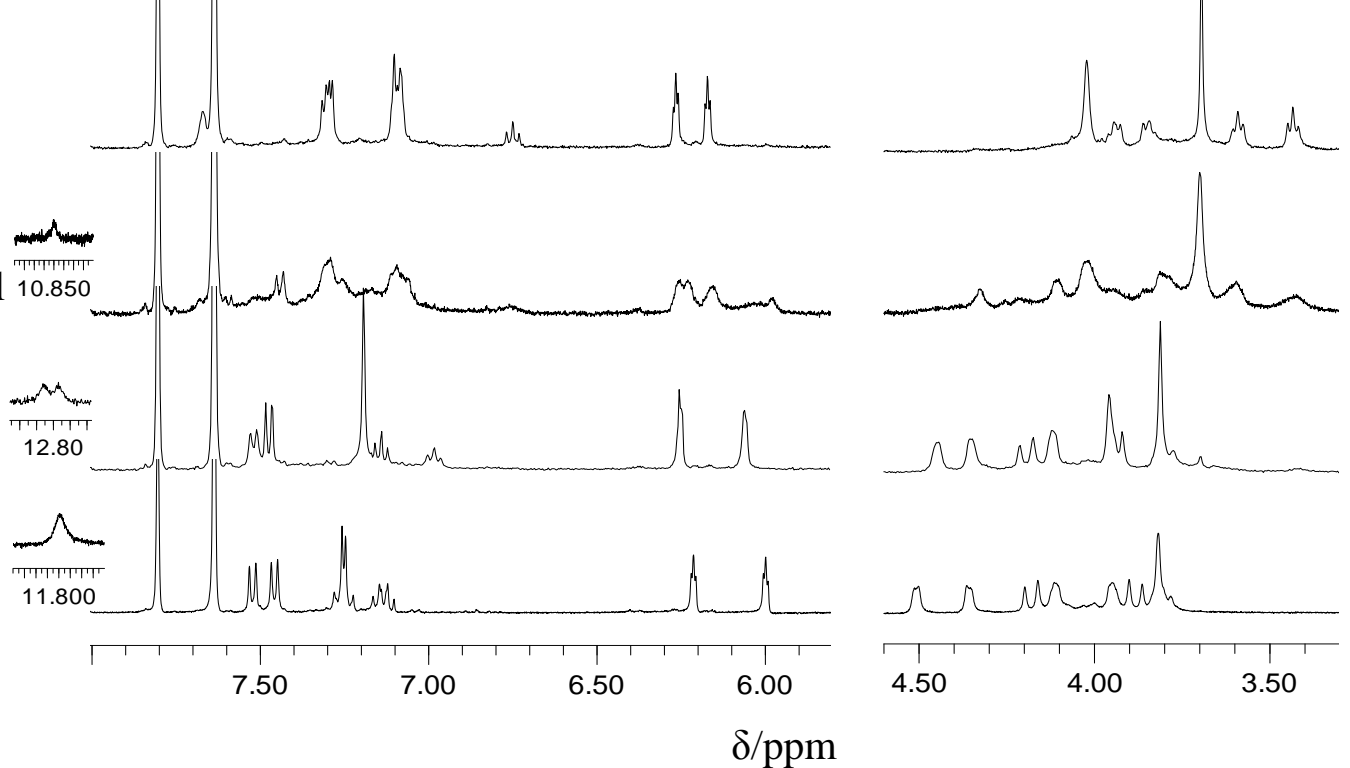

$\delta / \mathrm{ppm}$

Figure 5.24 Partial ${ }^{1} \mathrm{H}$ NMR spectra of nitrobenzene- $\mathrm{d}_{5}$ solutions of $\mathbf{5 . 3}$ after exposure to (a) an ion-free aqueous $\mathrm{D}_{2} \mathrm{O}$ solution, (b) an aqueous $\mathrm{D}_{2} \mathrm{O}$ solution of $\mathrm{CsF}$ ( 5 equiv), (c) an aqueous $\mathrm{D}_{2} \mathrm{O}$ solution of $\mathrm{CsCl}$ (5 equiv), (d) an aqueous $\mathrm{D}_{2} \mathrm{O}$ solution of $\mathrm{KF}$ (5 equiv) and (e) an aqueous $\mathrm{D}_{2} \mathrm{O}$ solution of $\mathrm{KCl}$ (5 equiv).

In contrast to what is true for $\mathrm{KCl}$ and $\mathrm{KF}$, in the case of $\mathrm{CsCl}$ and $\mathrm{CsF}$, receptor 5.3 is able to extract only $\mathrm{CsCl}$, although less well than it can extract $\mathrm{CsNO}_{3}$ or the corresponding potassium salts (Figure 5.24). The ${ }^{1} \mathrm{H}$ NMR spectrum shown in Figure $5.24 \mathrm{c}$ is fully consistent with $\mathrm{CsCl}$ being also extracted by receptor $\mathbf{5 . 3}$ in the form of an ion pair complex. Based on the studies detailed above, it is believed that the $\mathrm{Cs}^{+}$cation and the $\mathrm{Cl}^{-}$anion are bound to the calix[4]arene crown-5 ring and calix[4]pyrrole, respectively.

Further support for the proposed binding modes for receptor $\mathbf{5 . 3}$ with $\mathrm{CsF}, \mathrm{CsCl}$, $\mathrm{CsNO}_{3}, \mathrm{KF}$, and $\mathrm{KNO}_{3}$ inferred in solution came from single crystal X-ray diffraction 
analyses. The structures of the ion pair complexes formed from these five salts revealed structures in the solid states that are very similar to those that were thought to pertain in solution, as inferred from ${ }^{1} \mathrm{H}$ NMR spectra. A detailed discussion of the structures now follows. Suitable single crystals of the $\mathrm{CsF}$ complex were obtained by subjecting a chloroform/methanol solution of receptor $\mathbf{5 . 3}$ to slow evaporation in the presence of excess cesium fluoride. The resulting crystal structure revealed that $\mathbf{5 . 3}$ forms a 1:1 complex with cesium fluoride, 5.3. $\mathrm{CsF}$, wherein the $\mathrm{Cs}^{+}$cation is bound to the calix[4]arene crown-5 moiety (Figure 5.25). Calix[4] arene crown-5 species are expected to interact weakly with the $\mathrm{Cs}^{+}$cation. In fact, to the best of our knowledge, this structure is the first example wherein the $\mathrm{Cs}^{+}$cation is bound to the calix[4]arene crown-5 ring. The $\mathrm{Cs}^{+}$ion is encapsulated by the calix[4]arene crown ether ring with distances of $2.84-$ $3.03 \AA$ for the $\mathrm{Cs}^{+} \ldots \mathrm{O}$ separations. The distances between the $\mathrm{Cs}^{+}$ion and the aromatic carbon atoms in the meta- and para-position with respect to the phonoxy groups are on the order of $3.40-3.46 \AA$. It is thus inferred that $\pi$-metal interaction are playing a role in stabilizing the complex (Figure 5.25). Compared with the distances observed in the CsF complex of receptor $5.1\left(3.08-3.36 \AA\right.$ for the $\mathrm{Cs}^{+} \cdots \mathrm{O}$ distance and $3.43-3.63 \AA$ for $\pi$ metal interaction), those observed between the bound $\mathrm{Cs}^{+}$cation and the calix[4]arene crown-5 of receptor $\mathbf{5 . 3}$ is much shorter. This leads us to suggest that receptor $\mathbf{5 . 3}$ holds the $\mathrm{Cs}^{+}$cation more tightly than does receptor $\mathbf{5 . 1}$ in spite of the fact that the calix[4]arene crown-6 binds the $\mathrm{Cs}^{+}$cation much more strongly than does the calix[4]arene crown-5. On the other hand, in the complex of $\mathbf{5 . 3 \cdot C s F}$, the $\mathrm{F}^{-}$ion is bound to the $\mathrm{NH}$ protons of the calix[4]pyrrole with the relevant $\mathrm{N}^{\cdots} \mathrm{F}^{-}$distances being $2.77-$ $2.81 \AA$. One methanol molecule is also hydrogen bonded to the $\mathrm{F}^{-}$anion; the $\mathrm{O} \cdots \mathrm{F}^{-}$ distance being $2.58 \AA$ A In analogy to what was seen for the complex of compound $\mathbf{5 . 1}$ with $\mathrm{CsF}$, there is no direct interaction or solvent mediated interaction between the $\mathrm{Cs}^{+}$ 
and $\mathrm{F}^{-}$ions bound to receptor 5.3. We take this as meaning that the stabilization energy arising from the formation of the complex, $5.3 \cdot \mathrm{CsF}$, is large enough to offset Columbic energy penalty caused by what appears to be an unfavorable ion separation. The distance between the $\mathrm{Cs}^{+}$ion and the $\mathrm{F}^{-}$ion in the complex was found to be $10.29 \AA$ (Figure 5.26). Again, this lead us to suggest that the formation of the strong complex, namely $5.3 \cdot \mathrm{CsF}$ containing a methanol molecule, is energetically more stable than contact ion complexation. This is true in spite of the large separation between the $\mathrm{Cs}^{+}$and $\mathrm{F}^{-}$ions.
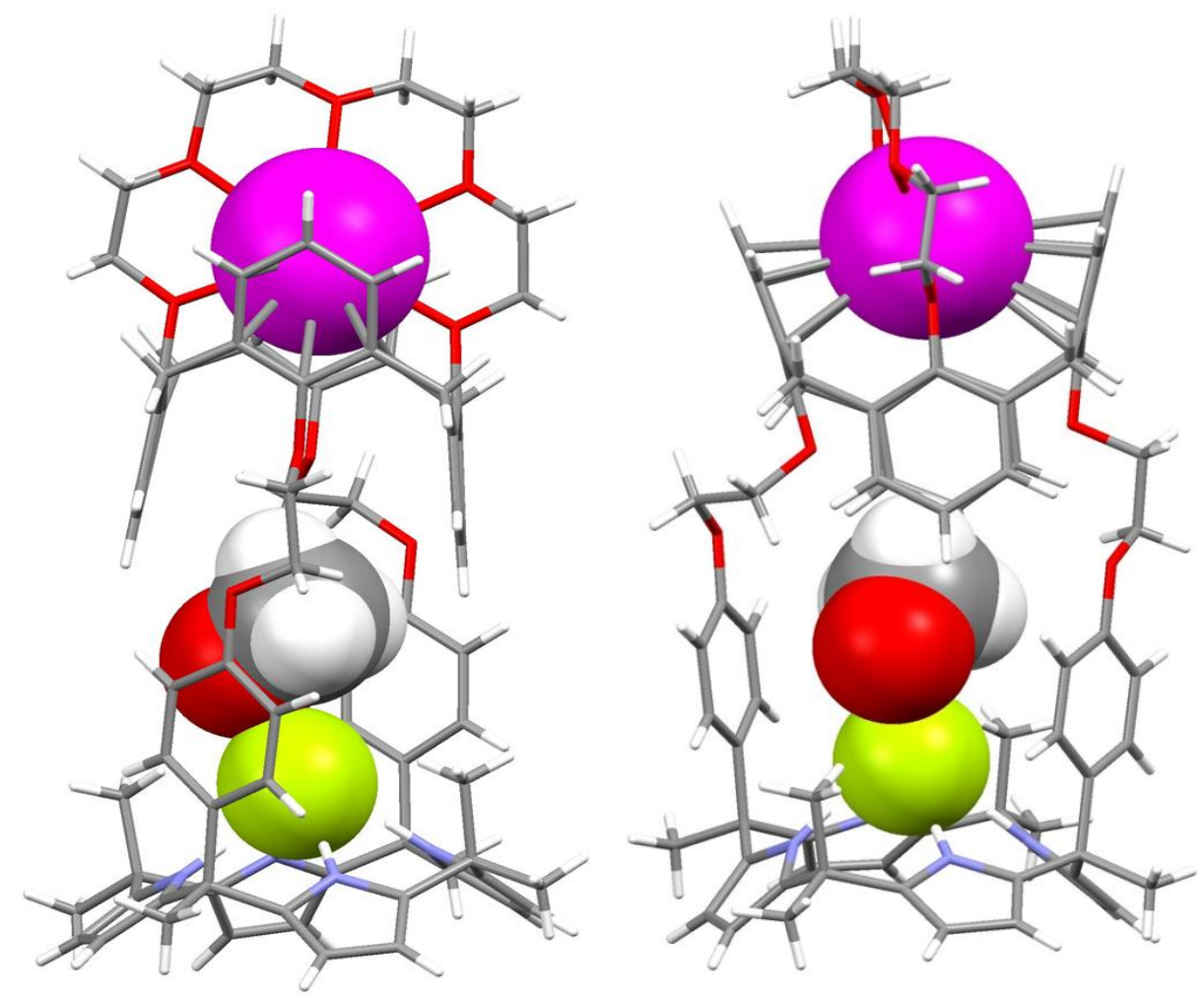

Figure 5.25 Two different views of the single crystal $\mathrm{X}$-ray diffraction structure of 5.3 $\mathrm{CsF} \cdot \mathrm{CH}_{3} \mathrm{OH}$. Solvent molecules not involved in the ion pair complex have been removed for clarity. 


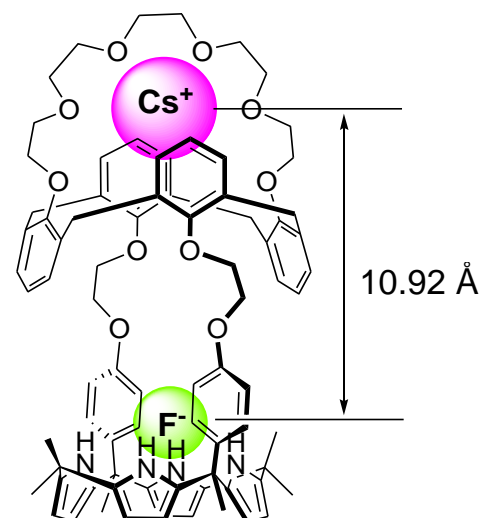

5.1. CsF

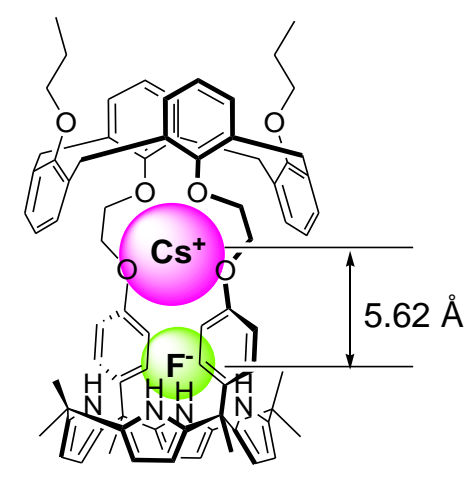

5.2. CsF

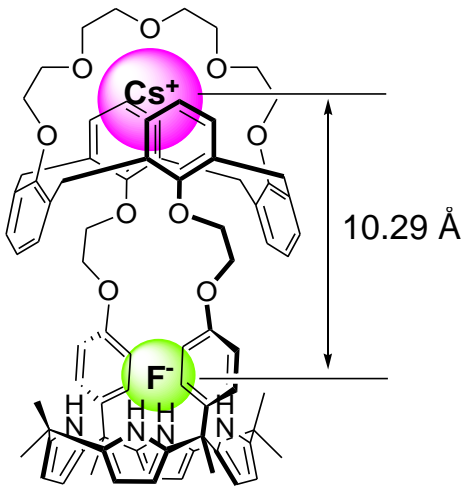

5.3. CsF

Figure 5.26 Limiting binding modes observed for the $\mathrm{CsF}$ ion pair complexes of receptors $\mathbf{5 . 1}$ - $\mathbf{5 . 3}$ as inferred from X-ray diffraction analysis. Also shown are the distances between the $\mathrm{Cs}^{+}$and $\mathrm{F}^{-}$ions determined from these X-ray diffraction analyses. The structures of the CsF complexes of $\mathbf{5 . 1}$ and $\mathbf{5 . 2}$ were reported in references 11 and 13 , respectively.

In analogy to what was seen for the CsF complex, receptor $\mathbf{5 . 3}$ forms a 1:1 complex with $\mathrm{CsCl}$ wherein the $\mathrm{Cs}^{+}$and the $\mathrm{Cl}^{-}$ion are bound to the calix[4]arene crown5 and the calix[4]pyrrole moieties, respectively (Figure 5.27). The $\mathrm{N}^{\cdots} \mathrm{Cl}^{-}, \mathrm{Cs}^{+} \cdots \mathrm{O}$ distances and the $\pi$-metal interaction involving the $\mathrm{Cs}^{+}$ion and the aromatic carbon atoms of the calix[4]arene core were found to be $3.23-3.31 \AA, 2.84-3.10 \AA$, and $3.29-$ $3.40 \AA$, respectively. One water molecule also interacts with the bound $\mathrm{Cl}^{-}$anion via hydrogen bonding. The relevant distance for $\mathrm{O}^{\cdots} \mathrm{Cl}^{-}$is $3.22 \AA$. 

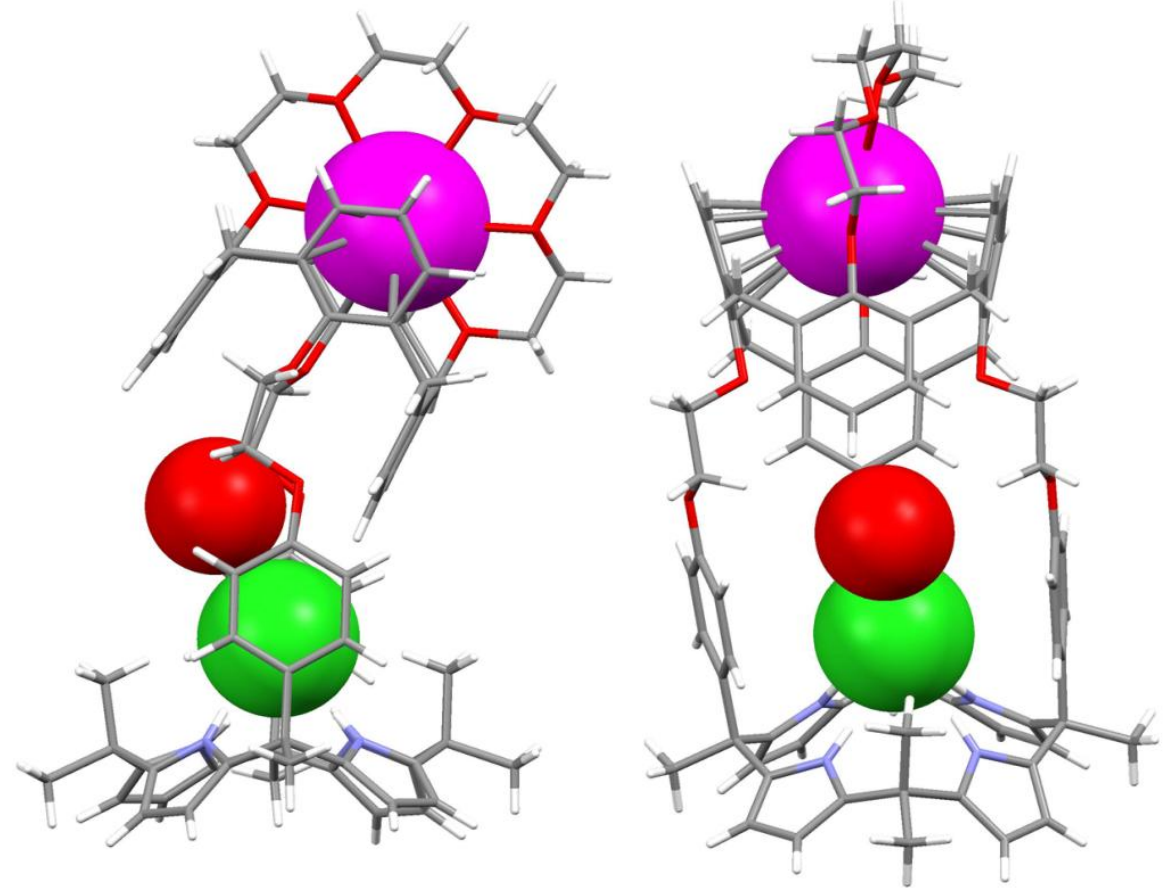

Figure 5.27 Two different views of the single crystal structure of $\mathbf{5 . 3} \cdot \mathrm{CsCl} \cdot \mathrm{H}_{2} \mathrm{O}$. Solvent molecules not involved in the ion pair complex have been removed for clarity.

The structure of the $\mathrm{CsNO}_{3}$ complex in the solid state was also determined by $\mathrm{X}$ ray diffraction analysis of single crystals obtained via the slow evaporation of an ethanol/chloroform solution of $\mathbf{5 . 3}$ in the presence of excess $\mathrm{CsNO}_{3}$. The resulting crystal structure revealed that, in contrast to what was seen for the $\mathrm{CsF}$ and $\mathrm{CsCl}$ complexes, the $\mathrm{Cs}^{+}$cation is coordinated by the oxygen atoms of the ethylene glycol spacers but not by the crown-5 ring (Figure 5.28). This leads us to sugges that cation binding to a specific subunit within $\mathbf{5 . 3}$ can be controlled and tuned by using different counteranions. The distances between the $\mathrm{Cs}^{+}$cation and the oxygen atoms of the ethylene glycolic spacers were found to be $3.01-3.63 \AA$ in the $\mathrm{CsNO}_{3}$ complex. In addition, the bound $\mathrm{Cs}^{+}$ion interacts closely with two oxygen atoms of the co-bound nitrate anion with $\mathrm{Cs}^{+} \cdots \mathrm{O}$ distances of 3.19 and $3.50 \AA$, as well as with an ethanol molecule. These relatively small 
separations between the $\mathrm{Cs}^{+}$ion and the two oxygen atoms of the $\mathrm{NO}_{3}{ }^{-}$ion are considered to be distinct evidence that the $\mathrm{CsNO}_{3}$ is bound to receptor $\mathbf{5 . 3}$ as a contact ion pair. Evidence of $\pi$-metal interactions between the $\mathrm{Cs}^{+}$cation and the aromatic carbon atoms of the inverted phenoxy groups of the calix[4]arene moiety are also inferred from the structural parameters. Specifically, distances of $3.50-3.66 \AA$ are seen for $\mathrm{Cs}^{+} \cdots \mathrm{C}$ contacts (Figure 5.28). One oxygen atom of the $\mathrm{NO}_{3}{ }^{-}$ion is also hydrogen-bonded to the calix[4]pyrrole $\mathrm{NH}$ protons with the relevant $\mathrm{N}^{\cdots} \mathrm{O}^{-}$distances being $2.92-3.00 \AA$. This latter finding is consistent with the proposed anion binding mode involving this portion of receptor $\mathbf{5 . 3}$.
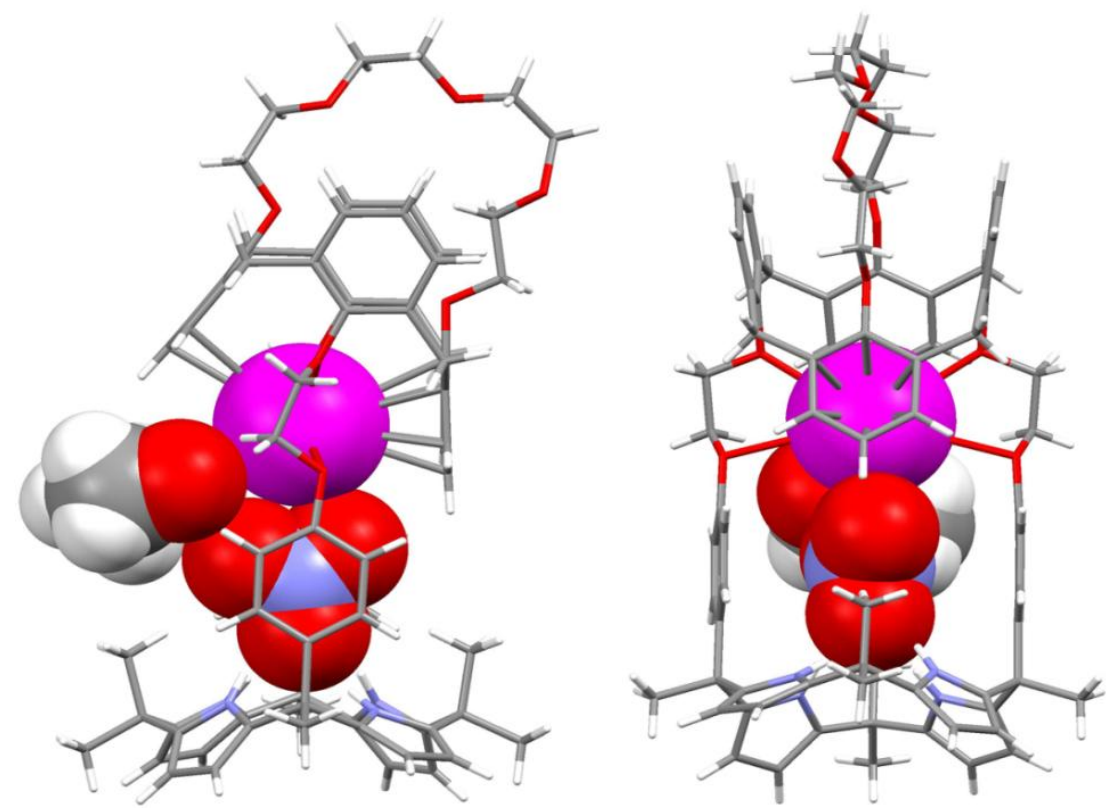

Figure 5.28 Two different views of the single crystal $\mathrm{X}$-ray diffraction structure of 5.3 $\mathrm{CsNO}_{3} \cdot \mathrm{CH}_{3} \mathrm{CH}_{2} \mathrm{OH}$. Solvent molecules not involved in the ion pair complex have been removed for clarity. 
Single crystals of the $\mathrm{KNO}_{3}$ complex of $\mathbf{5 . 3}$ were obtained by allowing a chloroform/ethanol solution of the preformed 5.3. $\mathrm{CsNO}_{3}$ complex to undergo slow evaporation in the presence of one molar equivalent of $\mathrm{KClO}_{4}$ relative to the added $\mathrm{CsNO}_{3}$ (Figure 5.18). That a new complex, containing $\mathrm{K}^{+}$instead of $\mathrm{Cs}^{+}$, is formed leads us to suggest that the formation of the $\mathrm{KNO}_{3}$ complex occurs via cation metathesis involving displacement of $\mathrm{Cs}^{+}$by $\mathrm{K}^{+}$ion in what is a thermodynamically driven process. The resulting crystal structure revealed that the $\mathrm{K}^{+}$cation is bound to the crown-5 ring rather than to the ethylene glycol moieties. The relevant distances are $2.73-2.84 \AA$ for the $\mathrm{Cs}^{+} \ldots \mathrm{O}$ and $3.07-3.31 \AA$ for the $\pi$-metal interactions, respectively (Figure 5.18). As expected, the $\mathrm{NO}_{3}{ }^{-}$anion is hydrogen-bonded to the calix[4]pyrrole moiety at an $\mathrm{N}^{\cdots} \mathrm{O}^{-}$ distance of $2.93-3.01 \AA$. The anion is separated from the co-bound $\mathrm{K}^{+}$cation by a distance of $8.32 \AA$.

The structure of the KF complex of receptor $\mathbf{5 . 3}$ in the solid state was also determined by X-ray crystallography. Suitable single crystals were obtained by allowing a chloroform/methanol solution of the $\mathrm{CsF}$ complex to undergo slow evaporation in the presence of one molar equivalent of $\mathrm{KClO}_{4}$. As shown in Figure 5.17, in the resulting structure, the $\mathrm{K}^{+}$cation is bound to the crown ether at distances that vary between 2.77 $2.87 \AA$ for $\mathrm{K}^{+} \ldots \mathrm{O}$. Evidence for a $\pi$-metal interaction between the aromatic rings of the calix[4]arene and the $\mathrm{K}^{+}$cation is seen in the $\mathrm{K}^{+} \ldots \mathrm{C}$ distances of $3.06-3.23 \AA$ for the presumed interaction (Figure 5.17). The $\mathrm{F}^{-}$anion is hydrogen bonded to the four pyrrolic

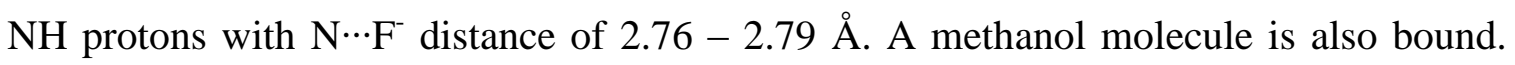
The relevant $\mathrm{O}^{\cdots} \mathrm{F}^{-}$distance is $2.69 \AA$ A. The separation between the $\mathrm{K}^{+}$and co-bound $\mathrm{F}^{-}$ was found to be $10.74 \AA$. 


\subsection{Conclusions}

In conclusion, a new ion pair receptor, 5.3, that contains a dedicated calix[4]pyrrole anion binding subunit and various sites suitable for $\mathrm{K}^{+}$and $\mathrm{Cs}^{+}$ complexaton, has been synthesized and characterized by standard spectroscopic means as well as by single X-ray crystal diffraction analysis. The ${ }^{1} \mathrm{H}$ NMR spectroscopic analyses and the X-ray crystal structural data reveal that both in the solid states and in the mixed methanol-chloroform, receptor $\mathbf{5 . 3}$ forms 1:1 complexes with various potassium and cesium salts. It forms complexes that are characterized by various binding modes and different binding strengths. Receptor $\mathbf{5 . 3}$ proved highly selective for potassium salts over other alkali metals salts including cesium salts. However, in the absence of potassium salts, it binds cesium salts selectively. In the case of several potassium salts, receptor $\mathbf{5 . 3}$ binds the cations and anions in a sequential manner. First, the $\mathrm{K}^{+}$cation is bound to the calix[4]arene crwon-5 moiety. After that, the counteranions are bound by the calix[4]pyrrole moiety to give a stable 1:1 ion pair complex that generally precipitates from solution. In contrast, cesium salts typically interact with receptor $\mathbf{5 . 3}$ in two different ways. In one mode, only the $\mathrm{Cs}^{+}$cation, but not its counteranion, interacts with the receptor. It does weakly and via the the calix[4]arene crown-5 ring. The net result is a fast equilibrium between the free receptor and the $\mathrm{K}^{+}$complex. The other mode which is favored for the cesium salts, such as $\mathrm{CsF}, \mathrm{CsCl}$ and $\mathrm{CsNO}_{3}$, involves concurrent binding of both the cation and anion to receptor $\mathbf{5 . 3}$ through the ethylene glycol spacers and the calix[4]pyrrole moiety, respectively. Once bound to the receptor via the ethylene glycol spacers, the $\mathrm{Cs}^{+}$cations of $\mathrm{CsF}$ and $\mathrm{CsCl}$ complexes move until they reside in the calix[4]arene crown-5 ring. This results in formation of solvent-separated ion pair complexes. In contrast, in the case of $\mathrm{CsNO}_{3}$, the $\mathrm{Cs}^{+}$cation stays in the ethylene glycol spacers to give a contact ion pair complex. The addition of potassium salts containing a 
non-coordinating anion, such as perchlorate, to ther preformed cesium ion pair complexes of 5.3 induces cation exchange from the $\mathrm{Cs}^{+}$to the $\mathrm{K}^{+}$. This produces new ion pair complexes containing the potassium cation. As evidenced by ${ }^{1} \mathrm{H}$ NMR spectroscopic analyses, receptor $\mathbf{5 . 3}$ displays a higher affinity for the $\mathrm{K}^{+}$cation relative to the $\mathrm{Cs}^{+}$ cation. This key feature enables receptor $\mathbf{5 . 3}$ to extract $\mathrm{CsNO}_{3}$, as well as various potassium salts, such as $\mathrm{KF}, \mathrm{KCl}$, and $\mathrm{KNO}_{3}$, from an aqueous phase to an organic layer consisting of nitrobenzene. By exploiting the cation metathesis features displayed by receptor $\mathbf{5 . 3}$ it is possible to release the $\mathrm{Cs}^{+}$salt back into the aqueous phase by washing the organic phase containing the complex of $\mathbf{5 . 3 \cdot} \mathrm{CsNO}_{3}$ with an aqueous $\mathrm{KClO}_{4}$ solution. The resulting $\mathrm{KClO}_{4}$ complex within the nitrobenzene phase may be further washed with chloroform and water. This strips out the $\mathrm{KClO}_{4}$ and leaves the free form of receptor $\mathbf{5 . 3}$ in the organic phase. This recovered receptor can be reused for a second round of extraction as described. The author thus believes that ion pair receptors such as the one described here could have a role to play in separations.

\subsection{REFERENCES}

(1) (a) Lehn, J.-M. Supramolecular Chemistry: Concepts and Perspectives; VCH: Weinheim, Germany, 1995. (b) Steed, J. W.; Atwood, J. L. Supramolecular Chemistry: An Introduction, Wiley, Chichester, U.K., 2000. (c) Beer, P. D.; Gale, P. A.; Smith, D. K. Supramolecular Chemistry, OUP, Oxford, U.K.,1999.

(2) Sessler, J. L.; Gale, P. A.; Cho, W.-S. Anion Receptor Chemistry; Monographs in Supramolecular Chemistry, Stoddart, J. F., Ed.; RSC Publishing: Cambridge, U.K., 2006.

(3) Gokel, G. W. In Comprehensive Supramolecular Chemistry: Molecular Recognition, Receptors for Cationic Guests; Lehn, J.-M.; Atwood, J. L.; Davies, J. E. D.; MacNicol, D. D.; Vögtle, F., Eds.; Pergamon: Oxford, U.K., 1996; Vol. 1.

(4) (a) Beer, P. D.; Gale, P. A. Angew. Chem., Int. Ed. 2001, 40, 486-516. (b) Gale, P. A. Coord. Chem. Rev. 2003, 240, 191-221. (c) Gale, P. A.; Quesada, R. Coord. 
Chem. Rev. 2006, 250, 3219-3244. (d) Gale, P. A.; García-Garrido, S. E.; Garric, J. Chem. Soc. Rev. 2008, 37, 151-190.

(5) (a) Smith, B. D. In Ion-pair Recognition by Ditopic Receptors, Macrocyclic Chemistry: Current Trends and Future Prospectives; Gloe, K.; Antonioli, B.,Eds.; Kluwer, London, U.K., 2005; pp 137-152. (b) Kirkovits, G. J.; Shriver, J. A.; Gale, P. A.; Sessler, J. L. J. Incl. Phenom. Macrocycl. Chem. 2001, 41, 69-75.

(6) (a) Pfeifer, J. R.; Reiß, P.; Koert, U. Angew. Chem., Int. Ed. 2006, 45, 501-504. (b) Sisson, A. L.; Shah, M. R.; Bhosale, S.; Matile, S. Chem. Soc. Rev. 2006, 35, 12691286. (c) Nakamura, T.; Akutagawa, T.; Honda, K.; Underhill, A. E.; Coomber, A. T.; Friend, R. H. Nature 1998, 394, 159-162. (d) Gokel, G. W.; Leevy, W. M.; Weber, M. E. Chem. Rev. 2004, 104, 2723-2750. (e) Davis, A. P.; Sheppard, D. N.; Smith, B. D. Chem. Soc. Rev. 2007, 36, 348-357.

(7) (a) Chrisstoffels, L. A. J.; De Jong, F.; Reinhoudt, D. N.; Sivelli, S.; Gazzola, L.; Casnati, A.; Ungaro, R. J. Am. Chem. Soc. 1999, 121, 10142-10151. (b) Rudkevich, D. M.; Mercer-Chalmers, J. D.; Verboom, W.; Ungaro, R.; Reinhoudt, D. N. J. Am. Chem. Soc. 1999, 117, 6124-6125. (c) Tong, C. C.; Quesada, R.; Sessler, J. L.; Gale, P. A. Chem. Commun. 2008, 6321-6323.

(8) (a) Mahoney, J. M.; Stucker, K. A.; Jiang, H.; Carmichael, I.; Brinkmann,N. R.; Beatty, A. M.; Noll, B. C.; Smith, B. D. J. Am. Chem. Soc. 2005, 127, 2922-2928. (b) Deetz, M. J.; Shang, M.; Smith, B. D. J. Am. Chem. Soc. 2000, 122, 6201-6207. (c) Mahoney, J. M.; Beatty, A. M.; Smith, B. D. Inorg. Chem. 2004, 43, 76177621. (d) Mahoney, J. M.; Davis, J. P.; Smith, B. D. J. Org. Chem. 2003, 68, 98196820. (e) Mahoney, J. M.; Beatty, A. M.; Smith, B. D. J. Am. Chem. Soc. 2001, 123, 5847-5858. (f) Mahoney, J. M.; Nawaratna, G. U.; Beatty, A. M.; Duggan, P. J.; Smith, B. D. Inorg. Chem. 2004, 43, 5902-5907. (g) Mahoney, J. M.; Marshall, R. A.; Beatty, A. M.; Smith, B. D.; Camiolo, S.; Gale, P. A. J. Supramol. Chem. 2003, 1, 289-292.

(9) Reeske, G.; Bradtmöller, G.; Schürmann, M.; Jurkschat, K. Chem. Eur. J. 2007, 13, 10239-10245.

(10) Kim, S. K.; Gross, D. E.; Cho, D. G.; Lynch, V. M.; Sessler, J. L. J. Org. Chem. 2011, 76, 1005-1012.

(11) Kim, S. K.; Sessler, J. L.; Gross, D. E.; Lee, C.-H.; Kim, J. S.; Lynch, V. M.; Delmau, L. H.; Hay, B. P. J. Am. Chem. Soc. 2010, 132, 5827-5836.

(12) Kim, S. K.; Sessler, J. L. Chem. Soc. Rev. 2010, 39, 3784-3809, and references cited therein. 
(13) Sessler, J. L.; Kim, S. K.; Gross, D. E.; Lee, C.-H; Kim, J. S.; Lynch, V. M. J. Am. Chem. Soc. 2008, 130, 13162-13166.

(14) Custelcean, R.; Delmau, L. H.; Moyer, B. A.; Sessler, J. L.; Cho, W. -S.; Gross, D.; Bates, G. W.; Brooks, S. J.; Light, M. E.; Gale, P. A. Angew. Chem. Int. Ed. 2005, 44, 2537-2542.

(15) Kim, S. K.; Lee, S. H,; Lee, J. Y.; Lee, J. Y.; Bartsch, R. A.; Kim, J. S. J. Am. Chem. Soc. 2004, 126, 16499-16506.

(16) (a) Kim, S. K.; Lee, J. K.; Lee, S. H.; Lim, M. S.; Lee, S. W.; Sim, W.; Kim, J. S. J. Org. Chem. 2004, 69, 2877-2880. (b) Kim, S. K.; Sim, W.; Vicens, J.; Kim, J. S. Tetrahedron Lett. 2003, 44, 805-809. (c) Kim, S. K.; Vicens, J.; Park, K.-M.; Lee, S. S.; Kim, J. S. Tetrahedron Lett. 2003, 44, 993-997. (d) Lee, J. K.; Kim, S. K.; Bartsch, R. A; Vicens, J.; Miyano, S.; Kim, J. S. J. Org. Chem. 2003, 68, 67206725. (e) Kim, J. S.; Lee, W. K.; Suh, I.-H.; Kim, J.-G.; Yoon, J.; Lee, J. H. J. Org. Chem. 2000, 65, 7512-7517.

(17) Kim, J. S.; Lee, W. K.; Sim, W.; Ko, J. W.; Cho, M. H.; Ra, D. Y.; Kim, J. W. J. Incl. Phenom. Macro. Chem. 2000, 37, 359-370.

(18) Sato, W.; Miyaji, H.; Sessler, J. L. Tetrahedron Lett. 2000, 41, 6731-6736.

(19) Marcus, Y. J. Chem. Soc. Faraday Trans. 1991, 87, 2995-2999.

(20) Aydogan, A.; Coady, D. J.; Kim, S. K.; Akar, A.; Bielawski, C. W.; Marquez, M.; Sessler, J. L. Angew. Chem., Int. Ed. 2008, 47, 9648-9652. 


\section{Chapter 6: Experimental Section}

All solvents and chemicals used were purchased from Aldrich, TCI, and Acros and used without further purification. Compounds 3.3, 4.4 and 5.7 were prepared as reported previously. ${ }^{1,2}$ NMR spectra were recorded on a Varian Mercury 400 instrument. The NMR spectra were referenced to solvent and the spectroscopic solvents were purchased from Cambridge Isotope Laboratories. Chemical ionization (CI) and electrospray ionization (ESI) mass spectra were recorded on a VG ZAB-2E instrument and a VG AutoSpec apparatus, respectively. TLC analyses were carried out by using Sorbent Technologies silica gel $(200 \mathrm{~mm})$ sheets. Column chromatography was performed on Sorbent silica gel $60 \mathrm{O}(40-63 \mathrm{~mm})$ or neutral alumina (50-200 mm, Brockmann grade II). For microcalorimetric titrations a MicroCal VP-ITC instrument was used.

Diethyl $N$-p-toluenesulfonylpyrrole-3,4-dicarboxylate (2.4). To a mixture of

diethyl pyrrole-3,4-dicarboxylate $(\mathbf{2 . 3})^{3}(3.00 \mathrm{~g}, 14.2 \mathrm{mmol})$ and $\mathrm{NaOH}(0.68 \mathrm{~g}, 17.0$ mmol $)$ in 1,2-dichloroethane $(250 \mathrm{ml})$ was added dropwise $p$-toluenesulfonyl chloride (5.51 g, $28.9 \mathrm{~mol})$ dissolved in 1,2-dichioroethane $(20 \mathrm{ml})$ at $0{ }^{\circ} \mathrm{C}$. After stirring for 48 hrs at room temperature, the reaction mixture was extracted with dichloromethane and washed with water two times. The organic layer was separated off and then dried over anhydrous $\mathrm{MgSO}_{4}$. The solvent was removed in vacuo to give a colorless oily solid. The crude product was purified by column chromatography over silica gel (eluent: ethyl acetate/hexane (1/3)) to give $5.0 \mathrm{~g}$ (96.3\% yield) of $\mathbf{2 . 4}$ as a white solid. All spectroscopic data for this compound proved consistent with those reported in the literature. ${ }^{3}$ 
$N$-p-toluenesulfonylpyrrole-3,4-dimethanol (2.5). To a suspension of $\mathrm{LiAlH}_{4}$ (1.56 g, $41.2 \mathrm{mmol})$ in THF (30 mL) was added a solution of $2.4(5.00 \mathrm{~g}, 13.7 \mathrm{mmol})$ in THF $(30 \mathrm{~mL})$ at $0{ }^{\circ} \mathrm{C}$. The reaction mixture was stirred for 10 minutes at $0{ }^{\circ} \mathrm{C}$ and then a small amount of water was added to quench the reaction. The reaction mixture was extracted with dichloromethane $(30 \mathrm{~mL})$ twice. The organic layer was collected, washed with water, and dried over anhydrous $\mathrm{MgSO}_{4}$. The solvent was evaporated in vacuo to give a white solid. The resulting solid was crystallized from dichloromethane/hexane (1/10) and filtered to give compound 2.5 (3.01 g, 78\% yield) as a white solid. All spectroscopic data for this compound proved consistent with those reported in the literature. $^{3}$

$N$-p-toluenesulfonyl-3,4-bis(bromomethy)pyrrole (2.6). A solution of 2.5 (4 g, $14.2 \mathrm{mmol})$ in dry $\mathrm{CH}_{2} \mathrm{Cl}_{2}(40 \mathrm{ml})$ was cooled to $0{ }^{\circ} \mathrm{C}$ under an argon atmosphere. To the resulting suspension was added phosphorus tribromide $(3.21 \mathrm{~mL}, 34.1 \mathrm{mmol})$ via syringe. The reaction mixture was warmed to room temperature and stirred for $2 \mathrm{hrs}$. At this point, $30 \mathrm{~mL}$ of aqueous $\mathrm{Na}_{2} \mathrm{CO}_{3}$ solution (sat.) was added slowly to the reaction mixture to quench the reaction. The organic phase was separated off, washed with water three times and dried over anhydrous $\mathrm{MgSO}_{4}$. Evaporation of the solvent in vacuo, followed by crystallization from dichloromethane/hexane (1/10), afforded the desired compound $\mathbf{2 . 6}$ $\left(5.15 \mathrm{~g}, 89 \%\right.$ yield) as a white solid. ${ }^{1} \mathrm{H}$ NMR $\left(300 \mathrm{MHz}, \mathrm{CDCl}_{3}\right): \delta 7.76(\mathrm{~d}, 2 \mathrm{H}, \mathrm{Ar} H$ (tosyl), $J=8.10 \mathrm{~Hz}$ ), 7.33 (d, 2H, ArH (tosyl), $J=8.10 \mathrm{~Hz}$ ), $7.18(\mathrm{~s}, 2 \mathrm{H}, \operatorname{Ar} H$ (pyrrole)), 4.45 (s, 4H, pyrrole- $\mathrm{CH}_{2} \mathrm{Br}$ ), 2.43 (s, 3H, $\left.\mathrm{ArCH}_{3}\right) .{ }^{13} \mathrm{C} \mathrm{NMR}\left(100 \mathrm{MHz}, \mathrm{CDCl}_{3}\right): \delta$ 146.0, 
135.6, 130.5, 127.4, 124.2, 121.1, 23.7, 21.9. HRMS (CI) $\mathrm{m} / z$ 405.9112 $(\mathrm{M}+\mathrm{H})^{+}$calcd for $\mathrm{C}_{13} \mathrm{H}_{14} \mathrm{NO}_{2} \mathrm{SBr}_{2}$, found 405.9111 .

$N$-p-toluenesulfonylpyrrolidinyl- $N$ - $p$-toluenesulfonylpyrrole $\quad(2.7)$. To a suspension of TsNHNa $(3.35 \mathrm{~g}, 17.3 \mathrm{mmol})$ in dry $\mathrm{CH}_{3} \mathrm{CN}(75 \mathrm{~mL})$ was added dropwise a solution of $2.6(3.00 \mathrm{~g}, 7.37 \mathrm{mmol})$ in dry DMF $(25 \mathrm{~mL})$ at $80{ }^{\circ} \mathrm{C}$. After the reaction mixture was stirred for a further 30 minutes, the hot mixture was filtered through Celite and the filter was washed with DMF. The filtrate was evaporated in vacuo to give a white solid, which was extracted with dichloromethane and washed with water three times. The organic phase was separated off and dried over anhydrous $\mathrm{MgSO}_{4}$. Crystallization from diethyl ether, following evaporation of solvents in vacuo, gave compound 2.7 (2.10 g, 68\% yield) as a white solid. ${ }^{1} \mathrm{H} \mathrm{NMR}\left(300 \mathrm{MHz}, \mathrm{CDCl}_{3}\right): \delta 7.71$ (dd, $4 \mathrm{H}, \mathrm{Ar} H$ (tosyl), $J=8.40$ $\& 1.50 \mathrm{~Hz}), 7.31(\mathrm{~d}, 2 \mathrm{H}, \operatorname{Ar} H(\operatorname{tosyl}), J=3.60 \mathrm{~Hz}), 7.28(\mathrm{~d}, 2 \mathrm{H}, \operatorname{Ar} H($ tosyl $), J=4.80 \mathrm{~Hz})$, $6.83\left(\mathrm{~s}, 2 \mathrm{H}, \mathrm{ArH}\right.$ (pyrrole)), 4.29 (s, 4H, pyrrole- $\left.\mathrm{CH}_{2} \mathrm{~N}\right), 2.40\left(\mathrm{~s}, 6 \mathrm{H}, \mathrm{ArCH}_{3}\right) .{ }^{13} \mathrm{C} \mathrm{NMR}$ $\left(100 \mathrm{MHz}, \mathrm{CDCl}_{3}\right): \delta 145.5,144.0,136.0,134.1,130.3,130.1,128.2,127.7,127.1,112.0$ 47.4, 21.9, 21.7. HRMS (CI) $m / z 417.0943(\mathrm{M}+\mathrm{H})^{+}$calcd for $\mathrm{C}_{20} \mathrm{H}_{21} \mathrm{~N}_{2} \mathrm{O}_{4} \mathrm{~S}_{2}$, found 417.0941.

$\boldsymbol{N}$-p-toluenesulfonylpyrrolidinylpyrrole (2.8). To a solution of 2.7 (1.50 g, 1.20 mmol) in dry THF/MeOH (3:1 v/v) was added $\mathrm{NaOMe}(30 \%$ solution in $\mathrm{MeOH}, 30$ equiv) via syringe. The resulting solution was heated at reflux for $20 \mathrm{~min}$ and then cooled to room temperature. After the solvent was removed in vacuo, the resulting crude product 
was extracted with dichloromethane and washed with water twice. The organic phase was separated off and dried over anhydrous $\mathrm{MgSO}_{4}$. Crystallization from hexane, following evaporation of solvents in vacuo, gave compound 2.8 (0.86 g, 91\% yield) as a white solid. ${ }^{1} \mathrm{H}$ NMR $\left(300 \mathrm{MHz}, \mathrm{CDCl}_{3}\right): \delta 8.22($ broad s, $1 \mathrm{H}, \mathrm{NH}), 7.76(\mathrm{~d}, 2 \mathrm{H}, \mathrm{Ar} H($ tosyl $), J=8.10$ Hz), 7.23 (d, 2H, ArH (tosyl), J = 8.70 Hz), 6.45 (s, 2H, ArH (pyrrole)), 4.42 (s, 4H, pyrrole- $\left.\mathrm{CH}_{2} \mathrm{~N}\right), 2.40\left(\mathrm{~s}, 3 \mathrm{H}, \mathrm{ArCH}_{3}\right) .{ }^{13} \mathrm{C} \mathrm{NMR}\left(100 \mathrm{MHz}, \mathrm{CDCl}_{3}\right): \delta 143.6,134.5,129.9$, 127.7, 122.9, 109.0, 48.3, 21.7. HRMS (CI) $m / z 263.0854(\mathrm{M}+\mathrm{H})^{+}$calcd for $\mathrm{C}_{13} \mathrm{H}_{15} \mathrm{~N}_{2} \mathrm{O}_{2} \mathrm{~S}$, found 263.0854 .

$N$-p-toluenesulfonylpyrrolidine-calix[4]pyrrole (2.2). To compound 2.8 (1.2 g, $4.57 \mathrm{mmol})$ in acetone $(150 \mathrm{ml})$ was added TFA $(0.52 \mathrm{~g}, 4.57 \mathrm{mmol})$ in one portion. The resulting solution was stirred for 24 hours at room temperature and taken to dryness in vacuo to give a brownish solid. To the crude product, dichloromethane (100 mL), water $(100 \mathrm{~mL})$, and triethylamine $(5 \mathrm{~mL})$ were added. The organic phase was then separated off and washed three times with water $(100 \mathrm{~mL})$. The organic layer was dried over anhydrous $\mathrm{MgSO}_{4}$ and evaporated in vacuo to give a yellowish solid. Column chromatography over silica gel (eluent: ethyl acetate/dichloromethane (99/1)), followed by recrystallization from methanol, gave the target compound $\mathbf{2 . 2}(0.28 \mathrm{~g}, 20 \%$ yield $)$ as a white solid. ${ }^{1} \mathrm{H}$ NMR (400 MHz, $\mathrm{CDCl}_{3}$ ): $\delta 7.73$ (d, 8H, ArH (tosyl), $J=8.41 \mathrm{~Hz}$ ), 7.35 (d, $8 \mathrm{H}, \mathrm{ArH}$ (tosyl), $J=8.01 \mathrm{~Hz}), 4.27\left(\mathrm{~s}, 16 \mathrm{H}\right.$, pyrrole- $\left.\mathrm{CH}_{2} \mathrm{~N}\right), 2.46\left(\mathrm{~s}, 12 \mathrm{H}, \mathrm{ArCH}_{3}\right)$, $1.32\left(\mathrm{~s}, 24 \mathrm{H}\right.$, pyrrole-C $\left.\left(\mathrm{CH}_{3}\right)_{2}\right) .{ }^{13} \mathrm{C} \mathrm{NMR}\left(100 \mathrm{MHz}, \mathrm{CDCl}_{3}\right): \delta 144.0,134.3,130.2$, 
127.7, 127.5, 118.1, 48.5, 36.4, 29.9, 21.9. HRMS (CI) $\mathrm{m} / 2.1209 .4434(\mathrm{M}+\mathrm{H})^{+}$calcd for $\mathrm{C}_{64} \mathrm{H}_{73} \mathrm{~N}_{8} \mathrm{O}_{8} \mathrm{~S}_{4}$, found 1209.4435 .

Compound 3.4. Under an argon atmosphere, compound 3.3 (3.00 g, $2.93 \mathrm{mmol})$, 4'-hydroxyacetophenone (0.96 g, $7.02 \mathrm{mmol})$ and $\mathrm{K}_{2} \mathrm{CO}_{3}(1.62 \mathrm{~g}, 11.7 \mathrm{mmol})$ in $125 \mathrm{~mL}$ of acetonitrile were heated to reflux. After heating at reflux for 24 hours, the acetonitrile was removed in vacuo. To the resulting colorless oil, $\mathrm{CH}_{2} \mathrm{Cl}_{2}(50 \mathrm{~mL})$ and $5 \%$ aqueous $\mathrm{HCl}(100 \mathrm{~mL})$ were added, and the organic layer was separated and washed three times with $50 \mathrm{~mL}$ of water. The organic layer was dried over anhydrous $\mathrm{MgSO}_{4}$ and the solvent was evaporated in vacuo to give a white solid. Column chromatography over silica gel (eluent: ethyl acetate) gave $2.6 \mathrm{~g}$ (93.2\% yield) of $\mathbf{3 . 4}$ as a white solid. ${ }^{1} \mathrm{H}$ NMR (400 $\left.\mathrm{MHz}, \mathrm{CDCl}_{3}\right): \delta$ 7.87-7.85 (d, 4H, $\left.\mathrm{Ar} H, J=8.81 \mathrm{~Hz}\right), \delta$ 7.15-7.13 (d, 4H, $\mathrm{Ar} H, J=7.20$ $\mathrm{Hz}), \delta$ 7.08-7.07 (d, 4H, ArH, J=7.20 Hz), 6.92-6.88 (t, 2H, ArH, $J=7.20 \& 7.61 \mathrm{~Hz}), \delta$ 6.83-6.81 (d, 4H, $\operatorname{Ar} H, J=9.21 \mathrm{~Hz}), 6.73-6.69(\mathrm{t}, 2 \mathrm{H}, \operatorname{Ar} H, J=7.61 \& 7.61 \mathrm{~Hz}), 3.84(\mathrm{~s}$, $8 \mathrm{H}, \mathrm{ArCH} \mathrm{H}_{2} \mathrm{Ar}$ ), 3.72 (s, $4 \mathrm{H}, \mathrm{OCH}_{2} \mathrm{CH}_{2} \mathrm{O}$ ), 3.71-3.63 (m, $16 \mathrm{H}, \mathrm{OCH}_{2} \mathrm{CH}_{2} \mathrm{O}$ ), 3.53-3.51 (t, $\left.4 \mathrm{H}, \mathrm{OCH}_{2} \mathrm{CH}_{2} \mathrm{O}, J=5.20 \& 4.40 \mathrm{~Hz}\right), 3.42-3.39\left(\mathrm{t}, 4 \mathrm{H}, \mathrm{OCH}_{2} \mathrm{CH}_{2} \mathrm{O}, J=5.60 \& 6.40\right.$ $\mathrm{Hz}), 2.53$ (s, 6H, $\left.\left.\mathrm{ArCOCH}_{3}\right) .{ }^{13} \mathrm{C} \mathrm{NMR} \mathrm{(100} \mathrm{MHz,} \mathrm{CDCl}_{3}\right): \delta$ 196.9, 162.7, 157.1, 156.1, 134.2, 134.1, 130.9, 130.6, 130.3, 130.1, 123.1, 122.6, 114.2, 71.5, 71.3, 70.3, 70.0, 68.6, 67.0, 38.0, 26.6. HRMS (CI) $\mathrm{m} / 2973.41335(\mathrm{M}+\mathrm{Na})^{+}$calcd for $\mathrm{C}_{58} \mathrm{H}_{62} \mathrm{O}_{12} \mathrm{Na}$, found 973.41520 .

Compound 3.5. To a mixture of pyrrole $(20 \mathrm{ml}, 288 \mathrm{mmol})$ and compound 3.4 (2.6 g, $2.73 \mathrm{mmol})$ was added trifluoroacetic acid $(2 \mathrm{ml}, 27.9 \mathrm{mmol})$. The reaction solution was heated to $65{ }^{\circ} \mathrm{C}$ and stirred for 8 hours. The reaction was quenched with 5 
$\mathrm{ml}$ of triethylamine and the residual pyrrole was removed by evaporation in vacuo. To the resulting black oily solid, $\mathrm{CH}_{2} \mathrm{Cl}_{2}(100 \mathrm{~mL})$ and $20 \%$ aqueous $\mathrm{NaOH}(100 \mathrm{~mL})$ were added, before the organic layer was separated off and washed three times with $100 \mathrm{~mL}$ of water. The organic layer was dried over anhydrous $\mathrm{MgSO}_{4}$ and the solvent was removed in vacuo to give a brown oily solid. The crude product was purified by column chromatography over silica gel (eluent: ethyl acetate/hexane (4/1)) to give $1.5 \mathrm{~g}(46.3 \%$ yield) of 3.5 as a white solid. ${ }^{1} \mathrm{H}$ NMR (400 $\left.\mathrm{MHz}, \mathrm{CDCl}_{3}\right): \delta 7.72($ broad s, 4H, $\mathrm{NH})$, 7.16-7.11 (d, 4H, ArH, J=7.61 Hz), $\delta$ 7.06-7.04 (d, 4H, ArH, $J=7.61 \mathrm{~Hz}), \delta$ 7.01-6.99 $(\mathrm{d}, 4 \mathrm{H}, \operatorname{ArH}, J=8.81 \mathrm{~Hz}), 6.89-6.86(\mathrm{t}, 2 \mathrm{H}, \operatorname{ArH}, J=7.61 \& 7.61 \mathrm{~Hz}), \delta 6.75-6.72(\mathrm{~d}$, $4 \mathrm{H}, \operatorname{Ar} H, J=8.81 \mathrm{~Hz}), 6.69-6.65(\mathrm{t}, 2 \mathrm{H}, \operatorname{Ar} H, J=7.20 \& 7.61 \mathrm{~Hz}), 6.63-6.61(\mathrm{~m}, 4 \mathrm{H}$, pyrrole- $H$ ), 6.17-6.15 (m, 4H, pyrrole- $H), 5.96-5.94(\mathrm{~m}, 4 \mathrm{H}$, pyrrole- $H), \quad 3.81-3.80(\mathrm{~d}$, $\left.8 \mathrm{H}, \mathrm{ArCH}_{2} \mathrm{Ar}, J=3.6 \mathrm{~Hz}\right), 3.79-3.76\left(\mathrm{t}, 4 \mathrm{H}, \mathrm{OCH}_{2} \mathrm{CH}_{2} \mathrm{O}, J=6.00 \& 4.80 \mathrm{~Hz}\right), 3.71(\mathrm{~s}$, $\left.4 \mathrm{H}, \mathrm{OCH}_{2} \mathrm{CH}_{2} \mathrm{O}\right), 3.69-3.62\left(\mathrm{~m}, 12 \mathrm{H}, \mathrm{OCH}_{2} \mathrm{CH}_{2} \mathrm{O}\right), 3.53-3.51\left(\mathrm{t}, 4 \mathrm{H}, \mathrm{OCH}_{2} \mathrm{CH}_{2} \mathrm{O}, \mathrm{J}=\right.$ $4.80 \& 3.80 \mathrm{~Hz}), 3.44-3.41\left(\mathrm{t}, 4 \mathrm{H}, \mathrm{OCH}_{2} \mathrm{CH}_{2} \mathrm{O}, J=5.60 \& 5.60 \mathrm{~Hz}\right), 2.00(\mathrm{~s}, 6 \mathrm{H}$, $\left.\operatorname{ArC}(\text { pyrrole })_{2} \mathrm{CH}_{3}\right) .{ }^{13} \mathrm{C}$ NMR $\left(100 \mathrm{MHz}, \mathrm{CDCl}_{3}\right): \delta$ 157.6, 157.0, 156.4, 140.0, 138.0, $134.1,134.0,130.3,130.2,128.9,122.9,122.7,117.3,114.4,108.4,106.5,71.5,71.4$, 71.3, 70.4, 70.2, 69.0, 66.8, 44.4, 37.9, 29.3. HRMS (CI) $\mathrm{m} / z 1205.56102(\mathrm{M}+\mathrm{Na})^{+}$ calcd for $\mathrm{C}_{74} \mathrm{H}_{78} \mathrm{~N}_{4} \mathrm{O}_{12} \mathrm{Na}$, found 1205.56012 .

Compound 3.1. To compound 3.5 (1.5 g, $1.27 \mathrm{mmol})$ in acetone $(500 \mathrm{ml})$ was added $\mathrm{BF}_{3} \bullet \mathrm{OEt}_{2}(0.1 \mathrm{ml}, 0.81 \mathrm{mmol})$ in one portion. The resulting solution was stirred for 3 hours at room temperature and evaporated in vacuo to give a brownish solid. To the crude product, dichloromethane $(100 \mathrm{ml})$, water $(100 \mathrm{ml})$, and triethylamine $(5 \mathrm{ml})$ were added and the organic phase was separated and washed three times with water $(100 \mathrm{ml})$. The organic layer was dried over anhydrous $\mathrm{MgSO}_{4}$ and evaporated in vacuo to give a 211 
yellowish solid. Column chromatography over silica gel (eluent: ethyl acetate), followed by recrystallization from methanol, gave $0.28 \mathrm{~g}$ (17.5\% yield) of $\mathbf{3 . 1}$ as a white solid. ${ }^{1} \mathrm{H}$ NMR (400 MHz, $\left.\mathrm{CDCl}_{3}\right): \delta$ 7.13-7.11 (d, 4H, $\left.\operatorname{ArH}, J=7.61 \mathrm{~Hz}\right), \delta$ 7.06-7.03 (d, 4H, $\operatorname{Ar} H, J=7.61 \mathrm{~Hz}), \delta 6.97-6.95(\mathrm{~d}, 4 \mathrm{H}, \operatorname{Ar} H, J=8.81 \mathrm{~Hz}), 6.94-6.91(\mathrm{t}, 2 \mathrm{H}, \operatorname{Ar} H, J=7.61$ \& 7.20 Hz), $6.74($ broad s, 4H, NH), $\delta 6.74-6.72(\mathrm{~d}, 4 \mathrm{H}, \operatorname{ArH}, J=8.81 \mathrm{~Hz}), 6.69-6.65(\mathrm{t}$, $2 \mathrm{H}, \operatorname{Ar} H, J=8.01 \& 7.20 \mathrm{~Hz}), 6.04-6.03(\mathrm{t}, 4 \mathrm{H}$, pyrrole- $H, J=2.80 \& 2.80 \mathrm{~Hz}), 5.96-$ $5.94(\mathrm{~m}, 4 \mathrm{H}$, pyrrole- $H, J=3.20 \& 2.80 \mathrm{~Hz}), 3.91-3.87\left(\mathrm{~m}, 8 \mathrm{H}, \mathrm{ArCH}_{2} \mathrm{Ar} ; 4 \mathrm{H}\right.$, $\mathrm{OCH}_{2} \mathrm{CH}_{2} \mathrm{O}$ ), 3.70 (s, $4 \mathrm{H}, \mathrm{OCH}_{2} \mathrm{CH}_{2} \mathrm{O}$ ), 3.65-3.58 (m, $\left.12 \mathrm{H}, \mathrm{OCH}_{2} \mathrm{CH}_{2} \mathrm{O}\right), 3.38-3.35(\mathrm{~m}$, $8 \mathrm{H}, \mathrm{OCH}_{2} \mathrm{CH}_{2} \mathrm{O}$ ), 2.00 (s, $\left.6 \mathrm{H}, \mathrm{ArC}(\text { pyrrole })_{2} \mathrm{CH}_{3}\right), 1.50$ (s, $6 \mathrm{H}$, pyrrole- $\left.\mathrm{C}\left(\mathrm{CH}_{3}\right)_{2}\right), 1.41$ (s, 6H, pyrrole-C $\left.\left(\mathrm{CH}_{3}\right)_{2}\right) .{ }^{13} \mathrm{C} \mathrm{NMR}\left(100 \mathrm{MHz}, \mathrm{CDCl}_{3}\right): \delta 157.5,156.8,156.1,139.1,137.0$, 136.9, 134.4, 134.3, 129.8, 129.6, 128.8, 123.4, 122.7, 113.8, 105.2, 105.1, 71.6, 71.4, 71.1, 70.2, 70.0, 66.8, 64.9, 44.6, 38.2, 35.9, 30.4, 30.2, 29.8. HRMS (CI) $\mathrm{m} / 2$ 1285.62362 $(\mathrm{M}+\mathrm{Na})^{+}$calcd for $\mathrm{C}_{80} \mathrm{H}_{86} \mathrm{~N}_{4} \mathrm{O}_{10} \mathrm{Na}$, found 1285.62360 .

Compound 4.5. Under an argon atmosphere, compound 4.4 (2.2 g, $2.43 \mathrm{mmol})$, 4'-hydroxyacetophenone $(0.76 \mathrm{~g}, 5.58 \mathrm{mmol})$ and $\mathrm{K}_{2} \mathrm{CO}_{3}(1.34 \mathrm{~g}, 9.70 \mathrm{mmol})$ in $125 \mathrm{~mL}$ of acetonitrile were heated to reflux. After heating at reflux for 24 hours, the acetonitrile was removed in vacuo. To the resulting white solid, $\mathrm{CH}_{2} \mathrm{Cl}_{2}(50 \mathrm{~mL})$ and $5 \%$ aqueous $\mathrm{HCl}(100 \mathrm{~mL})$ were added, and the organic layer was separated and washed three times with $50 \mathrm{~mL}$ of water. The organic layer was dried over anhydrous $\mathrm{MgSO}_{4}$ and the solvent was evaporated in vacuo to give a white solid. Column chromatography over silica gel (eluent: ethyl acetate/hexane (1:3)) gave $1.63 \mathrm{~g}$ (80.1\% yield) of $\mathbf{4 . 5}$ as a white solid. ${ }^{1} \mathrm{H}$ NMR (400 MHz, $\left.\mathrm{CDCl}_{3}\right): \delta$ 7.91-7.89 (d, 4H, $\left.\mathrm{Ar} H, J=8.41 \mathrm{~Hz}\right), 7.06-7.03$ (dd, 8H, $\operatorname{Ar} H), 6.92-6.90(\mathrm{~d}, 4 \mathrm{H}, \operatorname{Ar} H, J=8.81 \mathrm{~Hz}), 6.77-6.73(\mathrm{t}, 2 \mathrm{H}, \operatorname{Ar} H, J=7.61 \& 7.61 \mathrm{~Hz})$, 6.63-6.59 (t, $2 \mathrm{H}, \mathrm{Ar} H, J=7.61 \& 7.61 \mathrm{~Hz}), 3.97-3.94\left(\mathrm{t}, 4 \mathrm{H}, \mathrm{ArOCH}_{2} \mathrm{CH}_{2} \mathrm{OAr}, J=4.80\right.$ 212 
\& $4.80 \mathrm{~Hz}), 3.83-3.81\left(\mathrm{t}, 4 \mathrm{H}, \mathrm{ArOCH}_{2} \mathrm{CH}_{2} \mathrm{OAr}, J=4.80 \& 4.80 \mathrm{~Hz}\right), 3.70(\mathrm{~s}, 8 \mathrm{H}$, $\left.\mathrm{ArCH}_{2} \mathrm{Ar}\right), 3.56-3.53\left(\mathrm{t}, 4 \mathrm{H}, \mathrm{OCH}_{2} \mathrm{CH}_{2} \mathrm{CH}_{3}, J=7.20 \& 7.20 \mathrm{~Hz}\right), 2.55(\mathrm{~s}, 6 \mathrm{H}$, $\mathrm{ArCOCH}_{3}$ ), 1.62-1.54 (sextet, $4 \mathrm{H}, \mathrm{CH}_{2} \mathrm{CH}_{2} \mathrm{CH}_{3}$ ), 0.91-0.87 (t, $\mathrm{CH}_{2} \mathrm{CH}_{2} \mathrm{CH}_{3}, J=7.61$ \& $7.20 \mathrm{~Hz}) .{ }^{13} \mathrm{C} \mathrm{NMR}\left(100 \mathrm{MHz}, \mathrm{CDCl}_{3}\right): \delta 197.0,162.8,157.0,155.7,134.1,134.0$, $130.9,130.6,130.2,130.0,122.5,122.1,114.4,73.8,69.7,67.4,36.7,26.6,23.6,10.7$ HRMS (ESI) $m / z$ 855.3861 $(\mathrm{M}+\mathrm{Na})^{+}$calcd for $\mathrm{C}_{58} \mathrm{H}_{62} \mathrm{O}_{12} \mathrm{Na}$, found 855.38674.

Compound 4.6. To a mixture of pyrrole $(15 \mathrm{ml}, 216 \mathrm{mmol})$ and compound 4.5 $(1.0 \mathrm{~g}, 1.20 \mathrm{mmol})$ was added trifluoroacetic acid $(2 \mathrm{ml}, 27.9 \mathrm{mmol})$ in one portion. The reaction solution was heated to $70{ }^{\circ} \mathrm{C}$ and stirred for 8 hours. The reaction was quenched with $5 \mathrm{ml}$ of triethylamine and the residual pyrrole was removed by evaporation in vacuo. To the resulting black sticky oil, $\mathrm{CH}_{2} \mathrm{Cl}_{2}(100 \mathrm{~mL})$ and $20 \%$ aqueous $\mathrm{NaOH}(100 \mathrm{~mL})$ were added, before the organic layer was separated off and washed three times with 100 $\mathrm{mL}$ of water. The organic layer was dried over anhydrous $\mathrm{MgSO}_{4}$ and the solvent was removed in vacuo to give a black solid. The crude product was purified by column chromatography over silica gel (eluent: ethyl acetate/hexane (1:4)) to give $0.62 \mathrm{~g}(48.4 \%$ yield) of 4.6 as a white solid. ${ }^{1} \mathrm{H}$ NMR (400 MHz, $\left.\mathrm{CDCl}_{3}\right): \delta 7.76($ broad s, 4H, NH), 7.05-7.01 (m, 12H, ArH), 7.06-7.04 (d, 4H, ArH, J= 7.61 Hz), 6.85-6.83 (d, 4H, ArH, J $=9.21 \mathrm{~Hz}), 6.73-6.93(\mathrm{t}, 2 \mathrm{H}, \operatorname{Ar} H, J=7.61 \& 7.61 \mathrm{~Hz}), 6.65-6.63(\mathrm{~m}, 4 \mathrm{H}$, pyrrole- $H)$, 6.58-6.55 (t, 2H, ArH, $J=7.61 \& 8.01 \mathrm{~Hz}), 6.18-6.16(\mathrm{~m}, 4 \mathrm{H}$, pyrrole- $H), 5.98-5.96(\mathrm{~m}$, 4H, pyrrole- $H$ ), 3.99-3.97 (t, 4H, $\left.\mathrm{ArOCH}_{2} \mathrm{CH}_{2} \mathrm{OAr}, J=4.40 \& 4.20 \mathrm{~Hz}\right), 3.92-3.90(\mathrm{t}$, $\left.4 \mathrm{H}, \mathrm{ArOCH}_{2} \mathrm{CH}_{2} \mathrm{OAr}, J=5.6 \& 4.00 \mathrm{~Hz}\right), 3.70-3.61\left(\mathrm{dd}, 8 \mathrm{H}, \mathrm{ArCH}_{2} \mathrm{Ar}, J=14.01 \&\right.$ $14.01 \mathrm{~Hz}), 3.58-3.54\left(\mathrm{t}, 4 \mathrm{H}, \mathrm{OCH}_{2} \mathrm{CH}_{2} \mathrm{CH}_{3}, J=7.20 \& 7.20 \mathrm{~Hz}\right), 2.02(\mathrm{~s}, 6 \mathrm{H}$, ArC(pyrrole) $)_{2} \mathrm{CH}_{3}$ ), 1.69-1.62 (sextet, $4 \mathrm{H}, \mathrm{CH}_{2} \mathrm{CH}_{2} \mathrm{CH}_{3}$ ), 0.95-0.91 (t, $\mathrm{CH}_{2} \mathrm{CH}_{2} \mathrm{CH}_{3}, J=$ $7.20 \& 7.61 \mathrm{~Hz}) .{ }^{13} \mathrm{C}$ NMR $\left(100 \mathrm{MHz}, \mathrm{CDCl}_{3}\right): \delta 157.6,156.8,155.9,139.9,138.0$, 213 
$133.9,130.2,130.0,128.9,122.3,122.1,117.1,114.4,108.5,106.4,74.0,70.4,67.2$, 44.4, 36.3, 29.3, 23.8, 10.8. HRMS (CI) $\mathrm{m} / z$ 1065.5530 $(\mathrm{M}+\mathrm{H})^{+}$calcd for $\mathrm{C}_{70} \mathrm{H}_{73} \mathrm{~N}_{4} \mathrm{O}_{6}$, found 1065.5546 .

Compound 4.2. To compound $4.6(1.5 \mathrm{~g}, 1.41 \mathrm{mmol})$ in acetone $(500 \mathrm{ml})$ was added $\mathrm{BF}_{3} \bullet \mathrm{OEt}_{2}(0.1 \mathrm{ml}, 0.81 \mathrm{mmol})$ in one portion. The resulting solution was stirred for 2 hours at room temperature and then quenched with triethylamine $(5 \mathrm{ml})$. Evaporation of the reaction solution afforded a brown, sticky oil. To this crude product, dichloromethane $(100 \mathrm{ml})$, water $(100 \mathrm{ml})$, and triethylamine $(5 \mathrm{ml})$ were added and the organic phase was separated and washed three times with water $(100 \mathrm{ml})$. The organic layer was dried over anhydrous $\mathrm{MgSO}_{4}$ and evaporated in vacuo to give a yellowish solid. Recrystallization from methanol, following column chromatography over silica gel (eluent: dichloromethane/hexane (3:1)), gave 0.20 g (12.4\% yield) of 4.2 as a white solid. ${ }^{1} \mathrm{H}$ NMR (400 MHz, $\left.\mathrm{CDCl}_{3}\right): \delta$ 7.06-7.04 (d, 4H, $\left.\mathrm{ArH}, J=7.61 \mathrm{~Hz}\right), 7.04-7.01(\mathrm{~d}, 4 \mathrm{H}, \mathrm{ArH}$, $J=8.41 \mathrm{~Hz}), 6.97-6.95(\mathrm{~d}, 4 \mathrm{H}, \operatorname{Ar} H, J=8.41 \mathrm{~Hz}), 6.87-6.83(\mathrm{t}, 2 \mathrm{H}, \operatorname{Ar} H, J=7.61 \& 7.20$ Hz), 6.75 (broad s, 4H, NH), 6.74-6.72 (d, 4H, ArH, J = 8.81 Hz), 6.65-6.62 (t, 2H, ArH, $J=7.61 \& 7.20 \mathrm{~Hz}), 6.04-6.03(\mathrm{t}, 4 \mathrm{H}$, pyrrole- $H, J=3.60 \& 2.80 \mathrm{~Hz}), 5.96-5.94(\mathrm{~m}, 4 \mathrm{H}$, pyrrole- $H, J=2.80 \& 3.20 \mathrm{~Hz}), \quad 3.89-3.85\left(\mathrm{~m}, 8 \mathrm{H}, \mathrm{ArCH}_{2} \mathrm{Ar} ; 4 \mathrm{H}, \mathrm{ArOCH}_{2} \mathrm{CH}_{2} \mathrm{OAr}\right)$, 3.66-3.63 (t, 4H, $\left.\mathrm{ArOCH}_{2} \mathrm{CH}_{2} \mathrm{OAr}, J=7.61 \& 7.61 \mathrm{~Hz}\right), 3.36-3.33(\mathrm{t}, 4 \mathrm{H}$, $\left.\mathrm{OCH}_{2} \mathrm{CH}_{2} \mathrm{CH}_{3}, J=7.20 \& 7.20 \mathrm{~Hz}\right), 1.99\left(\mathrm{~s}, 6 \mathrm{H}, \operatorname{ArC}(\text { pyrrole })_{2} \mathrm{CH}_{3}\right), 1.49(\mathrm{~s}, 6 \mathrm{H}$, pyrrole- $\left.\mathrm{C}\left(\mathrm{CH}_{3}\right)_{2}\right), 1.41$ (s, 6H, pyrrole- $\left.\mathrm{C}\left(\mathrm{CH}_{3}\right)_{2}\right), 1.27-1.21$ (sextet, $4 \mathrm{H}, \mathrm{CH}_{2} \mathrm{CH}_{2} \mathrm{CH}_{3}$ ), 0.67-0.64 (t, $\left.\mathrm{CH}_{2} \mathrm{CH}_{2} \mathrm{CH}_{3}, J=7.20 \& 7.61 \mathrm{~Hz}\right) .{ }^{13} \mathrm{C} \mathrm{NMR}\left(100 \mathrm{MHz}, \mathrm{CDCl}_{3}\right): \delta 157.5$, 157.0, 156.0, 139.1, 137.1, 137.0, 134.5, 134.3, 129.7, 129.5, 128.7, 123.1, 122.2, 113.9, 105.1, 72.2, 67.0, 65.2, 44.6, 38.2, 35.9, 30.4, 30.1, 29.8, 23.0, 10.4. HRMS (ESI) $\mathrm{m} / \mathrm{z}$ 1145.6160 $(\mathrm{M}+\mathrm{Na})^{+}$calcd for $\mathrm{C}_{80} \mathrm{H}_{86} \mathrm{~N}_{4} \mathrm{O}_{10} \mathrm{Na}$, found 1145.61506. 
Compound 5.5. To a solution of $\mathbf{5 . 4}(10.0 \mathrm{~g}, 55.5 \mathrm{mmol})$ and $p$-tolunesulfonyl chloride $(11.1 \mathrm{~g}, 58.3 \mathrm{mmol})$ in $300 \mathrm{~mL}$ of THF under an argon atmosphere and in an ice bath was added dropwise a solution of $\mathrm{NaOH}(6.76 \mathrm{~g}, 166 \mathrm{mmol})$ in $15 \mathrm{~mL}$ of water. The reaction mixture was then stirred for at least $24 \mathrm{hrs}$ at room temperature. At this point, the solvents were removed in vacuo to give a yellowish oil. The crude product was partititioned between $\mathrm{CH}_{2} \mathrm{Cl}_{2}(200 \mathrm{~mL})$ and water $(200 \mathrm{~mL})$. The organic layer was collected and washed twice with water and dried over anhydrous $\mathrm{MgSO}_{4}$. The organic solvents were the removed in vacuo. This was followed by solidification by titration hexane. This gave $17.8 \mathrm{~g}$ (96\% yield) of compound $\mathbf{5 . 5}$ as a yellowish solid. ${ }^{1} \mathrm{H}$ NMR (400 MHz, $\left.\mathrm{CDCl}_{3}\right): \delta$ 7.91-7.88 (d, 2H, $\left.\operatorname{Ar} H, J=8.81 \mathrm{~Hz}\right), 7.82-7.80(\mathrm{~d}, 2 \mathrm{H}, \operatorname{Ar} H, J=$ $8.01 \mathrm{~Hz}), 7.35-7.33(\mathrm{~d}, 2 \mathrm{H}, \operatorname{Ar} H, J=8.01 \mathrm{~Hz}), 6.83-6.80(\mathrm{~d}, 2 \mathrm{H}, \operatorname{Ar} H, J=8.81 \mathrm{~Hz}), 4.40-$ $4.38\left(\mathrm{t}, 2 \mathrm{H}, \mathrm{ArOCH}_{2}, J=4.80 \& 4.40 \mathrm{~Hz}\right), 4.22-4.20\left(\mathrm{t}, 2 \mathrm{H}, \mathrm{ArOCH}_{2}, J=4.80 \& 4.40\right.$ $\mathrm{Hz}), 2.55\left(\mathrm{~s}, 3 \mathrm{H}, \mathrm{ArCOCH}_{3}\right), 2.45\left(\mathrm{~s}, 3 \mathrm{H}, \mathrm{ArCH}_{3}\right) .{ }^{13} \mathrm{C} \mathrm{NMR}\left(100 \mathrm{MHz}, \mathrm{CDCl}_{3}\right): \delta$ 196.9, 162.0, 133.0, 131.1, 130.8, 130.1, 128.2, 114.4, 68.0, 65.7, 26.6, 21.9.

Compound 5.6.To a mixture of compound $5.5(3.0 \mathrm{~g}, 8.97 \mathrm{mmol})$ and pyrrole (30 $\mathrm{ml}, 432 \mathrm{mmol})$ was added trifluoroacetic acid $(3.0 \mathrm{ml}, 41.9 \mathrm{mmol})$ in one portion. The reaction solution was heated to $70{ }^{\circ} \mathrm{C}$ and stirred for 7 hours. The reaction was quenched by adding of triethylamine $(5 \mathrm{ml})$ and the residual pyrrole was removed by evaporation in vacuo. To the resulting black sticky oil, $\mathrm{CH}_{2} \mathrm{Cl}_{2}(100 \mathrm{~mL})$ and $10 \%$ aqueous $\mathrm{NaOH}$ $(100 \mathrm{~mL})$ were added, before the organic layer was separated off and washed three times 
with $100 \mathrm{~mL}$ of water. The organic layer was dried over anhydrous $\mathrm{MgSO}_{4}$ and the solvent was removed in vacuo to give a black sticky oil. The crude product was purified by column chromatography over silica gel (eluent: ethyl acetate/hexane (1:4)) to give $2.51 \mathrm{~g}\left(62 \%\right.$ yield) of $\mathbf{5 . 6}$ as a white solid. ${ }^{1} \mathrm{H} \mathrm{NMR}\left(400 \mathrm{MHz}, \mathrm{CDCl}_{3}\right): \delta$ 7.82-7.80 (d, 2H, ArH, $J=8.41 \mathrm{~Hz}), 7.76(\operatorname{broad} \mathrm{s}, 2 \mathrm{H}, \mathrm{NH}), 7.35-7.33(\mathrm{~d}, 2 \mathrm{H}, \operatorname{Ar} H, J=8.01 \mathrm{~Hz})$, 7.00-6.98 (d, 2H, ArH, $J=8.81 \mathrm{~Hz}), 6.70-6.68(\mathrm{~d}, 2 \mathrm{H}, \operatorname{ArH}, J=8.81 \mathrm{~Hz}), 6.67-6.65(\mathrm{~m}$, $2 \mathrm{H}$, pyrrole- $H$ ), 6.18-6.15 (m, $2 \mathrm{H}$, pyrrole- $H$ ), 5.95-5.93 (m, 2H, pyrrole- $H$ ), 4.36-4.33 $\left(\mathrm{m}, 2 \mathrm{H}, \mathrm{ArOCH}_{2}\right), 4.13-4.11\left(\mathrm{~m}, 2 \mathrm{H}, \mathrm{ArOCH}_{2}\right), 2.45\left(\mathrm{~s}, 3 \mathrm{H}, \mathrm{ArCH}_{3}\right), 2.01(\mathrm{~s}, 3 \mathrm{H}$, ArC(pyrrole $\left.)_{2} \mathrm{CH}_{3}\right) .{ }^{13} \mathrm{C} \mathrm{NMR}\left(100 \mathrm{MHz}, \mathrm{CDCl}_{3}\right): \delta 156.9,145.2,140.5,137.8,133.1$, $130.1,128.8,128.3,117.2,114.3,108.5,106.4,68.4,65.7,44.3,29.2,21.9$.

Compound 5.8. Compound 5.6 (2.45 g, $5.44 \mathrm{mmol})$, calix[4]arene monocrwon-5 $(5.7)^{1}(1.52 \mathrm{~g}, 2.61 \mathrm{mmol})$ and $\mathrm{Cs}_{2} \mathrm{CO}_{3}(3.54 \mathrm{~g}, 10.9 \mathrm{mmol})$ were mixed in $125 \mathrm{~mL}$ of acetonitrile and then heated at reflux under an argon atmosphere. After allowing to cool to $\mathrm{RT}$, the acetonitrile was removed in vacuo. To the resulting brownish oil, $\mathrm{CH}_{2} \mathrm{Cl}_{2}(100$ $\mathrm{mL})$ and water $(100 \mathrm{~mL})$ were added, and the organic layer was separated off and washed three times with $50 \mathrm{~mL}$ of water. The organic layer was then dried over anhydrous $\mathrm{MgSO}_{4}$ and the solvent was evaporated in vacuo to give a brownish solid. Purificaton was effected via column chromatography over silica gel eluting first with ethyl acetate/hexane (1:1) and then, after removing relatively non-polar impurities, ethyl acetate/triethylamine (19:1). Removal of the solvents gave $1.82 \mathrm{~g}$ (61\% yield) of $\mathbf{5 . 8}$ as a white solid. ${ }^{1} \mathrm{H}$ NMR (400 MHz, $\left.\mathrm{CDCl}_{3}\right): \delta 7.71$ (broad s, 4H, NH), 7.13-7.11 (d, 4H, 216 
$\operatorname{Ar} H, J=7.61 \mathrm{~Hz}), 7.04-7.02(\mathrm{~d}, 4 \mathrm{H}, \operatorname{Ar} H, J=7.20 \mathrm{~Hz}), 6.99-6.96(\mathrm{~d}, 4 \mathrm{H}, \operatorname{Ar} H, J=8.81$ $\mathrm{Hz}), 6.93-6.89(\mathrm{t}, 2 \mathrm{H}, \operatorname{Ar} H, J=7.20 \& 7.20 \mathrm{~Hz}), 6.75-6.71(\mathrm{t}, 2 \mathrm{H}, \operatorname{Ar} H, J=7.61 \& 7.61$ Hz), 6.69-6.66 (d, 4H, $\operatorname{Ar} H, J=8.81 \mathrm{~Hz}), 6.62-6.60(\mathrm{~m}, 4 \mathrm{H}$, pyrrole- $H)$, 6.16-6.14 (m, 4H, pyrrole- $H$ ), 5.95-5.94 (m, 4H, pyrrole- $H$ ), 3.93-3.84 (dd, 8H, $\mathrm{ArCH}_{2} \mathrm{Ar}, J=17.2 \&$ 17.2 Hz ), 3.67-3.65 (t, $4 \mathrm{H}, \mathrm{OCH}_{2} \mathrm{CH}_{2} \mathrm{O}, J=5.60 \& 6.00 \mathrm{~Hz}$ ), 3.59 (broad s, $4 \mathrm{H}$, $\mathrm{ArOCH}_{2} \mathrm{CH}_{2} \mathrm{OAr}$ ), 3.57 (broad s, $4 \mathrm{H}, \mathrm{ArOCH}_{2} \mathrm{CH}_{2} \mathrm{OAr}$ ), 3.49-3.46 (t, $4 \mathrm{H}, \mathrm{OCH}_{2} \mathrm{CH}_{2} \mathrm{O}, J$ $=5.60 \& 6.00 \mathrm{~Hz}), 3.43-3.40\left(\mathrm{t}, 4 \mathrm{H}, \mathrm{OCH}_{2} \mathrm{CH}_{2} \mathrm{O}, J=6.00 \& 6.80 \mathrm{~Hz}\right), 3.16-3.13(\mathrm{t}, 4 \mathrm{H}$, $\left.\mathrm{OCH}_{2} \mathrm{CH}_{2} \mathrm{O}, J=6.40 \& 6.80 \mathrm{~Hz}\right), 1.99\left(\mathrm{~s}, 6 \mathrm{H}, \mathrm{ArC}(\right.$ pyrrole $\left.){ }_{2} \mathrm{CH}_{3}\right) .{ }^{13} \mathrm{C} \mathrm{NMR}(100 \mathrm{MHz}$, $\left.\mathrm{CDCl}_{3}\right): \delta 157.5,156.6,156.4,139.7,138.0,134.4,134.2,129.7,129.6,128.8,123.1$, $122.9,117.1,114.3,108.4,106.4,73.0,70.9,70.1,68.6,68.5,66.6,60.7,44.3,38.3,29.3$. HRMS (CI) $m / z 1139.5534(\mathrm{M}+\mathrm{H})^{+}$calcd for $\mathrm{C}_{72} \mathrm{H}_{74} \mathrm{~N}_{4} \mathrm{O}_{9}$, found 1139.5520 .

Compound 5.3. To compound $5.8(1.82 \mathrm{~g}, 1.60 \mathrm{mmol})$ in acetone $(500 \mathrm{ml})$ was added $\mathrm{BF}_{3} \cdot \mathrm{OEt}_{2}(0.3 \mathrm{ml}, 2.43 \mathrm{mmol})$ in one portion. The resulting solution was stirred for 2 hours at room temperature and then quenched with triethylamine $(5 \mathrm{ml})$. Evaporation of the volatile components in vасиo afforded a yellowish solid. To this crude product, dichloromethane $(100 \mathrm{ml})$, water $(100 \mathrm{ml})$, and triethylamine $(5 \mathrm{ml})$ were added and the organic phase was separated off and washed three times with water $(100 \mathrm{ml})$. The organic layer was dried over anhydrous $\mathrm{MgSO}_{4}$ and evaporated in vacuo to give a yellowish solid. Recrystallization from a mixture of dichloromethane and methanol (9/1), following by column chromatography over silica gel (eluent: ethyl acetate), gave $0.29 \mathrm{~g}$ (15\% yield) of 5.3 as a white solid. ${ }^{1} \mathrm{H}$ NMR $\left(400 \mathrm{MHz}, \mathrm{CDCl}_{3}\right): \delta$ 7.14-7.12 (d, $4 \mathrm{H}, \mathrm{ArH}, J=7.61$ 
$\mathrm{Hz}), 7.04-7.02(\mathrm{~d}, 4 \mathrm{H}, \operatorname{Ar} H, J=7.61 \mathrm{~Hz}), 6.96-6.92(\mathrm{~m}, 4 \mathrm{H}, \operatorname{Ar} H), 6.71-6.66(\mathrm{~m}, 6 \mathrm{H}$, $\operatorname{Ar} H$; 4H, NH), 6.05-6.03 (t, 4H, pyrrole- $H, J=3.20 \& 2.80 \mathrm{~Hz}), 5.96-5.94(\mathrm{t}, 4 \mathrm{H}$, pyrrole- $H, J=2.80 \& 2.8 \mathrm{~Hz}), 3.89-3.86\left(\mathrm{~m}, 8 \mathrm{H}, \mathrm{ArCH}_{2} \mathrm{Ar} ; 4 \mathrm{H}, \mathrm{OCH}_{2} \mathrm{CH}_{2} \mathrm{O}\right), 3.59-3.57$ (m, $8 \mathrm{H}, \mathrm{ArOCH}_{2} \mathrm{CH}_{2} \mathrm{OAr} ; 4 \mathrm{H}, \mathrm{OCH}_{2} \mathrm{CH}_{2} \mathrm{O}$ ), 3.42-3.39 (t, $4 \mathrm{H}, \mathrm{OCH}_{2} \mathrm{CH}_{2} \mathrm{O}, J=6.40 \&$ $6.40 \mathrm{~Hz}), \quad 3.17-3.13\left(\mathrm{t}, 4 \mathrm{H}, \mathrm{OCH}_{2} \mathrm{CH}_{2} \mathrm{O}, J=6.00 \& 6.80 \mathrm{~Hz}\right), 1.98(\mathrm{~s}, 6 \mathrm{H}$, $\left.\operatorname{ArC}(\text { pyrrole })_{2} \mathrm{CH}_{3}\right), 1.49$ (s, $6 \mathrm{H}$, pyrrole- $\left.\mathrm{C}\left(\mathrm{CH}_{3}\right)_{2}\right), 1.40$ (s, 6H, pyrrole- $\left.\mathrm{C}\left(\mathrm{CH}_{3}\right)_{2}\right) .{ }^{13} \mathrm{C}$ NMR (100 MHz, $\left.\mathrm{CDCl}_{3}\right): \delta 157.4,156.2,139.1,137.0,136.9,134.5,134.4,129.5,129.4$, $128.7,123.5,122.8,113.8,105.2,105.1,72.8,70.8,70.1,68.7,66.9,64.9,44.6,38.2$, $35.9,30.4,30.2,29.9$.

\section{REFERENCES}

(1) (a) No, K.; Lee, H. J.; Park, K. M.; Lee, S. S.; Noh, K. H.; Kim, S. K.; Lee, J. Y.; Kim, J. S. Journal of Heterocyclic Chemistry 2004, 41, 211-219. (b) Kim, J. S.; Shon, O. J.; Ko, J. W.; Cho, M. H.; Yu, I. Y.; Vicens, J. J. Org. Chem. 2000, 65, 2386-2392.

(2) Kim, J. S.; Lee, W. K.; Sim, W.; Ko, J. W.; Cho, M. H.; Ra, D. Y.; Kim, J. W. J. Incl. Phenom. Macro. Chem. 2000, 37, 359-370.

(3) Bush, L. C.; Heath, R. B.; Feng, X. U.; Wang, P. A.; Maksimovic, L.; Song, A. I.; Chung, W.-S.; Berinstain, A. B.; Scaiano, J. C.; Berson, J. A. J. Am. Chem. Soc. 1997, 119, 1406-1415. 


\section{Appendix: X-ray experimental and crystallographic data}

All crystals for X-ray crystallographic analyses described in this appendix were grown by the author. All crystal X-ray diffraction structures were solved by Dr. Vicent M. Lynch of this department. Structures described in this work but not included in this appendix have been deposited with the Cambridge Crystallographic Data Base and can be obtained from there. A general experimental method as provided by Dr. Lynch used in obtaining these structures, along with relevant data tables for each structure now follows.

X-ray Experimental for $\mathbf{2 . 2} \cdot\left(\mathrm{CH}_{3} \mathrm{OH}\right)_{2}$ : Crystals grew as long, colorless laths by slow evaporation from methanol. The data crystal was cut from a larger crystal and had approximate dimensions; $0.30 \times 0.07 \times 0.04 \mathrm{~mm}$. The data were collected on a Nonius Kappa CCD diffractometer using a graphite monochromator with $\mathrm{MoK} \alpha$ radiation $(\lambda=$ $0.71073 \AA$ ). A total of 311 frames of data were collected using $\omega$-scans with a scan range of $0.9^{\circ}$ and a counting time of 239 seconds per frame. The data were collected at $153 \mathrm{~K}$ using an Oxford Cryostream low temperature device. Details of crystal data, data collection and structure refinement are listed in Table A.1. Data reduction was performed using DENZO-SMN. The structure was solved by direct methods using SIR97 and refined by full-matrix least-squares on $\mathrm{F}^{2}$ with anisotropic displacement parameters for the non-H atoms using SHELXL-97. The hydrogen atoms were calculated in ideal positions with isotropic displacement parameters set to $1.2 \times$ Ueq of the attached atom $(1.5 \times$ Ueq for methyl hydrogen atoms). The hydrogen atom on the methanol oxygen atom, $\mathrm{O} 1 \mathrm{a}$, could not be located in a $\Delta \mathrm{F}$ map and was not included in the final refinement model. The function, $\Sigma \mathrm{w}\left(|\mathrm{Fo}|^{2}-|\mathrm{Fc}|^{2}\right)^{2}$, was minimized, where $\mathrm{w}=1 /\left[(\sigma(\mathrm{Fo}))^{2}+\right.$ $\left.(0.0606 * \mathrm{P})^{2}+(2.5237 * \mathrm{P})\right]$ and $\mathrm{P}=\left(|\mathrm{Fo}|^{2}+2|\mathrm{Fc}|^{2}\right) / 3 . \mathrm{Rw}\left(\mathrm{F}^{2}\right)$ refined to 0.237 , with $\mathrm{R}(\mathrm{F})$ 
equal to 0.0922 and a goodness of fit, $S,=1.007$. Definitions used for calculating $R(F)$, $\mathrm{Rw}\left(\mathrm{F}^{2}\right)$ and the goodness of fit, $\mathrm{S}$, are given below. The data were checked for secondary extinction effects but no correction was necessary. Neutral atom scattering factors and values used to calculate the linear absorption coefficient are from the International Tables for X-ray Crystallography (1992). All figures were generated using SHELXTL/PC.

Figure A.1 View of the complex in 2.2 showing the atom labeling scheme. Displacement ellipsoids are scaled to the 30\% probability level. Most hydrogen atoms have been removed for clarity. The macrocycle lies on a crystallographic inversion center at $1 / 2,1 / 2,1 / 2$. Atoms with labels appended by a ' are related by 1-x, 1-y, 1-z. Dashed lines are indicative of H-bonding interactions. The geometry of these interactions is: N1a-H1a ${ }^{\cdots} \mathrm{O} 1 \mathrm{a}, \mathrm{N} \cdots \mathrm{O}$

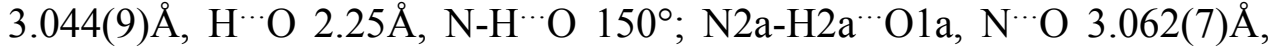
$\mathrm{H}^{\cdots} \mathrm{O} 2.27 \AA, \mathrm{N}-\mathrm{H}^{\cdots} \mathrm{O} 150^{\circ}$.

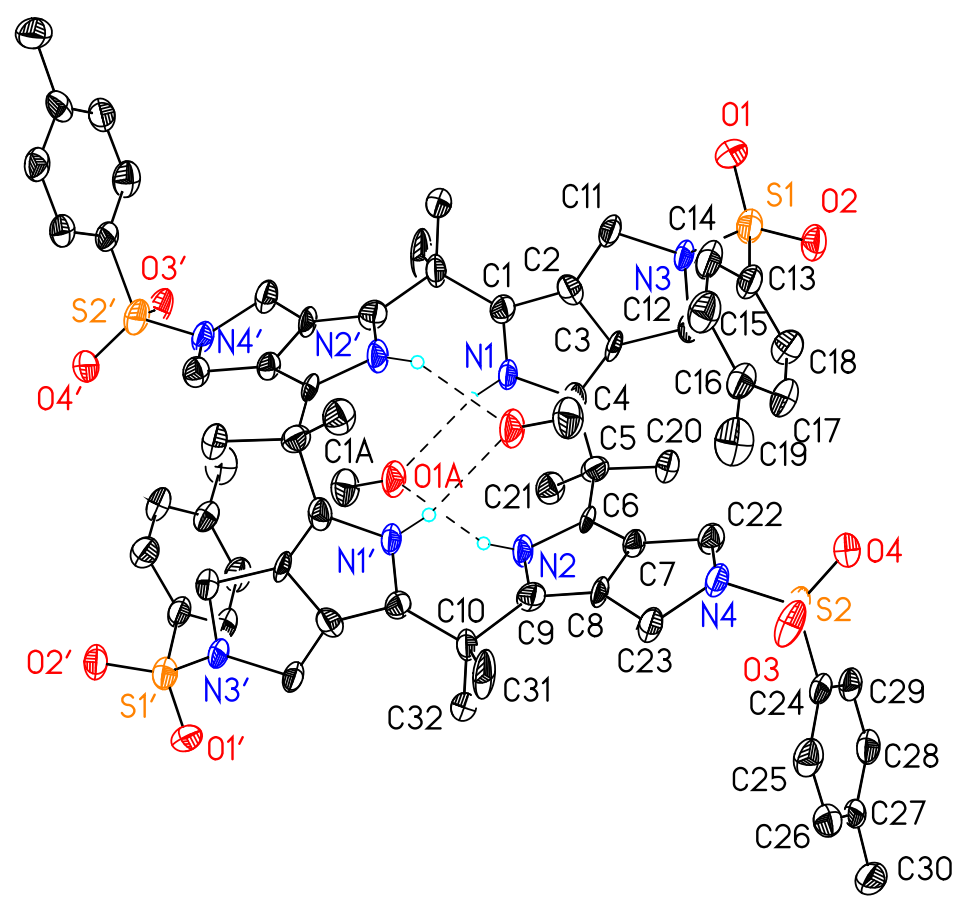


Figure A.2 Unit cell packing diagram for $\mathbf{2 . 2} \cdot\left(\mathrm{CH}_{3} \mathrm{OH}\right)_{2}$. The view is approximately down the a axis.

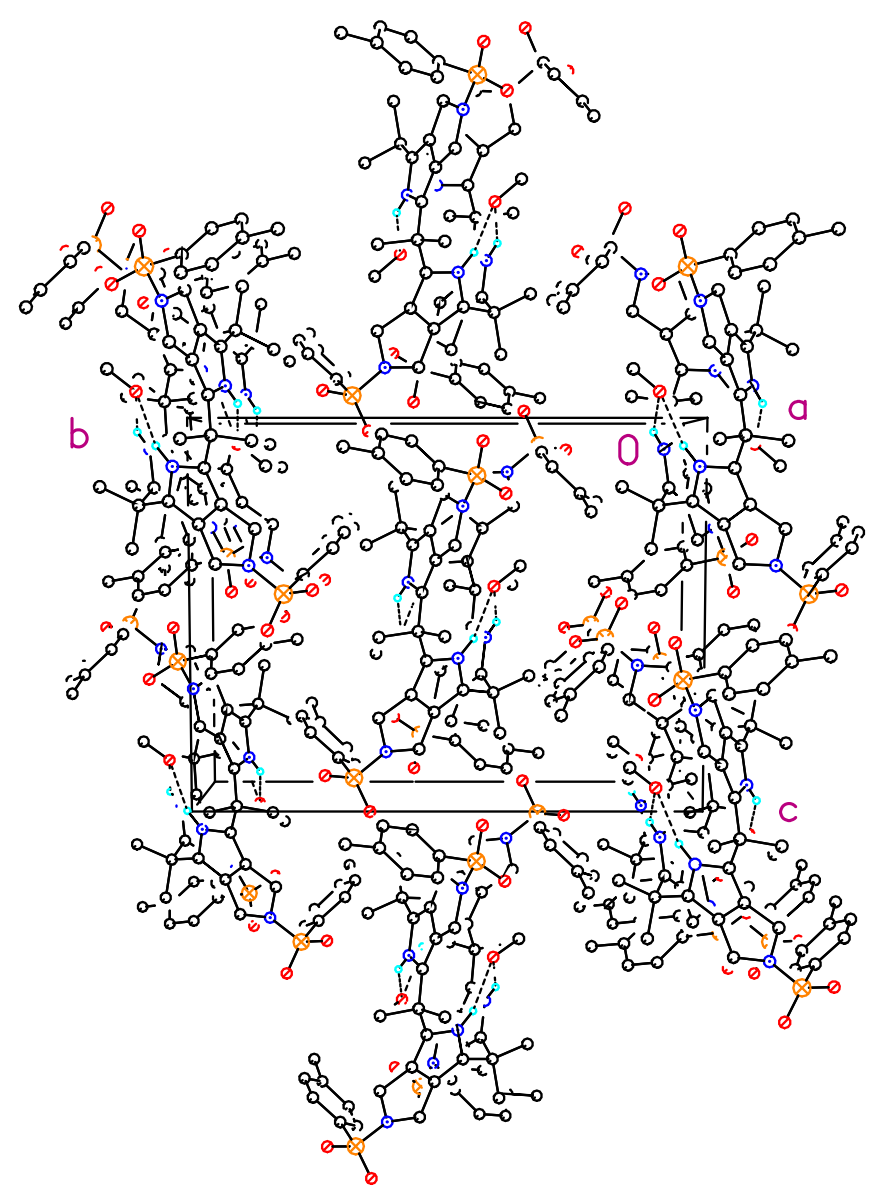


Table A.1 Crystal data and structure refinement for $\mathbf{2 . 2} \cdot\left(\mathrm{CH}_{3} \mathrm{OH}\right)_{2}$.

Empirical formula

Formula weight

Temperature

Wavelength

Crystal system

Space group

Unit cell dimensions

Volume

Z

Density (calculated)

Absorption coefficient

$\mathrm{F}(000)$

Crystal size

Theta range for data collection

Index ranges

Reflections collected

Independent reflections

Completeness to theta $=25.00^{\circ}$

Absorption correction

Refinement method

Data / restraints / parameters

Goodness-of-fit on $\mathrm{F}^{2}$

Final $\mathrm{R}$ indices [I $>2 \operatorname{sigma}(\mathrm{I})]$

$\mathrm{R}$ indices (all data)

Largest diff. peak and hole
C33 H40 N4 O5 S2

636.81

153(2) K

$0.71073 \AA$

Monoclinic

$\mathrm{P} 21 / \mathrm{n}$

$$
\begin{aligned}
& \mathrm{a}=12.817(3) \AA \quad \alpha=90^{\circ} \text {. } \\
& \mathrm{b}=17.885(6) \AA \quad \beta=98.261(11)^{\circ} \text {. } \\
& \mathrm{c}=13.861(5) \AA \quad \gamma=90^{\circ} \text {. }
\end{aligned}
$$

$3144.4(17) \AA^{3}$

4

$1.345 \mathrm{Mg} / \mathrm{m}^{3}$

$0.217 \mathrm{~mm}^{-1}$

1352

$0.30 \times 0.07 \times 0.04 \mathrm{~mm}$

2.32 to $25.00^{\circ}$.

$-15<=\mathrm{h}<=15,-21<=\mathrm{k}<=19,-16<=\mathrm{l}<=16$

8959

$5356[\mathrm{R}(\mathrm{int})=0.1094]$

$96.6 \%$

None

Full-matrix least-squares on $\mathrm{F}^{2}$

5356 / 0 / 403

1.007

$\mathrm{R} 1=0.0922, \mathrm{wR} 2=0.1696$

$\mathrm{R} 1=0.2844, \mathrm{wR} 2=0.2370$

0.303 and -0.192 e. $\AA^{-3}$ 
X-ray Experimental for $2.2 \cdot(\mathrm{DMF})_{4} \cdot\left(\mathrm{CH}_{2} \mathrm{Cl}_{2}\right)_{1 / 2}$ : Crystals grew as clusters of colorless needles by slow evaporation from DMF and dichloromethnae. The data crystal was cut from a large cluster and had approximate dimensions; $0.28 \times 0.18 \times 0.05 \mathrm{~mm}$. The data were collected on a Nonius Kappa CCD diffractometer using a graphite monochromator with $\operatorname{MoK} \alpha$ radiation $(\lambda=0.71073 \AA)$. A total of 205 frames of data were collected using $\omega$-scans with a scan range of $2^{\circ}$ and a counting time of 222 seconds per frame. The data were collected at $153 \mathrm{~K}$ using an Oxford Cryostream low temperature device. Details of crystal data, data collection and structure refinement are listed in Table A.2. Data reduction was performed using DENZO-SMN. The structure was solved by direct methods using SIR97 and refined by full-matrix least-squares on $\mathrm{F}^{2}$ with anisotropic displacement parameters for the non-H atoms using SHELXL-97. The hydrogen atoms on carbon were calculated in ideal positions with isotropic displacement parameters set to $1.2 \times$ Ueq of the attached atom $(1.5 \times$ Ueq for methyl hydrogen atoms $)$. The hydrogen atoms on the pyrrolic nitrogen atoms, $\mathrm{N} 1$ and $\mathrm{N} 2$, were observed in a $\Delta \mathrm{F}$ map and refined with isotropic displacement parameters.

There were two regions of disordered solvent in the lattice. One, near a crystallographic inversion center, appeared to be due to dichloromethane. Two peaks, about $3 \AA$ apart, were thought to be due to a partially occupied dichloromethane molecule. A second solvate molecule that was clearly DMF was located near the dichloromethane molecule. Both solvate molecules were badly disordered. The contribution to the structure factors due to these molecules was removed by use of the utility Squeeze in PLATON98. PLATON98 was used as incorporated in WinGX.

The macrocycle is located around a crystallographic inversion center at 1/2, 1/2, 1/2. The macrocycle is H-bound to two molecules of DMF. The DMF molecules are disordered about two orientations. The disorder was modeled by assigning the site occupancy factor of one orientation to the variable $\mathrm{x}$. The site occupancy factor for the second orientation was assigned to $(1-\mathrm{x})$. A common site occupancy factor was refined for all atoms of the two orientations. In this way, the site occupancy of the major component was $69(2) \%$. The geometry of the disordered molecules was restrained to be 
equivalent throughout the refinement. Anisotropic displacement parameters were used for the major component of the disorder. The atoms of the minor component were refined isotropically.

The function, $\sum \mathrm{w}\left(\left|\mathrm{F}_{\mathrm{O}}\right|^{2}-\left|\mathrm{F}_{\mathrm{C}}\right|^{2}\right)^{2}$, was minimized, where $\mathrm{w}=1 /\left[\left(\sigma\left(\mathrm{F}_{\mathrm{O}}\right)\right)^{2}+\right.$ $\left.(0.0533 * \mathrm{P})^{2}+(0.281 * \mathrm{P})\right]$ and $\mathrm{P}=\left(\left|\mathrm{F}_{\mathrm{O}}\right|^{2}+2\left|\mathrm{~F}_{\mathrm{C}}\right|^{2}\right) / 3 . \mathrm{R}_{\mathrm{w}}\left(\mathrm{F}^{2}\right)$ refined to 0.134 , with $\mathrm{R}(\mathrm{F})$ equal to 0.0525 and a goodness of fit, $\mathrm{S},=1.14$. Definitions used for calculating $\mathrm{R}(\mathrm{F})$, $\mathrm{R}_{\mathrm{w}}\left(\mathrm{F}^{2}\right)$ and the goodness of fit, $\mathrm{S}$, are given below. The data were corrected for secondary extinction effects. The correction takes the form: $\mathrm{F}_{\text {corr }}=\mathrm{kF}_{\mathrm{c}} /\left[1+\left(5.0(11) \times 10^{-6}\right)^{*} \mathrm{~F}_{\mathrm{c}}{ }^{2}\right.$ $\left.\lambda^{3} /(\sin 2 \theta)\right]^{0.25}$ where $\mathrm{k}$ is the overall scale factor. Neutral atom scattering factors and values used to calculate the linear absorption coefficient are from the International Tables for X-ray Crystallography (1992). All figures were generated using SHELXTL/PC.

Figure A.3 View of the macrocycle in $\mathbf{2 . 2}$ showing the atom labeling scheme. Displacement ellipsoids are scaled to the $50 \%$ probability level. The macrocycle lies on a crystallographic inversion center at $1 / 2,1 / 2,1 / 2$. Atoms with labels appended by a ' are related by 1-x, 1-y, 1-z. Two DMF molecules bound to the calix[4]pyrrole are omitted for clarity.

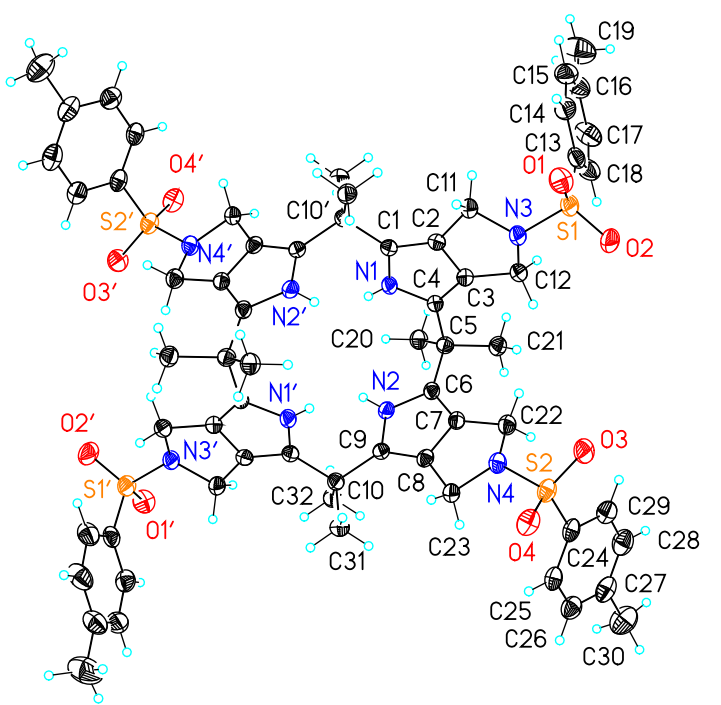


Table A.2 Crystal data and structure refinement for $\mathbf{2 . 2} \cdot(\mathbf{D M F})_{4} \cdot\left(\mathrm{CH}_{2} \mathrm{Cl}_{2}\right)_{1 / 2}$.

\begin{tabular}{|c|c|c|}
\hline Empirical formula & \multicolumn{2}{|c|}{ C76.50 H101 Cl N12 O12 S4 } \\
\hline Formula weight & \multicolumn{2}{|l|}{1544.38} \\
\hline Temperature & \multicolumn{2}{|l|}{$153(2) \mathrm{K}$} \\
\hline Wavelength & \multicolumn{2}{|l|}{$0.71073 \AA$} \\
\hline Crystal system & \multicolumn{2}{|l|}{ Triclinic } \\
\hline Space group & \multicolumn{2}{|l|}{$\mathrm{P}-1$} \\
\hline \multirow[t]{3}{*}{ Unit cell dimensions } & $a=11.4296(6) \AA$ & $\alpha=105.0390(10)^{\circ}$. \\
\hline & $b=12.6286(6) \AA$ & $\beta=90.9620(10)^{\circ}$ \\
\hline & $\mathrm{c}=15.0391(9) \AA$ & $\gamma=107.6010(10)^{\circ}$. \\
\hline Volume & \multicolumn{2}{|l|}{$1987.52(18) \AA^{3}$} \\
\hline $\mathrm{Z}$ & \multicolumn{2}{|l|}{2} \\
\hline Density (calculated) & \multicolumn{2}{|l|}{$2.581 \mathrm{Mg} / \mathrm{m}^{3}$} \\
\hline Absorption coefficient & \multicolumn{2}{|l|}{$0.440 \mathrm{~mm}^{-1}$} \\
\hline $\mathrm{F}(000)$ & \multicolumn{2}{|l|}{1642} \\
\hline Crystal size & \multicolumn{2}{|c|}{$0.28 \times 0.18 \times 0.05 \mathrm{~mm}$} \\
\hline Theta range for data collection & \multicolumn{2}{|l|}{1.93 to $27.50^{\circ}$. } \\
\hline Index ranges & \multicolumn{2}{|c|}{$-14<=\mathrm{h}<=14,-16<=\mathrm{k}<=16,-19<=\mathrm{l}<=19$} \\
\hline Reflections collected & \multicolumn{2}{|l|}{15170} \\
\hline Independent reflections & \multicolumn{2}{|c|}{$8976[\mathrm{R}(\mathrm{int})=0.0290]$} \\
\hline Completeness to theta $=27.50^{\circ}$ & \multicolumn{2}{|l|}{$98.2 \%$} \\
\hline Absorption correction & \multicolumn{2}{|l|}{ None } \\
\hline Refinement method & \multicolumn{2}{|c|}{ Full-matrix least-squares on $\mathrm{F}^{2}$} \\
\hline Data / restraints / parameters & \multicolumn{2}{|l|}{8976 / 38 / 459} \\
\hline Goodness-of-fit on $\mathrm{F}^{2}$ & \multicolumn{2}{|l|}{1.140} \\
\hline Final $R$ indices $[\mathrm{I}>2 \operatorname{sigma}(\mathrm{I})]$ & \multicolumn{2}{|c|}{$\mathrm{R} 1=0.0525, \mathrm{wR} 2=0.1250$} \\
\hline $\mathrm{R}$ indices (all data) & \multicolumn{2}{|c|}{$\mathrm{R} 1=0.0855, \mathrm{wR} 2=0.1341$} \\
\hline Extinction coefficient & \multicolumn{2}{|l|}{$5.0(11) \times 10^{-6}$} \\
\hline Largest diff. peak and hole & \multicolumn{2}{|c|}{0.353 and -0.393 e. $\AA^{-3}$} \\
\hline
\end{tabular}


X-ray Experimental for 2.2.TBACl: Crystals grew as colorless prisms by slow evaporation from Methanol and dichloromethane. The data crystal was a prism that had approximate dimensions; $0.13 \times 0.10 \times 0.08 \mathrm{~mm}$. The data were collected on a Nonius Kappa CCD diffractometer using a graphite monochromator with $\operatorname{MoK} \alpha$ radiation $(\lambda=$ $0.71073 \AA$ ). . A total of 151 frames of data were collected using $\omega$-scans with a scan range of $1.2^{\circ}$ and a counting time of 531 seconds per frame. The data were collected at $153 \mathrm{~K}$ using an Oxford Cryostream low temperature device. Details of crystal data, data collection and structure refinement are listed in Table A.3. Data reduction was performed using DENZO-SMN. The structure was solved by direct methods using SIR97 and refined by full-matrix least-squares on $\mathrm{F}^{2}$ with anisotropic displacement parameters for the non-H atoms using SHELXL-97. The hydrogen atoms were calculated in ideal positions with isotropic displacement parameters set to $1.2 \times$ Ueq of the attached atom $(1.5 \times$ Ueq for methyl hydrogen atoms).

The tetrakis-n-butylammonium ion was disordered. The disorder could not be adequately modeled. As a result, the utility, SQUEEZE in Platon98 was used to remove the cationic contribution to the scattering. Platon 98 was used as incorporated in WinGX.

The function, $\Sigma \mathrm{w}\left(\left|\mathrm{F}_{\mathrm{O}}\right|^{2}-\left|\mathrm{F}_{\mathrm{c}}\right|^{2}\right)^{2}$, was minimized, where $\mathrm{w}=1 /\left[\left(\sigma\left(\mathrm{F}_{\mathrm{O}}\right)\right)^{2}+\right.$ $\left.\left(0.11^{*} \mathrm{P}\right)^{2}\right]$ and $\mathrm{P}=\left(\left|\mathrm{F}_{\mathrm{O}}\right|^{2}+2\left|\mathrm{~F}_{\mathrm{C}}\right|^{2}\right) / 3 . \mathrm{R}_{\mathrm{w}}\left(\mathrm{F}^{2}\right)$ refined to 0.229 , with $\mathrm{R}(\mathrm{F})$ equal to 0.0861 and a goodness of fit, $S,=1.124$. Definitions used for calculating $R(F), R_{w}\left(F^{2}\right)$ and the goodness of fit, S, are given below. The data were checked for secondary extinction effects but no correction was necessary. Neutral atom scattering factors and values used to calculate the linear absorption coefficient are from the International Tables for X-ray Crystallography (1992). All figures were generated using SHELXTL/PC. 
Figure A.4 View of the macrocycle chloride complex in $\mathbf{2 . 2} \cdot \mathrm{Cl}^{-}$showing the atom labeling scheme. Displacement ellipsoids are scaled to the $30 \%$ probability level. The methyl hydrogen atoms have been removed for clarity. The macrocycle lies around a crystallographic 4-fold rotation axis at 1/2, 1/2, $\mathrm{z}$. Dashed lines are indicative of H-bonding interactions with geometry: N1$\mathrm{H} 1 \mathrm{a}{ }^{\cdots} \mathrm{Cl1}, \mathrm{N} \cdots \mathrm{Cl} 3.372(5) \AA, \mathrm{H}^{\cdots} \mathrm{Cl} 2.55 \AA, \mathrm{N}-\mathrm{H}^{\cdots} \mathrm{Cl}^{155^{\circ}}$.

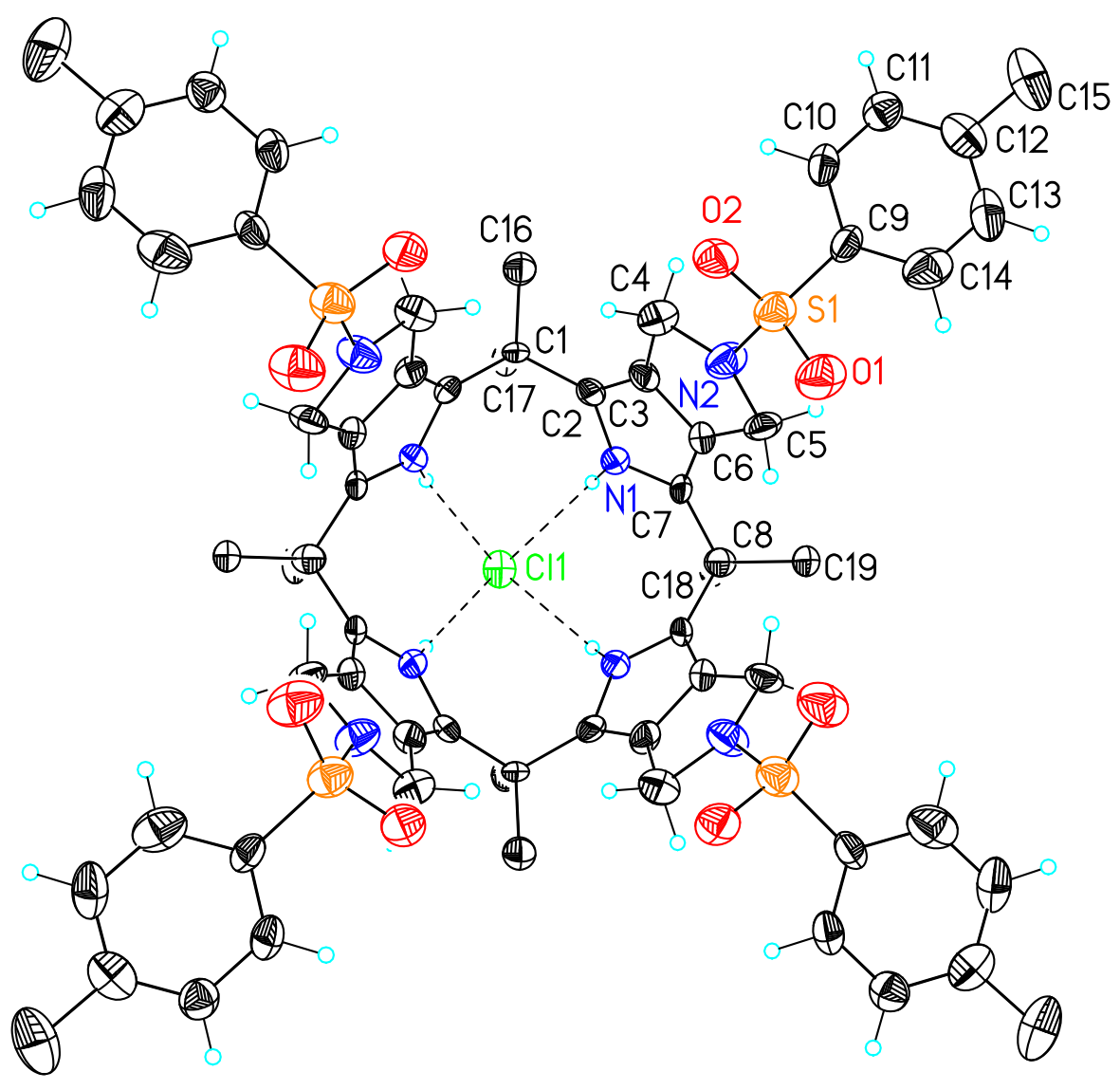


Table A.3 Crystal data and structure refinement for 2.2 $\mathrm{TBACl}$.

Empirical formula

Formula weight

Temperature

Wavelength

Crystal system

Space group

Unit cell dimensions

Volume

$\mathrm{Z}$

Density (calculated)

Absorption coefficient

$\mathrm{F}(000)$

Crystal size

Theta range for data collection

Index ranges

Reflections collected

Independent reflections

Completeness to theta $=25.02^{\circ}$

Absorption correction

Refinement method

Data / restraints / parameters

Goodness-of-fit on $\mathrm{F}^{2}$

Final $R$ indices [I>2sigma(I)]

$\mathrm{R}$ indices (all data)

Absolute structure parameter

Largest diff. peak and hole

\section{C80 H108 Cl N9 O8 S4}

1487.44

153(2) K

$0.71073 \AA$

Tetragonal

I-4/1md

$\mathrm{a}=23.5509(15) \AA$

$\alpha=90^{\circ}$.

$\mathrm{b}=23.5509(15) \AA$

$\beta=90^{\circ}$.

$\mathrm{c}=14.5959(9) \AA$ $\gamma=90^{\circ}$.
$8095.5(9) \AA^{3}$

4

$1.220 \mathrm{Mg} / \mathrm{m}^{3}$

$0.209 \mathrm{~mm}^{-1}$

3184

$0.15 \times 0.10 \times 0.08 \mathrm{~mm}$

2.38 to $25.02^{\circ}$.

$-27<=\mathrm{h}<=28,-26<=\mathrm{k}<=28,-17<=1<=17$

12049

$3746[\mathrm{R}(\mathrm{int})=0.1141]$

$99.8 \%$

None

Full-matrix least-squares on $\mathrm{F}^{2}$ 3746 / 1 / 205

1.124

$\mathrm{R} 1=0.0861, \mathrm{wR} 2=0.2084$

$\mathrm{R} 1=0.1379, \mathrm{wR} 2=0.2295$

$0.21(18)$

0.626 and -0.459 e. $\AA^{-3}$ 
$\mathrm{X}$-ray Experimental for $\mathbf{3 . 1} \cdot \mathrm{CsF} \cdot \mathrm{CH}_{3} \mathrm{OH} \cdot \mathrm{H}_{2} \mathrm{O} \cdot \mathrm{CHCl}_{3}$ : Crystals grew as colorless needles by slow evaporation from chloroform and methanol. The data crystal was a needle that had approximate dimensions; $0.40 \times 0.07 \times 0.07 \mathrm{~mm}$. The data were collected on a Nonius Kappa CCD diffractometer using a graphite monochromator with MoK $\alpha$ radiation $(\lambda=0.71073 \AA)$. A total of 417 frames of data were collected using $\omega$ scans with a scan range of $0.7^{\circ}$ and a counting time of 175 seconds per frame. The data were collected at $153 \mathrm{~K}$ using an Oxford Cryostream low temperature device. Details of crystal data, data collection and structure refinement are listed in Table A.4. Data reduction were performed using DENZO-SMN. The structure was solved by direct methods using SIR97 and refined by full-matrix least-squares on F2 with anisotropic displacement parameters for the non-H atoms using SHELXL-97. The hydrogen atoms on carbon were calculated in ideal positions with isotropic displacement parameters set to $1.2 \times$ Ueq of the attached atom $(1.5 \times$ Ueq for methyl hydrogen atoms $)$. The hydrogen atoms on the water molecule and the hydroxyl hydrogen atom on the methanol molecule were not observed in a $\Delta \mathrm{F}$ map and were not included in the final refinement model. The ether portion of the calixpyrrole was disordered. The disorder was modeled by assigning the variable $\mathrm{x}$ to the site occupancy factors of one component of the disorder composed of atoms C72a, O4a, C73a, C74a, O5a, C75a, C76a, O6a, C77a, C78a, O7a, C79a and (1-x) to the site occupancy factors of the alternate component of the disorder composed of atoms, C72b, O4b, C73b, C74b, O5b, C75b, C76b, O6b, C77b, C78b, O7b and $\mathrm{C} 79 \mathrm{~b}$. The geometry of the two components was restrained to be equivalent throughout the refinement. In this way, the site occupancy factor for the first component refined to $70(2) \%$. A molecule of chloroform was also disordered. The site occupancy factors were determined in a similar fashion as described above. The site occupancy refined to a value close to $50 \%$ and was subsequently fixed at $50 \%$ for the remainder of the refinement. The geometry of the two components of this molecule was also constrained to be equivalent. The function, $\Sigma \mathrm{w}\left(|\mathrm{Fo}|^{2}-|\mathrm{Fc}|^{2}\right)^{2}$, was minimized, where $\mathrm{w}=$ $1 /\left[(\sigma(\mathrm{Fo}))^{2}+(0.0812 * \mathrm{P})^{2}+(21.4957 * \mathrm{P})\right]$ and $\mathrm{P}=\left(|\mathrm{Fo}|^{2}+2|\mathrm{Fc}|^{2}\right) / 3 . \quad \mathrm{R}_{\mathrm{w}}\left(\mathrm{F}^{2}\right)$ refined to 0.228 , with $\mathrm{R}(\mathrm{F})$ equal to 0.0817 and a goodness of fit, $\mathrm{S},=1.25$. Definitions used for 
calculating $\mathrm{R}(\mathrm{F}), \mathrm{R}_{\mathrm{w}}\left(\mathrm{F}^{2}\right)$ and the goodness of fit, $\mathrm{S}$, are given below. The data were checked for secondary extinction effects but no correction was necessary. Neutral atom scattering factors and values used to calculate the linear absorption coefficient are from the International Tables for X-ray Crystallography (1992). All figures were generated using SHELXTL/PC.

Figure A.5 View of the Cs complex in $\mathbf{3 . 1}$ showing a partial atom labeling scheme. Displacement ellipsoids are scaled to the $30 \%$ probability level. The hydrogen atoms have been removed for clarity. The higher occupancy atoms of the disordered ether link are shown.

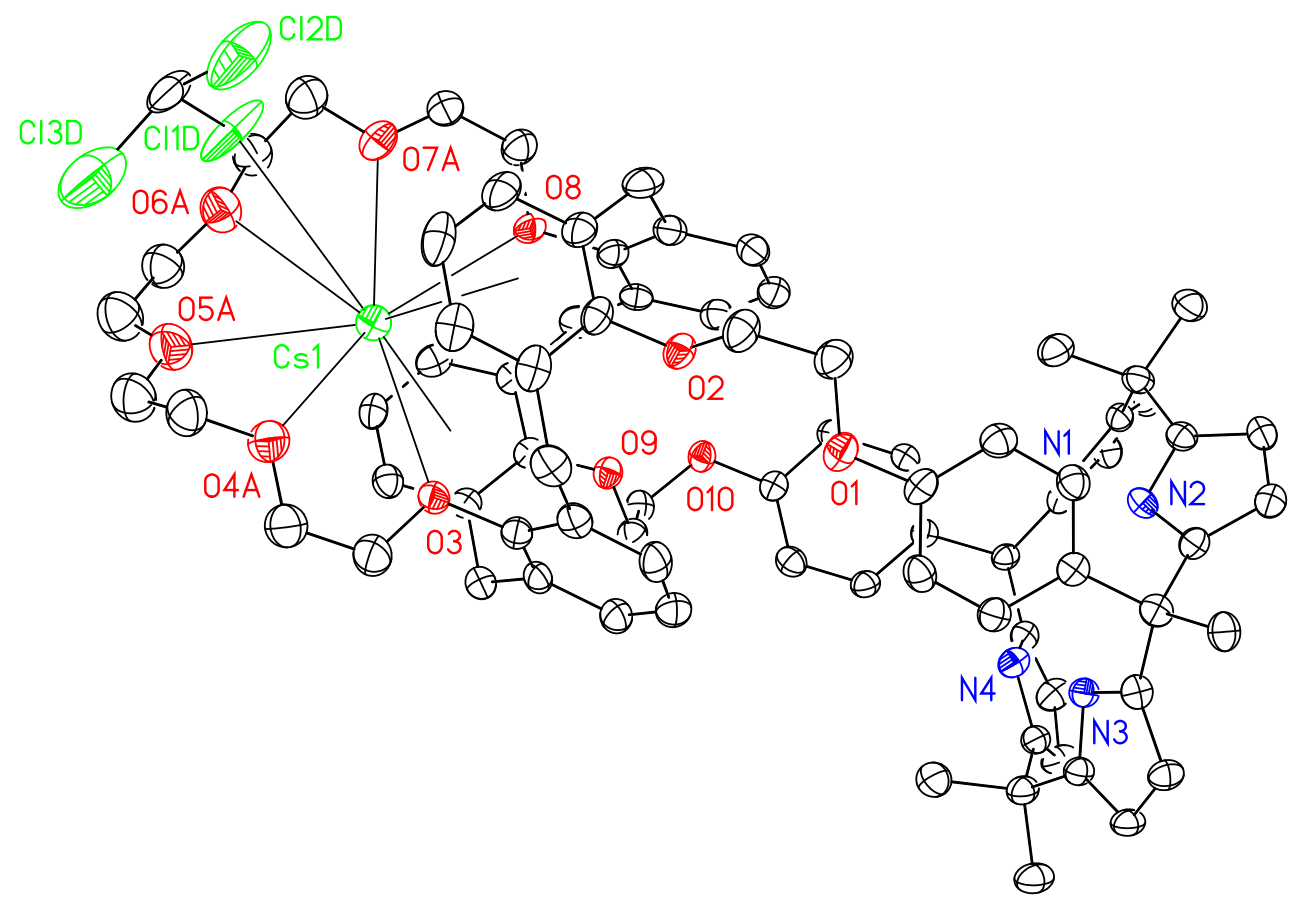


Table A.4 Crystal data and structure refinement for $\mathbf{3 . 1} \cdot \mathrm{CsF} \cdot \mathrm{CH}_{3} \mathrm{OH} \cdot \mathrm{H}_{2} \mathrm{O} \cdot \mathrm{CHCl}_{3}$.

Empirical formula

Formula weight

Temperature

Wavelength

Crystal system

Space group

Unit cell dimensions

Volume

Z

Density (calculated)

Absorption coefficient

$\mathrm{F}(000)$

Crystal size

Theta range for data collection

Index ranges

Reflections collected

Independent reflections

Completeness to theta $=25.00^{\circ}$

Refinement method

Data / restraints / parameters

Goodness-of-fit on $\mathrm{F}^{2}$

Final $\mathrm{R}$ indices [I $>2 \operatorname{sigma}(\mathrm{I})]$

$\mathrm{R}$ indices (all data)

Largest diff. peak and hole
C82 H93 Cl3 Cs F N4 O12

1584.86

153(2) K

$0.71073 \AA$

Orthorhombic

Pbca

$$
\begin{array}{ll}
\mathrm{a}=20.6810(5) \AA & \alpha=90^{\circ} . \\
\mathrm{b}=27.2620(12) \AA & \beta=90^{\circ} . \\
\mathrm{c}=28.7290(11) \AA & \gamma=90^{\circ} .
\end{array}
$$$$
\text { 16197.6(10) } \AA^{3}
$$

8

$1.300 \mathrm{Mg} / \mathrm{m}^{3}$

$0.619 \mathrm{~mm}^{-1}$

6592

$0.40 \times 0.07 \times 0.07 \mathrm{~mm}$

2.98 to $25.00^{\circ}$.

$-24<=\mathrm{h}<=24,-32<=\mathrm{k}<=32,-34<=\mathrm{l}<=34$

27324

$14231[\mathrm{R}(\mathrm{int})=0.0771]$

$99.8 \%$

Full-matrix-block least-squares on $\mathrm{F}^{2}$

14231 / 1282 / 1078

1.252

$\mathrm{R} 1=0.0817, \mathrm{wR} 2=0.2013$

$\mathrm{R} 1=0.1555, \mathrm{wR} 2=0.2284$

1.097 and -0.598 e. $\AA^{-3}$ 
X-ray Experimental for $\mathbf{4 . 2} \cdot\left(\mathrm{CH}_{3} \mathrm{OH}\right)_{2}$ : Crystals grew as cluster of colorless plates by slow evaporation from methanol. The data crystal was cut from a larger crystal and had approximate dimensions of $0.35 \times 0.18 \times 0.10 \mathrm{~mm}$. The data were collected on a Nonius Kappa CCD diffractometer using a graphite monochromator with MoK $\alpha$ radiation ( $\lambda=0.71073 \AA$ ). A total of 202 frames of data were collected using $\omega$ scans with a scan range of $2^{\circ}$ and a counting time of 434 seconds per frame. The data were collected at $153 \mathrm{~K}$ using an Oxford Cryostream low temperature device. Details of crystal data, data collection and structure refinement are listed in Table A.5. Data reduction was performed using DENZO-SMN. The structure was solved by direct methods using SIR97 and refined by full-matrix least-squares on $\mathrm{F}^{2}$ with anisotropic displacement parameters for the non-H atoms using SHELXL-97. The hydrogen atoms were calculated in ideal positions with isotropic displacement parameters set to $1.2 \times$ Ueq of the attached atom $\left(1.5 \times\right.$ Ueq for methyl hydrogen atoms). The function, $\Sigma \mathrm{w}\left(|\mathrm{Fo}|^{2}-\right.$ $\left.|\mathrm{Fc}|^{2}\right)^{2}$, was minimized, where $\left.\mathrm{w}=1 /\left[(\sigma(\mathrm{Fo}))^{2}+(0.0584 * \mathrm{P})^{2}+1.6633 * \mathrm{P}\right)\right]$ and $\mathrm{P}=\left(|\mathrm{Fo}|^{2}\right.$ $\left.+2|\mathrm{Fc}|^{2}\right) / 3 . \mathrm{R}_{\mathrm{w}}\left(\mathrm{F}^{2}\right)$ refined to 0.178 , with $\mathrm{R}(\mathrm{F})$ equal to 0.0696 and a goodness of fit, $\mathrm{S}$, = 1.00. Definitions used for calculating $R(F), R_{w}\left(F^{2}\right)$ and the goodness of fit, $S$, are given below. The data were corrected for secondary extinction effects. The correction takes the form: $\mathrm{F}_{\text {corr }}=\mathrm{kF}_{\mathrm{c}} /\left[1+\left(1.9(2) \times 10^{-6}\right) * \mathrm{Fc}^{2} \lambda^{3} /(\sin 2 \theta)\right]^{0.25}$ where $\mathrm{k}$ is the overall scale factor. Neutral atom scattering factors and values used to calculate the linear absorption coefficient are from the International Tables for X-ray Crystallography (1992). All figures were generated using SHELXTL/PC. 
Figure A.6 View of $\mathbf{4 . 2} \cdot\left(\mathrm{CH}_{3} \mathrm{OH}\right)_{2}$ showing the atom labeling scheme. Displacement ellipsoids are scaled to the $30 \%$ probability level. Most hydrogen atoms have been removed for clarity.Dashed lines are indicative of $\mathrm{H}$-bonding interactions. The geometry of these interactions is: $\mathrm{N} 1-\mathrm{H} 1 \mathrm{a}^{\cdots} \mathrm{O} 1 \mathrm{~A}, \mathrm{~N} \cdots \mathrm{O}$

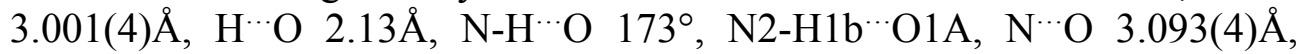
$\mathrm{H}^{\cdots} \mathrm{O} 2.26 \AA$, N-H ${ }^{\cdots} \mathrm{O} 157^{\circ}, \mathrm{N} 3-\mathrm{H} 3 b^{\cdots} \mathrm{O} 1 \mathrm{~A}, \mathrm{~N}^{\cdots} \mathrm{O} 3.201(4) \AA, \mathrm{H}^{\cdots} \mathrm{O} 2.33 \AA$,

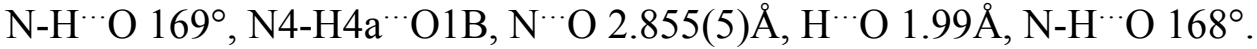

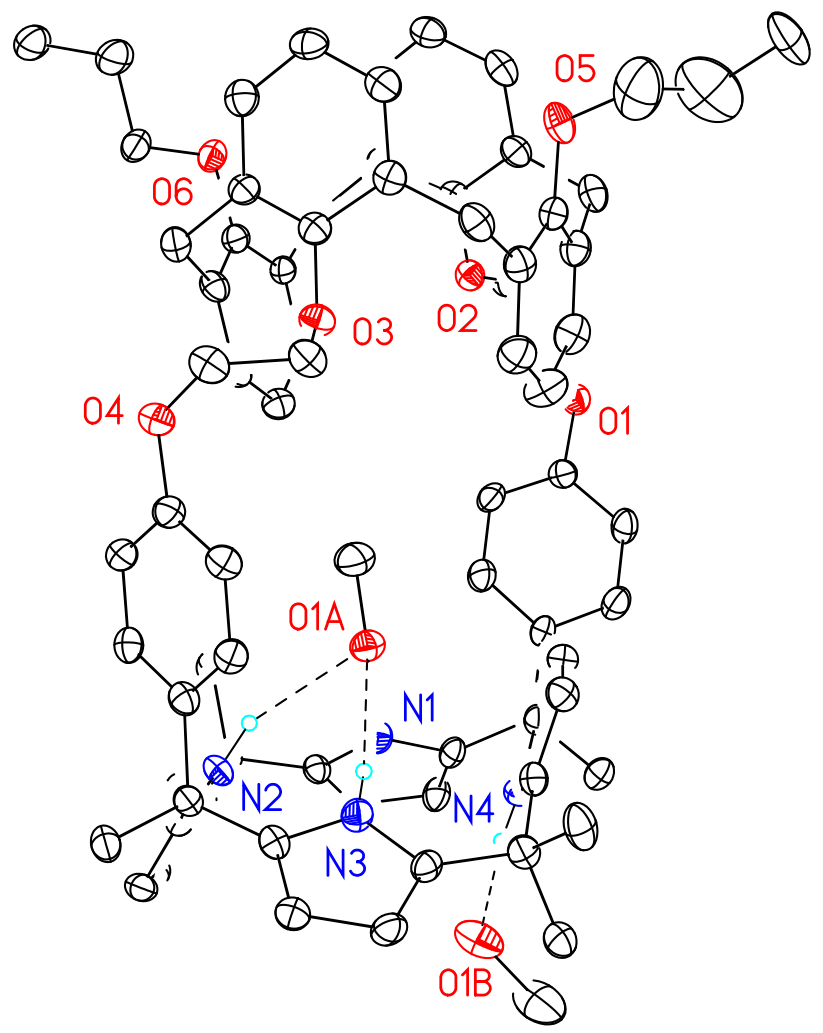


Figure A.7 Unit cell packing diagram for $\mathbf{4 . 2} \cdot\left(\mathrm{CH}_{3} \mathrm{OH}\right)_{2}$. The view is approximately down the a axis.

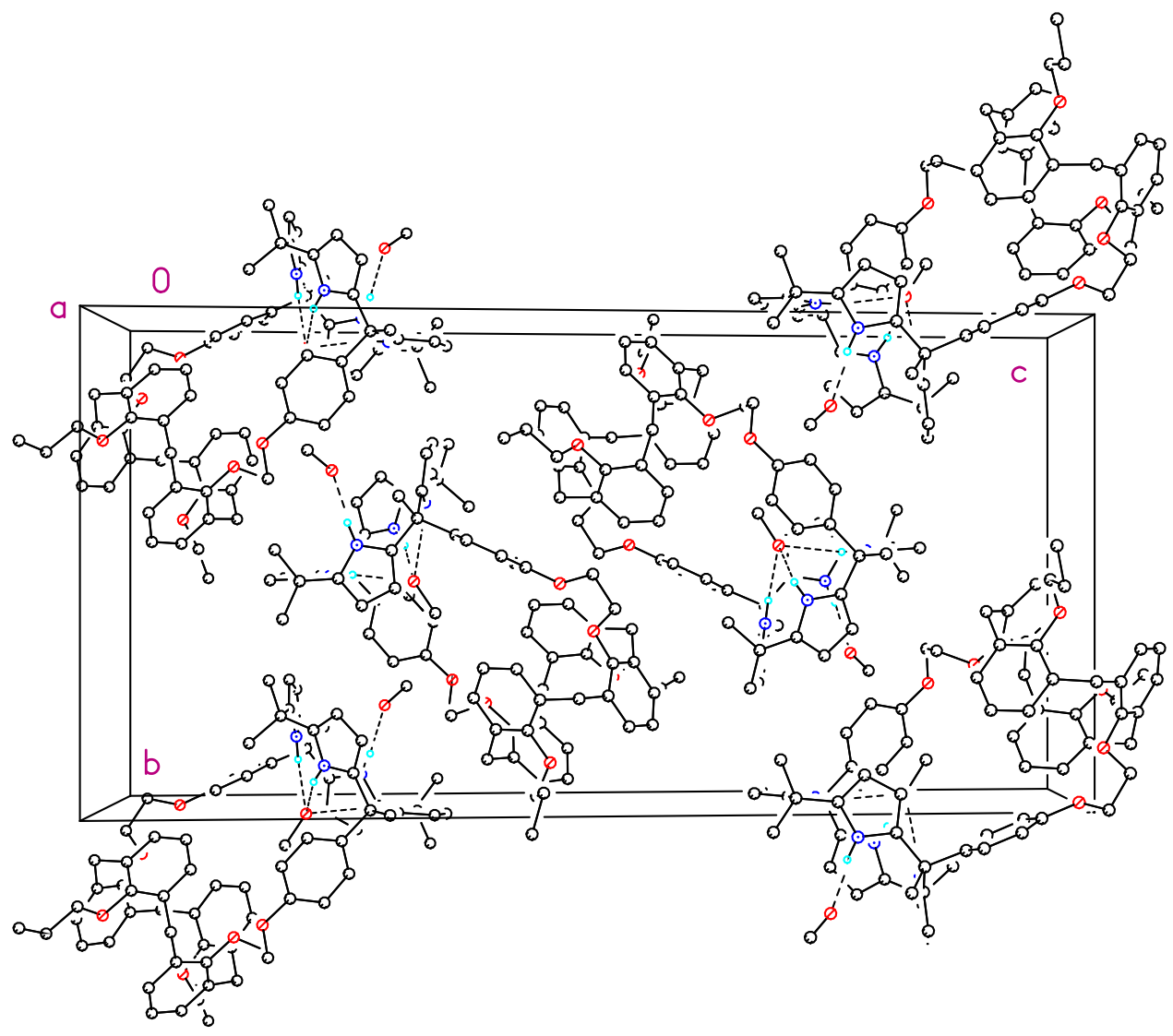


Table A.5 Crystal data and structure refinement for $4.2 \cdot \mathrm{CH}_{3} \mathrm{OH}$.

Empirical formula

Formula weight

Temperature

Wavelength

Crystal system

Space group

Unit cell dimensions

Volume

$\mathrm{Z}$

Density (calculated)

Absorption coefficient

$\mathrm{F}(000)$

Crystal size

Theta range for data collection

Index ranges

Reflections collected

Independent reflections

Completeness to theta $=24.86^{\circ}$

Absorption correction

Refinement method

Data / restraints / parameters

Goodness-of-fit on $\mathrm{F}^{2}$

Final $\mathrm{R}$ indices [I>2sigma(I)]

$\mathrm{R}$ indices (all data)

Extinction coefficient

Largest diff. peak and hole
C78 H88 N4 O8

1209.52

153(2) K

$0.71070 \AA$

Monoclinic

$\mathrm{P} 21 / \mathrm{n}$

$$
\begin{array}{ll}
\mathrm{a}=10.5877(5) \AA & \alpha=90^{\circ} . \\
\mathrm{b}=17.6496(8) \AA & \beta=95.510(2)^{\circ} . \\
\mathrm{c}=35.4397(13) \AA & \gamma=90^{\circ} .
\end{array}
$$$$
6592.0(5)^{3}
$$

4

$1.219 \mathrm{Mg} / \mathrm{m}^{3}$

$0.078 \mathrm{~mm}^{-1}$

2592

$0.35 \times 0.18 \times 0.10 \mathrm{~mm}$

2.95 to $24.86^{\circ}$.

$-12<=\mathrm{h}<=12,-20<=\mathrm{k}<=17,-41<=1<=41$

18906

$11035[\mathrm{R}(\mathrm{int})=0.1038]$

$96.4 \%$

None

Full-matrix-block least-squares on $\mathrm{F}^{2}$ 11035 / 0 / 814

1.000

$\mathrm{R} 1=0.0696, \mathrm{wR} 2=0.1359$

$\mathrm{R} 1=0.2145, \mathrm{wR} 2=0.1782$

$1.9(2) \times 10^{-6}$

0.488 and -0.365 e. $\AA^{-3}$ 
X-ray Experimental for $4.2 \cdot \mathrm{CsF} \cdot \mathrm{H}_{2} \mathrm{O} \cdot \mathrm{CH}_{3} \mathrm{OH}$ : Crystals grew as colorless plates by slow evaporation from methanol and water. The data crystal was cut from a larger crystal and had the following approximate dimensions: $0.20 \times 0.18 \times 0.07 \mathrm{~mm}$. The data were collected on a Nonius Kappa CCD diffractometer using a graphite monochromator with $\mathrm{MoK} \alpha$ radiation $(\lambda=0.71073 \AA)$. A total of 295 frames of data were collected using $\omega$-scans with a scan range of $1.8^{\circ}$ and a counting time of 198 seconds per frame. The data were collected at $153 \mathrm{~K}$ using an Oxford Cryostream low temperature device. Details of crystal data, data collection and structure refinement are listed in Table A.6. Data reduction was performed using DENZO-SMN. The structure was solved by direct methods using SIR97 and refined by full-matrix least-squares on $\mathrm{F}^{2}$ with anisotropic displacement parameters for the non-H atoms using SHELXL-97. The hydrogen atoms on carbon were calculated in ideal positions with isotropic displacement parameters set to $1.2 \times$ Ueq of the attached atom $(1.5 \times$ Ueq for methyl hydrogen atoms $)$. The function, $\Sigma \mathrm{w}\left(\left|\mathrm{F}_{\mathrm{O}}\right|^{2}-\left|\mathrm{F}_{\mathrm{c}}\right|^{2}\right)^{2}$, was minimized, where $\mathrm{w}=1 /\left[\left(\sigma\left(\mathrm{F}_{\mathrm{o}}\right)\right)^{2}+(0.0333 * \mathrm{P})^{2}+\right.$ (4.8859*P)] and $\mathrm{P}=\left(\left|\mathrm{F}_{\mathrm{O}}\right|^{2}+2\left|\mathrm{~F}_{\mathrm{c}}\right|^{2}\right) / 3 . \mathrm{R}_{\mathrm{W}}\left(\mathrm{F}^{2}\right)$ refined to 0.0973 , with $\mathrm{R}(\mathrm{F})$ equal to 0.0418 and a goodness of fit, $S,=1.02$. Definitions used for calculating $R(F), R_{W}\left(F^{2}\right)$ and the goodness of fit, S, are given below. The data were corrected for secondary extinction effects. The correction takes the form: $\mathrm{F}_{\mathrm{corr}}=\mathrm{kF}_{\mathrm{c}} /\left[1+\left(4.4(8) \times 10^{-7}\right)^{*} \mathrm{~F}_{\mathrm{c}}^{2} \lambda^{3 /(\sin 2 \theta)}\right]^{0.25}$ where $\mathrm{k}$ is the overall scale factor. Neutral atom scattering factors and values used to calculate the linear absorption coefficient are from the International Tables for X-ray Crystallography (1992). All figures were generated using SHELXTL/PC. 
Figure A.8 View illustrating the H-bonding interaction between the anions and the calixpyrrole $\mathrm{Cs}^{+}$complex in 4.2. Displacement ellipsoids are scaled to the $50 \%$ probability level. Most hydrogen atoms have been removed for clarity.

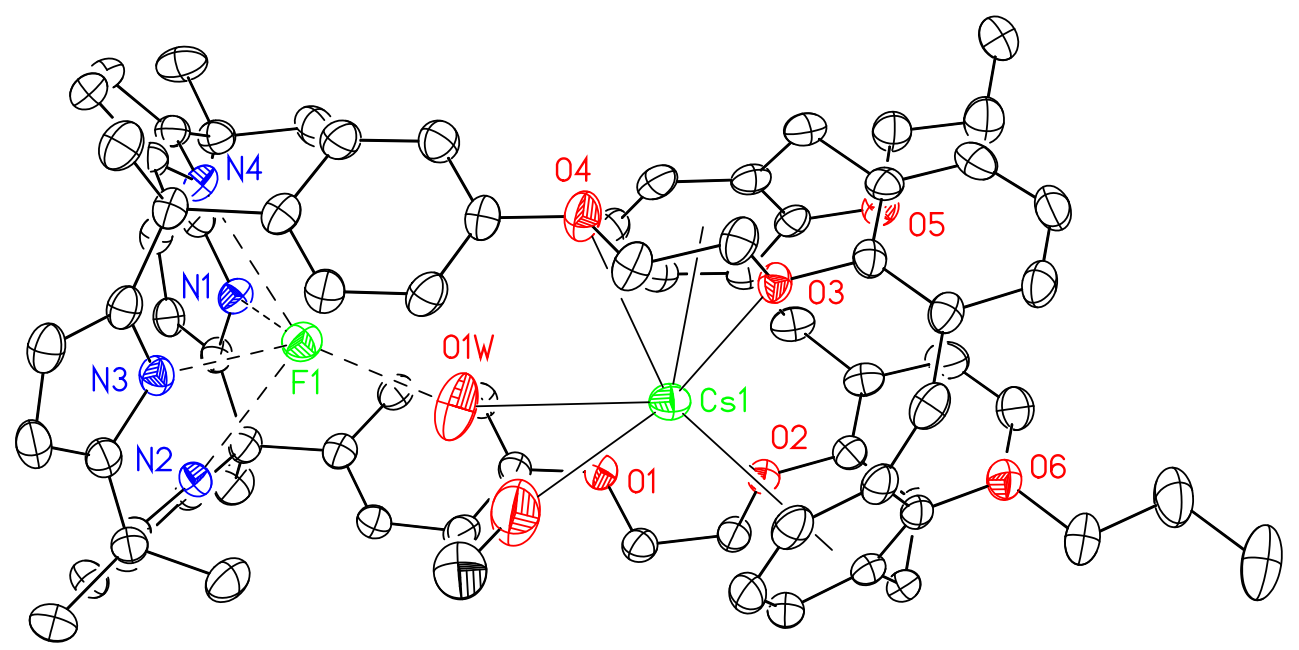


Table A.6 Crystal data and structure refinement for $4.2 \cdot \mathrm{CsF} \cdot \mathrm{H}_{2} \mathrm{O} \cdot \mathrm{CH}_{3} \mathrm{OH}$.

Empirical formula

Formula weight

Temperature

Wavelength

Crystal system

Space group

Unit cell dimensions

Volume

$\mathrm{Z}$

Density (calculated)

Absorption coefficient

$\mathrm{F}(000)$

Crystal size

Theta range for data collection

Index ranges

Reflections collected

Independent reflections

Completeness to theta $=27.46^{\circ}$

Absorption correction

Refinement method

Data / restraints / parameters

Goodness-of-fit on $\mathrm{F}^{2}$

Final $\mathrm{R}$ indices [I $>2 \operatorname{sigma}(\mathrm{I})]$

$\mathrm{R}$ indices (all data)

Extinction coefficient

Largest diff. peak and hole
C77 H86 Cs F N4 O8

1347.41

153(2) K

$0.71073 \AA$

Monoclinic

$\mathrm{P} 21 / \mathrm{c}$

$$
\begin{array}{ll}
\mathrm{a}=13.4993(2) \AA & \alpha=90.000(5)^{\circ} . \\
\mathrm{b}=26.0185(7) \AA & \beta=100.663(2)^{\circ} . \\
\mathrm{c}=19.6409(5) \AA & \gamma=90.000(5)^{\circ} .
\end{array}
$$$$
\text { 6779.4(3) } \AA^{3}
$$

4

$1.320 \mathrm{Mg} / \mathrm{m}^{3}$

$0.608 \mathrm{~mm}^{-1}$

2816

$0.20 \times 0.18 \times 0.07 \mathrm{~mm}$

1.72 to $27.46^{\circ}$.

$-17<=\mathrm{h}<=17,-33<=\mathrm{k}<=33,-25<=1<=25$

27746

$15419[\mathrm{R}(\mathrm{int})=0.0317]$

$99.5 \%$

None

Full-matrix-block least-squares on $\mathrm{F}^{2}$ 15419 / 0 / 829

1.019

$\mathrm{R} 1=0.0418, \mathrm{wR} 2=0.0839$

$\mathrm{R} 1=0.0803, \mathrm{wR} 2=0.0973$

$4.4(8) \times 10^{-7}$

0.877 and -0.596 e. $\AA^{-3}$ 
Crystallographic summary for $4.2_{2} \bullet(\mathrm{CsCl})_{2} \bullet \mathrm{CH}_{3} \mathrm{OH} \cdot \mathrm{H}_{2} \mathrm{O}$ : Long, colorless lathes were grown by slow cooling from a mixture of chloroform with methanol, triclinic, P-1 (No. 2), $Z=2$ in a cell of dimensions: $a=18.449(2), b=21.316(3), c=22.059(3) \AA, \alpha$ $=61.593(3), \beta=78.297(3), \gamma=74.265(3)^{\circ}, \mathrm{V}=7316.4(16) \AA^{3}, \rho_{\text {calc }}=1.26 \mathrm{~g}-\mathrm{cm}^{-3}$, $\mu=0.600 \mathrm{~mm}^{-1}, \quad \mathrm{~F}(000)=2894$. A total of 44962 reflections were measured, 25388 unique $\left(\mathrm{R}_{\mathrm{int}}=0.076\right)$, on a Rigaku AFC-12 with a Saturn $724+$ CCD using graphite monochromatized Mo $\mathrm{K} \alpha$ radiation $(\lambda=0.71073 \AA)$ at $-173{ }^{\circ} \mathrm{C}$. The structure was refined on $\mathrm{F}^{2}$ to an $\mathrm{R}_{\mathrm{w}}=0.206$, with a conventional $\mathrm{R}=0.105$ (11738 reflections with Fo $>4[\sigma(\mathrm{Fo})])$, and a goodness of fit $=1.41$ for 1681 refined parameters.

Crystallographic summary for $4.2 \cdot \mathrm{CsNO}_{3}$ : Colorless plates were grown by slow evaporation from a mixture of chloroform with methanol. Orthorhombic, Pbca (No. $61), Z=8$ in a cell of dimensions: $a=35 / 413(3), b=22,233(3), V=15632(5) \AA^{3}, \rho_{\text {calc }}=$

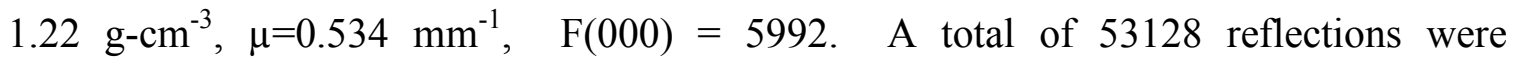
measured, 12717 unique $\left(\mathrm{R}_{\mathrm{int}}=0.23\right)$, on a Rigaku SCX-Mini with Mercury CCD using graphite monochromatized Mo K $\alpha$ radiation $(\lambda=0.71073 \AA)$ at $-40{ }^{\circ} \mathrm{C}$. The structure was refined on $\mathrm{F} 2$ to an $\mathrm{R}_{\mathrm{w}}=0.194$, with a conventional $\mathrm{R}=0.103$ (3417 reflections with Fo $>4[\sigma(\mathrm{Fo})])$, and a goodness of fit $=1.13$ for 835 refined parameters.

X-ray Experimental for 5.3 $\mathbf{C H}_{3} \mathbf{C N}$ : Crystals grew as colorless prisms by vapor diffusion of methanol into an acetonitrile solution of receptor 5.3. The data crystal had approximate dimensions; $0.30 \times 0.08 \times 0.04 \mathrm{~mm}$. The data were collected on a Rigaku AFC12 diffractometer with a Saturn 724+ CCD using a graphite monochromator with MoK $\alpha$ radiation $(\lambda=0.71073 \AA$ ). A total of 2006 frames of data were collected using $\omega$ scans with a scan range of $0.5^{\circ}$ and a counting time of 22 seconds per frame. The data were collected at $100 \mathrm{~K}$ using a Rigaku XStream low temperature device. Details of crystal data, data collection and structure refinement are listed in Table A.7. Data reduction was performed using the Rigaku Americas Corporation's Crystal Clear version 1.40. The structure was solved by direct methods using SIR97 and refined by full-matrix 
least-squares on $\mathrm{F}^{2}$ with anisotropic displacement parameters for the non- $\mathrm{H}$ atoms using SHELXL-97. The hydrogen atoms on carbon were calculated in ideal positions with isotropic displacement parameters set to $1.2 \times$ Ueq of the attached atom $(1.5 \times$ Ueq for methyl hydrogen atoms). The function, $\Sigma \mathrm{w}\left(\left|\mathrm{F}_{\mathrm{o}}\right|^{2}-\left|\mathrm{F}_{\mathrm{c}}\right|^{2}\right)^{2}$, was minimized, where $\mathrm{w}=$ $1 /\left[\left(\sigma\left(\mathrm{F}_{\mathrm{o}}\right)\right)^{2}+(0.043 * \mathrm{P})^{2}+(2.45 * \mathrm{P})\right]$ and $\mathrm{P}=\left(\left|\mathrm{F}_{\mathrm{o}}\right|^{2}+2\left|\mathrm{~F}_{\mathrm{c}}\right|^{2}\right) / 3 . \quad \mathrm{R}_{\mathrm{w}}\left(\mathrm{F}^{2}\right)$ refined to 0.174, with $\mathrm{R}(\mathrm{F})$ equal to 0.0867 and a goodness of fit, $\mathrm{S},=1.10$. Definitions used for calculating $\mathrm{R}(\mathrm{F}), \mathrm{R}_{\mathrm{W}}\left(\mathrm{F}^{2}\right)$ and the goodness of fit, $\mathrm{S}$, are given below. The data were corrected for secondary extinction. Neutral atom scattering factors and values used to calculate the linear absorption coefficient are from the International Tables for X-ray Crystallography (1992). All figures were generated using SHELXTL/PC. Tables of positional and thermal parameters, bond lengths and angles, torsion angles and figures are found elsewhere.

Figure A.9 View of 5.3. $\mathrm{CH}_{3} \mathrm{CN}$ showing a partial atom labeling scheme. Displacement ellipsoids are scaled to the $50 \%$ probability level.

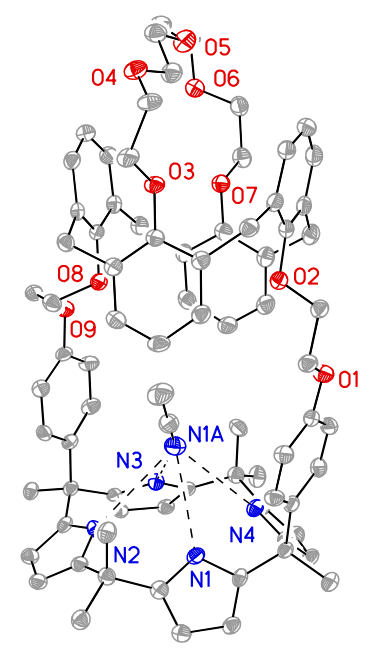


Table A.7 Crystal data and structure refinement for $\mathbf{5 . 3} \cdot \mathrm{CH}_{3} \mathrm{CN}$.

Empirical formula

Formula weight

Temperature

Wavelength

Crystal system

Space group

Unit cell dimensions

Volume

Z

Density (calculated)

Absorption coefficient

$\mathrm{F}(000)$

Crystal size

Theta range for data collection

Index ranges

Reflections collected

Independent reflections

Completeness to theta $=27.48^{\circ}$

Absorption correction

Refinement method

Data / restraints / parameters

Goodness-of-fit on $\mathrm{F}^{2}$

Final $\mathrm{R}$ indices [I $>2 \operatorname{sigma}(\mathrm{I})]$

$\mathrm{R}$ indices (all data)

Extinction coefficient

Largest diff. peak and hole
C84 H91 N7 O9

1342.64

120(2) K

$0.71073 \AA$

Triclinic

P-1

$$
\begin{array}{ll}
\mathrm{a}=10.5466(12) \AA & \alpha=85.338(3)^{\circ} . \\
\mathrm{b}=18.260(2) \AA & \beta=76.630(3)^{\circ} . \\
\mathrm{c}=19.653(2) \AA & \gamma=77.250(4)^{\circ} .
\end{array}
$$$$
\text { 3589.6(7) } \AA^{3}
$$

2

\section{$1.242 \mathrm{Mg} / \mathrm{m}^{3}$}

$0.081 \mathrm{~mm}^{-1}$

1432

$0.30 \times 0.08 \times 0.04 \mathrm{~mm}$

3.03 to $27.48^{\circ}$.

$-13<=\mathrm{h}<=13,-23<=\mathrm{k}<=23,-25<=\mathrm{l}<=25$

79139

$16355[\mathrm{R}(\mathrm{int})=0.1064]$

$99.3 \%$

None

Full-matrix least-squares on $\mathrm{F}^{2}$

16355 / 0 / 911

1.102

$\mathrm{R} 1=0.0867, \mathrm{wR} 2=0.1522$

$\mathrm{R} 1=0.1424, \mathrm{wR} 2=0.1743$

$1.8(5) \times 10^{-6}$

0.338 and -0.323 e. $\AA^{-3}$ 
X-ray Experimental for $5.3 \cdot \mathrm{KF} \bullet\left(\mathrm{CH}_{3} \mathrm{OH}\right)$ : Crystals grew as colorless prism by slow evaporation from a mixture of chloroform and methanol. The data were collected on a Rigaku R-Axis Spider diffractometer with an image plate detector using a graphite monochromator with $\mathrm{CuK} \alpha$ radiation $(\lambda=1.5418 \AA)$. A total of 144 images of data were collected using $\omega$-scans with a scan range of $5^{\circ}$ and a counting time of 360 seconds per image. The data were collected at $100 \mathrm{~K}$ using a Rigaku XStream low temperature device. Details of crystal data, data collection and structure refinement are listed in Table A.8. Data reduction was performed using the Rigaku Americas Corporation's Crystal Clear version 1.40. The structure was solved by direct methods using SIR97 and refined by full-matrix least-squares on $\mathrm{F}^{2}$ with anisotropic displacement parameters for the non- $\mathrm{H}$ atoms using SHELXL-97. The hydrogen atoms were calculated in ideal positions with isotropic displacement parameters set to $1.2 \times$ Ueq of the attached atom $(1.5 \times$ Ueq for methyl hydrogen atoms). The function, $\Sigma \mathrm{w}\left(\left|\mathrm{F}_{\mathrm{o}}\right|^{2}-\left|\mathrm{F}_{\mathrm{c}}\right|^{2}\right)^{2}$, was minimized, where $\mathrm{w}=$ $1 /\left[\left(\sigma\left(\mathrm{F}_{\mathrm{o}}\right)\right)^{2}+(0.0654 * \mathrm{P})^{2}+(15.2478 * \mathrm{P})\right]$ and $\mathrm{P}=\left(\left|\mathrm{F}_{\mathrm{o}}\right|^{2}+2\left|\mathrm{~F}_{\mathrm{c}}\right|^{2}\right) / 3 . \quad \mathrm{R}_{\mathrm{w}}\left(\mathrm{F}^{2}\right)$ refined to 0.278 , with $\mathrm{R}(\mathrm{F})$ equal to 0.140 and a goodness of fit, $\mathrm{S},=1.20$. Definitions used for calculating $\mathrm{R}(\mathrm{F}), \mathrm{R}_{\mathrm{w}}\left(\mathrm{F}^{2}\right)$ and the goodness of fit, $\mathrm{S}$, are given below. The data were checked for secondary extinction effects but no correction was necessary. Neutral atom scattering factors and values used to calculate the linear absorption coefficient are from the International Tables for X-ray Crystallography (1992). All figures were generated using SHELXTL/PC. Tables of positional and thermal parameters, bond lengths and angles, torsion angles and figures are found elsewhere. 
Figure A.10 View of $\mathbf{5 . 3} \cdot \mathbf{K F} \bullet\left(\mathbf{C H}_{3} \mathbf{O H}\right)$ showing the atom labeling scheme. Displacement ellipsoids are scaled to the $30 \%$ probability level. The hydrogen atoms have been omitted for clarity.

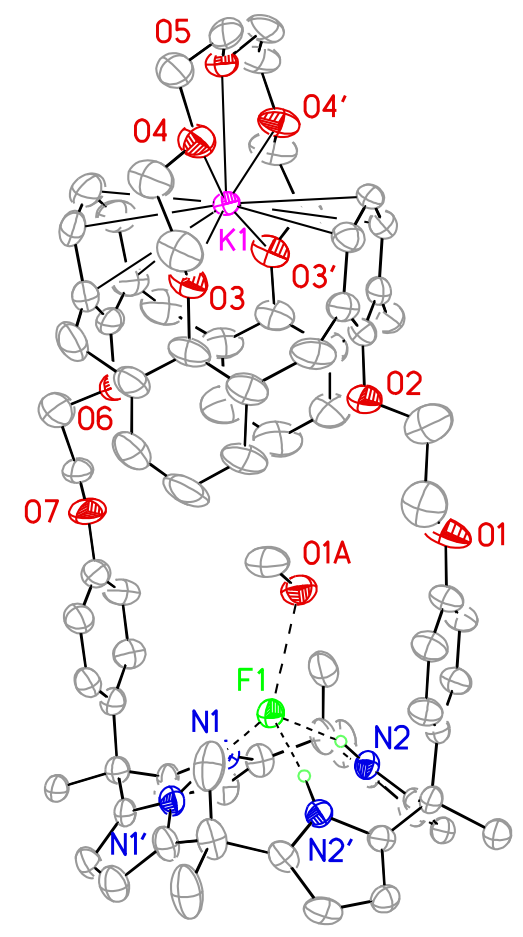


Table A.8 Crystal data and structure refinement for $\mathbf{5 . 3} \cdot \mathrm{KF} \bullet\left(\mathrm{CH}_{3} \mathrm{OH}\right)_{3}$.

Empirical formula

Formula weight

Temperature

Wavelength

Crystal system

Space group

Unit cell dimensions

Volume

Z

Density (calculated)

Absorption coefficient

$\mathrm{F}(000)$

Theta range for data collection

Index ranges

Reflections collected

Independent reflections

Completeness to theta $=70.00^{\circ}$

Absorption correction

Max. and min. transmission

Refinement method

Data / restraints / parameters

Goodness-of-fit on $\mathrm{F}^{2}$

Final $\mathrm{R}$ indices [I $>2 \operatorname{sigma}(\mathrm{I})]$

$\mathrm{R}$ indices (all data)

Largest diff. peak and hole
C81 H94 F K N4 O12

1373.70

100(2) K

$1.54180 \AA$

Orthorhombic

Pnma

$$
\begin{array}{ll}
\mathrm{a}=36.554(4) \AA & \alpha=90^{\circ} . \\
\mathrm{b}=15.5755(8) \AA & \beta=90^{\circ} . \\
\mathrm{c}=12.4572(6) \AA & \gamma=90^{\circ} .
\end{array}
$$$$
\text { 7092.5(9) } \AA^{3}
$$

4

$1.286 \mathrm{Mg} / \mathrm{m}^{3}$

$1.217 \mathrm{~mm}^{-1}$

2928

6.65 to $70.00^{\circ}$.

$-43<=\mathrm{h}<=44,-18<=\mathrm{k}<=16,-14<=\mathrm{l}<=15$

62427

$6945[\mathrm{R}(\mathrm{int})=0.0807]$

$99.5 \%$

Semi-empirical from equivalents

1.00 and 0.714

Full-matrix least-squares on $\mathrm{F}^{2}$

6945 / 12 / 472

1.196

$$
\begin{aligned}
\mathrm{R} 1= & 0.1404, \mathrm{wR} 2=0.2471 \\
\mathrm{R} 1= & 0.2000, \mathrm{wR} 2=0.2783 \\
& 0.637 \text { and }-0.416 \mathrm{e} . \AA^{-3}
\end{aligned}
$$


$\mathrm{X}$-ray Experimental for $\mathbf{5 . 3} \cdot \mathrm{KNO}_{3} \cdot\left(\mathrm{C}_{5} \mathrm{H}_{12}\right)_{1 / 2} \cdot \mathrm{CH}_{3} \mathrm{Cl} \cdot \mathrm{H}_{2} \mathrm{O}$ : Crystals grew as yellow prisms by vapor diffusion of pentane into a chloroform solution of the complex. The data were collected on a Rigaku AFC12 diffractometer with a Saturn 724+ CCD using a graphite monochromator with $\mathrm{MoK} \alpha$ radiation $(\lambda=0.71073 \AA)$. A total of 512 frames of data were collected using $\omega$-scans with a scan range of $0.5^{\circ}$ and a counting time of 60 seconds per frame. The data were collected at $100 \mathrm{~K}$ using a Rigaku XStream low temperature device. Details of crystal data, data collection and structure refinement are listed in Table A.9. Data reduction were performed using the Rigaku Americas Corporation's Crystal Clear version 1.40. The structure was solved by direct methods using SIR97 and refined by full-matrix least-squares on $\mathrm{F}^{2}$ with anisotropic displacement parameters for the non-H atoms using SHELXL-97. The hydrogen atoms were calculated in ideal positions with isotropic displacement parameters set to $1.2 \times$ Ueq of the attached atom $\left(1.5 \times\right.$ Ueq for methyl hydrogen atoms). The function, $\Sigma w\left(\left|F_{0}\right|^{2}-\left|F_{c}\right|^{2}\right)^{2}$, was minimized, where $\mathrm{w}=1 /\left[\left(\sigma\left(\mathrm{F}_{\mathrm{o}}\right)\right)^{2}+\left(0.06^{*} \mathrm{P}\right)^{2}\right]$ and $\mathrm{P}=\left(\left|\mathrm{F}_{\mathrm{o}}\right|^{2}+2\left|\mathrm{~F}_{\mathrm{c}}\right|^{2}\right) / 3 . \mathrm{R}_{\mathrm{w}}\left(\mathrm{F}^{2}\right)$ refined to 0.362 , with $\mathrm{R}(\mathrm{F})$ equal to 0.175 and a goodness of fit, $\mathrm{S},=1.70$. Definitions used for calculating $R(F), R_{w}\left(F^{2}\right)$ and the goodness of fit, $S$, are given below. The data were checked for secondary extinction effects but no correction was necessary. Neutral atom scattering factors and values used to calculate the linear absorption coefficient are from the International Tables for X-ray Crystallography (1992). All figures were generated using SHELXTL/PC. Tables of positional and thermal parameters, bond lengths and angles, torsion angles and figures are found elsewhere. 
Figure A.11 View of 5.3• $\mathrm{K}^{+}$showing the atom labeling scheme. Displacement ellipsoids are scaled to the $50 \%$ probability level.

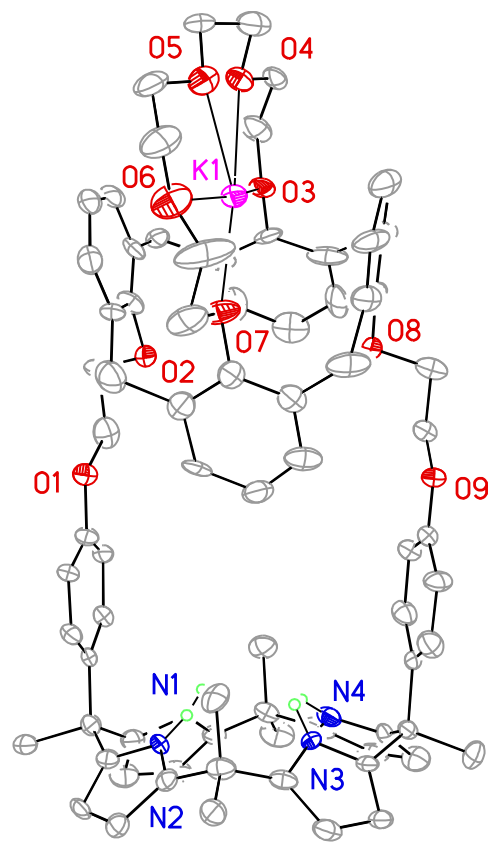


Table A.9 Crystal data and structure refinement for $\mathbf{5 . 3} \cdot \mathrm{KNO}_{3} \cdot\left(\mathrm{C}_{5} \mathrm{H}_{12}\right)_{1 / 2} \bullet \mathrm{CH}_{3} \mathrm{Cl} \cdot \mathrm{H}_{2} \mathrm{O}$.

Empirical formula

Formula weight

Temperature

Wavelength

Crystal system

Space group

Unit cell dimensions

Volume

Z

Density (calculated)

Absorption coefficient

$\mathrm{F}(000)$

Theta range for data collection

Index ranges

Reflections collected

Independent reflections

Completeness to theta $=25.00^{\circ}$

Refinement method

Data / restraints / parameters

Goodness-of-fit on $\mathrm{F}^{2}$

Final $\mathrm{R}$ indices [I $>2 \operatorname{sigma}(\mathrm{I})]$

$\mathrm{R}$ indices (all data)

Largest diff. peak and hole
C81.50 H91 Cl3 K N5 O13

1494.04

100(2) K

$0.71074 \AA$

Monoclinic

$\mathrm{P} 21 / \mathrm{c}$

$$
\begin{aligned}
& \mathrm{a}=15.839(2) \AA \quad \alpha=90^{\circ} . \\
& \mathrm{b}=14.841(2) \AA \quad \beta=93.290(4)^{\circ} \text {. } \\
& \mathrm{c}=35.024(4) \AA \quad \gamma=90^{\circ} \text {. }
\end{aligned}
$$

8219.4(18) $\AA^{3}$

4

$1.207 \mathrm{Mg} / \mathrm{m}^{3}$

$0.224 \mathrm{~mm}^{-1}$

3156

3.01 to $25.00^{\circ}$.

$-18<=\mathrm{h}<=18,-17<=\mathrm{k}<=17,-41<=\mathrm{l}<=39$

36435

13590 [R(int) $=0.1347]$

$93.9 \%$

Full-matrix-block least-squares on $\mathrm{F}^{2}$

13590 / 162 / 987

1.699

$\mathrm{R} 1=0.1751, \mathrm{wR} 2=0.3201$

$\mathrm{R} 1=0.3493, \mathrm{wR} 2=0.3622$

0.661 and -0.422 e. $\AA^{-3}$ 
X-ray Experimental for $5.3 \cdot \mathrm{CsF} \bullet\left(\mathrm{CH}_{3} \mathrm{OH}\right)_{2} \bullet\left(\mathrm{CHCl}_{3}\right)_{2}$ : Crystals grew as colorless needles by slow evaporation from chloroform and methanol. The data crystal was cut from a larger crystal and had approximate dimensions; $0.30 \times 0.04 \times 0.02 \mathrm{~mm}$. The data were collected on a Rigaku AFC12 diffractometer with a Saturn 724+ CCD using a graphite monochromator with $\operatorname{MoK} \alpha$ radiation $(\lambda=0.71073 \AA)$. A total of 650 frames of data were collected using $\omega$-scans with a scan range of $0.5^{\circ}$ and a counting time of 50 seconds per frame. The data were collected at $100 \mathrm{~K}$ using a Rigaku XStream low temperature device. Details of crystal data, data collection and structure refinement are listed in Table A.10. Data reduction was performed using the Rigaku Americas Corporation's Crystal Clear version 1.40. The structure was solved by direct methods using SIR97 and refined by full-matrix least-squares on $\mathrm{F}^{2}$ with anisotropic displacement parameters for the non-H atoms using SHELXL-97. The hydrogen atoms on carbon were calculated in ideal positions with isotropic displacement parameters set to $1.2 \times$ Ueq of the attached atom $\left(1.5 \times\right.$ Ueq for methyl hydrogen atoms). The function, $\Sigma \mathrm{w}\left(\left|\mathrm{F}_{\mathrm{o}}\right|^{2}-\left|\mathrm{F}_{\mathrm{c}}\right|^{2}\right)^{2}$, was minimized, where $\mathrm{w}=1 /\left[\left(\sigma\left(\mathrm{F}_{\mathrm{o}}\right)\right)^{2}+(0.0524 * \mathrm{P})^{2}+(1.4865 * \mathrm{P})\right]$ and $\mathrm{P}=\left(\left|\mathrm{F}_{\mathrm{o}}\right|^{2}+\right.$ $\left.2\left|\mathrm{~F}_{\mathrm{c}}\right|^{2}\right) / 3 . \quad \mathrm{R}_{\mathrm{w}}\left(\mathrm{F}^{2}\right)$ refined to 0.193 , with $\mathrm{R}(\mathrm{F})$ equal to 0.0917 and a goodness of fit, $\mathrm{S},=$ 1.26. Definitions used for calculating $\mathrm{R}(\mathrm{F}), \mathrm{R}_{\mathrm{w}}\left(\mathrm{F}^{2}\right)$ and the goodness of fit, $\mathrm{S}$, are given below. The data were checked for secondary extinction effects but no correction was necessary. Neutral atom scattering factors and values used to calculate the linear absorption coefficient are from the International Tables for X-ray Crystallography (1992). All figures were generated using SHELXTL/PC. Tables of positional and thermal parameters, bond lengths and angles, torsion angles and figures are found elsewhere. 
Figure A.12 View of $\mathbf{5 . 3} \cdot \mathbf{C s F} \bullet\left(\mathrm{CH}_{3} \mathrm{OH}\right)_{2}$ showing the atom labeling scheme. Displacement ellipsoids are scaled to the $50 \%$ probability level. The hydrogen atoms have been removed for clarity.

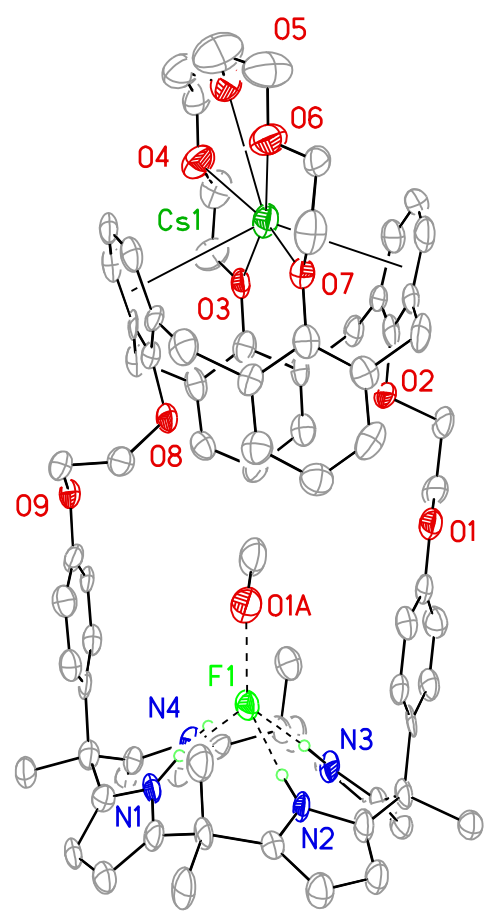


Table A.10 Crystal data and structure refinement for $\mathbf{5 . 3} \cdot \mathrm{CsF} \bullet\left(\mathrm{CH}_{3} \mathrm{OH}\right)_{2} \bullet\left(\mathrm{CHCl}_{3}\right)_{2}$.

Empirical formula

Formula weight

Temperature

Wavelength

Crystal system

Space group

Unit cell dimensions

Volume

Z

Density (calculated)

Absorption coefficient

$\mathrm{F}(000)$

Crystal size

Theta range for data collection

Index ranges

Reflections collected

Independent reflections

Completeness to theta $=25.00^{\circ}$

Absorption correction

Max. and min. transmission

Refinement method

Data / restraints / parameters

Goodness-of-fit on $\mathrm{F}^{2}$

Final $\mathrm{R}$ indices [I $>2 \operatorname{sigma}(\mathrm{I})]$

$\mathrm{R}$ indices (all data)

Largest diff. peak and hole
C82 H92 Cl6 Cs F N4 O11

1674.21

100(2) K

$0.71069 \AA$

Orthorhombic

Pbca

$$
\begin{array}{ll}
\mathrm{a}=20.6930(13) \AA & \alpha=90^{\circ} . \\
\mathrm{b}=26.3422(16) \AA & \beta=90^{\circ} . \\
\mathrm{c}=28.8106(16) \AA & \gamma=90^{\circ} .
\end{array}
$$$$
\text { 15704.6(16) } \AA^{3}
$$

8

$1.416 \mathrm{Mg} / \mathrm{m}^{3}$

$0.740 \mathrm{~mm}^{-1}$

6928

$0.30 \times 0.04 \times 0.02 \mathrm{~mm}$

2.99 to $25.00^{\circ}$.

$-24<=\mathrm{h}<=24,-31<=\mathrm{k}<=31,-34<=\mathrm{l}<=26$

94734

$13811[\mathrm{R}(\mathrm{int})=0.1549]$

$99.8 \%$

Semi-empirical from equivalents

1.00 and 0.61

Full-matrix least-squares on $\mathrm{F}^{2}$

$13811 / 0 / 863$

1.255

$\mathrm{R} 1=0.0917, \mathrm{wR} 2=0.1750$

$\mathrm{R} 1=0.1695, \mathrm{wR} 2=0.1926$

1.133 and -0.872 e. $\AA^{-3}$ 250 
X-ray Experimental for $5.3 \cdot \mathrm{CsCl} \cdot \mathrm{CHCl}_{3} \bullet\left(\mathrm{CH}_{3} \mathrm{CH}_{2} \mathrm{OH}\right)_{1 / 2}^{\bullet}\left(\mathrm{H}_{2} \mathrm{O}\right)_{1 \frac{1}{2}:}:$ Crystals grew as colorless prisms by slow evaporation from a mixture of chloroform and ethanol. The data were collected on a Rigaku AFC12 diffractometer with a Saturn 724+ CCD using a graphite monochromator with MoK $\alpha$ radiation $(\lambda=0.71073 \AA)$. A total of 371 frames of data were collected using $\omega$-scans with a scan range of $1.25^{\circ}$ and a counting time of 75 seconds per frame. The data were collected at $100 \mathrm{~K}$ using a Rigaku XStream low temperature device. Details of crystal data, data collection and structure refinement are listed in Table A.11. Data reduction were performed using the Rigaku Americas Corporation's Crystal Clear version 1.40. The structure was solved by direct methods using SIR97 and refined by full-matrix least-squares on $\mathrm{F}^{2}$ with anisotropic displacement parameters for the non-H atoms using SHELXL-97. The hydrogen atoms on carbon were calculated in ideal positions with isotropic displacement parameters set to $1.2 \times$ Ueq of the attached atom $(1.5 \times$ Ueq for methyl hydrogen atoms $)$.

The crystal was found to be twinned. The twin law was determined using ROTAX to be $(1,0,0 ; 0,-1,0 ; 0,0,-1)$ about 100 direct axis direction. The twin fraction refined to 0.507(2). ROTAX was used as incorporated in WinGX.

There were also some disordered solvent and solvent regions that did not appear to be fully occupied. One molecule of chloroform was disordered by rotation about a Cl$\mathrm{C}$ bond. The disorder was modeled by assigning the variable $\mathrm{x}$ to the site occupancy factors for $\mathrm{Cl} 2 \mathrm{a}$ and $\mathrm{Cl3a}$ and (1-x) to the site occupancy factors for $\mathrm{Cl} 4 \mathrm{a}$ and $\mathrm{Cl}$ a $\mathrm{a}$. A common isotropic displacement parameter was refined for the four chlorine atoms. The geometry of the group was restrained to be equal throughout the refinement. In this way, the site occupancy for the major component consisting of atoms $\mathrm{Cl} 2 \mathrm{a}$ and $\mathrm{Cl} 3 \mathrm{a}$ refined to $62(2) \%$.

A molecule of water, O1w, was within H-bonding distance to the chloride ion, $\mathrm{Cl1}$. Within $\mathrm{H}$-bonding distance to $\mathrm{O} 1 \mathrm{w}$ was a second atom of low electron density that was assumed to be water, O2w. It was assigned an occupancy factor of $1 / 2$. In addition, a 
third solvent molecule that appeared to be ethanol was also observed. Given its low electron density, the atoms of this molecule were assigned occupancy factors of $1 / 2$. The two water molecules and the molecule of ethanol were refined isotropically.

The function, $\sum \mathrm{w}\left(\left|\mathrm{F}_{\mathrm{o}}\right|^{2}-\left|\mathrm{F}_{\mathrm{c}}\right|^{2}\right)^{2}$, was minimized, where $\mathrm{w}=1 /\left[\left(\sigma\left(\mathrm{F}_{\mathrm{o}}\right)\right)^{2}+(0.1 * \mathrm{P})^{2}\right]$ and $\mathrm{P}=$ $\left(\left|\mathrm{F}_{\mathrm{o}}\right|^{2}+2\left|\mathrm{~F}_{\mathrm{c}}\right|^{2}\right) / 3 . \mathrm{R}_{\mathrm{w}}\left(\mathrm{F}^{2}\right)$ refined to 0.245 , with $\mathrm{R}(\mathrm{F})$ equal to 0.088 and a goodness of fit, $\mathrm{S},=$ 1.54. Definitions used for calculating $\mathrm{R}(\mathrm{F}), \mathrm{R}_{\mathrm{w}}\left(\mathrm{F}^{2}\right)$ and the goodness of fit, $\mathrm{S}$, are given below. The data were checked for secondary extinction effects but no correction was necessary. Neutral atom scattering factors and values used to calculate the linear absorption coefficient are from the International Tables for X-ray Crystallography (1992). All figures were generated using SHELXTL/PC. Tables of positional and thermal parameters, bond lengths and angles, torsion angles and figures are found elsewhere. 
Figure A.13 View of the $\mathrm{CsCl}$ complex in $\mathbf{5 . 3}$ showing a partial atom labeling scheme. Displacement ellipsoids are scaled to the $50 \%$ probability level. Most hydrogen atoms have been removed for clarity.

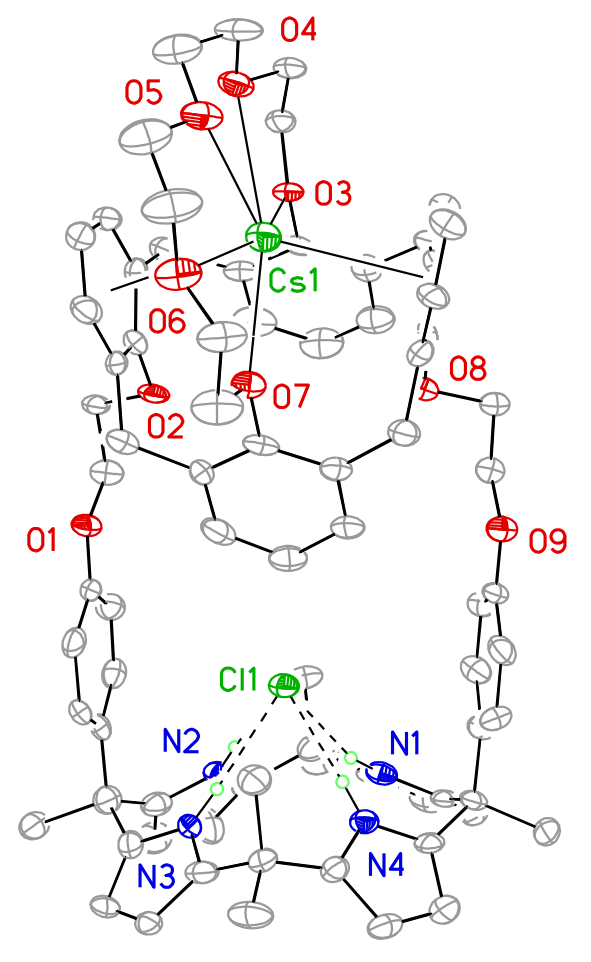


Table A.11 Crystal data and structure refinement for $5.3 \cdot \mathrm{CsCl} \cdot \mathrm{CHCl}_{3} \cdot\left(\mathrm{CH}_{3} \mathrm{CH}_{2} \mathrm{OH}\right)$ ${ }_{1 / 2} \cdot\left(\mathrm{H}_{2} \mathrm{O}\right)_{11 / 2}$

Empirical formula

Formula weight

Temperature

Wavelength

Crystal system

Space group

Unit cell dimensions

Volume

Z

Density (calculated)

Absorption coefficient

$\mathrm{F}(000)$

Theta range for data collection

Index ranges

Reflections collected

Independent reflections

Completeness to theta $=25.00^{\circ}$

Absorption correction

Max. and min. transmission

Refinement method

Data / restraints / parameters

Goodness-of-fit on $\mathrm{F}^{2}$

Final $R$ indices [I>2sigma(I)]

$\mathrm{R}$ indices (all data)

Largest diff. peak and hole
C84 H72 Cl Cs N4 O12

1497.82

100(2) K

$0.71069 \AA$

Monoclinic

$\mathrm{P} 21 / \mathrm{n}$

$$
\begin{array}{ll}
\mathrm{a}=15.832(2) \AA & \alpha=90^{\circ} . \\
\mathrm{b}=34.502(4) \AA & \beta=90.100(4)^{\circ} . \\
\mathrm{c}=15.103(2) \AA & \gamma=90^{\circ} .
\end{array}
$$

8249.8(18) $\AA^{3}$

4

$1.206 \mathrm{Mg} / \mathrm{m}^{3}$

$0.540 \mathrm{~mm}^{-1}$

3088

1.42 to $25.00^{\circ}$.

$-17<=\mathrm{h}<=18,-41<=\mathrm{k}<=41,-17<=\mathrm{l}<=17$

44622

44655

$95.9 \%$

Semi-empirical from equivalents

1.00 and 0.354

Full-matrix-block least-squares on $\mathrm{F}^{2}$

44655 / 640 / 923

1.468

$\mathrm{R} 1=0.0880, \mathrm{wR} 2=0.2307$

$\mathrm{R} 1=0.0968, \mathrm{wR} 2=0.2425$

2.557 and -0.898 e. $\AA^{-3}$ 
X-ray Experimental for $\mathbf{3}^{\bullet} \mathrm{CsNO}_{3} \cdot \mathbf{C}_{2} \mathrm{H}_{5} \mathrm{OH} \cdot \mathbf{C}_{6} \mathbf{H}_{14}$ : Crystals grew as colorless prisms by slow evaporation of a solution of the complex in $\mathrm{n}$-hexane, dichloromethane, and ethanol. The data crystal was cut from a larger crystal and had approximate dimensions; $0.45 \times 0.17 \times 0.12 \mathrm{~mm}$. The data were collected on a Nonius Kappa CCD diffractometer using a graphite monochromator with MoK $\alpha$ radiation $(\lambda=0.71073 \AA$ ). A total of 468 frames of data were collected using $\omega$-scans with a scan range of $0.8^{\circ}$ and a counting time of 137 seconds per frame. The data were collected at $153 \mathrm{~K}$ using an Oxford Cryostream low temperature device. Details of crystal data, data collection and structure refinement are listed in Table A.12. Data reduction were performed using DENZO-SMN. The structure was solved by direct methods using SIR97 and refined by full-matrix least-squares on $\mathrm{F}^{2}$ with anisotropic displacement parameters for the non- $\mathrm{H}$ atoms using SHELXL-97. The hydrogen atoms were calculated in ideal positions with isotropic displacement parameters set to $1.2 \times$ Ueq of the attached atom $(1.5 \times$ Ueq for methyl hydrogen atoms).

A molecule of n-hexane was disordered along a crystallographic two-fold rotation axis at $1 / 2, y, 1 / 4$. The molecule could not be satisfactorily modeled and was, therefore, removed by use of the utility, SQUEEZE, in Platon98. Platon98 was used as incorporated into WinGX.

The function, $\sum \mathrm{w}\left(\left|\mathrm{F}_{\mathrm{o}}\right|^{2}-\left|\mathrm{F}_{\mathrm{c}}\right|^{2}\right)^{2}$, was minimized, where $\mathrm{w}=1 /\left[\left(\sigma\left(\mathrm{F}_{\mathrm{o}}\right)\right)^{2}+\right.$ $\left.\left(0.0415^{*} \mathrm{P}\right)^{2}+(0.9360 * \mathrm{P})\right]$ and $\mathrm{P}=\left(\left|\mathrm{F}_{\mathrm{o}}\right|^{2}+2\left|\mathrm{~F}_{\mathrm{c}}\right|^{2}\right) / 3 . \quad \mathrm{R}_{\mathrm{w}}\left(\mathrm{F}^{2}\right)$ refined to 0.162 , with $\mathrm{R}(\mathrm{F})$ equal to 0.0692 and a goodness of fit, $\mathrm{S},=1.423$. Definitions used for calculating $\mathrm{R}(\mathrm{F}), \mathrm{R}_{\mathrm{w}}\left(\mathrm{F}^{2}\right)$ and the goodness of fit, $\mathrm{S}$, are given below. The data were checked for secondary extinction but no correction was necessary. Neutral atom scattering factors and values used to calculate the linear absorption coefficient are from the International Tables for X-ray Crystallography (1992). All figures were generated using SHELXTL/PC. Tables of positional and thermal parameters, bond lengths and angles, torsion angles and figures are found elsewhere. 
Figure A.14 View of the $\mathrm{CsNO}_{3}$ complex in $\mathbf{5 . 3}$ showing the atom labeling scheme. Displacement ellipsoids are scaled to the $30 \%$ probability level. The hydrogen atoms were removed for clarity. The disordered ethanol oxygen atoms have labels $\mathrm{O} 1 \mathrm{~b}$ and $\mathrm{O} 1 \mathrm{c}$.

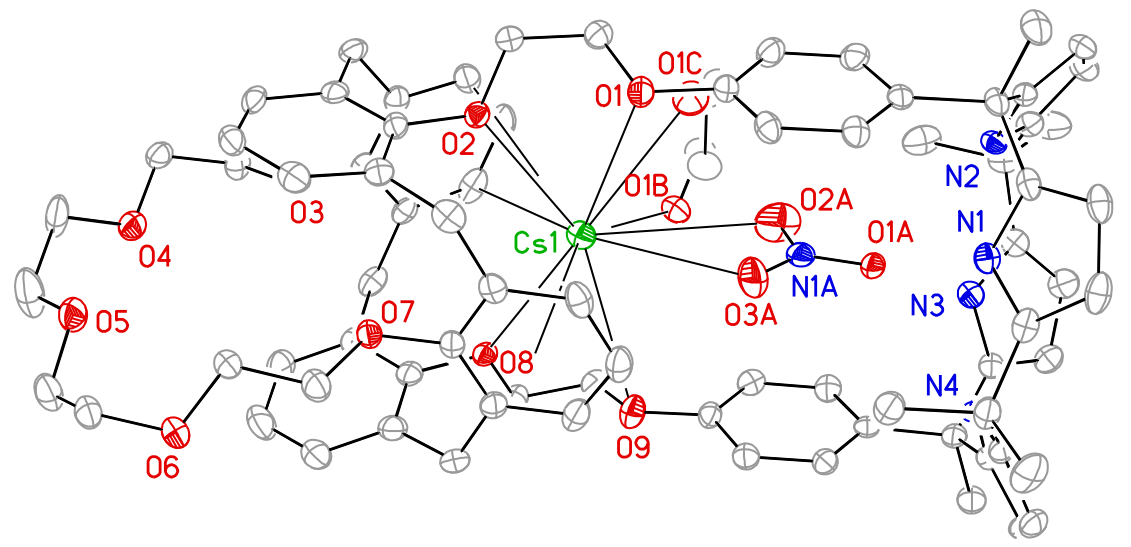


Table A.12 Crystal data and structure refinement for $\mathbf{5 . 3} \cdot \mathrm{CsNO}_{3} \bullet \mathrm{C}_{2} \mathrm{H}_{5} \mathrm{OH} \cdot \mathrm{C}_{6} \mathrm{H}_{14}$.

Empirical formula

Formula weight

Temperature

Wavelength

Crystal system

Space group

Unit cell dimensions

Volume

Z

Density (calculated)

Absorption coefficient

$\mathrm{F}(000)$

Crystal size

Theta range for data collection

Index ranges

Reflections collected

Independent reflections

Completeness to theta $=25.00^{\circ}$

Absorption correction

Max. and min. transmission

Refinement method

Data / restraints / parameters

Goodness-of-fit on $\mathrm{F}^{2}$

Final $\mathrm{R}$ indices [I $>2 \operatorname{sigma}(\mathrm{I})]$

$\mathrm{R}$ indices (all data)

Largest diff. peak and hole
C86 H102 Cs N5 O13

1546.64

153(2) K

$0.71074 \AA$

\section{Monoclinic}

$\mathrm{P} 21 / \mathrm{c}$

$$
\begin{aligned}
& \mathrm{a}=19.4783(6) \AA \quad \alpha=90^{\circ} . \\
& \mathrm{b}=11.2499(3) \AA \quad \beta=103.196(2)^{\circ} . \\
& \mathrm{c}=34.8595(10) \AA \quad \lambda=90^{\circ} \text {. }
\end{aligned}
$$

7437.0(4) $\AA^{3}$

\section{4}

\section{$1.381 \mathrm{Mg} / \mathrm{m}^{3}$}

$0.568 \mathrm{~mm}^{-1}$

3248

$0.45 \times 0.17 \times 0.12 \mathrm{~mm}$

1.07 to $25.00^{\circ}$. $-23<=\mathrm{h}<=23,-10<=\mathrm{k}<=13,-41<=1<=41$

21627

13075 [R(int) $=0.0298]$

$99.6 \%$

Semi-empirical from equivalents

1.17 and 1.00

Full-matrix-block least-squares on $\mathrm{F}^{2}$

13075 / 99 / 929

1.078

$\mathrm{R} 1=0.0572, w R 2=0.1586$

$\mathrm{R} 1=0.0820, \mathrm{wR} 2=0.1682$

0.937 and -0.599 e. $\AA^{-3}$ 